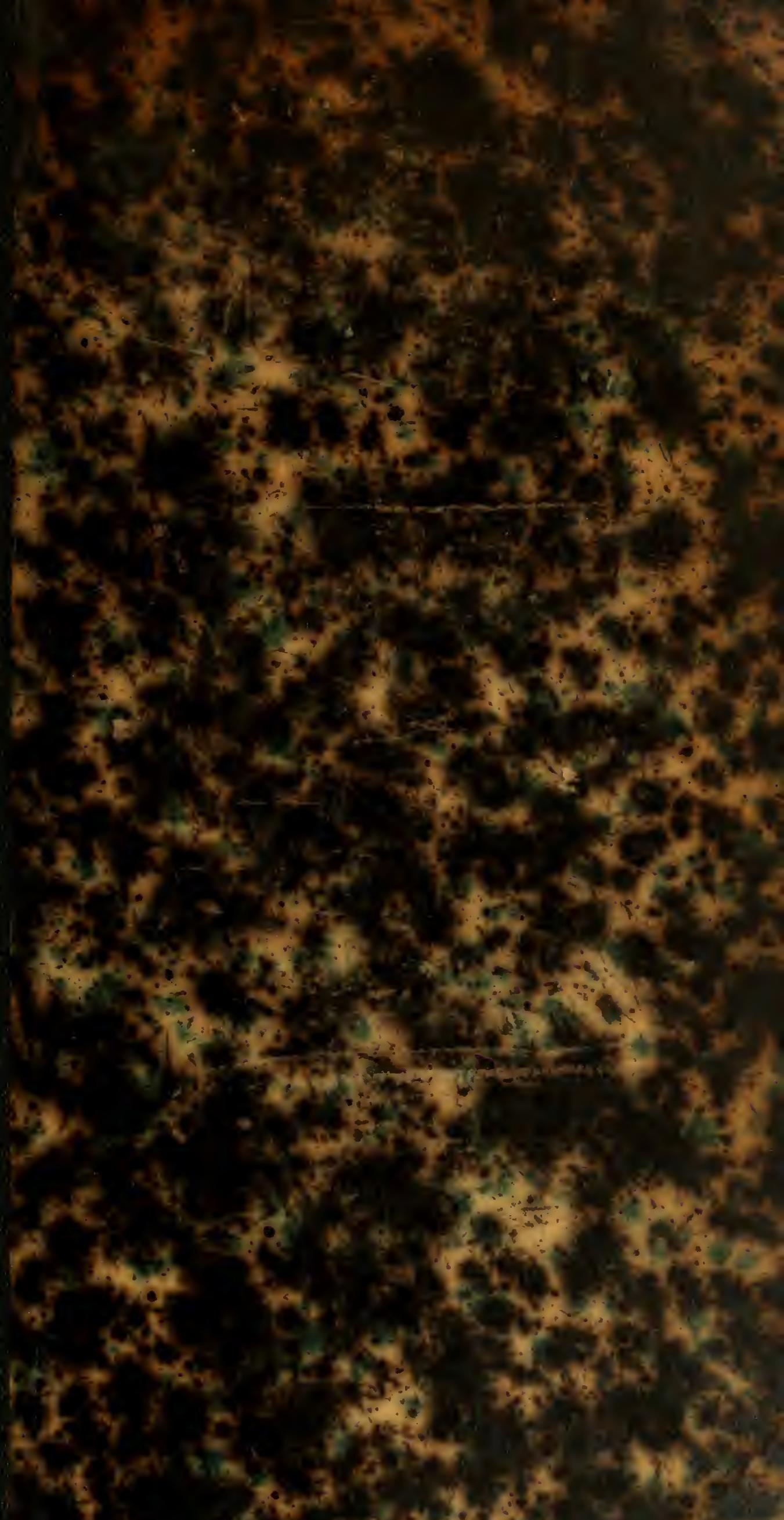




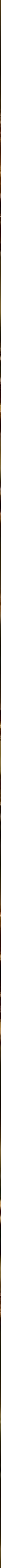




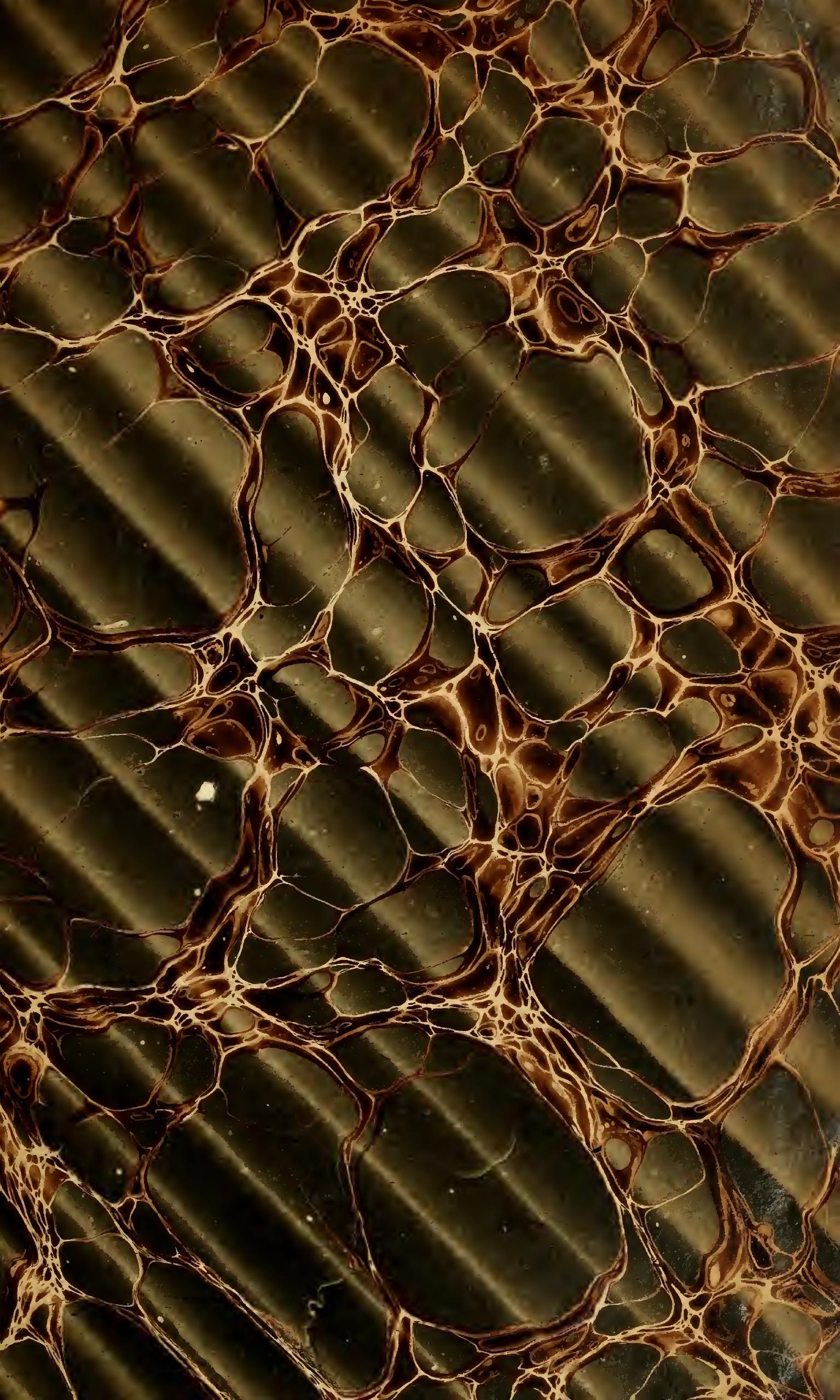






\section{HISTOIRE NATURELLE \\ DES}

\section{DROGUES SIMPLES}

TOME QUATRIÈME 
PIESSE. Des odeurs, des parfums et des cosmétiques, histoire natu. relle, composition chimique, préparation, recettes, industrie, effets physiolo. giques et hygiène, par S. PIESSE, chimiste-parfumeur á Londres; édition fran çaise publiée par O. ReverL. 1865 , in-18 jésus de 527 pages, avec $86 \mathrm{fig}$. $7 \mathrm{fr}$.

REVEIL. Formulaire raisonné des médicaments nouveaux et des médications nouvelles, par le docteur O. Reveil, pharmacien de l'hôpital des Enfants, professeur agrégé à la Faculté de médecine et à l'École de pharmacie. Deuxième édition. 1865, 1 vol. in-18 jésus, xı-696 pages, avec 48 figures..................................... 6 fr.

ROBIN. Traité du microscope, son mode d'emploi, ses applications à l'étude des injections, à l'anatomie humaine et comparée, à l'anatomie médicochirurgicale, à l'histoire naturelle animale et régétale et à l'économio agri. cole, par Cli. Robin, professeur à la Faculté de médecine de Paris, membre de l'Institut. 1871,1 vol. in.8 de 1028 pages, avec 317 figures et 3 planches,

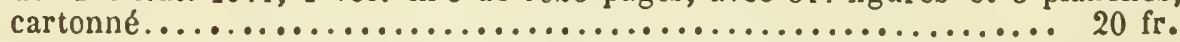

ROBIN ET VERDEIL. Traité de chimie anatomique et physiologiçue normale et pathologique, ou Des principes immédiats normanx et morbides qui constituent le corps de l'homme et des mammifères, par Ch. RoBis, professeur à la Faculté de médecine de Paris, et F. Verdeil. 1853, 3 forts vol. in-8, avec atlas de 45 planclies en partie coloriées.............. $36 \mathrm{fr}$.

SOUBEIRAN. Nouveau dictionnaire des falsifications et des altérations des aliments, des médicaments et de quelques produits employés dans les arts, l'industrie et l'économie domestique, exposé des moyens scientifiques et pratiques d'en reconnaitre le degré de pureté, l'état de conservation, de constater les fraudes dont ils sont l'objet, par J. Léon Soubeinan, professeur à l'École de pharmacie de Montpellier. 1874, 1 vol. gr. in-8 de 640 pages, a vec 218 figures. Cart............................... 14 fr.

TARDIEU (A.). Dictionnaire d'hygiène publique et de salubrité, ou Répertoire de toutes les questions relatives à la santé publique, considérées dans leurs rapports avec les Subsistances, les Épidémies, les Professions, les Établissements et institutions d'Hygiène et de Salubrité, par le docteur Ambroise Tardieu, professeur à la Faculté de médecine de Paris, président du Comité consultatif d'hygiène publique. Deuxiëme édition. 1862, 4 vol. grand

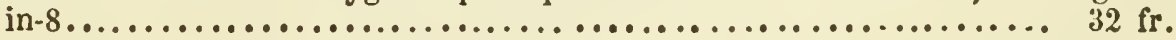

TARDIEU (A.). Étude médico-légale et clinique sur l'empoisonnement, avec la collaboration do Z. Roussin, professeur agrégé à l'École du Val-de-Grâce, pour la partie de l'expertise médico-légale relative à la recherche chimique des poisons. Deuxième édition, 1875. In-8̀ de xxil-1072 pag., avec 53 fig. et 2 planches.............................. \& fr.

VERLOT (B.). Le Guide du botaniste herborisant, conseils sur la récolte des plantes, préparation des herbiers, l'exploration des plantes pha. nérogames et cryptogames et les herborisations, par M. Bernard Verlot, chef de l'Ecole botanique au Muséum, avec une introduction, par M. Naudin, membre de l'Institut. 1865, in-18 de $600 \mathrm{p}$., avec fig. cart....... j fl. 50

VERNOIS. Traité pratique d'hygiéne industrielle et administra. tive, comprenant l'étude des établissements insalubres, dangereux ę incommodes, par Maxime Vernors, membre de l'Académie de médecine. 1860, 2 forts vol. in-8 de chacun 700 pages..................... $16 \mathrm{fl}$.

WEDDELL (H. A.). Histoire naturelle des quinquinas. 1849, 1 vol. in-folio, avec une carte et 32 planches, dont trois coloriées........ $60 \mathrm{fr}$.

WUND'T. Traité élémentaire de physique médicale, par le docteur W. Wund, professeur à l'Université de Heidelberg. Traduit avec de nombreuses additions, par Monoyer, professeur agrégé à la Faculté de médecine de Nancy. 1871, 1 vol. in-8 de 70't p. avec 396 fig., y compris une pl. en chromolithographie.................................. 12 fr.

WURTZ. Sur l'insalubrité des résidus provenant des distilleries, et sur les moyens proposés pour y remédier, par Ad. WuRTz, membre de l'Institut (Académie des sciences), doyen de la Faculté de médecine. Paris, 1859 , in $-8 \ldots \ldots \ldots \ldots \ldots \ldots \ldots \ldots \ldots \ldots \ldots \ldots \ldots \ldots \ldots \ldots \ldots \ldots$. 1 fr. 25 


\section{HISTOIRE NATURELLE}

DES

\section{DROGUES}

SIMPLES

OU

\section{GOURS D'HISTOIRE NATURELLE}

Professé à l'École supérieure de Pharmacie de Paris

\section{Par N.-J.-B.-G. GUIBOUR'T}

Professeur à l'École supérieure de pharmacie de Paris, membre de l'Académie de médecine

OUVRAGE COURONXÉ PAR L'INSTITUT (ACADÉMIE DES SCIENGES)

\section{SEPTIËME EDITION}

C.ORIGÉE ET A UGMENTÉE

\section{Par G. Pla ichon}

Docteur en médecine et Docteur ès sciences, professeur à l'École supérieure de pharmacis de Paris.

\section{PRÉCÉDÉE DE L'ÉLOGE DE GUIBOURT}

PAR H. BUIGNET

Professeur à l'École supérieure de pharmacie de Paris.

avec 1077 figures intercalées dans le texte.

\section{TOME QUATRIENE}

\section{PARIS}

LIBRAIRIE J.-B. BAILLIÈRE ET FILS

Rue Hautefeuille, 19, près du boulevard St-Germain 


\section{Digitized by the Internet Archive} in 2011 with funding from

Open Knowledge Commons and Harvard Medical School

$$
\begin{gathered}
\text { B. } \\
286,344 \\
200.26,1880
\end{gathered}
$$

http://www.archive.org/details/histoirenaturell004guib 


\section{HISTOIRE NATURELLE}

DES

\section{DROGUES SIMPLES}

\section{TROISIÈME PARTIE}

\section{ZOOLOGIE}

\section{CARACTERES DES ANIMAUX.}

Les régétaux out des organes nutrilifs extérieurs, se reproduisent par génération, et vivent où ils sont nés.

Les animaux ont en général une organisation beaucoup plus cumpliquée; ont des organes nutritifs intérieurs, peurent se mouvoir et chercher leur nourriture; exéculent leurs mouvements selon leur volonté; enfin ont des sens dont les végélaux sont dépourvus.

Pendant longtemps on a parlagé les animaux en deux grandes divisions fondées sur la présence ou sur l'absence d'un corps central osseux, nommé colonne épinière ou vertébrule. Les animaux qui offraient cette colonne étaient nommés vertébrés, et les autres invertébrés. Les premiers renfermaient les mammifères, les oiseaux, les reptiles et les poissons; les seconds, les mollusques, les vers, les crustucés, les insectes et les zoophytes. Mais, comme l'a observé G. Cuvier, cette classification, qui semble élablir une égale distance entre les mammifères et les oiseaux, par exemple, qu'entı'e les mollusques, les vers ou les insectes, est loin d'être satisfaisante; il convient d'en ehercher une qui fasse mieux ressortir le plus ou moins de différence qui existe entre ces classes.

Si donc " on considère le règne animal (1) en se débarrassant des préjugés élablis sur les divisions anciennement admises, et n'ayant égard qu'à l'organisalion et à la nature des animaux, et nou pas à leur grandeur, à leur utilité, au plus ou moins de connaissance que nous en avons, ni à toutes les autres circonstances accessoires, on trouvera qu'il existe quatre formes principales, quatre plans généraux, si l'on peut s'exprimer ainsi, d'après lesquels tous les animaux semblent avoir été modelés, et dont les divisions ultérieures, de quelque litre que les naturalistes les aient décorées, ne sont que des moditications assez légères, fondées sur le développement ou l'addition de quelques parties qui ne changent rien à l'essence du plan.

“I. Dans la premiere de ces formes, qui est celle de l'homme et des animaux qui lui ressemblent le plus, le cerveau et le tronc principal

(1) G. Cuvier, Le règne animal distribué d'après son organisation. Paris, 1817 et 1829 . 
du système nerveux sont renfermés dans une enveloppe osseuse qui se compose du crâne et des verlèbres; aux côtés de cette colonne mitoyenne s'attachenl les cotes el les os des membres, qui forment la charpente du corps; les muscles recouvrent en général les os qui les supportent, et les viscères sont renfermés dans la tête et dans le tronc.

"Nous appellerons les animaux de celle forme les animaux vertébrés.

"Ils ont lous le sang rouge, un cour musculaire; une bouche à deux mâchoires placées l'une au-dessus et au-devant de l'autre; des organes distincts de la vue, de l'ouïe, de l'odorat et du goût, placés dans les cavités de la face; jamais plus de quatre membres, des sexes toujours séparés, et une distribution à peu prìs la même des masses médullaires et des principales branches du système nerveux.

" En examinant de plus pris chacune des parties de cette grande série, on y trouve toujours quelque analogie, même dans les espèces les plus éloignées l'une de l'autre, et l'on peut suivre les dégradations d'un même plan, depuis l'homme jusqu'au dernier des poissons.

"II. Dans la deuxieme forme, il n'y a point de squelelle; les muscles sont attachés seulement à la peau, qui forme une cnveloppe molle, contractile en divers sens, dans laquelle s'engendrent, en beaucoup d'espèces, des plaques pierreuses, appelées coquilles, dont la position et la produclion sont analogues à celles du corps muqueux; le système nerveux est arec les viscères dans celle enveloppe générale, el se compose de plusieur's masses éparses, réunies par des filets nerveux, dont les principales, placées sur l'œsophage, portent le nom de cerveau. Des quatre sens propres on ne distingue plus que les organes de celui du goût et de celui de la vue; encore ces derniers manquent-ils souvent. Une seule famille montre des organes de l'ouïe. Du reste, il y a toujours un système complet de circulation, et des organes particuliers pour la respiration. Ceux de la digeation et des sécrétions sont à peu près aussi compliqués que dans les animaux vertébrés.

" Nous appellerons ces animaux, animaux mollusques.

"Quoique le plan général de leur organisation ne soit pas aussi uniforme, quant à la configuration extérieure des parties, que celui des animaux vertébrés, il y a toujours entre ces parties une ressemblance au moins du même degré dans la structure et dans les fonctions.

" III. La troisième forme esi celle qu'on observe dans les insectes, les vers, elc. Leur systìme nerveux consiste en de longs cordons régnant le long du ventre, renflés d'espace en espace en nouds ou ganglions. Le premier de ces nœuds, placé au-dessus de l'cesophage et nommé cerveau, n'est guère plus grand que les autres. L'enveloppe de leur' tronc est divisée par des plis transverses en un certain nombre d'anneaux, dont les téguments sont tantot durs, tantot mous, mais où les muscles sont loujours attachés à l'intérieur. Le tronc porte suuvent à ses cotés des membres articulés; mais souvent aussi il en est dépourvu.

"Nous donnerons à ces animaux le nom d'animaux annelés.

"C'est parmi eux que s'observe le passage de la circulation dans des vaisseaux fermes à la nutrition par imbibition, et le passage correspon- 
dant de la respiration dans des organes circonscrits à celle qui se fait paì des trachées ou vaisseaux aériens répandus dans loul le corps.

"Les organes du goût et de la vue sont les plus distincts clıez eux : une seule famillé en montre pour l'oüe. Leurs mâchoires, quand ils en ont, sont toujours latérales.

"IV. La quatrieme forme, qui embrasse les animaux connus sous le nom de zoo'hytes, peut aussi porter le nom d'animaux rayommés.

"Dans tous les précédents, les organes du mouvement et des sens étaient disposés symétriquement aux deux cotés d'un axe : il y a une face postérieure et une face antérieure dissemblables. Dans ceux-ci, ils le sont comme des rayons autour d'un centre, et cela est vrai même lorsqu'il n'y a que deux séries, car alors les deux faces sont semblables.

“ Ils approchent de l'homogénéité des planles; on ne leur voil ni systime nerveux bien dislinet, ni organes de sens particuliers; à peine aperçoit-on dans quelques-uns des vestiges de circulation, leurs organes respiratoires sont toujours à la surface de leur corps; le plus grand nombre n'a qu'un sac sans issue pour tout intestin, et les dernières familles ne présentent qu'une sorte de pulpe lomogène, mobile et sensible. "

Voici le tableau de ces quatre divisions avec les classes qu'on y a admises.

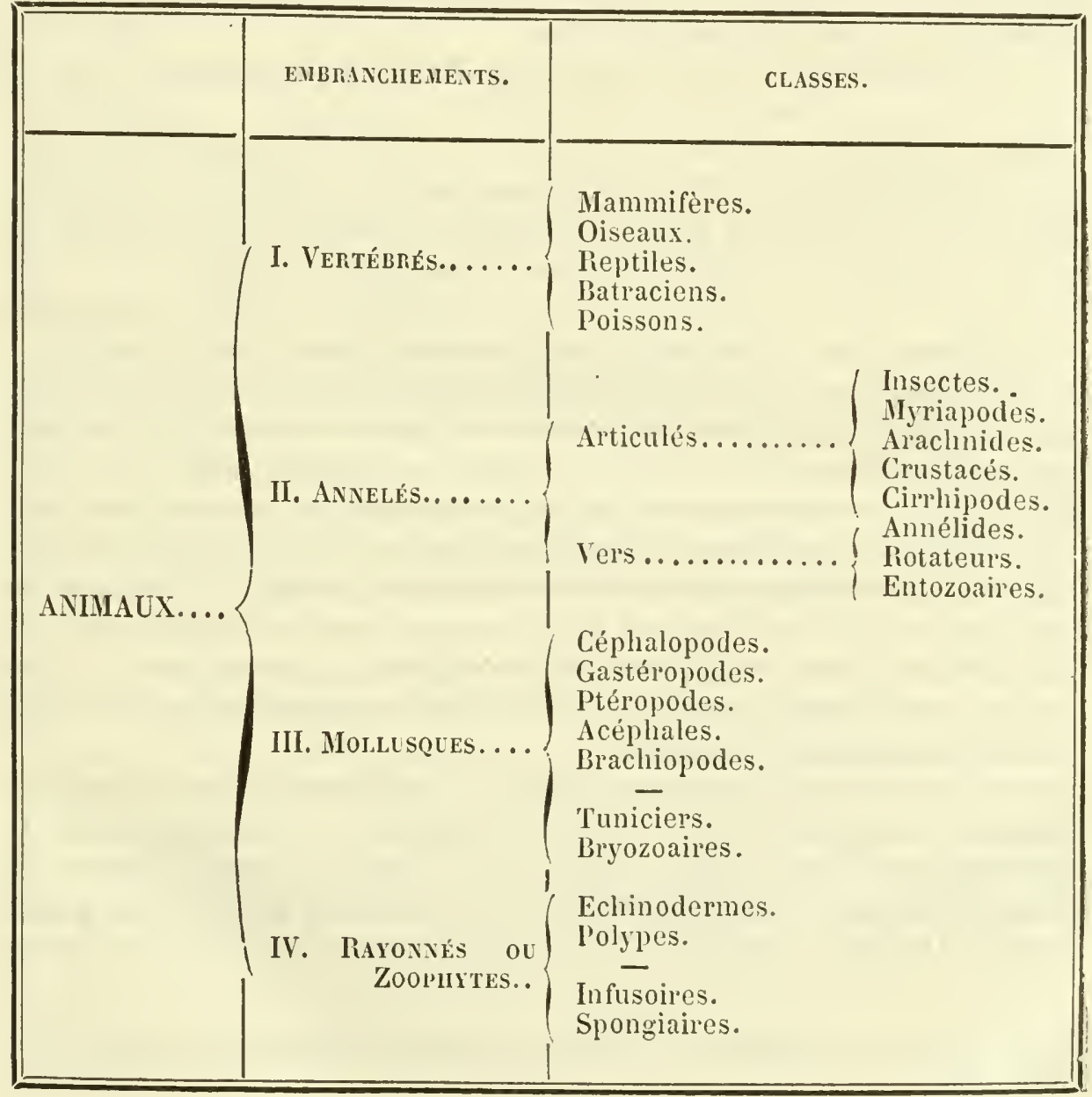




\title{
PREMIER EMBRANGHEMENT
}

\author{
A MMAUX VERTERTÉS
}

\section{PREMIÈRE CLASSE}

\section{LES MAMMIFÈRES}

“Les mammifìres doivent être placés à la tête du règne animal, nonseulement parce que c'est la classe à laquelle nous appartenons nousmêmes, mais encore parce que e'est celle de toules qui jouit des facultés les plus mullipliées, des sensations les plus délicates, des mouvements les plus variés, et où l'ensemble de toutes les propriétés paraît combiné pour produire une intelligence plus parfaite et plus susceptible de perfectionnement (1).

"Les mammifères sont, en général, disposés pour marcher sur la terre, et pour y marcher arec force et continuité : quelques-uns cependant peuvent s'élever dans l'air au moyen de membres prolongés et de nembranes étendues; d'autres ont les membres tellement raccourcis, qu'jls ne se meuvent aisément que dans l'eau, mais ils ne perdent pas pour cela les caractères généraux de la classe.

" lls ont tous - la mâchoire supérieure fixée au crâne, l'inférieure composée de deux pièces seulement, articulée par un condyle saillant à un temporal fixe; - le cou de sept vertebres, hors une seule espèce qui en a neuf; - les cotes antérieures attachées en avant, par des parties carlilagineuses, à un sternum formé d'un cerlain nombre de pièces à la file. Leur extrémité de devant commence par une omoplate non articulée, mais seulement suspendue dans les chairs, s'appuyant souvent sur le sternum par un os intermédiaire nommé clavicule; celte extrémité se continue par un bras, un avant-lras et une muin formée elle-même de deux rangées d'osselets appelés poignet ou curpe; d'une rangée d'os nommée mét carpe, et de doigls composés chacun de deux ou trois os nommés phalanges.

"Si l'on excepte les cétacés, ils ont tous la première parlie de l'extrémité postérieure fixée à l'épine et formant un bassin qui, dans la jeunesse, se divise en trois paires d'os : l'iléon qui tient à l'épine, le pubis qui forme la ceinture antérieure, et l'ischion qui forme la postérieure. $\Lambda$ u point de réunion de ces trois os est la fosse où s'articule la

(1) Voyez A. E. Brehm, la Vie des animaux. Mammifères. Paris, 1870, 2 vol. in-8. 
cuisse, qui porle elle-même la jambe, formée de deux os, le tibia et le péroné; cette extrémité est terminée par le pied, lequel se compose de parties analogues à celles de la main, savoir : d'un tar'se, d'un métutarse et de áoigts.

"La tête des mammifires s'articule toujours par deux condyles sur leur atlas ou première vertibre. Leur cerveau se compose toujours de deux liémisplières, réunis par une lame médillaire dite corps calleux, renfermant deux ventricules, et enveloppant les quatre paires de tubercules appelées corjos culleux, couches optiques, nates et testes. Entre les couches optiques est un troisieme ventricule qui communique avec le quatrième situé sous le cervelet; les jambes du cervelet forment toujours sous la moelle allongée une proéminence transverse appelée pont de Varole.

"Leur œil, loujours logé dans un orbile, préservé par deux paupières et le vestige d'une troisième, a son cristallin fixé par le procès ciliaire, et sa sclérotique simplement celluleuse.

" Dans leur oreille, on trouve loujours - une cavité nommée caisse, qui communique avec l'arriere-bouche par un canal nommé trompe, qui est fermée au delıors par une membrane nommée tympan, et contient une chaîne de quatre osselets appelés marteau, enclume, lenticulaire et étrier; - un vestibule sur l'entrée duquel appuie l'étrier et qui communique avec trois canaux semi-circulaires; - enfin un limacon qui donne par une de ses rampes dans la caisse, par l'autre dans le vestibule.

"Leur crîne se subdivise comme en trois ceintures, formées : l'antérieure par les deux os frontaux et l'etlımoïde; l'intermédiaire par les pariétaux et le sphénoïde; la postérieure par l'occipital. Entre l'occipital, les pariétaux et le spliénoïde, sont intercalés les temporaux, dont une partie appartient à la face.

"Leur face est essentiellement formée par les deux os maxillaires, entre lesquels passe le canal des narines, et qui ont, en avant, les deux intermaxillaires, en arrière les deux palatins; entre eux descend la lame impaire de l'ethmoïde, nommée vomer ; sur les entrées du canal nasal sont les os propres du nez; à ses parois externes adhèrent les cornets antérieurs; les cornels supérieurs appartiennent à l'ethmoïde; le jugal unit de chaque côté l'os maxillaire au temporal et souvent au frontal; enfin le lacrymal occupe l'angle interne de l'orbite et quelquefois une partie de la joue. Ces os, de même que ceux du crâno, présentent des subdivisions plus nombreuses dans l'état du fœtus.

"Leur langue est toujours charnue et attachée à un os appelé hyoïde, composé de plusieurs pièces, et suspendu au crâne par des ligaments.

"Leurs poumons, au nombre de deux, divisés en lobes, composés d'une infinité de cellules, sont toujours renfermés sans adhérence dans une cavité formée par les côtes et le diaphragme, et tapissée par la plèvre; l'organe de la voix est toujour's à l'extrémité supérieure de la trachée-artère; un prolongement charnu, nommé voile du palais, établit une communication directe entre leur larynx et leurs arrièrenarines. 
"Leur cœur présente quatre cavilés dont deux nommées ventricules et deux oreillettes. Ils ont la circulation du sang complète, c'est-ì-dire que la totalité du sang qui revient des extrémilés du corps passe par le poumon avant de retourner aux extrémilés pour les vivifier de nouveau.

Les mammifères, à l'exception des cétacés, qui vivent entièrement dans l'eau, ont la peau garnie de poils; leur cavilé abdominale est tapissée d'une membrane nommée péritoine, et leur canal intestinal est suspendu à un repli de ce péritoine nommé mésentère; l'urine, retenue pendant quelque temps dans une vessie, sort dans les deux sexes, à un très-petit nombre d'exceptions près, par les orifices de la génération.

"Dans la presque totalité des mammifères, la génération est essentiellement vivipaie, c'est-à-dire que le fotus, immédiatement après la conception, descend dans la matrice, enfermé dans ses enveloppes, dont la plus extérieure est nommée chorion, et l'intérieure amnios; il se fixe aux parois de la matrice par un ou plusieurs plexus de vaisseaux, appelés placenta, qui établissent entre lui et sa mère une communication d'où il tire sa nourriture. La conception exige toujours un accouplement effectif, pendant lequel le sperme du mâle est lancé dans la matrice de la femelle. Les pelits se nourrissent pendant quelque temps, après leur naissance, d'une liqueur particulière nommée litit, produite par les mamelles. Ce sont ces mamelles qui unt valu à la classe le nom de mammiféres, attendu que, lui étant exclusivement propres, elies la distinguent mieux des autres classes qu'ancun autre caractère extéricur (1)."

Division des mammifères en ordres. "Les caractères qui établissent les diversités essentielles des mammifères entre eux sont pris des organes du toucher, d'où dépend leur plus ou moins d'habileté ou d'adresse, et des organes de la manducution, qui déterminent la nalure de leurs aliments, et entrainent après eux non-seulement lout ce qui a rapport à la fonction digestive, mais encore une foule d'autres différences, relatives même à l'intelligence.

"La perfection des organes du toucher s'estime d'aprìs le nombre et la mobilité des doigts, et d'après la manière plus ou moins profonde dont leur extrémité est enveloppée dans l'ongle ou le sabot. Un sabot qui enveloppe tout à fait la partie du doigt qui touche à terre yémousse le tact et'rend le pied incapable de saisir. L'extrême opposé a lieu quand un ongle, formé d'unc seule lame, ne couvre qu'une des laces du bout du doigt et laisse à l'autre face toute la délicatesse du toucher.

"Le régime se juge par les dents mâchelières ou molciires, à la forme desquelles répond toujours l'articulation des mâchuires.

"Pour couperde la chair, il faut des mâchelières tranchantes comme une scie, et des mâchoires serrées comme des ciseaux qui ne puissent que s'ouvrir et fermer.

"Pour broyer des grains ou des racines, il faut des mâchelic̀res à couronne plate, et des mâchoires qui puissent se mouvoir horizontale-

(1) Tous ces caractères et les suivants sont extraits presque textuellement de Cuvier. Règne animal. 
ment; il faut encore, pour que la couronne de ces dents soit toujours inégale comme une meule, que sa substance soit formée de parties inégalement dures, et dont les unes s'usent plus vite que les autres.

"Les animaux à sabot sont tous de nécessité herbivores ou à couronnes de mîchelières plates, parce que leurs pieds ne leur permettraient pas de saisir une proie vivante.

"Les animaux à doigts pourvus d’ongles, ou onguiculés, élaient susceptibles de plus de variétés : il y en a de tous les régimes, et, outre la forme des mâchelières, ils diffèrent encore beaucoup entre eux par la mobilité et la délicatesse des doìrts. On a surtout saisi à cet égard un caractère qui influe prodigieusement sur l'adresse et multiplie leurs moyens d'industrie : c'est la faculté d'opposer le pouce aux autres doigts pour saisir les plus petiles choses, ce qui constilue la mair proprement dite; faculté qui est portée à son plus haut degré de perfection dans l'homme, où l'extrémité antérieure tout entière est libre et peut être employée à la préhension.

"Ces diverses combinaisons, qui déterminent rigoureusement la nature des divers mammifères, ont donné lieu à distinguer les ordres suivants :

"Parmi les onguiculés, le premicr qui est en même temps privilégié sous tous les autres rapports, l'homme, a des mains aux extrémités antéricures seulement; ses extrémités postérieures le soutiennent dans une situation verticale.

"L'ordre ie plus voisin de l'homme, celui des quadrumanes, a des mains aux quatre extrémilés.

"Un autre ordre, celui des carnassiers, n'a point de pouce libre et opposable aux exírémités antérieures. Ces trois ordres ont d'ailleurs chacun trois sortes de dents, savoir : des mâclıelìres, des canines et des incisives.

" Un quatrième ordre, celui des rongeurs, dont les doigts diffèrent peu de ceux des carnassiers, manque de canines et porte en avant des incisives disposées pour une sorte toute particulière de manducation.

"Viennent ensuite des animaux dont les doigts sont déjà fort gênés, fort enfoncés dans de grands ongles le plus souvent crochus, et qui ont encore celte imperfection de manquer d'incisives. Quelques-uns manquent même de canines, et d'autres n'ont pas de denls du tout. Nous les comprenons tous sous le nom d'édentés.

"Cetle distribution des animaux onguiculés serait parfaite et formerait une chaîne très-régulière, si la Nouvelle-Hollande ne nous fournissait pas une petite clıaine collatérale, composée des animaux ì l,ourse ou marsupiaux, dont tous les genres se tiennent entre eux par l'ensemble de l'organisation, et dont cependant les uns répondent aux calnassiers, les autres aux rongeurs et les troisièmes aux édentés, par les dents et par la nature de leur régime.

"Les animaux à sabols ou ongulés, moins nombreux, ont aussi moins d’irrégularités.

"Les ruminants composent un ordre Irès-distinct par ses pieds 
fourchus, sa mâchoire supérieure sans vraies incisives, el ses quatre estomacs.

"Tous les autres quadrupides à sabots se laissent réunir en un seul ordre que j’appellerai pachydermes ou jumenta, excepté l'éléphant, qui pourrait faire un ordre à part, et qui se lie par quelques rapports éloignés avec l'ordre des rongeurs.

"Enfin viennent des mammifères qui n’ont point du tout d'extrémités postérieures, et dont la forme de poisson et la vie aquatique pourlaient engager à faire une classe parliculière, si, pour tout le reste, leur économic n'était pas la même que dans la classe où nous les laissons. Ce sont les poissons à sang chaud des anciens, ou les cétacés, qui, réunissant à la force des aulres mammil'ères l'avantage d'être soutenus par l'élément aqueux, complent parmi eux les plus gigantesques de tous les animaux. ")

Voici le tableau de celte division des mammifères en neul ordres :

MAMMIFE்RES.

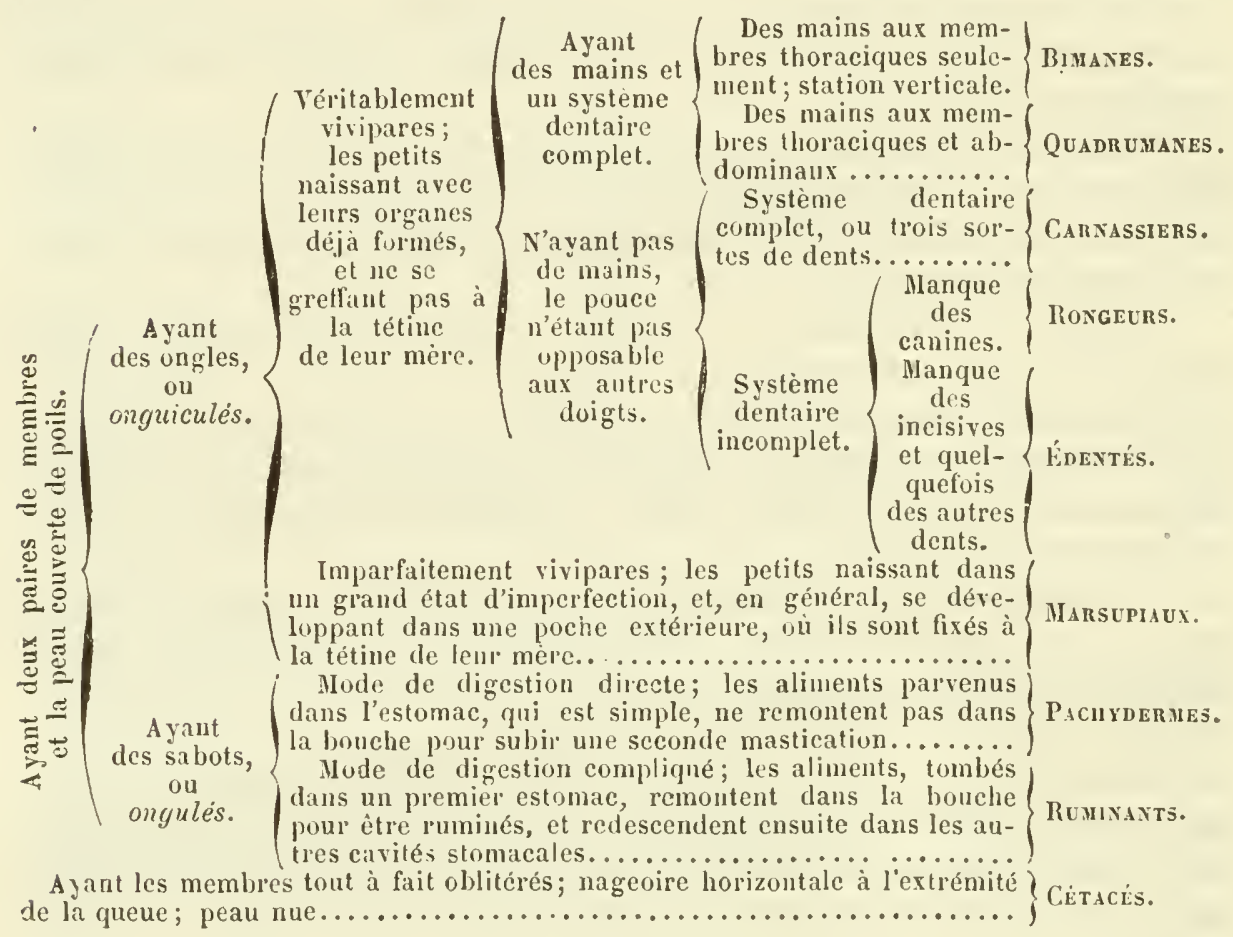

ORDRE DES BIMANES.

L'homme.

L'homme forme à lui seul tout l'ordre des bimanes; son organisation diffère très-peu de celle d'un grand nombre d'autres mammifères; mais il est placé bien au-dessus de tous par l'intelligence admirable dont il a été doué par la nature.

Le corps entier de l'homme est disposé pour la slation verticale. Son pied bien différent de celui des singes, est large et muni 
d'un talon renflé, sur lequel porte verticalement la jambe; les doigts en sont courts el peuvent à peine se ployer; le pouce, plus long et plus gros que les autres, est placé sur la même ligne et ne leur est pas opposable; les muscles qui retiennent le pied et la cuisse dans l'état d'extension sont plus vigoureux que chez aucun autre mammifère, et forme les saillies du mollet et de la fesse; le bassin est plus large, ce qui écarte les cuisses et les pieds, élargit la base du corps et en facilite l'équilibre; latête, dans cette situation verticale, est en équilibre sur le tronc, parce que son articulation est alors sous le milieu de sa masse.

L'homme doit se tenir sur ses pieds seulement; il conserve l'entière liberté de ses mains pour' les arts, et ses organes des sens sont situés plus favorablement pour l'observation.

"Aucun animal n'approche de l'homme pour la grandeur relalive et res replis des hémisphères du cerveau, c'est-ă-dire de la partie de cet organe qui sert d'instrument principal aux opérations intellectuelles; la partie postérieure du même organe s'étend en arrière de manière à recouvrir le cervelel; la forme même du cràne annonce cetle grandeur du cerveau, comme la petitesse de la face montre combien la partie du système nerveux affectée aux sens externes est peu prédominante (1).

"L'homme a une préćminence particulière dans les organes de la voix; seul des mammifères, il peut articuler des sons; la forme de sa bouche et la grande mobilité de ses lèvres en. sont probablement les causes: il en résulte pour lui un moyen de communication bien précieux, car les sons variés sont, de tous les signes que l'on peut employer commodément pour la transmission des idées, ceux que l'on peut faire percevoir le plus loin et dans plus de directions à la fois.

L'homme paraît fait pour se nourrir principalement de fruits, de racines et d'autres parties succulentes de végétaux; ses mains lui donnent la facilité de les cueillir'; ses mâchoires courtes et de force médiocre, d'un côté, ses canines ćgales aux autres dents, et ses molaires tuberculeuses, de l'autre, ne lui permettraient guère ni de paître de l'herbe ni de dévorer de la chair, s'il ne préparait ses aliments par la cuisson; mais, une fois qu'il a possédé le feu, et que ses arts l'ont aidé à saisir ou tuer de loin les animaux, tous les êtres vivants ont pu servir à sa nourriture, ce qui lui a donné les moyens de mulliplier infiniment son espèce.

"Ses organes de la digestion sont conformes à ceux de la mas-

(1) Voyez Leuret et Gratiolet, Anatomie comparée du système nerveux considéré dans ses rapports avec l'intelligence. Paris, 1839-57, 2 vol. et atlas. 
tication; son estomac est simple, son canal intestinal de longueur médiocre, ses gros intestins bien marqués, son cœcum gros et court, augmenté d'un appendice grêle; son foie est divisé seulement en deux lobes et un lobule; son épiploon pend au-devant des intestins jusque dans le bassin.

"Pour compléter l'idée abrégée de la structure anatomique de l'homme, nous ajouterons qu'il a 32 vertèlsres, dont 7 cervicales, 12 dorsales, $\breve{l}$ lombaires, 5 sacrées et 3 coccygiennes. De ses côtes, 7 paires s'unissent au sternum par des allonges cartilagineuses,

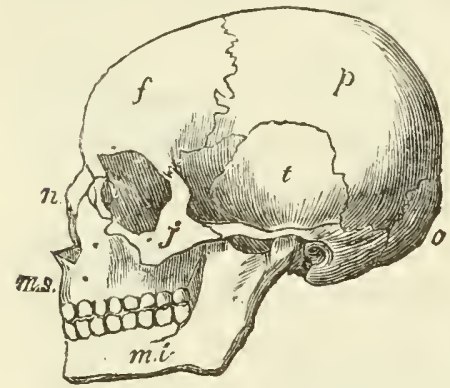

Fig. 823. - Tète d'homme $\left.{ }^{*}{ }^{*}\right)$. et se nomment vraies côtes; les õ paires suivantes sont nommées fausses côtes. Son crâne (fig. 823) à l'état adulte, a huit os, savoir : un occipito-basilaire, deux temporaux, deux pariélaux, un frontal, un elhmoïde et un sphénoüde. Les os de la face sont au nombre ie quatorze : deux maxillaires, deux jugaux, dont chacun joint le temporal au maxillaire du même côté par une espèce d'anse nommée arcade zygomatique; deux nasaux, deux palatins en arrière du palais, un vomer entre les narines, deux cornets du nez dans les narines, deux lacrymaux aux côtés internes des orbites, et l'os unique de la mâchoire inférieure. Chaque mâchoire a 16 dents, à savoir : 4 incisives tranchantes, au milieu; deux canines pointues, à la suite; et 10 molaires à couronnes tuberculeuses aux extrémités, כั de chaque côté : en toul 32 dents, qui sont de longueur sensiblement égale. L'omoplate a, au bout de son épine ou arête saillante, une lubérosité dite acromion, à laquelle s'ittache la clavicule, et, au-dessous de son articulation, une pointe nommíe bec coracoüle, pour l'attache de quelques muscles. Le radius (os antérieur de l'avant-bras) tourne complétement sur le cubitus, à cause de la manière dont il s'articule avec l'humérus. Le carpe a huit os, quatre pour chaque rangée; le tarse en a-sept. Ceux du reste de la main et du pied se compient aisément d'après le nombre des doigts (1). ")

Quoique l'espèce humaine paraisse unique, puisque tous les individus peuvent se mêler indistinctement et produire des individus féconds, on y remarque cependant, suivant les pays et

(1) Voy. Beaunis et Bouchard, Nourcaux éléments d'anatomie descriptive $2^{\mathrm{e}}$ édition. Paris, 1873.

$\left({ }^{*}\right) o$, os occipital; $t$, os temporal; $\rho$, os pariétal; $f$, os frontal; $n$, os nasal; $j$, os jugal ou os de la pommctte; ms, os de la màchoire surérieure; mi, oj de la màchoire inférieure. 
les climats, des différences qui transmettent indéfiniment par la génération, tant que les races ne se mêlent pas : aussi ne peut-on pas se refuser à admettre dans celte espèce unique plusieurs variélés distincles (1).

Les peuples qui habitent l'ancien monde paraissent appartenir à trois variétés principales, désignées sous les noms de race blanche ou caucasique, race jaune ou mongolique, et race noire ou éthiopique.

La race caucasique se distingue par la beauté de l'ovale que forme la tête, par le développement de son front, la position horizontale de ses yeux, le peu de saillie de ses pommettes et de ses mâchoires, ses cheveux longs et lisses, et la couleur blanche rosée de sa peau. Elle occupe toute l'Europe, l'Asie occidentale jusqu'au Gange et la partie septentrionale de l'Afrique; mais on la croit originaire des montagnes du Caucase, ce qui lui a valu son nom.

La race mongolique a la face aplatie, le front bas, oblique et carré, les pommettes saillantes, les yeux étroits et obliques, la barbe grêle, les cheveux droits et noirs, et la peau olivâtre. Elle paraît originaire des monts Altaï, d'où elle a envahi toute la Sibérie orientale, le Kamtschalka, les îles Aleutiennes, l’Amérique russe, la Chine, la Corée, le Japon, les îles Mariannes et les Philippines. Elle s'est étendue aussi dans les régions glacées de l'ancien hémisphère depuis l'embouchure de la Léna jusqu'au cap Nord, et paraît avoir produit les peuples abâtardis connus sous les noms de Samoïdes et de Lapons. Répanduc au midi dans les îles Moluques, mais mélangée sans doute à la race blanche, elle a produit la grande famille malaise, qui diffère à quelques égards de l'une et de l'aulre.

La variété nègre ou éthiopique, est caractérisée par son crâne comprimé, son néz écrasé, ses mâchoires saillantes, ses lèvres lippues, ses cheveux laineux el crépus, et sa peau plus ou moins noire. Elle est confinée en Afrique au midi de l'Atlas, et paraît se composer de plusieurs races distinctes, telles que la mozambique, la boschimanne et la hottentote.

Ja population primitive de l'Australie et d'une partie des al'chipels de l'Océanie est aussi une race noire qui a beaucoup de rapports avec la mozambique.

Enfin les peuples indigènes de l'Amérique, quoique généralement remarquables par leur teint cuivré, leur nez saillant, leurs

(1) Voy. J. C. Prichard, Hist. nat. de l'homme, traduit par Roulin. Paris, 1843, 2 vol. in-S. - Omalius d'Halloy, Des races humaines, ou Éléments d'ethnographie. Paris, 1845, 1 vol. in-8. - Quatrefages et Hamy, Crania ethnica, les crines des races humaines. Paris, 1871-1870. 
yeux grands ouverts, leurs cheveux longs et leur barbe rare, paraissent dérivés de deux races différentes, dont l'une provenant de la Mongolie, aurait suivi, du nord au sud, la côle occidentale du nouveau continent jusqu'au centre de l'A mérique méridionale, et dont l'autre, arrivée par le nord-est, et plus rapprochée de la race caucasique, se serail étendue du fleure Saint-Laurent à la Floride el de l'océan Atlantique jusqu'aux montagnes Rocheuses, à travers le bassin du Mississipi.

Les médicaments que l'on tirait autrefois de l'homme sont tombés en désuétude.

On employail le crảne pulvérisé contre l'épilepsie, el la graisse dans les douleurs arthritiques.

Le lait de femme est encore quelquefois recommandé comme analeptique (1);

L'urine sert dans l'art de la teinture et pour la préparation de l'orseille et des tournesols.

\section{ORDRE DES QUADRUMANES.}

Les quadrumanes se rapprochent beaucoup de l'homme par leur cerveau à Irois lobes de chaque côté, dont le postéricur recouvre le cervelet; par leur fosse temporale séparée

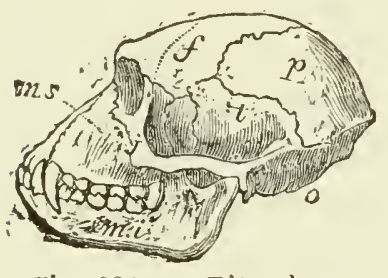

Fig. 824. - Tètc de guenon callitriche $\left(^{*}\right)$. de l'orbite au moyen d'une cloison osseusc ( $f g .824)$; par leurs yeux dirigés en avant, leur système dentaire, leur canal intestinal, leurs mamelles au nombre de deux seulement et placées sur la puitrine; enfin par leur verge pendante; mais ils s'en distinguent par leurs pieds de derrière dont le pouce est libre et opposable à des doigts longs et flexibles comme ceux de la main, ce qui leur permet de monter sur les arbres avec une grande facilité, tandis qu'ils ne se tiennent et ne marchent debout qu'avec peine, leur pied ne posant alors que sur le tranchant extérieur et leur bassin étroit ne favorisant pas l'équilibre. Ils s'éloignent d'ailleurs de notre forme par degrés, en prenant un museau de plus en plus allongé, une queue, une marche plus exclusivement quadrupède; néanmoins la liberté de leurs avant-bras et la conformation de leurs mains leur permettent à tous beaucoup d'actions et de gestes semblables à ceux de l'homme. On les divise en trois familles comprenant les singes, les ouistilis et les makis.

(1) Voy. Vernois et Becquerel, Du lait chez la femme dans l'état de santé et dars l'état de maludie. Paris, 1853, in-S. - Donné, Consei's aux mères sur la manière d'élever les enfants nouveau-nés, $5^{\mathrm{e}}$ édition. Paris, 1875, in-18.

$\left({ }^{*}\right) o$, os occipital; $t$, os temporal; $p$, os pariétal; $f$, os frontal; $j$, os jugal; $m s$, os de la màchoire supéricure; mi, os de la màchoire inférieurc. 
Les SINGEs ont à chaque mâchoire quatre dents incisives droites, et des ongles plats à tous les doigts; leurs molaires n'ont, comme les nôtres, que des tubercules mousses, et ils vivent essentiellement de fruits; mais leurs canines, dépassant les autres dents, leur fournissent une arme qui nous manque, et qui exigent un vide dans la mâchoire opposée, pour s'y loger quand la bouche se ferme. On les divise en deux tribus, sous la désignation de $\sin$ ges de l'ancien continent el de singes du nouveau continent. Les premiers ont le même nombre de molaires que l'homme, ont presque toujours des callosités aux fesses, jamais dequeue prenante, et souvent des abajoues ou poches creusées dans les joues et communiquant avec la bouche. Celle tribu comprend les singes qui ressemblent le plus à l'homme, comme le chimpansé du Congo et de la Guinée, l'orang-outang de la Cochinchine et de Bornéo, el le gibbon, de l'archipel Indien. On y trouve également les guenons, ou singes à queue non pronante, à fesses calleuses, à abajoues; les macaques, les magots, les cynocíphales et les mandrilles.

Les singes du nouveau continent ont quatre mâchelières de plus que les autres, ou trente-six dents en tout, la queue longue, pas d'abajoues, les fesses velues et sans callosités, les narines percées aux côtés du nez et non en dessous. Les uns ont la queuc prenante, c'est-à-dire que son extrémité peut s'entortiller autour des corps pour les saisir comme le ferait une main, ce qui leur permet de se suspendre aux branches des arbres, de s'y balancer et de se lancer d'un arbre à un autre. On leur donne le nom général de sapajous. Ceux dont la queue n'est pas prenante porient les noms de sagouins et de sakis.

Les outstitis forment une petite famille longtemps confondue avec les makis, dont ils offrent la tête ronde, le visage plat, les rarines latérales, les fesses velues, elc.; mais ils n'ont que vingt molaires comme les singes de l'ancien continent, et leurs pouces de devant s'écartent si peu des autres doigts qu'on hésite à leur donner le nom de quadrumanes.

Les MAKIS ou iÉMURIENS ont les quatre pouces bien développés et opposables aux autres doigts; mais ils présentent dans leur système dentaire des caractères qui les rapprochent des insectivores ou des édentés. lls comprennent les makis proprement dits, les loris el les tarsiers.

ORURE DES CARNASSIERS.

Les carnassiers forment une réunion considérable et variée de mammifères onguiculés, qui possèdent, comme l'homme et les quadru- 
manes, trois sortes de dents, mais qui n'ont pas de pouces opposables à leurs pieds de devant. Ils vivent tous de matières animales et d'autant plus exclusivement que leurs molaires ou mâchelières sont plus tranchantes. Ceux quiles ont en tout ou en parlie tuberculeuses, prennent aussi plus ou moins de substances végétales, et ceux qui les ont hérissées de poinles coniques se nourrissent principalement d'insectes. L'articulation de leur mâchoire inférieure, dirigée en travers et serrée comme un gond, ne lui permet aucun mouvement horizontal; elle ne peut que se fermer et s'ouvrir.

Leur cerveau, encore assez sillonné, n'a point de troisième loge et ne recouve point le cervelet, non plus que dans les ordres suivanls. Leur orbile n'est point séparé de leur fosse lemporale, dans le squelette; leur crâne est rétréci, et leurs arcades zygomatiques sont écartées et relevées, pour donner plus de volume et de force aux muscles de leurs mâchoires. Le sens quj domine chez eux est celui de l'odorat, et leur membrane pituitaire est généralement étendue sur des lames osseuses très-multipliées. On les divise en trois familles fort distinctes: les chéiroptères, les insectivores et les carnivores.

Les CIIÉIROptères (1) ont encore quelques affinités avec les qua. drumanes par leur verge pendante et par leurs mamelles placées sur la poitrine. Leur caractère distinctif consiste dans un repli de la peau qui pend aux côtés du cou, s'étend entre leurs quatre pieds et leurs doigts, les soutient en l'air et leur permet même de voler. Ils ont quatre grandes canines; mais le nombre de leurs incisives varie. On les divise en deux tribus, d'après l'étendue de leurs organes du vol. Dans les vrais chéiroptères (2), les bras, les avant-bras et les doigts, à l'exception lu pouce, sont excessivement allongés et forment, avec la membrane qui en remplit les intervalles, de véritables ailes, aussi étendues en surface que celles des oiseaux. Leurs muscles pectoraux ont une épaisseur proportionnće aıx mouvements qu'ils doivent exécuter, et leur sternum est pourvu d'une arête pour Jeur donner attache, comme celui des oiseaux. Leur pouce est court et armé d'un ongle crochu qui sert à ces animaux à se suspendre, dans l'état de repos, aux murs ou aux rochers; car ils ne posent guère à terre, où ils ne rampent qu'avec peine. Leurs pieds de derrière sont faibles, divisés en cinq doigls égaux et armés d'ongles aigus. Leurs yeux sont très-petits, mais leurs oreilles, sont généralement très-grandes, et forment avec leurs ailes une énorme surface membraneuse et sensible, qui leur sert à se diriger dans l'obscurité par la diversité des impressions de l'air. Ce sont des animaux nocturnes et qui passent l'hiver de nos climats en léthargie. On

(1) Dans les classifications actuelles on fait un ordre à part des chéiroptères, qu'on place immédiatement après les quadrumanes.

(2) De $\gamma_{\text {sip }}$, main, et $\pi \tau$ ćpor, aile : main ailée. 
les divise d'abord en roussettes et en chauves-souris: les premières, qui appartiennent à l'archipel Indien, se nourrissent en grande partie de fruits; les secondes, qui sont répandues dans les autres parties du monde, se nourrissent principalement des insectes qu'elles prennent au vol, et quelquefois, comme le vampire, du sang des animaux.

Les insectrvores ont, comme les chéiroptères, des màchelières hérissées de pointes coniques, et une vie le plus souvent nocturne et souterraine: ils se nourrissent principalement d'insectes, et, dians les pays froids, beaucoup d'entre eux passent l'hiver en léthargie. Ils n'ont pas de membranes latérales propres au vol; leurs pieds sont courts et leurs mouvements faibles. Leurs mamelles sont placées sous le ventre, et la verge est enfermée dans un fourreau. Aucun n'a de cœcum, el tolis appuient la plante entière du pied sur la terre en marchant.

Les uns ont de longues incisives en avant, suivies d'autres incisives et de canines toutes moins hautes que les molaires, ce qui les rapproche des tarsiers, parmi les quadrumanes, et un peu des rongeurs. Les autres ont de grandes canines écartées, entre lesquelles sont de pelites incisives, ce qui est la disposition la plus ordinaire aux quadrumanes et aux carnivores. Cette famille comprend les hérissons, les tenrecs, les musaraignes, les desmans, les taupes, les scalopes, etc.

Carnivones. Quoique l'épithète de carnassier's convienne à tous les mammifères onguiculés à trois sortes de dents et non quadrumanes, puisque tous se nourrissent plus ou moins de matières animales, cependani il en est beaucoup, spécialement ceux des deux familles précédentes, que leur faiblesse et les tubercules coniques de leurs dents mâchelières réduisent presque à vivre d'insectes. C'est dans la famille actuelle qua l'appétil sanguinaire se joint à la force nécessaire pour y subvenir, comme toujours. Les animaux qu'elle renferme sont d'autant plus es-

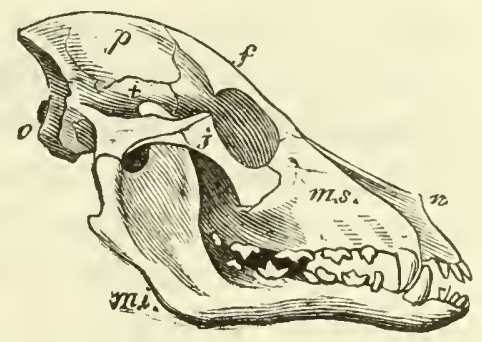

Fig. 825. - Tète de carnassier (ch'en). sentiellement carnivores que leurs dents sont plus complétement tranchantes. Ils ont tous quatre grosses et longues canines écartées, entre lesquelles sont six incisives à chaque mâchoire ( $f g .825)$. Les premières molaires sont les plus tranchantes et sont désignées sous le nom de fausses molaires; vient à la suite, à chaque mâchoire, une molaire plus grosse que les autres, pourvue d'un large talon tuberculeux, et servant surtout ì briser les os des animaux : on lui donne le nom de carnassière. Jer- 
rière elle se trouvent une ou deux molaires plus faibles et à tubercules mousses, nommées molaires tuberculeuses.

Dans cette division, les membres antérieurs ne servent plus guère qu'à supporter le poids du corps et à la locomotion sur terre; aussi la clavicule, ne devant plus tenir les épaules écartées, est-elle réduite à l'état rudimentaire et suspendue dans les chairs. Les membres postérieurs présentent, dans leur terminaison, des différences très-marquées, qui influent beaucoup sur les habitudes et sur le régime des carnivores ou qui en sont la conséquence, et qui les ont fait partager en trois tribus, sous les noms de plantigrades, de digitigrades et d'amphibies.

Les plantigrabes, de même que les quadrupèdes des familles précédentes, appuient la plante entière du pied de derrière sur la terre, Ior'squ'ils marchent ou qu'ils se tiennent debout, et I'on s'en aperçoit aisément par l'absence des poils sous toute cette partie. Ils participent à la lenteur et à la vie nocturne des insectivores et manquent comme eux de cœcum; la plupart de ceux des pays froids passent l'hiver en léthargie. Ils ont tous cinq doigts à tous les pieds. Cette tribu comprend les ours, les ratons, les coatis, les blaireaux, les gloutons, les ratels, etc.

Les ours sont de grands animaux dont le corps est généralement trapu, les membres épais, la queue très-courte; leurs allures sont lourdes, mais ils ont beancoup d'intelligence et sont doués d'une grande force.

L'ours brun (Ursus Arctos, L.), Labite les hautes montagnes couvertes de forêts de toute l'Europe et d'une partie de l'Asıe; il aime la solitude et établit sa demenre dans quelque caverne naturelle, ou dans un antre qu'il crcuse avec ses ongles forts et crochus; il vit principalement de fruits, de racines succulentes, de jeunes pousses d'arbres, et recherche le miel avec passion. Ce n'est guère que lorsque la faim le presse qu'il attaque les animaux; aussi ses dents molaires sont-elles moins tranchantes que celles de tous les autres carnassiers. Il est d'une grande prudence et s'éloigne de tout ce qu'il ne connaît pas; mais ce n'est pas manque de courage, et ses efforts deviennent terribles lorsqu'il est attaqué.

La fourrure de l'ours brun est très-épaisse, surtout en hiver, et se compose de poils longs et brillants; sa chair est bonne à manger quand il est jeune; sa graisse a joui d'une grande réputation pour la guérison des douleurs rhumatismales, pour faire crôitre les cheveux et pour s'opposer à leur chute. Elle est demifluide, d'une couleur légèrement citrine, d'une odeur assez forte, et se conserve longtemps sans rancir.

L'ours blane (Ursus maritimıs, L.), des mers polaires diffère 
du précédent par sa forme générale plus allongée, son pelage tout blanc el son habitude de vivre par troupes plus ou moins nombreuses. Il nage et plonge arec une grande facilité et poursuit les poissons, les phoques et les jeunes cétacés. Il est aussi très-dangerenx pour les naviga teurs égarés sur les mers polaires; cependant son régime exclusivement animal est une conséquence forcée du climat où il vit; lorsqu'on le tient en captivité, il s'habilue facilement au régime végélal des autres ours.

Le blaireau d'Europe, Meles Taxus, Schreb, a la taille d'un chien de médiocre grandeur. Sa queue est courte, et au-dessous se trouve une poche d'où suinte une humeur grasse et féticle; ses jambes sont très-courtes et ses poils si longs que son ventre paraît presque toucher à terre. Ses ongles de devant sont forls, allongés et Irès-propres à fouir; aussi se creuse-t-il facil ement des terriers tortueux où il passe solitaire la plus grande parlie de sa vie; il n'en sort guère que la nuit pour chercher sa nourriture, qui consiste en jeunes lapins, mulots, lézards, miel, œufs, etc. On le chasse à l'aide du basset qui pénètre dans son gîte, l'accule et facilite le moyen de le prendre avec des pinces, en ouvrant le terrier par-dessus. La fourrure du blaireau est épaisse, rude, peu brillante et peu estimée; mais les poils de sa queue sont très-recherchés pour la fabrication des pinceaux et des brosses à barbe. La graisse de blaireau ressemble beaucoup à celle de l'ours et étail autrefois employée aux mêmes usages.

Les DigitigRades, qui forment la seconde tribu des carnirores, ne marchent que sur le bout des doigts en relevant le tarse, leur course en devient plus rapide; ils sont essentiellement chasseurs et carnassiers; leurs pattes sont armés d'ongles puissants pour saisir leur proie, et leurs mâchoiros robustes ne présentent que des dents plus ou moins tranchantes. On les divise en trois petits groupes comprenant :

$1^{\circ}$ Les martes et les loutres, dites quadrupèdes vermiformes;

$2^{\circ}$ Les chiens et les civettes;

$3^{\circ}$ Les hyènes et les chats.

Les animaux du premier groupe ont reçu le nom de vermiformes, à cause de la forme allongée et comme cylindrique de leur corps et de leur brièveté de leurs pieds, qui leur permettent de passer par de très-petites ouvertures. Ils n'ont qu'une dent tuberculeuse en arrière de la carnassière d'en haut; ils manquent de cœclim, comme les insectivores et les plantigrades, mais ils ne tombent pas en léthargie pendant l'hiver. Quoique petits et faibles, ils sont très-cruels, vivent surlout de sang et sont la terreur des poulaillers et des garennes. Ils répandent presque tous une odeur infecte. Ils comprennent les genres putois, marte, mouffette et lou- 
tre. Parmi les putois, se trouvent notre putois commun, le furet, la belette, l'hermine dont le pelage, brun et rosâtre pendant l'été, devient tout blanc pendant l'hiver; le mink de Russie, et différents putois de Pologne, de Sibérie des États-Unis, du Cap, etc. Les martes comprennent la marte commune, la fouine, le vison de l'Amérique du Nord, et la marte zibeline dont la fourrure est si belle et si estimée, et que l'on chasse, au milieu de l'hiver, sur les montagnes glacées de la Sibérie. Les loutres habitent les rivières, dans toutes les parties du monde, et même les bords de la mer dans le nord de l'océan Pacifique; leurs pieds sont palmés, leur queue est aplatie, et elles se nourrissent exclusivement de poisson. Les Indiens savent les employer pour la pêche, comme nous nous servons des chiens pour la chasse.

Le deuxième groupe de carnivores digitigrades, comprenant les chiens et les civettes, est caractérisé par deux dents tuberculeuses aplaties derrière la carnassière supérieure, qui elle-même présente un talon assez large. Ils sont carnassiers, mais sans montrer un courage proportionné à leurs forces, et vivent souvent de charognes. Ils ont tous un petit cœcum.

"Le chien domestique (Canis familiaris) L., varie à l'infini pour la taille, la forme, la couleur et la qualité du poil. C'est la conquête la plus complète que l'homme ait faite sur le règne animal; toute l'espèce est_devenue notre propriété; chaque individu est tout entier à son maître, prend ses mœurs, connaît et défend son bien, et lui reste attaché jusqu'à la mort. La vitesse, la force et l'odorat du chien en ont fait pour l'homme un allié puissant contre les autres animaux. Il est le seul qui ait suivi l'homme par toute la terre."

Quelques naturalistes pensent que le chien est un loup, d'autres que c'est un chacal apprivoisé : les chiens redevenus sauvages dans les contrées désertes, tout en ayant les oreilles droites, ne ressemblent cependant ni à l'un ni l'autre, et conservent la queue recourbée du chien domestique.

Le loup (Canis Lupus) L., a la même organisation que le chien et peut produire avec lui des métis féconds; mais, au lieu d'être éminemment sociable comme le chien, il vit habituellement solitaire et ne se réunit à d"autres loups que pour mettre leur force en commun, lorsque la faim les presse. Il a la taille et la physionomie du mâtin, dont les oreilles seraient droites, le pelage fauve et la queue droite. Il attaque tous nos animaux domestiques, et ne montre pas cependant un courage proportionné à sa force. Ses habitudes et son développement physique ont beaucoup de rapport avec ceux du chien.

Le chacal, ou loup doré, a plus de rapport encore avec nos 
chiens. Il habite les contrées chaudes de l'Asie et de l'Afrique et vit en troupes nombreuses dont les membres chassent en commun et se défendent mutuellement. Il est plus petit que le loup, a le museau plus pointu, gris-brun, les cuisses et les jambes fauve clair, la queue droite n'atteignant guère qu'au talon.

Les renards (Vulpes vulgaris, Brisson) sont distingués des chiens et des loups par une queue plus longue et plus touffue, par un museau rétréci et plus pointu, par leurs pupilles qui, de jour, sont contractées en ligne verticale, comme celle des chats; enfin par leurs incisives supérieures moins échancrées. Ils répandent une odeur fétide, se creusent des terriers, sont très-rusés et n'altaquent que les animaux faibles. On en connaît un grand nombre d'espèces répandues dans toutes les parlies du monde.

La sous-tribu des crvettes présente trois fausses moaires en haut, quatre en bas, dont les antérieures tombent quelquefois; deux tuberculeuses en haut, une seule en bas. Leur carnassière inférieure est pourvue en avant et rlu côté interne de deux tubercules saillants, le reste de cette dent étant plus ou moins tuberculeux; leur langue est hérissée de papilles aiguës et rudes; leurs ongles se redressent plus ou moins dans la marche, et près de leur anus est une poche plus ou moins profonde, où des glandes particulières font suinter une matière onctueuse et odorante. Cetle sous-tribu renferme plusieurs genres ou sous-genres: les civettes proprement dites, les genettes, les mangoustes, etc.

Le genre propre des civettes comprend deux espèces, la vraie civette (Viverra Civetta, L.), et le zibeth (Viverra Zibetha, L.).

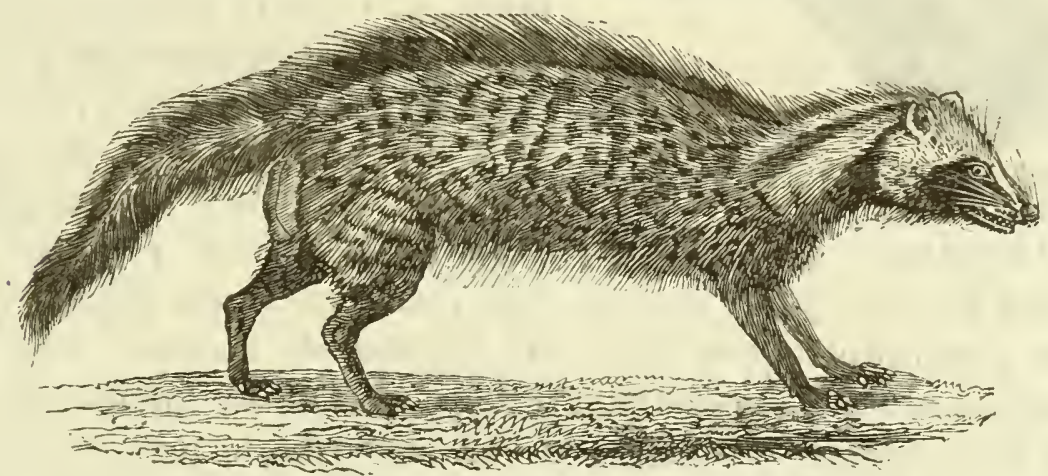

Fig. 826. - Civette.

La première ( $f g$. 826) hábite les contrées les plus chaudes de l'Afrique, depuis la Guinée et le Sénégal jusqu'en Abyssinie (1). Elle

(1): Voyez sur la structure des glandes odorantes : Joannès Chatin, Recherches pour servir à l'histoire anatomigue des glandes odorantes des mammi. fères (camassiers et rongeurs). (Thèse de doctorat et sciences, 1873, et Annales des sciences naturelles, t. XIX, $n^{\circ} 1$.) 
a environ 75 centimètres de long, non compris la queue, sur 27 à 32 centimètres de hauteur au garrot. Son museau est moins pointu que celui du renard et garni de longues moustaches; son poil est assez long, un peu grossier, el celui qui règne le long du dos et de la queue forme une sorte de crinière que l'animal relève lorsqu'on l'irrite; il est d'un gris variable, irrégulièrement rayé et tacheté de brun noirâtre. Les quatre jambes sont d'un brun noirâtre uniforme, ainsi que la moitié postérieure de la queve; le haut des membres et le commencement de la que ue sont marqués d'anneaux tigrés; la tête et le cou sont blanchâtres avec de larges bandes brunes.

Ce qui caractérise particulièrement la civette, c'est une bourse qui s'ouvre au dehors par une fente située entre l'anus et les organes de la génération (fig. 827). Cette fente est pareille dans l'un et l'autre sexe, ce qui les rend assez difficiles à distinguer extérieurement. Cette fente conduit dans deux cavités de la contenance d'une amande, dont la paroi interne est percée de

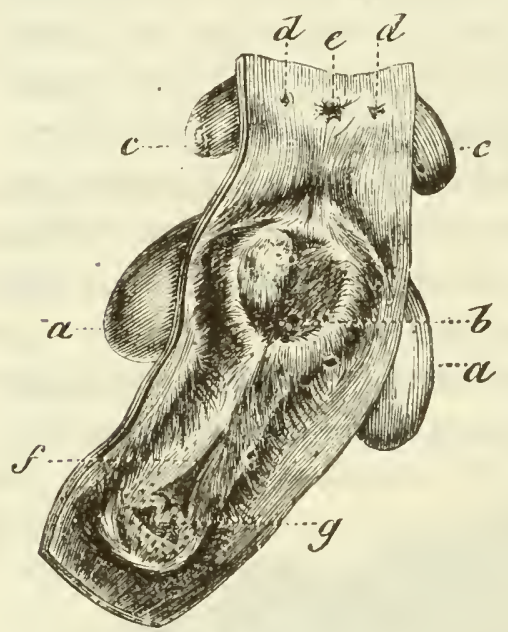

Fig. 827. - Appareil de la civette $(*)$.

plusieurs trous conduisant dans autant de follicules glanduleux dans lesquels se produit la substance odoriférante. Tous ces follicules sont enveloppés par une tunique gui reçoit beaucoup de vaisseaux sanguins, et le tout est recouvert d'un muscle qui peut comprimer les follicules et la bourse commune, et en faire sortir le parfum. Mais, pour se le procurer plus facilement, dans plusieurs parties de l'Afrique on élève les civettes en captivité, et, suivant des voyageurs, en Abyssinie, il y a des marchands qui en ont plus de 300 .

Tous les huit jours on vide leur poche avec une petite cuiller qu'on y introduit après avoir fixé l'animal de manière à ce qu'il ne puisse nuire à l'opérateur, ni faire des mouvemenț capables de le faire blesser lui-meme, et l'on renferme le parfum dans un vase qu'on bouche bien, ou mieux, à ce qu'il paraît, dans une corne creuse où la matière se dessèche en partie et acquiert un parfum plus agréable.

La civette parfum est une matière onctueuse de nature adiporésineuse; elle est d'abord jaunâtre et demi-fluide; mais elle brunit et devient très-épaisse en vieillissant. Telle que je l'ai,

(*) $a a$, glandes de la civette; $b$, leurs orifices sourrant daus la poche; $c c$, glandes anales; $d d$, leurs orifices; $e$, anus; $f$, vulve; $g$, clituris (Mloquin-Tandon). 
elle possède une odeur très-forte et ammoniacale, qui participe du musc et de la matière fécale, et qui est certainement fort désagréable; mais le papier qui recouvre le bouchon du flacon ne conserve qu'une odeur de musc pure et adoucie, qui explique la confusion qui a si longtemps existé, quant au nom et à la matière, entre le musc et la civette (1).

La civette a été usitée en médecine comme stimulante, nervale et antispamodique; mais elle n'est plus guère employée aujourd'hui que dans la parfumerie. N. Boutron en a donné une bonne description et un essai d'analyse (2).

Le zibeth $(f g .828)$ a beaucoup de ressemblance avec la civette; mais il a le poil plus court et touffu, pas de crinière, la

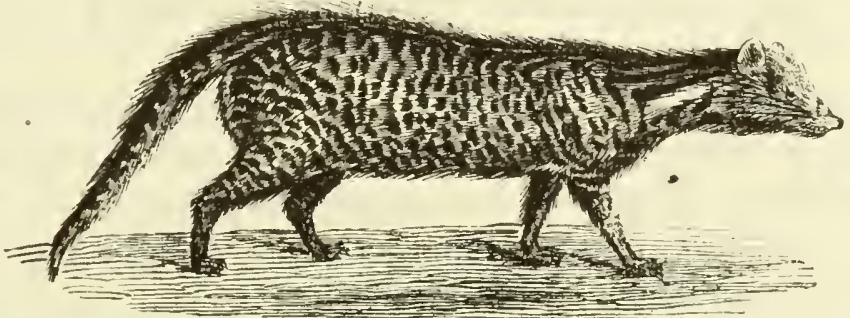

Fig. 828. - Zibeth.

queue ronde, à poil court et épais, blanchâtre, avec des demianneaux noir's sur toute sa longueur (3). Il habite les deux presqu'îles de l'Inde, les îles Moluques et les Philippines. On l'élève captif dans des cages, comme la civette d'Afrique, et on lui enlève sa substance odorante de la même manière, à l'aide d'une petite cuiller ou d'une tige creuse de bambou. On étale la matière sur des feuilles de poivre pour lui enlever les poils qui s'y trouvent mélangés, et on la lave, dit-on, avec de l'eau salée et du suc de limon, avant de la renfermer dans des boîtes de plomb.

Une troisième espèce de civette, propre à l'île de Java, nommée Viverra rasse, et qui est probablement l'animal au muisc de La Peyronie (4), produit un parfum comparable aux précédents; mais la genette commune (Genetta vulgaris, G. Cur.), qu'on trouve depuis la France méridionale jusqu'au cap de Bonne-Espérance, n'en fournit pas, sa poche à parfum se réduisant à un enfoncement très-léger presque sans excrétion. Cet animal diffère en outre des civettes par ses pupilles qui prennent à la lumière la

(1) C'est une espèce de civette qui se trouve décrite dans les Mémoires de l'Académie, année 1731, sous le nom de musc; d'un autre côté, les boîtes de musc de Chine contiennent, sous le couvercle, une représentation de la chasse d'un animal qui est une civette, et non un chevrotain porte-musc.

(2) Boutron, Journal de pharmacie, t. X, p. 537.

(3) Buffon, Hist. nat., t. IX, pl. 31 et 32.

(4) La Peyronie, Academie des sciences, 1731, p. 4 't3. 
forme d'une fente verticale, et par ses ongles qui se retirent entièrement entre les doigts comme ceux des chats.

Les mangoustes, Mangusta, ont la forme et les habitudes carnassières des fouines et des belettes, le poil et la dentition des civettes, dont elles diffèrent par leur poche simple et volumineuse, au fond de laquelle s'ouvre l'anus. Il en existe un assez grand nombre d'espèces ou de variétés, répandues dans toute l'Afrique, dans l'Inde et aux îles Malaises. Celle d'Égypte, (Mangusta Ichneumon), était connue des anciens sous le nom d'ichneu. mon et a élé nommée plus tard rat de Pharaon. Elle est longue de วั0 centimètres, mesurée depuis le bout du museau jusqu'à l'origine de la queue, et cette dernière partie est d'une longueur à peu près égale; la hauteur du corps n'atteint pas 20 centimètres.

Les anciens Égyptiens élevaient la mangouste en domesticité et lui rendaient une sorte de culte; elle leur rendait des services réels en détruisant les rats el les souris, les petits reptiles, et surtout en se nourrissant d'œufs de crocodile qu'elle sait très-bien trouver dans le sable où ils ont été déposés. Mais elle détruit la volaille et les lapins, étrangle les chats, attaque même les chiens, et sera d'autant moins utile et d'autant plus nuisible que le pays deviendra plus peuplé et plus civilisé. Elle y est plus rare qu'autrefois, et n'y est plus nulle part à l'État de domesticité.

La mangouste de I'Inde, et celle de ava (Mangusta javanica, E. Geoff.) décrite par Rumphius (1), ne ¿sont pas moins célèbres par leur instinct qui les porte à attaquer les serpents les plus venimeux, et par l'usage qu'elles font, dit-on, de certaines racines pour se guérir de leurs morsures. Ces racines, connues dans les Indes, ainsi que l'animal, sous le nom de mungo (dont Buffon a fait mangouste), sont surtout celle de l'Ophioxylum serpentinum et celle l'Ophiorhiza mungos, Rich., de la famille des Rubiacées.

La dernière subdivision des digitigrades manque complétement de petites dents derrière la grosse molaire d'en bas. Elle contient les animaux les plus cruels et les plus carnassiers de la classe; on les divise en deux genres, les hyènes et les chats.

Les hyènes (Hycena) ont trois fausses molaires en haut, quatre en bas, toutes coniques et singulièrement grosses; leur carnassière supérieure a un petit tubercule en dedans et en avant, mais l'inférieure n'en a pas et présente deux fortes pointes tranchantes. Cette armure vigoureuse leur permet de briser les os des plus fortes proies; leur langue est rude, leur train de derrière est beaucoup plus bas que celui de devant, et tous leurs

(1) Rumphius, Amboin. auctuar., p. 69, tab. 28. 
pieds n'ont que quatre doigts. Au-dessus de l'anus est une poche profonde et glanduleuse. Les muscles de leur cou et de leur mâchoire sont si robustes, qu'il est presque impossible de leur arracher ce qu'elles ont saisi, et qu'elles peuvent emporter dans leur gueule des proies énormes, sans les laisser toucher au sol. Malgré cette grande force, ce sont des animaux lâches et nocturnes, qui attaquent rarement les animaux vivants et se nourrissent plutôt de cadavres, qu'ils vont chercher jusque dans les tombeaux.

Les chats $(F e l i s)$ sont de tous les carnassiers les plus fortement armés; leur museau court et rond, leurs mâchoires garnies de dents fortes et tranchantes, et surtout leurs ongles rétractiles qui, cachés entre les doigts, dans l'état de repos, ne perdent jamais leur pointe ni leur tranchant, en font des animaux trèsredoutables, surtout les grandes espèces. Ils sont très-nombreux, presque tous semblables pour la forme du corps, la souplesse et l'élégance des mouvements, la force jointe à l'agilité, etc. Ils ne se distinguent guère que par la taille, la couleur et la lon. gueur du poil ou par d'autres caractères aussi peu importants. Les espèces principales sont, en Europe, le chat ordinaire et le lynx; en Asie, le tigre, le guépard et le mélas; en Afrique, le lion, la panthère, le léopard et le caracal; en Amérique, le jaguar, le couguar, l'ocelot, le serval, etc.

Carnassiers ampuibies. Cette troisième famille de l'ordre des carnassiers se compose d'animaux essentiellement aquatiques, qui passent la plus grande partie de leur vie dans la mer, qui ne viennent sur la plage, que pour se reposer ou allaiter leurs petits, et qui sont par conséquent organisés pour la nage et non pour la marche. Leurs pieds sont si courts et tellement enveloppés dans la peau du corps, qu'ils ne peuvent, sur terre, leur servir qu'à ramper; mais ils sont larges, aplatis, palmés et constituent d'excellentes rames. Leur forme générale se rapproche même un peu de celle des poissons; leur queue courte et cachée entre les pattes postérieures, qui sont dirigées en arrière dans le sens de l'axe du tronc; enfin leur poil est ras et serré contre la peau.

Les carnassiers amphibies se divisent en deux tribus : les phoques et les morses.

Les Phoques (Phoca) ont six ou quatre incisives en haut, quatre ou deux incisives en bas, des canines pointues ct des mâchelières au nombre de 20 à 24 , toutes tranchantes ou coniques, sans aucune partie tuberculeuse; cinq doigts à tous les pieds. Ils vivent de poisson, mangent toujours dans l'eau, et peuvent fermer leurs narines, quand ils plongent, au moyen d'une valvule. On les divise en phoques proprement dits, ou sans oreilles exté- 
rieures, et en phoques à oreilles extérieures ou otartes. On leur $\mathrm{r}$ donne vulgairement les noms de veau marin, lion marin, ours marin, selon que leur tête a paru ressembler à celle de ces animaux terrestres.

Les MORSES ( 7 richecus) ressemblent aux phoques par les membres et par la disposition générale du corps; mais ils en diffèrent beaucoup par la tête et par les dents. Leur màchoire inférieure manque d'incisives et de canines et se trouve comprimée en arrière par deux énormes canines ou défenses qui sortent de la mâchoire supérieure et se dirigent en bas, ayant quelquefois 60 centimètres de long sur une épaisseur proportionnée. On n'en distingue encore qu'une espèce, habitant les mers glaciales, et vulgairement nommée vache marine, à cause de sa taille qui surpasse celle des plus forts taureaux, et de son poil jaunâtre et ras. On la recherche pour son huile et pour ses défenses, dont l'ivoire, quoique grenu, peut être employé dans les arts. On îait avec sa peau d'excellentes soupentes de carrosses.

\section{ORDRE DES RONGEURS.}

Les rongeurs sont des mammifères onguiculés, véritablement vivipares, dont le système dentaire consiste en deux incisives à chaque mâchoire, séparées des molaires par un espace vide dû à l'absence des

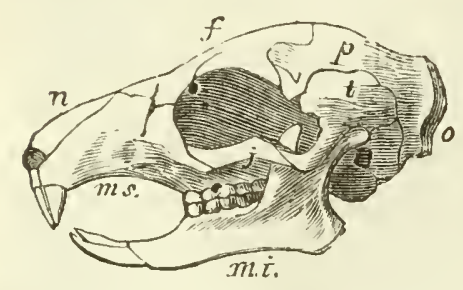

Fig. 829. - Tète d'écureuil $\left({ }^{*}\right)$. dents canines (fig. 829). Ces dents peuvent difficilement saisir une proie vivante et déchirer de la chair; mais elles peuvent, par un travail continu, réduire les corps dur's en parlicules déliées, en un mot les ronger. Pour mieux remplir cet objet, les incisives n'ont d'émail épais qu'en avant, en sorte que leur bord postérieur s'usant plus que l'antérieur, elles restent toujours taillées en biseau. En outre, la mâchoire inférieure s'articule par un condyle longitudinal, de manière à n'avoir de mouvement horizontal que d'arrière en avant, et vice versa, comme il convient pour l'action de ronger. Enfin les molaires ont des couronnes plates, dont les éminences d'émail sont toujours transversales, pour être en opposition au mouvement horizontal de la mâchoire, et mieux servir à la trituration.

Les genres où ces éminences sont de simples lignes et où la couronne est bien plane, sont plus exclusi vement frugivores; ceux dont les dents ont leurs eminences divisées en tubercules mousses sont omnivores; enfin, le pelit nombre de ceu $x$ qui ont des pointes altaquent plus volontiers les autres animaux et se rapprochent un peu des carnassiers.

La forme des rongeurs est en général telle que leur train de derrière

$\left(^{*}\right) m s$, maxillaire supérieur; mi, maxillaire inférieur; $n$, nasal; $f$, frontal, $p$, pariétal; $o$, occipital; $j$, pigal; $t$, temporal. 
surpasse celui de devant, en sorte qu'ils sautent plutot qu'ils ne marchent; leurs intestins sont fort longs, et leur cœeum souvent trisvolumineux. (Il manque dans le sous-genre des loirs.)

Dans tout cet ordre, le cerveau est presque lisse el sans circonvolulions; les orbjles ne sont pas séparées des fosses temporales; les yeux sont tout à fait dirigés de côté; les arcades zygomatiques, minces et c ourbées en bas, annoncent la faiblesse des mâchoires; les avant-bras ne peurent presque plus tourner, et leurs deux os sont souvent réunis : en un mol, l'infériorité de ces animaux se montre dans la plupart des détails de leur organisation. Cependant les genres qui ont de plus fortes clavicules jouissent d'une certaine adresse el se servent de leurs pieds de devant pour porter les aliments à leur bouche. On s'est servi de ce caractère pour diriser les rongeurs en deux sections, celle des noxgeurs CIAviculés et celles des RoNgeurs a clavicules impanfaites. La première renferme les tribus, genres ou sous-genres suivants :

Sciuriens : Écureuils, polatouches, aye-aye.

Muséides : Marmoltes, loirs, hydromys, rats, hamsters, gertilles.

Gerboisiens : Mérions, gerboises.

Héla Miens : Hélamys du Cap.

Arvicourifns : Campagnols, lemmings, ondatras.

Castoriens : Castors, coccias.

Rats-TAupes : Zemni ou rat taupe aveugle, oryctéres.

Chinchillens : Chinchillas, lagostomes, lagotis.

Les rongeurs à clavicules imparfaites comprennent les genres parcépic, pacca, lièrre, cabiai, cobaye, agouti.

Les rongeurs de petite taille, tels que les souris, les rats, les hamsters, les loirs et les campagnols, ne présentent aucune utilité sous le rapport de leur fourrure, et ne peuvent guère être cités que par les dommages que nous cause leur voracité; ceux de taille moyenne, comme les écureuils et les chinchillas, fournissent au commerce des pelleteries estimées; quant aux plus gros, tels que les castors, les lièvres et les lapins, on se sert de leurs dépouilles moins pour en faire des pelleteries proprement dites, que pour en séparer le poil avec lequel sont fabriqués les chapeaux de feutre. Les castors, que nous traiterons seuls en particulier, nous offrent un intérêt plus direct par la substance odorante qu'ils fournissent à l'art médical, où elle est connue sous le nom de castoréum.

\section{Castor et castoréum.}

Le castoréum est une sécrétion particulière au castor, Castor Fiber, L. ( $/ g .830)$, mammifère rongeur qui habite, rassemblé en société, les contrées incultes du Canada el de la Sibérie. Il paraît avoir été commun autrefois en Europe, et l'on en troure en- 
core quelques-uns en France, où on les nomme bièvres (1), en Allemagne, dans la Prusse et dans la Pologne; mais ils y deviennent de plus en plus rares. lls y sont fugitifs et solitaires, et n'y montrent pas cette industrie si vantée, qu'une vie plus tranquille leur permettrait sans doute de développer, comme dans le nord de l'Amérique ou de l'Asie.

Les plus gros castors ont de 10 à 13 décimètres de longueur, du museau à l'extrémité de la queue, et de 34 à 40 centimètres de largeur vers la poitrine. La tête ressemble à celle d'une

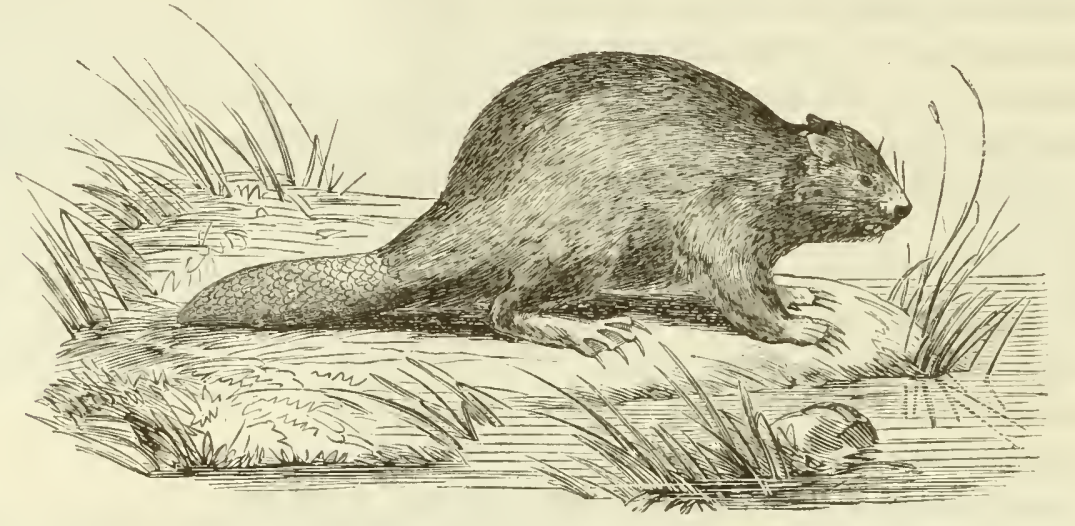

Fig. 830. - Castor.

marmolte, et est presque aussi large que longue, ayant 13,5 cen-

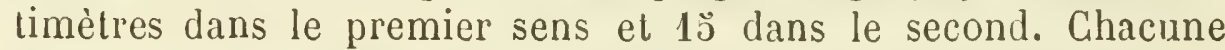
des mâchoires est garnie de dix dents, dont deux incisives sur le devant et quatre molaires de chaque côté. Les incisives infé. rieures sont longues de 27 millimètres el plus, mais celles d'en haut n'ont guère que 23 millimètres; elles sont toutes d'un jaune safrané au dehors, blanches en dedans, et fort tranchantes à l'extrémité qui est taillée en biseau, de dedans en dehors. Les molaires sont directement opposées les unes aux autres, à couronne plate, ayant l'air d'être faite d'un ruban osseux replié sur lui-même, en sorte qu'elles présentent une échancrure au bord interne et trois à l'externe dans les supérieures, et l'inverse dans

(1) Le castor se nommait de même en grec ( $x \dot{\alpha} \sigma \tau \omega \rho)$; mais toutes les nations occidentales de l'Europe l'appellent de noms qui ont une origine commune toute différente de la première. Ainsi les Latins le nommaient fiber, les Allemands l'appellent encore biber, les Italiens et les Espagnols bivaro, bevaro ou biverio, les Français tiëvre, les Anglais beaver, les Suédois baeffwer, les Polonais bobr. On pense que la petite rivière de Bièvre, qui se jette dans la Seine à Paris, doit son nom à ce qu'elle a été autrefois habitée par des castors; mais ils ont été plus abondants dans les îles du Rhône et dans ses affluents. Je crois que le dernier exemple d'un castor trouvé en France est celui pris sur les bords du Gardon, dans le Dauphiné, qui a vécu au Muséum disistoire naturelle. Il paraît qu'il en existe toujours sur le parcour's du Danube, et M. Théodore Martius compte le castoréum de Bavière au nombre de ceux qui servent à l'usage médical, en Allemagne. 
les inférieures. Toutes ces dents croissent pendant toute la vie de l'animal, et ne sont limitées dans leur longueur que par l'usure résultant de leur action sur les bois et les écorces, que les castors coupent ou dont ils se nourrissent. Les mamelles sont au nombre de quatre, dont deux placées près du cou, entre les paltes antérieures, et deux sur la poitrine.

La peau du castor est revêtue de deux sortes de poils : l'un gris, court, très-fin et bien fourni; l'autre brun, plus long, plus ferme et grossier. Les doigls des pieds de devant sont au nombre de cinq, courts, bien séparés, et garnis d'ongles très-forts; les doigts des pieds de derrière sont en nombre égal, mais beaucoup plus longs, réunis par une membrane pareille à celle des oiseaux palmipèdes, et destinés de même il la natation. La queue est aplatie, ovale, épaisse et couverte d'écailles comme le serait celle d'un poisson; on a même prétendu qu'elle en avait le goût: mais il paraît qu'on s'est exagéré la différence que son séjour habituel dans l'eau pouvait apporter à sa constitution intime. Cetle queue sert de gouvernail

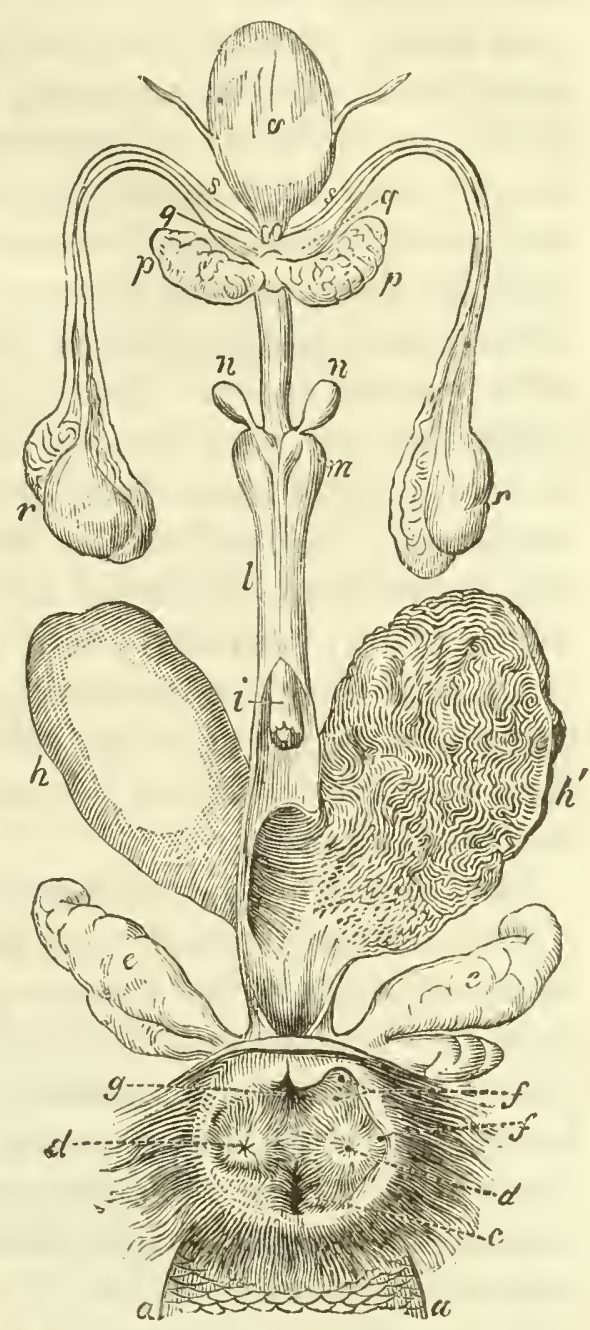

Fig. 831. - Parties de la génération et poches au castoréum du castor' mâle $\left({ }^{*}\right)$. à l'animal.

Les parties de la génération et l'anus.(fig. 831) s'ouvrent dans une poche commune qui aboutit à la naissance de la queue; la

(*) $a$, partie de la queue; $c$, ourerture de l'anus; $d d$, ourerture des glandes anales $e, e$, qui sécrètent une matière huileuse jaune, différente du castoı́ém. Chaeune de ces glandes est ordinairament aceompagnée de une ou plusieurs glandes plus petites renfermées avec elles dans um mème tissu cellulaire et dans une enveloppe musculaire commune, de sorte que, avant que cette envelopps soit ouverte, les glandes anales paraissent être au nombre de deux seulement; $f, f$, ouvertures des petites glandes anales; $g$, orverture du eanal préputial dans lequel viennent s'uavirir les deux glandes au castoréum, dont l'une $h$ est entière, et dont l'autre $h^{\prime}$ est représentée coupée longitudinalement, afin de montrer les replis membraneux de sa surface interne, d'où sécrète la substance du castoréum; $i$, prépuce cylindrique : il est couvert de petites papilles noirâtres, pointues, dirigées. en arrière; à l'extrémité du gland se trouve l'orifice de l'urètre; $l$, verge; elle contient dans toute sa longueur un os cartilagineux triangulaire; $m$, prostate; $n, n$, glandes de Cowper; $p, p$, vésicules séminales; $q, q$, vaisseaux déférents; $r, r$, testicules; $v$, ressie. 
verge, qui ne paraît pas au dehors, se dirige en arrière, et les. testicules sont cachés dans les aines: de chaque côté du conduit commun se trouvent deux paires de glandes, dont la paire inférieure, située près de l'anus et souvent accompagnée de quelques autres glandes plus petites, renferme une matière huileuse ja une, et d'odeur désagréable, qui n'est pas la sécrétion nommée castoréum. Celle-ci est contenue dans les deux glandes supérieures, que leur figure pyriforme et leur communication par leur partie la plus étroite font assez bien ressembler à une besace dont les deux poches seraient dirigées en haut. Dans l'animal adulte, ces poches n'ont pas moins de 8 centimètres de long, et elles peuvent en avoir jusqu'à 13. Elles sont bien différentes des testicules, qui sont placées dans les aines, comme je viens de le dire: d'ailleurs la femelle porte également ces glandes au castoréum, quoique moins développées que chez le mále. Ces détails montrent l'absurdité de l'opinion anciennement répandue, que le castor, poursuivi par les chasseurs, s'arrache les testicules, et les leur abandonne comme sa rançon, puisque les glandes au castoréum ne sont pas les testicules, et que les uns et les autres sont situés à l'intérieur du corps, et hor's de toute alteinte de la part de l'animal.

Au Canada, et probablement aussi en Sibérie, les castors vivent solitaires pendant l'été, dans des terriers qu'ils se creusent dans le roisinage des rivières; mais, aux approches de l'hiver, ils se rassemblent en grand nombre et choisissent un lieu propice pour y établir leurs communes demeures; c'est toujours sur le bord d'un lac ou d'une rivière assez profonde pour ne pas geler jusqu'au fond. Si l'eau est tranquille et dormante, ils élèvent immédiatement leurs cabanes sur le rivage ; si au contraire c'est une eau courante et sujette à des crues, ils commencent, avant tout, par bâtir au travers une forle digue composée d'arbres renversés, de branches, de pierres et de limon, le tout crépi et recouvert d'un enduit solide. Cette digue est toujours perpendiculaire du côté du courant, et taillée en talus ou en dos d'âne du côté opposé, de manière qu'elle a au plus 60 centimètres d'épaisseur à la partie supérieure, mais qu'elle en a 3 à 4 mètres à la base, ce qui lui donne une grande solidité. Dès qu'elle est élevée, les castors y adossent leurs cabanes, composées des mêmes matériaux, à plusieurs étages, et assez grandes pour loger chacune huit ou dix individus. 'Tous ces travaux ne se font que la nuit, et avancent avec une rapidité surprenante; les castors n'ont cependant pour outils que leurs dents, leurs ongles et leur queue. Lorsqu'ils ont terminé, ils s'approvisionnent d'écorces pour l'hiver, et se renferment chez eux. 
La chasse des castors se fait ordinairement en hiver, époque à laquelle leur fourrure est le mieux fournie et la plus belle. Lorsqu'ils entendent l'arrivée des chasseurs, ils fuient sous l'eau; mais le besoin de respirer les force à remonter dans des endroits où l'on a cassé la glace, et c'est alors qu'on les prend. Leur fourrure est recherchée, surtout à cause du duvet fin dont elle se compose en partie, lequel est très-estimé pour la fabrication des chapeaux de feutre. Mais la consommation en est considérablement diminuée, soit parce qu'on lui substitue presque entièrement le poil de lièvre ou de lapin, soit parce que la fabrication des chapeaux de soie a remplacé en grande partie celle des chapeaux feutrés.

Le castoréum, quoique beaucoup moins usité aujourd'hui qu'autrefois pour l'usage médical, reste encore cepenủant un objet de commerce assez important. On en distingue deux espèces principales, celui de Russie et celui d'Amérique. Ce dernier es le seul qui soit employé én France et en Angleterre, et c'est lui que je décrirai principalement.

Castoréum d'Amérique. On distingue encore dans le commerce anglais deux sortes de castoréum d'Amérique, celui du Canada et celui de la baie d'Hudson; mais je pense que celle distinction est plutôt nominale qu'effective, et que la presque totalité du castoréum d'Amérique est importée aujourd'hui par la compagnie de la baie d'Hudson. Je pense enfin que les castoréums de ces deux contrées peuvent offrir, chacun de leur côté, de grandes variations dans leur volume et dans leur qualité, suivant l'âge de l'animal, la nature et l'abondance plus ou moins grande de sa nourriture, l'époque de l'année, elc.; de sorte qu'il doit être fort difficile de leur assigner une origine cerlaine : c'est pourquoi je les comprends tous deux sous le seul nom de castoréum d'Amérique.

Ce castoréum est onctueux et presque fluide dans l'animal vivant, mais le commerce nous le présente desséché dans ses deux poches, encore unies ensemble, à la manière d'une besace, et plus ou moins ridées et aplaties. Il a encore une odeur trèsforte et même fétide; une couleur brune noirâtre à l'extérieur; brune, fauve ou jaunâtre à l'intérieur' une cassure résineuse entremêlée de membranes blanchâtres; une saveu $r$ âcre et amère. Souvent aussi, au lieu d'être tout à fait sec, le castoré um, étant plus nouveau, conserve une certaine mollesse, el alors son odeur et sa saveur sont encore plus fortes; mais il faut pren dre garde de confondre cette force avec celle résultant de l'altération qu'éprouve le castoréum conservé dans des lieux humides, et, dans tous les cas, il fitut préférer le castoréum sec, et pourvu de 
l'odeur forte qui lui cst propre. Il donne avec l'alcool et l'éther des teintures brunes très-foncées, qui blanchissent fortement par l'eau et laissent précipiter une matière résineuse brune odorante, molle et tenace.

Ainsi que je l'ai dit ci-dessus, le castoréum d’Amérique varie beaucoup en qualité suivant l'âge de l'animal, l'abondance et la nature de sa nourriture, et surtout, probablement, suivant l'époque plus ou moins éloignée du temps du rut à laquelle il a été tué. Tantôt, en effet, l'appareil membraneux et glanduleux qui forme l'intérieur des poches est presque vide de matière résinoïde odorante, et tantôt il en est entièrement gorgé. Dans le premier cas, le castoréum desséché présente une cassure ou une déchirure toute fibreuse, et dans le second il en présente une nette et résineuse, qui ne laisse apercevoir les fibres et les membranes interposées que lorsque la matière résineuse a été dissoute par l'alcool.

Je donne ici, entre beaucoup d'autres, trois figures remar-

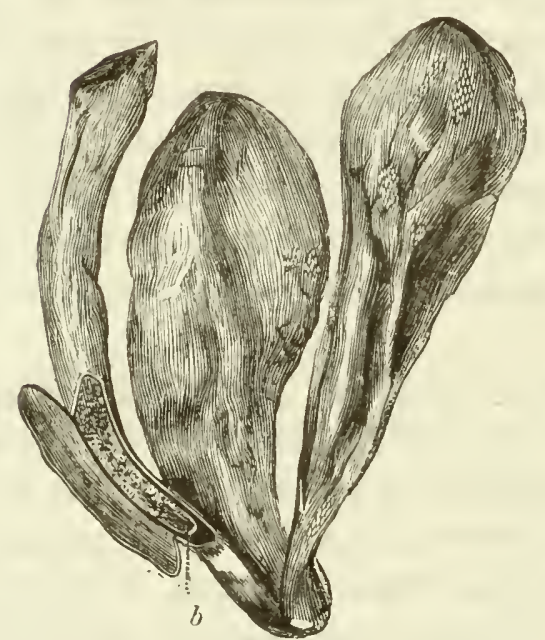

Fig. 832. - Castoréum d'Amérique.

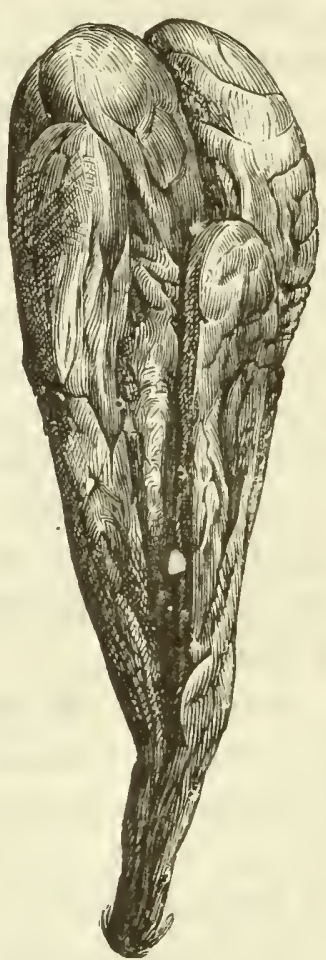

Fig. 833. - Castoréum d'Amérique.

quables de castoréum d'Amérique. Dans la figure 832, les deux poches, longues de 8 à 9 centimètres, sont accompagnées de la verge $a$ dont le gland, osseux et couvert de papilles épineuses, se termine en $b$. La figure 833 présente la réunion de quatre poches dont les deux supérieures, longues de 13 centimètres, sont les po- 
ches ordinaires du castorêum. Les deux autres poches, plus petites et plus étroites, sembleraient ne pouvoir être que les glandes anales, destinées à la sécrétion de la matière grasse et onctueuse qui sert probablement au castor à enduire sa queue et sa fourrure; et cependant elles sont conformées comme les premières, et la matière qu'elles renferment est semblable à celle qui est contenue dans les grandes poches. La figure 834 représente les quatre

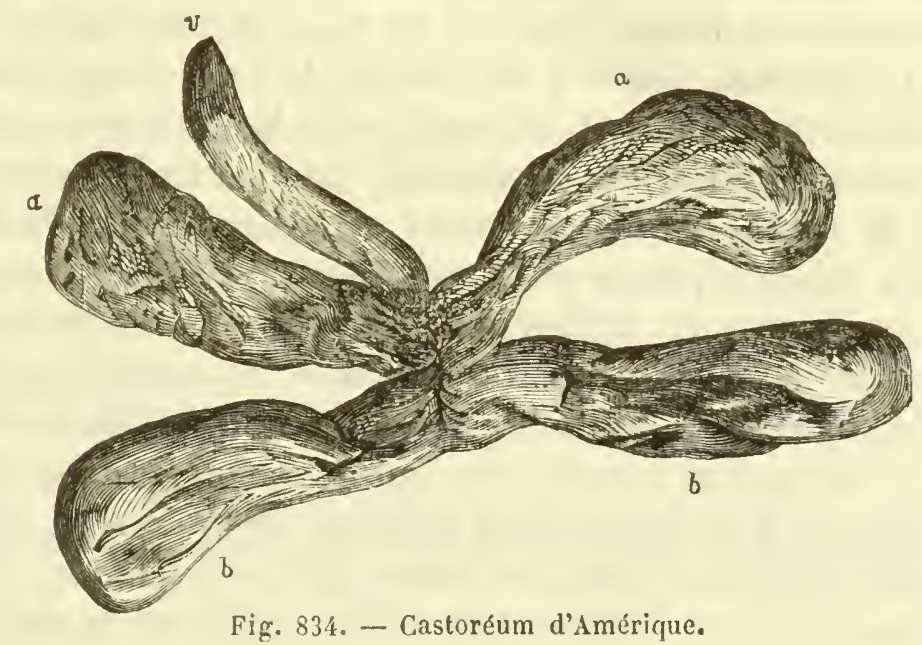

poches d'un jeune castor. La verge $v$ était collée contre l'une des poches a qui sont épaisses, charnues, d'une couleur brune noirâtre à l'intérieur, et remplies d'un suc résineux de même couleur. Ces poches paraissent être les vraies poches au castoréum non encore développées. Les deux poches $b$ sont beaucoup plus sèches à l'intérieur et d'un jaune rougeâtre. Ce sont les poches dites inférieures ou anales, qui sécrètent une liqueur jaune, félide, de nature adipeuse, différente du castoréum.

Castoréum rouge orangé, résineux. J'ai trouvé quelquefois dans le commerce une sorte de castoréum beaucoup plus belle en apparence que celle que je viens de décrire, mais qui lui est certainement inférieure en qualité : les poches sont très-volumineuses et arrondies, remplies d'une matière quelquefois molle, souvent sèche et cassante, toujours d'une assez belle couleur rouge, et donnant une poudre aurore, tandis que la poudre du bon castéorum est couleur de terre d'ombre. Celte matière est de nature résineuse, demi-transparente, peu entremêlée de membranes, d'une odeur faible, d'une saveur de cire qui serait aromatisée avec du castoréum : elle est presque entièrement soluble dans l'alcool et dans l'éther. Quelques personnes ont pensé que ce castoréum avait été altéré par l'introduction frauduleuse d'une matière résineuse dans les poch€s qui le contiennent; mais, ainsi qu'on le verra plus loin, je suis porté à croire que sa nature par- 
ticulière a été déterminée par celle des végétaux dont l’animal a fait sa nourriture habituelle.

M. Delime, pharmacien à Paris, m'a montré un très-bel échantillon de ce castoréum, qui lui a été envoyé d'Allemagne sous le nom de castoréum de Russie, et qui se rapporte en effet aux descriplions et aux analyses de cette sorte de castoréum qui ont élé faites en Allemagne; mais il diffère beaucoup par sa nature des castoréums de Russie que j'ai pu voir, et celte même nature purement résineuse, jointe à son odeur, le rapproche davantage du castoréum du Canada. L'échantillon de M. Delime se compose de deux poches pyriformes arrondies, longues de 8 centimè tres, larges de 6 , terminées brusquement et unies l'une à l'autre par un conduit desséché, large de 1 centimètre, long de 7, ayant au milieu une ouverture commune longue de 2 centimètres. Le poids total des poches est de 215 grammes; la membrane qui les recouvre est mince et noirâtre, comme celle du castoréum du Canada, la substance interne est complétement résineuse, d'un rouge orange, d'une odeur assez forte de castoréum du Canada, et d'une saveur amère jointe au même goûl aromatique. Elle se ramollit sous la dent comme une résine huileuse ou comme de la cire.

Castoréum de Itussie. La plupart des auteurs ont distingué deux sortes de castoréum, ceux de Russie et du C'anada, et plusieurs d'entre eux, tels que les continuateurs de Geoffroy et Valmont de Bomare, se bornent à dire que le castoréum qui nous vient de Russie et de Pologne, par la voie de Dantzick, est estimé meilleur que l'autre. Des auteurs plus modernes donnent des caractères pour distinguer ces deux produits; mais je pense qu'ils se sont généralement trompés en présentant le castoréum de Russie comme celui dont on fait principalement usage en médecine, et en décrivant comme tel le castoréum d'Amérique, qui est presque le seul que l'on trouve dans le commerce.

Quant à moi, jusqu'à l'année 1831, je n’avais vu et décrit que le castoréum d'Amérique (1). En cette année seulement, un négociant français, revenant de Moscou, rapporta 40 onces ( 1250 grammes) de castoréum de Sibérie; mais comme il ne voulait le livrer qu'au prix de 80 francs l'once, la vente ne put en être effectuée, et je ne sais ce que l'homme et la marchandise sont devenus.

Ge castoréum, montré à un médecin polonais, fut reconnu par lui pour le castoréum de Sibérie, usité en Pologne et en Galicie, où il est très-estimé et fort cher. Il paraissait probable cependant

(1) En supposant toujours que le castoréum rouge orangé résineux soit d'origine américaine. 
qu’il arait subi une préparation qui l'éloignait de son état naturel. Voici les caractères que je lui ai trouvés.

Au lieu d'être en poches isolées, allongées, pyriformes et ridées, comme le castoréum du Canada, celui de Sibérie était en poches pleines, arrondies, plus larges que longues, et comme formées de deux poches confondues en une seule. Un échantillon unique sur les 40 onces offrait deux poches ovoldes aux trois

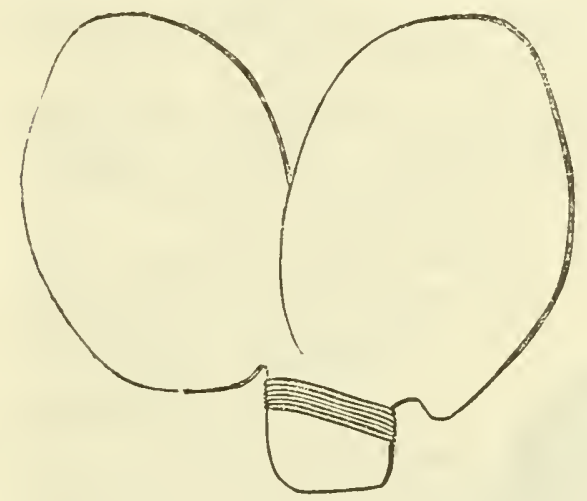

Fig. 835. - Castoréum de Sibérie.

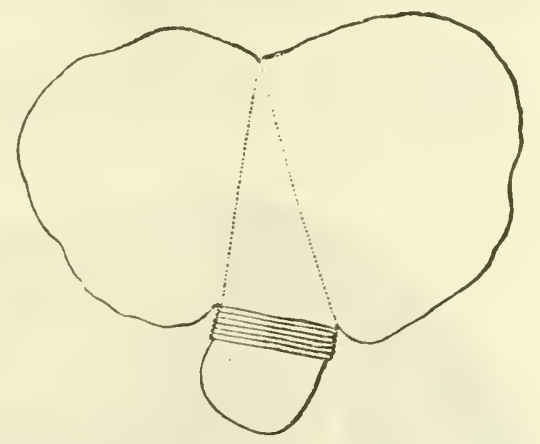

Fig. 836. - Castoréum de Sibérie.

quarts séparées ( $/ g .835)$, et la forme de quelques autres indiquait une division intérieure $(f \mathrm{~g} .836)$; mais la presque totalité offrait une fusion complète de deux poches en une seule ( $\mathrm{fg} .837$ ). Les dimensions naturelles de ces trois ćchantillons étaient, non compris le collet, pour le premier, 73 millimètres de largeur totale sur šs̆ millimètres de hauteur; pour le deuxième, 67 millimètres sur 45 ; pour le troisième, 84 millimètres sur 40 .

Ce castoréum a une odeur d'empyreume aromatique, analogue à celle du cuir de

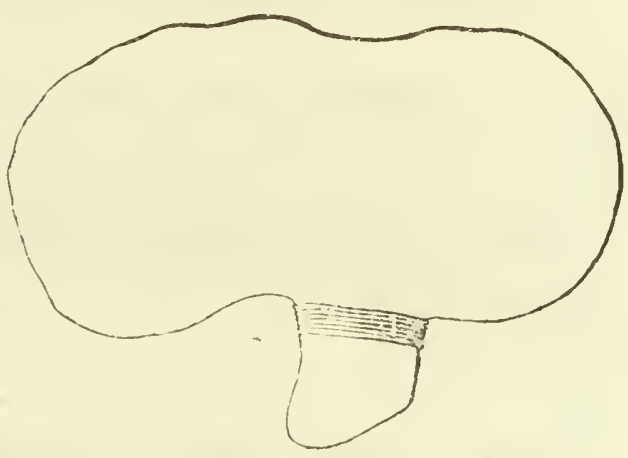

Fig. 837. - Castoréum de Sibérie.

Russie, très-forte et susceptible d'une grande expansion. Ce n'est que lorsque cette odeur s'est dissipée que les doigts qui l'ont touché laissent apercevoir l'odeur propre au castoréum du Canada. Il a une consistance solide, presque sèche et friable; il est jaunâtre, graveleux sous la dent, d'une saveur peu sensible d'abord, puis très-amère et aromatique. Il forme arec l'alcool une teinture à peine colorée, non-seulement parce qu'il lui fournit peu de matière soluble, mais encore parce qu'il manque du principe colorant rouge du castoréum du Canada. 
Il fait une vive effervescence avec les acides, et contient une forte proportion de carbonate de chaux.

Castoréum de Russie de M. Pereira (1). Dans celte sorle de castoréum (fig. 838), les poches sont accolées deux à deux, mais sont complétement distinctes, comme celles du castoréum d'Amérique; elles ne paraissent pas atteindre le volume des plus grandes poches d'Amérique; elles sont plus courtes el plus arrondies, diversement comprimées par la dessiccation, longues de 6 centimètres, larges de 3,5 à 4 centimètres (2).

La pellicule exlérieure est sèche, transparente et d'un gris brunâtre. On trouve au-dessous une membrane fibreuse, opaque,

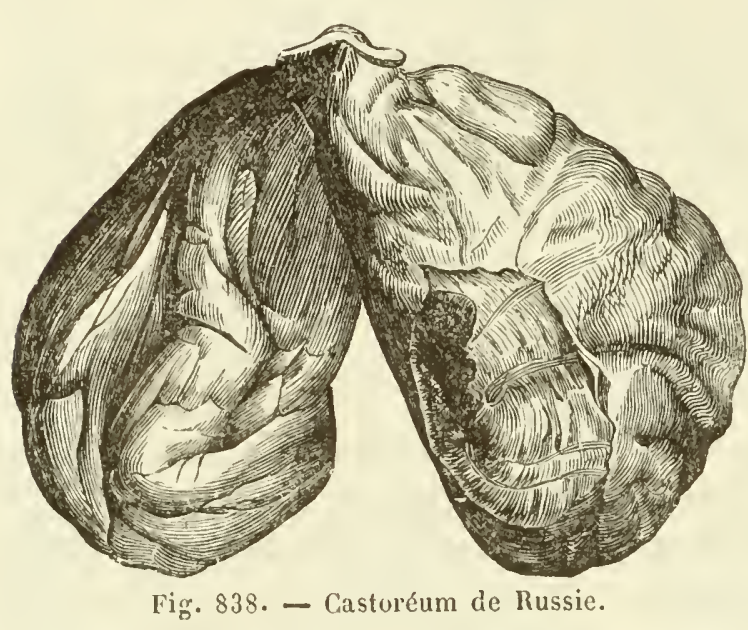

branche et nacrée, dont les plis pénètrent dans l'intérieur de la poche et paraissent la diviser en plusieurs chambres. Par la dessiccation, ces plis intérieurs se contractent et forment des brides, entre lesquelles la substance du castoréum se boursoufle au dehors et donne à la surface de la poche une apparence mamelon-

née. La substance même du castoréum est d'une couleur rougeâtre, d'une apparence lerne et grumeleuse, n'offrant pas la cassure résineuse du bon castoréum du Canada; elle ne se ramollit pas non plus sous la dent, mais s'y réduit en poudre. Ellc répand dans la bouche un goût très-fort, analogue à celui de la créosote, el finit par devenir amère. Elle offre une odeur mixte de castoréum et de cuir de Russie; enfin elle fait une vive effervescence avec l'acide chlorhydrique, quoique ce caractère soit moins marqué que dans le castoréum de Sibérie apporté en 1831.

Composition chimique. De toules les analyses de castoréum qui ont élé publiées, je ne rapporterai que les deux suivantes, dues à Rudolph Brandes.

(1) Pereira, London medical Gazette, t. XVII, p. 206.

(2) Les deux poches figurées ci-dessus, appartenant à M. Pereira, ne pèsent que 557 grains troy ( 35 grammes). Une poche isolée du même castoréum, conservée dans le droguier de l'École, pèse $28^{\mathrm{gr}}, 5$, ce qui fait 57 grammes pour deux. J'ai pesé un certain nombre de besaces de castoréum d'Amérique trèsbeau et très-sec: les plus légères pesaient $36^{\mathrm{gr}}, 5$; la plus lourde 86 grammes; la moyenne de toutes était de 60 grammes. 
Castoréum

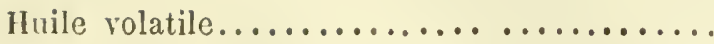

Résine de castoréum...................

- avec urate et benzoate de chaux......

Cholestérine.. .....................

Castorine............................... chaux.......................

Albumine avec un peu de phosphate de chaux.

Matière gélatineuse....................

Osmazome soluble dans l'eau et l'alcool......

Matière gélatineuse obtenue par la potasse.

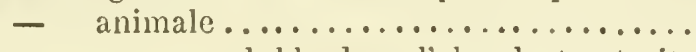

- _ soluble dans l'alcool et extraite par la potasse............

Mucilage albumineux analogue ì la corne...

Carbonate d'ammoniaque................

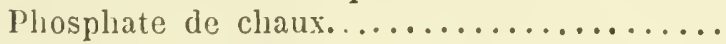

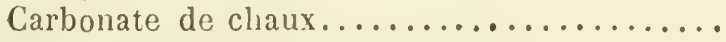

- de magnésie ...................

Sulfate de potasse, sulfate et phosphate de

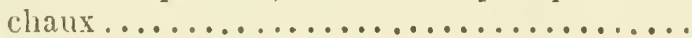

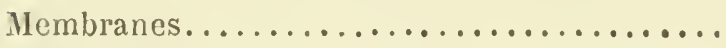

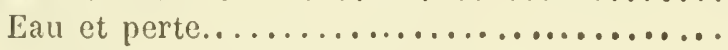

\begin{tabular}{|c|c|}
\hline $\begin{array}{c}\text { de Russie. } \\
20\end{array}$ & $\begin{array}{c}\text { du Canada. } \\
20\end{array}$ \\
\hline 586 & 122,5 , \\
\hline » & $16\}$ \\
\hline 12 & ) \\
\hline 25 & 51 \\
\hline " & 13,5 \\
\hline 16 & 0,5 \\
\hline 20 & ") \\
\hline $2 t$ & 2 \\
\hline $8 \dot{t}$ & $n$ \\
\hline 》 & 23 \\
\hline 16 & ) \\
\hline » & 23 \\
\hline 8 & 8,2 \\
\hline 14 & 14 \\
\hline 26 & 336 \\
\hline 2 & 4 \\
\hline » & 2 \\
\hline 33 & 192 \\
\hline 114 & 226,3 \\
\hline 1000 & 1000 \\
\hline
\end{tabular}

[Depuis lors, on a étudié, à nouveau la composition chimique de ces castoréums et l'on y a mentionné la présence de la salicine et de l'acide salycilique (1), ainsi que celle de l'acide carbolique. Quant à la castorine, corps de nature grasse, qu'on sépare du castoréum au moyen de la benzine, Hager (2) a montré qu'elle existe en plus grande quantité dans le castoréum de Russie que dans celui du Canada, le premier en contenant 46 pour 1000 , le second 19 seulement.

Quant aux moyens de distinguer les deux espèces de castoréum l'une de l'autre, Hager a, dans lemême travail, établi que :

Le castoréum de Russie a une saveur beaucoup plus prononcée que celui de Canada.

Traités par le chloroforme, après action de la benzine, les castoréums donnent une masse résineuse brunâtre, qui dans celui du Canada devient sèche et d'une odeur faible, tandis que dans celui de Russie elle est comme visqueuse et a l'odeur forte et spéciale de ce castoréum.

Si on traite le castoréum én poudre par l'alcool, puis par l'acide chlorhydrique étendu, on obtient, au bout de 10 ou 20 heures de repos, une liqueur jaune brun analogue à de la bière avec le

(1) Wöhler. Revue scientifique, XIV, 22.

(2) IIager, Pharm. centralhalle, X, 57, 
castoréum du Canarla, une liqueur brun foncé ou rouge brun avec celui de Russie. De même avec une solution ammoniacale la pouble de castoréum de Sibérie donne une solution plus foncée que l'autre espèce.

linfin, il faut rappeler, à côté de ces moyens de distinction, celui qui a ete indique il y a plus 50 ans par Kobli : la tcinture alconlique de castoréum donne avec l'eau un liquide laiteux, qui s'éclaireit si le castoréum est celni de liussic, qui reste plus au moins lrouble avee le castoréum du Canada.

Hyracínm. L'hyracéum est produit par le daman d'Afrique (Ilirax capensis, Bulf.), animal föt singulier, de la grandeur d'un fort lièvre, que plusieurs naturalistes ont rangé parmi les rongeurs, mais que Cuvier a placé daus les pachydermes, à la suite des rhinocéros, en raison de la conformite de structure de leurs dents mâchelieres. Cependant le daman da Cap diffère des rhinocéros, non-seulement par sa très-petite taille et par l'adjonelion de deux pelites canines à la mâchoire supérieure, mais encore parce qu’il a quatue doigh aux pieds antéricurs, et que le plus interne de ses trois doigts de derrière, au lieu d'être reconvert d’un pelitsabotatrondi, est armé d'un ongle crochu čloblique.

"Les Ilollentots, dil Bulfon (1), estiment beaucoup une sorle de remède que les Hollandais nomment pissal de blaireau (2)). C'est une substance noiratre el d'assez mauvaise odeur qu'on trouve dans les lentes des rochers el des cavernes. On prétend que e'est a l'urine de ces bêtes qu'elle doit son origine. Ces animaux, diton, ont l'habitude de pisser loujours dans le même endroit, et leur urine dépose cette substance qui, séchée avec le temps, prend de la consistance; cela est assez vraisemblable."

[L'examen microscopique confirme en partie celle opinion, en montrant, dans l'hyracéum des lamelles rhomboüdales d'acide urique. Mais en même lemps il y décèle la présence de débris végélaux bien caractérisés, intimcment mêlés a la substance. Ces fragments font évidemment partie des excréments de l'animal, qui se nourrit essentiellement de plantes et particulièrement du C'yclopia gonistordes nommé vulgairement Iluningthe (buison de miel). Il faut donc admeltre avec André Smith, Pereira et M. Léon Soubeiran, que l'hyracéum est un mélange de l'urine et des fèces du daman (3).]

L'hyracéum paraît avoir été utile. en Allemagne comme agent

(1) Buflui, Supplém., t. VI, p. 280.

(2) L'animal a aussi porté les noms de, blaircau des rochers et de marmotle du $C$ (u).

(3) Voir sur ce sujet: Pereiri, Pharmaceutical Jomrnal, t. X, 119, et Léon Soubeiran, Joitrn. rée pharm. et de chimie, $3^{\mathrm{e}}$ sérje, XXIX, 378. 
lbérapeutique, mais il est encore incornu en France. Il se présente sous la forme d'une masse brune foncee, dure, pesante quelque peu semblable au bdellium de l'Inde ou à de la myrrhe noire; il se laisse entamerau couteau et se ramollit entre les doigts. L'odeur en est urineuse, un peu analogue à celle du castoréum; la saveur en est amère et un peu astringente. Il est un peu soluble dans l'éther sulfurique et dans l'alcool pur, plus soluble dans l'alcool faible el encore plus dans l'eau. Les acides en degagent de l'acide carborique, et les alcalis fixes de l'ammoniaque (1). On en a publié ure analyse qui ne peut être exacte.

Laugier (2) a donné la description el l'analyse d'une excrétion animale que l'on a trouvée tapissant les parois de la grotte de l'Arc, dans l'île de Cáprée, sur l'origine de laquelle on ri'a pu faire que des conjectures, mais qui doit en avoir une analogue à celle de l'hyracéum. Celle substance avait une odeur mixte de tan, de castoréum et de fiente de vache; elle était en grande partie soluble dans l'eau, et renfermait, indépendamment d'une matière brune, extractive, azotée, du nitrate de potasse, du chlorure de potassium, du benzoate de potasse et du sulfate de chaux.

L'extrait aqueux, chauffé dans une cornue, avec un peu d'acide sulfurique affaibli, formait un sublimé d'acide !enzö̈que. Le castoréun du Canada, essayé comparativement, a donné lieu au mêrne résultat.

\section{Ondatra, ou rat musqué du Canada.}

L'ondatra (3) est un quadrupède rongeur, du genre des campagnols, qui habite en grand nombre le Canada. De même que le castor, il se réunit aux approches de l'hiver, sur le hord des eaux, pour se construire des hultes en terre, ou il habite en commun. Il se nourrit de plantes arquatiques et principalement de racines de nymphrea el d'acorus, dont la dernière ne parait pas être étrangère à la production du parfum qui le caractérise. Mais il est vorace el se nourrit de chair à défaut de végétaux; on dit même que les ondatras se dévorent entre eux, pendant l'hiver, lorsque toute autre nourriture vient à leur manquer, et que les chasseurs ne trouvent plus alors dans les huttes que les débris des animaux qui les avaient construites.

L'ondalra (Ondatra-zibethica), de même que les rats, n'a que trois molaires de chaque côté, à chaque mâchoire; mais ces molaires n'ont pas de racine et sont comme formées, sur toule

(1) Voir le Journ. de pharm. el de chirr.ie, t. XVII, p. 1:38.

(2) Arrales du. Uuséurn d'hist. not., t. IX, p. 321.

(2) Euffon, Hist. nrit., t. X, pl. I. 
leur hauteur, de prismes triangulaires placés alternativement sur deux lignes. Il a cinq doigts à tous les membres, et ceux de derrière sont demi-palmés; la queue est écailleuse comme celle du castor, mais couverte aussi d'un assez grand nombre de poils courts qui sortent au nombre de 1, 2 ou 3, de dessous chaque écaille. Elle est aussi plus étroite, aplatie dans le sens vertical, et comme à deux tranchants. La femelle a six mamelles abdominales, et l'ouverture de l'urètre distincte de celles du vagin et de l'anus, situées plus près de la queue. Il n'en est pas de même chez le mâle qui n'a qu'une seule ouverture pour l'urètre et pour la verge, située au-devant de l'anus. La verge est dirigée en arrière, et est accompagnée de deux glandes pyriformes écartées en forme de $\mathrm{V}$, comme dans le castor, et dont le canal excréteur se prolonge le long du pénis et vient s'ouvrir sous le prépuce. La femelle porte deux glandes semblables, mais plus petites, qui viennent s'ouvrir à l'entrée de l'urètre. Ces follicules excrètent une liqueur blanche et opaque comme du lait, et d'une forte odeur de musc, qui se communique au pelage de l'animal (1) et à sa queue. Je représente $(/ g .839)$ une de ces queues

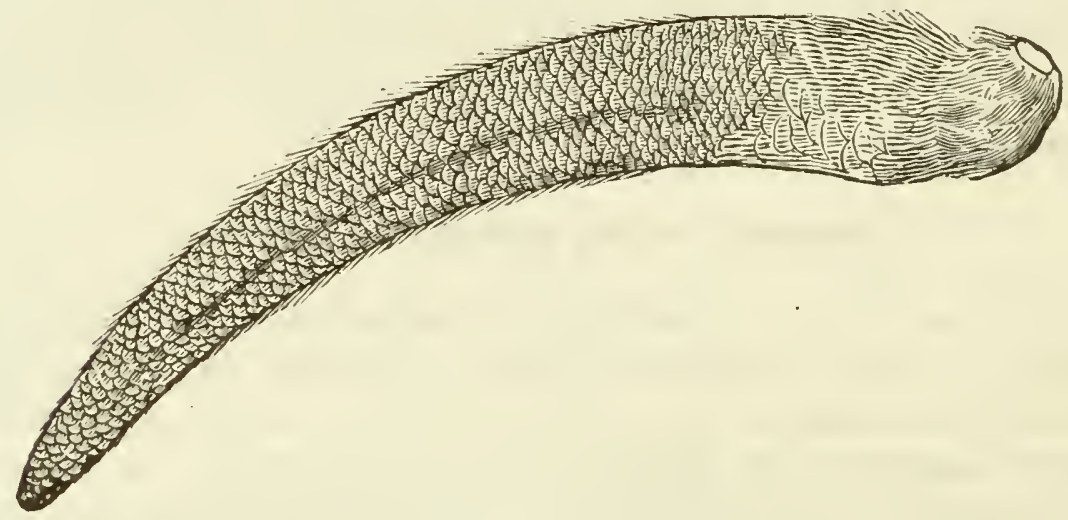

Fig. 839. - Queve d'ondatra.

prises, il y a nombre d'années, dans le commerce de la parfumerie, et qui conservent toujours une forte odeur de musc. Celle qui est ici représentée a 17 centimètres de longueur sur 2, ,̌ centimètres dans sa plus grande largeur: d'autres ont 19 centimètres de longueur sur $1, \check{\text { à }} 2$ centimètres seulement de largeur.

On connaît deux autres animaux sous le nom de rats musqués: l'un esl le rai musqué des Antilles ou pilori (Mus Pilorides, Pallas); il est long de 41 centimètres, non compris la queue qui est encore plus longue, écailleuse et cylindrique comme celle des

(1) De même que le castor, l'ondatra possède deux sortes de poils, dont le plus fin a été usité pour la fabrication des chapeaux. Sa peau ferait de belles fourrures, mais on ne l'emploie pas à cause de sa forte odeur musquée. 
rats; il est très-vorace et très-nuisible. L'autre est le rat musqué de Russie ou desman (1) (Mygale moscovita, Geoff.), mammifère insectivore dont le museau s'allonge en une petite trompe trèsflexible, dont tous les membres ont cinq doigts palmés et dont la queue est longue, écailleuse et aplatie sur les côtés comme celle de l'ondatra. Il est presque grand comme un hérisson, et fort commun le long des rivières et des lacs de la Russie méridionale. Il s'y nourrit de vers, de larves d'insectes et surtout de sangsues qu'il retire aisément de la vase avec son museau mobile; son terrier, creusé dans la berge, commence sous l'eau et s'élève de manière que lc fond se trouve placé au-dessus du niveau des plus grandes eaux. Son odeur musquée provient d'une matière onguentacée sécrétée dans de petits follicules placés sous la queue. Cette odeur se communique même à la chair des brochets qui mangent les desmans. La queue du desman, par ses dimensions et par sa forme, paraît devoir ressembler beaucoup à celle de l'ondatra.

\section{ORDRE DES ÉDENTÉS.}

Les mammifères de cet ordre manquent d'incisives et sont pourvus d'ongles très-gros qui embrassent l'extrémité des doigts et se rapprochent de la nature des sabots; ils sont peu nombreux et ne composen $t$ que deux familles, les tardigrades et les édentés vrais.

Les tardigrades ou paresseux ont la tête courte, deux mamelles pectorales et des membres tellement dispropurtionnés que leurs mouvements sont d'une extrême lenteur. Ils l'essemblent à des singes difformes et engourdis. Marchant difficilement sur la terre, ils se tiennent presque toujours sur les arbres, qu'ils ne quittent guère qu'après les avoir dépouillés de leurs fruits et de leurs feuilles. Leur estomac est divisé en quatre sacs assez analogues aux quatre estomacs des ruminants, mais sans feuillets à l'intérieur et ne servant pas à une véritable rumination. On n'en comple que deux ou trois espèces, dontl'une, nommée unau (choloepus didactylus) (2), a des dents canines triangulaires très-saillantes, des molaires cylindriques, les bras médiocrement plus longs que les jambes, sept vertèbres cervicales comme la généralité des mammifères, pas de queue, deux doigts seulement aux extrémités antérieures et trois aux postérieures. L'autre espèce, nommée aii (3), manque de canines et présente une molaire de plus à chaque coté des mâchoires; il a neul vertỉbres au cou, une queue très-courte, les membres antérieurs deux fois plus longs que les postérieurs, et trois doigts pourvus d'ongles très-for's à tous les pieds.

(1) Buffon, Hist. nat., t. X, pl. II; atlas du Dictionnaire des sciences naturelles, Mammiféres, pl. XXIII.

(2) Buffon, XIII, pl. I.

(3) Buffon, XIII, pl. VI. 
Les édentés ordinaires ont un museau pointu et sont dépourvus de dents incisives (1) et canines; mais les uns ont encore des mâchelieres, comme les tatous, les chlamyphores el les orycteropes; les autres n'ont aucune espice de dents, comme les fuurmiliers et les pangolins.

Les tatous (Dasypus) sont très-remarquables par leur test écailleux ct dur, composé de compartiments semblables à de petits pavés 'qui recouvrent leur tête, leur corps et souvent leurs membres et leur queue. Ils ont de grandes oreilles, de grands ongles, dont tantôt quatre, tantôt cinq devant, toujours cinq derrière. Leur museau est assez pointu; leurs mâchelières cylindriques, séparées les unes des autres, au nombre de sept à neuf partout, sans émail dans l'intérieur; la langue est lisse, peu extensible. lis se creusent desterriers et vivent de végétaux, d'insectes et de cadavres. Leur estomac est simple et leurinteslin sans cœcum. Ils sont tous originaires des parties chaudes de l'Amérique.

Les fourmiliers (Myrmecophaga) sont des animaux velus, à long museau terminé par une petite bouche sans aucune dent, d'où sort une langue filiforme, qui peut s'allonger beaucoup, ct qu'ils font pénétrer dans les fourmilières et les nids des termites, où elle retient ces insectes au moyen de la salive visqueuse dont elle est enduite. Ils vivent tous dans les parties chaudes et tempérées du Nouveau-Monde.

Les pangolins (Manis) ont l'organisation et les habitudes des fourmiliers: mais tout leur corps est revêtu de grosses écailles tranchantes, qu'ils relèvent en se meltant en boule, lorsqu'ils veulent se mettre en défense. Tous leurs pieds ont cinq doigts : leur estomac est légèrement divisé par le milieu; ils manquent de cœcum. Ils habitent l'Afrique el les Indes orientales.

L'ordre des édentés, si faible et si restreint aujourd'hui, comptait, avant l'époque actuelle, des animaux monstrueux, dont un, nommé mégathérium, a laissé ses ossements dans le terrain diluvien du Paraguay. Get animal était long de 6 mètres environ, haut de 3 mètres 50 , et tenait à la fois des paresseux, des fourmiliers et des tatous.

Une autre espèce, nommée mégalonyx, dont on a trouvé quelques os el des doigts entiers dans des cavernes de la Virginie, et dans une île près de la côte de Géorgie, était un peu moindre dans ses dimensions.

Une troisième espèce, dont on a trouvé une seule phalange onguéable dans une sablonnière du pays de Darmstadt, non loin du Rhin, devait avoir près de 8 mètres de longueur, et se rapprochait sans doute beaucoup des pangolins.

(1) Une seule espèce de tatou, le talou encoubert, a des dents incisives. 
Ainsi que nous l'avons indiqué dans le tableau de la division des mammifères en neuf ordres (page 9), les marsupiaux sont des mammifères onguiculés qui sont imparfaitement vivipares, leurs petits naissant dans un état de développement à peine comparable à celui auquel les fœlus ordinaires parviennent quelques jour's après la conception. Incapables de mouvement, montrant à peine des germes de membres et d'autres organes extérieurs, ces petits s'altachent aux tétines de leur mère, el y restent fixés jusqu'à ce qu'ils aient atteint le degré de développement auquel les animaux naissent ordinairement. A cet effet, presque toujours la peau de l'abdomen est disposée en forme de poche autour des mamelles, et les petits y sont contenus comme dans une seconde matrice (1). Longtemps même après qu'ils ont commencé à marcher, ils y reviennent quand ils craignent quelque danger. Deux os particuliers, attachés au pubis, et interposés dans les muscles de l'abdomen, donnent appui à la poche et se trouvent cependant aussi dans les mâles et dans les espèces où le repli qui forme la poche est à peine sensible. On donne ì ces deux os, qui sont tout à fait caractéristiques, le nom d'os marsupiaux.

La matrice des animaux de cet ordre n'est pas ouverte par un seul orifice dans le fond du ragin; elle y communique par deux tubes latéraux en forme d'anse. Les males ont le scrolum pendant en avant de la verge, au contraire des autres mammifères, et la verge, dans l'état de repos, est dirigée en arrière.

Une autre particularité des marsupiaux, c'est que, malgré une ressemblance générale tellement frappante qu'on n'en a fait longtemps qu'un seul genre, ils diffèrent tellement par les dents, par les organes de la digestion et par les pieds, qu'ils passent, à cet égard, par des nuances insensibles, des carnassiers aux rongeurs, et de ceux-ci aux édentés. On dirait, en un mot, qu'ils forment une classe distincte parallìle à celle des quadrupèdes ordinaires et divisible en ordres semblables ; en sorte que, si l'on plaçait ces deux classes en regard, sur deux colonnes, les sarigues, les dasyures et les péramèdes seraient, ris-à-vis des carnassiers insectivores à longues canines, tels que les tenrecs et les taupes; les phalangers et les potoroos vis-à-vis des hérissons et des musaraignes; les kanguroos ne se laisseraient guère comparer à rien; mais les phascolomes prendraient place vis-à-vis des rongeurs. Linfin, si l'on n'avait égard qu'aux os propres de la bourse, et si l'on regardait comme marsupiaux tous les animaux qui les possèdent, les ornithorhynques et les échidnés, qui forment aujourd'hui un petit ordre particulier sous le nom de monotremes, offriraienl, dans la série des marsupiaux, un groupe parallèle à celui des édentés.

Quel que soit l'intérêt qui s'attache à ces animaux, tous habitants de l'Amérique et de la Nouvelle-Hollande, à cause même de leurs ca-

(1) De là vient le nom de didelphes que Linné leur a donné. Le nom marsupiaux est dérivé du mot latin marsupium (bourse ou gibecière). 
ractères anormaux, leur complète inutilité sous le rapport de la matière médicale m'autorise à passer sous silence leur description particulière.

\section{ORDRE DES PACHYDERMES.}

Les édentés, qui terminent la série ordinaire des mammifères onguiculés, nous présentent des espèces dont lesongles enveloppent tellement l'extrémité des doigts, qu'ils se rapprochent jusqu'à un certain point des animaux à sabots. Cependant ils ont encore la faculté de ployer ces doigts autour des divers objets et de saisir avec plus ou moins de force. L'absence entière de celte faculté caractérise les animaux à sabots. Se servant de leurs pieds uniquement comme de soutiens, ils n'ont jamais de clavicules; leur's avant-bras restent toujours dans l'état de pronation, et ils sont réduits à paître les végétaux. Leurs formes comme leurs habitudes offrent beaucoup moins de variétés que celles des onguiculés, et l'on ne peut guère y établir que deux ordres, ceux qui ruminent ou les ruminants, et ceux qui ne ruminent pas, que nous désignerons en commun sous le nom de pachydermes (1). Ces derniers forment trois familles : les proboscidiens ou pachydermes it trompe, les pachydermes ordinaires et les solipédes.

Les proboscidiens ne comprennent que les seuls éléphants (Elephas); ils ont cinq doigts à tous les pieds, bien complets dans le squelette,'mais tellement encroûtés'dans la peau calleuse qui entoure le pied, que ces doigts n'apparaissent au dehors que par les ongles attachés sur le bord de cette espèce de sabot. Les dents mâchelières sont au nombre de quatre seulement, une de chaque côté des mâchoires; mais elles se renouvellent sept ou huit fois d'arrière en avant, à mesure qu'elles s'usent par la trituration; de telle manière qu'aux époques de la crue des nouvelles dents, elles se trouvent doublées ou au nombre de huit. Toutes les autres dents manquent; mais dans les os incisifs supérieurs sont implantées deux fortes défenses qui sortent de la bouche et peuvent prendre un accroissement considérable. La grandeur nécessaire aux alvéoles de ces défenses rend la mâchoire si haute et raccourcit tellement les os du nez que les narines se trouvent dans le squelette vers le haut de la face; mais elles se prolongent dans l'animal vivant en une trompe cylindrique, flexible en tous sens, d'une force considérable, et terminée par un appendice en forme de doigt. Cette trompe donne à l'éléphant presque autant d'adresse que la main peut en donner au singe. Il s'en sert pour saisir tout ce qu'il veut porter à sa bouche et pour pomper sa boisson qu'il lance ensuite dans son gosier, suppléant

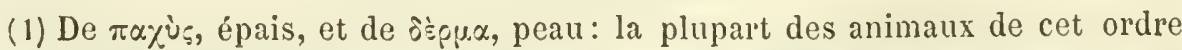
étant remarquables par l'épaisseur et la dureté de leur peau. 
ainsi à un long cou qui n'aurait pu porter sa grosse tête et ses lourdes défenses.

Les éléphants sont les plus grands et les plus massifs des animaux terrestres aujourd'hui vivants. On en distingue deux espèces principales, celui des Indes, Elephas asiaticus, Blum, et celui d'Afrique, Elephas africanus, Blum. Le premier a la tête oblongue, le front concave et les oreilles plus petites que l'autre. Les couronnes de ces dents mâchelières présentent des rubans transverses ondoyants, qui sont les coupes des lames qui les composent, usées par la trituration. L'éléphant d'Afrique a le front convexe, les oreilles très-grandes, la couronne des màchelières dessinée en losanges. Les femelles ont des défenses presque aussi grandes que les mâles, et cette arme est en général plus volumineuse que dans l'espèce des Indes; on en voit qui ont plus de 2 mètres $1 / 2$ de longueur et une grosseur proportionnée. La matière de ces défenses constitue l'ivoire. Ces défenses sont recouvertes d'un épiderme grisâtre, mais à l'intérieur elles sont blanches, d'un tissu compacte disposé en réseau, et susceptibles de recevoir un très-beau poli. Elles ne.sont pleines qu'à partir de l'extrémité jusqu'à la moitié de leur longueur; le reste est creux, ce qui en allége beaucoup le poids, mais rend les pièces d'ivoire d'un cerlain volume difficiles à tourner.

L'ivoire est très-employé dans la tabletterie. Calciné dans un creuset fermé, il laisse un charbon d'un noir velouté très-beau, usité dans la peinture, nommé noir d'ivoire; calciné fortement avec le contact de l'air, il donne le spode, qui n'est composé, pour la plus grande partie, que de phosphate de chaux.

On trouve par toute la terre, dans le terrain de transport ou diluvien contemporain de la dernière grande catastrophe qui a donné aux continents leur forme actuelle, une quantité considérable d'ossements que leur grandeur avait fait supposer appartenir à une race d'hommes-géants aujourd'hui détruite; mais ces ossements sont dus à un éléphant nommé mammouth. Cet éléphant a laissé des milliers de ses cadavres, par toute l'Europe et l'Asie, depuis l'Espagne jusqu'aux limites les plus éloignées de la Sibérie; on le trouve aussi dans l'Amérique septentrionale. Ses défenses sont encore si bien conservées, dans les pays froids, qu'on les emploie aux mêmes usages que l'ivoire récent.

On peut employer également les dents des mastodontes, animal fossile voisin des éléphants, qui en diffère surtout par ses mâchelières dont la couronne est hérissée de grosses pointes coniques. Ce sont ces dents fossiles qui, colorées en bleu verdatre par le 
phosphate, forment la turquoise de la nouvelle roche dont nous avons déjà parlé (1).

Les PACHYDERMES ORDINAIRES OU 'SANS TROMPE nOUS présentent sept genres à espèces peu nombreuses encore vivantes, les rhinocéros, les damans, les tapirs, les hippopotames, les corkons, les phacochares, et lespécaris; et huit genres complétement éteints, les genres anoplotherium, palcostherium, choropotame, adapis, anthracotherium, elasmotherium, lophiodon et dinotherium.

Les rhinocéros sont de grands animaux à formes lourdes et trapues dont les os du nez, très-épais et réunis en une sorte de voûte, portent sur la ligne médiane une corne solide, adhérente à la peau et de nature cornée ou comme formée de poils fortement agglutinés. Dans quelques espèces, il existe une seconde corne de même nature, placée également sur la ligne médiane. Leurs pieds sont tous divisés en trois doigts garnis de sabots; leur queue est très-courte, et leur peau sèche, rugueuse et dépourvue de poils, est si épaisse et si dure qu'elle constitue une sorte de cuirasse, souvent pourvue de plis profonds, sur le cou, les épaules et les cuisses. Ils ont tous 28 dents mâchelières, mais ils ont tantôt deux fortes incisives à chaque mâchoire, accompagnées ou non de deux autres très-petites, et quelquefois ces dents manquent complétement. Ils aiment les lieux humides et fangeux, vivent d'herbes et de jeunes branches d'arbres, ont l'estomac simple et les intestins fort longs. Ils sont d'un naturel stupide el féroce. Le plus anciennement connu est le rhinocéros unicorne de l'Inde (Rhinoceros unicornis), qui est presque de la taille el de la force d'un éléphant. Le rhinocéros d'Afrique (lilinoceros bicornis, L.),' est un peu plus petit, porte deux cornes sur le nez el manque d'incisives. On connaît également un petit rhinocéros de Java à une corne, et un de Sumatra à deux cornes, dont la taille égale celle d'un petit bœuf.

Les tapirs se rapprochent des cochons par la forme générale de leur corps; mais leur nez est prolongé en une petite trompe mobile quia quelque rapport avec celle de l'éléphant, quoiqu'elle manque de l'espèce de doigt qui fait de la trompe de l'éléphant un organe de préhension. Les pieds de devant ont quatre doigts armés de pelits sabols courls et arrondis, et ceux de derrière n'en ont que trois. Ils ont à chaque mâchoire six incisives et deux canines séparées des mâchelières par un espace vide. On en connaîl deux espèces, celle d'Amérique (Tapirus americanus) qui est de la taille d'un petit âne et qui a sept mâchelières de chaque côté des mâchoires, et le tapir de l'Inde (Tapirus indicus)

(1) Voyez t. I, 336. 
qui a sept mâchelières de chaque côté à la mâchoire supérieure, et six seulement à l'inférieure. On trouve dans la terre les ossements d'un grand nombre d'animaux fossiles très-voisins des tapirs, qui sont les lophiodons et les dinothériums.

J'ai parlé précédemment du daman d'afrique (page 36).

Le monde actuel n'offre plus qu'une espèce d'hippopotame (Hippopotamus amphibius) qui s'avançait autrefois jusqu'en Égypte, mais qui est aujourd'hui reléguée dans les rivières du milieu el du sud de l'Afrique. C'est un animal stupide, redoutable par sa force et sa férocité, dont le corps est massif el couvert d'un cuir très-épais, dur et presque dépourvu de poils. Ses jambes sont très-courtes, son ventre traîne presque à terre, et son énorme tête est terminée par un large museau renflé. Son es. tomac est divisé en plusieurs poches comme celui des ruminants; il porte à tous les pieds quatre doigts presque égaux, terminés par de petits sabots; il a six dents mâchelières partout, dont les trois antérieures coniques et les trois postérieures hérissées de deux paires de pointes qui prennent en s'usant la forme d'un trèfle; quatre incisives à chaque mâchoire, dont les supérieures courtes, coniques, recourbées en bas, et les inférieures longues, cylindriques, dirigées en avant; les deux du milieu sont beaucoup plus fortes que les autres. De chaque côté des incisives on trouve, à chaque mâchoire, une dent canine; la supérieure est droite, assez courte; l'inférieure est beaucoup plus longue, cannelée, recourbée vers le haut, et vient s'user en forme de biseau contre la canine qui lui est opposée. Ces dents ont quelquefois 30 centimètres de tongueur; elles constituent une espèce d'ivoire fort dure et qui ne jaunit pas. On les tourne comme l'ivoire et on en fabrique des dents artificielles.

Les cochons ont à tous les pieds deux doigts mitoyens, grands el armés de forts sabots (ce qui leur donne le pied fourchu), et deux doigts latéraux beaucoup plus courts et ne touchant pas à terre; leurs incisives sont en nombre variable, mais les inférieures sont toujours couchées en avant; les canines sont très-fortes, privées de racines, croissent pendant toute la vie el sortent de la bouche en se recourbant l'une et l'autre vers le baut; elles forment des défenses redoutables; le museau est terminé par un boutoir tronqué, propre à fouiller la terre; l'estomac est peu divisé.

L'espèce principale pour nous est le sanglier (Sus Scrofa), qui est la souche de nos cochons domestiques. Il a six incisives à chaque mâchoire, les canines prismatiques, s'usant en un biseau tranchant par leur frottement réciproque, mais de telle manière 
que l'inférieure reste plus longue que la supéricure et constitue la principale défense de l'animal. Les mâchelières sont au nombre de sept de chaque côté des deux mâchoires. Il a le corps trapu, les oreilles droiles, la peau épaisse et dure, le poil grossier noir et hérissé. Il habite les forêts, où il se nourrit principalement de racines et de fruits; mais le manque de cette nourriture peut le rendre carnivore, et il attaque même alors les animaux vivants. Les vieux sanglicrs vivent seuls, dans un fourré épais nommé bauge, où ils ont établi leur retraite. Les femelles, qui portent le nom de laies, se réunissent avec leurs portées de deux à trois ans pour se défendre en cornmun.

Le cochon commun (1) diffère du sanglier par ses oreilles allongées el pendantes, ses défenses plus faibles et plus courtes, ses poils plus faibles, plus rares et généralement d'un blanc sale : plusieurs races cependant ont gardé le poil noir du sanglier, et d'autres sont pies. Ce sont des animaux remarquables par leur malpropreté et par leur gloutonnerie qui leur fait accepter presque toute espèce de nourriture. On leur donne, suivant les circonstances, des fruits abattus par le vent, des glands, des faînes, des châtaignes, des pois, des fèves, du maïs, de l'orge, du son trempé, toutes sortes de débris d'animaux, des résidus de.cuisines, de sucreries, de brasseries, etc. En France, il n'y a guère de ménage de paysan qui n'engraisse un ou deux cochons chaque année pour les besoins de sa famille. A Paris, on mange plus de 80,000 cochons par an, tirés de la plupart des départements, sans compter la viande salée ou fumée, consommée sous un grand nombre de formes particulières. Cette viande est lourde, de difficile digestion et parfois infestée de vers, tels que les cysticerques et les trichines, qui, se développant dans le corps de l'homme, peuvent produire des états morbides sérieux. Le poil du sanglier et du cochon est connu sous le nom de soies, et sert à la fabrication des brosses et des balais. Le plus estimé, en raison de sa force et de sa roideur, est le poil de Russie, dont on importe annuellement en lirance plus de 200, 000 kilogrammes.

Le porc fournit deux espèces de graisse : l'une, qui est beaucoup moins ferme que l'autre, se nomme lard, et se trouve immédiatement sous la peau; l'autre, plus solide, nommée panne, est placée près des côtes, des intestins et des reins. C'est elle qui, fondue el purifiée, constitue la graisse de porc dite aussi axonge ou saindoux.

La graisse de porc est blanche, solide, grenue, d'une légère

(1) On l'appelle aussi porc; la femelle se nomme truie, et le mâle non châtré verrat.

(2) Voir pour plus de dévéloppements l'article Entozvaires. 
odeur qui lui est propre, et d'une saveur agréable; elle se fond dans les doigts, se solidifie à environ 27 degrés, lorsqu'elle a été fondue au feu; 100 parties d'alcool froid, à 9ŏ centièmes, en dissolvent, d'après M. Boullay, 1,04; 100 parties d'alcool bouillant, 1,74 ; et 100 parties d'éther froid, 25 parties. Cette graisse est employée en pharmacie comme excipient des pommades, ou comme partie constituante des onguents et des emplâtres. Il faut autant que possible la préparer soi-même; el, lorsque, en raison de la grande consommation qu'on en fait, on est obligé de la prendre dans le commerce, il faut la choisir blanche, ayant le moins d'odeur possible, privée d'eau et non battue à l'air, moyen par lequel on lui procure de la blancheur, mais qui la rancit très. promptement.

La graisse de porc a été regardée anciennement comme un produit immédiat simple, de même que les autres corps gras végétaux ou animaux. M. Chevreul nous a appris le premier qu'elle était formée de deux et peut-être de trois substances grasses inégalement fusiles, nommées oléine, margarine et stéarıne. La première est encore liquide à 0 , et se convertit par la saponification en acide oléique et en glycérine; la seconde fond à 38 degrés et forme de l'acide margarique fusible à 60 degrés; la troisième fond à 62 degrés, et forme de l'acide stéarique fusible à 70 degrés.

M. Braconnot a également reconnu la nature complexe des corps gras, et a employé, pour les analyser, un moyen qui a généralement frappé par sa simplicité. Il consiste à soumettre le corps gras à une forte presse, enveloppé de plusieurs doubles de papier non collé, et sous une température déterminée et d'autant plus basse que le corps contient plus de graisse fluide: celle-ci s'imbibe dans le papier, l'autre reste en masse solide : on la fond avec un peu d'essence de térébenthine bien rectifiée, et on l'exprime de nouveau; enfin on la débarrasse de l'essence de térébenthine par la chaleur. La graisse fluide se retire du papier, soit par l'expression avec un peu d'eau, soit par l'alcool bouillant.

M. Braconnol a retiré, par ce moyen, de la graisse de porc: huile liquide ou oléine 62 , graisse solide 38 : total 100.

Les paCHYDERMES SOLIPĖDES ne forment qu'un seul genre (celui (les chevaux), caractérisé surtoul par la disposition insolite de leurs membres qui sont terminés par un seul doigt et un seul sabot (fig. 810).

Ils portent six incisives à chaque mâchoire, et partout six molaires à couronne carrée, marquées par des lames d'émail d'un dessin irrégulier. Les mâles ont de plus deux petites canines à la mâchoire supérieure el quelquefois aux deux mâchoires (fig. 841). Ces canines manquent presque toujours aux femelles. Entre les 
canines et la première molaire se trouve un espace vide répondant à l'angle des lèvres, où l'on place le mors au moyen duquel l'homme est parvenu à dompter ces vigoureux quadrupèdes. L.eur

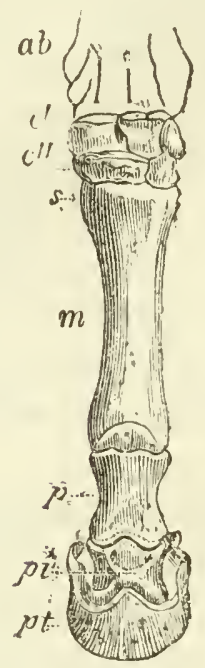

Fig. 810. - Pied de devant du cheral $(*)$.

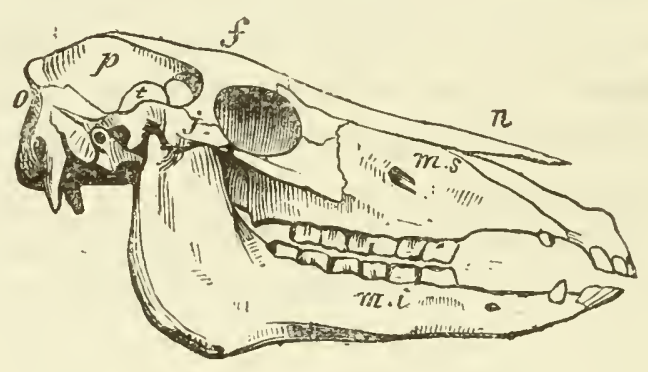

Fig. 841. - Tète de cheval màle $\left(^{* *}\right)$.

estomac est simple et médiocre, mais les intestins sont trèslongs, et leur cœcum est énorme. Les mamelles sont entre les. cuisses (1).

Le cheval proprement dil(Equus Caballus, L.) est le plus beau et le mieux soigné de nos animaux domestiques. Il se distingue des autres espèces du genre par sa couleur uniforme et par sa queue garnie dans toute son étendue de longs poils très-solides nommés crins, et par la crinière longue et tombante qui lui recouvre aussi le cou, depuis le sommet de la tête jusqu'au garrot. Il paraît originaire des grandes plaines de l'Asie centrale; mais, devenu le compagnon de l'homme à la guerre, dans les voyages et dans les travaux de l'agriculture, du commerce el des arts, il a été transporté dans tous les pays où la civilisation a pénétré, et l'espèce tout entière a subi l'influence de la domesticité. Dans les vastes steppes de la Tartarie, berceau de leur race, on trouve encore des chevaux sauvages, mais altérés probablement par leur mélange continuel, avec des individus échappés à la domesticité.

(1) Voyez Chauveau et Arloing, Traité d'anatomie comparée des animaux domestiques, $2^{e}$ édition. Paris, 1871.

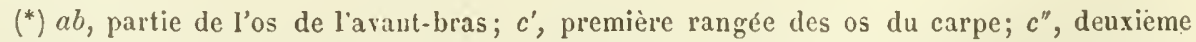
rangée de cet os; $m$, os du métacarpc, ou canon; $s$, vestige d'un second os du métacarpe, nonmé stylet; $p$, première phalange du doigt, ditc paturnn; pi, deuxième phalange ou phalangine, dite couronne; $p t$, troisième phalange ou phalangette, enveloppée par Ie sabot.

$\left(^{* *}\right) o$, os oecipital; $p$, pariétal; $f$, frontal; $j$, jugal; $n$, masal; $m s$, màchoire supérieure; im, os intermaxillaire portant les incisives supérieures; mi, màchoire inférieure. 
Dans toute l'Amérique, où il n'existait aucun cheval avant l'arrivée des Espagnols, on trouve aujourd'hui des troupes immenses de chevaux sauvages que l'on chasse au lasso, et qui redeviennent domestiques avec une grande facilité (1).

La chair du cheval, lorsqu'il est jeune et bien nourri, est saine, de fort bon goûl et très-nourrissante. L'usage de la viande de cheval touche à l'un des problèmes les plus importants de notre époque, l'alimentation des classes pauvres. Cetle question, grâce aux efforts d'un assez grand nombre d'expérimentateurs, de M. Bellat (2), qui a avancé que le bouillon qu'on prépare avec elle est au moins aussi bon que celui qu'on prépare avec le bœuf, d'Isid. Geoffroy-Saint-Hilaire qui l'a préconisée dans divers travaux (3), a fait un pas immense. Il est dès lors nécessaire de fixer les idées à cet égard. J'insisterai donc sur les essais qui ont été tentés, et, pour cela, j'emprunterai à Camille Delvaille des détails qu'il a lui-même puisés dans les leçons d'Isidore GeoffroySaint-Hilaire.

Un fait incontestable et douloureux, c'est qu'il y a des millions de Français qui mangent à peine de la viande. M. Le Play a établi que :

$1^{0}$ Les vignerons de l'Armagnac ont une alimentation suffisante: ils font par jour quatre repas, dont deux avec de la viande ;

$2^{\circ}$ Ceux du Morvan ne mangent de la viande qu'une fois par an, le jour de fète communale; ils se nourrissent ordinairement de pain et de pommes de terre assaisonnées de lait ou de graisse;

$3^{\circ}$ Les paysans du Maine mangent de la viande deux fois par an: le jour de la fête communale el le mardi gras ;

$4^{\circ}$ Ceux de la Bretagne, qui sont les plus malheureux de tous, se partagent en ceux qui ne mangent jamais de viande, et ceux qui en mangent aux grands pardons, c'est-à-dire cinq à six fois dans l'année ;

$5^{\circ}$ Les mineurs des montagnes de l'Auvergne ne mangent de la viande que six fois par an;

$6^{\circ}$ Les tisserands de la Sarthe ne mangent de la viande que les jours de fête ;

$7^{\circ}$ Les maîtres nourrisseurs de la banlieue de Paris ont une alimentation simplement suffisante ;

(1) Voyez Brehm, La vie des animaux illustrée. Paris, 1870.

(2) Bellat, Comptes rendus de l'Acad. des sciences. Séance du 19 arril 1858.

(3) Voyez en particulier : Isid. Geoffroy-St-Hilaire, Emploi alimentaire de la viande de cheval, elc. Paris, 1856. 
$8^{\circ}$ Les cordonniers de la ville mangent de la viande une ou deux fois par semaine.

M. Le Play, dans une lettre adressée à Isid. Geoffroy-SaintHilaire, a ainsi résumé tous ces faits : a Pour la grande catégorie des ouvriers français, les journaliers agriculteurs, la quantité de viande consommée est à peu près nulle."

Or, à côté de ce fait, dont l'observation et l'expérience journalière démontrent la vérité, qu'il y a des millions de Français qui ne mangent pas assez de viande, vient se placer cet autre fait déplorable, qu'il y a tous les mois des millions de kilogrammes de viande qui ne sont pas employés comme nourriture, et qui pourraient l'être.

Si la viande de cheval est insalubre ou excessivement repoussante, il faudra subir l'état actuel : mais, s'il en est autrement, ne sera-t-on pas en droit de dire aux classes pauvres: Ne mourez pas de faim en présence d'aliments que vous laissez perdre.

Il faut donc démontrer que la viande de cheval n'esı ni insalubre ni repoussante.

$1^{\circ}$ Elle n'est pas insalubre.-Des faits nombreux et authentiques le démontrent. Hippocrate range la viande de cheval parmi les viandes légères. Larrey parle des bons effets qu'il a retirés de l'emploi de la viande de cheval et de l'influence salutaire qu'a exercée sur les malades le bouillon qui en provenait. ParentDuchâtelet la recommande comme pouvant être très-utile aux classes pauvres.

$2^{\circ}$ Elle n'est pas répugnante. - Certaines peuplades, telles que les Tartares et les Toungours, mangent les chevaux qu'elles tuent, d'après Pallas (1).

Gmelin dit que les peuples de ce pays mangent des chevaux et les préfèrent aux vaches. Il en est de même des Chinois. M. Le Play raconte que, lorsque les Baskirs reçoivent un étranger, ils considèrent comme un raffinement d'hospitalité et comme un grand régal de leur offrir un mets dans lequel il entre de la viande de cheval et une pâtée de riz. Selon Hérodote, chez les peuples de l'Asie, cette viande était très-estimée.

A lous ces faits viennent s'ajouter des expériences récentes, instiluées dans le but d'apprécier, d'une manière plus exacte et plus pratique, les qualités de cette chair.

E. Renault, directeur de l'école vétérinaire d'Alfort, donna au mois d'août 185 ŏ un repas dans lequel on servit de la viande de cheval et de la viande de bœuf arrangées de deux manières. On trouva qu'en résumé, la viande d'un vieux cheval de vingt-trois

(1) Pallas, Voyages, t. I, p. 76, et t. V, p. 421. 
ans donnait: un bouillon supérieur ; un bouilli bon et agréable ; un rôti exquis.

Lavocat, de Toulouse, a répété l'expérience de Renault,d'Alfort, avec les mêmes résultats.

Isidore Geoffroy-Saint-Hilaire donna aussi un déjeuner dans lequel on servit du cheval. L'un des invités, un médecin, interrogé sur la qualité de la viande qu'il mangeait, crut qu'il s'agissait d'un animal nouveau, et répondit: "Je pense qu’il sera utile d'acclimater ce mammifère. "

A près les détails dans lesquels je viens d'entrer, il est incontestable que la viande de cheval, loin d'être insalubre et repoussante, offre des qualités qui sont de nature à la faire accepter comme un aliment utile.

Évaluons maintenant les ressources que pourrait nous fournir l'introduction de la viande de cheval dans notre alimentation; c'est là une question de la plus haute importance.

Nous avons en France, d'après plusieurs statistiques, trois millions de chevaux, auxquels il faut ajouter quatre cent mille mulets; en admettant qu'il en meure chaque année le quinzième, nous arrivons au chiffre de 226,000 shevaux, qui donneront $50,774,000$ kil. de viande, ce qui fait 1,כ29 kil. par jour. Or, d'après Payen, la race bovine nous en fournil 302,000 kil., il en résulte que la quantité de viande retirée du cheval est le sixième de celle que produit le bœuf. Sur ce nombre il y a à déduire les chevaux non mangeables, ce qui fait environ le quart.

Tels sont les résultats auxquels on arrive pour la France. Voici ceux de Paris. Sous Louis XVI, par ordre de Necker, on arriva à savoir que l'on abattait par an 9,125 chevaux, produisant 2,044,027 kil, de viande. Sous l'Empire et la Restauration, Huzard a vu qu'il mourait 12,775 chevaux, dont la chair pouvait être évaluée à 2,861,000 kil.

Supposons qu'aujourd'hui il meure annuellement 15,000 chevaux, cela fait $3,360,000 \mathrm{kil}$. de viande pour Paris. Que devient cette viande? et, si elle n'est pas utilisée, ne la voit-on pas produire des effets funestes.

A Vienne, en 1853, un banquet organisé pour l'appréciation de la viande de cheval fut empêché par une émeute populaire. Eh bien! en 1854, un an après, 32,000 livres de cet aliment furent vendues en quinze jours. On compte dans cette ville dix mille personnes qui en mangent, et on la vend à quinze et vingt centimes la livre.

On objectera peut-être que les chevaux sont atteints de maladies contagieuses, telles que le farcin et la morve, et que dès 
lors il pourrait être dangereux d'utiliser pour l'alimentation la viande qu'ils fournissent.

Cette objection est plus séricuse en apparence qu'en réalité. La réponse que nous ferons sera applicable, non-seulement à la viande de cheval, mais à celle des animaux malades. Des faits nombreux, dit L. Fleury, attestent que des hommes ont mangé, sans éprouver aucun accident, de la chair provenant d'animaux morts de la pustule maligne, du typhus, de la rage. Pendant la revolution de 1789, des indigents de Saint-Germain et d'Alfort mangèrent sept à huit cents chevaux morveux et farcineux, sans être le moins du monde incommodés. En 1814, 1815̆, 1816, tous les animaux morts du typhus contagieux furent consommés, sans que le moindre accident ait été signalé. Depuis un temps immémorial on consomme dans Paris les vaches attaquées de phthisie pulmonaire.

Il paraît constant, d'après Huzard, que les viandes provenant d'animaux malades (1), lorsqu'elles ont été dénaturées par la cuisson, ne peuvent être regardées que comme viande de médiocre qualité, et non comme un aliment dangereux.

Il résulte d'une longue série de recherches entreprises par E. Renault : $1^{\circ}$ qu'il n'existe aucune raison sanitaire de prohiber l'alimentation des porcs et des poules nourris avec les débris des clos d'équarrissage, quels qu'ils soient ; $2^{\circ}$ qu'il n'y a aucun danger pour l'homme à manger la chair cuite ou le lait bouilli, provenant de bœufs, vaches, porcs, moulons, poules, affectés de maladies contagieuses, quelle que soit la répugnance bien naturelle que puissent inspirer ces produits.

A Alfort, et dans un grand nombre de porcheries, les porcs sont nourris avec de la viande provenant de chevaux morts de toutes espèces de maladies, et sous l'influence de celte nourriture ils engraissent rapidement et fournissent une viande excellente et parfaitement saine à l'alimentation de l'homme.

Qu'y a-t-il donc à faire pour répandre parmi nous l'usage de la viande de cheval, en altendant que les autorités des villes et des départements croient pouvoir prendre des mesures à ce sujet? Il faut que chacun fasse tous ses efforts pour propager les notions puisées dans les données de l'expérience et éclairer ceux qui ne sont pas convaircus.

En résumé, le peuple manque de viande; qu’il ne laisse pas perdre des millions de kilogrammes qu'il peut utiliser pour sa nourriture.

(1) Voir sur ce sujet le rapport à l'Académie de médecine de M. Bouley : De emploi de la viande des animux atteints de la peste bovine, pour l'alimentation. (Journ. de pharm. et de chimie, é $^{\mathrm{e}}$ série, XIII, 51.) 
Un sait que la viande de cheval tend maintenant à entrer dans l'alimentation ordinaire et qu'un certain nombre de boucheries spécialement affectées à cette vente ont été ouvertes à Paris depuis quelques années. Les nombres suivants montrent qu'elles prennent de l'importance. A Paris, de juillet 1866 à 1868, c'est-à-dire en deux ans et demi 5,475 chevaux abattus pour la boucherie ont permis de livrer à la consommation 1,095,000 kilog. de viande. On sait combien pendant le siége de 1870-71 cette source d'alimentation a élé précieuse à la population. De nouvelles boucheries se sont établies dans ces derniers temps dans diverses villes de France. Dans les grandes villes, on utilise la chair des chevaux usés par la vieillesse, le travail ou les maladies, pour la transformer en engrais, leurs os pour la fabrication du noir animal, et leur peau pour faire des cuirs tenaces propres aux tiges de bottes et aux empeignes de souliers. Le crin de cheval est aussi d'une grande utilité pour la fabrication des sommiers, des meubles, des tamis et de divers lissus employés dans les arts. Il n'y a pas jusqu'au fumier de cheval qui ne soit un engrais précieux dont on fait principalement usage pour la culture des jardins et la composition des couches.

L'âne (Equus Asinus, L.) se distingue du cheval par ses longues oreilles, par la houppe de poils dont l'extrémité de sa queue est garnie, par sa crinière plus courte et non tombante, et par la croix noire qu'il présente sur les épaules. De même que le cheval, il est originaire des grands déserts de l'intérieur de l'Asie, où il vit encore à l'état sauvage et en troupes innombrables. Il rend en France des services importants à la petite culture par sa sobriété el sa patience.

L'âne et le cheval produisent facilement des métis, nommés mulets, qui participent des formes et des qualités des deux espèces, mais qui sont toujours stériles, de sorte que leur race ne peut se perpétuer. Ceux qui proviennent d'un âne et d'une jument sont mieux faits et plus grands que ceux portés par une ânesse. Ceux-ci, qui sont plus rares, portent le norn particulier de bardeaux.

La viande d'âne a été utilisée ; en France, on abat un nombre considérable d'ânes pour en faire du saucisson.

Le lait d'ânesse est souvent ordonné comme aliment aux personnes maladives et particulièrement aux phthisiques : il contient plus de sucre de lait et moins de matière grasse que celui de vache.

L’usage du lait d’ânesse, dit Brehm (1), si général maintenant

(1) Brehm, La vie des animaux. Nammifères. Paris, 1870, t II, p. 421. 
en Europe, fut introduit en France par un juif. Voici comment : François I ${ }^{\text {er }}$ était très-faible; ses fatigues guerrières et ses excès l'avaient réduit à un état de langueur qui s'aggravait tous les jours : les remèdes n'y changeaient rien. On parla alors au roi d'un Juif de Constantinople gui avait la réputation de guérir ces sortes de maladies. François I ${ }^{\text {er }}$ ordonna à son ambassadeur en Turquie de faire venir à Paris ce docteur israélite, quoi qu'il en dût coûter. Le médecin juif arrvia et n'ordonna que du lait d'ânesse : ce remède doux réussit très-bien au monarque, et tous les courtisans s'empressèrent de suivre le même régime.

On apporte de Chine une sorte de gélatine préparée avec la peau d'âne, et qui est connue sous le nom de colle de peau d'âne ou de heckiak. Telle que je l'ai vue anciennement, elle était sous forme de petites tablettes carrées, très-épaisses, d'un gris terne et demi-opaques. Elle était recommandée comme analeptique.

On trouve dans les déserts de l'Asie centrale une troisième espèce de cheval nommée hemiome ou daigguetai (Equus Hemionus), qui tient le milieu, pour les proportions, entre le cheval et l'âne, mais qui est de formes très-élégantes et d'une vitesse à la course supérieure à celle du cheval. Il est de couleur isabelle (jaune fauve clair) avec la crinière et la ligne dorsale noires, ainsi que la houppe de crins qui termine sa queue. En hiver, son pelage devient épais et frisé. Il vit en troupes composées d'une vingtaine de juments, de poulains et d'un mâle qui en est le chef.

L'Afrique possède trois autres espèces du genre cheval. Le plus anciennement connu est le zèbre, (Equus $Z e b r a$, L. $)$ qui a la forme d'un âne, mais qui a tout le corps et les membres couverts de ban. des transversales d'un brun noirâtre sur un fond jaune. On le rencontre depuis l'Abyssinie jusqu'au cap de Bonne-Espérance. Le couagga (Equus Quaccha) ressemble davantage au cheval et ne présente de bandes transversales que sur les épaules et le dos. Le dauw ou onagga (Equus montanus) n'est connu que depuis peu de temps; il est plus petit que l'âne, et porte sur la tête, le cou et le tronc, des raies noires alternativement plus larges et plus étroites sur un fond isabelle.

ORDRE DES RUMINANTS.

Cet ordre est peut-être le plus naturel et le mieux déterminé de la classe des Mammifères; car les ruminants ont l'air d'être presque tous construits sur le même modèle, les chameaux seuls présentant quelques exceptions aux caractères communs.

Le nom de ruminants indique la faculté singulière que pos- 
sèdent ces animaux de mâcher une seconde fois leurs aliments, qu'ils ramènent dans la bouche après uné première déglutition, faculté qui tient à la structure de leur estomac. Ils en ont toujours quatre ( $\mathrm{fg} .842)$, dont les trois premiers sont disposés de façon que les aliments peuvent entrer à volonté dans l'un des trois, parce que l'œsophage aboutit au point de communication. Le premier et le plus grand se nomme la panse; il re-

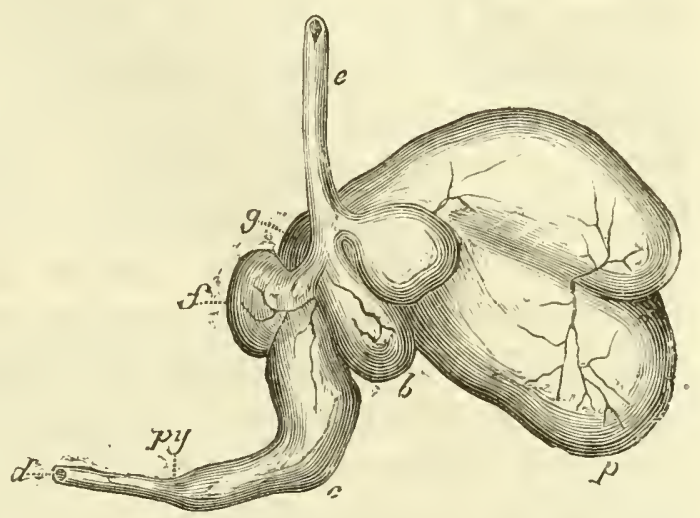

Fig. 849. - Estomac de mouton $\left({ }^{*}\right)$. çoit en abondance les herbes grossièrement divisées par une première mastication. Elles se rendent de là dans le second, appelé bonnet, dont les parois ont des lames semblables à des rayons d'abeilles. Cet estomac, fort petit et globuleux, saisit l'herbe, l'imbibe et la comprime en petites pelotes qui remontent ensuite successivement à la bouche pour y être remâchées. L'animal se tient en repos pour celte opération, qui dure jusqu'à ce que toute l'herbe, avalée d'abord et remplissant la panse, l'ait subie. Les aliments, ainsi remâchés, descendent dans le troisième estomac nommé feuillet, parce que ses parois ont des lames longitudinales semblables aux feuillets d'un livre, et de là dans le quatrième ou caillette, dont les parois n'ont que des rides, et qui est le véritable organe de la digestion, analogue à l'estomac simple des animaux ordinaires. Pendant que les ruminants teltent et ne vivent que de lait, la caillette est le plus grand de leurs estomacs. La panse ne se développe et ne prend son énorme volume qu'à mesure qu'elle reçoit de l'herbe. Le canal intestinal est fort long et peu boursouflé; le cœcum est de même long et assez lisse.

Les ruminants n'ont d'incisives qu'à la mâchoire inférieure, presque toujours au nombre de huit. Elles sont remplacées en haut par un bourrelet calleux. Entre les incisives et les molaires est un espace vide où se trouvent, seulement dans quelques genres, une ou deux canines. Les molaires, presque toujours au nombre de six partout, ont leur couronne marquée de deux loubles croissants dont la convexité est tournée en dedans dans les

(*) $e$, œsophage; $g$, point où se troure la gouttière œsophagienne; $f$, feuillet; $p y$, pylore ; $d$, duodénum; $c$, caillette; $b$, bonnet; $p$, panse. 
supérieures, en dehors dans les inférieures. Les quatre pieds sont terminés par deux doigts et par deux sabots qui se regardent par une face aplatic, en sorte qu'ils ont l'air d'un sabot unique qui aurait été fendu. Derrière le sabot sont quelquefois deux vestiges de doigts latéraux. Les deux os du métacarpe et du métatarse (os de la main et du pied) sont réunis en un seul qui porte le nom de canon. Quelques espèces présentent des vestiges des métacarpiens et métatarsiens latéraux.

Les ruminants forment quatre groupes dont les caractères distinctifs se tirent de l'absence ou de la présence des cornes, qui sont deux proéminences plus ou moins longues des os frontaux, et qui ne se trouvent dans aucune autre classe d'animaux.

$A$. Les ruminants sans cornes; ils ont des canines aux deux mâchoires. Ils comprennent les chameaux, les lamas et les chevrotains, au nombre desquels est l'animal qui porte le musc.

$B$. Les ruminants à cornes rameuses et osseuses, caduques chaque année : par exemple, les cerfs.

$C$. Les ruminants à proéminences coniques persistantes, toujours recouvertes d'une peau velue; celte section ne comprend que la girafe.

$D$. Les ruminants à cornes creuses, non caduques, élastiques, croissant par couches sur des proéminences osseuses. Ex. : les bceufs, les moutons, les chèvres et les antilopes.

Les chameaux ont non-seulement deux canines aux deux mâchoires, mais encore deux dents pointues implantées dans l'os incisif supérieur. lis n'ont que six incisives à la mâchoire inférieure et dix-huit ou vingt molaires seulement. Au lieu du grand sabot fendu et aplati du côté interne, qui enveloppe la partie inférieure de chaque doigt et détermine la forme fourchue ordinaire du pied des ruminants, ils ont deux petits sabots distincts, renfermant seulement la dernière phalange des doigts, et ceux-ci sont réunis en dessous (à l'exception de cette dernière phalange qui reste libre) par une semelle commune, de nature cornée, qui pose à terre dans toute son étendue. Ce sont des animaux de haute taille que leur lèvre supérieure fendue, leurs yeux saillants, leur long cou arqué, leur dos chargé de une ou deux énormes loupes graisseuses, leur train de derrière affaibli, rendent difformes et très-disgracieux; mais leurs membres sont loin d'être aussi faibles qu'ils le paraissent. Les chameaux sont très-robustes; ils ont les sens délicats et sont renommés par leur extreme sobriété et par la faculté qu'ils ont de pouvoir passer plusieurs jours sans boire, ce qui les rend d'une extrême utilité, comme bêtes de somme et de transport, pour voyager à travers les déserts sablonneux de l'Asie et de l'Afrique. On con- 
naît deux espèces de chameaux : celle à deux bosses (Camelus Bactrianus), qui porte plus spécialement le nom de chameau, et qui est originaire du centre de l'Asie; celle $\dot{a}$ une bosse, ou dromadaire (Camelus Dromedarius), qui est plus répandue dans les contrées d'A sie voisines de l'Arabie et dans toute l'Afrique, depuis la Méditerranée jusqu'au Niger. La chair des jeunes chameaux paraît être très-bonne à manger. Leur poil, qui est fin et moelleux, sert à faire des étoffes; il se renouvelle tous les ans par une mue complète.

Les lamas (Auchenia) représentent les chameaux dans le nouveau monde, comme le tapir y est un diminutif de l'éléphant et du rhinocéros. Mais, s’ils n'ont pas la force et la taille des chameaux, ils n'en offrent pas non plus la laideur. Ce sont, au contraire, des animaux assez sveltes, sans bosse sur le dos, et dont les doigts, n'étant pas réunis par une semelle cornée, conservent leur mobilité, ce qui leur permet de gravir les rochers avec agilité. On en connaît deux espèces, le guanaco (Auchenia Glama) et la vigogne (A uchenia Vicunna). Celle-ci est grande comme une brebis et couverte d'une laine fauve d'une finesse et d'une douceur admirables. On en fabrique des étoffes précieuses. L'autre espèce est de la taille d'un cerf et présente deux variétés, le lama proprement dit (A. Glama et l'alpaca Auchenia Llacma), Le premier sert de bête de somme au Pérou, mais son poil grossier est peu estimé; le second est couvert de poils laineux fort longs et d'une grande finesse, qui servent à la fabrication des étoffes.

Le troisième groupe des ruminants sans cornes est celui des chevrotains. Ces animaux, indépendamment de l'absence des cornes, diffèrent des ruminants ordinaires par une longue canine, qui, dans les mâles, sort de la bouche de chaque côté de la mâchoire supérieure, et parce qu'ils ont dans le squelette un péroné qui n'existe pas même dans les chameaux. Ils habitent tous les pays chauds de l'ancien continent. M. Alph. Milne Edwards (1) les a divisés en deux familles, les moschidées et les tragulidées. La première nous intéresse spécialement. Elle ne contient qu'une seule espèce, le chevrotain porte-musc (Moschus moschiferus, L.,), qui fournit à la pharmacie et à la parfumerie la substance connue sous le nom de musc. Cet animal habite les montagnes les plus escarpées du Thibet et de la Chine. Il est trèscraintif, très-agile, et vit presque isolé, si ce n'est à l'automne où il se rassemble par troupes. Il se nourrit d'écorces d'arbres, de racines et de feuilles. Il produit spécialement les muscs les plus es-

(1) Alph. Milne-Edwards, Recherches anatomiques, zoologiques et paléontologiques sur la famille des chevrotains. Paris, 106t. Thèse soutenue à l'École supérieure de pharmacie de Paris (Annales des sciences naturelles, 1864). 
timés, nommés musc de la Chine et musc tonquin. C'est lui pareillement, ou une variété peu distincte, qui, parcourant tout le vaste plateau de la grande Tartarie jusqu'aux frontières de la Sibérie, fournit le musc inférieur nommé musc de Russie ou musc kabardin.

Le porte-musc est de la grandeur d'une chèvre. Celui dont je donne ici la figure ( $f g .843$ ) d'après Buffon (1) a vécu trois ans en

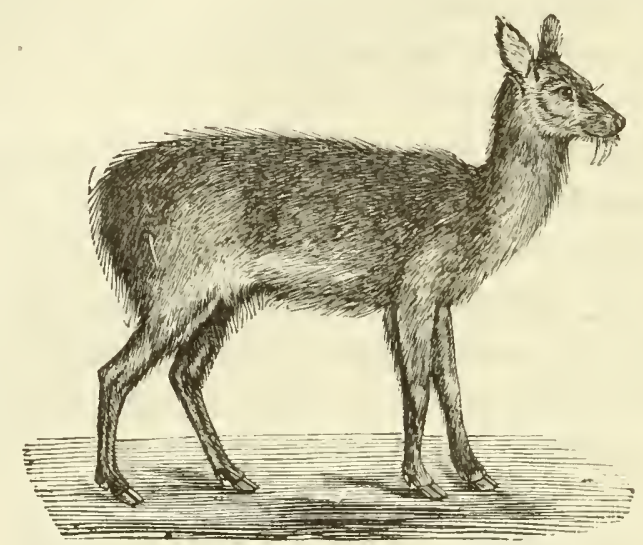

Fig. 843. - Chevrotain porte-musc.

France, dans un parc, auprès de Versailles. Il avait 73 centimètres de longueur, $5 \mathbf{4}$ centimètres de hauteur au train de derrière et š3 centimètres au train de devant. "Il est vif, très-léger à la course et dans tous ses mouvements; ses jambes de derrière sont considérablement plus longues et plus fortes que celles de devant, et il saute en courant à peu près comme un lièvre. Il est armé, à la mâchoire supérieure, de deux défenses dirigées en bas et recourbées en arrière, tranchantes sur leur bord postérieur et finissant en pointe; elles sont de couleur blanche, et leur substance est une sorte d'ivoire. Les yeux sont grands à proportion du corps; le bord des paupières et les naseaux sont noirs; les oreilles sont longues de 4 pouces $(11$ centimètres), larges de 2 pouces 4 à 5 lignes (63 à 6 ă millimètres), garnies en dedans de longs poils d'un blanc grisâtre, et au-dessus de poils noirs roussatres mêlés de gris, comme celui du front et du nez. Le poil du corps est noirâtre, mélangé de fauve et de roussatre et de conleur variable d'ailleurs, suivant le sens dont on le regarde, parce que les poils ne sont colorés en brun ou en fauve qu'à l'extrémité, et que le reste est blanc et paraît plus ou moins, sous différents aspects. Ses pieds sont petits; ceux de devant ont deux ergots qui touchent à terre. Les sabots des pieds de derrière sont inégaux, l'intérieur étant beaucoup plus long que l'autre; il en est de même des ergots, dont l'interne est

(1) Buffon, Supplèm., t. VI, pl. XXIX. 
aussi bien plus long que l'externe. Les uns et les autres sont de couleur noire. Il n'a pas de queue apparente. ")

La poche qui contient le musc ( $/ g .844)$ est particulière au mâle, située sur la ligne médiane du ventre, entre l'ombilic et la verge, et beaucoup plus près de celle-ci. D'après Brandt et Ratzeburg (1), dans l'état de repos, la verge $(a)$ est en grande partie renfermée dansle ventre et repliée sur elle-même; elle n'a qu'un seul corps caverneux et un gland mince et aplati $(e)$, au delà duquel se prolonge l'urètre filiforme $(c)$, formant une saillie de 14 millimètres.

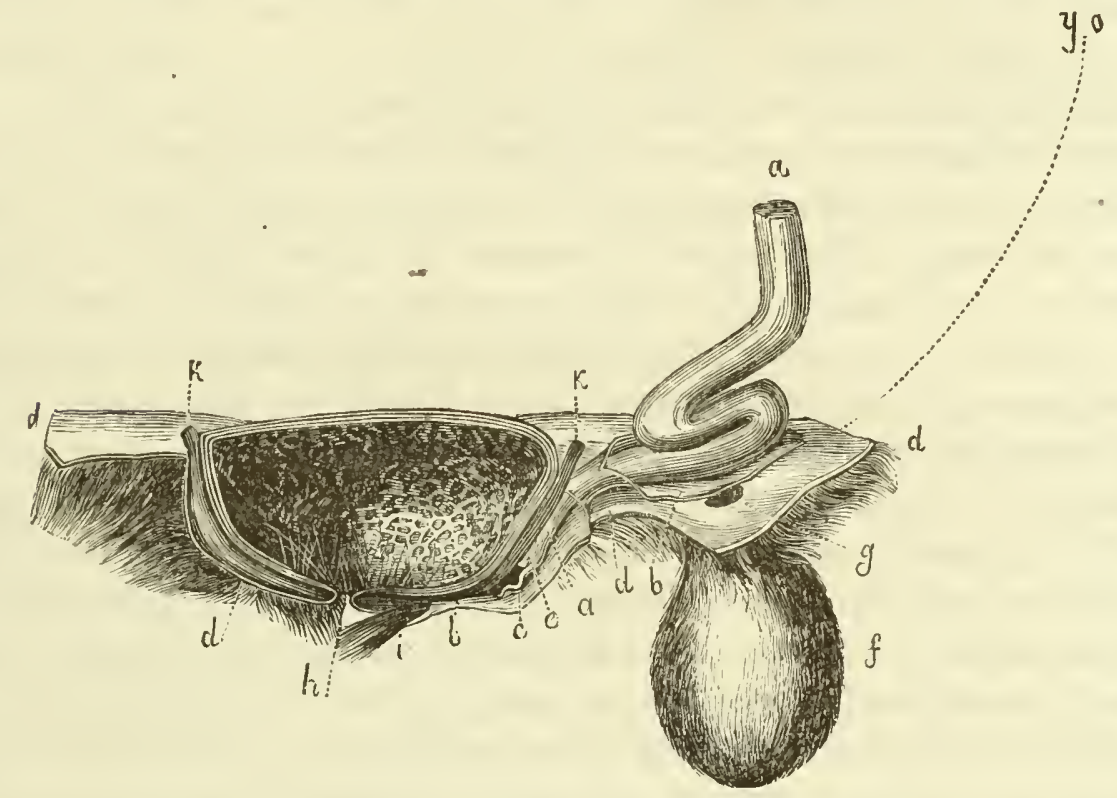

Fig. 844. - Appareil du musc (*).

Sur le devant, la verge est entourée d'un canal préputial, garni à son orifice ( $i$ ) de poils nombreux, de couleur rousse, saillants sous la forme d'un pinceau. Ce canal est appliqué contre la face postérieure de la poche au musc et semble faire corps avec elle, étant renfermé sous la même peau velue, et se reconnaissant seulement quelquefois, dans les poches desséchées du commerce, à un léger sillon qui occupe, d'arrière en avant, la moitié environ de la longueur de la poche, et se termine par le pinceau de poils roux dont il vient d'être parlé. La poche au musc est ronde ou ovale, presque plane et nue par sa face supérieure, qui est appliquée contre les muscles abdominaux; sa face inférieure, ou celle qui regarde le sol, est convexe et couverte de poils. Chez

(1) Brandt et Ratzeburg, Medizinische Zoologie. Berlin, 1829.

(**) $b b$, fourıeau préputial en partie ouvert; $d d d$, partie de la peau du ventre; $f$, scrotum; $g$, ouverture donnant passage aux cordons spermatiques; $y$, position de l'anus (Brandt et Ratzeburg, Medizinische Zoologie. Berlin, 1829). 
les adultes, cette poche atteint de ๖ว à 68 millimètres de longueur sur $3 \zeta$ à 47 millimètres de largeur et 14 à 20 millimètres de hauteur. A la partie la plus basse, un peu en avant de l'orifice préputial, se tronve un canal fort court $(h)$, un peu oblique, large de 2 millimètres, se terminant à l'extérieur par une ouverture semi-lunaire. Ce canal s'ouvre directement dans la poche au musc, et son orifice intérieur est entouré par un certain nombre de poils semblables à ceux qui recouvrent la peau à l'extérieur. Ce sont ces poils que l'on trouve toujours mêlés au musc extrait de la poche. En enlevant la peau (épiderme et derme) qui recouvre la poche à l'extérieur, on distingue deux faisceaux musculaires $(k k)$ qui, d'après Pallas, partent des aines et se contournent autour de la poche. Sous ces couches musculaires, on découvre l'enveloppe propre du musc, laquelle forme un sac complet qui entoure le musc de toutes parts, à l'exception du petit canal (h), et qui se compose de trois membranes. La première (enveloppe fibreuse, Pereira), présente à l'extérieur quelques plis longitudinaux, et à l'intérieur des dépressions nombreuses en forme de mailles, entourées de plis et dans les quelles se portent les ramuscules de vaisseaux sanguins que Pallas regarde com me dérivés de l'artère iliaque. Cette membrane n'est autre chose que le derme de la peau, dont l'organisation a été modifiée, et qui, en se continuant en dedans du sac, à travers l'ouverture $(h)$, est devenu apte à sécréter et projette encore quelques poils isolés. Sous cette membrane, il s'en trouve une seconde (enveloppe nacrée, Pereira), délicate, blanchâtre et nacrée, dont la facc extérieure offre des saillies correspondantes aux excavations de la première membrane et de nombreux sillons répondant aux plis ramifiés. Enfin, la troisième membrane (enveloppe épidermoïdale, Pereira), analogue à l'épiderme et encore plus délicate que la seconde, se laisse diviser en deux couches, dont l'extérieure est argentée, tandis que l'intérieure est d'un brun rouge jaunâtre. Celle couleur ne doit pas être seulement attribuée au musc contenu à l'intérieur, car elle persiste après une longue macération dans l'eau et dans l'espril-de-vin. Les excarations et les plis y sont encore plus prononcés que dans les autres membranes, et chaque excavation contient deux corpuscules ou plus, aplatis, généralement ovales et d'un brun rouge jaunâtre. Ces corpuscules sont formés par une membrane très-mince, renfermant une petite masse brunâtre qui est considérée comme l’organe glandulaire qui sécrète le musc.

Le musc de bonne qualité présente, à l'état récent, une consistance de miel, une couleur rouge brunâtre, et une odeur tellement forte, que les chasseurs ont peine à la supporter. Par 
la dessiccation il devient presque solide, grumeleux et d'un brun noirâtre. Il a une saveur amère aromatique, une odeur encore très-lorte et difficile à supporter, lorsqu'elle est concentrée; mais susceptible d'une grande expansion et devenant fort agréable lorsqu'elle est suffisamment affaiblie.

On ne distingue communément dans le commerce que deux sortes de musc, le musc tonquin et le musc kabardin; mais il y en a un bien plus grand nombre de sortes que je ne connais pas toutes et sur lesquelles je n'ai pu avoir que des données incomplètes. Voici ce que je puis dire de plus certain sur les sortes que j’ai vues.

I. Musc de Chine, première sorte. Ce musc est apporté dans de petites boîtes rectangulaires en carton, d'environ 20 contimètres de long, 11 centimètres de large et $\mathbf{2 1 , 5}$ de haut. Ces boîtes sont revêtues extérieurement d'une étoffe de soie et sont doublées à l'intérieur par une autre boîte en feuilles de plomb exactement soudées. Sur les boîtes qui renferment le musc de première qualité, on lit ces mots: lingchong musk, et sur le couvercle de la boîte de plomb on voit un dessin grossier représentant une chasse au musc dans laquelle des chasseurs tirent l'animal, tandis qu'un autre est occupé à couper la poche à ceux qui sonl abaltus. Mais, ce qu'il y a de singulier, c'est que, par tradition sans doute, l'animal ainsi chassé est une civette, reconnaissable à ses cinq doigts à tous les pieds, à sa longue queue hérissée,enfin à sa forme générale, et qu'on y a seulement ajouté sous le ventre un petit cercle figurant la poche au musc; ce qui montre au moins que l'auteur primitif de cette gravure supposait que le musc était produit par une espèce de civette. On trouve dans la boîte environ vingt-cinq poches dont chacune est enveloppée dans un papier fin portant cette inscription rouge, en anglais : Musc collecled in Nankin by Tung-t-hin-chung-chung-Kee; au-dessus de l'étiquette se trouve un médaillon qui représente une divinité chinoise ayant à ses pieds une civette et portant une banderolle qui indique qu'on vend dans ce magasin le musc le plus précieux. Enfin les poches mêmes portent sur leur surface plane et nue une inscription chinoise en encre rouge, mais illisible (1).

Les poches de musc de Chine sont arrondies ou quelque peu ovales, larges de 5 à 6 centimètres, généralement peu épaisses

(1) Quelques persommes pensent que ces inscriptions et dessins ne sont d'aucune importance, et qu'ils sont fabriqués en Angleterre. Cela pourrait être, mais les inscriptions anglaises ont pu tout aussi bien être faites en Chine, où les Chinois n'ont guère affaire qu'ì des commerçants anglais. Il est certain d'ailleurs que le musc de Chine qui présente ces marques extérieures est de la meilleure qualité, et que celui qui en est dépourvu, quoique renfermé dans des boîtes de même forme et de même volume, est moins estimé. 
et aplaties $(f g .845)$; les poils qui les recouvrent se dirigent de tous les points de la circonférence vers l'ouverture au musc, qui est toujours située entre le centre et le bord antérieur de la poche.
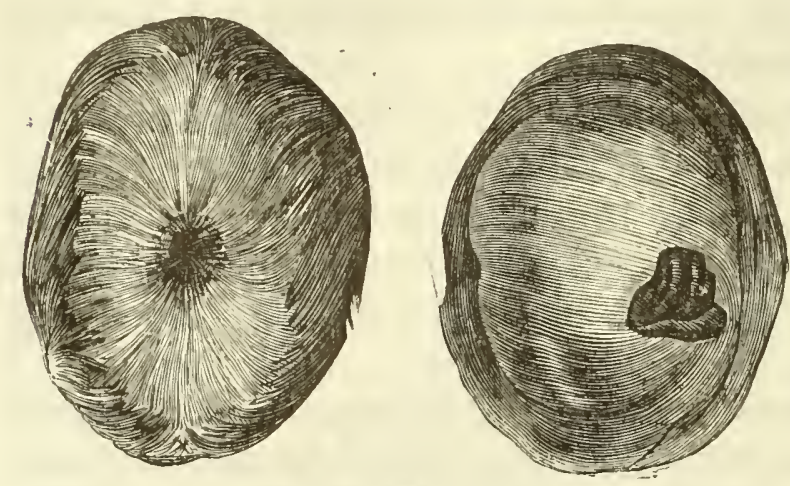

Fig. 845. - Musc de Chine. Ces poils se dirigent vers l'ouverture, non directement, mais en s'arrondissant en forme de tourbillon; ils sont généralement grisâtres, courts (2), grossiers et cassants à la circonférence, et prennent plus de finesse, plus de longueur, et une couleur

brunâtre en s'approchant de l'ouverture au musc, où ils forment une sorte' de pinceau brunâtre. Aux endroits où les poils sont détachés de la peau, celle-ci paraît d'un brun foncé. Le côté de la bourse qui touchait au ventre est formé par une peau sèche, brunâtre, unie, peu épaisse et sans ouverture. Ce musc étant d'un prix très-élevé, n'est jamais desséché qu'en partie, et les commerçants ont soin de le renfermer dans des vases exactement fermés, afin qu'il ne perde rien du poids qu'il avait lorsqu'ils l'ont acheté. Il conserve donc à l'intérieur la consistance d'une pâte grumeleuse, et il éprouve une fermentation ammoniacale, qui exalte considérablement son odeur et la rend fort difficile à supporter. Celte odeur, cependant, n'offre rien de l'odeur fécale de la civette.

II. Muse tonquin. Ce musc arrive par la voie de Canton. Tel que je l'ai vu chez M. Charles Garnier, négociant à Paris, il est en poches moins larges, plus épaisses et plus également bombées sur les deux faces que ne l'est communément le musc de Nankin; enfin il présente une forme lenticulaire arrondie presque régulière. Il est couvert d'un poil très-court et blanchâtre, et toute sa surface est comme couverte d'une fine efflorescence blanche. Il est plus sec que le musc de Nankin, non ammoniacal, mais il me paraît doué d'une puissance odoriférante plus faible; peutêtre tous ces caractères tiennent-ils à ce que ce musc étant plus sec, n'a pas fermenté et n'a pas imprégné ses enveloppes de son suc brunâlre intérieur. Il serait donc en réalité plus naturel que le musc de Nankin; mais est-ce un avantage, s'il est moins odoriférant?

(1) Parce qu'ils ont été coupés. 
M. Garnier m'a montré un autre musc d'une forme très-remarquable, mais que je regarde comme une simple variété du précédent. Il est en petites poches presque rondes en tous sens, et de 35 millimètres de diamètre. 11 est recouvert d'un poil trèsras, et présente partout une teinte blanchâtre uniforme. Il est généralement percé d'un trou rond assez considérable, formé par l'agrandissement de l'ouverture naturelle de la poche, el obstrué avec un petit bouchon de papier gris tortillé.

III. Muse d'Assam. Assam est un royaume d'Asie assez élendu, situé au nord du Bengale, et dont les Anglais ne se sont pas encore emparés, sans doute par la raison qu'il y a temps pour tout. Il nourrit dans les montagnes une grande quantité de portemusc, dont les poches arrivent par la voie du Bengale, contenues au nombre de deux cents environ dans un sac de peau, lequel est lui-même renfermé dans une caisse de bois ou de fer-blanc, Ce musc présente les formes les plus variées et les plus irrégulièrcs. On y trouve des poches plates presque identiques avec celles du musc de Nankin; des poches qui étaient fortement proéminentes au dehors de l'animal, et dont la partie nue, qui les unissait au ventre, présente un diamètre beaucoup moins grand que celui de la poche extérieure; enfin des poches tellement rétrécies par le haut qu'elles paraissent n’avoir tenu au ventre que par un pédicule (1), et qu'on les prendrait pour des scrotums, si l'on n'y observait d'ailleurs l'ouverture ordinaire du musc et la disposition tourbillonnée des poils qui caractérise les poches au musc. Ces poils sont hérissés, très-grossiers, blancs et très-cassants. Toutes ces poches sont très-pleines et très-dures, ce qui semblerait indiquer qu'elles ont été remplies artificiellement, quoiqu'elles ne soient pas cousues; mais on a pu les remplir par l'ouverture naturelle de la poche. La substance intérieure est brune-noirâtre, consistante, d'une odeur très-forte de musc, mêlée de l'odeur fécale de la civette, ce qui donnerait à penser que ce musc a pu être additionné de civeite. Nonobstant ce mélange réel ou supposé, ce musc se vend facilement en France et paraît être d'un bon emploi pour la parfumerie, l'odeur fécale disparaissant par la dessiccation, ainsi que je l'ai dit pour la civette.

IV. Autres muses venus par le Bengale ( $/ \mathrm{h}$. 846 et 847$)$. On trouve quelquefois dans le commerce des muscs venus par la voie

(1) Plusieurs de ces poches paraissent avoir été étranglées par une ligature, ainsi qu'on le trouve recommandé dans quelques lives chinois (Mémoires des missionnaires de Pékin, t. IV, p. 497); mais ce procédé ne peut être praticable qu'autant que la poche au musc est déji très-rétrécie elle-même par la partie supérieure; il ne pourrait être appliqué au musc de Nankin. 
de Calcutta, qui sont garnis d'un morceau considérable de peau poilue ou de poils forts longs. L'école de pharmacie possède deux échantillons de ces muscs. Le premier, qui se rapproche par sa nature du musc de la Chine, est pourvu d'un large morceau de peau du ventre, couvert d'un poil assez mince, long de 6,5 à 7 centimètres d'un blanc sale à la base, ensuite d'une teinte brunâtre dans une assez grande partie de son étendue, cnfin terminé par une petite pointe blanche. D'autres fois, après la couleur blanche de l'extrémité, revient une coloration noire, et la pointe est noire; enfin ce poil offre un caractère tout particulier, qui consiste en ce qu'il est ondulé dins toute son étendue et qu'il ressemble à une ligne tremblée (fig. 848). L'autre poche, qui me paraîl se rapprocher du musc tonquin, est de forme à peu près ronde et présente 3,5 centimètres de largeur sur 4 d'épaisseur verticale. La moitié supérieure, qui touchait au ventre de l'animal, est nue, très-renflée et rétrécie à l'endroit où commence le poil. Il n'y a aucun vestige de peau du ventre, et tous les poils sont

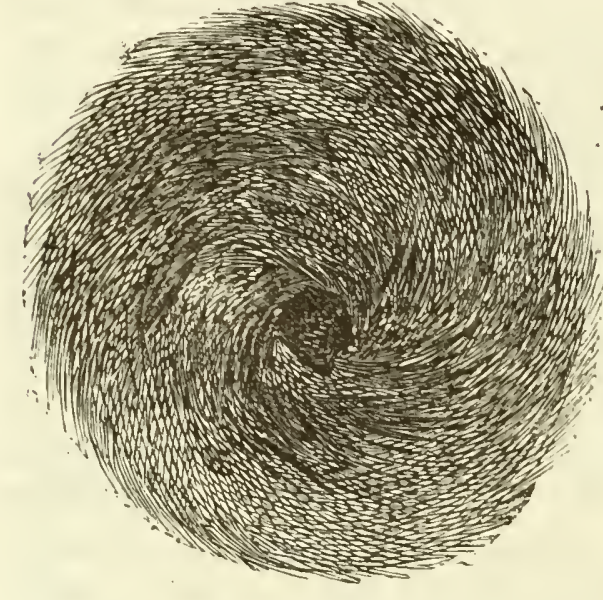

Fig. 8.16. - Nusc du Bengale.

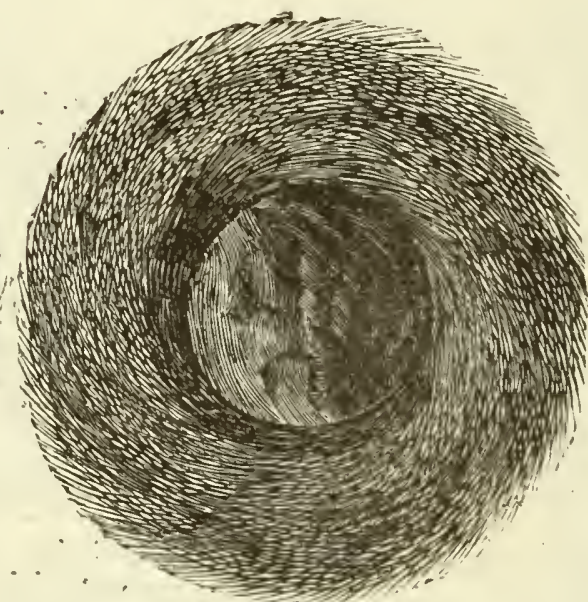

Fig. 817. - Mlusc du Bengale.

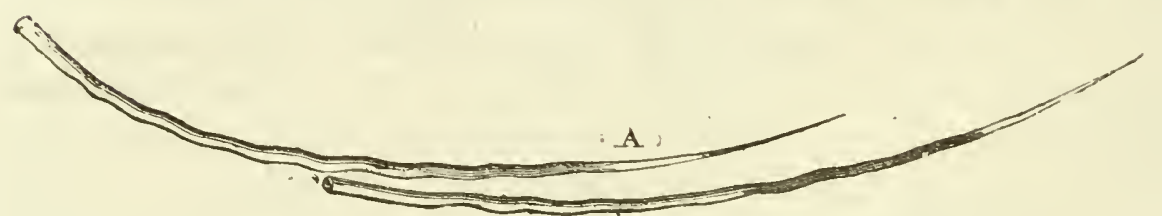

Fig. S\$S. - Poils de muse de grandeur naturelle.

fixés circulairement autour de la face inférieure de la poche, formant une boule de $8, \breve{a}$ à 9 centimètres de diamètre. Ces poils

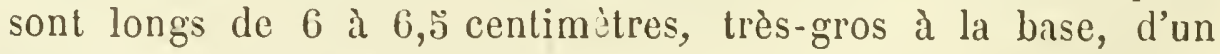
blanc opaque et nacré dans la plus grande partie de leur longueur, puis ils prennent une teinte fauve brunatre qui se fonce de plus en plus en approchant de l'extrémité; mais cette coloration cesse brusquement un peu avant l'extrémité, el la pointe 
est toujours blanche. Ces poils sont très-cassanls, de même que ceux de la poche précédente; ils me paraissent moins ondulés, plus durs, mais ne méritent guère encore, cependant, d'être comparés à des épines. Cette poche m'a paru tellement remarquable que je l'ai fait représenter ici par sa face supérieure ( $(f g .846)$ et par sa face inférieure (fig. 847). Sa substance intérieure est presque sèche et sort facilement par une déchirure faite à la pellicule supérieure, sous forme de grumeaux brunâtres, d'une odeur musquée facile à supporter. Cette poche es d'ailleurs fort ancienne et a été piquée.

V. Muse de sibérie oll muse kabardin (fig. 849). Ce muse paraît venir des monts Altaï par la voie de Saint-Pétersbourg. Les loourses qui le composent sont généralement plus petiles que celles de Chine, mais elles sont surtout plus allongées d'arrière en avant, plus sèches, plus plates et marquées d'un sillon longitudinal plus apparent répondant au fourreau de la verge. Le poil extérieur est propre, sec, blanchâtre et comme argenté; la peau nue, qui touchait au ventre, ressemble à un parchemin jaune brunâtre, reconvert par une légère fleur blanchâtre. La substance même du musc est plus sèche, d'un brun-chocolat clair, non ammoniacale, d'une odeur musquée moins forte, moins tenace et comme se rapprochant d'une odeur aromatique végétale. Il est aussi beaucoup moins estimé.

Enfin on distingue dans le commerce, indépendamment de toute origine, le muse en poche ou en vessie de celui qui est hors vessie. Le mieux est d'acheter le musc en vessie el de vider soi-même, en pratiquant une incision circulaire à la peau qui touchait au ventre. Car, s'il est déjà assez difficile d'avoir du inusc en vessie qui n'ait pas été falsifié, on conçoit qu'il n'y a plus guère moyen d'être assuré de l'espèce el de la pureté de celui qui a élé retiré des poches; et qui peut être mélangé soit de musc ka-

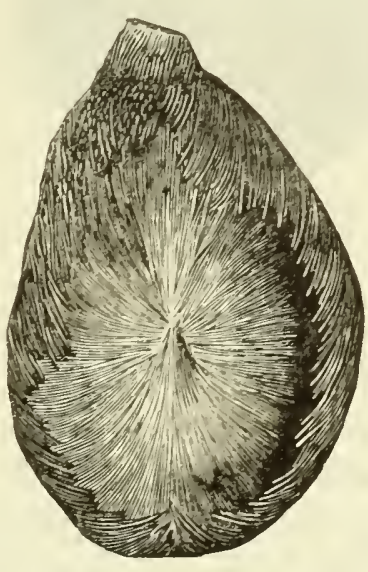

Fig. 846. - Musc de Sibérie ou musc kabardin. bardin, soit de toute autre matière étrangère. Quant à la quantité du musc hors vessie que l'on peut retirer des poches, elle est extrêmement variable. Pereira, dans sa matière médicale, donne d'après un droguiste de Londres, les poids de six poches de musc de Chine qui pesaient 
ensemble 37 drachmes et 15 grains (poids-troy), ou 144 grammes 71 centigrammes, et qui ont fourni 64 grammes 13 centigrammes de musc hors vessie (1), ou 43,61 pour 100; tandis que six poches de muse de Chine, que j'ai vidées à différentes époques, m’ont donné les résultats suivants :

\begin{tabular}{|c|c|c|c|c|c|c|c|}
\hline \multicolumn{4}{|c|}{2 poches ensemble.... } & \multicolumn{2}{|c|}{$\begin{array}{l}\text { Entic̀res. } \\
67^{\mathrm{gr}}, 06\end{array}$} & \multicolumn{2}{|c|}{$\begin{array}{l}\text { Muse hors vessie } \\
\qquad 4.3^{\mathrm{gr}}, 95\end{array}$} \\
\hline 2 & - & - & $\ldots \ldots$ & 49 & 80 & 37 & 76 \\
\hline 1 & - & - & $\ldots$ & 32 & 23 & 23 & 44 \\
\hline \multirow[t]{3}{*}{1} & - & - & & 42 & 31 & 31 & 25 \\
\hline & & Tot & & 191 &, 40 & $136^{6}$ &, 40 \\
\hline & & Moy & де... & 31 & 90 & 22 & 73 \\
\hline
\end{tabular}

Rapports : $100: 71,27$ ou $7: 5$.

Ces poches étaient plus forles que celles mentionnées par Pereira et mont offert un produit beaucoup plus avantageux. Il est vrai que tout en ayant soin de ne prendre que des poches de trèsbonne qualité, je choisissais celles qui devaient m'être le plus profitables.

Musc falsifié. Le musc, en raison de son prix élevé, est trèssujet à être falsifié (2), niême en Chine : on y introduit des grains de plomb ou de petits morceaux de fer, ou bien on y mêle du sang desséché, du sel ammoniac et un peu de potasse, quelque-

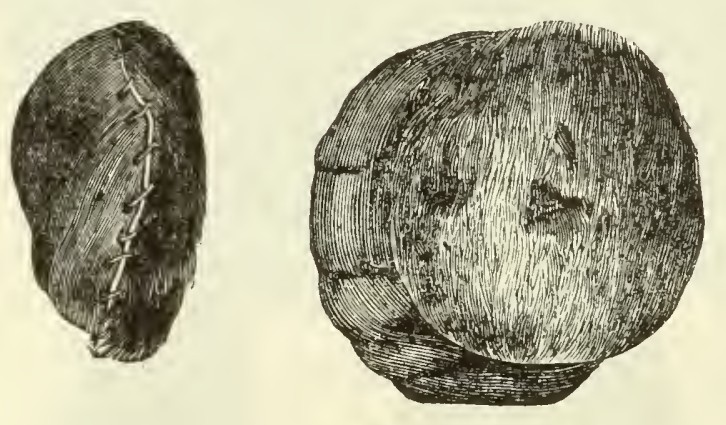

Figg. 8วั0. - IIuse fạlsifié.

fois même du tabac à priser. Tantôt ce musc falsifié est introduit dans des poches vides dont on recoud tout autour la peau ventrale avec un fil fin; et je pose pour première règle qu'il ne faut acheter que des poches qui n’aient pas été recousues sur le bord;

tantôt le musc falsifié est renfermé dans une fausse poche, fabriquée avec un morceau de la peau du chevrotain (fig. 850). Alors ces poches n'offrent pas la disposition centripète des poils des poches véritables, ni le pinceau roux cachant l'ouverture naturelle du musc. On trouve entin quelquelois des poches de musc ovoüdes ou presque globuleuses formées par un morceau de peau noirâtre, n'offrant que des vestiges de poils de porte-musc, replié sur lui-même et cousu suivant une ligne sinueuse qui parcourt

(1) Moyenne pour une poche : entière, $24^{\mathrm{gr}}, 12$; - hors vessie, $10^{\mathrm{gr}}, 5 \%$. Rapport approché, $7: 3$.

(2) Voy. Soubeiran, Nouveau Dictionnaire des falsifications et des altérations Paris, 1874. 
sa surface, enfin ne présentant aucune distinction de face supérieure ni inférieure. Ce musc est toujours de très-mauvaise qualité et doit être rejeté.

Le musc de Chine sorti de sa poche est mou, grumeleux, d'un brun noirâtre, mélangé de quelques poils courts, qu'il faut en retirer avec une petite pince avant de l'employer comme médicament. Il possède une odeur très-forte, toujours un peu ammoniacale (1); il ne doit pas être trop humide et ne doit présenter aucun corps dur sous le doigt, ou lorsqu'on l'écrase sur une feuille de papier, qu'il colore en brun rougeâtre ; il est aux trois quarts soluble dans l'eau et lui donne une couleur brune rougeâtre. La teinture de noix de galle et l'acétate de plomb précipitent la dissolution, mais non le deuto-chlorure de mercure. L'acide nitrique affaibli la rend presque incolore.

Analyse chimique. Blondeau et moi avons fait, en 1820, une analyse du musc tonquin dont voici les résultats :

Produits obtenus :

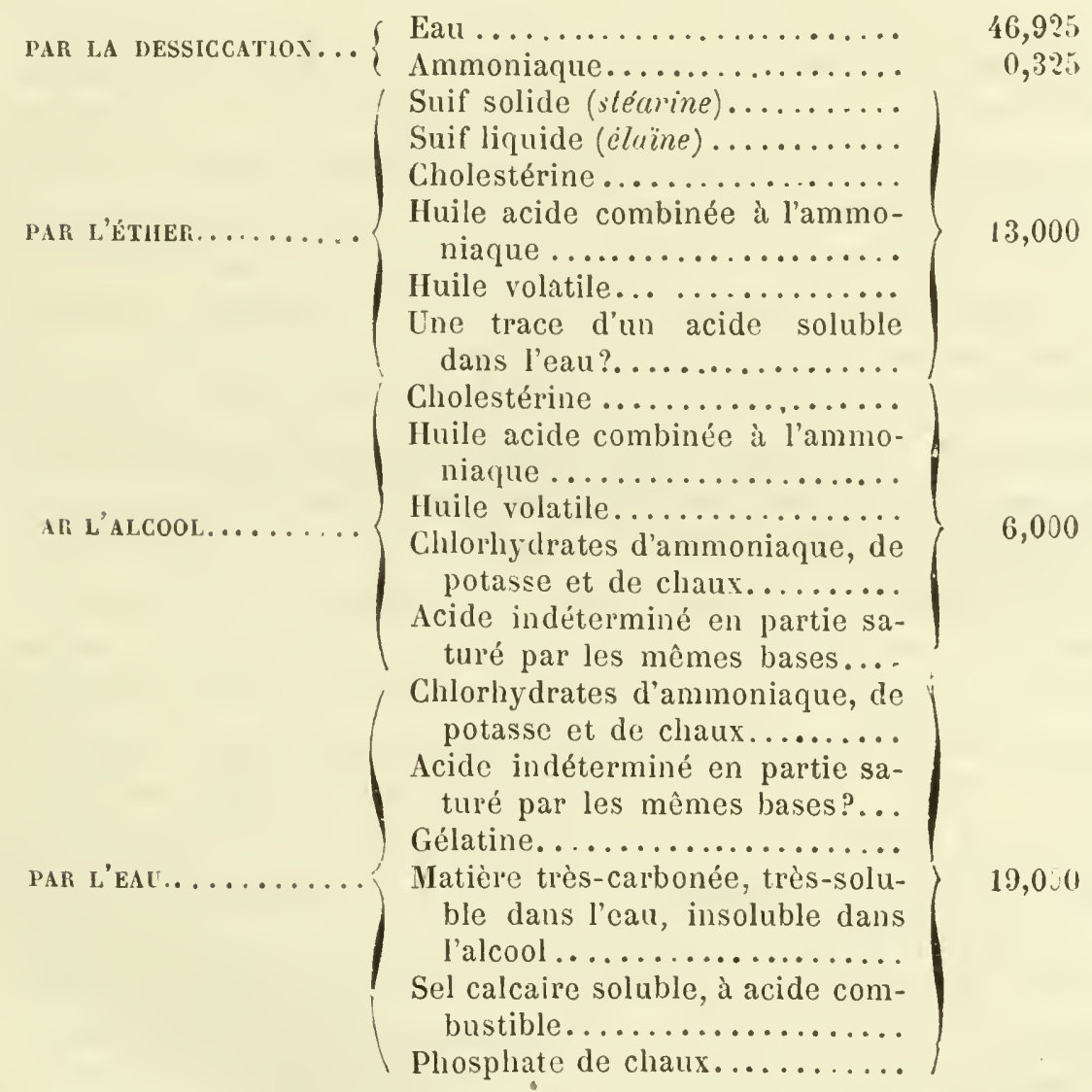

(1) C'est un fait assez remarquable, que l'odeur du musc disparaît par l'addition de quelques substances, telles que le soufre doré d'antimoine et les amandes amères. Elle disparaît aussi complétement lorsqu'il est entièrement desséché au moyen du chlorure de calcium fondu. Je regarde plutôt comme nuisible qu'utile cette disparition d'odeur', dans l'application médicale. 


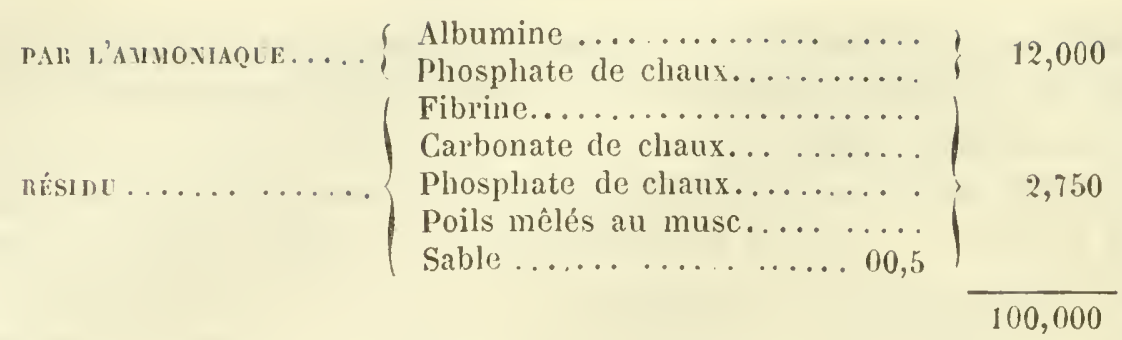

[Geiger et Riemann (1) ont donné l'analyse suivante du musc :

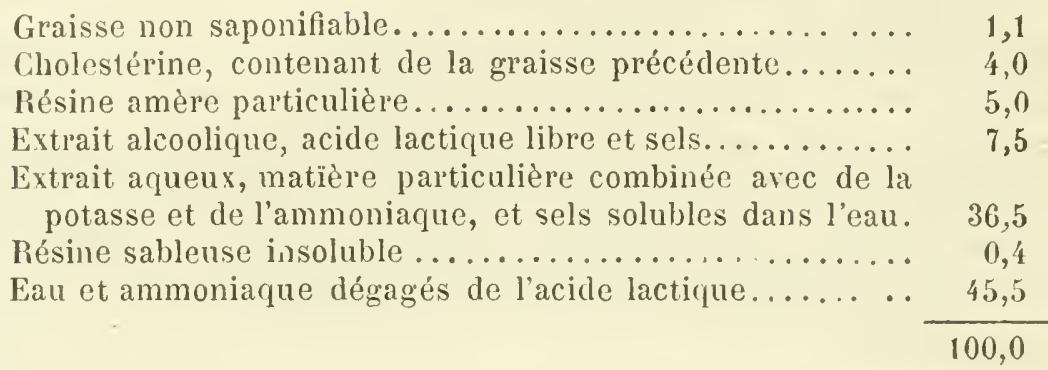

La résine a l'odeur du musc. L'extrait aqueux est formé surtout de l'acide que Büchner a appelé l'acide du musc el qui se présente sous la forme d'une poudre pulvérulente, brune, inodore, insoluble lorsqu'elle est isolée, mais dont les combinaisons avec la potasse et l'ammoniaque peuvent se dissoudre dans l'eau.]

"Le musc élant d'un très-haut prix, les marchands ont intérêt à ce qu'il augmente de poids, plutôt que d'en perdre. Ils le conservent donc alternativement dans des lieux humides, et dans des vases hermétiquement bouchés, qui retiennent l'humidité dont il s'est chargé. Mais on conçoit que le musc, placé dans de pareilles circonstances, éprouve bientôt une altération qui porte surtout sur les principes azotés, el que l'ammoniaque, qui esl un des produits de celte altération, étant forcée de rester dans la masse, réagit à son tour sur le suif, et le convertit en partie en graisse acide, formant avec elle une combinaison semblable au gras des cadavres. Tous les muscs n'offrent pas celte altération au même degré, mais ils le présentent cependant, et les médecins doivent compter employer, non le musc naturel, mais bien celui qui a été ainsi altéré. Nous ne croyons pas que celte connaissance doive les éloigner d'employer nn médicament énergique dans plusieurs circonstances; car l'altération dont nous parlons ne porte que sur l'albumine, la gélatine et la fibrine, substances inertes, et les remplace en partic par de l'ammoniaque réduite à l'état savonneux,

(1) Gmelin, Hundbuch der Chemie, If, 449, d'après Alp. Milne-Edwards, op. cit., p. 31. 
dont l'effet, d'ailleurs, a dù entrer de tout temps dans les propriétés médicales qui ont été reconnues au musc. Nous pensons que l'autre produit de la décomposition des matières azotées cidessus nommées est la matière très-carbonée el non azotée précédemment décrite : cette matière est probablement inerte comme celles qui lui ont donné naissance, et ne doit rien changer aux propriétés du musc (1). ")

Le musc est un puissant tonique et excitant. Les parfumeurs aussi en font un très-grand usage (2).

Les ruminants a CORnes osseuses et caduques ne composent qu'un seul genre, qui est celui des cerfs. Ces animaux sont en général remarquables par l'élégance de leurs formes et la rapiditéde leur course. Les mâles ont la tête armée de cornes rameuses nommées bois, qui tombent et se renouvellent chaque année. Les femelles en sont dépourvues, excepté dans la seule espèce du renne.

Le mode de formation et de renouvellement de ces cornes est très-simple. A un certain âge, ordinairement lorsque le jeune animal cesse de lêter sa mèr e, il se forme, de chaque côté de l'os frontal, une proéminence légère recouverte de peau, et où un grand nombre de vaisseaux se répandent, car on y sent une vivè chaleur. Bientôt cette proéminence s'accroît, en soulevant avec elle la peau qui la recouvre; mais, quelques mois plus tard, il se forme à la base du prolongement osseux un cercle de tubercules qui, en grossissant, comprime les vaisseaux nourriciers et les oblitère. D'abord la peau se dessèche et se déchire en lambeaux; le bois mis à nu se détache à son tour de la base et tombe. Une petite hémorrhagie suit ordinairement, mais après vingt-quatre heures les vaisseaux qui répandaient le sang sont fermées, une mince pellicule recourre toute la plaie, et la production d'un nouveau bois commence immédialement. Ge nouveau bois acquiert généralement de plus grandes dimensions que celui auquel il succède, et le nombre des branches est aussi plus considérable ; mais sa durée n'est pas plus grande, el il se renouvelle toujours chaque année.

On peut diviser les cerfs en deux tribus, suivant que les divisions de leurs bois sont rondes ou aplaties. Trois espèces seulement les ont aplaties: c'est l'élan, le renne el le daim. 'Tous les autres, parmi lesquels se trouvent les vrais cerfs et les chevreuils, ont les bois arrondis.

L'élan (Cervus Alces, I.) est le plus grand des animaux de ce genre; il égale presque la taille du cheval. Il manque de dents

(1) Journ. de pharm., t. VI, p. 105.

(2) Voyez S. Piesse, Des odeurs, des parfums et des cosmétiques. Traduit de l'anglais par O. Reveil. Paris, 1865. 
canines et de mufle; ses bois s'écartent de la tête et forment deux grandes lames aplaties et profondément dentelées ( $f g .831)$, dont le poids s'élève quelquefois à $25 \mathrm{ki}$ logrammes.Poursupporter un tel poids, l'élan a reçu un cou plus court et plus ro. buste que les autres cerfs, et qui lui donne un air beaucoup moins élancé, moins noble et même dis-

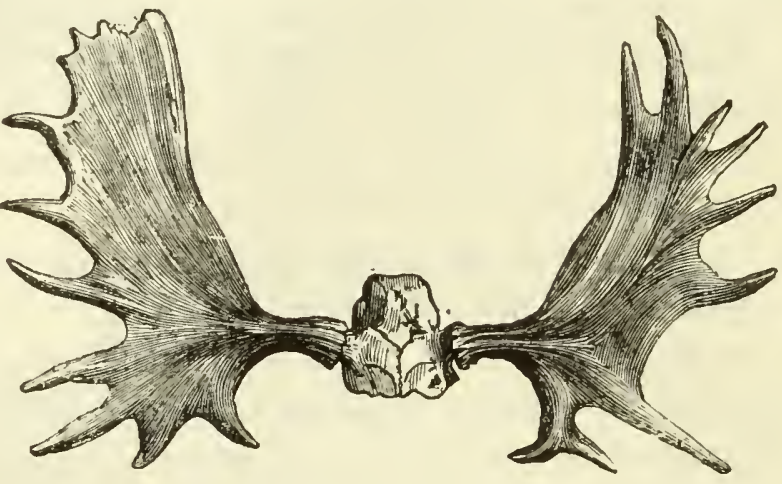

Fig. 851. - Bois de l'élan . gracieux. Il a les jambes élevées، surtout celles de devant, ce qui le force à les écarter ou à se mettre à genoux lorsqu'il veut paître à terre. Son poil est grossier et cassant; celui de la nuque et du garrot est beaucoup plus long et forme une épaisse crinière, et l'animal porte sous la gorge une proéminence ou pendeloque couverte de longs poils noirs.

L'élan habite les forêts marécageuses dans le nord des deux continents. Il est très-sauvage et paisible, à moins qu'il ne soit irrité; alors sa force le rend très-dangereux. Comme il lui arrive quelquefois de tomber en fuyant les chasseurs, et qu'alors on a cru voir qu'il s'introduisait le bout dı pied gauche dans l'oreille, on en a conclu qu'il élait sujet à des attaques d'épilepsie dont il se délivrait par ce moyen, et par suite que le sabot de ce pied gauche, pris à l'intérieur, était efficace pour guérir l'homme de cette terrible maladie. L'origine des propriétés médicales d'un grand nombre de substances autrefois usitées n'est souvent pas mieux fondée.

On trouve encore dans le commerce le sabot de l'élan, avec le bas du pied de derrière de l'animal, réduit aux deux grands doigts moyens ongulés, accompaznés par derrière et de chaque côté d'un doigt beaucoup plus court qui ne posait pas à terre, ainsi que cela a lieu dans toute la famille des ruminants. Le poil des doigts est assez court et roussâtre; les ongles sont noirs, de la nature de la corne. et celui du côté intérieur est constamment plus allongé que l'autre.

Le renne (Cervus Tarandus, L.) manque de dents canines et de mufle. La femelle, ainsi que le mâle, porte des bois ramifiés dont les andouillers et les ernpaumures sont palmés (fig. 8ว2). Il est à peu près de la taille du cerf: mais il est plus trapu, pourvu de jambes plus fortes et plus courtes, et son poil laineux, qui est 
brun foncé au commencement de l'année, devient presque blanc aux jours caniculaires. Il habite les contrées glacées des deux continents et constitue la principale richesse des Lapons, auxquels il sert de bête de somme et de trait, et qui trouvent dans son lait et dans sa chair une nourriture substantielle, et dans sa peau un vêtement chaud et solide. la nourriture des rennes consiste principalement en une espèce de lichen nommé à cause de cela $\mathrm{Li}$ -

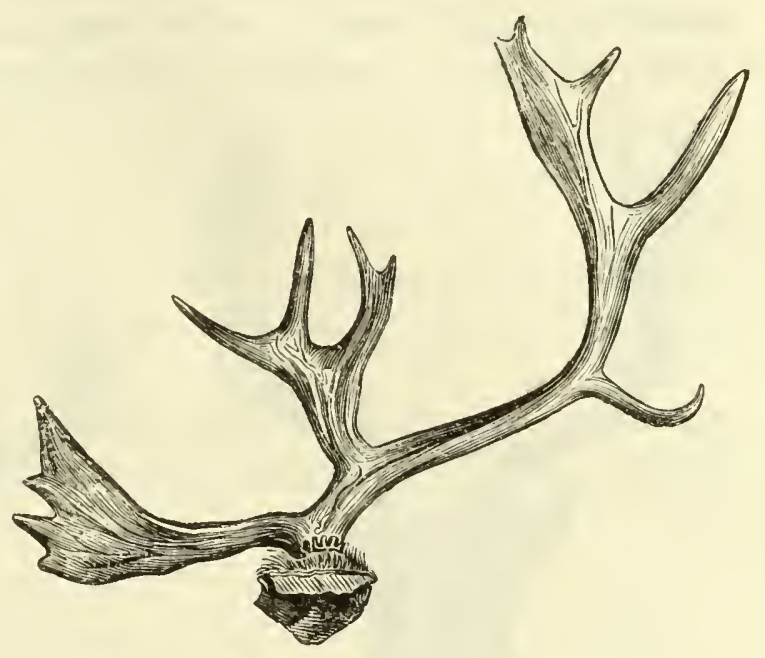

Fig. 852. - $\mathbf{B}$ ois de renne. chen rangiferus, L. (Cenomyce rangiferina, Ach.), qui est presque la seule production végétale qui se développe pendant le long hiver des régions polaires.

Le daim (Cervus Dama, C.) habite l'Europe tempérée et miéridionale, une grande partie de l'Asie et se trouve aussi en Abyssinie. Il présente, chez le mâle seulement, des bois divergents, à base ronde avec un andouiller pointu, aplatis el dentelés en dehors dans le reste de leur longueur (fig. 85̃3). C'est le platyceros de Pline, et non son dama, qui appartient aux antilopes. Il n'a pas de dents canines, mais il est pourvu d'un mufle comme le cerf.

Le daim est un peu plus petit que le cerf; il est en été d'un brun fauve tacheté de blanc, et en hiver d'un brun foncé uniforme. Cependant les fesses sont blanches en tout temps, avec une raie noire de chaque côté, et le ventre et l'intérieur des cuisses sont blanchâtres. La queue est plus longue que celle du cerf, noire en dessus, blanche en dessous. Les mœurs du daim sont analogues à celles du cerf. On en connaît une variété d'un brun noirâtre presque uniforme.

Le cerf commun (C'ervus Elaphus, L.) habite les forêts de toute l'Europe et de l'Asie tempérée, jusqu'au Japon. Le mâle est pourvu de dents canines à la mâchoire supérieure, et de bois ronds et ramifiés. Le mâle et la femelle adultes ont en été le dos, les flancs et le dehors des cuisses d'un fauve brun, avec une ligne noirâtre régnant tout le long de l'épine, et garnie de chaque côté de petites taches fauve pâle. En hiver, ces parties sont d'un gris brun uniforme. La croupe et la queue sont, en tout temps, d'un fauve beaucoup plus pâle. Le petit, âgé de moins de six 
mois, nommé fuon, a tout le corps parsemé de petites taches blanches. A six mois environ, deux bosses commencent à se montrer sur le front du mâle; mais ce n'est que pendant la conde anuée que les bois se développent, sous la forme de tiges

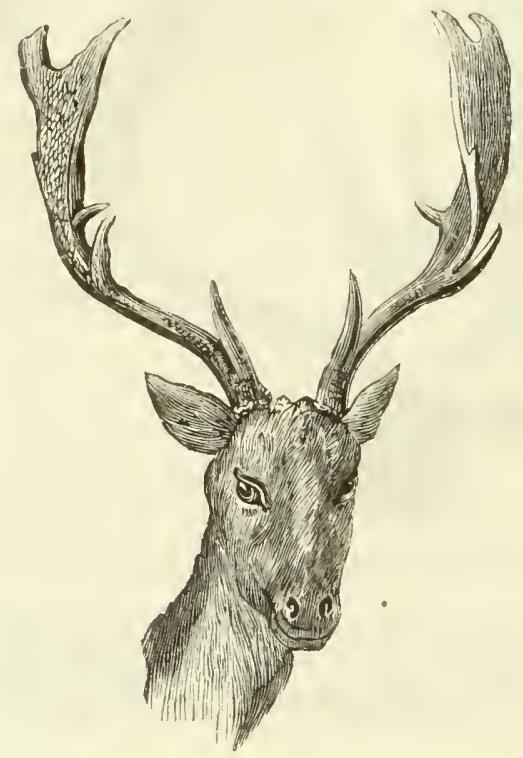

Fig. 853. - Tète de daim.

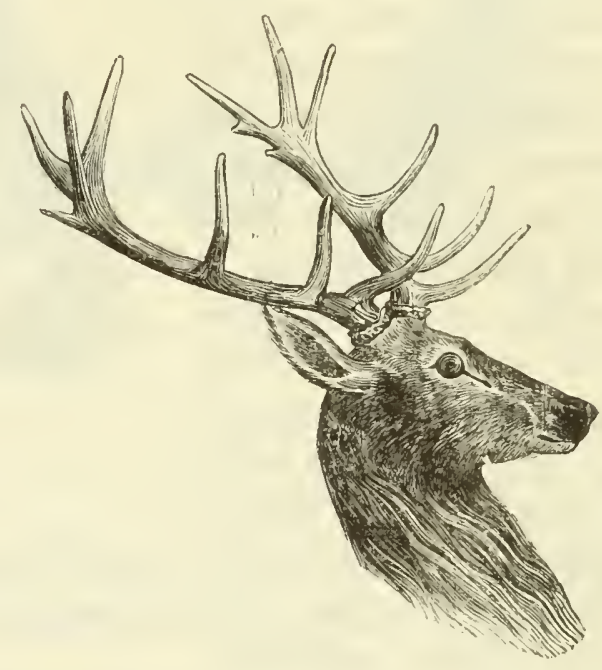

Fig. 854. - Tète de cerf.

simples qui portent le nom de dagues. L'année suivantes les branches ou andouiller's se forment sur la face antérieure de la tige principale, nommée perche ou merrain; enfin, pendant la quatrième année, les bois se couronnent d'une empaumure un peu élargie, divisée en plusieurs pointes (fig. 854).

La chasse du cerf a fait de tout temps l'exercice des guerriers et l'amusement des hommes puissants. Sa chair est peu estimée, mais sa peau est recherchée pour la chamoiserie : ses bois constiluent une sorte d'ivoire commun dont la coutellerie fait un assez grand usage.

Ces bois, principalement composés, comme les os, de phosphate de chaux, de carbonate de chaux et de gélatine, mais sans graisse, sont aussi usités en pharmacie sous le nom de corne de cerf. On les râpe et on les fait bouillir dans l'eau pour en faire des gelées, ou bien on les caleine au blanc, on les porphyrise ensuite, et l'on en forme des trochisques. On emploie également l'huile empyreumatique et l'esprit ammoniacal qui proviennent de leur décomposition dans une cornue.

Le commerce nous offre la corne de cerf sous deux formes: $1^{\circ}$ sous celle de cornichons, qui sont les extrémités des andouillers; on les destine à la calcination; $2^{\circ}$ râpée : celle-ci est sujette à être falsifiée avec des os de bœuf. Celte substitution est même tel- 
lement reçue, qu'on distingue deux sortes de corne de cerf râpée : la grise, qui est la véritable, et la blanche, qui n'est formée que d'os râpés. A moins donc que d'insister pour avoir de la corne de cerf grise, on vous donnera des os râpés avec autant d'assurance et de repos de conscience qu'on vous livrera une autre fois du sulfate de soude sur une demande de sel d'Epsom, par la raison qu'à force de substituer le premier au second, on a fini par lui donner le nom absurde de sel d'Epsom de Lorraine, et qu'il est devenu par là, aux yeux de bien des gens, une espèce de sel d'Epsom.

M. Müller (1) a analysé la corne de cerf et est arrivé aux résulsuivants, qu'il a mis en regard de l'analyse faite par Berzélius sur les os de bœuf :

\begin{tabular}{|c|c|}
\hline Phosphate de chaux tribasique. & $\begin{array}{l}\text { Corne de cerf. } \\
\quad 50,0 ?\end{array}$ \\
\hline - de magnésie. & 2,00 \\
\hline Carbonate de chaux $\ldots \ldots \ldots \ldots \ldots \ldots \ldots$ & 6,15 \\
\hline $\begin{array}{l}\text { Natières organiques................................ } \\
\text { Natron et chlorure de sodium (en petite }\end{array}$ & 41,75 \\
\hline 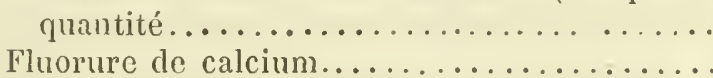 & $\begin{array}{c}\text { " } \\
\text { aces }\end{array}$ \\
\hline
\end{tabular}

On voit que la proportion de matières organiques est beaucoup plus considérable dans la corne de cerf que dans les os. - M. Müller a cherché si l'on ne pourrait pas indiquer un moyen facile de reconnaître la falsification de la corne de cerf par les os, et il propose le suivant comme le plus simple : on réduit la substance en poudre fine, on la sèche à $100^{\circ}$, on lui prend 2 grammes qu'on fait bouillir dans l'eau distillée; on filtre, on lave le résidu, on le fait dessécher à $100^{\circ}$ et on pèse. Si on a affaire à de la corne de cerf, on obtient 14 pour 100 environ, tandis qu'avec les os, on ne dépasse jamais la proportion de 6 pour 100. De là un moyen de reconnaître, non-seulement la substitution d'une des substances à l'autre, mais encore leurs mélanges divers.

On employait autrefois la graisse et la moelle de cerf : on pourrait le faire encore, si l'on était certain de les avoir pures et en bon état; faute de cette assurance, il n'y a pas d'inconvénient à les remplacer par de la graisse et de la moelle de bœuf.

On employait également ce qu'on nommait l'os de cœur de cerf, qui n'est autre chose que la crosse de l'aorte endurcie et presque ossifiée dans les vieux cerfs; elle est tout à fait oubliée.

Le cerf du Canada n'est probablement qu'une variété de notre cerf commun; il est d'un quart plus grand, et ses bois, qui sont très-développés, n'offrent pas d'empaumure élargie à l'ex-

(1) Müller, Archiv der Pharmacie, CXGI, 123. 
trémité. Le cerf de la Louisiane (Cervus Virginianus, Gmelin) est au contraire plus petit que le nôtre; il a les bois plus courts et courbés en arc de cercle en dedans et en avant. L'Inde possède aussi plusieurs espèces de cerf dont une très-élégante, nommée axis (Cervus Axis), ressemble beaucoup au daim par sa taille, sa livrée de taches blanches répandues sur tout le corps, et la longueur de sa queue; d'un autre côté, l'axis se rapproche du cerf par ses bois ronds, mais il s'en distingue parce qu'il ne porte jamais qu'un andouiller à la base de la perche et un second vers l'extrémité. Ces bois se trouvent dans le commerce et peuvent être employés comme ceux du cerf.

Le'chevreuil (Cervus'Capreolus, L. ) est le plus petitdes cerfs d'Europe. Ses bois, peu développés, s'élèvent perpendiculairement sur

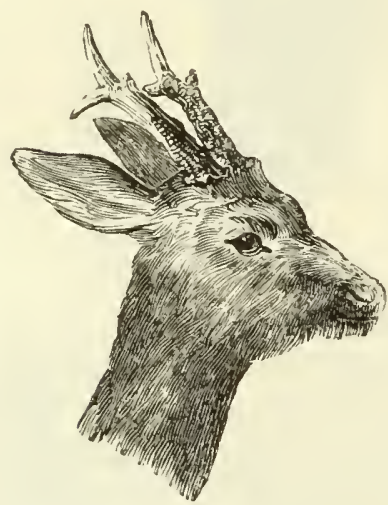

Fig. 855.- Tête de chevrcuil. la tête, sont ronds et ne portent qu'un andouiller très-court aux extrémités (fig. 8ãŏ). Il est ordinairement d'un brun roux.

La girafe (Camelopardalis Girafa, L.) constitue à elle seule une des divisions de la famille des ruminants, caractérisée par deux pelites cornes coniques, persistantes et loujours recouvertes par une peau velue. Leur noyau osseux est d'abord articulé par une suture sur l'os frontal; mais il finit par s'y souder. Au milieu du chanfrein est un tubercule que l'on doit considérer comme une troisième corne, plus large et beaucoup plus courte que les deux autres. Cet animal est d'ailleurs un des plus remarquables qui existent, par la hauteur disproportionnée de ses jambes de derant et la longueur de son cou, qui élèvent sa petite tête à environ 6 mètres du sol. Son pelage est ras, lisse et de couleur grise, tout parsemé de taches anguleuses fauves. Il porte sur le cou une petite crinière grise ou fauve. Il habite les déserts de l'Afrique, où il se nourrit de feuilles d'arbres. Il est d'un naturel fort doux et vit par petites troupes de cinq ou six individus. Il fuil arec une grande vitesse devant le danger, mais se défend par des ruades vigoureuses si la fuite lui est impossible.

Les RUMinants a CORNES GREUSES NON CADUQUES sont très-nombreux et renferment ceux dont l'homme civilisé fait sa principale nourriture. Leurs cornes sont principalement composées d'une gaîne élastique, formée de poils agglutinés, de même que le sabot de leurs pieds, et constituant la substance qui porte spécialement aussi le nom de corne. Ces cornes se développent sur deux protubérances de l'os frontal, et la principale différence 
d'organisation observéc dans cette famille depend de la structure de ces protubérances qui, dans le genre antilope, sont solides et sans cavités apparentes, tandis que, dans les genres ou sous-genres chèvre, mouton et bouf, ces protubérances ou chevilles osseuses présentent des cavités qui communiquent avec les sinus frontaux.

Les antilopes resscmblent pour la plupart aux cerfs, par l'élégance de leur taille et la vitesse de leur course. On connaît un grand nombre d'espèces répandues par toute l'A frique et dans une grande partie de l'Asie, où elles servent de pâture au lion, à la panthère, au tigre et aux autres forts carnassiers. Les principales espèces sont :

La gazelle commune d'A frique (Antilope Dorcas, L.) (1). Elle a la forme élégante du chevreuil, et la douceur de son regard fournit une comparaison sans cesse renaissante à la poésie galante des Arabes. Elle a les cornes rondes, grosses, noires, annelées, pointues et à double courbure. La corinne, le kevel el l'ahu de Kæmpfer en diffèrent très-peu.

Le saiga (Antilope Saïga. Pall., colus de Strabon), habite la Sibérie méridionale, la Russie, la Pologne, la Hongrie, la Moldavie et la Valachie. Il est grand comme un daim et a les cornes de la gazelle, mais jaunâtres et transparentes. Son museail cartilagineux, gros et bombé, le force à brouter en rétrogradant, comme l'élan. Il se réunit quelquefois en troupes de plus de dix mille.

L'antilope des Indes (Ant. Cervicapra, Pall.) (2). Elle est très-semblable à la gazelle, mais grande comme un daim et pourvue de cornes rougeâtres, à 3 ou 4 courbures. La femelle n'en porte pas.

Le bubale des anciens (Ant. Bubalis, L.) (3). ll est commun en Barbarie. Il est de la taille d'un cerf, mais il a les proportions plus lourdes, la tête plus longue et plus grosse, le pelage fauve, excepté le bout de la queue, qui est terminé par un amas de poils noirs. Ses cornes sont annelées, à double courbure dirigée en sens contraire des précédentes, avec la pointe brusquement tournée en arrière. Le caama, ou cerfdu Cap des Hollandais, en diffère peu.

L'antilope à longues cornes droites (4). Cet animal habite l'Afrique, au nord du Cap de Bonne-Espérance. Il est grand comme un cerf. Ses cornes sont noires, grêles, presque droites, longues de 60 à 100 centimètres, annelées en spirales interrom-

(1) Buffon, t. XII, pl. XXIII.

(2) Idem, Supplém., t. VI, pl. XVIII et XIX.

(3) Id., Ibid., t. VI, pl. XIV.

(4) ld., Itid., t. VI, pl. XVII. 
pues dans leur moitié inférieure, presque unies dans l'autre moitié, et très-aiguës à la pointe. Ce doit être une arme fort dangereuse. La femelle en porte de semblables, mais plus petites. Le même animal ou une espèce très-voisine, décrite par Pallas sous le nom d'antilope Oryx, se trouve au Thibet. C'est lui qui, ayant perdu accidentellement une de ses cornes, a été décrit par les anciens naturalistes sous le nom de licorne.

L'antilope à longues cornes courbes, ou l'algazel (Antilope Gazella, L., Ant. ltucoryx, Lichtenst.). Cette espèce habite l'Afrique septentrionale, depuis la Nubie jusqu'au Sénégal. Ses cornes ne diffèrent de celles de la précédente que parce qu'elles sont courbées en un arc de cercle tel que, par une corde de 73 centimètres, la distance de la corde au milieu de l'arc est de 12 centimètres (1). Cet animal est probablement l'oryx des anciens.

Le coudons (Antilope strepsiceros, Pall.). Ce bel animal se trouve représenté par Bufton (2). Il est grand comme un cerf, d'un gris brun rayé de blanc, et le mâle seul porte une paire de cornes longues de 1 mètre, lisses (3), à triple courbure, avec une seule arête longitudinale légèrement spirale. Il a une petite barbe sous le menton et une crinière le long de l'épine. 11 vit isolé au nord du cap de Bonne-Espérance.

Le nylgau (Ant. picta, Gmel.) (4). Grand comme un cerf el plus; des cornes très-courtes, unies, coniques, courbées en avarit; un bouquet de barbe sous le milieu du cou; doubles anneaux noirs el blancs fort tranchés aux quatre pieds, immédiatement au-dessus des sabots. La femelle n'a pas de cornes. Il habite les Indes.

Le gnou (Antilope Gnu, Gmel.)(つั). Animal fort singulier, vivant dans les montagnes, au nord du Cap. Il a le corps et la croupe d'un petit cheval, avec une queue garnie de longs poils blancs, une crinière redressée sur le cou, une autre crinière sous la gorge et sous le fanon, un cercle de cils blancs autour des yeux et une garniture de longs poils tout autour du museau. Les deux sexes ont des cornes dirigées d'abord en avant, puis brusquement recourbées vers le haut.

Le chamois (Antilope Ruprcapra, L.) (6). C'est le seul rumi-

(1) Une autre corne d'algazel, dont la corde a 88 centimètres, présente 15 centimètres de perpendiculaire au milieu; une corne d'oryx du Cap, don la corne a 99 centimètres, ne présente que $6^{\circ}, 7$ de perpendiculaire.

(2) Buffon, Supplém., t. VI, pl. XIII.

(3) Idem, Hist. nat., t. XII, pl. XXXIX.

(4) Id., Supplém., t. VI, pl. X et XI.

(5) Id., Ibid.., t. VI, pl. VIII et IX.

(6) Id., t. XIl. pl. XY 
nant propre à l'Europe que l'on puisse assimiler aux antilopes; car le saïga, qui en habite les parties orientales, paraît y être venu de la Sibérie. Le chamois est de la taille d'une grande chèvre; il a le pelage brun foncé, avec une bande noire descendant de l'œil vers le museau. Ses cornes sont droites avec une pointe subitement recourbée en arrière comme un hameçon ( $f g .85 \% 6)$. Il habite les Alpes et les Pyrénées, où il porte le nom d'isard. Il court avec la plus grande facilité sur les pentes les plus escarpées, et franchit les précipices en bondissant de rocher en rocher. Aussi sa chasse est-elle très-pénible et souvent dangereuse. Sa chair passe pour être bonne à manger, tandis qu'elle serait malsaine, sui-

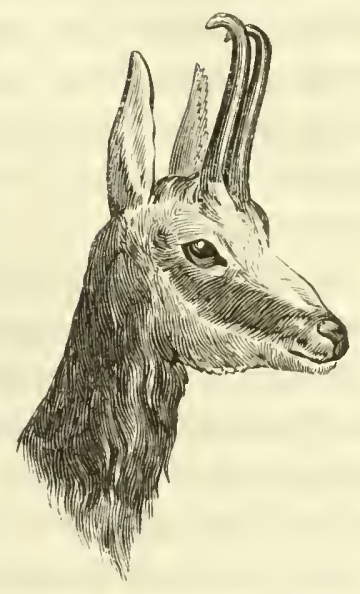

Fiv. 856 .

Tète de chamois. vant d'autres. Il fournit un suif de bonne quaiité, el sa peau débourrée, parée et foulée à l'huile, dans l'art du chamoiseur, présente quelques qualités particulières et une grande souplesse. Elle est surtout propre à passer le mercure que l'on veut débarrasser de ses impuretés, ou séparer des amalgames produits dans l'exploitation des métaux précieux.

Les chèvres et les moutons constituent non-seulement un seul genre, mais sont formés d'espèces tellement voisines, que celles-ci peuvent toutes produire ensemble des métis féconds, ce qui, joint à l'état de domesticité où la plupart ont été réduites, en multiplie beaucoup les variétés et rend la filiation des races difficile à établir. Quatre espèces primitives et sauvages, particulières à certaines contrées, paraissent cependant avoir produit toutes les races de chèvres et de moutons. C'est, pour les chèvres, l'xugagre et le bouquetin, et, pour les moutons, l'argali et le mouflon.

Les chèvres ont pour caractères particuliers: des cornes comprimées, dirigées en laul el en arrière, ridées transversalement; le chanfrein droit ou concave (1); le menton généralement garni d'une longue barbe.

L'rgagre (Capra AEgagrus, Gm.), paraît être la souche de nos chèvres domestiques, dont il offre la taille et les allures; -mais il est d'un gris roussâtre en dessus, avec une ligne dorsale noire et la queue noire. La tête est pareillement noire en avant et rousse sur les côtés. La gorge et la barbe sont brunes. Le mâle, ou le bouc, a les cornes très-grandes et fortement arquées en arrière, sans retour sur les côtés. Elle sont tranchantes par-devant, arron-

(1) Le chanfrein est le devant de la tête, depuis les yeux jusqu'aux naseaux. 
- dies sur leur face postérieure, avec des anneaux transversaux très-marqués. La femelle a des cornes très-petites ou nulles. Cet animal habile par troupes les montagnes du Caucase, de l'Arménie, de la Perse el du Thibet. Les Persans le nomment pasèn et attribuent de grandes propriétés à une concrétion résineuse formée dans ses intestins; je la décrirai plus loin sous le nom de bézoard oriental.

Quelques personnes ont pensé que l'ægagre se trouvait également sur les montagnes d'Europe, et l'on voit souvent, en effet, à la tête des troupeaux de chèvres qui paisseni sur les Alpes et les Pyrénées, quelques individus d'une espèce plus grande, qui offrent les caractères de l'ægagre; mais il y a lieu de croire que ce sont des mélis nés du bouquetin et de la chèvre.

La chèvre domestique (Capra Hircus, J..), bien représentée par Buffon (1), diffère de l'ægragre par ses cornes qui, après s'être élevées en se couchant en arrière, comme dansl'ægagre, se recourbent horizontalement en dehors et un peu en avant, de manière à tigurer un commencement de spirale $(f g$. 8577). Elles sont arron-

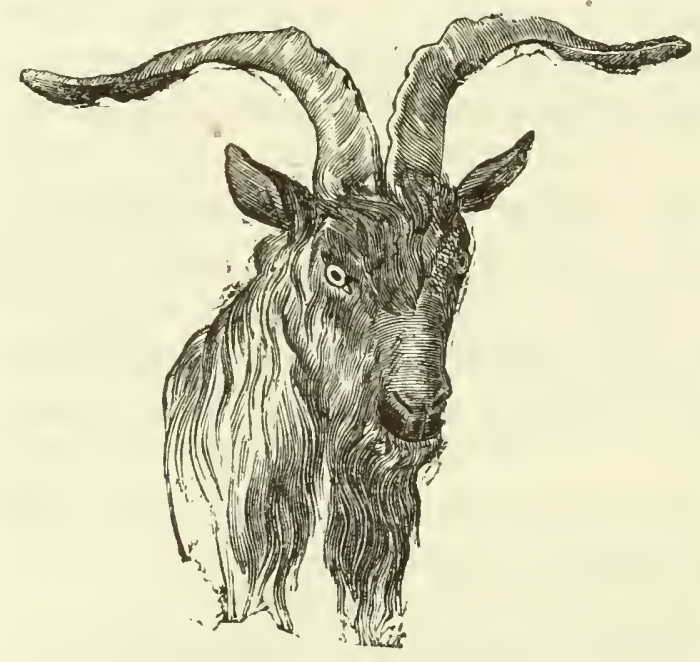

Fig. 857. - Tête de chèvre (bouc).

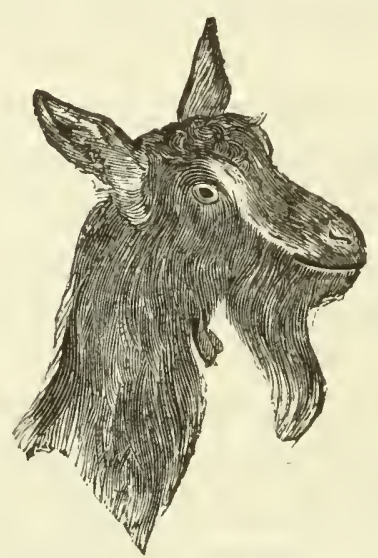

Fig. 858. - Tête de chèvre.

dies sur chaque face et sur le bord postérieur et extérieur; mais le bord antérieur est tranchant, inégal et quelquefois tuberculeux d'espace en espace. La surface de ces cornes est marquée sur presque toute leur longueur d'annelures transversales, ondoyantes et très-rapprochées. La femelle, ou la chèvre proprement dite, a souvent des cornes comme le bouc, mais elle les a moins fortes et moins grandes, et elle peut en manquer complétement ( $f \mathrm{~g} .858)$, Les couleurs les plus ordinaires du bouc et de la chèvre sont le blanc et le noir, et il y en a de blancs et de noirsen entier;

(1) Buffon, t. V, pl. VIII et IX. 
mais le plus grand nombre sont en partie noirs et blancs. Le poil est dur et de longueur inégale sur les différentes parties lu corps. Ces animaux, malgré leur état de domesticité, ont conservé les allures de l'état sauvage; ils sont vifs, alertes, capricieux, vagabonds, et aiment à grimper sur les endroits élevés. Ils ne prospèrent pas dans les pays de plaine et recherchent les pâturages secs et montueux; ils ébourgeonnent aussi les arbres et leur causent un grand préjudice. La chèvre, lorsqu'elle est bien nourrie, donne beaucoup de lait proportionnellement à sa grosseur. Ce liquide a un goût particulier et ne produit qu'un beurre d'une qualité médiocre; mais on l'emploie ávec avantage à la fabrication des fromages. On ne mange guère que la chair du chevreau; la peau de chèvre sert à faire du maroquin et du parchemin. Les outres dont on se sert dans les pays chauds pour contenir de l'eau, du vin et de l'huile, se font ordinairement en peau de bouc.

La domesticité et le croisement des races ont apporté de grands changements chez ces animaux. La chèvre commune a conservé les oreilles droites et mobiles; mais la chèvre mambrine ou de Syrie les a très-allongées et pendantes, avec les cornes trèscourtes el le poil fauve et court. La chèvre d'Angora a les oreilles pendantes également; mais le mâle a les cornes très-grandes et contournées en spirales cylindriques (en lire-bourre) qui s'écartent horizontalement de la tête, et la femelle les a plus courtes, réduites à former un seul cercle ou tour de spire, qui vient, se terminer en avant, tout auprès de l'œil (1). Mais ce qui donne du prix à cette variété, c'est son poil très-long, très-fin, ondoyanl et lustré comme la soie, et dont on fait de très-belles étolfes. Les chievres du Thibet, dites de Cachemire, et celles du pays des Kirghis, qui ont été introduites en France en 1819, par les soins de M. Amédée Jaubert, sont encore plus précieuses sous ce rapport. Il he paraît pas, malheureusement, que ces chèvres se soient répandues en France, ni qu'elles aient exercé une influence avantageuse sur notre race indigène.

Le bouquetin, ou bouc-estain (Capra Ibex, L.) (2), habite les sommets les plus escarpés des Alpes. Il est de la taille d'un bouc ordinaire, couvert d'un poil gris fauve sur le dessus du corps, avec une bande noire sur toute l'épine du dos, jusqu'au bout de la queue; le dessous du corps est d'un blanc sale. Le mâle se distingue par la grandeur de ses cornes comparée à la sienne propre. Buffon en a fait figurer une paire ayant 89 centimètres de longueur;

(1) Buffon, t. V, pl. X et XI.

(2) Bouc-estain signifie bouc des rochers; en allemand, stein-bork. 
mais celles qui existent à l'École de Pharmacie n'ont que 72 cen $^{-}$ limètres pris suivant la courbure de l'arêta interne de la face, el 42 centimètres pour la longueur de la corde. Elles ne sont guère séparées sur le front que de l'épaisseur d'un doigt; mais elles s'écartent insensiblement, en se recourbant en arrière et faiblement en dehors, de manière à offrir à l'extrémité une ouverture de $69^{c}, \breve{a}$. Eilles ont $25^{c}, \breve{a ~ d e ~ t o u r ~ a ̀ ~ l a ~ b a s e . ~ E l l e s ~ s o n t ~ c o m p r i-~}$ mées latéralement, plus en arrière qu'en avant, et présentent une face antérieure reclangulaire, dont l'angle interne est bien marqué par une arête saillante, et l'angle externe arrondi. Elles présentent des plis circulaires très-nombreux et très-rapprochés qui, de distance en distance, prennent un plus grand développement et forment des saillies transversales, et, plus haut, des tubercules très-proéminents. On compte ainsi 19 fortes saillies transversales tuberculeuses. La face postérieure des cornes est plus étroite que l'antérieure, beaucoup plus unie, arrondie des deux côtés, et finit en s'amincissant par former une seule arête arrondie. Les deux cornes pèsent ensemble plus de 3 kîlogrammes.

Le bouquetin de Crète, observé par Belon, diffère très-peu du précédent, ainsi que le bouquetin du Caucase, dont les cornes sont cependant plutôt triangulaires que carrées, obtuses par-devant, mais du reste semblables.

Le sang du bouquelin desséché était autrefois usité en médecine comme antipleurétique. On le trouve encore, dans le commerce, enfermé dans de petites vessies qui ont la forme d'un saucisson. Il est noir, luisant, cassant et sans saveur. Il n'est plus employé.

Les moutons ont le chanfrein tombé, les corpes arrondies, ridées et annelées, le menton non barbu. On les croit tous descendus de deux races primitives, l'argali de Sibérie et le mouflon de Corse.

L'argali de Sibérie (Ovis Ammon, L. ; Pall.) (1), porte chez le mâle de très-grosses cornes à base triangulaire, arrondies aux angles, aplaties en avant, striées en travers, courbées en arrière et en dehors, de manière à former un tour de spire presque complet et à venir se terminer près de l'œil. La femelle les a comprimées et en forme de faux. Le poil d'été est ras et gris fauve; celui d'hiver est épais, dur, gris roussâtre. Cel animal habite les montagnes de toute l'A sie; il est grand comme un daim, et se rapproche plus par ses allures et son agilité du bouquetin que du mouton domestique.

(1) Pallas, Spicelegia, XI, 1. 
Le moufon de Corse (Ovis Musimon, Pall.) était nommé par les Latins musmon ou musimon: les Sardes l'ont appelé mufione, etc'est. de l'une ou l'autre de ces appellations qu'est dérivé son nom actuel. Sa taille est un peu plus grande et plus élancée que celle de nos moutons domestiques. Sa toison de laine est courte et grisâtre, et disparaît sous un poil plus long, analogue à celui de la chèvre, fauve ou noirâtre; il a la queue courte, une crinière sous le cou, des cornes très-grosses et arrondies qui se recourbent en demi-cercle et n'atteignent pas le garrot (le haut de l'épaule). La femelle n'a des cornes que rarement, et fort petites.

Le mouton domestique (1) (Ovis Aries, L., fig. 859), au lieu d'avoir les formes sveltes et gracieuses, et l'agilité des races sauvages, est lourd, indolent et presque dénué d'intelligence. Il présente un trèsgrand nombre de variétés qui diffèrent par leur taille grande ou petite, par leurs cornes plus ou moins grandes, manquant chez la femelle ou dans les deux sexes; par leur laine commune ou fine, etc. Les variétés les plus recherchées pour leur toison sont celle du mérinos d' Espagne, à laine fine et crépue et à grandes cornes spi-

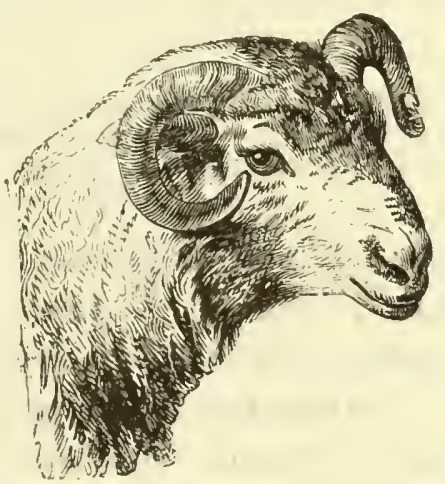

Fig. S3̆9. - Tète de mouton. rales chez le mâle, et celle d'Angleterre, à laine fine et longue. Les moutons des Indes et de Guinée sont privés de cornes et ont la queue longue, les jambes élevées, le chanfrein très-convexe, les oreilles pendantes, le poil ras. La race de Perse et de Tartarie a la queue entièrement transformée en un double globe de suif. Celle de Syrie et de Barbarie a la que!ıe semblable, mais plus longue et quelquefois d'un poids si considérable, qu'on est obligé d'atteler l'animal à une brouette destinée à la supporter. Dans toutes deux, les oreilles sont pendantes, les cornes grosses aux béliers et la laine mêlée de poils.

Le mouton est précieux par sa chair, son suif, son lait, sa laine ( $/ \mathrm{g}$. 860) et son fumier. Les troupeaux qui en sont formés, étant bien employés, portent la fertilité partout. Sa peau dépouillée de

(1) Le mouton est plus particulièrement le mẩle châtré : maìs comme c'est lui qui forme la plus grande partie des troupeaux, il a donné son nom à l'espèce; de même que la chévre, composant la presciue totalité des troupeaux de chèvres, a domné également son nom à l'espèce. Le mouton au-dessous d'un an porte le nom d'agneau; d'un an à deux, on le nomme antenois; le mâle adulte se nomme bélier et la femelle, trebis. 
sa laine, a aussi d'importants usages. C'est avec elle que l'on prépare, suivant le procédé de fabrication, la basane qui couvre les livres reliés et les chaussures légères; la peau blanche qui sert

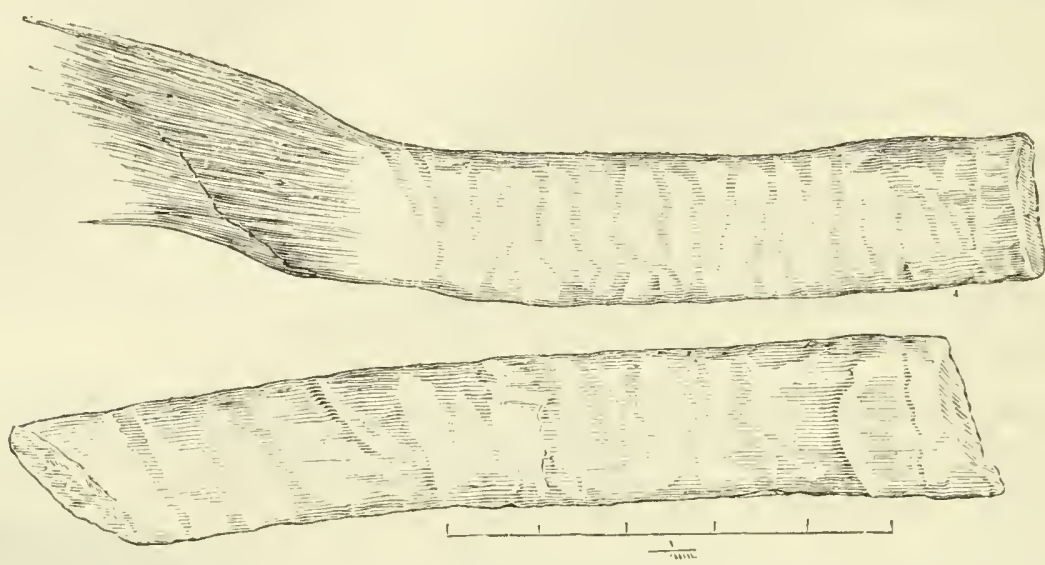

Fig. 860. - Fil de laine grossi mille fois, présentant des fibres rondes, opalines, formées de petits cornets imbriqués; la base des cornets est indiquée par des stries obliques et par un léger renflement (E. Parkes).

à la confection des gants et à la doublure des souliers; le parchemin, le vélin et les peaux chamoisées et maroquinées, substituées souvent au chamois et au vrai maroquin.

Les bœufs sont de grands animaux à mufle large, à taille trapue, à jambes robustes, dont les cornes sont dirigées de côté et reviennent ensuite, sous forme de croissants, en haut, en avant ou en arrière, suivant les variétés.

Le bouf commun (1) (Bos Taurus, L.) paraîl avoir été naturellement répandu autrefois dans toutes les parties tempérées de l'ancien continent, mais il n'y existe plus aujourd'hui à l'état sauvage. Les anciens l'ont cependant connu à cet état et l'ont décrit sous le nom d'Urus. Il a le front plat, plus haut que large, et les cornes rondes et coniques, placées aux deux extrémilés de la ligne la plus élevée qui sépare le front de l'occiput. Dans les crânes fossiles qui paraissent avoir appartenu à la race sauvage, les cornes se recourbent en avant et vers le bas; mais dans les nombreuses variétés produites par la domesticité, elles ont des directions et des grandeurs bien différentes, quelquefois même elles manquent tout à fait.

Le bœuf commun a treize côtes et six vertèbres lombaires, comme la plupart des ruminants; sa tête est terminée par un large mufle, et la peau inférieure du cou, lâche et pendante,

(1) Le bœuf est proprement le mâle coupé; mais comme c'est lui qui domine dans les troupeaux, il a donné son nom à l'espèce et mème à tout le genre. Le mâle se nomme taureau, la femelle, vache, et, quand elle n'a pas encore été couverte, génisse; le petit se nomme veau. 
forme un grand pli, nommé fanon, qui se prolonge jusqu'à l'intervalle qui sépare les jambes de devant.

Il a le poil ras et couché sur la peau, à l'exception d'une petite crinière placée entre les cornes et sur la partie supérieure du cou. Il est le plus ordinairement de couleur fauve rougeâtre; mais il est souvent taché de noir et de blanc ou de couleur pie, et quelquefois tout noir ou tout blanc.

Le bœuf domestique s'est propagé en abondance dans les quatre parties du monde. Il s'est prodigieusement multiplié en Amérique, où il a été importé par les Espagnols, et il y est même retourné en partie à la vie sauvage. OOn y utilise depuis quelque temps la chair des nombreux individus, qu'on y abat, pour la préparation d'un extrait de viande, connu sous le nom de viande de Liébig ou extractum carnis. Cet extrait, qui contient les principes nutritifs de la chair, débarrassés de la graisse et de la partie gélatineuse, qui dans les tablettes de bouillon ordinaire s'altèrent rapidement et donnent bientôt un goût très-désagréable, peut se conserver très-longtemps, et rendre des services dans bien des occasions.]

Des expériences récentes, celles en particulier qui ont été faites par M. Tellier, permettent d'espérer qu'on poura un jour recevoir en Europe les masses considérables de viande, qui se perdent dans les pampas de l'Amérique méridionale. Soumises à un refroidissement que peuvent maintenil, dans une chambre de capacité considérable, l'évaporation et la condensation alternatives de l'éther méthylique, ces viandes pourront conserver, avec toutes leurs qualités nutritives, une saveur analogue à celle de la chair fraîche (1).

On trouve dans l'Inde, dans la Perse, l'Arabie et dans toute l'Afrique au sud de l'Atlas, une variélé du bœuf nommée zébu, remarquable par une forte loupe graisseuse portée sur les épaules, et ces zébus peuvent différer considérablement par la taille, qui tantôt égale presque celle de notre bœuf et tantôt ne dépasse pas celle du cochon. Tantôt également ils ont des cornes trèsgrandes et solides, el d'autres fois ils en ont qui sont trèspetites, adhérentes seulement à la peau et mobiles, parce que l'axe osseux ne s'est pas développé. Les bneufs de nos climats diffèrent moins entre eux, quoiqu'ils offrent encore de grandes variations sous le rapport de la taille, de la grandeur et de la direction des cornes, elc. Le bœuf ordinaire peut avoir de $2^{\mathrm{m}}, 20$ à $2^{\mathrm{m}}, 45$ de longueur en ligne droite, depuis l'extrémité

(1) Voir Poggiale, Rapport fait au Conseil de salubrité de la Seine sur ith conservation de la viande par le froid (Joum. de pharm. et ie chimie, qe serie, MIX, 389. 
du mufle jusqu'à l'origine de la queue; $1^{\mathrm{m}}, 20$ à $\mathrm{f}^{\mathrm{m}}, 30$ de hauteur aux épaules; 2 mètres de circonférence derrière les jambes de devant, et il pèse, lerme moyen, $3 ð 00$ kilogrammes. Mais, en France, les bœufs ne pèsent souvent que 200 kilogrammes, et l'on en a vu d'autres peser 1,500 kilogrammes ou davantage.

Les bœufs sont, en général, lents dans leur's mouvements et faciles à conduire, mais leur force est considérable; la colère les rend furieux, et leurs cornes, dont ils se font une arme puissante, les rendent alors très-dangereux. La vache est plus douce et susceptible d'attachement pour les personnes qui la soignent; mais le taureau est toujour's farouche et très-irascible. Aussi ne conservet-on entiers que ceux que l'on destine à la propagation de l'espèce; tous les autres sont châtrés à l'âge de dix-huit mois ou deux ans, puis employés aux travaux de l'agriculture pendant quelques années, et enfin engraissés pour êire livrés au boucher.

Les vaches peuvent servir aux mêmes usages; mais, en général, on les consacre exclusivement à la multiplication de l'espèce et à la production du lait. Dans l'état demi-sauvage où elles se trouvent en quelques pays, dans la Colombie, par exemple, les mamelles sont peu développées et le lait se tarit aussitôt que le petit cesse de téter; mais, dans l'état de domesticité. les mamelles prennent un volume considérable et continuent à fournir du lait jusqu'au moment où la vache est près de vêler de nouveau. La quantité qu'elle peut en fournir varie suivant l'âge, la race, l'abondance le la nourriture, etc. C'est à l'âge de cinq ou six ans, et dans les premiers mois qui suivent le part, qu'elle en donne le plus. Les vaches ordinaires de nos campagnes en donnent près de 6 litres par jour; les belles vaches suisses en fournissent de 10 à 11 litres, et celles de la Frise, jusqu'à 13 litres. La vache paraît n'avoir qu'une seule mamelle à quatre tétins ( $f g .861$ ), éloignée de la vulve de 60 centimètres environ. Mais ces tétins sont disposés de manière que les deux d'un même côté ne sont distants l'un de l'autre que de $5^{c}, 5$, tandis que les deux postérieurs sont éloignés entre eux de 8 centimètres et les deux antérieurs de 12 centimètres, ce qui indique la connexion de deux mamelles collatérales portant chacune deux mamelons. Cette distinction devient encore plus certaine à l'intérieur, où l'on trouve deux glandes mammaires collatérales, réunies par du tissu cellulaire, chaque glande mammaire présentant à sa partie inférieure deux cavités qui répondent chacune à un tétin, et se terminant par un petit canal de 2 millimètres de diamètre (fig. 862).

L'aurochs, nommé par les anciens Bonasus et Bison, a passé 
pendant longtemps pour être la souche sauvage de nos bœufs domestiques; d’autant plus que le nom urus, que les anciens donnaient au bœuf sauvage, aujourd'hui disparı, parait être l'origine du nom aurochs. Mais les ossements fossiles du vrai bœuf sauvage, qui ont été trouvés en divers endroits de l'Europe, joints aux différences essentielles qui existent entre les squelettes du bœuf et de l'aurochs, montrent que celui-ci est une espèce très-distincte du premier. L'aurochs a le front bombé, plus large que haut, et ses cornes sont attachées au-dessous de la crête occipitale. Il a

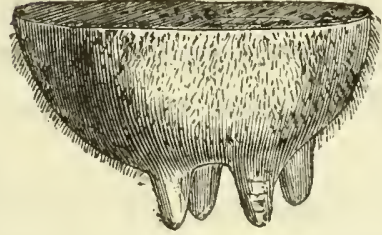

Fig. 861. - Tétins de la vache.

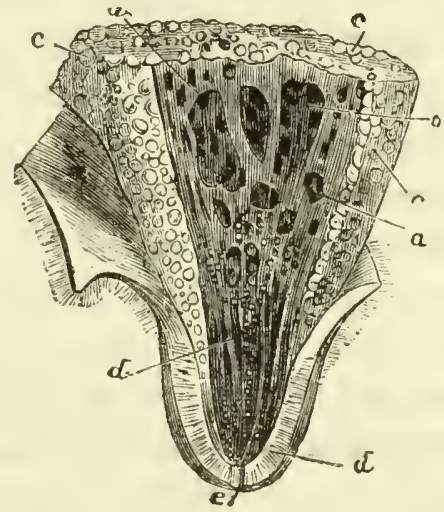

Fig. 862. - Tétin de vache uuvert, présentant une des cavités inférieures de la glande mammaire $\left({ }^{*}\right.$ ).

une paire de côtes de plus et une vertèbre lombaire de moins; il a les jambes plus hautes, les cornes petites, la queue longue, et une crinière laineuse qui lui couvre la tête, toute l'encolure jusqu'aux épaules et le dessous de la mâchoire, le cou et le poitrail. Le mâle répand une forte odeur de musc. C'est un animal farouche, qui vivait autrefois dans toute l'Europe tempérée, mais qui n'existe plus aujourd'hui que dans les forêts marécageuses de la Lithuanie, de la Hongrie et du Caucase. C'est le plus grand des quadrupèdes propres à l'Europe; sa peau a deux fois l'épaisseur de celle du bœuf.

Le bison d'Amérique (Buffalo des Américains, Bos americanus) a beaucoup de rapport avec l'aurochs par sa grande taille (1), par sa tête couverte d'une longue laine crépue, ainsi que tout le cou, le poitrail et les épaules. Mais il a quinze paires de côtes, et quatre vertèbres lombaires seulement; it a le dos plus élevé et

(1) Il a $3^{\text {nu }}, 30$ de longueur du bout du museau à l'origine de la queue, et pèse de 800 ì 1,000 kilogrammes.

(*) Celle-ci est composće d'un nombre infini de granules mous d'une teinte jaunàtre ou rougeàtre, renfermant les dernières ramifications des vaisseaux sanguins et les premières des conduits lactifères. Ces conduits se réunissent peu à peu pour former huit ou dix conduits principaux $a, \iota, "$, qui viemnent s'ouvirir dans la cavité du tétin. $c, c, c$, granules glanduleur; $d, d$, tube conique du tétiu, présentant un certain nombre de plis à sa surface inerne; $e$, ouverture du tétin. 
comme bossu à l'endroit des épaules, la croupe plus laible et la queue plus courte.

Le buffle (Bos Bubalus, Brisson) est originaire de l'Inde, d'où il a passé, pendant le moyen âge, en Arabie, en Grèce et en Italie. Il a le front bombé, aussi large que haut, très-épais. Ses cornes sont placées, comme dans le bœuf, aux deux extrémités de l'arête cervicale; mais elles sont dirigées de côté et en arrière, et marquées en avant d'une arête longitudinale saillante. Il a le même nombre de côtes que le bœuf, la peau très-épaisse et le poil très-ras, excepté aux joues et à la gorge. Il aime les terrains marécageux et se nourrit de plantes grossières qui ne pourraient suffire au bœuf. Il est d'une force considérable, et très-difficile à dompter.

Le buffle du Cap (Bos Cafer, Sparm.) a les cornes très-grandes, dirigées de côté et en avant, remontant de la pointe, aplaties, et tellement larges ả leur base qu'elles recouvrent presque tout le front. C'est un très-grand animal, d'un naturel excessivement féroce, qui habite les bois de la Cafrerie.

Le bue uf musqué d'Amérique (Bos moschatus, Gm.) a les cornes rapprochées et dirigées comme le précédent, mais se rencontrant sur le front par une ligne droite. Son front est bombé, et le bout de son museau est garni de poils. Il est couvert d'un poil touffu qui pend jusqu'à terre. Il répand avec plus de force que tous les autres l'odeur musquée commune à tout le genre. On ne le voit que dans les parties les plus froides de l'Amérique septentrionale; mais on en a trouvé quelques ossements en Sibérie.

L'espèce du bouf domestique ne se recommande pas seulement par les services qu'elle rend à l'agriculture, par le lait qu'elle fournit, ęt par sa chair qui, appliquée à la nourriture des nations européennes, est peut-être la cause première de leur suprématie numérique, intellectuelle et industrielle (1). Toutes les parties du bœuf sont utiles, et leur exploilation a créé un grand nombre d'industries que je ne puis qu'indiquer.

La peau de bøuf tannée, ou rendue imputrescible par la combinaison de l'acide tannique de l'écorce de chêne ou du sumac avec la substance gélatineuse qui la constitue presque entièrement, se change en cuir fort, qui forme la semelle de nos chaussures, et que l'on applique également à la carrosserie et à une multitude d'autres usages. Les peaux de vache et de veau fournissent des cuirs plus minces qui sont ouvrés, assouplis, imbibés de suif ou d'huile, teints en noir à l'aide du sulfate de fer, ou colorés de

(1) Il est évident que les $\Lambda$ nglo-Américains font partie de la grande famille européenne. 
toute autre manière, ou laissés dans leur couleur naturelle, et appliqués de même à la confection des chaussures, à la carrosserie, à la sellerie, à la reliure des livres, etc. A Paris seulement, on tanne, chaque année, plus de 50,000 peaux de bœufs ou de vaches, et plus de 60,000 peaux de veaux. On évalue à plus de 36 millions la valeur des peaux employées annuellement en France par les tanneurs, et on estime que leur conversion en cuir plus ou moins ouvré en double le prix; mais toutes ces peaux ne proviennent pas du sol; on en importe une grande quantité du Brésil, de Buenos-Ayres, de Russie, etc.

Les poils dont on dépouille ces peaux sont employés à divers usages : après les avoir filés, on en fait une étoffe grossière nommée thibaude, dont les rouliers se servent comme de manteau, et qui sert aussi à la doublure des tapis de pied.

La corne des bœufs, qui est formée d'une substance fibreuse, élastique, demi-transparente, de la même nature que les poils, est employée à faire des peignes et d'autres ouvrages de tabletterie. On la colore avec des sels métalliques pour lui donner l'apparence de l'écaille, ou bien on la décolore par le moyen du chlore, on la ramollit par une longue ébullition dans l'eau, on la soude et l'on en forme des masses comparables à l'agate, que l'on moule ou que l'on tourne pour en faire une foule d'ustensiles et d'objets d'ornement.

La membrane musculaire des petits intestins sert aux boyaudiers pour faire des cordes pour les instruments de musique, et la membrane séreuse qui fixe ces intestins aux parois de l'abdomen, étant convenablement préparée, devient de la baudruche.

La graisse de breuf, à laquelle on donne le nom de suif, est moins consistante à froid et un peu plus fusible que celle du mouton; mais, comme elle est beaucoup plus abondante, en raison du poids de l'animal, c'est elle qui forme la majeure partie du suif consommé par l'art du chandelier et aujourd'hui par le fabricant d'acide stéarique.

Le sang de bauf récent est employé, à l'instar de l'albumine de l'œuf, pour la clarification des sirops de sucre, ou bien, étant desséché, mélangé avec de la terre, il constitue un excellent engrais.

Les os de bouf n'ont pas des applications moins variées ni moins importantes. Les plus gros, après avoir servi dans les cuisines, à la préparation du bouillon, sont livrés aux tourneurs et aux tabletiers qui en font des spatules, des manches de couteau, des étuis, des dominos, etc. C'est l'ivoire du peuple, comme la corne en est l'écaille. Les débris qui proviennent de cette fabrication, bien loin d'être perdus, servent à toutes les iabrications suivantes. 
Les os ordinaires servent à la préparation de la gélatine. A cet effet, ils sont lavés, cassés ou broyés grossièrement, puis portés à l'ébullition dans l'eau, afin d'en extrairc la graisse qui vient nager à la surface. On les traite ensuite par l'acide chlorhydrique affaibli, qui les prive de phosphate de chaux et les réduit à leur partie cartilagineuse. On soumet celle-ci à une forte ébullition dans l'eau qui la convertit en gélatine susceptible de se prendre en gelée ferme par le refroidissement. Cette gelée est ensuite coupée par plaques minces que l'on pose sur des cordes tendues sur des châssis, et dont on opère la dessiccation dans de vastes séchoirs. On peut également extraire la gélatine des os en les traitant directement par l'eau, à une température supérieure à $\mathbf{1 0 0}$ degrés, dans un autoclave ou marmite de Papin ; mais on n'obtient par ce procédé qu'une gélatine de qualité inférieure. Les os qui ont subi cette opération et tous ceux qui ne servent pas à la fabrication de la gélatine sont décomposés par le feu, dans des vases fermés, et convertis en charbon animal, noir animal ou nor d'os, très-usité dans la peinture commune, et dont les raffineurs de sucre font aussi un grand usage pour la décoloration de leurs sirops.

Lal gélatine animale n'est pas toute extraite des os et prend différents noms dans le commerce, suivant qu'elle est destinée à l'alimentation ou aux arts. Celle qui est presque incolore, inodore, insipide, réduite en plaques très-minces el de la plus belle transparence, s'appelle grenétine, du nom du fabricant de Rouen qui l'a préparée d'abord. On l'extrait des os traités par l'acide chlorhydrique, ou mieux encore de peaux récentes de jeunes animaux et de cartilages de veaux.

La colle de Flandre ordinaire est en plaques un peu plus épaisses, longues de 18 centimètres, larges de כ̊ à 6 , jaunes et d'une transparence un peu nébuleuse. Elle est quelquefois sèche et inodore, et c'est la meilleure, le plus souvent hygrométrique et d'une odeur désagréable. On l'emploie dans une foule d'arts et en pharmacie, pour la composition des bains gélatineux. Enfin la colle forte des menusiers ou colle de Givet est sous forme de plaques carrées, de 16 à 18 centimètres de côté, épaisses de un centimètre, plus ou moins brunes et en partie solubles dans l'eau.

\section{Du lait.}

Le lait est un liquide blanc, opaque, d'une saveur douce et sucrée, sécrété du sang par les glandes mammaires, dans les animaux qui ont pris de cette conformation le nom de mammifères, et destiné à servir de première nouriiture à leurs petits qui nais- 
sent vivants, mais hors d'état de se suffire à eux-mêmıs. Ce liquide, considéré dans les animaux herbivores, qui sont les seuls dont le lait soit appliqué à la nourriture de l'homme, et même dans d'autres animaux qui ne se nourrissent pas exclusivement de matières animales, comme est l'homme lui-même, est à peu près identique dans sa composition et ne varie guère que par la proportion de ses matériaux. Celte composition, qui est d'ailleurs itssez simple, est telle qu'elle forme un aliment complet et qui suffit au développement des jeunes animaıx. Elle leur présente, dans la caséine, une matière azotée organisable, capable de produire tous les tissus de l'économie; dans le beurre et le sucre de lait ou lactose, les éléments combustibles qui deviennent la principale source de calorification; enfin dans ses sels inorganiques, ceux qui doivent faire partie du sang et ceux qui doivent concourir au développement de la charpente osseuse. La nature pourvoit à tout ce qui est nécessaire aux êtres qu'elle a créés.

Le lait tient à l'état de dissolution une grande partie de sa cuséine, le lactose et les sels, et à l'état de suspension des granulations extrêmement fines de caséine et le beurre sous la forme de très-petits globules sphériques qui nagent dans le liquide, sans être pourvus d'aucune enveloppe, comme se trouve l'huile dans une émulsion d'amandes. Mais ce beurre, en raison de sa moins grande densité, tendant à se séparer peu à peu du lait conservé en repos, se rassemble à sa surface et forme une couche plus ou moins épaisse et jaunâtre, qui porte le nom de crème. A cette époque, la caséine est encore presque entièrement dissoute; mais déjà le lait, dont l'état normal est de montrer une faible réaction alcaline, en manifeste une sensiblement acide. Si le liquide reste plus longtemps abandonné à lui-même, avec le contact de l’air, il s'aigrit par la formation de l'acide lactique, et alors la caséine, devenant insoluble, forme un coagulum nommé caséum ou fromage. Ce coagulum nage au milieu d'un liquide jaune verdâtre, nommé sérum ou petit-lant, qui contient le sucre de lait et les sels. Il arrive souvent que cette altération du lait n'est pas assez avancée pour que le caséum en soit visiblement séparé; mais la coagulation s'effectue aussitôt qu'on met le liquide sur le feu; alors on est obligé de le rejeter. Pour s'opposer à cette altération du lait, qui est souvent présentée par celui que l'on apporte de la campagne dans les grandes villes, on le soumet préalablement à l'ébullition et on y ajoute souvent une peitte quantité de bicarbonate ou de carbonate de soude.

C'est en battant la crème dans une sorle de tonneau fait exprès, et nommé baratte, qu'on prépare le beurre. Dans cette opération, le sérum s'acidifie assez fortement pour redissoudre la caséine 
qui aurait pu se coaguler d'abord, et les molécules huileuses, restant presque seules en présence les unes des autres, se réunissent peu à peu en une seule masse.

Le beurre, à part la petite quantité de caséum et de sérum qu'il contient encore, est composé de deux corps gras, la margarine et l'oléine ou l'éléobutyrine, et d'une petite quantité de quelques autres corps que la saponification change en acides odorants et volatils qui ont été nommés par M. Chevreul acides butyrique, caprique et caprö̈que. D’après M. Broméis, le beurre frais est composé de :

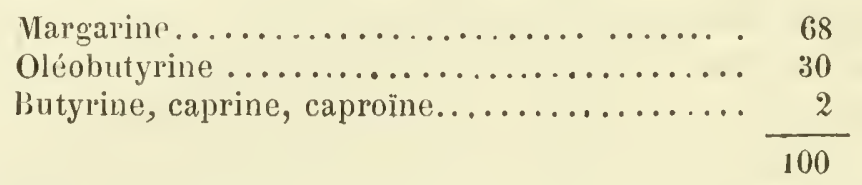

A ces substances il faut ajouter la myristicine, la palmitine et la stéarine, trouvées par M. Heintz et la léčthine, matière grasse phosphorée signalée par M. Gobley (1).

Le caséum sert à la fabrication des différents fromages. A cet effet, on le sale et on lui fait subir différentes préparations qui le font varier a l'infini pour la consistance, la saveur et les autres caractères physiques.

Le sérum purifié donne le petit-lait, que l'on prépare dans les pharmacies, en coagulant le lait par un acide qui est ordinairement le vinaigre ou l'acide tartrique, ou bien en se servant de présure, qui est un lait caillé que l'on trouve dans l'estomac des jeunes veaux, salé et séché. Le même sérum, évaporé convenablement, fournit par le refroidissement une matière cristalline que l'on fait redissoudre et cristalliser de nouveau pour l'avoir plus blanche et plus pure, et qui est le lactose, lactine ou le sucre de lait, dont la composition relative $\left(\mathrm{C}^{12} \mathrm{H}^{12} \mathrm{O}^{12}\right)$ est semblable à celle du sucre liquide, du glucose séché à - 100 degrés, de l'acide lactique liquide et de l'acide acélique hydraté (2).

Le sucre de lait est ordinairement en masses assez épaisses ou en bâtons cylindriques et stalactiformes, durs, demi-transparents, sans odeur, d'une saveur douce et faiblement sucrée. Il est inaltérable à l'air, soluble dans š à 6 parties d'eau froide et dans 2 parties 1/2 d'eau bouillante; il est insoluble dans l'éther et l'alcool; il n'est précipité ni par les dissolutions métalliques ni par la noix de galle; les acides minéraux étendus le transforment en sucre de raisin; l'acide nitrique concentré le convertit en

(1) Voyez, sur les caractères de la lécithine, Gobley, Sur la lécithine et la cérébrine (Journ. de pharmacie. et de chimie, $4^{\mathrm{e}}$ série, XIX, 346).

(2) L'acide lactique liquide égale $\mathrm{C}^{6} \mathrm{H}^{6} \mathrm{O}^{6} ;$ l'acide acétique hydraté $=\mathrm{C}_{4}^{4} \mathrm{H}^{4} \mathrm{O}^{4}$. 
acide mucique et ensuite en acide oxalique. Suivant les conditions dans lesquelles il est placé, le sucre de lait peut éprouver la fermentation alcoolique, ou la fermentation lactique. A la température de $40^{\circ}$, le lait subit la première fermentation et son sucre donne de l'alcool et de l'acide carbonique.

Exposé à l'air dans les conditions ordinaires, il devient acide au bout de quelque temps, et la lactine s'y transforme en acide lactique.

Le lait est toujours plus pesant que l'eau, et, ce qui est facile à comprendre, il est plus dense lorsqu'il est écrémé que lorsqu'il ne l'est pas. Sa densité varie même, pour le même animal, d'une traite à l'autre, et du commencement d'une traite à la fin (1). Cependant ces variations ne sont pas aussi fortes qu'on pourrait le croire, et on peut se servir de la densité pour estimer la pureté et la bonne qualité des laits plus usuels. Voici, d'après Brisson, ces laits rangés suivant l'ordre de leur plus grande densité moyenne :

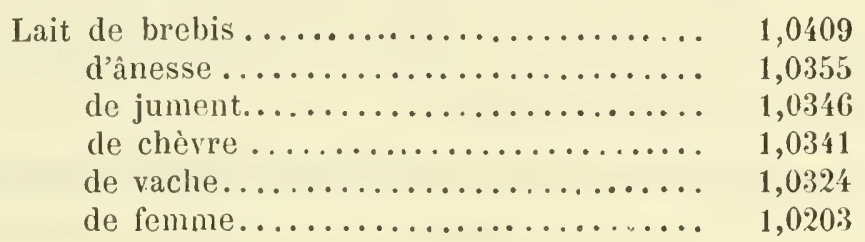

1,0409

, 0355

1,0346

, 0341

$1,0203(2)$

Le lait étant d'autant plus nutritif qu'il contient plus de beurre, de casóine, de lactose, de sels, et moins d'eau, on est souvent appelé à déterminer la proportion de ces divers principes: je pense que le procédé suivant est à la fois le plus facile à suivre et le plus exact (3).

On prend un poids déterminé de lait récent et non écrémé; on le chauffe presque jusqu'à l'ébullition, et on y verse par trèspetite quantité, et à la fin, goutte à goutte, de l'acide acétique étendu de deux fois son poids d'eau. Lorsque la coagulation est

(1) Contrairement à ce qu'on aurait pu croire, le lait de la fin de la traite est plus dense et plus chargé de principes solides que celui du commencement.

(2) M. F. Simon, ayant examiné quatorze fois le lait d'une femme, dans l'espace de quatre mois, a trouvé que la densité de son lait variait de 1,0300 à 1,0345 ; la moyenne était de 1,03:4, comme pour le lait de vache. (Voyez Vernois et Alf Becquerel, Analyse du lait des principaux types de vache, chère, Lrebis, bufflesse présentées au concours agricole de 1855. Paris, 1857, in-8, et Annales d'hygiène puhlıque, 1857, 2érie, t. VII, p. 27 l. - O. Réveil, Du Lait. Paris, 1857, in-8.)

(3) Un grand nombre d'autres procédés ont été indiqués poul atteindre ce but. Nous renvoyons, pour leur étude, aux traités de chimie ou aux mémoires spéciaux sur le lait. (Voir en particulier Adrian, Thèses de l'École supérieure de pharmacie de Paris, 1859. - Reynès, Thèses pour le doctorat en médecine. Montpellier, 1860. - Baudrimont). 
bien opérée, on passe à travers un linge fin pour recueillir le caséum, on filtre le sérum au papier, et on l’évapore à la chaleur du bain-marie jusqu'à réduction des deux tiers. On filtre de nouveau pour séparer une petite quantité de caséum qu'on lave et que l'on réunit au premier. On réunit l'eau de lavage au sérum. filtré, on évapore à siccité, et on termine la dessiccation dans une étuve chauffée à 100 degrés. Considérant le résidu comme formé de lactose et de sels inorganiques (ce qui suffit pour le but qu'on se propose), on le pèse et on le calcine dans un creuset jusqu'à incinération complète. On pèse le résidu salin, et la perte donne le poids du lactose.

D'un autre côté, on fait dessécher le caséum de la même manière qu'on a fait sécher le sérum, et on le pèse. En réunissant son poids à celui du sérum desséché, et en défalquant la somme de la quantité de lait employée, on connaît la quantité d'eau du lait. Enfin, en traitant le caséum desséché par l'éther pour lui enlever la matière grasse, le poids du résidu desséché donne la caséine, et l'éther évaporé fournit le beurre. C'est en opérant d'une manière semblable que MM. Chevallier et Ossian Henry (1) ont obtenu les résultats suivants :

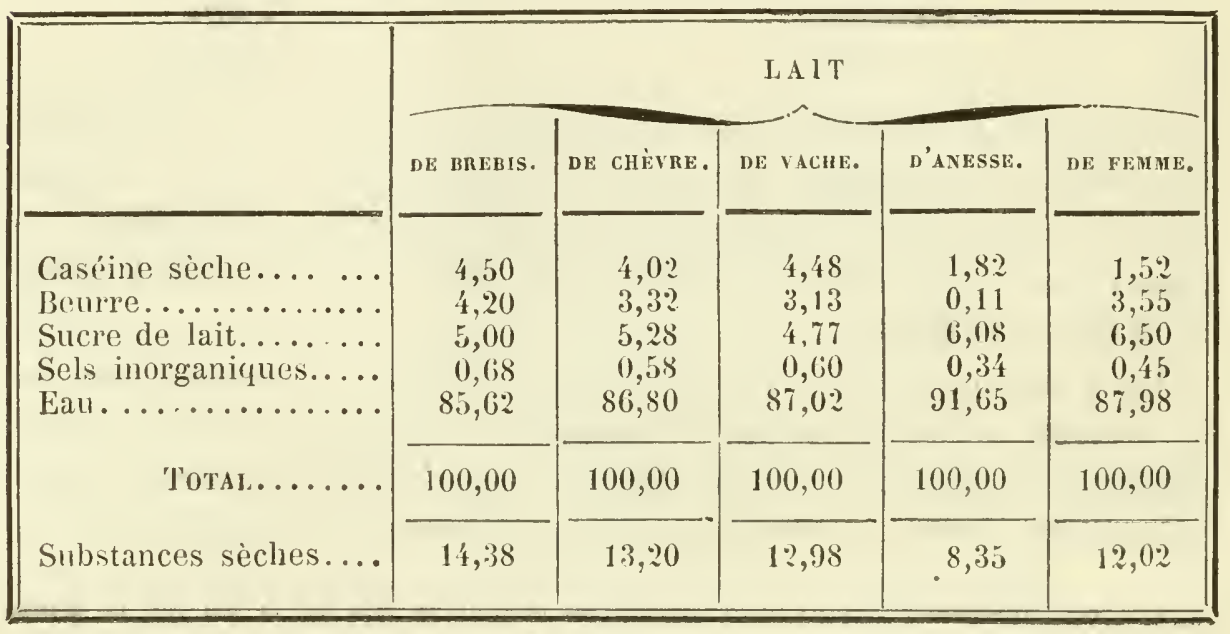

Ces analyses tiennent à peu près le milieu entre celles qui ont été faites par beaucoup d'autres chimistes, à l'exception de ce qui regarde le lait d'ânesse, qui contient certainement moins de matière grasse que les autres laits, mais qui en renferme plus que n'en ont obtenu MM. Ossian Henry et Chevallier : M. Péligot en a extrait 1,28 pour 100. Le lait de femme contient plus de beurre que le lail d'ânesse, autant de sucre de lail et aussi peu de caséum. Il ne forme pas de coagulum isolé par les acides,

(1) Chevallier et Ossian IIenry Mémoire sur le lait, sa composition, ses modifications, ses altérations (Ann. d'hyg., 1839, t. XXII, p. 238). 
quoique le caséum paraisse séparé au microscope; mais il reste divisé dans le liquide. Ce lait est plus manifestement alcalin que ceux des animaux; il est d'ailleurs très-sujet à varier, en raison des causes morales qui agissent sur les femmes.

Le lait de vache éprouve beaucoup moins de variations; mais en raison de la grande consommation que l'on en fait dans les villes, indépendamment de ce qu'il est presque toujours privé de sa crème, il est toujours plus ou moins altéré par une addition d'eau. Pour reconnaître si un lait a été privé de sa crème, ou, si on l'aime mieux, pour apprécier la bonne qualité d'un lait, qui est toujours en raison directe de la quantité de crème qu'il peut fournir, on remplit de ce lait, bien mêlé, un tube de verre de la contenance de 100 centimètres cubes, gradué par centimètres, et on le laisse en repos, pendant vingt-quatre heures, dans un lieu frais. Sur 87 iaits essayés de cette manière par M. Quevenne, 18, c'est-à-dire plus du cinquième, ont donné de 7 à 9 centièmes de crème; ce sont les laits faibles : 51 (ou 58 pour 100) ont donné de 10 à 12 centièmes de crème; ce sont les bons laits : 12 ont fourni de 13 à 14 centièmes de crème; ce sont les laits forts: $\mathbf{2}$ ont fourni 15 centièmes de crème, 3 en ont donné de 17 à 18, un en a fourni 21; ce sont là des faits tout à fait exceptionnels.

[Le crémométre de Quevenne demande beaucoup de temps pour donner des résultats approximatifs. Aussi a-t-on proposé d'autres instruments pour apprécier la richesse du lait. Nous citerons entre autres le lactoscope de M. Donné (1)(fig. 863) qui est basé sur

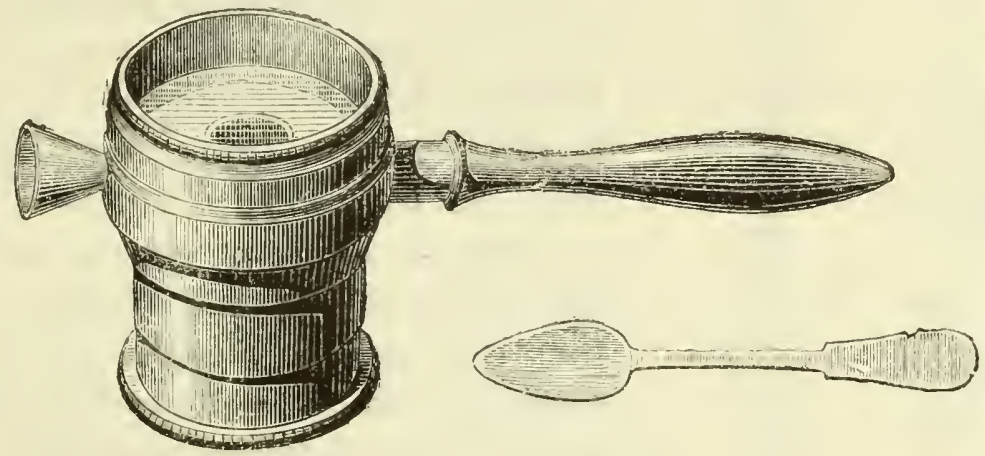

Fig. 863. - Lactoscope de M. Donne.

l'opacité que les globules de matière grasse communiquent au lait. Il en résulte que plus le lait sera riche en beurre et plus sera mince la couche de ce liquide nécessaire pour faire disparaître aux yeux de l'observateur une lumière regardée au travers. Les conditions de l'expérience se trouvent réalisées au moyen d'une

(1) Donné, Conseils aux mères sur la manière 'l'élever leur's enfants' nouvecu-nés, $5^{\mathrm{e}}$ édition. Paris, 1875. 
lunette dont les verres parallèles peuvent se rapprocher l'un de l'autre et qui peut ainsi contenir dans son intérieur des épaisseurs variables de liquide. Le degré d’écartement des deux verres, nécessaire pour éteindre à l'œil la lumière d'une bougie placée à un mètre de distance, permet d'arriver, au moyen de tables, à la richesse du lait en matière grasse.

Un instrument d'un autre genre est le lacto-butyromètre (fig. 864 et 86ว̃) de M. Marchand, de Fécamp (1).

Il est fondé sur la solubilité du beurre dans l'éther, lorsque le liquide qui baigne les globules contient

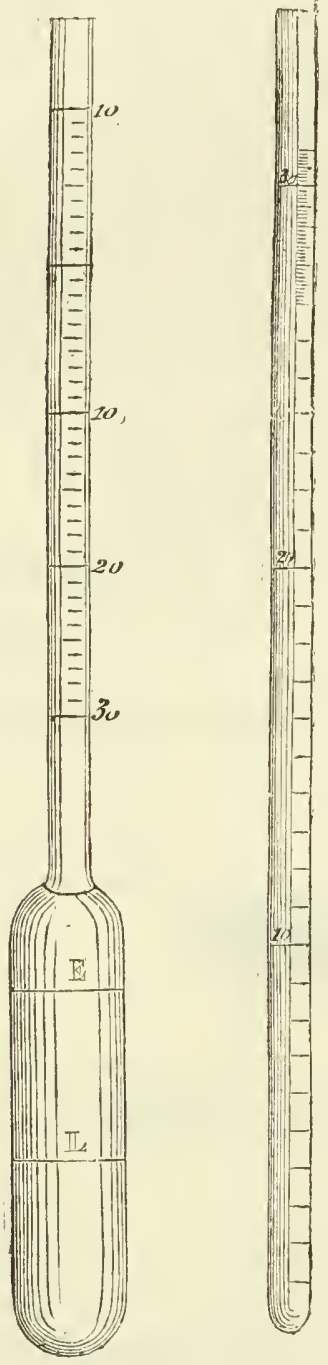

Fig. 864 et 865 . - Lacto-butyromètre de Marchand. des traces d'alcali libre; sur l'inaction de cette petite quantité d'alcali sur la matière grasse mêlée à la caséine et à la lactine; enfin sur le peu de solubilité de cette matière dans un mélange à parties égales d'alcool et d'éther. Un tube de verre de 40 centimètres de longueur, de 10 à 11 millimètres de diamètre, porte trois divisions qui le partagent en parties de capacité égale $\left(10^{\mathrm{c}} .^{\mathrm{c}}\right)$. On verse dans la portion inférieure le lait à essayer après l'avoir préalablement agité : on y ajoute une ou deux gouttes de lessive des savonniers. On remplit d'éther la portion moyenne; on bouche le tube et on mélange intimement les deux liquides. Puis on verse de l'alcool à $86^{\circ}$ jusqu'au trait supérieur; on agite le tube et on le plonge verticalement dans un bain d'eau à $40^{\circ}$. - On voit, au bout de quelque temps, se former au-dessus du mélange d'alcool et d'éther une couche oléagineuse, butyroéthérée, dont on peut apprécier l'épaisseur par des divisions marquées sur le tube au-dessus et au-dessous du trait qui limite la portion réservée à l’alcool. La lecture doit se faire de bas en haut et s'arrêter au niveau du ménisque concave qui termine la colonne oléagineuse. Des tables permettent de conclure de l'épaisseur de cette couche la richesse réelle en matière grasse (2).]

(1) Marchand, Bull. de l'Acad. de médec., t. XIX, p. 1101.

(2) Voir, sur le lait, Payen, Journ. de chim. méd., 18:28, t. IV, 1. 118. - Las- 
Pour reconnaître si un lait a été coupé avec de l'eau, il faut en déterminer la densité, soit au moyen d'un aréomètre-densimètre dont la longue tige marque la densité de 1014 à 1040, soit au moyen d'un aréomètre adapté à cette destination spéciale, tel que le lacto-densimètre de Quevenne; soit avec le pẻse-sel de Baumé offrant les degrés de 0 à 6 ; soit enfin avec le galactomètre centé. simal de Dinocourt, fabriqué sur les indications de MM. Chevallier et Henry, pour la température de 1 ŏ degrés centigrades, et qui porte une double échelle pour le lait écrémé et non écrémé.

Voici quelques-unes des indications fournies par cet instrument, que l'on peut regarder comme approchant beaucoup de la vérité, moyennant l'attention d'opérer à la tempéralure de 15 degrés.

\begin{tabular}{|c|c|c|c|c|c|c|c|c|c|}
\hline \multicolumn{5}{|c|}{ LAIT NON ÉCKÉMÉ. } & \multicolumn{5}{|c|}{ LA IT ÉCRÉMÉ. } \\
\hline \multicolumn{2}{|c|}{ MÉLANGE } & \multirow{2}{*}{ 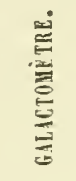 } & \multirow{2}{*}{ 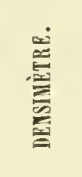 } & \multirow{2}{*}{$\begin{array}{l}\text { PÈse-SEL } \\
\text { de } \\
\text { BaumE. }\end{array}$} & \multicolumn{2}{|c|}{ MÉLANGE } & \multirow{2}{*}{ 偐 } & \multirow{2}{*}{ 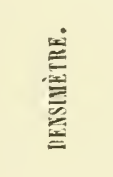 } & \multirow{2}{*}{$\begin{array}{l}\text { PÈSH-SEL } \\
\text { de } \\
\text { BaunÉ. }\end{array}$} \\
\hline $\begin{array}{c}\text { de } \\
\text { LAIT. }\end{array}$ & D'EAU. & & & & $\begin{array}{c}\text { de } \\
\text { LAIT. }\end{array}$ & D'EAU. & & & \\
\hline 100 & 0 & $109^{\circ}$ & 1029 & $4^{\circ}, 0$ & 100 & 0 & $100^{\circ}$ & 1032,2 & $4^{0}, \overline{0}$ \\
\hline 90 & 10 & 30 & 1026 & 36 & 90 & 10 & 90 & 1029 & \\
\hline 80 & 20 & 80 & 1023 & 32 & 80 & 20 & 80 & 1025,8 & 35 \\
\hline 70 & 30 & 70 & 1020 & 28 & 70 & 30 & 70 & 1022,3 & \\
\hline 60 & 40 & 60 & 1017 & 24 & 60 & 40 & 60 & 1019 & 26 \\
\hline 50 & 50 & 50 & 1014 & 20 & 50 & 50 & 50 & 1015,2 & 215 \\
\hline
\end{tabular}

On a indiqué un assez grand nombre d'autres falsifications du lait; mais il en est très-peu qui aient été constatées. Le sucre se reconnaît facilement à la saveur et par la prompte fermentation

saigne, Ann. de chim. et de phys., 1832, t. XLIX, p. 31. - Péligot, ibid., 1836, t. LXII, p. 61. - Lecanu, Journ. de pharm., 1839, t. XXV, p. 201. - Chevallier et Henry, Journ. de chim. méd., 1839, t. V, p. 145 et 195, et Ann. d'hyg., 1839, t. XXII, p. 238. - T. A. Quevenne, Mimoire sur le lait (Ann. l'hyg., 18:1, t. XXVI, p. 5). - A. Donné, Cours de microscopie. Paris, 1844, et Conseils aux mères sur la manière d'élever leurs enfants nouveau-nés, 5" édition. Paris, 1875. - Boussingault, Ann. de chim. et de phys., t. LXXI. - Poggiale, Dosuge du sucre de lait par la méthode des volumes, et Détermination de la richesse du lait (Comptes rendus de l'Académie des sciences, avril 1840), et Traité d'analyse chimique pur la méthodle des volumes. Paris, 1858. - L. Doyère, Étude du lait, au point de vue phigsiologique et économique (Ann. de l'Institut ayronomique de Versailles, 1852). - O. Réveil, Du Lait (Thèse de concours de l'agrégation de la Faculté de médecine. Paris, 1856). - Vernois et Becquerel, Analyse du lait des principanx types de vache, chèvre, brebis, bufflesse présentées au concour's agricole de 1855 (Ann. d'hygiène publique, 1857, $2^{\mathrm{e}}$ série, t. VII, p. 271). Bouchut, Hyyiène de la première enfance, $6^{\mathrm{e}}$ édition. Paris, 1874. $-\mathrm{N}$. Joly ct Filhol, Recherches sur le lait. Bruxelles, 1856. Adrian, Thèse citée. lieynès, Thèse citée. 
que le lait éprouve, étant additionné d'un peu de levûre. On constaterait la présence de la gomme, en coagulant le caséum par l'acide acétique, filtrant le sérum, et y ajoutant le double de son volume d'alcool rectifié, qui y forme, dans ce cas, un précipité très-marqué, blanc mat et opaque. L'amidon et la farine se reconnaissent facilement par l'iode, auquel on joint, s'il est nécessaire, l'usage du microscope. On constate la présence des oufs battus, en filtrant le lait au papier, et soumettant le liquide filtré à l'ébullition. Il se trouble plus ou moins lorsqu'il contient de l'albumine en dissolution. La cervelle de mouton, que l'on dit aussi avoir été quelquefois ajoutée au lait, doit pouvoir se reconnaître par le mẻme moyen, el aussi par l'usage du microscope, qui ne doit montrer dans le lait de bonne qualité que des globules transparents de matière grasse, disséminés dans un liquide parfaitement transparent lui-même.

[Nons avons vu que le sucre de lait pouvait subir la fermentation alcoolique. Certains peuples utilisent cette circonstance pour préparer avec le lait une boisson spiritueuse. Tel est le koumiss ou kumys (1), que les Kirghiz, les Tartares, les Kalmoucks, et autres peuplades des provinces méridionales et orientales de la Russie, font avec le lait de leurs juments. Ce lait est fortement sucré, comme le lait de femme. On le verse dans des outres en cuir de cheval séchées, enfumées el enduites de beurre à l'intérieur. De la levûre de bière ou du koumiss desséché provoque la fermentation, qu'on laisse durer trois jours environ par une température de $22^{\circ}$ à $20^{\circ}$. Le koumiss est alors à l'état d'un liquide blanc bleuâtre, d'un goût aigre: mis en bouteille, il mousse assez fortement pour faire sauter le bouchon au bout de quelques heures. C'est une boisson en même temps qu'un moyen de médication employé fréquemment par les médecins russes. On fait des cures de koumiss, principalement dans le traitement de la phthisie (1). La distillation du koumiss donne une sorte d'eau-de-vie connue sous le nom de rack. Un koumiss de deux jours, fabriqué avec du lait de jument des steppes de Kirgis, a donné à M. Stalberg:

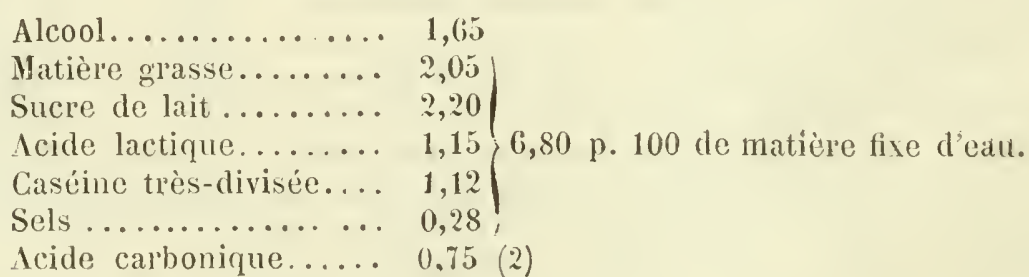

(1) Гoyez Fonssagrives, Hygiène alimentaire. Paris, 1869, p. 647. - Fonssagrives, Therapeutique de la phthisie pulmonaire. Paris, 1866, p. 123. - Sthalberg, Bull. de l'dcad. de méd. Paris, 1867, t. IXXII, p. 1024.

(2) Voir Journ. de pharmacir et de chimie, a sérice, t. XX, p. 32't. 


\section{De la Pepsine.}

La pepsıne est un principe sécrété par la muqueuse de l'estomac des mammifères et des oiseaux, et qui joue un rôle important dans la digestion des substances azotées; aussi a-t-on songé à l'administrer comme médicament dans les cas de dyspepsie. Un grand nombre de procédés ont été donnés pour sa préparation. Nous nous bornerons à indiquer celui qui sert de base aux préparations admises par le Codex de 1866 (1).

On ouvre la caillette dı mouton au moment où il vient d'être tué : on la lave et on frotte rudement la membrane muqueuse avec une brosse de chiendent. On obtient ainsi une pulpe, qu'on délaye dans un volume d'eau double du sien; on laisse macérer et on agite souvent pendant deux heures. On jette sur une toile yrossière, et on ajoute au liquide qui a filtré une solution d'acétate de plomb cristallisé. Il se forme un précipité très-abondant; on décante le liquide qui le surnage et on le remplace deux fois par de l'eau claire. On délaye une dernière fois le précipité dans de nouvelle eau et on y fait passer un courant d'acide sulfhydrique, jusqu'ì ce qu'il y en ait un excès manifeste. On divise alors le liquide et le précipité noir sur un grand nombre de filtres et l'on soumet immédiatement le liquide à une évaporation non interrompue dans des vases peu profonds et à une température qui ne doit pas dépasser $55^{\circ}$ centigrades. On évapore jusqu'à siccité et on recueille à l'aide d'un conteau ou d'une corne flexible la pâte ferme qui s'est formée et qui porte le nom de pepsine officinale. A cet état, elle a une couleur ambrée, une transparence imparfaite et une odeur peu agréable, mais qui n'est ni repoussante ni putride.

Cette pepsine officinale agit comme un dissolvant énergique de la fibrine; mais, son activité pouvant varier suivant diverses circonstances, on prépare pour le commerce une pepsine, à laquelle on ajoute une quantité d'amidon telle que un gramme de mélange possède la propriété de dissoudre 6 grammes de fibrine humide. On a ainsi un médicament d'une énergie déterminée. Cette pepsine porte le nom de pepsine amylacée. On y ajoute le plus souvent une certaine quantité d'acide tartrique, qui facilite la digestion stomachale (2).]

(1) Codex medicamentarius. Paris, 1866, p. 283.

(2) Voir pour plus de détails, Guibourt, Rapport sur la pepsine fait à la Société de pharmacie de Paris (Journ. de pharm. et de chim., $4^{\mathrm{e}}$ série, t. II, p. 81), dont nous avons extrait les renseignements ci-dessus. 


\section{De la Bile de bouf ou Fiel de bouf.}

La bile ou le fiel est une sécrétion qui parait essentielle à la fonction des organes digestifs d'un très-grand nombre d'animaux, car on la trouve dans tous les vertébrés, dans les mollusques el dans une parlie des animaux articulés. Dans le bœuf, qui nous fournit celle que nous employons, comme dans tous les mammifères, ce fluide ne paraît pas être sécrété directement du sang artériel, mais paraît résulter de l'action d'un organe nommé foie, sur le sang qui y est apporté de l'appareil intestinal par des veines réunies en un gros tronc, nommé veine porte. Ce vaisseau, partagé en deux branches, pénètre dans le foie, et s'y divise à l'infini. Là, dans ses dernières ramifications, le sang se sépare en deux parties, dont l'une, qui est la bile, est portée par des conduits particuliers dans une poche nommée vésicule du fiel, lorsqu'elle existe (ex. dans le bœuf), ou est versée directement dans l'intestin duodenum, lorsque la vésicule manque (ex. dans le cheval) : l'autre partie du sang, qui n'a pas servi à la confeclion de la bile, es! rendue à la circulation par les veines hépatiques.

La bile de bœuf est donc contenue dans une vésicule; elle est d'un jaune verdatre, plus ou moins épaisse et visqueuse, d'une odeur nauséabonde qui lui est propre, d'une saveur amère repoussante. Elle présente une faible réaction alcaline; elle se mélange avec l'eau en toutes proportions et donne un liquide qui mousse comme de l'eau de savon et en possède la propriété décrassante.

La bile a été examinée par un grand nombre de chimistes, parmi lesquels on doit citer Thénard, Berzélius, Gmelin, M. Demarçay, Liebig, Redtenbacher, etc. Mais ce sont les résultats obtenus par M. Demarçay, Liebig, Strecker, qui ont fixé l'opinion sur la nature de cette sécrétion, et qui la font regarder comme une sorte de savon à base de soude (cholate et choléate de soude), coloré par une matière qui n'est pas essentielle à sa composition; quoiqu'il faille reconnaître, cependant, que cette matière colorante, jaune, vert jaunâtre ou fauve, accompagne la bile et la caractérise dans toutes les classes d'animaux où celte sécrétion peut se montrer.

La bile de bœuf, desséchée au bain-marie, se dissout aisément dans l'alcool reclifié, avec une couleur vert jaunâtre foncé, et en laissant une substance insoluble azolée, de la nature du mucus. On peut obtenir la bile parfaitement incolore en mettant la solulion alcoolique en digestion sur du charbon animal, ou en y ajoutant avec précaulion de l'eau de baryte qui forme une combinaison insoluble avec la matière colorante. Cette matière peut offrir 
différentes couleurs, qui paraissent dépendre de plusieurs degrés d'oxygénation. Indépendamment de celle qui est dissoute dans la bile de bœuf et qui lui communique sa couleur vert-jaune, ce liquide en contient quelquefois une certaine quantité à l'état de suspension, qui est d'un jaune foncé, et la vésicule du fiel présente aussi quelquefois des concrétions de même couleur, qui sont presque entièrement formées de la même matière et qui sont usitées dans la peinture.

La bile de bœuf renferme de la cholestérine dont on peut la priver en mélangeant sa dissolution alcoolique, décolorée avec le charbon et concentrée avec deux fois son volume d'éther. L'éther dissout la cholestérine et précipite la bile sous forme sirupeuse. La bile ainsi purifiée, étant déssechée, forme une masse solide, transparente et friable, semblable à la gomme arabique, entièrement soluble dans l'eau et dans l'alcool. [C'est sous cet état que la bile est considérée comme formée par la combinaison de la soude avec deux acides organiques azotés. L'un de ces acides a été rommé par M. Demarçay acide choléique, par M. Liebig, acide brlique (1) : on l'appelle aussi acide taurocholique. Sa formule est $\mathrm{C}^{52} \mathrm{H}^{45} \mathrm{HAzO}{ }^{14} \mathrm{~S}^{2}$. Chauffé avec les alcalis, il fixe les éléments de l'eau et se transforme en un acide azoté, l'acide cholalique, et en une substance neutre, soluble dans l'eau, insoluble dans l'alcool, cristallisant en gros prismes incolores, d'une saveur fraiche, inaltérables à l'air. Celte substance très-remarquable a été découverte par Gmelin, qui la croyait partie constituante de la bile et lui a donné le nom de tuurine. Des analyses failes par plusieurs chimisies la faisaient considérer comme formée de carbone, azote et oxygène, lorsque M. Redtenbacher a constaté qu'elle contenait une proportion considérable de soufre, ce qui force à conclure que ce corps est aussi un des éléments de l'acide choléique.

Le second acide, acide cholique ou glycocholique $\mathrm{C}^{32} \mathrm{H}^{43} \mathrm{AzO}^{12}$, a été découvert par M. Strecker. C'est lui qui prédomine dans la bile du bœuf. Il n'est pas sulfuré comme l'acide taurocholique; sous l'influence des alcalis, il donne comme lui de l'acide cholalique, mais, au lieu de taurine, du sucre de gélatine ou glycocolle $\left.\mathrm{C}^{4} \mathrm{H}^{5} \mathrm{AzO}^{4}(2) \cdot\right]$

\section{Du ause indien.}

Je pense que cette magnifique couleur n'est autre chose que la substance décrite par Kæmpfer sous le nom de masang de vaca (3).

(1) Liebig, Traité de chimie, t. III, p. 294.

(2) Voir Strecker, Ann. der Chimie und Pharmacie, LXI, 9, LVII, 1, LXX, 161.

(3) Masang de vaca. On nomme ainsi une concrétion biliaire qui se forme 
Seulement Kæmpfer suppose que cette substance vient d'A frique, tandis que l'odeur très-forte de cuir de Russie ou de castoréum de Sibérie, qu'elle possède, jointe au nom de naypaul kupur sous lequel je l'ai trouvée à la douane du Havre, m'a fait supposer qu'elle devait provenir du nord de l'Asie, ou au moins des contrées septentrionales de l'Inde. Ainslie mentionne également un bézoard de bouf trouvé dans la vésicule du fiel d'une vache commune dans le Népaul, et un bézoard de chameau retiré de la vésicule de cet animal, et très-estimé comme couleur par les peintures hindous (1). Me fondant encore sur l'odeur de cette concrétion, je la croirais plutôt produite par un chameau que par un bœuf ou une vache, dont toutes les concrétions intestinales sont empreintes d'une faible odeur ambrée-musquée.

Le jaune indien, tel que je me le suis procuré à la douane du Havre, en 1841, est sous forme de concrétions ou de masses arrondies d'un volume variable, mais pouvant avoir jusqu'à 5 ou 7 centimètresde diamètre. Ces masses sont couvertes à la surface d'une sorte d'enduit noirâtre ; mais, à l'intérieur, elles sont d'un jaune doré et d'un aspect uniforme et pulvérulent. Elles ont un toucher un peu gras et s'écrasent avec une grande facilité entre les doigts: Enfin elles ont l'odeur forte indiquée plus haut et une saveur faiblement amère. Ce jaune indien, examiné au microscope, paraît entièrement formé de cristaux plats, jaunes, transparents, ayant la forme de fer de lance. J'en ai une seconde qualité qui est d'un jaune plus pâle et un peu verdâtre, d'une odeur moins forte, d'un aspect plus sec et comme terreux, qui paraît formé au microscope de particules cristallines brisées, mélangées d'une matière amorphe.

D'après M. Stenhouse, le jaune indien, connu dans le commerce sous le nom de purree, est essentiellement composé de magnésie en combinaison avec un acide organique non azoté, qu'il a nommé acide pur'ééque, et auquel M. Erdmann a donné ensuite le nom d'acide euxanthique. Cet acide est peu soluble dans l'eau froide, plus soluble dans l'eau bouillante qui le laisse cristalliser en longues aiguilles jaunâtres; il est soluble dans l'alcool bouillant et dans l'éther; il forme des combinaisons jaunes avec les alcalis et la plupart des oxydes métalliques. Chauffé au delà de.

dans la vésicule des vaches. Elle a quelquefois la grosseur d'un œuf de poule, est de forme ronde, d'une couleur jaune, d'une substance légère, friable et sèche, non formée de couches, mais d'une seule masse compacte et d'une saveur amère. On la trouve principalement sur la terre d'Afrique, aux environs de l'île Mozambique, d'où les Portugais l'apportent dans l'Inde (Kæmpfer, Amœn. exot., p. 392).

(1) Ainslie, Mat. indica, t. I, p. 36. 
100 degrés, il donne lieu à un produit cristallin neutre qui a reçu le nom de purréon.

D'après M. Stenhouse, l'acide purréique $=\mathrm{C}^{20} \mathrm{H}^{9} \mathrm{O}^{11}$, le purréate de plomb $=\mathrm{C}^{20} \mathrm{H}^{9} \mathrm{O}^{11}+\mathrm{PbO}$, le purréon $=\mathrm{C}^{13} \underline{\mathrm{H}}^{4} \mathrm{O}^{4}$. M. Stenhouse pense que le purree, au licu d'être une matière animale, comme on l'a cru, est un suc végétal saturé artificiellement par la magnésie et évaporé à siccité.

J'ai de la peine à croire qu'il en soit ainsi, et d'ailleurs la composition du jaune indien est plus compliqué qu'on ne vient de le dire. Celui que j'ai décrit d'abord est à peine attaquable par l'alcool; mais il est en partie soluble dans l'eau et communique à ce liquide, surtout à l'aide de l'ébullition, une couleur jaune un peu brunâtre et un peu verdâtre, assez semblable à celle de la bile; il lui cède de cette manière un composé magnésien soluble, d'où l'acide chlorhydrique précipite immédiatement l'acide sous forme de flocons grisâtres très-abondants. La parlie du jaune indien insoluble dans l'eau est d'un jaune magnifique et forme 60 pour 100 de la substance primitive.

Cette partie insoluble, traitée par l'éther, lui cède une petite quantité d'une matière jaune, cristallisable en belles aiguilles rayonnées, pouvant supporter une assez forte chaleursans éprouver aucune altération, mais finissant par se fondre et par se dissiper en une fumée blanche inodore.

Le jaune indien qui a été traité par l'eau et par l'éther, étant délayé dans l'eau et additionné d'un peu d'acide chlorhydrique, éprouve une eff'ervescence manifeste et perd aussitôt sa couleur' jaune. Il se forme dans la liqueur un magma grisâtre très-volumineux. Si l'on fait chauffer la liqueur, il se produit une seconde effervescence très-jrolongée, et qui paraît due plulôt à quelque réaction organique qu'à la décomposition d'un carbonate. La liqueur filtrée laisse précipiter, en se refroidissant, des flocons faiblement jaunâtres ; mais la plus grande partie de l'acide organique paraît ne pas se dissoudre dans l'eau. Il est très-soluble au contraire dans l'alcool bouillant, et se prend presque en masse formé de mamelons rayonnés, par le refroidissement.

La liqueur dans laquelle on a décomposé le jaune indien par l'acide chlorhydrique retient la magnésie en dissolution.

\section{Egagropiles.}

Les agagropiles (1) sont des concrétions trouvées dans la caillette des animaux ruminants, qui sont principalement formées de poils que ces animaux ont avalés en se léchant, et que les mou-

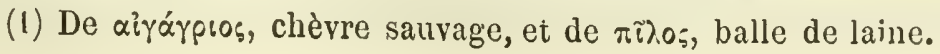


vements de leur estomac ont rassemblés en boules feutrées. On en trouve aussi quelquefois dans les intestins du cheval. Les anciens attribuaient à ces concrétions des propriétés analogues à celles des bézoards; mais elles ne sont plus aujourd'hui que de simples objets de curiosité.

On se procure facilement dans les abattoirs de Paris les ægagropiles de veaux, de bœufs et de moutons. Les premiers sont d'une forme sphérique ou cylindrique, el sont uniquement composés de poils feutrés d'une manière très-dense, et tous couchés en tourbillonnant autour de l'axe. Ils ne sont recouverts d'aucun enduit et acquièrent quelquefois des dimensions considérables; j'en ai un arrondi et un peu ovoïde, qui a 8 , 5 centimètres de diamètre, et un autre cylindrique, long de 11,5 centimètres et épais de 5.

Les ægagropiles de bœuf sont feutrés d'une manière toute différente, les poils qui les forment étant entremêlés sans aucun ordre et dans toutes sortes de directions. Ils sont de plus parfaitement sphériques, du volume d'une grosse coloquinte, et couverts, seulement à leur surface, d'une couche de mucus brun, poli et brillant. C'est un fait très-remarquable que ce mucus, qui n'a pas concouru à la formation de la concrétion, soit sécrété à un moment donné par l'estomac, pour envelopper cette masse qui le gêne et l'empêche de s'accroître davantage. L'ægagropile de bœuf que je possède a 7 centimètres $1 / 2$ de diamètre.

Les ægagropiles de mouton présentent une forte odeur de bouc; ils sont plus ou moins sphériques, couverts, comme ceux du bœuf, d'un enduit noirâtre, poli et brillant. Le plus gros que

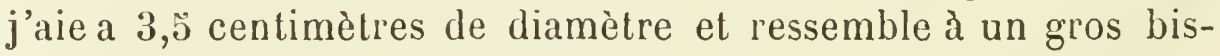
caïen. A l'intérieur, ceux que j'ai ouverts sont formés de poils feutrés sans ordre, comme ceux de bœuf; mais ils offrent au centre une sorte de noyau dont les poils sont plus courts el plus serrés que ceux de la couche extérieure, avec une ligne de séparation très-nette entre les deux feutrages.

On trouve sur les rivages de l'Océan el de la Méditerranée, vers Marseille surtout, dans les anses ou criques, des pelotes composćes de fibres végétales feutrées par le ballotage des flots, et qui ont une forme exactement sphérique, avec le volume d'une orange ou plus. On donne à ces pelotes le nom de pelotes de mer, ou agagropiles marins. Elles peuvent être formées par les débris de plusieurs plantes marines; mais celle dont elles sont le plus habituellement composées est la zostère marine, de la famille des Nayadées, dont les feuilles desséchées servent à faire des emballages et des matelats doués d'une odeur iodée, qui ont été recommandés pour les enfants rachitiques et scrofuleux. Ces 
pelotes de mer, par leur volume, leur forme et le feutrage de leurs fibres, ressemblent tellement à des ægagropiles de bœuf qui seraient privés de leur enveloppe de mucus; qu'on aurait peine à les distinguer à la vue. On reconnaît facilement leur origine à leur odeur iodée et à ce que leurs fibres chauffées sur une capsule de platine se charbonnent sans se ramollir, en dégageant une odeur végétale toujour's mêlée de l'odeur d'iode, tandis que les fibres des ægagropiles animaux se ramollissent en se charbonnantau feu et exhalent une fumée blanche qui a l'odeur de la corne brûlée.

\section{Ges Bézonrds animanx.}

On employait autrefois en médecine, sous le nom de bézoards, des calculs retirés des intestins de plusieurs mammifères ruminants, auxquels on attribuait la propriécé toute merveilleuse et si banale de résister à la malignité des humeurs, à la peste, aux venins, etc. On les distinguail en orientaux et en occudentaux. Les premiers, qui étaient les plus estimés, étaient altribués généralement à l'ægagre de Perse ou pasèn que l'on croit être, ainsi que nous l'avons vu, la souche de nos chèrres domestiques. Les seconds, que l'on supposait venir d'Amérique, étaient altribués aux lamas et aux vigognes; mais je n'ai jamais pu m'assurer qu'aucun bézoard du commerce vìnt véritablement d'A mérique, et lout porte à croire, au contraire, qu'iis étaient tous apportés d'Asie.

J'ai donné (1) un exlrait de Kæmpfer (2), sur les différentes espèces de bézoards, parmi lesquels il compte le masang de vaca, la pierre de porc, celle de serpert, un calcul résineux bézoardique, le vrai bézoard oriental produit par la chèvre pasèn, celui provenant de l'antilope ahu, la pierre bugie ou pierre de singe, et enfin le béozard artificiel ou pierre de Goa. De tous ces produits je n'ai que le masang de vaca, décrit plus haut sous le nom de jaune indien, le vrai bézoard du Pasèn, le faux bézoard ou pierre de Goa, et, suivant ce que je crois, la pierre de porc et le bézoard de l'Ahu. Je vais les décrire successivement.

Bézoard de I aegagre. Celle concrétion porte aussi les noms de vrai bézoar oriental, bézoard résineux vert, et j’y ai ajouté celui de bézoard lithofellique, qui le caractérise par le nom de l'acide que MM. Gœbel et Wœhler en ont retiré. Celui que je possède m'a été donné par M. Périnet, ancien pharmacien major à l'hôtel des

(1) Guibourt, Mémoire sur les concrétions intestinales d'animnux, connues sous le nom de bézoards (Revue scientifique, t. XIV, 1843).

(2) Kæm!fer, Amœntatum exoticarum fasciculi V. Lemgoviæ, 1712. 
Invalides: il a une forme ovoïde-triangulaire, et il pèse encore aujourd'hui 33 grammes, malgré la perte d'une partie de substance qui en a été retirée autrefois pour l'usage médical. Celui qui a servi aux expériences de M. Wœhler pesait 40 grammes; enfin celui conservé dans le Musée de Rennes devait peser dans son entier près de 200 grammes, si j'en juge par le morceau assez considérable que m'en a montré M. Malaguti.

Ce bézoard est d'un vert sale à l'extérieur et a l'apparence d'un morceau de cire polie. A l'intérieur, il est formé d'un trèsgrand nombre de couches concentriques très-minces, alternativement d'un vert clair et d'un vert foncé, sans aucune texture cristalline. Il n'a pas même la cassure grenue de la cire : il présente plutôt la cassure nette et luisante de la résine. Il est très-fragile et éclate en parcelles sous la scie. Il est pourvu d'une saveur amère et d'une odeur aromatique végétale toute particulière. Il pèse spécifiquement 1,132; il laisse sur un papier blanchi avec de la céruse une trace verte. Il fond très-facilement à la chaleur, et se laisse pénétrer par une aiguille chauffée à la flamme de l'al-. cool et refroidie au point de n'être plus lumineuse; il brûle avec l'éclat d'une résine; enfin il est facilement soluble, même à froid, dans l'alcool à 9 š centièmes, et se dissout encore plus facilement dans l'alcool chaud, et presque sans résidu. La liqueur filtrée esi d'un vert brunâtre et laisse déposer, en refroidissant, quelques flocons noirâtres; mais elle ne cristallise pas, à moins qu'elle ne soit très-concentrée ou qu'on ne l'ait évaporée au tiers ou au quart de son volume. Alors il se forme au fond une couche cristallisée, bianche et brillante d'acide lithofellique. Cet acide cristallisé, qui avait été obtenu anciennement par Fourcroy et Vauquelin, se fond à 205 degrés; mais si on le chauffe un peu audessus de son point de fusion, il se prend, en refroidissant, en une masse claire et vitreuse, fusible à 10 ơ ou 110 degrés. Il se dissout en grande quantité dans l'acide acétique concentré et y cristallise par l'évaporation spontanée. Il se dissout aussi facilement dans l'ammoniaque, et la liqueur évaporée spontanément laisse l'acide exempt d'alcali, ce qui dénote une bien faible acidité. Il forme avec la potasse un composé soluble dans l'eau, mais précipitable par un excès d'alcali, comme cela a lieu avec le savon et la bile ordinaire; l'acide lithofellique est un acide ternaire dont la formule paraît être : $\mathrm{C}^{40} \mathrm{H}^{36} \mathrm{O}^{8}$ ou $\mathrm{C}^{40} \mathrm{H}^{35} \mathrm{O}^{7}+\mathrm{HO}$.

D'après Kæmpfer, Ta production du bézoard par la chèvre ægagre ou pasèn est subordonnée à la présence de quelques plantes très-résineuses et aromatiques que les chèvres broutent avec excès, et qui croissent principalement sur le mont Baarsi, dans l'Aar' et dans le Korasan, en Perse. Ce rapport entre les vé- 
gétaux dominanis d'une contrée et certaines sécrétions animales m'a également frappé, et il y a longtemps que je suis persuadé que les castoréums du Canada et de Sibérie, tout aussi bien que les muscs de Chine, Tonquin et Kabardin, doivent leurs différences d'odeur et de composition à la nature diverse des végétaux dont se nourrissent les castors et les porte-muscs.

Bézoard fauve ou bézoard ellagique. Je pense que ce bézoard est celui dont Kæmpfer et beaucoup d'autres auteurs ont parlé sous le nom de pierre de porc, ou de porc-épic, ou de pierre de Nalacca. En 1808, le schah de Perse en envoya trois en présent à Napoléon, ce qui montre que ces concrétions, quoique très-différentes de celles de l'ægagre, sont d'un très-grand prix en Perse. Berthollet, qui fut chargé de les examiner, les confondit cependant avec les précédents, dont Fourcroy et Vauquelin les avaient bien distingués.

Le bézoard fauve n'est pas aussi rare que je l'avais cru d'abord: l'École en possède plusieurs, dont un ovö̈de-allongé, d'un fauve clair et de la grosseur d'une petite noix, enfermé dans deux cercles d'argent, surmontés d'un anneau destiné à suspendre le bézoard en forme d'amulette, ou à le plonger dans l'eau pour en composer une boisson douée des propriétés les plus merveilleuses, ainsi que l'indique Kempfer (1). Un autre est cylindrique, arrondi aux deux bouts, inégal et mamelonné à sa surface, long de 38 millimètres, épais de 10, à surface polie et d'un vert-noir très-foncé. Quatre autres sont de la grosseur d'une aveline, de couleur noirâtre ou fauve verdâtre, arrondis, mais de forme trèsirrégulière, et mamelonnés à leur surface. Ayant brisé un de ces calculs, je l'ai trouvé formé d’un globule excrémentitiel (2) occupant la plus grande partie du bézoard, et recouvert d'un certain nombre de couches mamelonnées, très-compactes, d'un vert brunâtre et jaunâtre foncé. Plusieurs de ces couches réunies se séparent souvent facilement des autres, et simulent, quant à la forme, celles de la malachite ou de l'arsenic natif testacé. Indépendamment de leur forme testacée, ces couches présentent préque toujours à la loupe une struclure finement rayonnée. Enfin l'École de Pharmacie possède aujourd'hui un fort beau bézoard, évidemment semblable aux précédents, qui a appartenu à Beaumé et dont M. Ménier lui a fait présent en 1846. Ce bézoard est ovoïde, un peu réniforme, du poids de 29,9 grammes, à surface polie et

(1) Kæmpfer, p. 39'.

(2) Ce globule excrémentitiel, dont la forme irrégulière détermine celle du calcul, est fauve rougeâtre et formé d'un détritus végétal finement broyé. Il ne ressemble nullement à celui des ruminants ni des pachydermes; il a plus de rapport avec celui des rongeurs dont le porc-épic fait partie. 
brillante, d'un brun foncé, fauve et un peu verdâtre à l'extérieur, mais fauve rougeâtre à l'intérieur.

J'ai dans mon droguier trois bézoards fauves ou ellagiques: l'un d'cux a la forme d'un cône arrondi aux deux bouts; il est long de 57 millimètres, épais de 15 millimètres à la base, et pèse 15 grammes. Il a une surface très-unie, brillante et d'un fauve verdâtre et brunâtre foncé. Le second, qui m’a été donné par M. Pelletier, a été décrit séparément, sous le nom de bézoord noirâtre rayonné (1); mais il est le même nature que les précédents. Il est cylindrique, arrondi aux deux bouts, et du poids de 4 grammes. Le dernier m'a été donné par M. O. Henry; il est elliptique, un peu aplati d'un côté, très-brillant à sa surface et d'un fauve un peu verdâtre. On trouve au centre une cavité en forme de croissant, propre et nette comme l'intérieur d'un noyau de fruit. C'est probablement cet état de vacuité apparente, dont Boèce de Boot a même fait une marque de qualité supérieure, qui a fait dire à Fourcroy et Vauquelin que ces sortes de calculs avaient presque toujours pour noyau une coque de fruit. Mais en réalité cette cavité est remplie par une matière peu cohérente, qui disparaît par le mouvement de va-et-vient de la scie, ou est emportée par le lavage.

Il résulte de ce qui précède que le bézoard fauve peut affectel. toutes sortes de formes, mais qu'il ne parait guère pouvoir dépasser le volume d’une noix. Il se distingue d'ailleurs du bézoard lithofellique par les caractères suivants:

Il pèse de 1,593 à 1,661 . Il est dur, non fusible et ne se laisse pas pénétrer par la pointe d'une aiguille rougie au feu; il est insipide, mais il exhale, quand on le scie ou quand on le pulvérise, une odeur nauséeuse et débilitante qui m'a paru semblable à celle dégagće du sang de porc par l'acide sulfurique. Il est trèspeu soluble dans l'alcool, même bouillant. J'ai montré du reste que l'alcool sépare le bézoard fauve en trois parties: $1^{\circ}$ une matière résineuse brune, qui se dissout presque complétement par le premier traitement alcoolique; $2^{\circ}$ une matière peu soluble dans l'alcool bouillant, mais facile à obtenir par plusieurs traitements successifs, qui la laissent cristalliser par refroidissement. Toute celte matiẹre, étant redissoute dans l'alcool bouillant et cristallisée de nouveau, constitue l'acide bézoardique de MM. Merklein et Wœhler, mais plus pur probablement que ces chimistes n'ont pu l'obtenir en faisant agir la polasse caustique sur la totalité du calcul; $3^{\circ}$ le bézoard fauve épuisé par l'alcool laisse un résidu assez considérable formé de matière Jaune unie à l'acide bé-

(1) Pelletier, Revue scientifique, t. XIV, p. 29. 
zoardique qu'elle soustrait à l'action du liquide. On peut les séparer par l'ammoniaque qui forme avec la matière jaune un composé jaune-brun très-soluble dans l'alcali, et avec l'acide bézoardiques un sel insoluble dans l'ammoniaque, dans l'eau et dans l'alcool.

L’acide bézoardique cristallisé se présente sous forme de pyramides quadrangulaires très-aiguës, ou de prismes à quatre pans, plus étroits à une extrémité qu'à l'autre et terminés par un ou deux biseaux très-allongés. Il est infusible au feu et se décompose dans un tube fermé, en donnant naissance à des cristaux jaunes d'une substance volatile anciennement obtenue par Fourcroy et Vauquelin et présentée par eux comme le caractère distinctif du bézoard fauve. Enfin MM. Merklein et Wœhler, en comparant toutes les propriétés de l'acide bézoardique avec celles de l'acide ellagique de la noix de galle, regardent ces deux acides comme identiques. Ce résultat me paraît d'autant plus probable que, de même que l'acide bézoardique, dans le bézoard fauve, est accompagné d'un acide jaune très-altérable à l'air dans ses dissolutions alcalines, de même l'acide ellagique est accompagné, dans la noix de galle, d'un acide jaune que j'ai fail connaître sous le nom d'acide lutéogallique, et qui jouit de la même altérabilité (1). Cette 'oüncidence ne fail d'ailleurs que confirmer la proposition de Kæmpfer, que j’ai étendue à toutes les productions analogues, à savoir que les bézoards, le castoréum, le musc, la civette, etc., tirent principalement leurs principes huileux, résineux, salins et odorants, des végétaux qui servent à la nourriture des animaux qui les fournissent (2).

BBézoard factice, ou pierre de Goa. Cette pierre, destinée à être substituée aux vrais bézoards, est ainsi nommée du nom de la ville où elle est fabriquée. On la compose avec des espèces cordiales au nombre desquelles est la vraie pierre bézoard (Kæmpfer). Elle est de forme ovale ou ronde, grise intérieurement, noirâtre à l'extérieur, luisante, souvent recouverte d'une feuille d'or. Aujourd'hui, ajoute Kæmpfer, le révérend père Nicolas Monilius en fabrique qui se distinguent par les N M gravées à la surface, le côté opposé portant le signe d'une chèvre ou d'un autre animal.

L'École de pharmacie possède une pierre de Goa qui porte ces deux indications. J'ajoute que ces pierres sont formées, pour la plus grande partie, d’une argile plastique qui leur clonne la dou-

(1) Merklein et Wohler, Revue scientifique, t. XIII, p. 61.

(2) Consultez, sur les espèces et la nature des bézoards, les Annales du Muséum d'histoire naturelle, t. IV, p. 329; la Revue scientifique et industrielle, t. XIV, p. 5; le Journ. de pharm., t. XXVII, p. 678, et le Journ. de pharm. et chim., t. IX, p. 59, et t. X, p. 87 . 
ceur de toucher qu'on y recherche; qu'elles ont généralement une cassure terreuse, sans apparence de couches concentriques. Quelquefois cependant les fabricants sont parvenus à leur donner cette structure; mais la pierre artificielle se reconnait toujours à la loupe, qui fait apercevoir un mélange de différentes substances puJvérisées et de petites vacuoles d'air interposé.

Bézoards orientaux, de phosphate calcaire. Au nombre des bézoards qui existent dans la collection de l'École de pharmacie, il s'en trouve une espèce bien caractérisée, malgré ses différences de forme et de volume. Ces bézoards varient, en effet, depuis le volume d'un pois jusqu'à celui d'une petite noix; ils offrent le plus souvent pour noyau quelques débris grossiers d'aliment végétal, comme de la paille ou des fragments de tige; quelquefois aussi de petites pierres ou de petits excréments semblables à ceux de chèvre; quelquefois enfin le noyau ne paraît pas différer du reste du calcul. Quant à la forme, elle est très-variable. Beaucoup sont arrondis et formés de couches concentriques autour d'un noyau central; un certain nombre ont la forme conique d'une noix d'arec; d'autres sont didymes ou sont formés de deux calculs accolés, autour desquels se sont ensuite déposées des couches communes enveloppantes. Un de ces calculs a la forme d'un agaric comestible pourvu de son pédicule, d'autres sont lenticulaires. Enfin un dernier a la forme d'un tétraèdre sphérique dans lequel on entend sonner un noyau mobile. Ces bézoards sont généralement d'un blanc jaunâtre à l'extérieur; mais ils sont souvent recouverts, par places, d'un enduit noirâtre. La substance même du calcul est blanche, assez peu dense, tantôt nette, tantôt brillante et nacrée. Dans ce dernier cas, la matière offre une structure cristalline et divergente, partant de différents centres, ce qui la fait ressembler à de la mésotype.

Dans la collection de l'Écule, ces bézoards portaient le nom de bézoards occidentaux de l'Antilope Rupicapra ou du chamois; mais je les avais dans ma collection particulière sous le nom de béozards orientaux, et je crois cette désignation plus exacte, parce que ces bézoards me paraissent être ceux que Kæmpfer attribue à l'antilope $a h u$, bézoards qu'il dit être jaunes, roux ou de plusieurs couleurs, inégaux, difformes ou formés de un ou deux tubercules arrondis.

Ces calculs, traités par l'acide azotíque concentré, se colorent en rouge, et l'acide prend lui-même la même couleur. Par la soude caustique, les calculs pulvérisés ne dégagent pas d'ammoniaque, et ne forment ni coloration ni dissolution apparentes. Après avoir été calcinés, ils se dissolvent sans effervescence dans l'acide azotique étendu; la liqueur précipite par l'oxalate de po- 
tasse, et on obtient ensuite, par l'addition de l'ammoniaque, une cristallisation peu abondante de phosphate ammoniaco-magnésien. Enfin ces calculs, pulvérisés et soumis à l'ébullition dans l'eau, forment un soluté de surphosphate de chaux mélangé de surphosphate de magnésie. Ils sont donc formés des phosphates neutres de ces deux bases, décomposables par l'eau bouillante, ainsi que je l'ai reconnu, en surphosphates solubles et en sousphosphates insolubles.

J'ai fait connaître (1) la composition de plusieurs autres concrétions animales, dont j'indiquerai seulement les résultats. Le $\mathrm{n}^{\circ} \mathrm{IV}$, que j'avais dans ma collection, sous le nom de bézoard occidental, consiste en un fragment de calcul qui devait etre ovoïde et d'un volume considérable. Il était composé de phosphate de chaux mélangé de phosphate ammoniaco-magnésien. C'est en analysant ce calcul, que j'ai reconnu la propriété que possèdent les deux phosphates neutres de chaux et de magnésie et le phosphate ammoniaco-magnésien, de se transformer à l'aide de l'ébullition dans l'eau en surphosphates de chaux et de magnésie solubles et en sousphosphates insolubles; propriété qui avait échappé à Vauquelin et à Berzélius, et qui avait conduit le premier à admettre l'existence peu probable de calculs de phosphate acide de chaux.

J'ai fait connaître également la composition d'un magnifique calcul intestinal donné par M. Dubail à l'École de pharmacie, qui m'a présenté le résultat le plus inattendu : il était composé d'oxalatè de chaux presque pur. Ce bézoard est d'un blanc grisâtre et d'une forme ovoïde un peu aplatie; son plus grand diamètre est de 15 centimètres, et il pesait 1088 grammes. Il était formé d'un très-grand nombre de couches superposées, et offrait au centre un espace de 4 centimètres sur $2,0 ั$, occupé par une masse de fibres végétales. Ce calcul entier offrait une faible odeur d'ambre gris, commune à beaucoup de calculs intestinaux de ruminants; mais par la pulvérisation l'odeur devenait semblable à celle du crottin de cheval. On suppose que ce calcul a pu provenir d'un chameau. Voici quelle en était la composition :

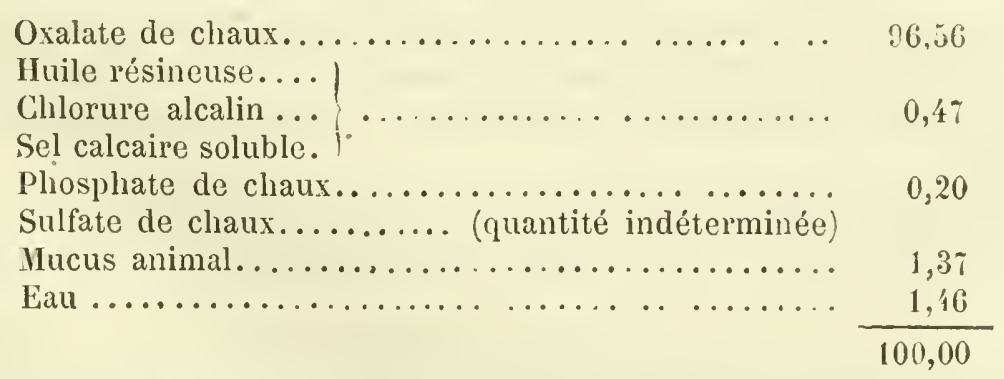

(1) Guibourt, Mémoire sur les bézourds (Revue scientifique, t. XIV, 1843). 
Un autre calculde même nature, de la grosseur d'un ceuf de cygne et du poids de $\mathbf{1 2 5}$ grammes, se trouvait dausma collection. Il est d'un gris jaunâtre assez foncé, d'une odeur d'ambre gris et offre un noyau composé de fibres végétales entremêlées. La sciure du calcul mélangée de celle de la substance ligneuse interne, a donné 90,33 pour 100 d'oxalate dẹ chaux. Le calcul seul en contient par conséquent davantage.

Un dernier calcul (celui $n^{\circ}$ III), que j’ai présenté comme étant un calcul intestinal de cheval, avait probablement une origine différente, les calculs intestinaux de chevaux étant presque exclusivement formés de phosphate ammoniaco-magnésien(Lassaigne). Ce calcul est composé de :

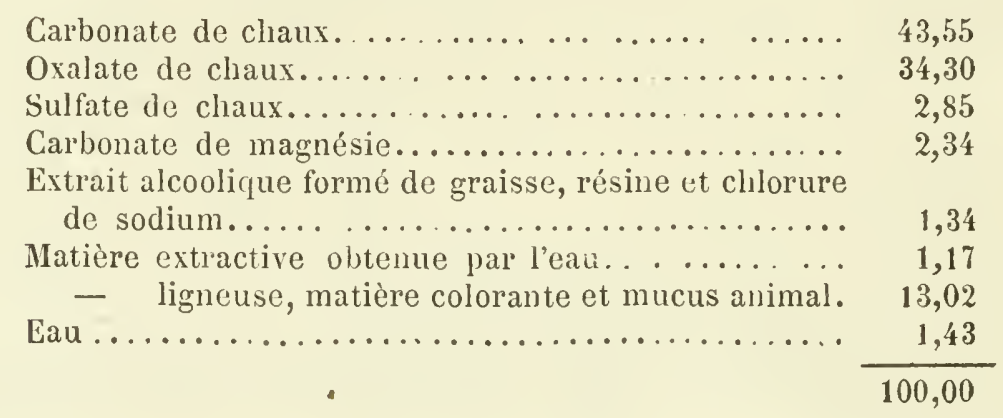

ORDRE DES CÉTACÉS.

"Les cétacés (1) sont des mammifères sans pieds de derrière; leur tronc se continue arec une queue épaisse que termine une nageoire cartilagineuse horizontale, et leur tête se joint au tronc par un cou si court et si gros qu'on n'y aperçoit aucun rétrécissement. Enfin leurs membres antérieurs ont les premiers os raccourcis, et les suivants aplatis et enveloppés dans une peau tendineuse qui les réduit à l'état de nageoires. C'est presque en tout la forme des poissons, excepté que ceux-ci ont la nageoire de la queue verticale. Les vrais cétacés se tiennent constamment dans les eaux, mais; comme ils respirent par des poumons, ils sont obligés de revenir souvent à la surface pour y prendre de l'air. Leur sang chaud, leurs oreilles ouvertes à l'extérieur, quoique par des trous fort petits et sans conque externe; leur estomac divisé en quatre poches comme celui des ruminants, ou en un plus grand nombre de caviés; leur génération vivipare, les mamelles au moyen desquelles les femelles allaitent leurs petits, et tous les détails de leur anatomie, les distinguent d'ailleurs suffisamment des poissons. ")

Cet ordre se compose de deux familles qui se disiinguent par leur régime, leurs dents et plusieurs autres particularités d'organisation :

(1) Voir sur les Cétacés et sur leur distribution géographique, Raoul Guél'in, Études zoologiques et paléontologiques sur la famille des Célacés (Thèses (de l'École de pharmacie de Paris, 1874). 
ce sont les cétacés herbivores, dont les narines s'ouvrent au dehors à l'extrémité du museau, et les cétacés souffleurs, dont les narines sont percées au sommet de la tête.

Les CÉTACÉS IIERBIVores comprennent deux genres d'animaux, les manates et les dugongs, qui ont été longtemps confondus avec les phoques, dont ils ont la forme, moins les pieds de derrière, et dont ils partagent la vie amphibie. Ils ont des dents machelières à couronne plate, les membres antérieurs flexibles et propres à ramper sur terre, ce qui leur permet de venir paître sur le rivage. Ils ont des moustaches sur le mufle et des poils épars sur le reste du corps. Enfin ils portent deux mamelles sur la poitrine, ce qui de loin, lorsqu'ils font sortir verticalement leur partie antérieure hors de l'eau, a pu les faire prendre pour des femmes ou des hommes marins, et a pu donner lieu à l'ancienne fable des sirènes et des tritons.

Les vRAis cÉtAcÉs ou cÉtACÉs SOUfFleurs ont tout à fait la forme des poissons et sont constitués pour vivre uniquement dans l'eau; mais, pour faliciter l'arrivée de l'air aux poumons, sans gu'ils aient besoin de sortir la tête ou la bouche hors de l'eau, leurs narines s'ouvrent au sommet de la tête. Mais elles leur servent encore à un autre usage; ces animaux engloutissant avec leur proie de grands volumes d'eau, il leur fallait une voie pour s'en débarrasser; cette eau passe donc à travers les narines, au moyen d'une disposition particulière du voile du palais, et s'amasse dans un sac placé près de l'orifice extérieur de la cavité du nez, d'où elle est cbassé avec violence par la compression de muscles puissants. C'est ainsi qu'ils produisent ces jets d'eau qui les font remarquer de loin des navigateurs. Ils n'ont aucun vestige de poils, et tout leur corps est couvert d'une peau lisse sous laquelle est un lard épais et abondant en huile, principal objet pour lequel on leur fait une chasse meurtrière. Leurs mamelles sont près de l'anus et ils ne peuvent rien saisir avec leurs nageoires antérieures. Leur estomac a cinq et quelquefois jusqu'à sept poches distinctes; ceux qui ont des dents les ont toutes coniques et semblables entre elles; ils ne mâchent pas leur nourriture, mais l'avalent rapidement. Plusieurs ont sur le dos une nageoire verticale, de substance tendineuse, et non soutenue par des os. Leurs yeux pelits et aplatis en avant ont une sclérotique épaisse et solide; leur langue n'a que des téguments lisses et mous. Les principaux genres compris dans cette famille sont les dauphins, les marsouins, les narvals, les cachalots et les baleines.

Les dauphins (Delphinus) ont des dents aux deux mâchoires, 
toutes simples et presque toujours coniques; ils ont une nageoire dorsale, le front bombé, et leur museau forme en avant une espèce de bec plus mince que le reste. Ils sont très-carnassiers et manquent de cœcum.

Les marsouins (Phocæna Rondeltii, Will.) ne diffèrent des dauphins que parce que leur museau est court et uniformément bombé. Le marsouin ordinaire (Delphinus Phocceno, L.) est le plus petit des cétacés el n'a pas plus de $1^{\mathrm{m}}, 3$ à $\mathbf{1}^{\mathrm{m}}, 6$ de longueur; mais une autre espèce, nommée épaulard, acquiert souvent 7 à 8 mètres et est l'ennemi le plus cruel de la baleine. Il se réunit en troupe pour la harceler jusqu'à ce qu'elle ouvre la gueule, et alors il lui dévore la langue.

Les narvals (Monodon) n'ont pas de dents proprement dites; mais seulement une longue défense droite et pointue implantée dans l'os intermaxillaire et dirigée dans le sens de l'axe du corps. L'animal a bien le germe de deux défenses, mais d'ordinaire celle du côté gauche est la seule qui se développe et sorte de son alvéole. On ne connaît bien qu'une seule espèce de narval dont la défense est longue de 2 mètres 1/2 à 3 mètres et plus. Elle est formée d'un bel ivoire blanc, mais ne peut être utilisée pour les ouvrages du tour, étant creuse à l'intérieur et composée de grosses fibres distincles, tordues en spirale à la manière d'une corde. Le corps du narval est assez gros, ovoïde-allongé, marbré de brun et de blanc, et n'a guère que le double ou le triple de la longueur de la défense.

Les cachalots (Physeter) sont d'énormes cétacés dont la tête très-volumineuse égale presque le tiers de leur longueur tolale; mais ni le crane ni le cerveau ne participent à cette disproportion, due tout entière à un énorme développement des os de la face. Leur mâchoire supérieure est large, élevée, privée de dents, leur mâchoire inférieure est beaucoup plus petite, étroite, allongée et est armée de chaque côté de grosses dents coniques qui se logent, lorsque la bouche se ferme, dans des cavités correspondantes de la mâchoire supérieure. L'évent est unique et non double comme celui de la plupart des autres côtacés souffleurs, -et placé vers l'extrémité supérieure du museau, dont la face antérieure est large et comme tronquée. La partie supérieure de leur énorme tête ne consiste presque qu'en grandes cavités séparées par des cartilages, et remplies d'une huile qui se fige en refroidissant et dont la partie solide a été nommée blanc de baleine ou spermaceti, mais porte aujourd'hui le nom plus convenable de cétine. Celte substance fait le principal profit de la pêche des cachalots, leur corps n'étant pas garni de beaucoup de lard. Les cavités qui la renferment sont très-différentes du véritable crâne, 
qui est assez pelit, placé sous la partie postérieure, et qui contient le cerveau comme à l'ordinaire.

La plupart des naturalistes ont admis plusicurs espèces de cachalots, et quelques-uns d'entre eux les ont même partagés en trois genres, sous les noms de cachalots proprement dits, de physales et de physétères. Il est possible, en effet, que plusieurs espèces existent, il est même probable qu'il n'y en a pas qu'une seule (Physeter macrocephalus); mais jusqu'à présent elles ne sont rien moins que prouvées, ainsi que le montre le passage suivant que j'emprunte à G. Cuvier (1).

"Ne sera-ce pas maintenant une grande témérité, à moi, après avoir exposé les idées de tant de savants hommes, de prétendre qu'il n'y a encore aujourd'hui qu'une seule espèce de cachalot qui puisse être considérée comme vraiment connue, je veux dire le cachalot vulgaire, l'animal du sperma-ceti ?

"Et cependant, lorsqu'on a fait justice des mauvaises combinaisons de synonymes et des doubles emplois, lorsqu'on a éliminé le beliga et le grampus ou le globiceps, confondus mal à propos dans ce genre, que reste-t-il, sinon des cétacés de très-grande taille, à tête énorme, en grande partie remplie de sperma-ceti, à dents coniques plus ou moins arquées, plus ou moins émoussées, au nombre de quarante ì cinquante environ, mais le plus souvent très-mal comptées, dont le dos est muni d'une proéminence peu saillante, que les uns ont appelée nageoire, les autres, arête longitudinale, et les autres, bosse ou tubercule, et que quelques autres, comme Clusius (2), n'ont pas vue du toul, parce qu'ils n'ont observé qu'un animal échoué sur le dos, et que l'on ne retourne pas facilement un cadavre de 60 ou 70 pieds de long sur 20 pieds d'épaisseur? A peine est-il sur le rivage, que la populace accourt et le dépèce; heureux si le naturaliste en trouve encore quelques os intacts...

"Quant à son extérieur, il paraît, d'après ce qu'il y a de plus authentique dans les rapports que l'on en a, que c'est un des plus grands cétacés, qu'il atteint 70 à 80 pieds de longueur, que sa tête est trèsgrande, très-grosse, et que l'on n'a pas beaucoup exagéré sa longueur en disant qu'elle fait le tier's du total; que son museau est très-obtus et comme tronqué; que son étroite mâchoire inférieure est reçue entre les lèrres supérieures comme dans un sillon; que ses dents entrent, quand sa gueule est fermée, dans des trous des bords du palais (quelques-uns pensent même qu'il y a dans ou entre ces trous d'autres petites dents qui ne restent pas dans le squelette); que son évent est sur l'extrémité de son museau; que ses pectorales sont petites et obtuses; qu'il a une dorsale très-peu saillante vers l'arriere du dos, quelquefois réduite à une protubérance, ou à deux ou trois; que sa caudale, fort

(1) Georges Cuvier, Ossements fossiles, t. VIII, $2^{\mathrm{e}}$ partie, p. 20\$-213.

(2) Clusius a, le premier, donné une figure assez exacte et une bonne description du cachalot, dans le VIe livre de ses Exoticarum, 1) 131.

Gurbourt, Drogues, te édit.

T. IV, -8 
large, est échancrée au milieu et pointue de chaque côté; que ses yeux sont non-seulement fort petits, mais inégaux, et même qu'il ne voit pas de l'œil gauche: que sa couleur est en dessus d'un gris plus ou moins noirâtre et quelquefois verdâtre, et en dessous blanchâtre ainsi qu'autour des yeux; que l'immense concavité du dessus de son crâne, recouverte par une voûte simplement cartilagineuse ou tendineuse, est divisée intérieurement en concamérations également tendineuses communiquant les unes avec les autres, et en cellules remplies d'une huile qui est fluide tant que l'animal est chaud, et qui, en se refroidissant, prend la forme concrète sous laquelle on l'emploie. C'est cette huile à laquelle on donne le nom assez ridicule de spermaceti, et que plus ridiculement encore on a regardée penidant longtemps comme la cervelle de l'animal; mais la véritable cervelle n'occupe dans l'intérieur du crâne qu'un fort petit espace. Celte substance du sperma-ceti est répandue aussi le long du dos et dans plusieurs parties du corps d'une manière qui n'est pas encore clairement expliquée. C'est dans les intestins de la même espèce que l'on trouve l'ambre gris ; mais on n'apoint encore bien fait connuître dans quelle parlie du corps il se forme, ni quelles sont les causes accidentelles de sa formation.

"Ce caclialot vit en grandes troupes, et, à moins qu'il n'y ait entre ceux des divers parages des différences qui n'ont point été indiquées, on doit croire qu'il se trouve dans toutes les mers. Aujourd'hui c'est dans les mers méridionales et des deux côtés de l'Amérique que l'on en prend le plus.

"Existe-t-il, en outre, des cachalots à dorsale? en existe-t-il dont l'évent soit percé près du front sur le milieu de la tête ? en existe-t-il où les bránches de la mâchoire inférieure ne soient pas réunies sur la plus grande partie de leur longueur en une symphyse cylindrique? Voilà ce qui reste à chercher, ce qui reste à prouver autrement que par des figures tracées par des matelots. Ce n'est qu'après que des hommes éclairés auront observé ces êtres avec soin, et en auront déposé les parties osseuses dans des collections où elles puissent être vérifiées par des naturalistes, qu'il sera possible à la critique de les admettre dans le catalogue des animaux."

Les baleines (Balcena) sont plus exactement connues. Elles égalent les cachalots pour la taille et pour la grandeur proportionnelle de la tête, mais elles n'ont aucunes dents. Leur mâchoire supérieure, en forme de carène, ou de toit renversé, a ses deux côtés garnis de lames transverses minces et serrées, appelées fanons, formées d'une espèce de corne fibreuse, effilées à leurs bords, et servant à retenir les petits animaux dont ces énormes cétacés se nourrissent. Leur mâchoire inférieure, soutenue par deux branches osseuses arquées en dehors et vers le haut, sans aucune armure, logre une langue charnue fort épaisse, et enveloppe, quand la bouche se ferme, toute la partie interne de la 
mâchoire supérieure et les lames cornées dont elle est revêtue. Cies organes ne permettent pas aux baleines de se nourril d'animaux aussi grands que leur taille pourrait le faire croire. Elles vivent de harengs, de maquereaux, de sardines, et principalement de crustacés, de mollusques et de zoophytes d'une extrême petitesse, mais dont les légions innombrables, une fois entrées avec l'eau, dans leur énorme gueule, s'y trouvent retenues par les barbes de leurs fanons. Elles ont un cœcum très-court.

Les baleines ont été divisées en trois sous-genres: le premier comprend la baleine franche(Balcena Mysticclus, L.), qui manque de nageoire sur le dos et n'a pas la gorge plissée. Elle peut avoir 22 mètres de longueur et surpasse toutes les autres baleines par la grosseur de son corps, dont le poids équivaut presque à celui de 300 bœufs gras. Son lard forme sous la peau une couche épaisse de plusieurs pieds, dont on retire environ 120 tonneaux d'huile, et qui est la cause de la chasse active qu'on lui fait tous les ans. Autrefois la baleine franche se montrait dans nos mers et était assez commune dans le golfe de Gascogne; mais elle s'est retirée peu à peu jusqu'au fond du Nord, où le nombre en diminue chaque jour. Outre son huile, elle fournit encore au commerce ses fanons noirâtres et flexibles, longs de $2^{\mathrm{m}}, 60$ à $3^{\mathrm{m}}, 2 \breve{~}$, qui sont connus sous le nom vulgaire de buleines; chaque inciividu en a huit ou neuf cents de chaque côté du palais. On dit que ce monstrueux célacé ne se nourrit que de très-petits mollusques qui fourmillent dans les mer's qu'il habite. Ses excréments sont d'un jaune safrané ou rougeâtre qui teint assez bien la toile.

Les balénoptères se rapprochent de la baleine franche par leur gorge dépourvue de plis, mais en diffèrent par une nageoire dorsale. On n'en connaît qu'une espèce nommée gibbar par les Basques (Balcena Physalus, L.), et encore n'est-il pas certain que ce gibbar ne soit pas une jubarte mal observée. Le gibbar est aussi long, mais hien plus grêle que la baleine franche; il est très-commun dans les mêmes parages, mais les pêcheurs l'évitent parce qu'il donne peu de lard et qu'il est difficile à prendre et dangereux pour les embarcations, ì cause de la violence de ses mouvements quand il est attaqué.

Les rorquals ont une nageoire dorsale et la peau du dessous de la gorge et de la poitrine plissée longitudinalement, et susceptible, en conséquence, d'une grande dilatation. On en connaît plusieurs espèces dont une, nommée jubarte des Basques (1), (Rorqualus rostratus) surpasse par sa longueur la baleine franche,

(1) Par corruption sans doute du mot gibbar. 
mais présente, pour la pêche, les mêmes inconvénients que le gibbar. Le rorqual de la Méditerranée n'en diffère que par quelques caractères peu importants.

\section{Des huiles de Cétacés.}

Ces huiles sont produiles principalement par la baleine, le cachalot, les dauphins et les marsouins. Mais elles sont souvent mélangées d'huiles de phoques, de morses et même d'huiles de poissons, ce qui rend l'exposition de leur's caractères distinctifs difficile à faire.

L'h uile du marsouin à tête ronde (Globicephalus melas, Lesson; Delphinus gloliceps, Cuv.) - a été examinée par M. Chevreul, dans le cours de ses savantes recherches sur les corps gras. Cette huile est d'un jaune citrin, d'une odeur forte et d'une pesanteur spécifique de 0,9178 à la température de 20 degrés. Elle est très-soluble dans l'alcool, puisque 100 parties d'alcool à 0,812 de densité en dissolvent 100 à la température de 70 degrés, et que 100 parties d'alcool anhydre en prennent 123 parties à la température de 20 degrés.

Cette huile, exposée pendant longtemps à des températures décroissantes de 10 à 3 degrés, laisse déposer des cristaux de cétine. L'huile privée de cétine est plus foncée en couleur, d'une odeur plus forte, et elle est encore plus soluble dans l'alcool; elle se convertit par la saponification en glycérine et en acides oléique, margarque et phocénique. Ce dernier, dont la composition est $\mathrm{C}^{19} \mathrm{H}^{7} \mathrm{O}^{3} \mathrm{HO}$, est un acide volatil analogue à l'acide butyrique. Il se produit en outre deux huiles non acides et plus fusibles que l'éthal, ce qui semble indiquer dans l'huile de marsouin la présence de corps gras différents de l'oléine, de la margarine, de la phocénine et de la cétine, qui la composent principalement.

Huile de baleine. Aussitôt qu'une baleine est morte d'épuisement, par suite de la perte de sang causée par la profonde blessure que lui a faite le harpon dont elle a été frappée, les pêcheurs la fixent comme une ceinture autour de leur navire; puis, armés d'énormes couteaux et d'un instrument qui ressemble à une grande bêche, ils descendent sur son corps, enlèvent par tranches le lard qui le recouvre, et le déposent dans des barils pour être fondu à leur plus prochaine relâche. L'huile qui en résulte est plus ou moirs brune, d'une odeur de poisson rance, épaisse et congelable à la température de zéro. Elle contient une plus grande quantité de cétine que l'buile de marsouin, beaucoup moins de phocénine, de l'oléine, de la margarine et d'autres corps bien moins déterminés. 
Iluile de cachalot et blanc de baleine. Ainsi que nous l'avons vu, l'huile de cachalot, peu abondante dans le tissu. graisseux sous-cutané, est principalement contenue dans de vastes chambres qui occupent la partie supérieure et antérieure de Jeur énorme tête. Cete huile, qui est à l'état liquide, dans l'animal vivant, se fige en refroidissant et se présente sous la forme de lames cristallines, tenues en suspension dans une huile d'un jaune ambré. On lui donne en cet élat le nom de blanc de baleine brut. En séparant par la filtration les deux parties dont elle se compose, on obtient une partie liquide qui est considérée comme huile de baleine, et une partie grenue, d'une couleur brune, d'une odeur forte et de la consistance d'un miel épais, qui est connue sous le nom de blanc de baleine filtré, et qui contient encore 60 pour 100 d'huile liquide. Cette matière, soumise à une forte pression, forme le blanc de baleine messé, qui est de couleur beaucoup moins foncée, sec, sonore et de structure cristalline. Pour obtenir le blanc de baleine purifié, on traite celui qui a été exprimé par une faible solution de potasse, on le lave et on le fond dans l'eau bouillante. On le coule enfin sous la forme de pains carrés, du poỉs de 15 à 16 kilogrammes, qui sont d’un blanc éclatant, translucides, presque inodores, formés de cristaux brillants, nacrés, onctueux au toucher, un peu flexibles entre les doigts, se divisant, par une pression plus forte, en lames minces, transparentes et nacrées. A cet état, le blanc de baleine fond à 44 degrés 'et n'est pas encore un produit simple. L'alcool froid, à 0,821 de densité, en extrait une huile incolore, qui se saponifie en donnant les mêmes produits comme deux états différents du même corps. La matière cristalline, ou la cétine pure, fond alors à 49 degrés; à la température de 360 degrés, elle entre en ébullition et peut être distillée sansaltération; à une température plus élevée, elle se décompose en partie en produisant de l'acide mal'garique et de l'acide oléique. Elle brûle avec une belle flamme blanche, comme la cire; 100 parties d'alcool anhydre bouillant en dissolvent 15,8; mais l'alcool à 0,834 n'en dissout que 3 , dont la plus grande partie se précipite par le refroidissement. Elle se dissout dans les huiles fixes et volatiles.

La cétine se saponifie beaucoup plus difficilement que les autres corps gras, et laisse presque la moilié de son poids d'un corps neutre auquel M. Chevreul a donné le nom d'éthal(1), et qui paraît

(1) M. Chevreul, qui a parfaitement déterminé la composition de l'éthal hydraté $\left(\mathrm{C}^{32} \mathrm{H}^{34} \mathrm{G}^{2}\right)$, lui a donné ce nom, à cause des rapports de composition et de propriêtés qui unissent ce corps à l'éther et à l'alcool. L'éthal, traité par' l'acide phosphorique anhydre, se réduit en effet à l'état d'un carbure d'hydrogène liquide, nommé cétène, isomère du gaz oléifiant $\left\{\mathrm{C}^{\prime} \mathrm{H}^{4}\right\}$, mais dont la compo- 
jouer, par rapport à la cétine, le rôle de la glycérine pour les corps gras ordinaires. Seulement M. Ghevreul avait pensé que l'autre produit de la saponification de la cétine était un mélange d'acides oléique et margarique, tandis que M. Laurence Smith a montré que ce produit est un acide particulier que M. Dumas avait déjà obtenu en faisant réagir la potasse caustique solide sur l'éthal, et qu'il avait nommé acide éthalique. Cet acide est également le même que l'acide palmitique résultant de la saponification de l'huile de palme; le nom d'acide cétique est celui qui lui conviendrait le mieux.

D'après M. Lrurence Smith, la composition de la cétine $=\mathrm{C}^{64} \mathrm{H}^{64} \mathrm{O}^{4}$, et, de même que pour les corps gras ordinaires, cette composition correspond à celle de l'acide cétique et de l'éthal anhydres, de sorte qu'il faut y ajouter 2 équivalents d'eau, pour en retirer ces deux corps cristallisés et hydratés.

$$
\left\{\begin{array}{l}
\mathrm{C}^{64} \mathrm{H}^{64} \mathrm{O}^{4}=\mathrm{C}^{32} \mathrm{H}^{31} \mathrm{O}^{3}+\mathrm{C}^{32} \mathrm{H}^{33} \mathrm{O} \\
\text { cétine }=\text { acide cétique anh. }+ \text { éthal anhlidre. } \\
\mathrm{C}^{64} \mathrm{H}^{64} \mathrm{O}^{4}+\mathrm{H}^{2} \mathrm{O}^{2}=\mathrm{C}^{32} \mathrm{H}^{32} \mathrm{O}^{4}+\mathrm{C}^{32} \mathrm{H}^{34} \mathrm{O}^{2} \\
\text { cétine }+\bar{z} \text { eau }=\text { ac. cétique hydr. }+ \text { éthal hydraté. }
\end{array}\right.
$$

On doit choisir le blanc de baleine le plus récent possible, car il se rancit très-facilement, ce qu'il doit sans doute à la graisse liquide qu'il retient toujours. On l'emploie en pommade cosmétique, uni à l'huile d'amandes douces, mais son plus grand usage est pour la fabrication des bougies.

Fourcroy avait cru que le blanc de baleine, le gras des cadavres et la matière grasse des calculs biliaires, étaient un seul et même corps gras, et avait proposé de leur donner également le nom d'apocire. M. Chevreul a prouvé que ces trois substances étaient essentiellement différentes, et a proposé, pour le blanc de baleine pur, le nom plus convenable de cétine, tiré de xĩ̃os ou de cetus.

\section{De I'Ambre gris.}

L'ambre gris est une matière solide, plus légère que l'eau, se ramollissant et se fondant comme de la cire à l'aide de la chaleur; d'une couleur grise jaunâtre ou noirâtre; qui disparaît souvent sous une efflorescence blanche formée à sa surface; il a

sition, pour 4 volumes de vapeur, $=\mathrm{C}^{32} \mathrm{H}^{32}$. Alors l'éthal hydraté $\left(\mathrm{C}^{32} \mathrm{H}^{32}, \mathrm{H}^{2} \mathrm{O}^{2}\right)$ est un biliydrate de cétène, de même que l'alcool $\left(\mathrm{C}^{4} \mathrm{H}^{4}, \mathrm{H}^{2} \mathrm{O}^{2}\right)$ est un bihydrate de carbure hydrique. Pareillement l'éthal anhydre $\left(\overline{\mathrm{C}}^{3} \mathrm{H}^{330}\right.$ on $\mathrm{C}^{32} \mathrm{H}^{32}, \mathrm{HO}$, tel qu'on le suppose exister dans la cétine, est le représentant de l'éther hydratique $\left(\mathrm{C}_{4}^{4} \mathrm{H}^{5} \mathrm{O}\right.$ ou $\left.\mathrm{C}_{4}^{4} \mathrm{H}^{4}, \mathrm{HO}\right)$.

L’éthal est solide, cristallisable, insipide, inodore, fusible à 48 degrés, soluble dans l'alcool et l'étlier volatil el pouvant être distillé sans altération. 
une odeur assez douce, suave, susceptible d'une grande expansion; il est presque insipide.

L'ambre gris est en masses irrégulières, tantôt formé de petils grains blancs jaunâtres arrondis, dispersés dans une pâte grise uniforme; le plus souvent composé de couchès concentriques superposées, comme un calcul ou un bézoard animal. Ses morceaux pèsent ordinairement moins de 500 grammes; mais on en cite des masses de 5 et de 10 kilogrammes, et quelques-unes même de 50 à 100 kilogrammes. On le trouve flottant sur la mer, aux environs du Japon, des îles Moluques, de l'Inde, de Madagascar, du Brésil, des Antilles et des îles Lucayes, ou bien on le retire des intestins de plusieur's grands cétacés.

On a formé bien des hypothèses sur l'origine de l'ambre gris; on l'a successivement regardé comme un bitume, comme des excréments d'oiseaux, des rayons de cire, des résines végétales provenant des terres voisines, et ensuite bituminisées par l'action simultanée de l'eau salée, de l'air el du soleil. Plus récemment, Tirey a émis l'opinion que l'ambre gris était une espèce d'adipo. cire ou de gras des cadavres, résultant de la décomposition spontanée des poulpés odorantes qui abondent dans la Méditerranée et entre les tropiques; il est inutile que je reproduise ici les raisons que j'ai opposées à cette hypothèse, que rien ne justifie.

On fait généralement honneur à Schwédiawer ou Swédiaur, de l'opinion admise aujourd'hui que l'ambre gris est produit par un cétacé. Pour être juste, il faul que je rapporte ce qu'a écril l'Écluse ou Clusius sur l'origine de cette substance, bien avant Schwédiawer, et avant bien des opinions erronées émises sur le même sujet, Voici ce que dit L'Écluse (1):

"Quant à ce que peut être l'ambre gris, je dirai ce que m'a rapporté, en 15:93, un homme d'une bonne foi éprouvée, Servat-Narel, bourguignon, qui avait parcouru un grand nombre de pays pour faire le commerce de l'ambre, du musc el des pierres précieuses. Lui ayant dit que je ne connaissais de l'ambre que ce qu'en avaient décrit Garcias $a b$ Horto el Nicolas Monard, il me répondit : Je les ai lus l'un et l'autre, mais que rapportent-ils autre clrose que des témoignages douteux d'auteurs qui s'égarent? Croyez-moi, l'ambre n'est autre chose qu'un résidu d'aliment amassé pendant longtemps dans l'estomac (ou l'intestin) de la vraie baleine. Je dis vraie, parce que la plupart donnent à d'autres cétacés, tels que l'orque, physeter et autres pourvus de dents, le nom de baleine, tandis que la baleine légitime n'a pas de dents, dévore les poissons entiers, ef aime surtout à se nourrir de mollusques, tels que poulpes, seiches et autres. Celte nourriture étant mal digérée, il en résulte beaucoup de matière épaisse, qui se coagule

(1) L’Écluse, Exoliques, p. 148, 149. 
et se trouve rejetée chaque année, ou à des intervalles plus courts, lorsque l'estomac en est trop surchargé. Cette matière, ainsi gardée pendant longtemps dars l'estomac, rejetée ensuite et nageant sur la mer, est l'ambre gris, dans lequel on trouve quelquefois les becs des poulpes dévorés (Swiédiaur et Romé de l'Isle se sont disputé, deux cents ans après, la découverte de ce fait). Lor:que la baleine est prise, étant réccmment débarrassée de cette matière, on n'y trouve pas d'ambre gris; quand on la prend quelque temps après, on y trouve un peu d'ambre, mais d'une qualité inférieure; mais la matière croît peu à peu, acquiert de la qualité en vieillissant, et si l'on prend la baleine avant qu'elle l'ait rendue, c'est alors qu'on y trouve la plus grande quantité et la meilleure qualité d'ambre. On en chercherait en vain dans les autres cétacés que j'ai nommés. Il n'y a donc rien d'étonnant si ceux qui les ont ouverts, les prenant pour des baleines, n'y ont pas trouvé d'ambre gris."

Kæmpfer (1), après avoir vengé, suivant son expression, l'ambre gris des ridicules hypothèses du Journal des Savants, nous apprend qu'on trouve très-souvent de l'ambre gris dans les intestins d'un célacé nommé mokos, long de 3 à 4 brasses, que l'on prend aux environs du Japon. L'ambre est commun au Japon, tant celui trouvé dans les entrailles des baleines que celui qu'elles ont rejeté à la mer, avec leurs excréments, pendant leur vie; d'où les Japonais appellent l'ambre kusura no fuu, c'est-à-dire excrément de baleine.

Suivant Swédiaur, cependant (2), l'a mbre gris est l'excrément du cachalot, physeter macrocephalus, L., endurci contre nature, et mêlé arec quelques parties de sa nourriture qui n'ont pu être digérées. Les raisons qu'il donne pour altribuer l'ambre à ce cétacé, et non aux autres, sont $1^{\circ}$ que les pêcheurs américains sont tellement convaincus de ce fait, que, lorsqu'on leur parle d'un parage où l'on trouve l'ambre gris, ils en concluent de suite qu'il doit être fréquenté par le cachalot, qui est également l'animal dont on retire le blanc de baleine; $2^{\circ}$ les gens qui sont employés à la pêche de la baleine ne prennent que le cachalot macrocéphale, et l'examinent d'abord pour s'assurer s'il contient de l'ambre gris, à moins que l'animal n'ait vomi et rendu ses excréments après avoir été harponné; car alors il est inutile de rechercher l'ambre dans ses intestins; $3^{\circ}$ les sèches font la nourriture principale du cachalot, et les becs de sèches noirs et cornés, que l'on trouve dans l'ambre gris, sont encore une preure qu'il provient de ce cétacé.

Cette opinion de Swédiaur est tellement accréditée depuis

(1) Kæmpfer, Amœnitatum exoticurum, p. 635.

(2) Swédiaur, Journal de plıysique, t. XXV, p. ?78. $178^{\prime}$. 
longtemps que j'ai peine à croire qu'elle ne soit pas fondée (1); cependant deux des trois raisons sur lesquelles il l'appuie sont tout à fait inexactes; car il est faux que les gens qui vont à la pêche de la baleine ne prennent que des cachalots, et il est faux également que ce cétacé se nourrisse principalement de mollusques, puisqu'il a des dents dures et aiguës, et qu'il poursuit avec acharnement les phoques, les baleinoplères, les dauphins et les requins (2).

La baleine franche, au contraire, comme l'a très-bien remarqué Servat-Marel (que Swédiaur a eu le tort de ne pas citer), n'ayant pas de dents, est obligée de se nourrir principalement de mollusques, et cette observation, qui montre que l'homme qui l'a faite n'était pas un simple marchand d'ambre gris, mérite que l'on examine de nou veau si son opinion ne serait pas fondée, et si la baleine franche, plutôt que le cachalot ou, tout au moins, tout aussi bien que lui, ne produirait pas l'ambre gris.

Différents chimistes ont concouru à nous faire connaître la nature de l'ambre gris, entre autres Geoffroy, Bucholz, et MM. Pelletier et Caventou.

Geoffroy nous apprend (3) que l'espril-de-vin ne dissout pas entièrement l'ambre gris : qu'il reste un peu d'une matière noire sur laquelle il n'agit pas; que sa dissolution forme, après quelque temps, un sédiment blanc très-abondant, qui, desséché, devient folié et brillant, et qui n'est pas différent du blanc de baleine.

Suivant Bucholz (4), l'ambre gris, à part la petite quantité de matière noire insoluble dans l'alcool, est une substance sui generis, qui tient le milieu entre la cire et la résine, et qu'il a nommée principe ambré. Il a reconnu son insolubilité presque complète dans les alcalis, et a donné cette propriélé comme un caractère distinctif de l'ambre gris.

Pelletier et M. Caventou sont partis de l'opinion de Geoffroy, que le principe cristallisable de l'ambre gris était du blanc de baleine; ils en ont démontré la fausseté, et ont prouvé que ce principe, qu'ils ont nommé ambréine, était différent des autres connus jusque-là, et que celui dont il se rapprochait le plus était la cholestérine, ou principe cristallisable des calculs biliaires humains.

Les auleurs du Mémoire, s'appuyant sur ce rapprochement,

(1) Un cachalot trumpo mâle, échoué, en 1741, près de Bayonne, fournit dix tonneaux d'adipocire, et on trouva dans ses intestins une masse d'ambre gris du poids de 12 livres. Ce fait prouve au moins que le cachalot peut produire de l'ambre gris.

(2) Sonnini, Histoire des célacés, p. 30 i.

(3) Geoffroy, Matière médic., t I, p. 287.

(4) Bucholz, Amn. de chim., t. LXXIII, p. $\vdots 5$. 
discutent ensuite la question de l'origine de l'ambre gris. Ils admettent, avec Swédiaur (1), que cette matière se forme dans les intestins du cachalot; mais ils combattent son opinion qu'elle est un excrément endurci, et la regardent plutòt comme une sorte de bézoard ou de calcul biliaire(2).

En résumant les opinions les plus probables émises sur l'origine de l'ambre gris, on voit que Servat-Marel l'attribuait à la baleine franche, et Swédiaur, au cachalot; que celui-cile considère comme un excrément endurci, et MM. Pelletier el Caventou, comme un calcul biliaire. Je puis éclaircir cette dernière question et montrer que l'ambre gris participe à la fois de la nature de l'un et de l'autre.

En 1832, j'ai vu chez M. Chardin-Hadancourt, parfumeur, de l'ambre gris récent, qui était formé d'excrément de célacé recouvert de couches concentriques adipocireuses. L'excrément avait la forme du crottin de cheval, élail mou et jaune, et avait l'odeur de la matière fécaic humaine. Il était tanlôt isolé, et d'autres fois réuni au nombre de 3 ou 4, au milieu des couches concentriques. Des masses plus considérables étaient formées de masses partielles ayant chacune leur noyau de 1, 2, 3 ou 4 excréments globuleux, puis réunies et enveloppées ensemble dans de nouvelles couches adipocireuses. C'est alors que l'ambre gris doit nuire aux fonctions des intestins et à la santé des individus qui le portent. Alors aussi on conçoit comment sa masse s'accroît promplement jusqu'à un poids considérable. La masse d'ambre du poids de 182 livres, qui appartenait à la compagnie hollandaise des Indes Orientales, el qui se trouve figurée par Vander (3), est formée, comme je viens de l'indiquer, de masses partielles rapprochées et enveloppées dans un cerlain nombre de couches superficielles générales.

Le 31 octobre 1832, j'ai soumis à la dessiccation lente, dans une bcîle de carton, un rragment d’ambre gris mou et récent, pesant $\breve{4}^{\mathrm{gr}}, 69$. Il s'est desséché ou plutôt durci, sans perdre de son poids, et, le 31 janvier 1836, il avail encore exactement le même poids; cependant il élait tout à fait dur, d'une forte odeur d'ambre, el n'offrait plus d'indice de son odeur primitive qu'au centre du noyau excrémentitiel (4). Ce noyau est d'une

(1) Swédiaur, Journ. de pharm., t. VI, p. 49.

(2) Journ. de pharm., t. VI, p. 49.

(3) Vander, Thescurus cochlerirum. Lugd. Bat., 1711, tab. LIII et LIV.

(4) Le 4 septembre 1850 , ce morceau d'ambre pesait $5{ }^{1}{ }^{\mathrm{Br}}, 3 \%$. Comme il est toujours resté, depuis l'année 1836 , renfermé dans une conserve de verre, il possède une forte odeur d'ambre toujours mélangée d'une odeur d'étable, qui le rend moins agréable en nature que s'il était resté exposé à l'air; mais je suis persuadé que cet ambre aurait, pour la parfumerie, une puissance odoriférante beaucoup plus grande. 
pâte grise uniforme, parsemée de petites taches jaunes; les couches concentriques sont noires, comme huileuses, et constituent la variété d'ambre que l'on nomme ambr noire, moins estimé que le gris, quoique très-odorant (d'autres fois les couches sont grises, plus sèches et forment alors l'ambre le plus estimé); le tout s'est recouvert d'une efflorescence très-blanche d'ambréine.

L’ambre gris est employé en médecine comme excitant et aphrodisiaque; mais son plus grand usage est pour les parfums. Il est souvent falsifié dans le commerce : on reconnaîtra le bon en s'attachant aux caractères que j'ai indiqués au commencement, el encore plus peut-être par l'habitude d'en manier.

\title{
DEUXIÈME CLASSE
}

\author{
LES OISEAUX.
}

Les oiseaux sont des animaux vertébrés, ovipares, à sang chaud, à circulation et respiration doubles, éminemment bipèdes et destinés à vivre dans l'air, où ils se soutiennent au moyen de leurs membres antérieurs développés en ailes.

“Leurs poumons non divisés, fixés contre les côtes, sont enveloppés d'une membrane percée de grands trous, et qui laisse passer l'air dans plusieurs cavités de la poitrine, du bas-ventre, des aisselles et même de l'intérieur des os, en sorte que ce fluide baigne, non-seulement la surface des vaisseaux pulmonaires, mais encore celle d'une infinité de vaisseaux du reste du corps. Ainsi les oiseaux respirent, à certains égards, par les rameaux de leur aorle comme par ceux de leur artère pulmonaire, et l'énergie de leur irritabilité, de même que l'augmentation de leur caloricité, sont une conséquence de la grande étendue et de la quantité de leur respiration.

"Les extrémités antérieures, destinées au vol, ne pourant servir à la station ni à la préhension, les oiseaux sont bipèdes et prennent les objels à terre avec leur bouche; alors, leur corps devant être penché en avant de leurs pieds, les cuisses se portent aussi en avant, et les doigts s'allongent pour former au corps une base suffisante. Le bassin est très-étendu en longueur pour fournir des attaclıes aux muscles qui supporlent le trone sur les cuisses; il existe même une suite de muscles allant du bassin aux doigts, en passant sur le genou et le talon, de manière que le simple poids de l'oiseau fléchit les doigts. C'est ainsi qu'ils peuvent dormir perchés sur un pied. 
"Le cou et le bec s'allongent pour pouvoir atteindre jusqu'à terre, et le premier a la mobilité nécessaire pour se reployer en arrière dans la station tranquille. Il a donc beaucoup de vertèbres. Au contraire, le trone qui sert d'appui aux ailes a dû etre peu mobile; le sternum surtout, auquel s'attachent les muscles qui abaissent l'aile pour choquer l'air dans le vol, est d'une grande étendue et augmente encore sa surface par une lame saillante, dans son milieu, qui porte le nom de bréchet. La fourchette produite par la réunion des deux clavicules et les deux vigoureux arcs-boutants formés par les apophyses caracoïdes, tiennent les épaules écartées, malgré les efforts que le vol détermine en sens contraire. L'aile soutenue nar l'humérus, par l'avant-bras, et par la main qui est allongée et montre un doigt et les vestiges de deux autres, porte sur toute sa longueur une rangée de pennes élastiques qui étendent beaucoup la surface qui choque l'air. Les pennes adhérentes à la main se nomment primaires, et il $\mathrm{y}$ en a toujours. 10; celles qui tiennent à l'avant-bras s'appellent secondaires, et leur nombre varie; des plumes moins fortes attachées à l'humérus s'appellent scapulaires; l'os qui représente le pouce porte encore quelques pennes nommées bâtardes; sur la base des pennes règne une rangée de plus petites plumes nommées cou"vertures.

"La queue osseuse est très-courte, mais elle porte aussi une rangée de fortes pennes qui, en s'étalant, contribuent à soutenir l'oiseau; leur nombre est ordinairement de 12, quelquefois de 14; dans les gallinacés, il va jusqu'à 18.

"Les membres postérieurs ont un fémur, un tibia et un péroné qui tiennent au fémur par une articulation à ressort dont l'extension se maintient sans effort de la part des muscles. Le tarse et le métatarse y sont représentés par un seul os terminé vers le bas en trois poulies.

" Il y a le plus souvent trois doigts en avant et le pouce en arrière; celui-ci manque quelquefois. Le nombre des articulations crôit à chaque doigt, en commençant par le pouce qui en a deux, et en finissant par le doigt externe qui en a cinq.

" L'œil des oiseaux est disposé de manière à distinguer également bien les objets de loin et de près; une membrane vasculeuse et plissée, qui se rend du fond du globe au bord du cristallin, y contribue probablement en déplaçant cette lentille. La face antérieure du globe est d'ailleurs renforcée par un cercle de pièces osseuses; et, outre les deux paupières ordinaires, il y en a toujours une troisième placée à l'angle interne, et qui, au moyen d'un appareil musculaire remarquable, peut couvrir le devant de l'œil comme un rideau. La cornée est très-convexe; mais le cristallin est plat, et le vitré petit.

"L'oreille des oiseaux n'a qu'un osselet, formé d'une branche adhérente au tympan, et d'une autre terminée par une platine qui s'appuie sur la fenêtre ovale; leur limaçon est un cône peu arqué; mais leurs canaux semi-circulaires sont grands et logés dans une partie du crâne, oủ ils sont environnés de toutes parts de cavilés aériennes qui communiquent avec la caisse. Les oiseaux de nuit ont seuls une conque extérieure, qui cependant ne fait point de saillie comme celle des quadru- 
pèdes. L'ouverture de l'oreille est généralement recouverte de plumes à barbes plus cffilées que les autres.

" L'organe de l'odorat, caché dans la base du bec, n'a d'ordinaire que des cornels cartilagineux, au nombre de trois, qui varient en complication; il est très-sensible, quoiqu'il n'ait pas de sinus creusés dans l'épaisseur du crâne. La langue a peu de substance musculaire et est peu délicate dans la plupart des oiseaux.

"Les plumes, ainsi que les pennes, qui n'en diffèrent que par la grandeur, sont composées d'une tige creuse à la base, et de barbes latérales qui en portent elles-mêmes de plus petites; elles tombent deux fois par an. Dans certaines espèces, le plumage d'hiver diffère par ses couleurs de celui d'été, el, dans le plus grand nombre, la femelle differe du mâle par des teintes moins vives. Dans ce cas, les petits des deux sexes ressemblent ì la femelle. Lorsque les adultes mâles et femelles sont de même couleur, les petits ont une livrée qui leur est propre.

"La trachée des oiseaux a ses anneaux entiers; à sa bifurcation est une glotte le plus suuvent pourvue de muscles propres, et nommée larynx inférieur: c'est là que se forme la voix des oiseaux. L'énorme volume d'air contenu dans les sacs aériens contribue à la force de cette voix, et la trachée, par ses diverses formes et par ses mouvements, à ses modifications. Le larynx supérieur, fort simple, yentre pour peu de chose.

"La face ou Je bec supérieur des oiseaux, formée principalement de leurs os intermaxillaires, se prolonge en arrière de deux arcades, dont l'interne se compose des os palatins et ptérygoïdiens, et l'externe des os maxillaires et des jugaux, el qui s'appuient l'une et l'autre sur un os tympanique mobile, vulgairement dit os carré, répondant à l'os de la caisse. En dessus, cette même face est articulée ou unie au crâne par des lames élastiques; ce mode d'union lui laisse toujour's quelque mobilité. Lasubstance cornée qui revêt les deux mandibules tient lieu de dents et est quelquefois hérissée de manière à en représenter. Sa forme, ainsi que celle des mandibules qui la soutiennent, varie selon le genre de nourriture que prend chaque espèce.

"La digestion des oiseaux est en proportion avec l'activité de leur' vie et la force de leur respiration. L'estomac est composé de trois parties: le jabot, qui est un renflement de l'œsophage; le ventricule succenturié, sac membraneux garni dans l'épaisseur de ses parois d'une multitude de glandes dont l'humeur imbibe les aliments; cnfin le gésier, armé de deux muscles vigoureux, et dans lequel les aliments se broient d'autant plus aisément que les oiseaux ont soin d'avaler de petites pierres pour augmenter la force de la trituration.

"Le cloaque est une poche où aboutissent le rectum, les uretères et les canaux spermatiques, ou, dans les femelles, l'oviducte. Il est ouvert au dehors par l'anus. Dans la règle, les oiseaux n'urinent pas au dehors, parce que leur urine, peu abondante, se mêle aux excréments solides. Les autruches ont seules le cloaque assez dilaté pour que l'urine s'y accumule à l'état liquide.

"Dans la plupart des genres, l'accouplement se fait par la seule 
juxtaposition des anus : les autruches et plusieurs palmipèdes ont cependant une verge creusée d'un sillon, par où la semence est conduite. Les teslicules sont situés à l'intérieur, au-dessus des reins et près du poumon. Il n'y a qu'un oviducte de développé; l'autre est réduit à une petite bourse. ")

L'œuf détaché de l'ovaire, où l'on n'y aperçoit que le jaune, s'entoure dans le haut de l'oviducte de la liqueur nommée le blanc ou l'albumen, et se garnit de sa coque calcaire dans le bas du même canal. C'est dans cet état que l'œuf est pondu; mais le germe, placé sur un point blanchâtre (cicatricule) de la surface du jaune, ne s'y développe que moyennant un certain degré de chaleur que communique la mère à ses œufs, en les recouvrant de son corps, après les avoir déposés dans un nid propre à les abriter. Entre tous les oiseaux, les autruches seules, vivant au milieu des déserts sablonneux de l'Afrique, paraissent se dispenser de couver leurs œufs, et peuvent les abandonner à la chaleur des rayons solaires, après les avoir rassemblés dans un creux pratiqué dans le sable; mais elles les courent dans les climats moins chauds. Après un temps d'incubation qui est constant pour chaque espèce, le petit, qui a épuisé la nourriture contenue dans l'œuf et qui est suffisamment déreloppé pour pouvoir en recevoir du dehors, fend la coquille au moyen d'une pointe cornée qu'il a sur le bout du bec et qui tombe peu après sa naissance.

On divise les oiseaux en six sortes, qui sont les rapaces, les passereanx, les grimpeur's, les gallinacés, les échassiers et les palmipédes.

\section{ORDRE DES RAPACES.}

"I. Les RAPACES, ou OISEAUX DE PROIE (Accipitres, L.), se reconnaissent à leur bec et à leurs ongles crochus, armes puissantes au moyen desquelles ils poursuivent les autres oiseaux et même les quadrupèdes faibles etles reptiles. Ils sont parmi les oiseaux ce que sontles carnassiers parmi les quadrupèdes. Les muscles de leurs cuisses et de leurs jambes indiquent la force de leurs serres; leurs tarses sont rarement allongés; ils ont tous quatre doigts; l'ongle du pouce el celui du doigt interne sont les plus forts.

\section{"Ils forment deux familles : les diumes et les nocturnes.}

"Les RAPACES DiuRnes ont les yeux dirigés sur les côtés, une membrane, appelée cire, couvrant la base du bec et dans laquelle sont percées les narines; trois doigts devant, un derrière, sans plumes; les deux antérieurs externes presque toujours réunis à leur base par une courte membrane. Ils ont le plumage serré, les pennes fortes, le vol puissant. Leur estomac est presque entièrement membraneux, leurs intestins peu étendus, leurs cœecums très-courts, leur sternum large el complélement ossifié pour donner aux muscles des ailes des altaches plus étendues, et leur fourchette demi-circulaire est très-écartée, pour mieux 
résister dans les abaisse ments violents de l'humérus qu'un vol rapide exige."

Les principaux genres ou sous-genres compris dans cette famille sont les vautours (fig. 866), les griffons, les faucons, les

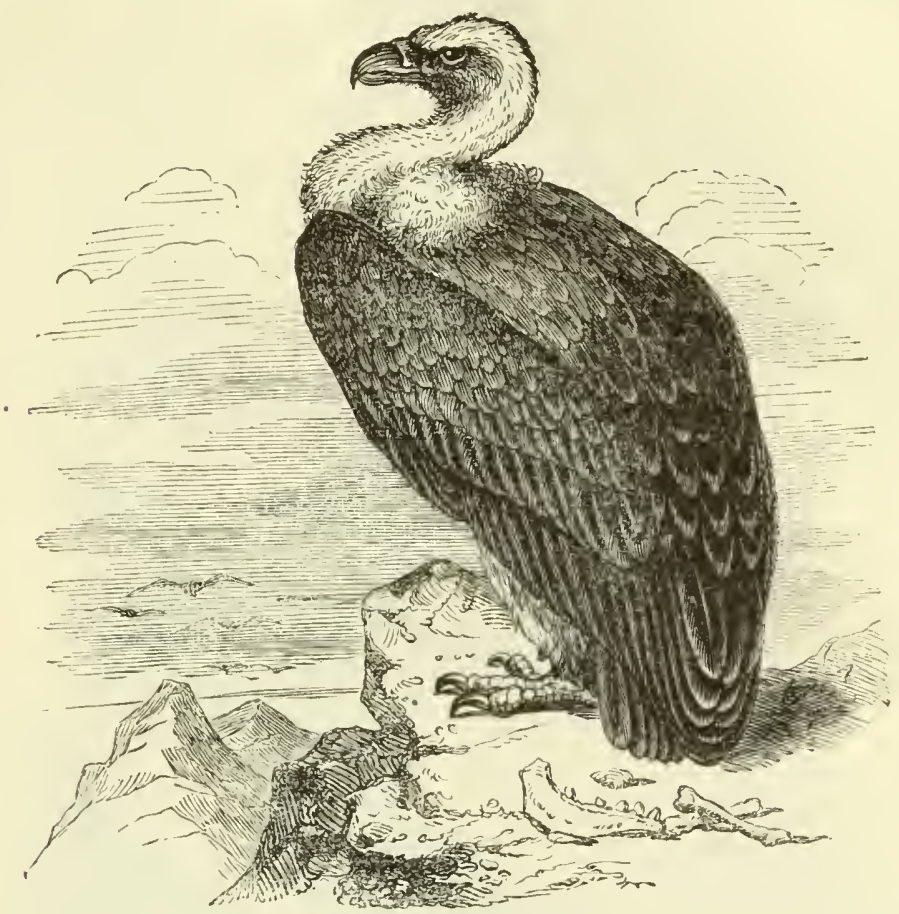

Fig. 866. - Vautour.

aigles, les harpres, les autours, les milans, les buses, les busards et les messagers ou secrétaires.

Les Rapaces nocturnes ont la tête grosse, de très-grands yeux dirigés en avant, entourés d'un cercle de plumes effilées, dont les antérieures recouvrent la cire du bec, el les postérieures l'ouverture de l'oreille. Leur énorme pupille laisse entrer tant de rayons qu'ils sont éblouis par le plein jour; aussi volent-ils surtoul pendant le crépuscule et le clair de lune. Ieur crâne épais, mais d'une substance légère, a de grandes cavités qui communiquent avec l'oreille et renforcent probablement le sens de l'ouie; mais l'appareil relatif au vol n'a pas une grande force; leur fourchetle est peu résistante; leurs plumes à barbes douces, finement duvelées, ne font aucun bruit en rolant. Le doigt externe du pied se dirige à volonté en avant ou en arrière. Leur gésier est assez musculeux, quoique leur proie soit tout animale, consistant en souris, petits oiseaux et insectes; il est précédé d'un grand jabot, et leurs cœcums sont longs et élargis à leur fond. Les pelits oiseaux ont contre eux une antipathie naturelle, et se réunissent de toutes parts, pendant le jour, pour les assail- 
lir, ce qui fait qu'on les emploie pour attirer les oiseaux au piége. Les rapaces nocturnes comprennent plusieurs sous-genres nom-

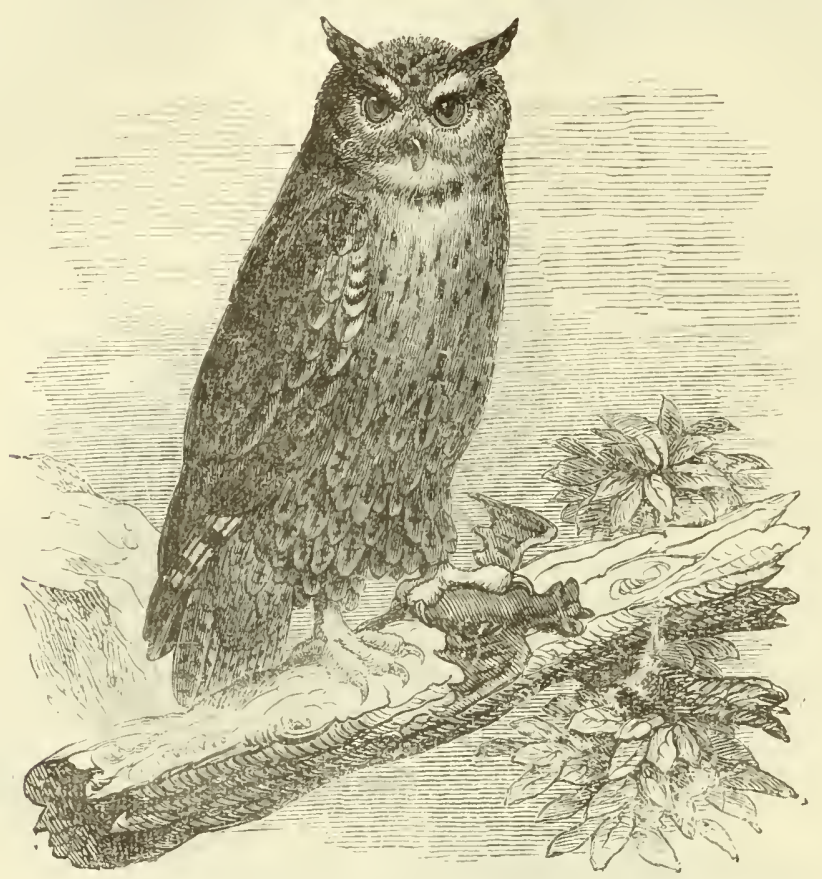

Fig. S67. - Grand-Duc.

més hiboux, chouettes, effruies, chats-huants, ducs (fig. 867), chevêches et scops.

ORDRE DES PASSEREAUX.

"II. L'ordre des PASSEREAUX est le plus nombreux de toute la classe. Son caractère semble d'abord purement négatif, car il embrasse tous les oiseaux qui ne sont ni nageurs, ni échassiers, ni grimpeurs, ni rapaces, ni gallinacés. Cependant, en les comparant, on saisit bientot entre eux une grande ressemblance de structure, et surtout des passages tellement insensibles d'un genre à l'autre, qu'il est difficile d'y établir des subdivisions.

"Ils n’ont ni la violence des oiseaux de proie, ni le régime déterminé des gallinacés ou des oiseaux d'eau; les insectes, les fruits, les grains, fournissent à leur nourriture : les grains, d'autant plus exclusivement que leur bec est plus gros; les insectes, qu'il est plus grêle. Ceux qui sont forts poursuivent même les petits oiseaux.

"Leur estomac est en forme de gésier musculeux; ils ont généralement deux très-petits cœcums; c'est parmi eux qu'on trouve les oiseaux chanteurs, et les larynx inférieurs les plus compliqués. »)

Une première division peut atre établie entre les passereaux fondée sur la disposition de leurs deux doigts externes, qui tantôt 
sont inégaux et réunis par une ou deux phalanges seulement, et tantôt sont presque égaux et réunis jusqu'à l'avant-dernière articulation. On donne à ces derniers, qui sont peu nombreux, le nom de syndactyles. Les autres ont été divisés en quatre familles, d'après la forme de leur bec, et ont reçu les noms de Dentirostres, Conirostres, Fissirostres el T'énuirostres.

On trouve dans les Dentirostres, dont le bec est échancré aux deux côtés de la pointe, les pies-grièches (pies-grièches propres, cassicans, choucaris, etc.), les gobe-mouches (tyrans, moucherolles, gobe-mouches propres, colingas, etc.), les tangaras, les merles, les martins, les loriots, les lyres, les becs-fins (rubiettes, fauvettes et rossignols, roitelets, hochequenes, etc., etc.).

Les Fissirostres sont peu nombreux, mais très-distincts par

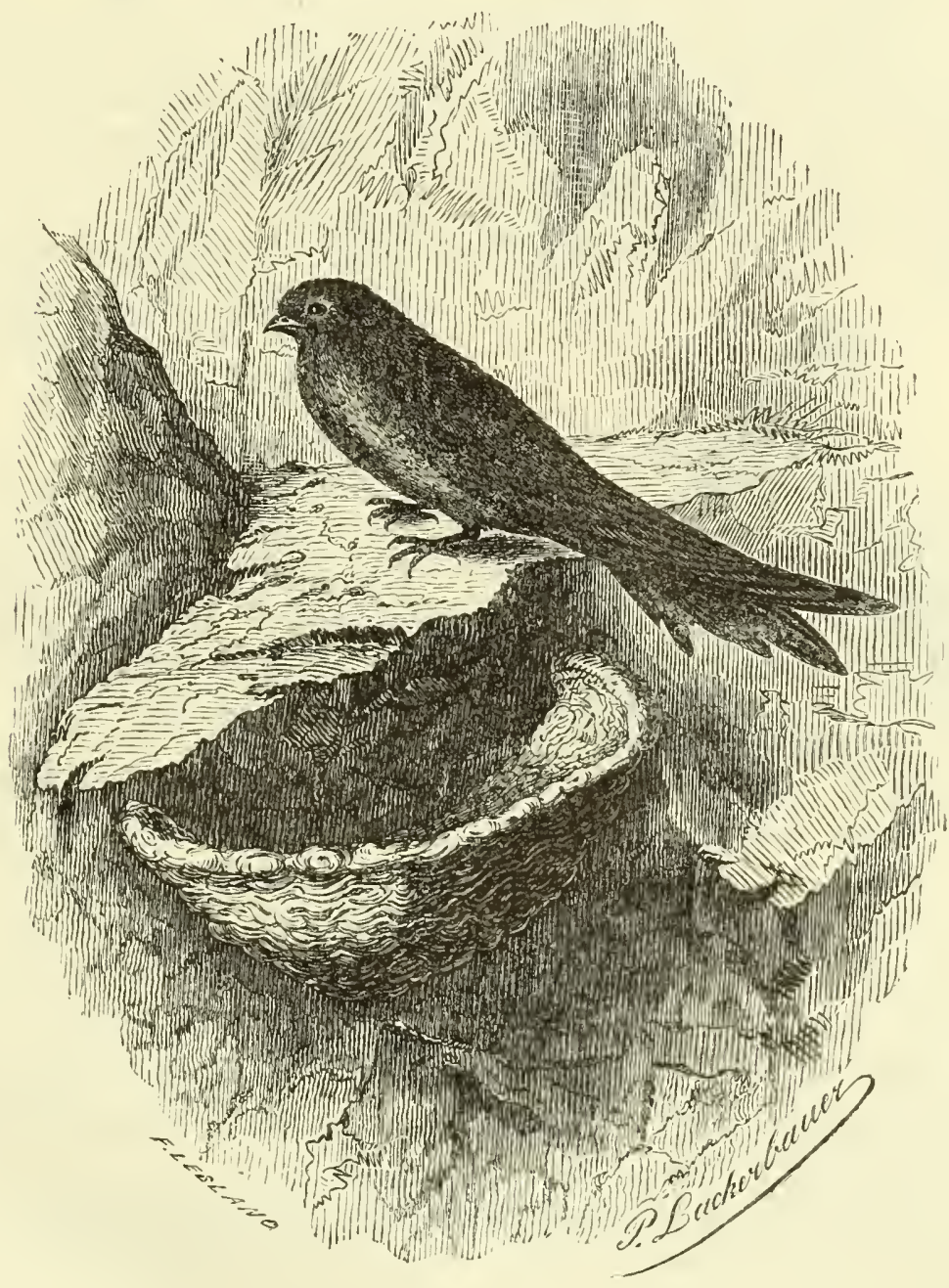

Fig. 868. - Salangane.

leur bec court, large, aplati horizontalement, légèrement crochu, sans échancrure et fendu très-profondément; en sorte que l'ou- 
verlure de leur bouche est très-large, et qu'ils engloutissent aisément les insectes qu'ils poursuivent au vol. Telles sont les hirondelles, charmants oiseaux qui nous quittent à l'automne pour aller jusqu'en Afrique chercher la nourrilure dont lit mauvaise saison les priverait chez nous, mais qui reviennent au printemps nous annoncer les beaux jours, et reprendre à nos fenêtres, sous l'abri de nos toits ou sur nos cheminées, le nid qu'ils y avaient laissé l'année précédente.

Parmi les hirondelles répandues dans les autres parties du monde, il faut remarquer la salangane ( $f g .868)$, très-petite espèce de l'Archipel indien (1), célèbre par ses nids construits à l'aide d'une substance gélatineuse très-estimée en Chine comme aliment, et dont il s'y fait un commerce considérable.

J'ai décrit ces nids précédemment (tome II, p. 3ّ̋).

Les conirostres comprennent les genres à bec fort, plus ou moins conique et sans échancrure; ils vivent d'autant plus exclusivement de grains que leur bec est plus fort et plus épais. On y trouve :

Les alouettes, les mésanges, les bruants, les moineaux (tisserins,

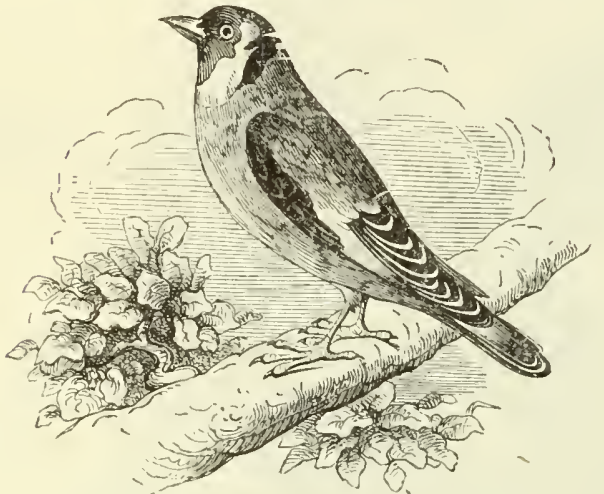

Fig. 869. - Chardonneret. moineaux francs, pinçons, linottes et chardonnerets (fig. 869), serins ou tarins, veuves, gros-becs, etc.), les bouvreuils, les becs-croisés, les cassiques, les étourneaux, les corbeaux (corbeaux propres, pies, geais, casse-noix, etc.), les rolliers, les oiseaux de paradis, etc.

Les TÉnUiRostres renferment le reste des oiseaux du premier groupe des passereaux, ceux dont le bec est grêle, allongé, tantôt droit, tantôt plus ou moins arqué, sans échancrure. Ils sont à peu près aux conirostres ce que les becs-fins sont aux autres dentirostres. On y trouve les sittelles, les grimpereaux, les colibris et les oiseaux-mouches, dont une espèce (Trochilus minimus) n'excède pas la grosseur d'une abeille, les huppes, etc.

Les Syndactyles, dernière famille des passereaux dans laquelle le doigt externe, presque aussi long que celui du milieu, lui est uni jusqu'à l'avant-dernière articulation, nous offrent les guêpiers, les martins-pêcheurs, les ceyx, les todier's et les calaos. Ces dernier's

(1) Rumphius, Amboin., VI, p. 183, tab. 75. 
sont de grands oiseaux d'Afrique et des Indes, remarquables par leur énorme bec dentelé, surmonté d'une proéminence quelquefois aussi grande qu'eux-mêmes et qui les lie aux toucans, tandis que leurs habitudes les rapprochent des corbeaux, et leurs pieds des martins-pecheurs.

ORDRE DES GRIMPEURS.

III. Le troisième ordre des oiseaux, ou les GRIMPEURS, se compose de ceux dont le doigt externe se dirige en arrière, comme le pouce, d'où il résulte pour eux un appui plus solide, que quelques genres mettent à profit pour se cramponner au trone des arbres et y grimper. Ces oiseaux nichent d'ordinaire dans les trous de vieux arbres; leur vol est médiocre; leur nourriture, comme celle des passereaux, consiste en insectes ou en fruits, selon que leur bec est plus ou moins robuste. Le sternum de la plupart des genres a deux échancrures en arrière; mais dans les perroquets il n'a qu'un trou, et souvent il est absolument plein. Les principaux genres compris dans cet ordre sont les jacumars, les pics, les torcols, les concous, les barbus, les couroucous, les toucans, les perroquets (aras, perruches, cacatoës, perroquets propres, loris, psittacules, perroquets à trompe, etc.); on y a joint deux oiseaux de genres différents nommés touraco et musophage, qui ont de l'analogie avec les gallinacés.

ORDRE DES GALLINACÉS.

"IV. GALLINACÉS. Les oiseaux de ce quatrième ordre sont ainsi nommés, à cause de leur affinité avec le coq domestique. lls ont généralement, comme lui, la mandibule supérieure voûtée, les narines percées dans un large espace membraneux de la base du bec, et recouvertes par une écaille cartilagineuse. Ils ont le port lourd, les ailes courtes, le sternum diminué par deux échancrures si larges qu'elles en occupent presque les deux côtés; la crêle en est tronquée obliquement en avant, en sorte que la pointe aiguë de la fourchette ne s'y oint que par un ligament; toutes circonstances qui, en affaiblissant les muscles pectoraux, rendent le vol difficile. Leur queue a le plus souvent 14 et quelquefois jusqu'à 18 pennes. Leur larynx inférieur est très-simple, aussi n'en est-il aucun qui chante agréablement. Ils ont an jabot trislarge et un gésier fort vigoureux. Si l'on excepte les alectors, ils pondent et couvent leurs œufs à terre, sur quelques brins de paille ou d'herbes grossièrement étalés. Chaque mâle a ordinairement plusieurs femelles, et ne se mêle point du nid ni du soin des petits, qui sont généralement nombreux, et qui, le plus souvent, sont en état de courir au sortir de l'œuf."

" Cet ordre se compose d'abord d'une famille très-naturelle (les gallinacés propres), à laquelle se rapportent spécialement les caractères précédents et qui nous fournit la plupart de nos oiseaux 
de basse-cour. Les genres qu'elle contient ont les doigts antérieurs réunis à leur base par une courte membrane, et dentelés le long de leurs bords. Pour ne pas trop multiplier les ordres, on leur a réuni la famille des pigeons, quoiqu'ils soient monogames, qu'ils aient un vol élevé, qu'ils nichent sur les arbres, que leurs doigts soient entièrement divisés, et que leur queue n'ait presque toujours que 12 pennes, tous caractères qui les rapprochent des passereaux.

"Les principaux genres admis dans la famille des gallinacés

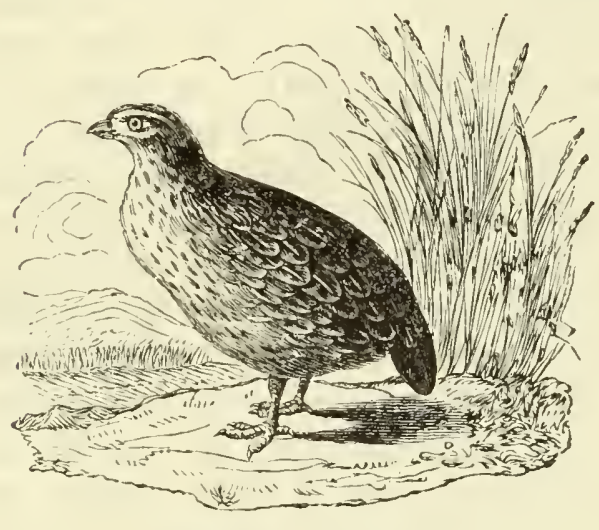

Fig. 870. - Caille. sont les alectors, les paons, les dindons, les pintades, les faisans (coq et poule ordinaires, faisans propres, tragopans, etc.), les tétras (coqs de bruyère, perdrix, cailles ( $f g$. 870), tridactyles, etc.). La famille des pigeons ne comprend qu'un genre divisé en trois sous-genres : les colombi gallines, que leur manière de vivre, leur taille, et d'autres caractères, rapprochent des gallinacés; les pigeons propres comprenant les tourterelles, et les colombars d'Afrique, à bec plus gros, solide et comprimé sur les côtés.

\section{ORDRE DES ÉCHASSIERS.}

"V. Les ÉCHASSIERS, qui forment le cinquième ordre des oiseaux, tirent leur nom de la nudité du bas de leurs jambes, et le plus souvent de la longueur de leurs tarses, deux circonstances qui leur permettent d'entrer dans l'eau jusqu'à une cerlaine profondeur, sans se mouiller les plumes, d'y marcher à gué et d'y pêcher, au moyen de leur cou et de leur bec, dont la longueur est généralement proportionnée à celle des jambes. Ceux qui ont le bec fort vivent de poissons ou de reptiles; ceux qui l'ont faible, de vers et d'insectes. Très-peu se contentent de graines et d'herbages, et ceux-là seulement vivent éloignés des eaux. Le plus souvent le doigt extérieur est uni par sa base à celui du milieu, au moyen d'une courte membrane ; quelquefois il y a deux membranes semblables; d'autrefois elles manquent entièrement, et les doigts sont tout à fait séparés; il arrive aussi, mais rarement, qu'ils sont palmés jusqu'au bout; le pouce enfin manque à plusieurs genres, toutes circonstances qui influent sur leur genre de vie. Presque tous ces oiseaux, si l'on excepte les autruches et les casoars, ont les ailes longues et volent bien. Ils étendent leur's jambes en arrière, lorsqu'ils volent, au contraire des autres oiseaux, quiles reploient sous le ven- 
tre. On établit dans cet ordre cinq principales familles et quelques genres isolés. ")

Les BRÉVIPENNEs, qui forment la première famille, quoique semblables, en général, aux autres échassiers, en diffèrent beaucoup par la brièveté de leurs ailes qui leur ôte la faculté de voler; mais leurs extrémités postérieures ont acquis en force ce que les ailes ont perdu; aucun d'eux n'a de pouce; leur bec et leur régime leur donnent d'ailleurs de nombreux rapports avec les gallinacés. On en a fait deux genres, les autruches et les casoars.

Les autruches ont les ailes revêtues de plumes lâches et flexibles encore assez longues pour accélérer leur course. On connaît l'élégance des panaches formés de ces plumes à tige mince, dont les barbes, quoique garnies de barbules, ne s'accrochent point ensemble, comme celles de la plupart des oiseaux. Leur bec est déprimé horizontalement, de longueur médiocre, mousse au bout; leur cil est grand, et les paupières sont garnies de cils. Leurs jambes et leurs tarses sont très-élevés, munis de muscles d'une grande force, qui lui permettent de dépasser tous les autres animaux à la course, et, lorsqu'on les poursuit, elles savent lancer des pierres en arrière, avec beaucoup de vigueur. Elles vivent d'herbages et de graines, mais ont un goût si obtus, qu'elles avalent à peu près indifféremment des cailloux, des morceaux de fer, etc. Elles ont un énorme jabot, un ventricule considérable entre le jabot et le gésier, des intestins volumineux, de longs cœcums, et un vaste réceptacle où l'urine s'accumule comme dans une vessie: aussi sont-elles les seuls oiseaux qui urinent. Leur verge est très-grande et se montre souvent au dehors. On en connaît deux espèces, dont une (Struthio Camelus, L.) habite les déserts sablonneux de l'Afrique et de l'Arabie, et atteint 2 à 3 mètres de hauteur; elle n'a que deux doigts à chaque pied, et le doigt externe, plus court de moitié que l'autre, manque d'ongle. Elle vit en grandes troupes, pond des œufs qui pèsent jusqu'à 1,500 grammes, qu'elle se borne à exposer dans le sable, à la chaleur du soleil, dans les pays les plus chauds, mais qu'elle couve sous la latitude des tropiques, et qu'elle soigne et défend partout avec courage. L'autruche d'Amérique (Struthio Rhea, L.) est de moitié plus petite, a les plumes moins fournies, d'un gris uniforme, et trois doigts à chaque pied, tous munis d'ongle. On n'emploie ses plumes que pour faire des plumeaux.

Les casoars ont les ailes plus courtes que les autruches, et totalement inutiles pour la course; leurs pieds ont trois doigts 
tous munis d'ongles; leurs plumes ont des barbes si peu garnies de barbules qu'elles ressemblent, de loin, à des poils ou à des crins tombants. On en connaît deux espèces, le casoar à casque ou Emeu (Casarius-Emu L.), qui habite le grand archipel Indien, et le casoar à tête nue (Casarius Novoe Hollandice Lab.), qui est propre à l'Australie.

La famille des pressirostres comprend des genres à hautes jambes, sans pouce, ou dont le pouce est trop court pour toucher le sol; le bec est médiocre, assez fort pour percer la terre et y chercher des vers. Les espèces qui l'ont le plus faible parcourent les prairies et les terres fraîchement labourées pour y recueillir cette nourriture; celles qui l'ont plus fort mangent en même temps des grains et des herbes. Les genres de cette famille sont les outardes, les pluviers, les vanneaux, les huîtriers, les courevite et les cariama.

La troisième famille, ou celle des cultrinostres, se reconnait à son bec gros, long et fort, le plus souvent même tranchant et pointu; dans un grand nombre d'espèces le mâle a la trachée diversement repliée; les cœcums sont courts, et même les hérons proprement dits n'en ont qu'un. Linné avait réuni tous ces oiseaux dans son genre Ardea, mais on en forme aujourd'hui trois tribus et dix genres qui sont les grues (agamis, numidiques, grues propres, courlans et caurales), les savacous, les hérons (crabiers, onorés, aigrettes, butors et bihoreaux), les cigognes, les jabirus, les ombrettes, les becs-ouverts, les dromes, les tantales et les spatules.

La famille des longriostres, qui vient ensuite, est caractérisée par un bec grêle, long et faible, qui ne leur permet guère que de fouiller dans la vase pour y chercher des vers et de petits insectes. Tous ont à peu près les mêmes formes, les mêmes habitudes, et souvent même presque les mêmes distributions de couleurs, ce qui les rend très-difliciles à distinguer entre eux. A l'exception des avocettes, dont le bec effilé est fortement courbé en haut, dont le pouce est beaucoup trop court pour toucher à terre, et dont les autres doigts sont palmés presque juscu'au bout, tous les autres peuvent être rangés dans le seul genre bécasse (Scalopax), qui renferme les oiseaux nommés ibis, courlis, bécasses propres, barges, maubèches, alouettes de mer, cocorlis, combattants, tourne-pierres, chevaliers, échasses, etc.

La dernière famille des échassiers, celle des MaCRODactyles, a les doigts des pieds fort longs et propres à marcher sur les herbes des marais et même à nager; cependant il n'y a pas de membranes entre leurs doigts. Le bec, plus ou moins comprimé sur les côtés, s'allonge ou se raccourcit selon les genres, sans arriver 
jamais à la minceur ni à la faiblesse de celui de la famille précédente. Le corps de ces oiseaux est aussi singulièrement comprimé, conformation déterminée par l'étroitesse du sternum; leurs ailes sont médiocres ou courtes, et leur vol faible. Ils ont tous un pouce assez long. Les principaux genres de cette famille sont les jacanas, les râles et les foulques comprenant les poules d'eau, les poules sultanes, les foulques propres, etc. On place à la suite les vaginales, les glaréoles et les flamants.

ORDRE DES PALMIPÈDES.

VI. Les PALMIPÉDES, qui forment le sixième el dernier ordre des oiseaux, ont les pieds complétement faits pour la natation, c'est-à-dire implantés à l'arrière du corps, portés sur des tarses courts et comprimés, et palmés entre les doigts. Ils sont pourvus d'un plumage serré, lustré, imbibé d'un suc huileux qui les garantit de l'eau sur laquelle ils vivent. Ce sont aussi les seuls oiseaux où le cou dépasse, et quelquefois de beaucoup, la longueur des pieds, ce qui leur permet de chercher leur nourriture au fond de l'eau, tout en nageant à sa surface. Leur sternum est très-long, propre a garantir la plus grande partie de leurs viscères, et n'ayant de chaque coté qu'une échancrure ou un trou ovale garni de membranes. Ils ont généralement le gésier musculeux, les cœcums longs, et le larynx inférieur simple. Cet ordre se laisse assez nettement diviser en quatre familles, qui sont celles des plongeurs, des longipennes, des totipalmes et des lamellirostres.

Les pLONGEURS ont les jambes implantées plus en arrière que tous les autres oiseaux, ce qui leur rend la marche pénible et les oblige à se tenir sur terre dans une position verticale. La plupart d'ailleurs sont mauvais voiliers, et plusieurs même ne peuvent pas voler du tout, ce qui les force à vivre presque dans l'eau : aussi leur plumage est-il des plus serrés et à surface lisse et lus trée. Ils nagent sous l'eau en s'aidant de leurs ailes presque comme des nageoires. Leur gésier est assez musculeux et leurs cœcums médiocres. On en forme trois genres: les plongeons, les pingouins et les manchots.

Les LONGIPENNES OU GRANDS YOILIERS sont, au contraire, des oiseaux de haute mer, qui au moyen de leur vol étendu se sont répandus partout. Ils ont le pouce libre ou nul, les ailes très-longues, le bec sans dentelures, crochu dans les premiers genres, simplement pointu dans les autres. De même que dans les précédents, le larynx inférieur n'a qu'un muscle propre de chaque côté; leur gésier est musculeux et leurs cœcums courts. Cette lamille comprend les pétrels, les albatros, les goëlands, les hirondelles de mer et les becs-en-crseaux. 
Les totipalmes ont cela de remarquable que leur pouce est réuni avec les autres doigts dans une seule membrane, et que, malgré cette organisation qui fait de leurs pieds des rames plus parfaites, presque seuls parmi les palmipèdes, ils se perchent sur les arbres. Tous sont, bons voiliers et ont les pieds courts. On y compte les pélicans (pélicans propres, cormorans, frégates, fous), les anhingas et les paille-en-queue.

Enfin, les lamellirostres ont le bec épais, revêtu d'une peau molle plutôt que d'une véritable corne; les bords dı bec sont garnis de lames ou de petites dents; la langue estlarge, charnue, dentelée sur les bords; les ailes sont de longueur médiocre. Ils vivent plus sur les eaux douces que sur la mer. Dans le plus grand nombre, la trachée-artère du mâle est renflée près de sa bifurcation en capsule de diverses formes. Leur gésier est grand, très-musculeux, leurs cœcums longs. Ces oiseaux ne forment pour ainsi dire qu'un seul genre, celui des canards, dans lequel se trouvent compris les cygnes, les oies, les bernaches et les canards propres, comprenant eux-mêmes les macreuses, les eiders, les souchets el les tadornes. Les harles forment un genre peu nombreux qui a le port des canards, mais dont le bec est plutôt cylindrique qu'aplati, et armé tout le long de ses bords de petites dents pointues comme celles d'une scie.

Je n'ai donné presque aucune description particulière des oiseaux, malgré la place importante qu'ils occupent dans la création, la variété et la vie qu'ils répandent dans l'immensité de l'air, les agréments qu'ils procurent à l'homme par leurs mélodies ou les vives couleurs dont ils sont souvent parés. Je dois, en effet, me restreindre surtout aux êtres qui apportent quelques secours à la thérapeutique, et si un certain nombre d'oiseaux ou de leurs produits ont autrefois fait partie de la matière médicale, depuis longtemps ils en ont été barinis par les progrès de la science et de la raison.

Faut-il rappeler d'ailleur's que dans nos temps d'égalité et de recherche du bien-être général, où les etres ne sont plus estimés que par l'utilité réelle dont ils sont pour nous, un certain nombre d'oiseaux chasseurs dont l'usage et la possession étaient devenus l'apanage et la marque distinctive d'une caste privilégiée, ont perdu toute leur importance et ne sont plus guère cités que pour le soin que nous apportons à nous garantir de leurs déprédations. Alors aussi, l'aigle, le roi des airs, était rangé parmi les oiseaux ignolles, faute par lui d'avoir pu se plier au service des grands; tandis que les faucons, les hobereaux, l'émerillon et le gerfault, plus faibles, mais plus dociles, étaient qualifiés d'oiseaux nobles. Qui pourrait rendre aux faucons le rang qu'ils ont perdu? 
D’autres oiseaux encore, considérés au point de vue de l'homme, peuvent être regardés comme des animaux nuisibles par le dommage qu'ils causent aux poissons, dont ils dépeuplent les rivières, les lacs et les étangs : tels sont l'orfraie et le balbusard (Falco Ossifraga et Falco Halicetus, L.), le pélican et le cormoran (Pelicanus Onocrotalus et Pel. Carbo, L.), ie héron (Ardea major, L.), le cygne lui-même, qui fait l'ornement des caux tranquilles par la grâce et la majesté de son allure; tandis que les oiseaux qui se nourrissent d'animaux nuisibles méritent notre reconnaissance. C'est à ce titre que les anciens Égyptiens rendaient une espèce de culte à l'ibis a u Nil (Ibis religiosa, Cav.) et à la cigogne (Ciconia alba, Briss.), qui les délivraient des petits reptiles qui abondaient sur les bords du Nil. C'est à ce titre que plusieurs rapaces nocturnes, tels que le grand-duc (Strix Bubo, L.), le hibou (Strix Otus, L.), la chouette (Strix Aluco, L.) et l'efrraie (Strix Flammula, L.), au lieu d'être un sujet d'effroi pour les crédules habitants de nos campagnes, el d'être cloués morts à la porte des fermes, devraient être ménagés et honorés pour la destruction des rats, souris, mulots, taupes et musaraignes qui nuisent tant à l'agriculture. Les gobe-mouches, tous les becs-fins, les hirondelles, les engoulevents, les mésanges, les étourneaux, les rolliers, les pies, les coucous el beaucoup d'autres, qui vivent exclusivement d'insectes, en détruisent une immense quantité et nous en délivrent d'autant.

La mollesse et le luxe se sont emparés des plumes des oiseaux pour en faire des fourrures, de moelleux coussins ou des ornements. Le duvet de l'eider (Anas mollissima, L.) et celui du cygne, servent à faire des fourrures, des manchons et des courrepieds aussi chauds que légers. Les petites plumes qui revêtent le corps de l'oie nous procurent, par leur élasticité, des lits et des coussins où nous trouvons réunies la chaleur et la souplesse. Le peuple, pour qui les plumes de l'oie sont trop chères, les remplace par celles du canard, de la poule ou d'autres, et en retire des avantages proportionnés à ses forces moins énervées. De tous temps aussi, chez les nations sauvages, tout aussi bien que chez les plus policées, les plumes ont servi à la parure des femmes, des chefs et des guerriers; celles qui sont le plus usitées sont fournies par les autruches, les hérons-aigrettes (Ardea Garzetta alba), les paons, les faisans, les coqs, les toucans, les colibris, sans oublier les oiseaux de paradis (Paradisæa apoda, rubra etmagnifica), originaires de la Nouvelle-Guinée et des îles voisines, que les naturels fort barbares de ces contrées préparent pour en faire des panaches, en leur arrachant les pieds et les ailes; en sorte qu'on a cru pendant quelque temps, en Europe, que ces oiseaux manquaient 
réellement de membres, et vivaient toujours dans l'air, soutenus par les longues plumes deleurs flancs. Ces oiseaux vivent de fruits et principalement de ceux des muscadiers. Ils appartiennent aux passereaux conirostres.

La chair des oiseaux est en général un aliment sain et agréable. Celle des oiseaux de proie est maigre et peu agréable, mais n'a rien de malsain. En général, les oiseaux qui se nourrissent de graines, d'herbes et de fruits, sont plus faciles à digérer que ceux qui vivent d'insectes, de chair ou de poisson. Les oiseaux le plus en usage sur les tables, en Europe, sont l'oie, le canard, la macreuse, la sarcelle, la pintade, le faisan, la poule et le coq, le coq de bruyère, la gelinotte, la perdrix, la caille, le pigeon, l'ourdeat, le pluvier, le vanneau, la bécasse, la ponle d'eau, l'alouette, l'ortolan, la grive, etc. Les paysans mangent volontiers le paon, la pie, le geai et tous les petits oiseaux.

Les œufs de presque tous les oiseaux seraient une bonne nourriture si nous étions maîtres de les avoir à temps en notre possession; la difficulté de se les procurer est cause que nous n'employons guère que ceux de poule, dont la fécondité est si grande qu'elle nous en donne assez pour satisfaire à nos besoins et à la propagation de son espèce. Les œufs de poule sont le premier aliment que les médecins permettent aux convalescents, un de ceux qu'ils conseillent aux personnes faibles, dont l'estomac digère mal la viande et les mets ordinaires; ils conviennent également aux hommes en état de santé.

Le coq et la poule sont soumis depuis si longtemps à l'empire de l'homme, qu'on ignore le lieu de leur origine. On présume cependant qu'ils descendent d'une espèce sauvage trouvée à Java par Lechenault et nommée Gallus Bankiva. La domesticité en a produit un grand nombre de variétés. Le coq est assez connu par sa fierté, son courage, ses amours et ses combats; la poule par sa patience, sa vigilance et sa tendre sollicitude pour ses petits. Le chapon, objet des mépris de l'un et de l'autre, est recherché sur nos tables, à cause de la succulence de sa chair. Une poule produit communément plus de cinquante œufs par an; après en avoir pondı un certain nombre, au printemps, elle éprouve le besoin de couver et le manifeste par un cri particulier. L'incubation dure vingt et un jours, pendant lesquels les organes se forment et se développent successivement; car il n'est pas vrai, comme on le supposait autrefois, que le poulel existe en miniature, avec tous ses organes, dans le germe placé sur l'un des points de la surface jaune (1); il est certain, au contraire, que

(1) Cette observation s'étend au germe de tous les animaux. 
ce germe ne présente d'abord, aux plus forts grossissements, qu'une ligne médiane blanchâtre, arrondie au sommet, qui marque la place où se développera le cordon cérébro-spinal ( $f g .871)$. Vers la dix-huitième heure de l'incubation, le germe se dessine

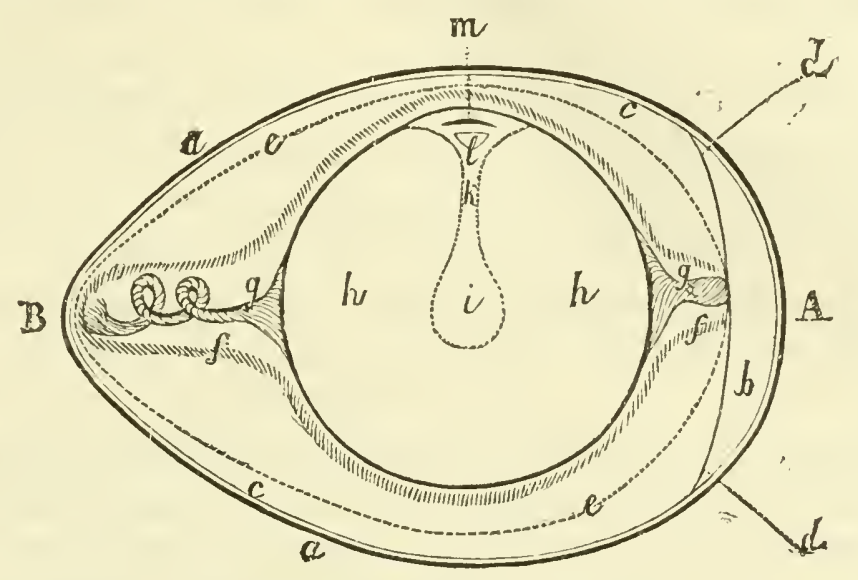

Fig. 871. - Coupe idéale de l'œuf de poule d'après Baer $\left(^{*}\right)$.

davantage et prend à peu près la forme d'un fer de lance, arrondi à l'extrémité antérieure, vers laquelle se forme un pli transversal qui est le premier indice de la séparation de la tête et du tronc; vers la vingt-quatrième heure, on voit apparaitre, le long de la ligne médiane, trois paires de points arrondis, qui sont les premiers rudiments des vertèbres, dont le nombre augmente ensuite rapidement. Vers la vingt-septième heure, apparaît le premier vestige de l'oreillette gauche du cœur; vers la trentesixième heure l'oreillette devient distincte du ventricule, et le cœur commence à battre: alors aussi on commence à apercevoir les yeux, puis l'extrémité pointue qui correspond au bec, ensuite les premiers vestiges des membres supérieurs, enfin successivement tous les autres. Lorsque le petit poulet est prêt à naître, il brise sa coquille et peut presque immédiatement chercher sa nourriture.

L'œuf de poule, considéré en lui-même, est un corps d'une forme elliptique, rétrécie à une extrémité, ce qui constitue proprement la forme ovale. Il est composé d'abord d'une coquille blanche et dure, de nature calcaire, sous laquelle s'étend une membrane mince, opaque, assez consistante, qui enveloppe deux liquides albumineux de viscosité différente, et des ligaments visqueux destinés à suspendre le jaune au centre de l'œuf, et dis-

(*) A, gros bout; B, petit bout de l'œuf; $a$, coquille; $b$, chambre à äir; $c c$, membrane extérieure du blanc; $d d$, limites du blanc du côté de la chambre à air; ef, matière albumineuse enveloppant le vitellus; $g h$, chalazes; $h$, vitellus; $i$, latebra; $l$, vésicule germinative; $m$, cicatricule. 
posés de telle manière que la partie du jaune où se trouve la cicatrice est toujours tournée vers le haut et reçoit directement la chaleur de la mère, pendant l'incubation.

La coquille de l'œul' est composée, d'après l'analyse qu'en a faite Vauquelin (1), de carbonate de chaux, qui en fait la plus grande partie, de carbonate de magnésie, de phosphate de chaux, d'oxyde de fer, et d'une matière animale probablement de la nature du mucus, qui sert de liant à ces parties. Pour l'usage de la pharmacie, on lave les coquilles d'œufs, on les prive le plus exactement possible de leur pellicule intérieure, et on les fait sécher, pour ensuite les pulvériser et les tamiser; enfin on les broie sur le porphyre à l'aide de l'eau, et l'on en fait des trochisques.

La pellicule de l'œuf est composée d'albumine coagulée, et probablement aussi d'un peu des principes fixes qui se trouvent dans la coquille. On luiattribuait autrefois la propriété de guérir la fièvre intermittente, étant appliquée sur le bout du petit doigt au commencement de l'accès. La fièvre ne guérissait pas; mais il paraît, d'après Lemery, qu'il en résultait une douleur assez vive, dont les causes et les effets pourraient être examinés de nouveau.

Le blanc d'œuf est composé, d'après les expériences de Bostock, d'albumine 15,5 ; mucus 4,5 ; eau contenant quelques sels de soude, 80,0 : total, 100,0. M. Couerbe, en abandonnant pendant un mois le blanc d'œuf à une température de $0^{\circ}$ à 8 degrés, en a extrait un réseau membraneux non azoté, et qui diffère par conséquent de l'alburnine et de la fibrine. Ce principe, qu'il a nommé Ocnin, est insoluble dans l'eau, solide, blanc, incolore, soluble dans l'acide chlorhydrique (2).

Le blanc d'œuf sert à clarifier les sirops et un grand nombre d'autres liqueurs; cet usage est fondé sur la propriété que possède l'albumine, qui en forme la majeure partie, de se coagule! par la chaleur; de sorte que, lorsqu'on mêle le blanc d'œuf, battu avec de l'eau et contenant beaucoup d'air interposé, à une liqueur en ébullition, ou près d'y entrer, les molécules albumineuses, en se solidifiant et en se contractant, forment comme un réseau qui enveloppe l'air et les impuretés de la liqueur, et les fait monter à sa surface.

La coagulation de l'albumine, par les liqueurs alcooliques et acides, et par le vin qui est un mélange des deux, opère le même effet et produit la clarification de ces liqueurs; la seule différence

(1) Vauquelin, Ann. de chim., t. LXXXI, p. 304.

(2) Couerbe, Journ. de pharm., t. XV, p. 497. 
est que la matière coagulée, au lieu d'être portée à la surface par l'ébullition, en raison de la dilatation de l'air interposé, tombe au fond du liquide clarifié.

Le jaune d'œuf contient de la vitelline, substance protéique se rapprochant de la fibrine par sa composition, de l'huile et une matière visqueuse brune, de nature complexe, qui se trouvent intimement mêlées à la première. [L'huile se compose d'oléine, de margarine, d'une petite quantité de cholestérine et de matière colorante. La matière visqueuse est très-intéressante; elle contient à elle seule presque tout le phosphore de l'œuf : on peut en séparer une matière phosphorée particulière, et une substance analogue aux matières que l'on extrait du cerveau (1).] Lorsqu'on délaie un jaune d'œuf dans de l'eau, ses différents principes s'y divisent parfaitement et forment une liqueur jaune, émulsive, nommée lait de poule. Cette propriété du jaune d'œuf fait qu'on s'en sert comme d'intermède pour suspendre dans l'eau du camphre, des huiles ou des résines.

L'huile de jaune d'œuf est très-estimée pour la guérison des gerçures au sein. On l'obtient, soit par l'expression à chaud des jaunes d'œufs desséchés au bain-marie, soit par l'action directe de l'éther sulfurique sur les jaunes d'œufs récents (2). Cette huile est d'une belle couleur jaune, d'une saveur très-douce, peu soluble à froid dans l'alcool, soluble en toutes proportions dans l'éther. Elle est composée, indépendamment de sa matière colorante, doléine, de margarine et d'une petite quantité de stéarine et de cholestérine. Ces trois dernières substances s'en séparent en partie par le froid et lui donnent la consistance de l'huile d'olive figée.

Pour les voyages sur mer, et pour la mauvaise saison où les poules ne pondent que très-rarement, il est très-utile de pouvoir conserver les œufs dans leur état de fraîcheur. Le moyen d'y parvenir est d'obstruer d'une manière quelconque les pores de la coquille, par lesquels l'eau de l'intérieur s'évapore, et l'air de l'extérieur pénètre à l'intérieur. Un vernis résineux ou un léger enduit d'huile, de graisse ou de cire, produit ce résultat (3). On a aussi conseillé de remplir des vases de terre, lit par lit, avec des œufs et de la cendre. Il paraît même qu'on peut, en déposant simplement les ouf's produits dans le mois d'août, dans des lieux frais et obscurs, les conserver assez bien pour les livrer au com-

(1) Voir sur la composition du jaune les très-intéressantes recherches de M. Gobley (Journ. de pharm. et de chim., t. IX, 5; XI, 409 ; XII, 5. et XIX, 3'46).

(2) Henry et Guibourt, Pharmacopée raisonnée, p. 136.

(3) Voir Violette, Expériences sur la conservation des aufs (Journ. de pharm. et de chim., $4^{\mathrm{e}}$ série, $\mathbf{X}, 170$ ). 
merce, à mesure du besoin, pendant l'hiver. Mais le meilleur procédé de conservation consiste à remplir aux trois quarts d'œufs récents, dans le mois d'août, des pots en terre étroits et profonds, nommés pots de tannevanne. Chacun de ces pots peut contenir 200 wufs. On les place à la cave et on les remplit avec un lait de chaux préparé en faisant éteindre, pour chacun, environ 1 kilogramme de chaux vive dans suffisante quantité d'eau, et refroidir. On couvre chaque pot avec un couvercle de terre qui le ferme bien. La coquille des œufs ainsi conservés est beaucoup plus unie, plus compacte, et est devenue cependant manifestement moins opaque, à cause de la continuité qui s'est opérée entre ses parties. Ces œufs ne peuvent pas être couvés, la coquille n'étant plus propre à laisser pénétrer l'air dans l'intérieur. Lorsqu'on veut conserver les œufs pour les faire couver, il faut les recouvrir d'un vernis résineux à l'alcool, que l'on dissout par la même menstrue, lorsque le moment est venu de les employer.

\section{TROISIÈME CLASSE}

\section{LES REPTILES.}

" Les reptiles ont le cœur disposé de manière qu'à chaque contraction il n'envoie dans le poumon qu'une portion de sang qu'il a reçu des diverses parties du corps, et que le reste de ce fluide retourne aux parties sans avoir passé par le poumon, et sans avoir respiré.

“ Il résulte de là que l'action de l'oxygène sur le sang est moindre que dans les mammifères, et que, si la quantité de respiration de ceuxci, où tout le sang est obligé de passer par le poumon, s'exprime par l'unité, la quantité de respiration des reptiles devra s'exprimer par une fraction d'autant plus petite que la portion du sang qui se rend aux poumons, à chaque contraction du cœur, sera moindre.

"Comme c'est la respiration qui domne au sang sa chaleur, et à la fibre musculaire sa susceptibilité pour l'irritation nerveuse, les reptiles ont le sang froid et les forces musculaires moindres, en totalité, que les quadrupèdes, et, d̀ plus forte raison, que les oiseaux; et quoique plusieurs sautent et courent fort vite en certains moments, généralement leurs habitudes sont paresseuses; il n'exercent guère que les mouvements du ramper et du nager; leur digestion est excessivement lente, et, dans les pays froids ou tempérés, ils passent presque tous l'hiver en léthargie. Leur cerveau est très-petit et ne paraît pas être aussi nécessaire que dans les premières classes à l'exercice de leurs facultés animales et vitales; leurs sensations semblent moins se rap- 
porter à un centre commun; ils continuent de vivre et de montrer des mouvements volontaires, un temps très-considérable après avoir perdu le cerveau; leur chair conserve également son irritabilité longtemps après avoir été séparée du reste du corps; leur cœur bat plusieurs heures après qu'on l'a arraché, et sa perte n'empêche pas le corps de se mouvoir encore longtemps. La petitesse des vaisseaux pulmonaires permet aux reptiles de suspendre leur respiration sans arrêter le cours du sang; aussi plongent-ils plus aisément et plus longtemps que les mammifères et les oiseaux; les cellules de leurs poumons sont moins nombreuses, beaucoup plus larges, et ces organes ont quelquefois la forme de simples sacs à peine celluleux.

" Les reptiles, n'ayant pas le sang chaud, n'avaient pas besoin de téguments propres à retenir la chaleur, et ils sont couverts d'écailles.

( Les femelles ont un double ovaire et deux oviductes; les mâles de plusieurs genres ont une verge fourchue ou double.

Les reptiles sont ovipares comme les oiseaux, mais aucun ne couve ses cufs: dans quelques genres, notamment dans les couleuvres, le petit est déjà formé et assez avancé au moment où la mère fait sa ponte; dans quelques espèces, l'œuf se déchire à ce moment même, et le petit naît vivant.

Les reptiles sont actuellement distribués en quatre ordres de la maniere suivante :

I. CHÉLONIENS. Pénis simple. Cœur à trois cavités; à ventricule unique, incomplétement divisé par une cloison: cotes soudées à une carapace.

II. CROCODILIENS. Pénis simple. Ventricules du cœur presque complétement séparés en deux par une cloison. Côtes nombreuses non soudées à une carapace.

III. SAURIENS. Pénis bifide. Cœur à deux oreilleltes et à un seul ventricule. Une ou deux paires de pattes, bien développées ou simplement représentées par les rudiments de l'épaule et du bassin. Un sternum.

IV. OPHIDIENS. Pénis bifide. Cœur à un seul ventricule. Pas de membres: pas de sternum.

ORDRE DES CIIÉLONIENS.

Les reptiles qui composent ce premier ordre ont une forme tellement semblable et caractérisée, que tout le monde leur donıe, en commun, le nom de tortues, et que Liuné n'en a formé qu'un seul genre sous le nom latin Testudo. Tous ont un cœur composé de deux orcillettes el d'un ventricule à deux chambres inégales qui commuriquent ensemble. Le sang du corps entre däns l'oreillette droite; celui du poumon dans la gauche; les deux sangs se mêlent plus ou moins en passant par le ventricule.

"Ces animaux se distinguent au premier coup d'œil par le double bouclier dans lequel leur corps est renfermé, et qui ne laisse passer au dehors que la tête, le cou, la queue et les quatre pattes. 
"Le bouclier supérieur, nommé carapace, est formé par leurs côtes, au nombre de luuit paires, élargies et réunies par des sutures dentées. n'étant unies entre elles qu'avec des plaques adhérentes à la portion annulaire des vertèbres dorsales, en sorte que toutes ces parties sont privées de mobilité. Le bouclier inférieur, nommé plastron, est formé. de pièces qui représentent le sternum, et qui sont ordinairement au nombre de neuf. Un cadre composé de pieces osseuses auxquelles on a cru trouver quelque analogie avec la partie sternale ou cartilagineuse des côtes, entoure la carapace et réunit toutes les parties qui la composent. Les vertêbres du cou et de la queue sont les seules mobiles, et les deux enveloppes osseuses étant recouvertes immédiatement par la peau ou par les écailles qui la représentent, l'omoplate et tous les muscles du bras et du cou, au lieu d'être attachés sur les côtes et sur l'épine, comme dans les autres animaux, le sont par-dessous; il en est de même des os du bassin et des muscles de la cuisse, ce qui fait que la tortue peut être appelée, à cet égard, un animal retourné.

"Les poumons sont fort étendus et dans la même cavité que les autres viscères. Le thorax étant immobile dans le plus grand nombre, c'est par le jcu de la bouche que la tortue respire, en tenant les mâchoires fermées et en abaissant et élevant alternativement son os hyoïde. Le premier mouvement laisse entrer l'air par les narines; et la langue, fermant ensuite leur ouverture intérieure, le deuxième mouvement contraint cet air à pénétrer dans le poumon. »

Les tortues n'ont point de dents; leurs mâchoires sont revêtues de corne comme celles des oiseaux, excepté dans les chélides, où elles ne sont garnies que de peau; leur estomac est simple; leurs intestins sont de longueur médiocre et dépourvus du coecum. Elles ont une fort grande vessie. Le mâle a une verge simple et considérable; la femelle produit des ceufs revêtus d'une coque dure, qu'elle enfonce dans le sable, où la chaleur du soleil suffit pour les faire éclore. Les tortues. sont très-vivaces; on en a vu se mouvoir sans tête pendant plusieurs semaines. Il leur faut très-peu de nourriture, et elles peuvent passer des mois entiers sans manger.

Les torlues de Linné, ou Jes chéloniens, ont été divisés en cinq genres, qui sont: les tortues de terre, ou tortues proprement diles ; les tortues d'eau douce, ou émydes; les tortues de mer, ou chélonées; les tortues molles, ou trionyx; et les tortues à gueule, ou chélides.

Les tortues de terre, ou vraies tortues, ont la carapace bombée, loute solide et soudée par la plus grande partie de ses bords au plastron. Les jambes sont comme tronquées, à doigts fort courts et réunis de très-près jusqu'aux ongles; elles peuvent, ainsi que la tête, être retirées entièrement entre les boucliers. Les pieus de devant ont cinq ongles gros et coniques; ceux de derrière, quatre. L'espèce la plus commune en Europe est la tortue grecoue (Testudo groeca, L.). Elle vit en Grèce, en Italie, en Sardaigne ei lout aulour de la Méditerranée. Sa carapace est 
large, également bombée, à écailles relevées, granulées au centre, striées au bord, marbrées de jaune et de noir. Elle atteint rarement 30 centimètres de long: elle vit de feuilles, de fruits, d'insecles, d'escargots et de vers; elle se creuse un trou pour y passer l'hiver, s'accouple au printemps et pond quatre ou cinq œufs semblables à ceux des pigeons. Elle se confond, sous le rapport alimentaire ou médical, avec la tortue bourbeuse et la tortue ronde; mais elle passe pour donner un bouillon préférable, et c'est elle principalement que l'on tire de Barbarie pour cet usage. Diverses parties de la tortue, telles que la bile, le sang, les œufs, la graisse, étaient autrefois préconisées contre un grand nombre de maladies. Le bouillon seul, fait avec la chair, est encore usité comme analeptique, restaurant, dépuratif, sudorifique, rafraîchissant, etc., etc. On connait un grand nombre d'espèces ou de variétés de tortues terrestres: telles sont la tortue géométrique, qui atteint à peu près la grandeur de la tortue grecque, et qui a la carapace noire et chacune de ses écailles régulièrement ornée de lignes jaunes rayonnantes, partant d'un disque de même couleur; et la tortue de I'Inde, qui a plus de un mètre de longueur, et dont la carapace, comprimée en avant, a le bord antérieur relevé au-dessous de la tête.

Les tortues d'EAu douce, ou les émydes, ont la carapace généralement plus aplatie que celle des tortues de terre; leurs doigts sont plus séparés, mobiles, terminés par des ongles plus longs, et leurs intervalles sont occupés par des membranes. On leur compte de même cinq ongles aux pieds de devant et quatre à ceux de derrière. La forme de leurs pieds accuse des habitudes plus aquatiques. Ce genre, qui est très-nombreux en espèces, a été divisé en deux sections: dans la première, le plastron est d'une seule pièce et immobile, de même que dans les tortues de terre; dans la seconde, le plastron est divisé par une charnière en deux battants, dont un seul ou tous les deux sont mobiles. Je citerai la tortue ronde et la tortue bourbeuse, comme exemples de la première section, et la tortue close, comme exemple de la seconde.

La tortue ronde, ou émyde d'Europe (Cistudo orbicularis, Flem.; Emys europoea, Dum.; Testudo europcea, Schn.), est répandue dans tout le midi et l'orient de l'Europe, jusqu'en Prusse, dans les eaux bourbeuses el les marais. Sa carapace est ovale, peu convexe, longue de 22 centimètres, large de 14; elle est assez lisse, noirâtre, toute semée de points jaunâtres disposés en rayons; elle a cinq doigts onguiculés aux pieds de devant et quatre à ceux de derrière. Elle vit dans les eaux bourbeuses et dans les marais, où elle se nourrit d'insectes, de mollusques, de petits poissons et 
d'herbes. On la vend sur quelques marchés en Allemagne, à cause de l'usage que l'on fait de sa chair, soit comme nourriture, soit pour l'usage de la médecine.

La tortue bourbeuse (Emys lutaria, Dum.; Testudo lutaria, L.) est assez commune dans les eaux marécageuses de l'Europe méridionale, et on l'élève en domesticité dans beaucoup de jardins du midi de la France, qu'elle purge de limaçons, de vers de terre et d'insectes nuisibles. Sa carapace est un peu aplatie, noirâtre, longue de 22 centimètres, large de 11 . Les plaques dorsales sont irrégulièrement sillonnées et faiblement pointillées dans le centre. La plupart des individus n'ont pas d'ongle au doigt extérieur des pieds de devant. La peau du cou est nue, plissée et épaisse; celle des paltes est écaillcuse; la queue est longue et comme annelée, toujours roide et dirigée horizontalement en arrière.

L'émyde close (Emys clausa) ( $f g .872$ et 873 ) habite les marais de l'Amérique septentrionale, et principalement de la Caroline. Elle

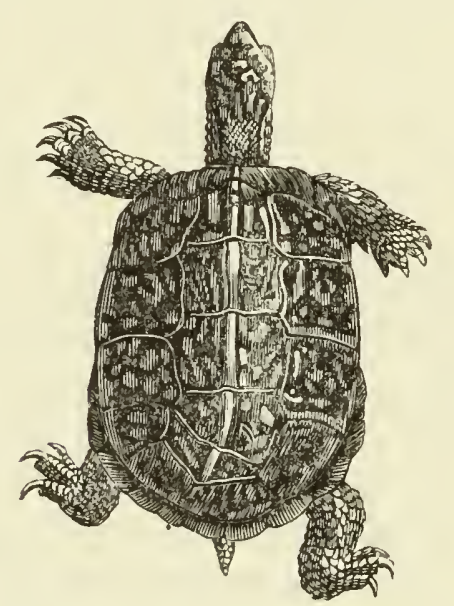

Fig. 879. - Émyde close, vue de dos.

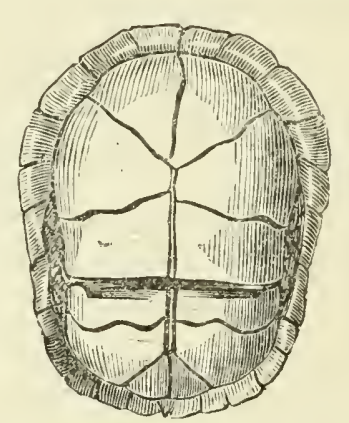

Fig. 873. - Émyde close, vue de dessous.

a la carapace très-solide, et l'on dit qu'elle peut supporter un poids de 500 livres sans cesser de marcher; mais il y a probablement erreur ou exagération dans le fait, car l'animal n'a guère que 16 à 19 centimètres de longueur. Il a les doigts presque palmés, cinq ongles aux pieds de devant, quatre seulement à ceux de derrière; la carapace brune, marbrée de jaune fortement carénée. Le plastron est divisé en deux parties, dont l'antérieure seule est mobile, et peut être serrée avec assez de force contre la carapace pour étouffer les serpents, dont l'animal se nourrit en partie.

Les TORTUES DE MER, ou CHÉLONÉEs, ont leur enveloppe trop petite pour recevoir leur tête et leurs pieds, qui sont très-allongés (surtout ceux de devant), aplatis en nageoires, et dont tous les doigts sont réunis et enveloppés dans une même membrane. Les 
deux premiers doigts de chaque pied ont seuls des ongles pointus, les autres sont terminés par des lames écailleuses aplaties. Les pièces de leur plastron ne forment pas une plaque continue, mais sont dentelées et laissent entre elles de grands intervalles occupés par du cartilage. La queue est fort courte, conique, obtuse, couverte d'écailles; l'œsophage est armé de pointes cartilagineuses dirigées vers l'estomac. Elles se nourrissent de plantes marines et de mollusques. L'espèce la plus commune est la tortue franche, ou tortue verte'(Chelonia viridis, Schneid.), qui surpasse toutes les autres par la grandeur de sa taille et par son poids, car elle a souvent plus de 2 mètres de long, et elle pèse de $3 \check{0} 0$ à 400 kilogrammes. Sa carapace est formée d'écailles verdâtres, ni imbriquées, ni carénées, dont celles du milieu figurent à peu près des hexagones réguliers. Sa chair fournit un aliment précieux et salutaire aux navigateurs, dans tous les parages de la zone torride, et leur graisse, qui est liquide et très-abondante, sert d'huile à brûler. Cette tortue paît en grandes troupes les algues au fond de la mer et vient rarement à terre. L'accouplement a lieu dans la mer, et dure, d'après Catesby, plus de quatorze jours. Les femelles viennent faire leur ponte sur le rivage et déposent leurs œufs, en nombre considérable, dans un trou creusé dans le sable, au-dessus de la ligne de la plus haute marée. C'est alors qu'on s'en empare facilement en les renversant sur le dos. Les œufs sont ronds, volumineux, enveloppés d'une membrane molle, semblable à du parchemin mouillé; ils sont très-bons à manger. L'écaille est peu estimée et n'est pas employéc.

Une autre espèce non moins importante est le caret (Chelonia imbricata, Brongn.; Testudo imbricata, L.), quoiqu'il soit moins grand que la tortue franche (il pèse rarement plus de 100 kilogrammes), et que sa chair soit désagréable et malsaine; mais ses œufs sont très-bons à manger, et sa carapace fournit la plus belle écaille dont on se sert, de temps immémorial, pour fabriquer des coffrets, des étuis, des peignes, des manches de couteaux, des garnitures de meubles, etc. Le caret a le museau plus allongé que la tortue franche, les deux mâchoires dentelées, les écailles du dos lisses et se recouvrant par leur bord postérieur comme les tuiles d'un toit. Ces écailles sont transparentes, brunes-noirâtres, avec des taches irrégulières, blondes ou roussâtres. On les détache de la carapace en mettant du feu par dessous; elles se soulèvent d'elles-mêmes. Elles peuvent prendre le plus beau poli, et on leur donne la forme que l'on veut en les soumettant à la presse, entre des moules, dans l'eau chaude. On peut même en fondre les fragments et les rognures, de manière à en former de 
l'écaille fondue, que l'on emploie aux mêmes usages que la naturelle, mais qui est moins belle, non transparente, et difficile à polir.

Le caret se trouve principalement dans l'océan Atlantique, proche des côtes de l'Amérique, et dans tout le golfe du Mexique. On le rencontre aussi sur les côtes de Guinée et dans la mer des Indes.

ORDRE DES CROCODILLENS.

Les CROCODILIENS sont de grands et puissants reptiles qui habitent les parties les plus chaudes de l'ancien et du nouveau continent, et se tiennent d'ordinaire dans les fleuves el les lacs d'eau douce. Ils sont très-carnassiers et redoutables, même pour l'homme. Ils ont les mâchoires armées d'un seul rang de dents fortes et pointues, une langue plate et charnue, la queue aplatie sur les côtés, cinq doigts plus ou moins palmés aux pieds de devant, quatre aux pieds de derrière, sur lesquels les trois internes de chaque pied sont seuls armés d'ongles. Le dos et la queue sont couverts d'écailles carrées très-fortes et sulmontées d'une pointe conique ou d'une arête au milieu. Les poumons ne s'enfoncent pas dans l'abdomen, ce qui, joint à leur cœur divisé en trois loges, et où le sang qui vient du poumon ne se mêle pas avec celui du corps aussi complétement que dans les autres reptiles, rapproche un peu plus les crocodiliens des quadrupèdes à sang chaud (1). Leurs œufs sont durs, de la grossêur des œufs d'oie; les femelles le: surveillent et soignent leurs petits pendant quelques mois après leur naissance. Les crocodiliens se divisent en trois sous-genres : les gavials, qui ont le museau très-allongé et les dents à peu près égales; les crocodiles, qui ont le museau oblong et déprimé et les dents inégales ; enfin les caimans, qui ont le museau large et obtus, les dents inégales, et dont les quatriemes d'en bas entrent dans les trous et non dans des échancrures de la mâchoire supérieure.

ORDRE DES SAURIENS.

Cet ordre comprend les lacertiens, les iguaniens, İes caméléoniens, les scincoidiens et les orvets.

Les Lacertiens ont une langue mince, extensible et terminée en deux filets comme celle des couleuvres; leur corps est allongé, leur marche rapide; tous leurs pieds ont cinq doigts armés d'ongles, séparés, inégaux, surtout ceux de derrière; leurs écailles sont disposés, sous le ventre et autour de la queue, par bandes transvęrsales et parallèles. On compte parmi eux les lézards de

(1) La disposition du cœur est telle, que toute la partie postérieure du corps reçoit un mélange de sang artéricl et de sang veineux, tanclis que la tête reçoit du sang artériel pur. 
nos pays et d'assez grands sauriens des pays chauds, qui ont reçu le nom de monitors et de sauvegardes, sur l'opinion que l'on avait anciennement, qu'ils avertissaient de l'approche des crocodiles: ils sont en réalité très-utiles à l'homme, en détruisant beaucoup d'autres reptiles el en dévorant les œufs des crocodiles.

Les CAMÉLÉONIENs ne comprennent qu'un seul genre, les caméléons, animaux disgracieux, bien distincts des autres sauriens par plusieurs de leurs caractères. Ils ont toute la peau chagrinée par de petits grains écailleux; le corps comprimé et le dos comme tranchant; la queue ronde et prenante; cinq doigts à tous les pieds, mais divisés en deux paquets opposables l'un à l'autre, l'un de deux, l'autre de trois, chaque paquet réuni par la peau jusqu'aux ongles: cette disposition des doigts, jointe à leur queue prenante, en fait des animaux grimpants destinés à vivre sur les branches d'arbres. Leur langue est charnue, cylindrique et extrêmement allongeable; les dents sont trilobées; les yeux trèsgrands, mais presque couverts par la peau, excepté un petit trou vis-à-vis de la prunelle, et mobiles indépendamment l'un de l'autre; l'occiput est relevé en pyramide; les premières côtes se joignent au sternum, les suivantes se continuent chacune à sa correspondante pour envelopper l'abdomen par un cercle entier. Leur poumon est si vaste que, lorsqu'il est gonflé, leur corps paraît comme transparent. Ils vivent d'insectes qu'ils prennent avec l'extrémité gluante de leur langue, qu’ils meuvent avec une grande vitesse. Ces animaux, déjà si singuliers, le sont encore plus par la faculté qu'ils ont de changer de couleur presque subitement, et, si l'on en croyait d'anciens écrivains, ils pourraient prendre successivement la teinte de tous les objets dontils se trouvent environnés, afin de mieux se dérober à la vue de leurs ennemis. Aussi ont-ils été pris de tout temps pour l'emblème des courtisans, des flatteurs et des revireurs politiques. Les observations des modernes, tout en dépouillant l'histoire des caméléons des fables lont on l'avait clrargée, ont en effel constaté qu'ils peuvent, sous l'impression des variations de température, de la crainte ou de la colère, éprouver des changements très-remarquables, et être tantôt blancs, tantôt jaunâtres, d'autres fois verts, rougeâtres ou presque noirs. Pendant longtemps on a attribué ces changements à la distension plus ou moins grande des poumons et à des modifications correspondantes dans la qualité du sang envoyé à la peau ; mais il faut en chercher la cause dans la structure particulière de cette membrane qui renferme plusieurs matières colorantes, dont les unes peuvent tantôt se montrer à la surface et masquer les autres, et d'autres fois se retirer en-dessous et laisser à découvert le pigment superficiel. Le caméléon le plus 
connu, est celui d'Égypte que l'on trouve bien représenté dans le Règne aninal de Cuvier (1). Celui qui est ici gravé (fig. 874) est le caméléon à nez bifide des îles Moluques.

La cinquième famille des sauriens est celle des scrncoïdiens, qui sont reconnaissables à leurs pieds très-courts, à leur langue non

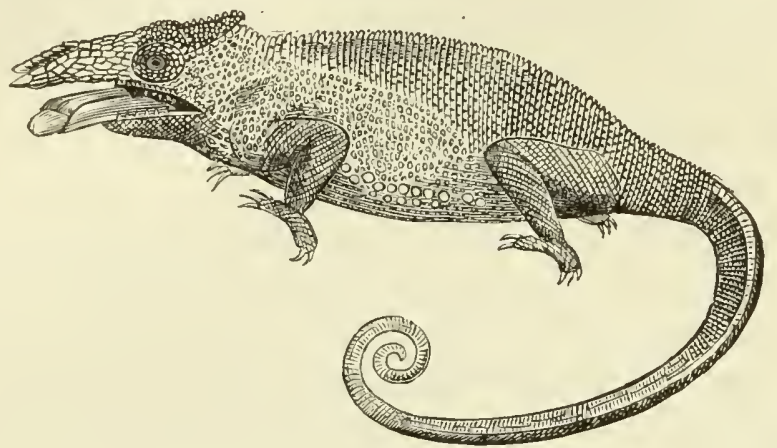

Fig. 874. - Camèléon à nez bifide.

extensible, et aux écailles égales et imbriquées qui leur couvrent tout le corps. Les uns ont la forme d'un fuseau; d'autres, cylindriques et très-allongés, ressemblent à des serpents; chez plusieurs, les pieds sont trop courts pour servir à la locomotion, et il en est même chez lesquels l'une des deux paires de membres, soit l'antérieure, soit la postérieure, manque complétement. Aussi les scincoïdiens établissent-ils un passage évident entre les sauriens et les ophidiens.

Le scinque officinal (Scincus officinalis, Schn.; Lacerta Scincus, L.) a été autrefois usité en médecine. Il habite l'Égypte, l'Abyssinie et l'Arabie. Il est long de 19 à 22 centimètres, a les

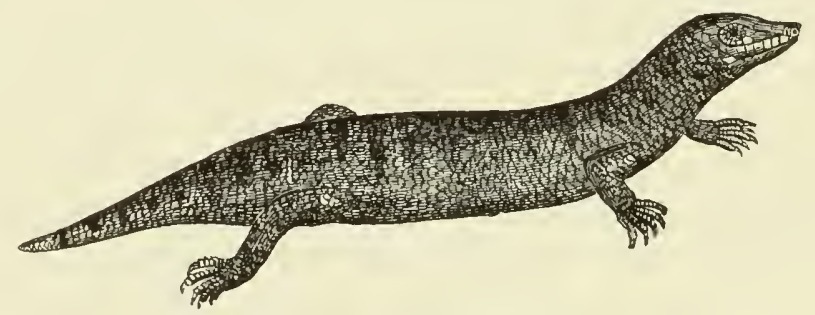

Fig. 875. - Scinque officinal.

pieds courts $(f y .875)$, la queue presque d'une venue avec le corps et plus courte que lui; le corps jaunâtre, argenté, traversé de bandes noirâtres, convert d'écailles uniformes, luisantes, disposées comme les tuiles d'un toit. Pour le conserver, on en retire les intestins que l'on remplace par des plantes aromatiques; on le fait sécher et on l'enveloppe de feuilles d'absinthe sèches.

(1) Cuvier, Règne animal, Reptiles, pl. XXI. 
C'est ainsi qu'on nous l'envoie encore quelquefois; on le croit aphrodisiaque; il entre dans l'électuaire de Mithridate.

On a vanté comme sudorifiques et antivénériens quelques autres reptiles sauriens mangés crus. Ce sont le petit anolis des Antilles ou roquet (Anolis bullaris); l'iguane (Iguana delicatissima, Latreille) (1); le lézard commun (Lacerta agilis, L.), et d'autres. Ils ne sont plus employés, du moins en France.

Les orvets, ou Anguis, se rapprochent des sauriens, et particulièrement des scincoïdiens, par leur tête osseuse, leur langue charnue et peu extensible, leur œil muni de trois paupières, et leur corps tout recouvert d'écailles imbriquées. Enfin, on trouve chez plusieurs d'entre eux les vestiges d'un bassin et des os de l'épaule. D'un autre côté, ils ressemblent aux vrais serpents par leur forme très-allongée et par la petitesse de l'un de leurs poumons. Ce sont des animaux très-doux et qui ne cherchent pas mêrne à mordre quand on les saisit. Ils vivent de mollusques terrestres et d'insectes. Nous en avons une espèce fort commune er Europe, nommée proprement orvet (Anguis fragilis, L.), qui esI jaune argenté en dessus, noirâtre en dessous, long de 3 à 40 cen. timètres. Sa queue est très-fragile, comme celle des lézards, et l'on dit même que son corps peut se rompre quand il se roidit; il fait ses petits vivants.

ORDRE DES OPHIDIENS.

Les OPHIDIENS sont des reptiles sans pieds, et par conséquent ceux de tous qui méritent le mieux la dénomination de reptiles (2); leur corps, très-allongé, se meut au moyen des replis qu'il fait sur le sol. On donne communément à tous le nom de serpents; mais ce nom s'applique plus spécialement aujourd'hui à ceux qui présentent une organisation intérieure propre, distincte à la fois de celles des sauriens et des batraciens.

Les SERPENTs sont sans sternum ni vestiges d'épaules, mais les côtes entourent encore une grande partie de la circonférence du tronc, et le corps des vertèbres s'articule encore par une facette convexe dans une facette concave de la suivante. Ils man-

(1) Ces deux genres de reptiles appartiennent à la famille des iguaniens, avec les stellions, les agames, les dragons, les basilics, etc., dont j'ai cru pouvoir me dispenser de parler. On trouve également dans les anciennes conches calcaires du globe, depuis le lias jusqu'au terrain wealdien qui a précédé la craie, les restes fossiles d'un assez grand nombre de sauriens d'une taille gigantesque.

(2) Reptile vient de reptare, ramper; ophidien est dérivé d'ôpıs, serpent; ché-

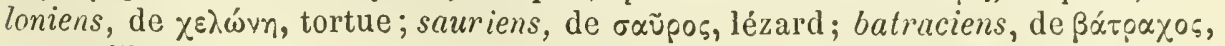
grenouille. 
quent de troisième paupière et de tympan, mais l'osselet de l'oreille existe sous la peau, et son manche passe derrière l'os tympanique.

On les divise en deux groupes : $1^{\circ}$ celui des doubles MarGieurs, qui a la mâchoire inférieure portée, comme dans tous les reptiles précédents, par un os tympanique immédiatement articulé au crâne, les deux branches de cette mâchoire soudées en avant, et celles de la mâchoire supérieure fixées au crâne et à l'os intermaxillaire. Cette disposition est cause que leur gueule ne peut se dilater comme dans la tribu suivante, que leur tête est tont d'une venue avec le reste du corps, et qu'elle se confond facilement, à la première vue, avec leur extrémité postérieure, qui est obtuse et à peu près aussi volumineuse. Cette forme leur permet de marcher également bien en avant et en arrière, ce qui leur a valu le nom de doubles marcheurs, ou d'amphisbènes (1). Les anciens leur croyaient même deux têtes. Ils ne sont pas venimeux.

"Le second groupe, ou celui des SERPENTS proprement dits, a l'os tympanique, ou pédicule de la mâchoire inférieure, mobile et presque toujours suspendu lui-même à un autre os analogue au mastoïdien ( $f g .876)$, attaché sur le crâne par des muscles et

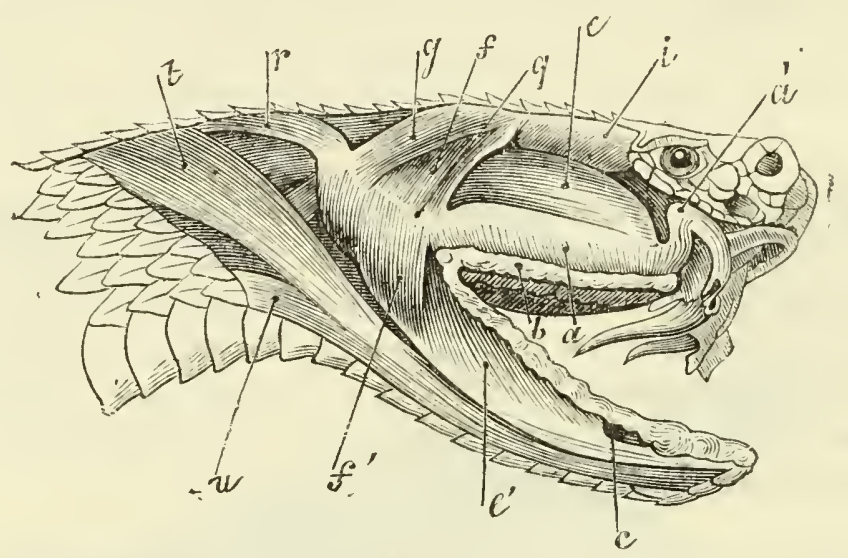

Fig. 876. - Appareil venimeux du crotale $(*)$.

des ligaments qui lui laissent de la mobilité. Les branches de cette mâchoire ne sont pas aussi unies l'une à l'autre, et celles de la mâchoire supérieure ne le sont à l'intermaxillaire, que par des ligaments, en sorte qu'elles peuvent s'écarter et donner à ces ani-

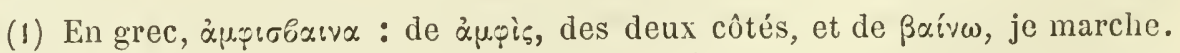

$\left(^{*}\right) a$, glande venimeuse; $a^{\prime}$ son canal excréteur ; $b$, glande sus-maxillaire; $c$, glande sousmaxillaire; $e, e^{\prime}$ temporal antérieur; $f f$, temporal postérieur; $g$, digastrique; $i$, temporal moyen; $q$, ligamentarticulo-maxillaire; $r$, muscle cervico-angulaire; $t$, vertébro-mandibulaire; $u$, costo-mandibulaire. 
maux la faculté d'ouvrir leur gueule au point d'avaler des corps plus gros qu'eux.

“ Leurs arcades palatines participent à cette mobilité, et sont armées de dents aiguës et recourbées en arrière; leur trachéeartère est très-longue; leur cœur placé fort en arrière; la plupart n'ont qu'un grand poumon avec un petit vestige d'un second.

"Ces serpents se divisent en non venimeux et venimeux, et ceuxci se subdivisent en venimeux à plusieurs dents maxillaires, et venimeux à crochets mobiles et isolés.

“ Dans les Non venimeux, les branches des deux mâchoires, ainsi que les branches palatines, sont garnies tout du long de dents fixes et non percées. Il y a donc quatre rangées de ces dents dans le dessus de la bouche, et deux dans le dessous.»

Ceux d'entre eux qui ont les os mastoïdiens compris dans le crâne, l'orbite incomplet en arrière, la languc épaisse et courte, ressemblent encore aux doubles marcheurs : ils ont été autrefois réunis avec les orvets, et portent le nom de rouleaux. Ceux des serpents non venimeux qui ont, au contraire, les mastoïdiens détachés, et dont les mâchoires peuvent beaucoup se dilater, ont l'occiput plus ou moins renflé, et la langue fourchue et très-extensible. On en fait deux groupes principaux, les boas et les couleuvres, distingués par les plaques du dessous de la queue, qui sont simples dans les premiers, doubles dans les seconds.

C'est parmi les boas qu'on trouve les plus grands de tous les serpents; car il y en a qui atteignent de 10 à 13 mètres de longueur, et qui, quoique non venimeux, sont à redouter à cause de leur force prodigieuse et de leur agilité. Tapis sous l'herbe ou suspendus par la queue aux branches des arbres, ils altendent le moment de s'élancer sur leur proie, qu'ils entourent de leurs plis et qu'ils serrent si fortement, que l'animal est bientôt étouffé et a les os broyés. Alors, après l'avoir enduit de sa bave et avoir énormément dilaté ses mâchoires et son gosier, le boa l'avale lentement. On assure qu'ils se nourrissent ainsi de chiens, de cerfs, et même de bœufs qu'ils mettent plusieurs jours à avaler. Après un repas semblable, les boas demeurent immobiles, dans un endroit écarté, jusqu'à ce que leur digestion, qui est fort longue, soit terminée. C'est alors qu'on peut les tuer avec le moins de danger.

Les couleuvres comprennent un nombre très-considérable de serpents dépourvus de crochets mobiles, venimeux, et dont les plaques de dessous la queue sont divisées par deux ou rangées par paires; on les divise en un grand nombre de groupes, sous les noms de pythons, cerbères, hétérodons, hurrias, oligodons, couleuvres propres, acrochordes, etc. Je n'en mentionnerai que deux espèces de notre pays, la couleuvre à collier et la couleuvre vipérine. 
La conlenvre à collier (Tropidonotus natrix; Colubernatrix, L.) est très-commune en France, dans les prés qui bordent des eaux, sur la lisière des bois; elle est longue de $7 a ̀$ 14 décimètres, a la tête oblongue et ovale ( $f g .877$, déprimée, couverte d'un petit nombre d'écailles (ordinairement 9) beaucoup plus grandes que celles du cou et du dos. Les écailles sont carénées, c'est-à-dire relevées d'une arête au milieu ; celles de dessus le cou sont blanchâtres ou jaunâtres, et lui forment un demi-collier qui tranche avec la couleur de deux grandes taches noires triangulaires sur la partie postérieure de la tête, et de deux taches semblables en arrière du cou. Le corps est cendré avec des taches noires sur ledos, devenant plus larges le long des flancs. Du reste, il en existe beaucoup de variétés qui diffèrent par leur couleur. Cette couleuvre, comme toutes ses congénères, vit exclusivement d'animaux vivants, tels que insectes, vers, mollusques, poissons, oiseaux, petits quadrupèdes, etc. Jamais elle ne mange de fruit dans les jardins, ni ne vient sucer le lait des vaches, comme le préjugé en a

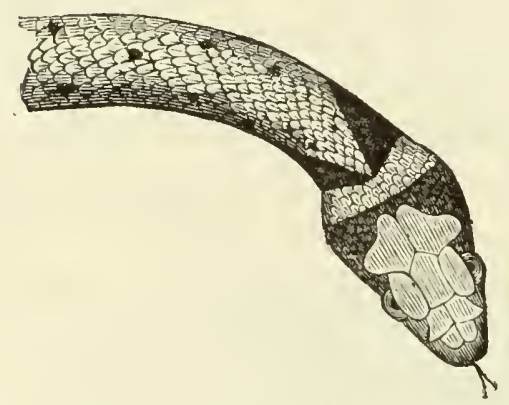

Fig. 877. - Couleurre à eollier.

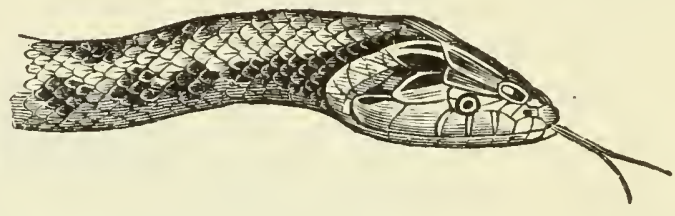

Fig. 878. - Couleuvre vipérine.

été répandu. Flle nage avec une grande facilité, et grimpe avec agilité sur les arbres pour aller surprendre les jeunes oiseaux. Elle est inoffensive pour les animaux dont elle ne peut se nourrir, ne cherche à les mordre que lorsqu'elle est très-irritée, et sat morsure n'est pas dangereuse. On peut l'élever en domesticité; on la mange dans quelques pays, et l'on en prépare des bouillons qui ont été recomnıandés contre les scrofules, les rhumatismes et les maladies de la peau. Elle pond de 15 à 40 œufs dans des trous sur le bord des eaux, dans le fumier, dans les meules de foin; ils sont ovales, gros comme le doigt, attachés en chapelet, et éclosent au milieu de l'été.

La couleuvre vipérine (Tropidonotus viperinus; Coluber viperi-. nus, Latr.) est longue seulement de 50 centimètres, d'ur gris brun avec une suite de taches noires qui forme un zigzag le long du dos, et une autre de taches plus petites sur les côtés; le ventre est tacheté en damier, de noir et de grisâtre ; les écailles sont ca- 
rénées. Cet animal habite la France et peut se rencontrer dans les environs de Paris. Il est vivipare comme la vipère, et sa grande ressemblance avec ce dangereux reptile lui a valu son nom. On peut l'en distinguer à la forme de sa tête qui, de même que celle de la couleuvre commune, est ovale-oblongue, obtuse en avant (fig. 878), couverte de grandes plaques carénées, à l'absence des crochets venimeux et à sa queue plus longue et moins brusquement rétrécie.

Le serpent d'Esculape est une espèce de couleuvre beaucoup plus grande (Callopeltis Asculapii Aldrow ; Coluber Assculapii, Shaw), qui habite l'Italie, la Hongrie et l'Illyrie. Il est brun en dessus, jaune-paille aux flancs et en dessous, à écailles du dos presque lisses. C'est lui que les anciens ont représenté dans leurs statues du dieu de la médecine.

Les serpents venineux par excellence, ou a crochets isolés, ont une structure très-parliculière dans leurs organes de manducation. Leurs os maxillaires supérieurs s ont très-petits, portés sur un long pédicule, et très-mobiles : il s'y fixe une dent aiguë, percée d'un petit canal, qui donne issue à une liqueur sécrétée par une glande considérable située sous l'œil. C'est cette liqueur qui, versée dans la plaie par la dent, porte le ravage dans le corps des animaux, et y produit des effets si funestes. Cette dent se cache dans un repli de la gencive, quand le serpent ne veut pas s'en servir, et il y a derrière elle plusieurs germes destinés à la remplacer lorsqu'elle se casse dans une plaie. L'os maxillaire supérieur ne porte pas d'autres dents, en sorte que, dans ces serpents, on ne voit, dans le haut de la bouche, que les deux rangées de dents palatines, qui sont aiguës et recourbées en arrière, conformation nécessaire pour retenir et faire avancer la proie, souvent très-volumineuse, qui pourrait s'échapper par le manque de points d'appui et de force des mâchoires (Voy. la fig. 874).

Toutes ces espèces venimeuses, dont on connaît bien la reproduction, font leurs petits vivants; on les divise en deux genres principaux, les crotales et les vipères.

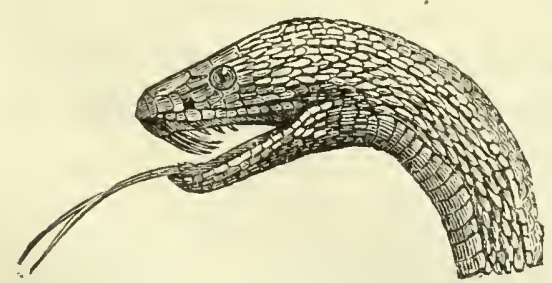

Fig. 879. - Crotale (tète).

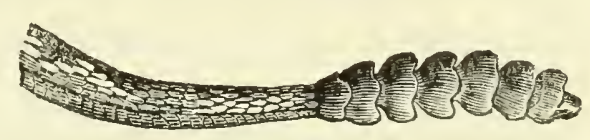

Fig. 880. - Crotale (queue).

Les crotales ( $f g .879)$ (C'rotalus) sont célèbres, entre tous les autres serpents venimeux, par l'atrocité de leur venin. Ils ont, 
comme les boas, des plaques transversales simples sous la queue, (fig. 880), qui est formée de cornets écailleux emboîtés lâchement les uns dans les autres, qui résonnent quand l'animal rampe ou quand il remue la queue. Toutes les espèces viennent d'Amérique, et sont d'autant plus dangereuses que la contrée ou la saison sont plus chaudes; mais leur naturel est en général tranquille, et ils ne mordent que 'lorsqu'ils sont provoqués ou que lil faim les y pousse.

Les trigonocéphales (Trigonocephalus) sont aussi dangereux que les crotales, et ont comme eux une petite fossette arrondie derrière chaque narine; mais ils manquent de l'appareil écailleux et sonore de la queue, dont les écailles peuvent être doubles ou simples. Le plus connu est le trigonocéphale jaune des Antilles (Trigonocephalus lanceolatus, Oppel.), qui atteint 2 mètres et plus de longueur, vit dans les champs de cannes, où il se nourrit de rats; mais il fait aussi périr beaucoup de nègres.

Les vipères ont été confondues par Linné avec les couleuvres, comme ayant les plaques ventrales simples, et celles de la queue presque toujours doubles; mais elles ont dû en être séparées à cause de leurs crochets à venin. Elles se distinguent, d'un autre côté, des crotales et des trigonocéphales, par l'absence des fossettes derrière les narines. Voici, du reste, les caractères principaux auxquels on peut les reconnaître.

Reptiles de l'ordre des ophidiens ou des serpents à mâchoires supérieures mobiles et armées de deux crochets à venin, tête raccourcie, élargie postérieurement, couverte en dessus d'écailles granulées ou de plaques; dessous de l'abdomen couvert de grandes plaques entières et transversales; queue ronde, conique, pointue, garnie en dessous d'un double rang de plaques disposées par paires. On peut les diviser en plusieurs groupes, tels que les vipères propres, les najas, les élaphs, les oplocéphales, les langahas, etc.

L'espèce la plus redoutable pour nous, parce qu'elle habite la France et toute l'Europe tempérée, est la vipère commune (Vipera Aspis, fig. 881). Lorsqu'elle a pris tout son accroissement, elle est longue de 6 contimètres et épaisse de 22 à 24 millimètres, par le milieu du corps (1); seulement la femelle est plus volumi-

(1) Voir, sur la vipère, Léon Soubeiran (De la vipère, de son venin et de sa morsure), thèse soutenue ì la Faculté de médecine de Paris en 1855. On consultera aussi avéc fruit le très-intéressant, mémoire de M. Viaud Grand-Marais (Études médicales sur les serpents de la Vendée et de la Loire-Inférieure. Nantes, 1867-69), où des caractères zoologiques des serpents de la région, les symptômes produits par la piqùre des vipères, le mode de traitement des accidents qui en résultent, sont exposés avec de précieux détails. 
neuse quand eile approche du moment de mettre au jour ses vipéranx. La vipère a la tête déprimée ou aplatie supérieurement, plus large à la partie postérieure que le cou, qui est rétréci. Elle présente à l'avant une espèce de mufle un peu retroussé, formé

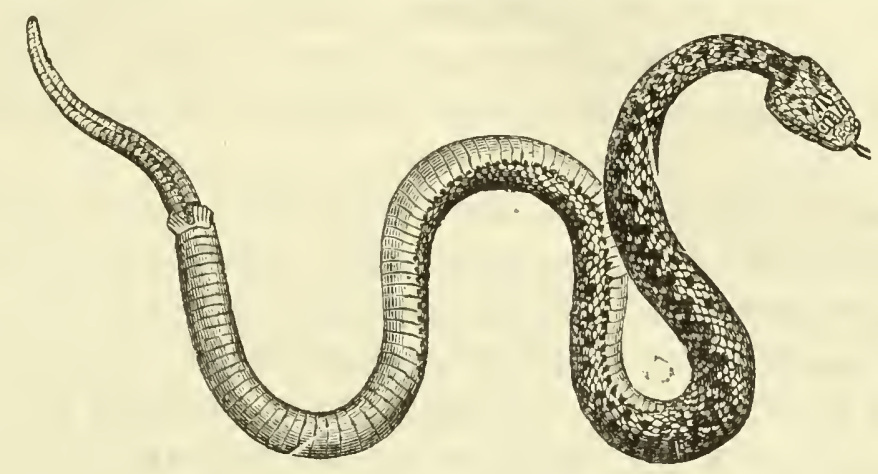

Fig. 8si. - Vipere commune.

par un repli de la peau, et elle a une forme générale trianğulaire, quoique arrondie aux angles. Elle diffère en cela de la couieuvre, qui a la tête ovoïde, non aplatie, et terminée en avant par un contour émoussé et arrondi.

La tete de la vipère $(\kappa g .882$ à 881$)$ a en tout 27 millimètres de long, 16 à 18 millimètres de large à la partie postéricure, 9 à 11 millimètres à la hauteur des yeux, et 5 à 6 millimètres seulement de
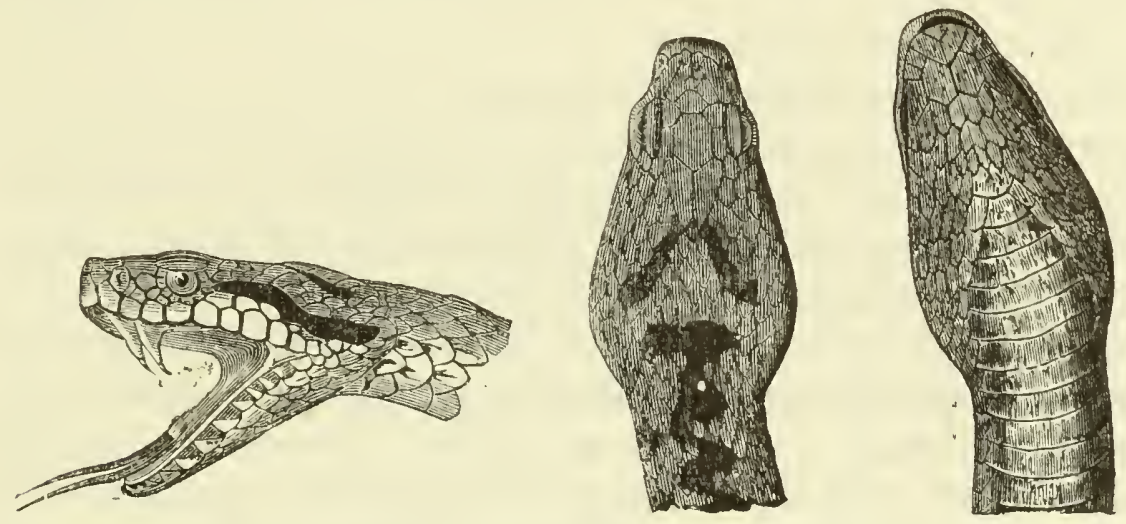

Fig. 8s2, 883 et 85 t. - Tètes de vipères.

largeur à l'extrémité du museau. Cette extrémité est couverte par six écailles un peu plus grandesque les autres, ou petites plaques, dont les latérales sont percées par les narines. Entre cette extrémité et les yeux se trouvent plusieurs rangs d'écailles ordinaires, arrondies et imbriquées, dont plusieurs sont noirâtres et forment une ou plusieurs taches en ce tendroit. Chaque æil se trouve surmonté par une plaque allongée et saillante, qui lui sert comme de sourcil, et entre ccs plaques s'en trouvent cinq autres dont celle du milieu est la plus grande; mais aucune de ces plaques 
n'est comparable pour la grandeur à celles de la couleuvre; leur nombre est plus considérable, et tout le reste de la tete est couvert de petiles écailles ovoïdes, imbriquées.

Le fond de la couleur de la vipère est variable, et il y a des vipères blanchâtres, grises, noirâtres, jaunâtres et rougeâtres; mais cette teinte générale est interrompue par des taches qui ont une certaine régularité, et qui peuvent encore servir à caractériser le reptile.

Ainsi, sur le sommet de la tête et en arrière des yeux, on trouve toujours deux taches linéaires noirâtres qui s'écartent d'avant en arrière, sous forme de $\mathrm{V}$, et qui comprennent entre elles, et plus en arrière encore, une tache ronde assez étendue, qui est la première des taches souvent disposées en zigzag que l'on observe tout le long du dos (1). Pareillement en arrière de chaque œil et sur la même ligne horizontale, se trouve une longue tache linéaire qui est la première des taches arrondics et isolées qui se trouvent tout le long des flancs. Enfin, les plaques ventrales et les plaques doubles de la queue sont d'une teinte uniforme plus ou moins foncée, mais toujours ardoisée.

Les vipères changent de peau tous les ans, an printemps et quelquefois en automne. Sous la peau écailleuse qu'elles quittent, il s'en troure une autre toute formée, qui parait d'abord bien plus belle que l'ancienne, et qui se ternit ensuite à mesure qu'il s'en forme une autre par-dessous.

Les yeux de la vipère sont très-vifs, el son regard est fixe et menaçant; sa langue est renfermée dans une gaine d'où elle sort lorsque l'animal est irrité. Alors il la darde et la retire par des mouvements successifs et très-rapides. Elle est linéaire, bifide à l'extrémité, et semble être une arme menaçante; mais elle ne pique pas et n'a rien de venimeux. Elle sert probablement à la vipère pour attraper de petits insectes, quoique sa nourriture principale consiste en mulots, taupes, lézards, grenouilles, crapauds, salamandres et jeunes oiseaux. Elle ne mange pas en captivité, et, de même que beaucoup d'autres reptiles, elle peut supporter un jeûne de plusieurs mois, et même, dit-on, de plusieurs années. Les vipères passent tout l'hiver engourdies, le plus souvent réunies en société et entrelacées les unes dans les autres, sous des pierres ou dans des troncs d'arbres cariés, où la gelée ne peut les

(1) Ces taches ne sont pas toujours disposées de la même manière sur le dos: tantôt elles forment des lignes transversales, parallèles et distinctes, comme dans la vipère de Charas, d'autres fois elles ne forment toutes ensemble qu'une ligne longitudinale ployée en zigzag, comme dans la vipère qui s'était beaucoup multipliée, il y a un certain nombre d'années, dans la forêt de Fontainebleau. On trouve aussi des vipères qui sont presque noires. 
atteindre. Elles s'accouplent au printemps et restent, pendant un temps fort long, embrassées dans une copulation dont le résultat est de vivifier de 12 à $20 ّ$ œufs, qui éclosent dans le ventre de la femelle, où le vipéreau, roulé sur lui-même, atteint la taille de 8 à 11 centimètres avant de paraître au jour.

On doit à Fontana des observations sur le venin de la vipère, contenu, ainsi que nous l'avons vu, dans deux glandes qui communiquent par ur canal avec les deux crochets mobiles de l'animal.

Ce venin a une consistance qui tient le milieu entre celles de l'huile d'olive et d'une solution de gomme arabique; il n'est ni acide, ni alcalin, et n'a pas de saveur bien marquée; il jaunit par la dessiccation et se concrète à la manière du mucus ou de l'albumine; il se conserve pendant longtemps sans altération dans la cavité de la dent, séparée ou non de l'os qui la supporte, et il est dangereux d'être blessé par les crochets d'une vipère morte.

[Le prince Lucien Bonaparte a analysé le venin de la vipère et en a isolé un principe spécial, appartenant à la catégorie des alcaloïdes, qu'il a nommé échidnine ou vipérine; cetle substance est gommeuse, neutre, soluble dans l'eau froide, précipitée par l'alcool, mais pouvant ensuite se redissoudre dans l'eau. Cette propriété la rapproche de la ptyaline : mais elle se distingue de ce dernier produit parce qu'elle est précipitée par le sulfate de sesquioxyde de fer (1).]

Le venin de la vipère est innocent pour quelques animaux, tels que la vipère elle-même, l'orvet, la sangsue et le colimaçon. Parmi les autres animaux, il n'est constamment mortel que pour ceux de petite taille, qui servent de nourriture ordinaire au reptile; un chat résiste quelquefois et un mouton échappe très-souvent à ses suites. L'homme éprouve, à la suite d'une morsure de vipère, des accidents formidables, qui se terminent souvent par la mort, à moins qu'on n'applique à temps les moyens curatifs que l'expérience a fait connaître.

Ces symptômes sont ordinairement une douleur aiguë dans la partie mordue, qui devient gonflée, luisante, rouge, chaude, violette, puis livide, froide, et comme insensible, la douleur et l'inflammation se propagent le long des gros troncs nerveux et des vaisseaux lymphatiques; les yeux rouges et ardents versent des pleurs en abondance; bientôt se manifestent des lipothymies, des nausées, de la gastralgie, de la dyspnée, de la cardialgie, des vomissements bilieux, une sueur froide et colliquative, de la tympanite, des tranchées aiguës, une vive douleur lombaire, un relâ-

(1) L. Bonaparte, Gaz. tosc. delle sc. medica-fis., p. 169, 1843. D'après Gervais et Van Beneneden, Zoologie médicale, 1859, t. I, p. 171. Voyez aussi Journal de pharmacie et de chimie, $4^{\mathrm{e}}$ série, p. 138. 
chement du sphincter de l'anus, une sorte de paralysie du col de la vessie, et par suite des selles et des évacuations d'urine involontaires. Alors aussi le pouls est petit, serré, concentré, intermittent, convulsif; la peau acquiert la pâleur jaunâtre de la cire, et un sang noir, liquide et sanieux découle de la plaie en apparence gangrenée. Si un ensemble d'accidents aussi graves n'est pas bientôt calmé par les forces de la nature ou par les secours de l'art, ils s'augmentent encore, et les parties du corps envahies par l'œdème se couvrent de phlyctènes, qui annoncent le prochain développement d'un sphacèle précurseur de la mort. La première précaution à prendre, lorsqu'un homme a été mordu par une vipère, est, lorsque la disposition des parties le permet, d'établir une ligature au-dessus de l'endroit blessé, et d'appliquer immédiatement une ventouse à pompe sur la plaie, pour en faire sortir le venin avec le sang; mais, à défaut de cet instrument, i] faut que le patient lui-même, si personne ne consent à le faire, suce la plaie avec persévérance : car cette opération est absolument sans danger pour l'opérateur, pourvu qu'il n'ait pas d'excoriation aux lèvres ou dans la bouche. La succion opérée, si bien faite qu'on le suppose, ne dispense pas de recourir ensuite à la cautérisation et à l'usage interne de l'ammoniaque, seul remède trouvé efficace; l'expérience ayant appris que la thériaque, l'orviétan, la poudre de vipère et tous les autres arcanes de l'ancienne polypharmacie, sont complétement inefficaces pour arrêter les effets du terrible venin.

Les expériences de Fontana ont démontré que le venin de la vipère, si dangereux lorsqu'il est porté dans le sang par une plaie faite à la peau, pouvait être introduit imp unément dans la bouche et dans l'estomac, pourvu que la surface de ces organes fût sans excoriations, et l'on a pu supposer que l'innocuité du poison, dans ce cas, provenait de ce qu'il était digéré, c'est-ì-dire altéré dans sa nature par l'action du. fluide digestif. Mais, indépendamment de ce que l'application inoffensive du venin de la vipère sur la conjonctive de l'œil et sur la membrane pituitaire d'une greonuille, avait antérieurement démontré que l'action du suc gastrique n'entrait pour rien dans ce phénomène, les expériences de M. Claude Bernard (1) sur le curare, poison très-analogue à celui de la vipère, paraissent démontrer que celte innocuité des venins dans l'estomac est due seulement à la propriété que possède sa membrane muqueuse de repousser ces poisons, el de les tenir en dehors de l'économie, jusqu'à ce qu'ils soient sortis de la cavité intestinale.

(1) Claude Bernard, Lecons sur les substances toxiques. Paris, 1857. 
La vipère est très-commune dans nos départements méridionaux; on la prend avec de petites pincettes de bois, et on la garde dans des tonneaux ou dans des boîtes garnies de son et percées de quelques trous. Ellle peut vivre ainsi très-longtemps sans manger, à cause du peu de mouvement qu'elle se donne alors et de la perte extrêmement petite qu'elle fait par la transpiration. Lorsqu'on veut en faire usage, on la saisit avec des pincettes près de la tête, on coupe celle-ci avec des ciseaux, et on la reçoit dans un vase rempli d'alcool, afin de la faire mourir et d'en éviter la morsure, qui serait encore dangereuse. On dépouille le corps de sa peau, on rejelte les intestins et l'on fait sécher le reste, ou bien on l'emploie récent et coupé par morceaux pour en faire des gelées ou des bouillons, auxquels on a attribué les propriétés restaurante, sudorifique, aphrodisiaque, etc., accordées également autrefois à la poudre de vipère. La vipère sèche entre dans la thériaque.

La VIPÈRe AMMOdYTe (Vipera Ammodytes) (fig. 88วั) se dislingue très-neltement des autres espèces par son museau prolongé en pointe molle. Elle habite les lieux arides et pierreux de l'Europe centrale: on la trouve en France, dans le Dauphiné.

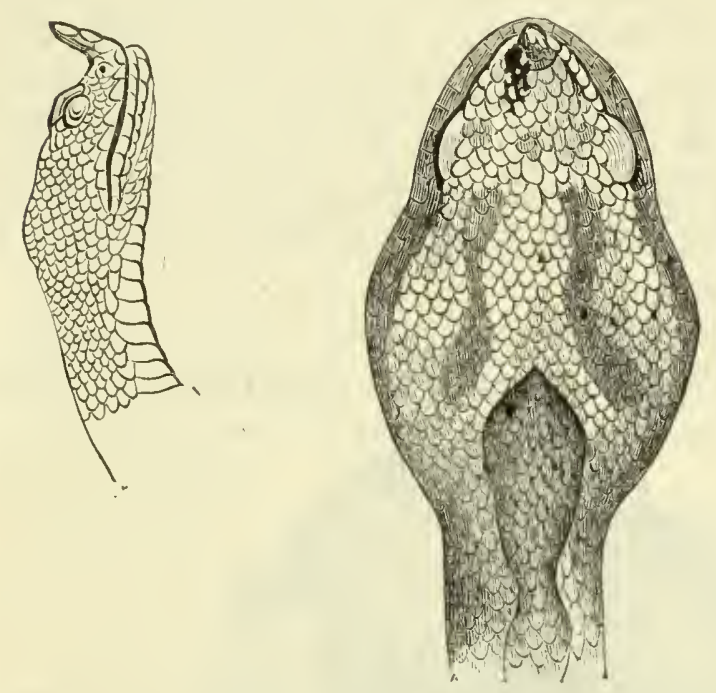

lig. 885. - Vipère ammodyte.

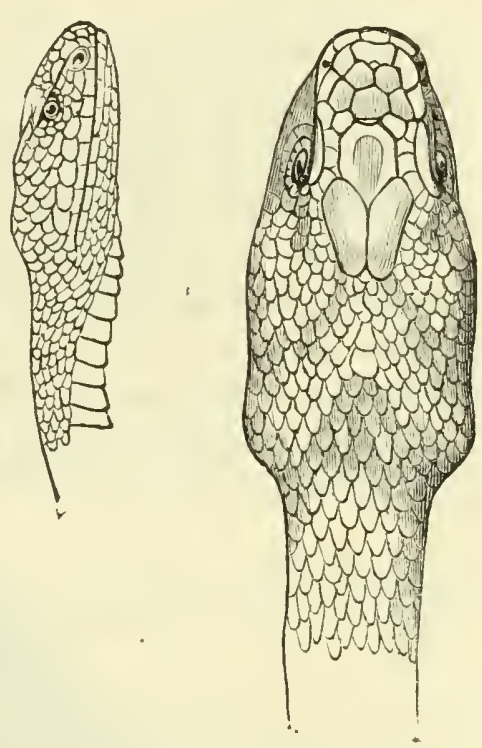

Fig. 886. - Pelias berus.

Petite vipère (Pelias Berus, Nerrem ; Vipera Chersea, L.; ( $f \mathrm{~g} .886)$. Cette vipère vit en Italie, dans les Cévennes, les Corbières, les Pyrénées, dans la France centrale, et se retrouve en Flandre, en Belgique et en Angleterre. Elle est moins grande que la vipère commune: sa longueur est de 58 à 60 centimètres; sa couleur est brunâtre ou roussâtre, et sa tête ovale triangulaire recouverte d'é- 
cailles granuliformes, au centre desquelles se trouvent, entre le: yeux, trois plaques rapprochées en triangle.

Les NAJAS sont des serpents venimeux très-rapprochés des vipères, par la disposilion de leurs plaques ventrales et caudales; mais qui peuvent redresser en avant leurs côtes antérieures, de manière à dilater cette partie du tronc en un disque plus ou moins large. L'espèce la plus célèbre est le naja de l'Inde, serpent à lunettes, ou Cobra capello des Portugais (Naja tripudians, Merrem.; Coluber Naja, L.; fig. 887). Ce serpent est ainsi nommé

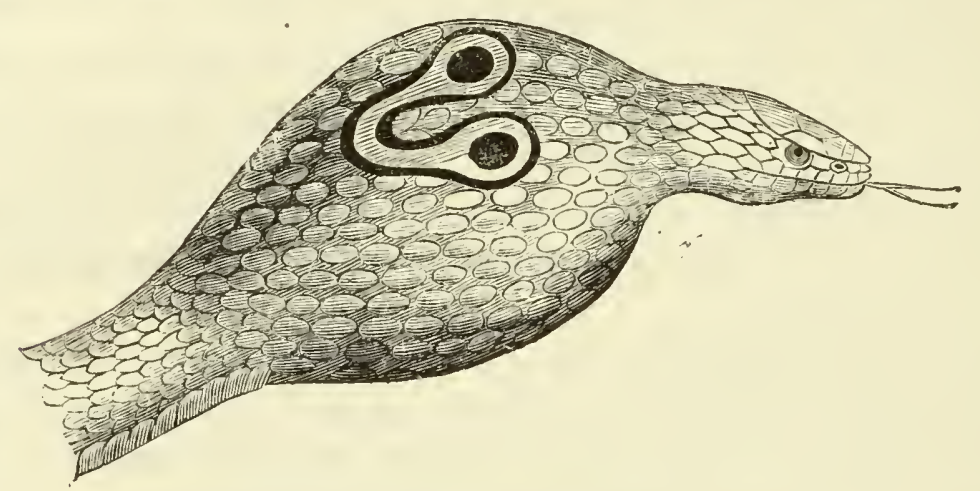

Fig. 887. - Naja.

à cause d'un trait noir, en iorme de lunettes, dessiné sur la partie élargie du disque. Il est très-venimeux; mais on prétend que la racine de l'Ophiorhyza Mungos, de la famille des rubiacées, est un spécifique certain contre sa morsure. Les bateleurs indiens apprivoisent ce serpent et savent le faire danser et jouer pour amuser le peuple, après, toutefois, lui avoir arraché les crochets à venin.

On en trouve une autre espèce en Égypte, nommée haje et qui n'est autre chose que l'aspic des anciens dont Cléopâtre s'est

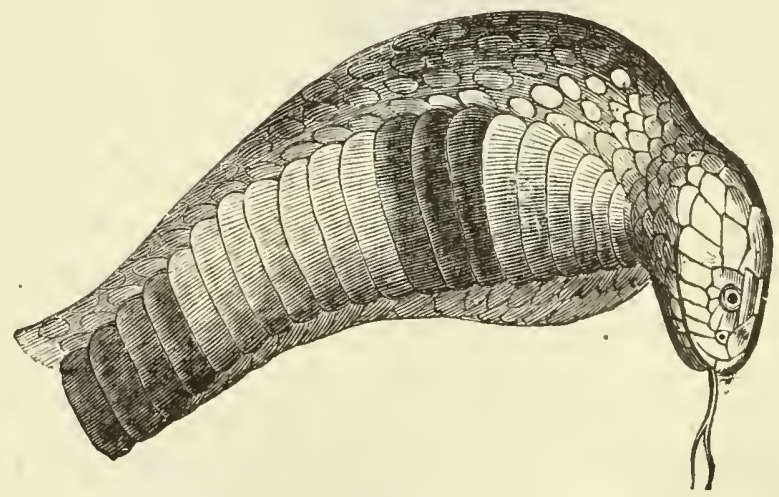

Fig. 888. - Aspic des anciens.

servie pour se donner la mort. Son cou s'élargit un peu moins (fig. 888), et ne porte pas le signe noir en forme de lunettes de 
l'espèce indienne. L'habitude qu'a l'haje de se redresser, quand on l'approche, avait fait croire aux anciens Égyptiens qu'il gardait les champs qu'il habite; ils en faisaient l'emblème de la divinité protectrice du monde, et c'est lui qu'ils plaçaient sur le portail de tous leurs temples, des deux côtés d'un globe.

\section{QUATRIÈIE CLASSE}

LES BATRACIENS.

[Cuvier arait placé les batraciens parmi les reptiles et en avait fait le dernier ordre de cette classe. Cependant des différences notables existent entre ces deux groupes, et, de nos jours, les zoologistes adoptent généralement l'idée émise pour la première fois par Blainville, en 1816 , et en font deux classes bien distinctes. La première comprend les reptiles, que nous avons déjà étudiés, dont la peau est revêtue d'ćcailles, qui respirent toute leur vie par des poumons, et présentent des leur naissance la forme qu'ils auront à l'état adulte. La seconde est formée par des animaux à peau nue, subissant la plupart des métamorphoses, et respirant au moins pendant une partie de leur existence par des branchies. A ces caractères distinctifs viennent s'en joindre d'autres plus importants encore tirés du mode de déreloppement. Les reptiles écailleux appartiennent à ce groupe de vertébrés, que l'on a nommés allantoidiens, parce qu'ils ont, dans leur état fotal, à part la vésicule ombilicale, une seconde vésicule nommée allantoïde. Ils se rapprochent ainsi des mammiferes et des oiseaux. Les batraciens, au contraire, n’ont que la vésicule ombilicale et se placent ainsi d̀ cóté des poissons, avec lesquels ils ont d'ailleurs, dans le premier âge, bien d'autres rapports par leur respiration branchiale et leur cœur à une seule oreillette.

La plupart des batraciens perdent, en avançant en âge, les branchies et l'appareil qui les supporte. Les sirènes, les protées, les ménobranches et les axolotes les conservent toute leur vie.]

"Tant que les branchies subsistent, l'aorte, en sortant du cœur, se partage en autant de rameaux, de chaque côté, qu'il y a des branchies. Le sang des branchies sort par des veines qui se réunissent vers le dos en un seul tronc artériel, comme dans les poissons; c'est de ce tronc que naissent la plus grande partie des artères qui nourrissent le corps et même celles qui conduisent le sang pour respirer dans le poumon. Mais, dans les espèces qui perdent leurs branchies, les rameaux qui s'y rendent s'oblitèrent, excepté deux qui se réunissent en une artère dorsale et qui donnent chacun une petite branche au poumon. C'est une circulation de poisson métamorphosée en une circulation de reptile. 
Les batraciens, à un seul genre près, manquent d'ongles aux doigts. Leurs nufs sont couverts d'une simple membrane; le mâle dispose la femelle à les pondre par des embrassements très-longs et, dans plusieurs espèces, ne les féconde qu'à l'instant de leur sortie. Toutefois il y a aussi des espèces vivipares.

On a divisé les batraciens en trois familles, sous les noms de $B$. anoures, urodèles et branchifères. Les premiers n'ont ni queue ni branchies à l'état parfait, et sont pourvus de quatre membres, ex. : les grenouilles et les crapauds; les seconds ne perdent que leurs branchies, conservent leur queue et acquièrent des membres, par exemple les salumandres; les troisièmes conservent toujours leurs branchies et leurqueue qui, amincie et aplatie latéralement, leur donne une forme générale analogue à celles de poissons qui seraient pourvus de membres; tels sont l'axolote du Mexique, les protées et les sirènes. Les naturalistes retirent maintenant les cécilies ou serpents nus de l'ordre des ophidiens et en forment une quatrième famille des batraciens.

Les Grenoulles (Rana; $f i g .889$ ) ont quatre jambes et point de

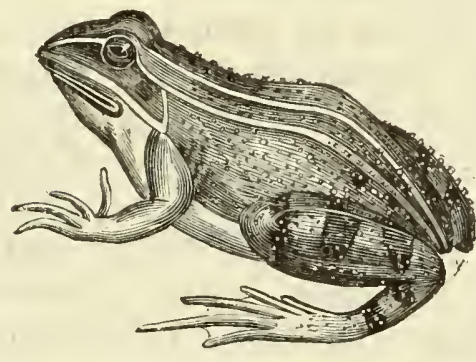

Fig. 889. - Grenouille.
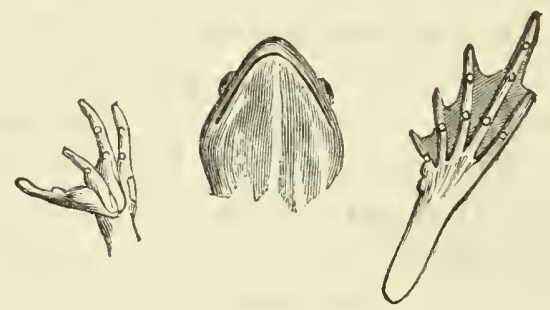

Fig. 890. - Tète et pattes.

queue dans leur état parfait ; leur tête est aplatie, leur gueule trèsfendue; leur langue est molle et ne s'attache pas au fond du gosier, mais au bord de la mâchoire inférieure, et se reploie en dedans; la mâchoire supérieure est garnie tout autour d'un rang de petites dents fines, et il y en a une rangée transversale interrompue, au milieu du palais. Leur corps est effilé et couvert d'une peau lisse; leurs pieds de devant n'ont que quatre doigts; ceux de derrière, qui sont très-longs et pourvus de cinq doigts palmés, leur permettent de faire des sauts considérables sur terre, et de nager avec vitesse dans l'eau. Leur squelette est dépourvu de côtes; une plaque cartilagineuse à fleur de tête tient lieu de tympan et fait reconnaître l'oreille par dehors. L'œil a deux paupières charnues et une troisième cachée sous l'inférieure, transparente et horizontale. Le mâle a de chaque côté, sous l'oreille, une poche à membrane mince qui se gonfle d'air quand il crie. 
L'inspiration de l'air ne se fait que par les mouvements des muscles de la gorge, laquelle, en se dilatant, reçoit de l'air par les narines, et en se contractant, pendant que les narines sont fermées au moyen de la langue, oblige ce fluide à pénétrer dans le poumon. L'expiration, au contraire, s'exécute par les muscles du basventre; aussi, quand on ouvre le ventre de ces animaux vivants, les poumons se dilatent sans pouvoir s'affaisser, et, si l'on en force un à tenir la bouche ouverte, il s'asphyxie, parce qu'il ne peut plus renouveler l'air de ses poumons.

Les embrassements du mâle sont très-longs. Ses pouces ont un renflement spongieux qui grossit au temps du frai et qui l'aide à mieux serrer sa femelle. Il féconde les œufs au moment de la ponte. Ces œufs tombés au fond de l'eau y restent quelques jours, après lesquels ils montent à sa surface. Nommés alors frai ou sperniole, on les employait autrefois comme rafraîchissants. On y distingue une infinité de points noirs qui sont les germes, entourés chacun d'une matière glaireuse analogue à l'albumen de l'œuf. Peu à peu ces points noirs grossissent, s'allongent et sortent de leur enveloppe : à cet état on les nomme tétards. Dans les premiers temps le tétard reste encore logé dans la liqueur glaireuse, qui a beaucoup augmenté de volume en absorbant de l'eau, et qui nage au milieu de la masse de liquide comme un nuage; il en sort seulement de temps en temps pour se fortifier par l'exercice : enfin il s'en sépare tout à fait.

Le tétard ressemble d'abord à un petit poisson et ne peut vivre que dans l'eau. Sa tête est très-grosse, et son corps, dépourvu de membres, se termine par une queue comprimée qui, dans les jours suivants, s'allonge beaucoup. Sa bouche n'est encore qu'un trou à peine perceptible, et ses branchies ne consistent qu'en un tubercule placé de chaque côté à la partie postérieure de la tête. Bientôt ces appendices s'allongent et'se divi-

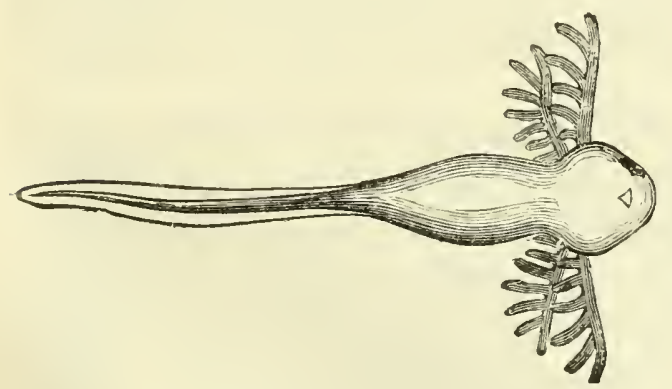

Fig. 891. - Tétard.

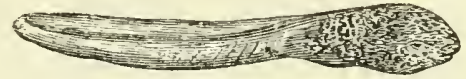

Fig. \$92. - Tétard.

sent en lanières; les yeux se dessinent à travers la peau. Un peu plus tard, les branchies se ramifient $(f i g$. 891) et les lèvres se 
recouvrent d'une sorte de bec corné, à l'aide duquel l'animal se fixe aux végétaux dont il fait sa principale nourriture. Au bout de quelques jours, les franges branchiales, qui flottaient de chaque côté du cou, s'enfoncent sous la peau pour y former les branchies (fig. 892). Celles-ci sont de petites houppes très-nombreuses, attachées aux quatre arceaux cartilagineux placés de chaque côté du cou et adhérant à l'os hyoïde. L'eau arrive à ces branchies par la bouche, en passant par l'intervalle des arceaux et, après les avoir baignées, en sort par une ou deux fentes extérieures. L'appareil respiratoire présente alors la plus grande ressemblance avec celui des poissons. Quelque temps après, les pattes postérieures se montrent et se développent petit à petit ( $f g .893)$; leur longueur est déjà assez grande, qu'on ne voit pas

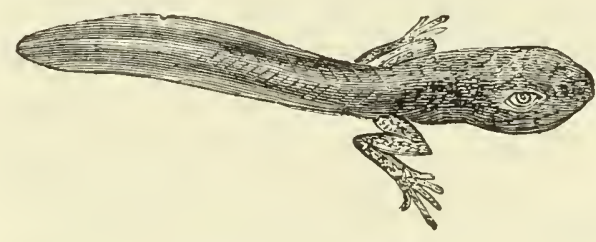

Fig. 893. - Tétard.

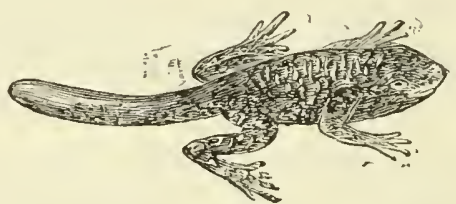

Fig. 894. - Tétard.

encore les pattes antérieures. Celles-cise développent sous la peau qu'elles percent plus tard ( $f g .894)$; la queue est résorbée par degrés (fig. 893); le bec tombe et laisse paraître les véritables

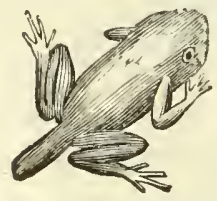

Fig. 895 et $896 .-$ Tétard et petite grenouille.

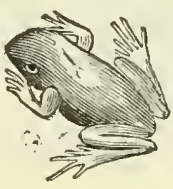

mâchoires; les branchies s'anéantissent et laissent les poumons exercer seuls la fonction de respirer qu'elles venaient partager avec eux; la queue disparait complétement ( $/ \mathrm{ig} .896)$ et le petit animal prend la forme qu'il doit toujours conserver. Alors aussi il change de régime: d'herbivore qu'il était d'abord il devient peu à peu exclusivement carnivore, et à mesure que sa métamorphose s'achève, son canal intestinal, de long, mince et contourné en spirale qu'il était, devient court et presque droit.

Les grenouilles se tiennent d'ordinaire sur le bord des mares et des ruisseaux et se précipitent dans l'eau au moindre danger'; elles ne se nourrissent que de proie vivante, comme larves d'insectes, vers, mouches et petits mollusques. Elles s'enfoncent, pendant l'hiver, sous terre ou dans la vase, sous l'eau, et peuvent y vivre sans manger et sans respirer, tandis que, dans la belle saison, elles périssent si on les empêche de respirer en leur tenant la bouche ouverte pendant quelques minutes. L'espèce la plus commune dans les eaux dormantes de nos contrées est la 
grenouille verte (Rana esculenta, L.) qui est d'un beau vert tacheté de noir, avec trois raies jaunes sur le dos et le ventre jaunâtre. Elle est très-incommode en èté par la continuité de ses clameurs nocturnes. Elle fournit un aliment sain et agréable. Les Allemands la mangent tout entière, la peau et les intestins exceptés; mais, en France, on ne fait usage que du train de derrière. On en forme aussi des bouillons médicinaux. En 1789, Galvani, professeur d'anatomie à Bologne, en faisant des recherches sur l'irritabilité des cadavres de grenouilles par l'électricité, a reconnu les premiers faits d'électricité animale, qui ont conduit Volta à la découverte de la pile qui porte son nom, el qui ont été le point de départ de toutes les brillantes découvertes dues à l'électricité dynamique (1).

Les rainettes ( $H y l a)$ ne diffèrent des grenouilles que parce que l'extrémité de chacun de leurs doigts est arrondie en une pelote visqueuse, qui leur permet de se fixer aux corps et de grimper aux arbres. Elles s'y tiennent, en effet, tout l'été et y poursuivent les insectes; mais elles pondent dans l'eau et s'enfoncent dans la vase en hiver, comme les grenouilles. Le mâle a sous la gorge une poche qui se gonfle quand il crie.

Les crapauds $(B u f o)$ ont le corps ventru, couvert de verrues ou papilles qui laissent suinter un enduit visqueux, et, derrière l'oreille, un gros bourrelet percé de pores qui sécrètent une humeur laiteuse et fétide. Ils manquent complétement de dents, ont les pattes de derrière peu allongées, sautent mal et se tiennent cependant plus généralement éloignés de l'eau. Ce sont des animaux hideux et dégoûtants, mais qui ne sont pas venimeux. Le crapaud commun ( $B u f o$ vulgaris, Laur.; Rana Bufo, L.) est gris roussâtre ou noirâtre, couvert de tubercules arrondis; ses pieds de derrière sont demi-palmés. Il se tient dans les lieux obscur's et étouffés el passe l'hiver dans des trous qu'il se creuse. Son accouplement se fait dans l'eau, au printemps; la femelle produit des œufs innombrables, réunis par une gelée transparente en deux cordons très-longs, que le mâle traîne avec les pieds de derrière.

Le crapaud jouissait autrefois d'une grande réputation en médecine; on l'appliquait tout vivant contre la céphalalgie, la gastralgie, les scrofules, le cancer, etc., ou bien desséché et réduit en poudre contre la fièvre quarte, l’épilepsie, etc. II faisait partie du baume de Leictour et du baume tranquille, de même que les grenouilles figuraient encore dans le dernier siècle au nombre des ingrédients de l'emplâtre de Vigo, simple ou mercuriel.

(1) Voy. de la Rive, Traité d'électricité théorique el pratıque, Paris, 1554-58. 


\title{
CINQUIÈME CLASSE
}

\author{
LES POISSONS.
}

La classe des poissons, qui est la dernière des animaux vertébrés, se compose des vertébrés ovipares organisés pour vivre toujours dans l'eau. Leur circulation est complète, c'est-d̀-dire qu'aucune portion de sang veineux ne retourne au corps sans avoir été changé en sang artériel; mais leur respiration s'opère uniquement par l'intermède de l'eau. A cet effet, ils ont aux deux côtés du cou un appareil nommé branchies, lequel consiste en feuillets suspendus à des arceaux tenant à l'os hyoïde, et composés chacun d'un grand nombre de lames recouvertes par d'innomblables vaisseaux sanguins. L'cau que le poisson avale s'échappe entre ces lames par des ouvertures nommées ouies, et agit, au moyen de l'air qu'elle contient, sur le sang continuellement envoyé aux branchies par le cœur, qui ne représente que l'oreillette et le ventricule droits des animaux à sang chaud (1).

Ce sang, après avoir respiré, ne repasse donc pas par le cœur, et se rend directement dans un tronc artériel situé sous l'épine du dos, et qui, faisant fonction de ventricule gauche, l'envoie par tout le corps, d'où il revient au cœur par les veines.

La structure entière des poissons est aussi évidemment disposée pour la natation que celle des oiseaux pour le vol. Suspendus dans un liquide presque aussi pesant qu'eux-mêmes, les premiers n'ont pas besoin de grandes ailes pour se soutenir, et la plupart sont pourvus d'une vessie pleine d'air, dite vessie natatoire, placée immédiatement sous l'épine, et qui, en se comprimant ou en se dilatant, fait varier la pesanteur spécifique de l'animal, et l'aide à monter ou à descendre. La progression s'exécute en partie par les mouvements de la queue qui choque l'air alternativement à droite et à gauclie; les branchies peuvent $\mathrm{y}$ contribuer aussi, en poussant l'eau en arrière; le reste de l'action progressive est produit par les membres qui, se trouvant ainsi aidés, n'ont pas besoin d'être bien puissants et sont en général fort réduits. Les pièces analogues aux os des bras et des jambes très-raccoureies, ou même entièrement cachées ; des rayons plus ou moins nombreux, soutenant une larne membraneuse, représentent grossièrement les doigts des mains et des pieds, et forment les nageoires. Celles qui répondent aux membres antérieurs se nomment pectorales; celles qui répondent aux postérieurs, ventrales. D’autres rayons, attacliés à des

(1) Voy. J. Cuvier et Valenciennes, IIistoire naturelle des poissons. Paris, 1829-1849. 22 vol. in-8 avec atlas. - E. Blanchard, Les poissons des eaux douces de la France. Paris, 1866, in-8. 
os placés sur ou entre les extrémilés des apophyses épineuses, soutiennent des nageoires supplémentaires qui sont situées verticalement sur le dos, sous la queue ou à son extrémité. On appelle les nageoires supérieures dorsales, les inférieures anales et celle du bout de la queue caudale.

On observe dans les poissons autant de variétés que parmi les reptiles pour le nombre des membres (nageoires pectorales et ventrales). Le plus souvent, il y en a quatre; quelques-uns n'en ont que deux; d'autres en manquent tout à fait. Dans la plupart, les vertebres sont pourvues de longues apophyses épineuses qui soutiennent la forme verticale $\mathrm{du}$ corps; les côtes sont souvent soudées aux apophyses transverses. On désigne communément ces cotes et ces apoplyyses par le nom d'arêtes.

La tête des poissons varie beaucoup quant à la forme, et cependant elle se laisse presque toujours diviser dans le même nombre d'os que celle des autres ovipares; les narines sont de simples fossettes creusées au bout du museau, presque toujours percées de deux trous et tapissées d'une pituitaire plissée très-régulièrement. Leur œil a la cornée

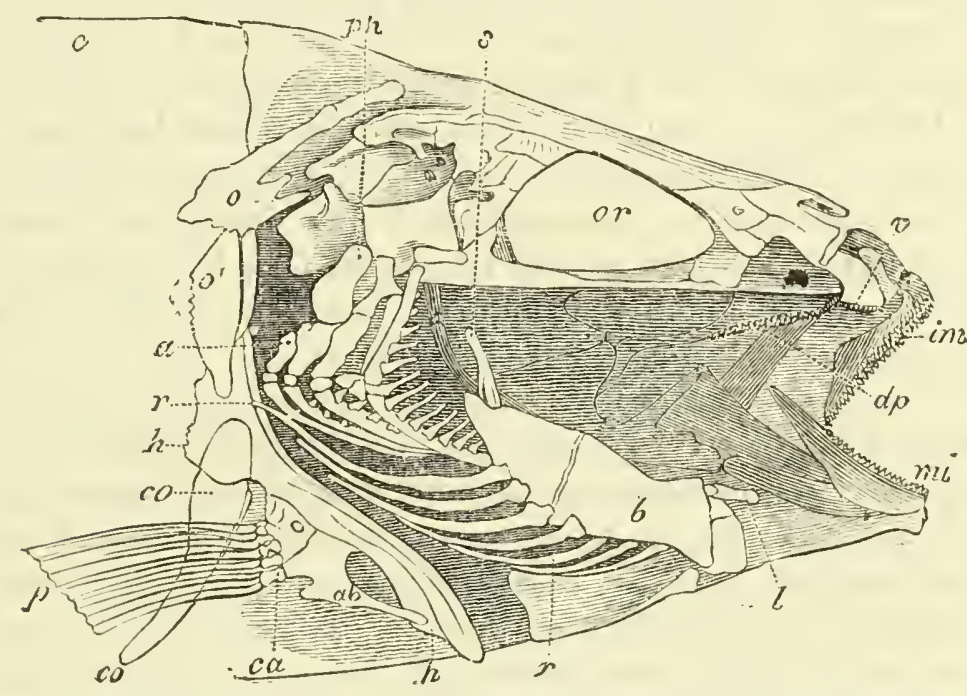

Fig. 897. - Tête ossense de,la perche dont on a enlevé, d'un côté, les mâchoires, la cloison jugale et l'opercnle, pour montrer l’intérieur de la bouche et l'appareil hyoïdien (*).

très-plate, peu d'humeur aqueuse, mais un cristallin sphérique trèsdur. Leur oreille est presque toujours logée tout entière dans la cavité du crâne, sur les côtés du cerveau, et ne consiste guère qu'en un vestibule surmonté de trois canaux semi-circulaires, auquels les ondes sonores n'arrivent qu'après avoir mis en vibration les téguments communs et les os du crâne.

(*) c, cråne; or, orbite; $\theta$, vomer (armé de dents); im; màchoire supérieure; $d p$, dents implantées sur l'arcade palatine; $m i$, mâchoire inférieure; $l$, os lingual; $b$, branches latérales de l'appareil hyoüdien; $s$, stylet servant à suspendre ces branches à la face interne des cloisons jugales; $r$, rayons branchiostèges; $a$, anneaux branchiaux; $p h$, os pharyngiens supérienrs; $o$ d̀ $h$, ceinture ossense supportant la nageoire pectorale $p$; $o$ et $o^{\prime}$, omoplate divisée ell denx pièces; $h$, humérus; $a b$, os de l'avant-bras; $a c$, os du carpe; co, os caracoïdien. 
Les poissons sont très-voraces, mais ils ont le goût peu développé, et ils paraissent avaler sans choix tous les petits animaux qui sont à leur portée. Il y en a fort peu qui se nourrissent de matières végétales. Leur langue est en partie osseuse et souvent garnie de dents ou d'autres enveloppes dures; il peut y avoir aussi des dents à l'intermaxillaire, au maxillaire, à la mâchoire inférieure, au vomer, aux palatins, aux arceaux des branchies el jusque sur des os situés en arrière de ces arceaux, tenant comme eux à l'os hyoïde el nommés os pharyngiens (fig. 897).

Outre l'appareil des arcs branchiaux, l'os hyoïde porte de chaque côté des rayons qui soutiennent la membrane branchiale. Une sorte de battant, composé de trois pièces osseuses, l'opercule, le subopercule et l'interopercule, se joint à cette membrane pour fermer la grande ouverlure des ouïes; il s'articule à l'os tympanique et joue sur une pièce nommée le préopercule. Plusieurs poissons cartilagineux manquent de cet appareil.

L'estomac et les intestins varient beaucoup pour l'ampleur, la figure et les circonvolutions; les reins sont fixés le long des côtés de l’épine; mais la vessie est au-dessus du rectum et s'ouvre derriere l'anus et derrière l'orifice de la génération, ce qui est l'inverse des mammifères.

Les testicules sont deux énormes glandes appelées communément laites; et les ovaires, deux sacs à peu près correspondants aux laites pour la forme et la grandeur, et dans les replis internes desquels sont logés une quantité souvent innombrable d'œufs. Quelques poissons seulement peuvent s'accoupler et sont vivipares; tous les autres n'ont pas d'accouplement et pondent des œufs sur lesquels le mâle ne fait que passer pour y répandre sa laite el les féconder.

La peau des poissons est quelquefois nue, mais presque to ujours elle est couverte d'écailles. Quelquefois ces écailles ont la forme de grains rudes, de tubercules très-gros, ou de plaques épaisses; mais en général ce sont des lamelles fort minces, se recouvrant comme des tuiles et enchâssées dans des replis du derme. Quant aux couleurs dont elles peuvent être ornées, elles étonnent par leur variété el leur éclat; tantôt elles ne peuvent être comparées qu'à l'or ou à l'argent; tantot ce sont les teintes les plus riches du vert, du bleu, du rouge ou du noir. La matière argentée, qui leur donne souvent un éclat métallique si beau, est sécrétée par le derme et se compose d'une multitude de très-pelites lames polies.

La classe des poissons est celle qui offre le plus de difficultés, quand on veut la diviser en ordres, d'après des caractères fixes et sensibles. Après bien des efforts, Cuvier s'est déterminé pour la classification don t voici le tableau : 


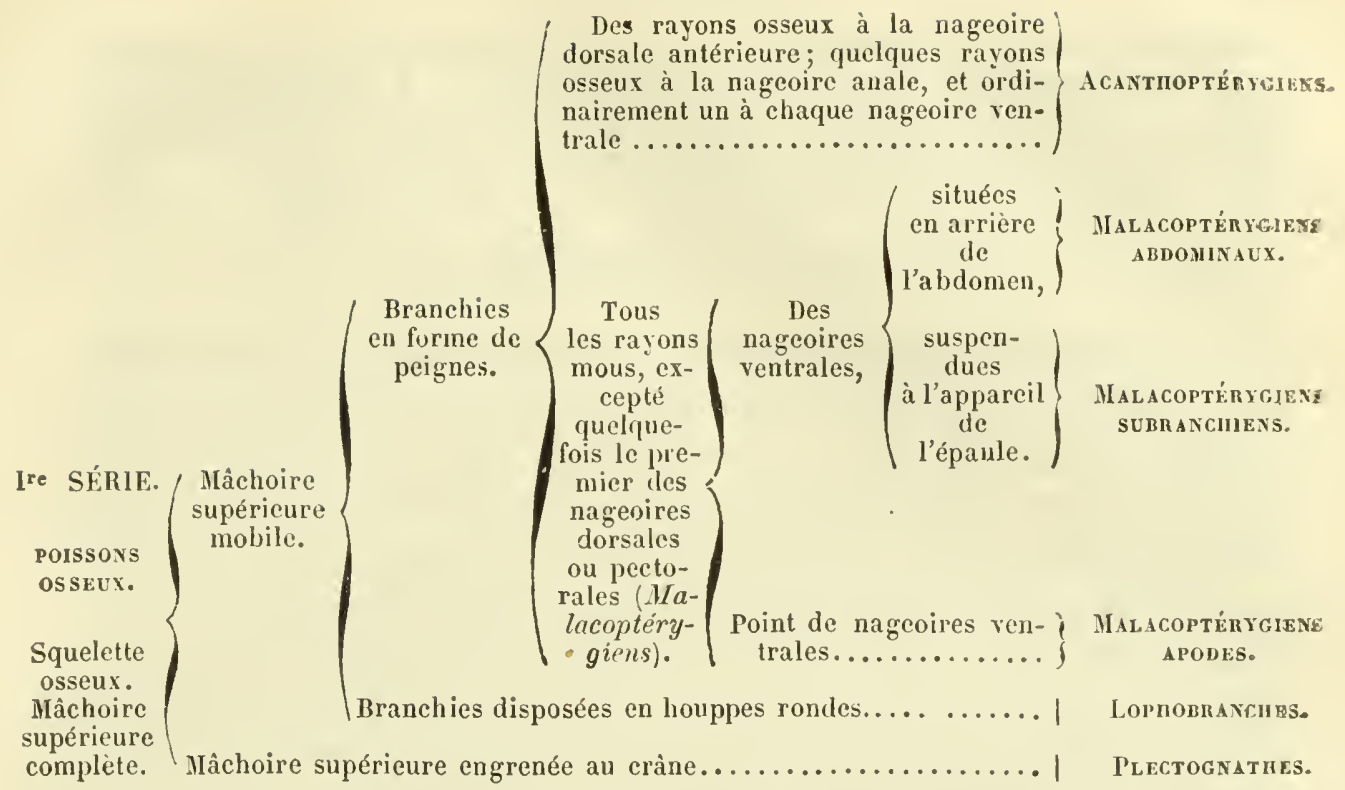

Chovdroptérygiexe ARATCHES LIBRES ou Stuhioniens.

Sélaciexs.

Cyclostones。

Squelette cartilagineux. rieure remplacés par? (Chondroptérygiens à Måchoires sondées en un ) les palatins......... branchies fixes $). . . . .$. ( cercle immobile.....

A ne voir que le tableau précédent, on prendrait une idée bien peu exacte de la valeur numérique relative des neuf ordres qui composent la méthode ichthyologique de Cuvier : les acanthoptérygiens qui paraissent ne former que le neuvième de la totalité de la classe des poissons, composent à eux seuls la moitié des familles et près des deux tiers des genres ou sous-genres (1). Ils forment, si l'on peut s'exprimer ainsi, le peuple ou la tourbe de l'jmmense nation des poissons, dont les individus se mangent bien un peu les uns les autres, mais qui deviennent, en définitive, la proie des dominateurs de l'eau, sans compter l'homme qui leur fait une guerre active dans toutes les parties du monde, et qui les sacrifie par légions à la nécessité de pourvoir à sa propre nourriture. Je sortirais tout à fait du cadre que je me suis tracé, si je citais

Acanthoptérygiens................

Malacoptérygiens abdominaux......

- $\quad$ subrachiens.................

Lophobranches..................

Plectognates...................

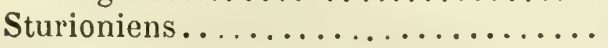

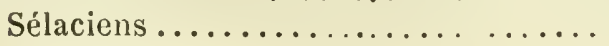

Cyclostomes................

familles. ou sous-genrez.

\begin{tabular}{rr}
$\overline{15}$ & $\overline{243}$ \\
5 & 86 \\
3 & 23 \\
1 & 17 \\
1 & 4 \\
2 & 9 \\
1 & 4 \\
1 & 23 \\
1 & 5 \\
\hline 30 & 414
\end{tabular}


seulement tous les poissons qui servent à la nourriture de l'homme; je ne dirai quelques mots que des principaux, en y joignant ceux qui offrent quelque particularité remarquable dans leur organisation, ou qui fournissent des produits utiles aux arts ou à la médecine.

\section{ORDRE DES ACANTHOPTÉRIGIENS.}

En tête des acanthoptérygiens, et dans la famille des percoïdes, nous trouverons d'abord les percties qui ont le corps oblong et couvert d'écailles dures; les nageoires ventrales attachées sous les pectorales; le préopercule dentelé, l’opercule osseux et terminé en deux ou trois pointes aiguës; la langue lisse. L'espèce principale qui est la perche commune (Perca fluviatilis, L.), vit dans les lacs, les rivières et les ruisseaux d'eau vive d'Europe et d'Asie; elle atteint ordinairement 40 à 50 centimètres de longueur, avec un poids de 2 kilogrammes à $2^{\text {kil }}$, כั00, et quelquefois plus de 6 centimètres avec un poids de 15 kilogrammes. Elle est d'un vert doré, avec trois bandes verticales noirâtres, et les nageoires ventrales et l'anale rouges; elle se nourrit de vers, d'insectes et de petits poissons : c'est un des plus beaux et de nos meilleurs poissons d'eau douce.

Le bars commun (Labrax Lupus, Cuv.) est un grand poisson des côtes de France, commun surtout dans la Méditerranée et très-estimé pour la table. Il est de couleur argentée, avec des reflets d'un bleu céleste sur le dos; ses deux nageoires dorsales sont d'un rose tendre, les pectorales et les ventrales jaunâtres. Une tache noire marque la pointe de ses opercules. Sa grande voracité lui a fait donner le nom de loup de mer: il peut arriver au poids de 30 kilogrammes.

Les vives (Trachinus) diffèrent des percoïdes précédents par la position de leurs nageoires ventrales qui, au lieu d'être attachées sous les pectorales, le sont sous la gorge, en avant des pectorales (1). Elles ont la tête comprimée, les yeux rapprochés, la bouche oblique, la première dorsale très-courte, la deuxième trèslongue, les pectorales très-amples et un fort aiguillon à l'opercule. Elles habitent près des côtes de l'Océan et de la Méditerranée, et se tiennent le plus souvent cachées dans le sable; on redoute beaucoup la piqûre des aiguillons de leur première dorsale; leur chair est agréable.

Les Mulles (Mullus) ont deux dorsales très-séparées; tout leur corps et leurs opercules sont couverts d'écailles large qui tombent facilement; leur préopercule n'a point de dentelures; leur bouche

(1) On leur donne, à cause de cela, le nom de percoïdes jugulaires; les autres portent celui de percoïdes thoraciques. 
est peu ouverte, faiblement armée de dents, et ils se distinguent surtout par deux longs barbillons qui leur pendent sous la mâchoire inférieure. On en connaît surtout deux espèces, dont une, nommée mulle barbu, ou rouget barbu (Mullus barbatus, L.), élait recherchée des Romains débauchés de l'Empire, qui faisaient cuire le rouget tout vivant sur leur table, dans des canaux de cristal remplis d'eau lentement échauffée, afin de jouir du barbare plaisir de voir le rouge éclatant du poisson se changer successivement en pourpre, en violet, en gris bleuatre et en blanc, à mesure qu'il approchait du terme de son existence. Le goùt de cet affreux spectacle devint même une telle fureur, qu'un ancien consul, nommé Ceier, paya un rouget 8,000 sesterces ( 1,5 əั8 $\mathrm{fr}$.), et que, sous Tibère, trois autres furent achetés 30,000 sesterces $(\tilde{0}, 844$ fr.); Tibère lui-même en vendit un qui fut acheté par Oclavius pour 5,000 sesterces. Il est vrai que ces mulles étaient d'un poids peu ordinaire, et que le dernier pesait à peu près 5 livres romaines ( 1,606 grammes).

Le rouget barbu est très-répandu sur les côtes de la Méditerranée et se trouve également sur celles d'Espagne, de Portugal et du golfe de Gascogne; on le vend quelquefois à Paris. Il est long de 22 à 27 centimètres, a le corps et la queue rouges, même après aroir été dépouillé de ses écailles; il a la queue fourchue, la tête comme tronquée en avant, et la mâchoire inférieure accompagnée de deux barbillons aussi longs que les opercules. Il a la chair blanche, ferme et d'un goût exquis. On lui substitue souvent le surmulet (Mullus Surmuletus, L..) qui est plus grand, à profi! moins vertical, rayé en longueur de jaune, et qui, étant plus commun sur les côtes de l'Océan, arrive plus facilement à Paris. On vend encore à Paris, sous le nom de rougets, plusieurs autres poissons du genre Trigla, de la famille des joues cuirassées, qui sont le rouget comm un (Trigla pini, Bl.), le rouget camard (Trigla lineata, L.), le perlon (Trigla Girundo, L.), la lyre (Trigla Lyra, L.), le gurnard (Trigla Hurnardus, L.) et surtout le grondin rouge (Trigla Cuculus, Bl.). Tous ces poissons ont la tête trèsgrosse, comme cubique, dépourvue de barbillons en dessous; mais ils portent plusieurs rayons libres en avant de leurs nageoires rentrales, et leurs nageoires pectorales sont très-développées, quoiqu'elles ne le soient pas assez pour leur permettre de s'élever au-dessus de l'eau, comme peuvent le faire les dactyloptères si connus sous le nom de poissons volants.

Les épinoches sont de très-petits poissons d'eau douce, appartenant aux joues cuirassées comme les précédents, dont les épines dorsales sont libres et non réunies en nageoires, et dont le bassin, réuni à des os huméraux très-larges, garnit leur ventre d'une 
sorle de cuirasse osseuse ; de là vient leur nom générique Gasterosteus. Leurs ventrales, placées en arrière des pectorales, se r'éduisent presque à une seule épine. L'espèce la plus commune de nos ruisseaux est celle nommée épinarde ou escharde (Gasterasteus aculeatus, L.); elle est longue de 8 à 9 centimètres; elle a ia bouche grande, les yeux saillants, la ligne latérale du corps recouverte de plaques osseuses, formant de chaque côté une espèce de cuirasse; deux forts aiguillons allongés et un troisième plus petit en avant de la nageoire du dos, une forte épine double remplaçant les nageoires ventrales et une autre petite en avant de roanale. Elle a le dos d'un brun verdâtre parsemé de points noirs ; le ventre argenté, la gorge souvent rouge de rubis et les nageoires dorées. Sa chair est fade et sans saveur ; aussi ne l'aurais-je pas citée, sans l'instinct particulier qui porte le mâle à construire un nid au fond de l'eau, dans lequel il appelle successivement plusieurs femelles dont il féconde les œufs, dont il se constitue le gardien, et qu'il défend avec courage contre l'attaque des autres poissons. Ces faits, déjà signalés en partie par Valmont de Bomare, ont été étudiés et complétés par M. Coste (1).

La famille des scombéroüdes se compose d'une multitude de poissons à petites écailles, à corps lisse, à cœcums nombreux, souvent réunis en grappes, dont la queue et la nageoire caudale sont très-vigoureuses. Le genre des scombres, qui la commence, présente une première nageoire dorsale entière, tandis que les derniers rayons de la seconde, ainsi que ceux qui leur correspondent à l'anale, sont au contraire divisés en plusieurs petits groupes formant ce qu'on nomme des fausses nageoires. Ce genre se subdivise en plusieurs sous-genres comprenant les maquereaux, les thoris, les germons, les sardes, etc.

Le maquereau commun (Scomber Scombrus, L.) a le corps en forme de fuseau, long de 40 à 80 centimètres, couvert d'écailles nniformément petites et lisses. Il a le dos bleu marqué de raies ondées noires, et le ventre argenté, nuancé de jaune, de vert et de violet. La deuxième dorsale est séparée de la première par un espace vide, et il porte cinq fausses nageoires en haut et en bas; sa chair est ferme et très-estimée. Ce poisson arrive en abondance en été sur nos côtes de l'Océan, et y donne lieu à des pêches et à des salaisons presque aussi importantes que celles du hareng. Il est remarquable qu'il n'ait pas de vessie natatoire, et que cet organe se trouve cependant dans plusieurs espèces très-voisines.

Les thons ont autour du thorax une sorte de corselet formé par des écailles plus grandes et moins lisses que celles du reste

(1) Coste, Comptes rendus de l'Academie des sciences, t. XXII, p. 814. 
du corps, et leur première dorsale se prolonge presque jusqu'à la seconde. Le thon commun (Scomber Thinnus, L.) a neuf fausses nagcoires au-dessus et all-dessous de la queue. Il peut acquérir des dimensions considérables telles que $2^{\mathrm{m}}, 2 \breve{\text { a }}$ à $3^{\mathrm{m}}, 2 \mathrm{\partial}$ de longueur, $1^{\mathrm{m}}, 8$ de circonférence, et un poids de 1500 à 200 kilogrammes. On le pêche depuis la plus haute antiquité dans la Méditerranée, tt il forme une des richesses de la Provence et de la Sardaigne, par son abondance extraordinaire. Sa chair est très-délicate et a beaucoup de rapports avec celle du veau. On la mange íraîche, salée, marinée ou conservée dans l'hnile.

La bonite des Tropiques est une espèce de thon à quatre bandes longitudinales noirâtres, sur chaque côté du ventre.

L'espadon (Xiphias Gladius, L.) appartient encore à la famille des sombéroïdes et se rapproche particulièrement des thons, par ses écailles infiniment petites, par les carènes des côtés de sa queue, par la force de sa caudale, et par toute son organisation intérieure. Il manque de nageoires ventrales et n'a qu'une longue dorsale très-élevée de l'avant; ses branchies, au lieu d'être divisées en dents de peigne, sont formées chacune de deux grandes lames parallèles réticulées; son caractère distinctif le plus apparent consiste dans le bec ou la longue pointe en forme d'épée qui termine sa mâchoire supérieure et lui fait une arme offensive très-puissante, avec laquelle il attaque les plus grands animaux marins. Il a souvent lui-même plus de 6 mètres de long, et nage avec une vitesse qui ne le cède à celle d'aucun autre habitant des mers. Il est très-commun dans la Méditerranée et se rencontre aussi dans l'Océan Atlantique et dans la mer des Indes. Sa chair est excellente à manger.

ORDRE DES MALACOPTÉRIGIENS ABDOMINAUX.

Les Malacoptérygiens abdominaux, on le second ordre des poissons osseux, sont formés de ceux dont tous les rayons des nageoires sont mous, excepté quelquefois le premier rayon des nageoires dorsales ou pectorales, et dont les nageoires ventrales sont siluées en arrière de l'abdomen. Cet ordre est encore trèsnombreux, et comprend, indépendamment de plusieurs poissons marins, la plupart des poissons d'eau douce. Je citerai seulement les plus connus :

La carpe vulgaire.

La dorade de la Chinc

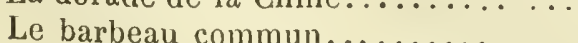

Le goujon $(f i g .898) \ldots \ldots \ldots \ldots \ldots \ldots$.

La tanche vulgaire (fig. 899)
Cyprinus Carpio, L.

- auratus, L.

- Barbus, L.

- Gobio, L.

- Tinca, L. 
La brême commune (fig. 900$). \ldots$... Cyprinus Brama, L.

L'ablette meunier............ . - Dobula, L.

L'ablette commune.......... _ - alburnus, L.

Le véron................ - Proxinus, L.

Le chevaine (fig.901).......... Squalius Cephalus, L.

La loche franche............. Cobitis Barbatula, L.

- d'étang............. - fossilis, L.

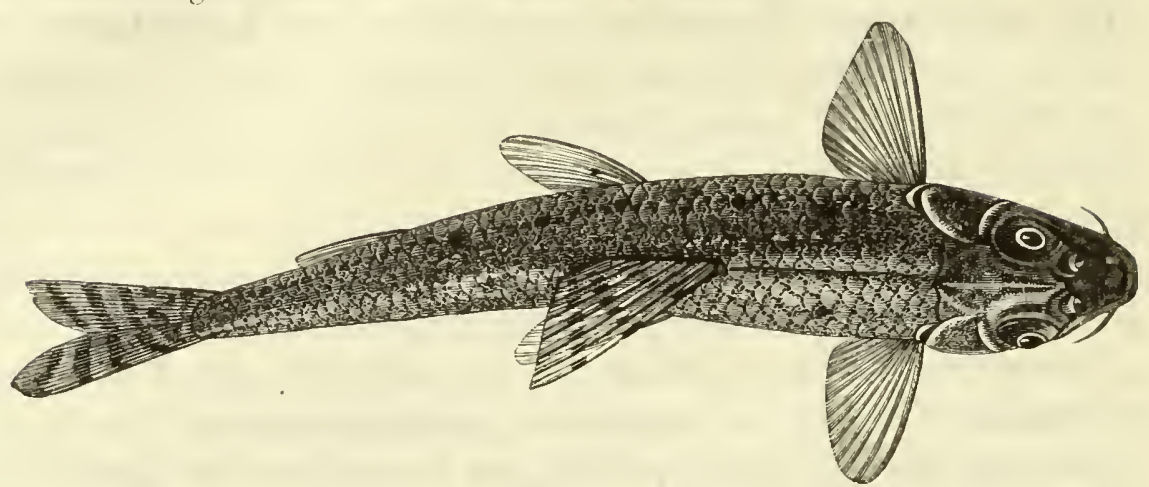

Fig. 898. - Le goujon de rivière.

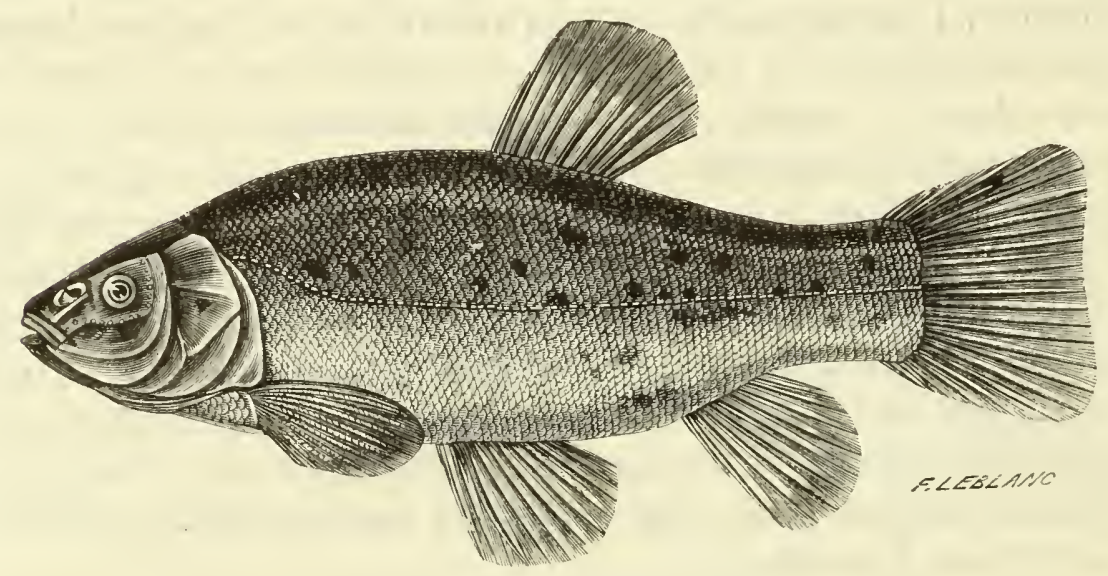

Fig. 899. - La tanche commune.

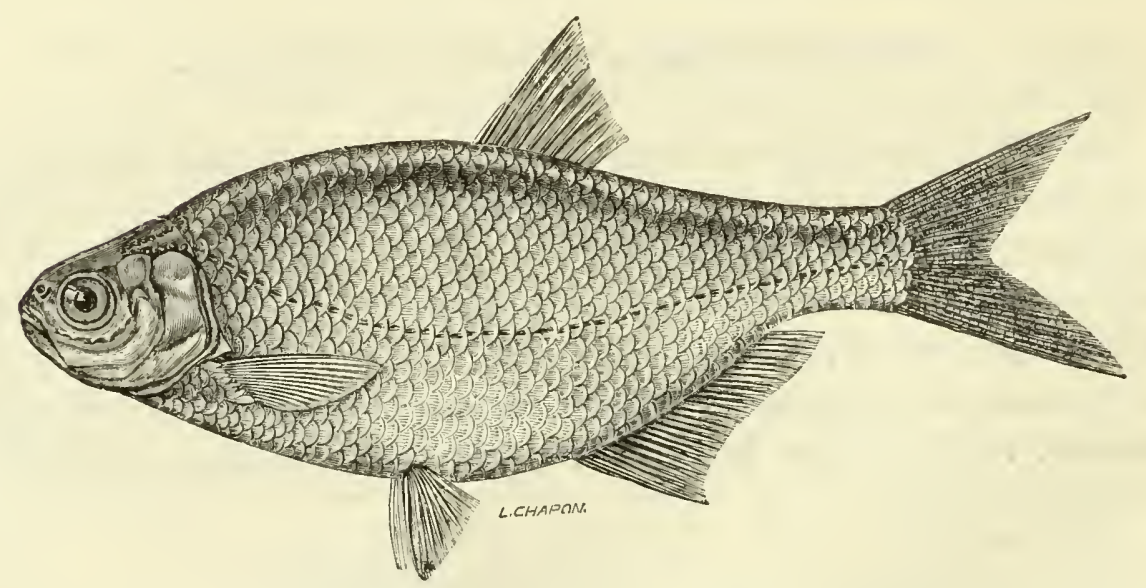

Fig. 900, - La brème commune.

Le brochet.................. . Esox Lucius, L.

L'exocet volant... . ........... Exocetus iolitans, Bl. 
Le saluth des Suisses............ Silurus Glani, L.

Le saumon $(f g .902) \ldots \ldots \ldots \ldots$ Salmo Solar, L.

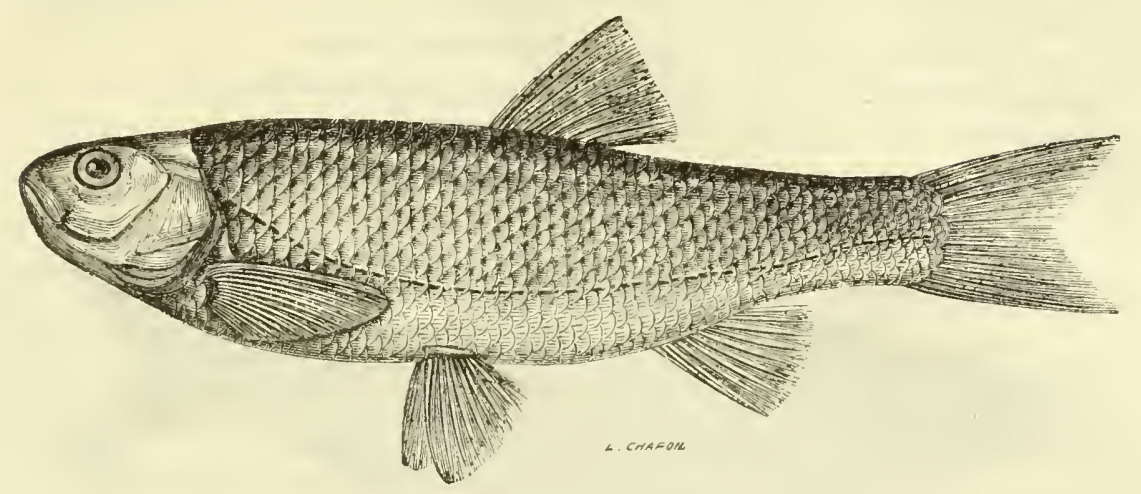

Fig. 901 . - Le chevaine.

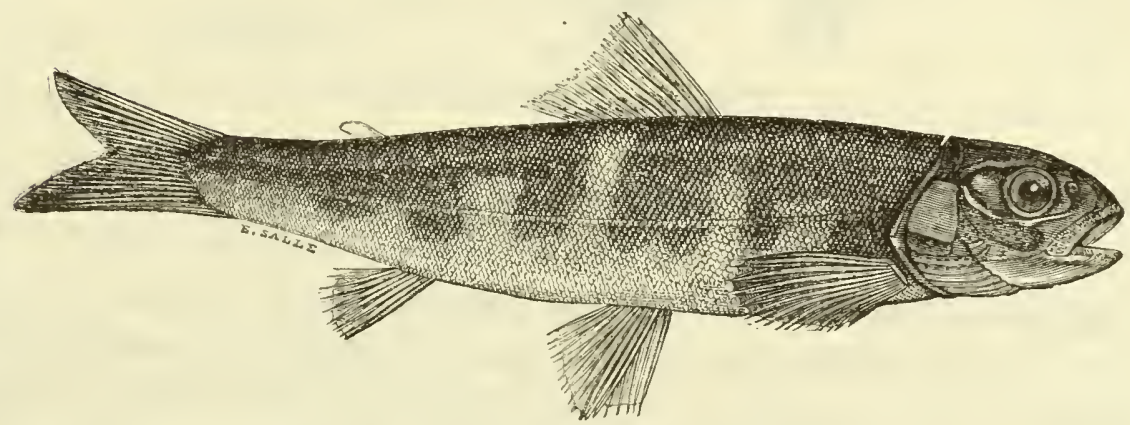

Vig. 90z. - Jeune saumon ou sammonileau.

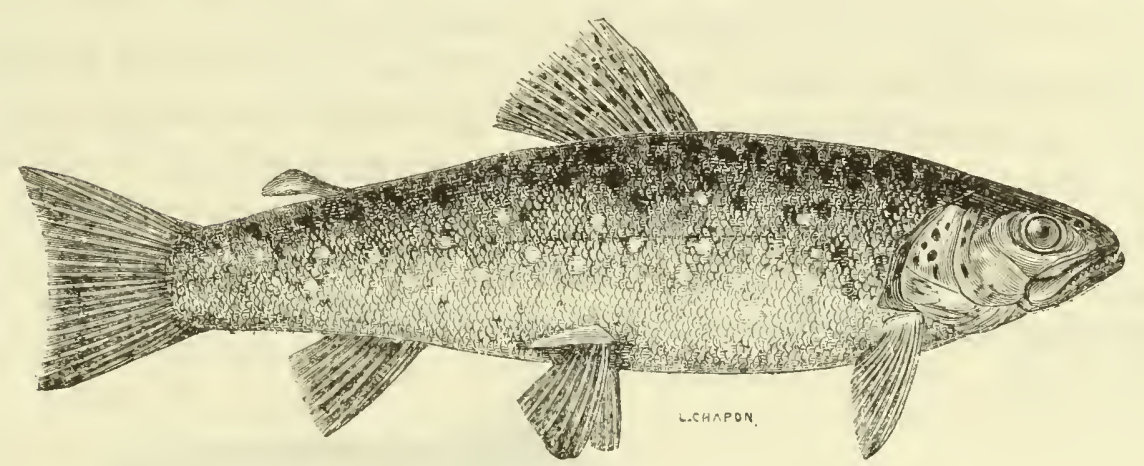

Fig. 903. - La truite commmne.

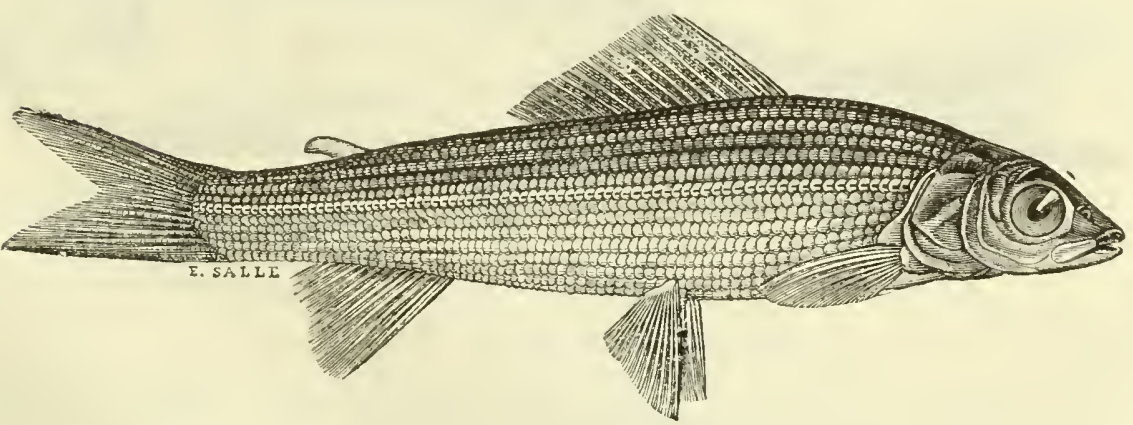

Fig. 90x. - L'ombre commune.

La truite de mer.............. Salmo Schiefermilleri, Bl.

La grande truite du Léman.......... - lemanus, Cur. 
La truite saumonéc.............. Salmo Truittn, L.

- commune $(f i g .903) \ldots \ldots \ldots \ldots$ - Fario, L.

L'éperlan.................. - Eperlanus, L.

L'ombre commune $(f g .90$ i)........ Thymallus rexifer.

Le hareng commun........... Clupea Harengus, L.

La blanquette............... - cutulus, Cuv.

La sardine................ - Sardina, Cuv.

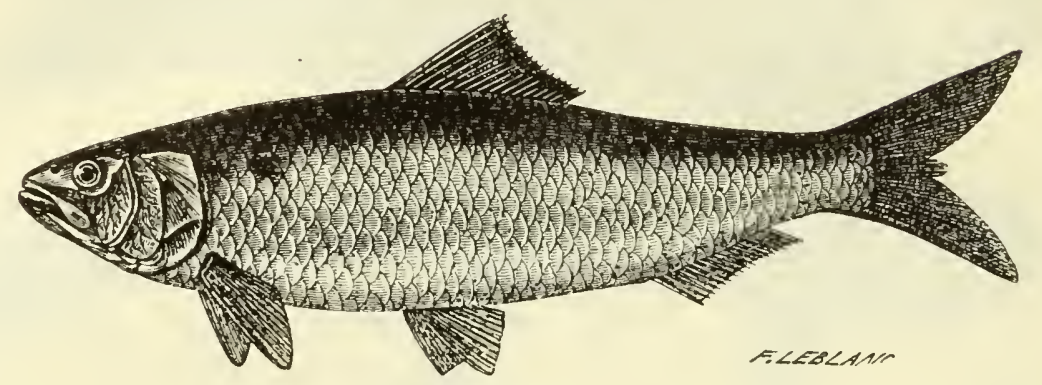

Fig. 905. - L'alose commune.

Lalose $(f i g .905) \ldots \ldots \ldots \ldots \ldots \ldots$. Alosa, L.

L'anchois vulgaire............ - Encrasicholus, L.

Essence d'Orient. On nomme ainsi la matière nacrée quien. toure la base des écailles de l'ablette, et dont on se sert pour fabriquer les fausses perles. Pour l'obtenir, on écaille les poissons de celle espèce au-dessus d'un baquet plein d'eau. Lorsque le fond du baquet est couvert d'une certaine épaisseur d'écailles, on frotte celles-ci entre les mains, on laisse reposer et on décante l'eau qui est salie par du sang et des mucosités; on lélaye le précipité dans l'eau et l'on jette le tout sur un tamis fin, au-dessus d'un autre baquet: l'essence d'Orient passe seule et tombe au fond de l'eau. On la lave plusicurs fois et on l'obtient enfin sous forme d'une masse boueuse d'un blanc bleuâtre, très-brillante et

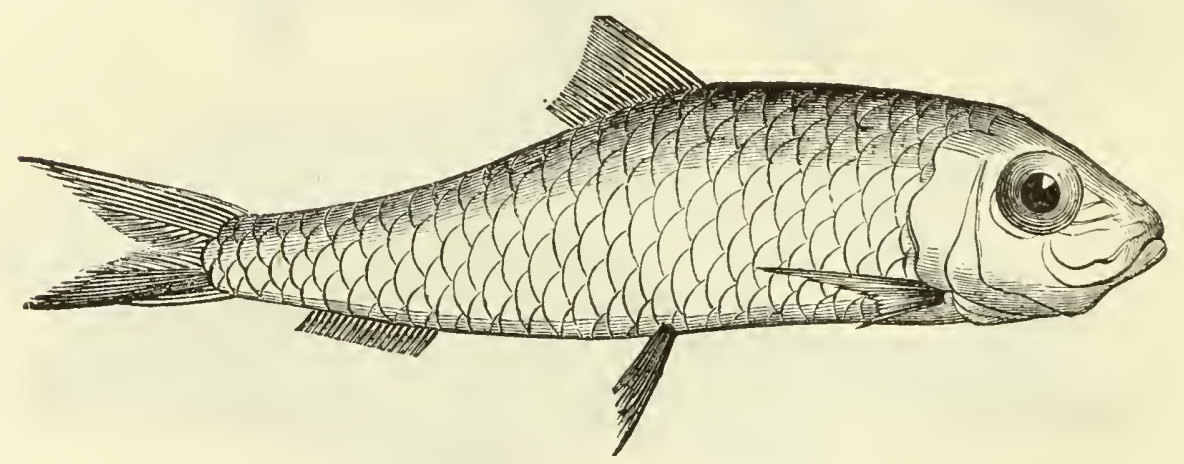

lig. 906. - La melette vénéneuse.

nacrée. On la livre au commerce délayée dans suffisante quantité d'ammoniaque liquide qui la préserve de la putréfaction, et renfermée dans des flacons bouchés. 
M. Fonssagrives (1) a signalé les dangers de la melette vénéneuse (Meletta venenosa), sorte de sardine des Tropiques (f $g .889$ ).

\section{ORDRE DES MALACOPTÉRYGIENS SUBRACHIENS.}

Les malacoptérygiens subrachiens sont caractérisés par leurs ventrales attachées sous les pectorales et par leur bassin immédiatement suspendu aux os de l'épaule. Ils présentent 'd'abord la famille des GADOÏDEs, composée presque entièrement par le genre Gadus de Linné, qui a les ventrales attachées sous la gorge et aiguisées en pointe, le corps médiocrement allongé, peu comprimé, couvert d'écailles molles peu volumineuses; la tête bien proportionnée, sans écailles; toutes les nageoires molles; les mâchoires et le devant du vomer armés de petites dents pointues, faisant la carde ou la râpe ; les ouïes grandes, à sept rayons. Presque tous portent deux ou trois nageoires sur le dos, une ou deux derrière l'anus, et une caudale distincte. Ils ont une vessie aérienne grande, à parois robustes, souvent dentelée sur les côtés. La plupart vivent dans les mers froides ou tempérées, et forment d'importants articles de pêche; ils ont la chair blanche, aisément divisible par couches et généralement saine, légère et agréable. On les divise aujourd'hui en plusieurs sous-genres qui sont les morues, les merlans, les merluches, les lottes, les motelles, les brosmes, etc. Les malacoptérygiens subrachiens comprennent encore les poIssons pLats ou PLEURONECTES de Linné, caractérisés par le défiut de symétrie de leur tête, où les deux yeux sont d'un côté, lequel reste supérieur quand l'animal nage, et cst toujours fortement coloré, tandis que le côté où les yeux manquent est toujours blanchatre. La bouche est aussi irrégulière, le corps est très-comprimé, muni d'une dorsale qui règne tout le long du dos; l'anale occupe pareillement tout le dessous du corps et s'unit, presque en avant, avec les ventrales; il y a des rayons aux ouïes et pas de vessie natatoire. Les pleuronectes fournissent le long des côtes de presque tous les pays une nourriture agréable et saine ; on les divise en plies, flétants, turbots, soles, etc. Les principales espèces sont :

\footnotetext{
La plie franche ou carrelet........ Platesin Platessu, Cuv.

Le flet, ou picaud............... - Flesus.

La pole, ou limandelle........... - Pola.

La limande.................. - Limanda.

l.e turbot.................... Rhombus maximus.

La barbue.................. - barbatus.

La sole.................... - Solea viblgaris, etc.
}

(1) Fonssagrives, Traité d'hygiène navale. Paris, 1856, p. 693. 
De tous les poissons 'de cet ordre, je ne traiterai en particulier que de la morue, dont le foie fournit une huile aujourd'hui universellement usitée contre toutes les formes de la dégénérescence scrofuleuse, et principalement contre la phthisie tuberculeuse.

La morue franche ou cahelliau (Morrha vulgaris, Cloq.; Gadus Morrhua, L.) est un poisson de la famille des Gadoüdes qui habite toutes les parties de l'océan Septentrional comprises entre le $40^{\circ}$ et le $70^{\circ}$ degré de latitude, el qui se rassemble tous les ans, vers le mois de mars, en nombre véritablement incalculable, sur une montagne sous-marine nommée le grand banc de Terre-Neuve, lequel occupe en avant de l'île du même nom un espace de 1 ŏ0 lieues. Ce poisson, lorsqu'il a pris tout son accroissement, eśt long de 100 à 130 centimètres, large de 30 centimètres environ, et pèse de 7 à 9 kilogrammes. On en a vu cependant de beaucoup plus grands. Il a la tête forte et comprimée, la bouche grande et la mâchoire inférieure munie d'un barbillon, ( $/$ g. 907$)$; les yeux grands et voilés par une membrane trans-

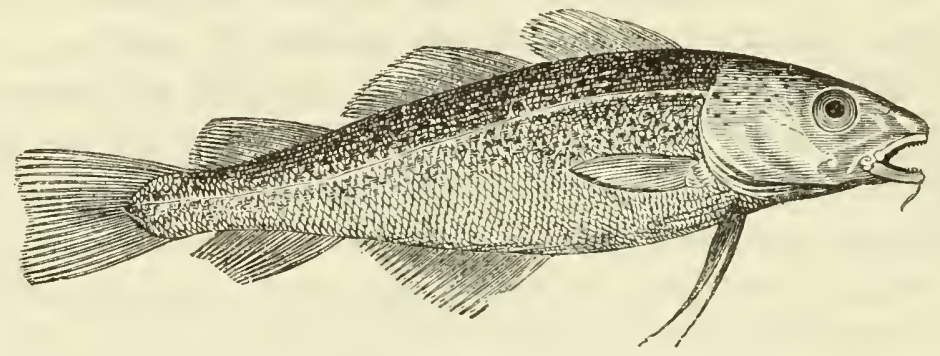

Fig. 907. - IIorue franche.

parente; le corps lisse el fusiforme, d'un gris jaunâtre, tacheté de brun sur le dos; une large ligne blanche de chaque côté, allant de l'angle supérieur des ouïes à la queue; le ventre blanchâtre. Les anciens, à cause de celte couleur comparée à celle de l'âne ou du cloporte, donnaient à la morue le nom d'Asellus. Elle a trois nageoires dorsales, deux nageoires anales et la caudale non fourchue. Le premier rayon de la première anale est court et épineux.

L'estomac de la morue est vaste et robuste, et il est suivi, vers le pylore, de six cœcums branchus; le canal intestinal est assez court, le foie très-gros et divisé en trois lobes allongés; la vésicule du fiel est d'un volume médiocre, les ovaires renferment une énorme quantité d'œufs, qui peut s'élever, d'après Leuwenhoëck, à 9,344,000 par individu. La vessie natatoire, qui est grande, a des parois robustes et fortifiées encore par un plan musculaire à fibres prononcées; elle est profondément lobée sur les bords; 
elle peut fournir une bonne ichthyocolle et est d'ailleurs considérée comme un manger délicat.

La morue est très-vorace et se nourrit de poissons, de harengs surtout, de mollusques et de crustacés. Elle digère très-vite et paraît avoir une croissance très-rapide. On la pêche quelquefois sur les côtes de la Manche, davantage sur celles de la mer du Nord, et principalement sur le banc de Terre-Neuve, qui est tous les ans, au printemps, le rendez-rous des pécheurs de toutes les nations maritimes; ceux-ci, année communc, ne rersent pas moins de 36,000,000 de morues, salées ou séchées, dans le commerce de l'Europe.

Le foie de morue est très-volumineux et fournit une grande quantité d'huile qui est employée depuis longtemps, pour l'éclairage, dans les pays maritimes; et qui est très-usitée surtout sous le nom d'huile de poisson, et préférablement à l'huile de baleine, pour la préparation des peaux chamoisées. Mais on conçoit que, tant que cette huile n'a pas été recommandée pour l'usage médical, on se soit peu inquiété de l'avoir pure; de sorte que, en réalité, ce qu'on nommait huile de poisson, il y a une dizaine d'années encore, quoique formé principalement peut-être d'huile de foie de morue, contenait aussi l'huile des foies d'anarrhique, de lotte, de thon, de congre, de raie, de pastenague, de requin, etc. Aujourd'hui que l'huile de foie de morue est d'un si grand usage en médecine, je pense qu'on la livre à l'état de pureté au commerce, quoique j'avoue ne pouvoir dire à quels caractères certains on peut reconnaître qu'elle se trouve à cet état. J'admets d'ailleurs que l'on puisse employer indifféremment l'huile des autres espèces de gades, telles que l'égrefin (Gadus LElefinus, L.), le dorseh (Gadus Callarias, L.), le merlan noir (Gadus carbonarius, L. ), la merluche (Gadus Merlucius, L. ), la lingue ou morue longue (Gadus Molus, L.), la lotte (Gadus Lota, L.), etc.

Inile de foie de morue. A Paris, on se procure cette huile en la tirant de nos ports de mer et principalement de Dunkerque, d'Ostende, d'Angleterre et de Hollande. M. le docteur de Jongh, qui a fait en 1842 et 1843 l'analyse des diverses huiles de morue du commerce, et qui depuis s'en est fait marchand, tire la sienne de Berghen en Norwége, et la donne pour de l'huile pure de foie de dorsch, ou petite morue des mers du Nord, vendue quelquefois à Paris'sous le nom de faux merlan.

On trouve dans le commerce trois variétés d'huile de foie de morue, et ces trois variétés penvent se retirer également du foie de tous les poissons. L'luile blanche est celle qui se sépare la première, par le simple tassenent des foies rassemblés dans une cuve, et qui forme environ la moitié de leur poids. L'huile brune 
se sépare plus tard, lorsque le parenchyme hépatique commence à s'altérer; l'huile noire est obtenue en faisant bouillir dans l'eau la matière plus ou moins putride qui a fourni les deux huiles précédentes. Il y a peu d'années encore, ces trois huiles ne se trouvaient dans le commerce que telles qu'elles étaient sorties des opérations précédentes, c'est-à dire troubles, épaisses et dégoutantes à boire; mais aujourd'hui on les trouve tout à fait transparentes, souvent même décolorées par quelque procédé chimique, et plus ou moins privées de leur odeur caractéristique, ce qui peul diminuer beaucoup leurs propriétés dans l'application médicale.

[En Norwége et en Russie, on opère actuellement sur les foies de morue, au moyen d'appareils à double fonds, entre les parois desquels circule un jet de vapeur. Les foies placés dans ces vases donnent d'abord, à une douce chaleur, une huile blanche, qu'on prend la précaution de filtrer. On remue ensuite les foies, et on obtient ainsi l'huile blonde. On pousse enfin le chauffage, on fait bouillir pendant dix heures environ et on obtient l'huile brune. Les résidus sont en général utilisés comme engrais (1).]

J'ai trouvé chez M. Ménier, à Paris, quatre qualités différentes d'huiles purifiées. La première est celle qui cst vendue par M. Jongh, comme véritable huile de foie de morue, préparée aux îles Lofoden en Norwége (2). Elle est transparente, de couleur vin de Malaga, de consistance onclueuse, d'une odeur très-forte d'huile de poisson, d'un goût supportable et privé de rancidité. La seconde, vendue sous le nom d'huile de foie de morue brune, est de couleur semblable à la première, mais plus fluide, d'une odeur moins forte et d'un goût moins désagréable; c'est celle qui est la plus employée. La troisième, nommée huile blonde, est à peu près de la couleur du vin de Madère, d'une odeur encore plis faible que la précédente, et peut être employée au début, pour accoutumer les malades au goût de poisson. Quant à la dernière, vendue sous le nom d'huile de foie morue blanche, et qui vient d'Angleterre, elle est presque incolore, d'un goût très-faible, et doit avoir élé décolorée, au moins à l'aide du charbon. Je la crois peu active, dans la persuasion où je suis que le principe aromatique particulier aux huiles de poisson doit entrer pour beaucoup dans leur propriété tonique et restaurante.

(1) Voir L. Soubeiran, Sur l'Exposition internationale des produits et engins de péche à Berghen. Paris, 1866 (Extrait du Bulletin de la Société impériale zoslogique d'acclimatalion).

(2) Ces îles sont situées près de la còte de Norwége, au delà du cercle polaire. Elles sont en hiver le rendez vous de près de 400 bateaux montés par 20,000 pêcheurs. On en exporte par an 16 millions pesant de morue sèche. 
M. de Jongh a publié les analyses des trois huiles de foie de morue, blanche, brune et noire. Je suppose qu'il s'agisssait alors des huiles brutes du commerce, et que ce qu'il nomme huile blanche est l'huile blonde d'à présent. M. de Jongh commençait par traiter l'huile par l'eau, pour en extraire les parties solubles qui se composent principalement des éléments de la bile; ensuite il saponifiait l'huile et examinait tous les produits de celte opération; le soufreet le phosphore ont été déterminés en détruisant l'huile au moyen de l'acide nitrique.

\begin{tabular}{|c|c|c|c|}
\hline & $\begin{array}{c}\text { HOILF } \\
\text { X } 01 \text { \& E. }\end{array}$ & $\begin{array}{c}\text { IIGILE } \\
\text { B R U N E. }\end{array}$ & $\begin{array}{c}\text { HUILE } \\
\text { BLANCHE. }\end{array}$ \\
\hline 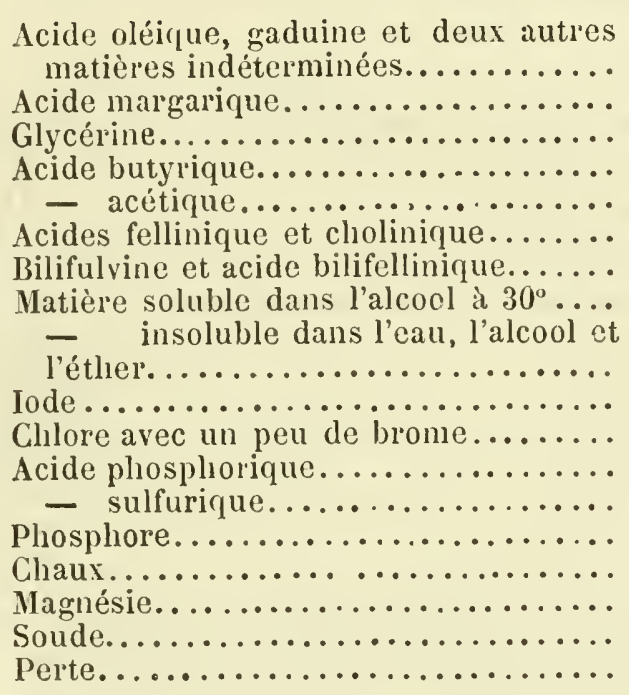 & $\begin{array}{c}69,785 \\
16,145 \\
9,711 \\
0,159 \\
0,125 \\
0,299 \\
0,876 \\
0,038 \\
\\
0,005 \\
0,0295 \\
0,084 \\
0,054 \\
0,010 \\
0,0075 \\
0,082 \\
0,001 \\
0,018 \\
2,569\end{array}$ & $\begin{array}{c}71,757 \\
15,421 \\
9,075 \\
0 \\
" \\
0,062 \\
0,415 \\
0,015 \\
\\
0,002 \\
0,011 \\
0,159 \\
0,079 \\
0,086 \\
0,0114 \\
0,012 \\
0,012 \\
0,068 \\
2,603\end{array}$ & $\begin{array}{r}71,033 \\
11,757 \\
10,177 \\
0,074 \\
0,046 \\
0,043 \\
0,263 \\
0,006 \\
0,001 \\
0,037 \\
0,149 \\
0,091 \\
0,071 \\
0,021 \\
0,009 \\
0,009 \\
0,055 \\
3,009\end{array}$ \\
\hline & 100,000 & 100,000 & 100,000 \\
\hline
\end{tabular}

Plusieurs autres chimistes ont cherché à déterminer la composition de l'huile de foie de morue. En France, MM. Girardin et Preisser se sont plutôt occupés de la comparer à l'huile de foie de raie, et d'appuyer sur la supériorité de celte dernière pour l'usage médical; mais cette supériorilé était en partie fondée sur ce que l'huile de foie de raie, transparente et d'un jaune doré, préparée avec soin par des pharmaciens, répugnait beaucoup moins aux malades que celles de foie de morue du commerce, qui était trouble et noirâtre. On doit peu compter d'ailleurs sur les caractères qui ont été donnés pour distinguer ces deux huiles.

D'après MII. Girardin et Preisser, l'huile de foie morue se colore rapidement en brun foncé par un courant de chlore, tandis que celle de foie de raie conserve sa couleur jaune, même après une demi-heure d'action.

L'huile de foie de morue prend rapidement une teinte noire par 
l'action d'un peu d'acide sulfurique froid. Le même acide colore l'huile de raie en rouge clair, el le mélange agité après un quart d'heure de contact acquiert une couleur violette foncée.

Les deux huiles contiennent l'iode à l'état d'iodure de potassium; 1 litre d'huile de foie de raie en a fourni 18 centigrammes et celle de foie de morue 13 (1).

D'après M. Gobley, l'huile de foie de raie, préparée par l'action directe de la chaleur sur le foie, est d'un jaune doré et présente une propriété caractéristique qui consiste à développer immédiatement une belle couleur violette, lorsqu'on mêle 1 gramme d'huile avec une goutte d'acide sulfurique concentré. Cette couleur passe au rouge après quelques instants. L'huile préparée par ébullition dans l'eau ne présente pas cette propriété.

Un litre d'huile de foie de raie, préparée par l'action direcle du feu, a fourni à $\mathrm{M}$. Gobley 20 centigrammes d'iodure de potassium. Ce chimiste n'a pu y découvrir la présence du phosphore (2).

D'après M. Personne, préparateur de chimie à l'École de pharmacie (3), les huiles de foie de morue et de raie contiennent l'iode à l'état de combinaison quaternaire avec les éléments ordinaires de l'huile, ê non à l'état d'iodure de potassium; l'huile de foie de morue en contient plus que celle de raie ; l'huile de foie de morue brune en contient plus que la blanche. Le foie de raie, résidu de l'extraction de l'huile, contient beaucoup plus d'iode que l'huile qui en a été retirée.

M. Personne pense que l'iode se trouve dans le foie à l'état d'iodure de potassium, et que c'est par l'action réunie de l'air et des acides gras résultant de l'altération d'une partie de l'huile, que l'iode est mis en liberté et réagit sur le corps gras, à la manière du chlore et du brome, en s'y combinant par substitution à l'hydrogène. M. Personne a été conduit par cette théorie à proposer de remplacer les huiles de morue et de raie, dans l'usage médical, par de l'huile d'amandes douces combinée artificiellement avec une dose déterminée d'iode, plus considérable et plus efficace que celle qui existe dans les huiles naturelles.

Suivant M. Personne, les huiles de foie de morue et de foie de raie pures ne renferment aucune trace de phosphore. Les huiles dans lesquelles ce corps a été trouvé, le contenaient à l'état de phosphate de chaux, inhérent au parenchyme hépatique tenu en suspension dans le liquide.

[M. Delattre a envoyé en 18509 , à l'Académie de médecine, un mémoire dans lequel il a étudié comparativement la composition chimique des huiles de foie de morue, de foie de raie et de squale. 11 prépare ces huiles à l'abri du contact de l'air, en plaçant les foies de poissons frais, bien lavés, dans de grands ballons en verre à moitié enterrés dans du sable, et communiquant tous avec un réservoir d'où s'échappe un cou-

(I) Girardin et Preisser, Journ. de pharm, et chim., t. I, p. 50 i.

(2) Gobley, Joum. de pharm. et chim., t. V, p. 305.

(3) G. Personne, Recherches sur les huiles de foie de morue et de raie, et príparations d'une huile iodée pour les remplacer dons l'usage médical (Bulletin de l'Acarlémie de médecine. Paris, 1849-50, t. XVे,-p. 1068). 
rant d'acide carbonique. En chauffant le bain de sable à $50^{\circ}$ seulement, il obtient l'huile vierge ou parfaitement pure : à $60^{\circ}$ l'huile est ambrée; à une température de $70^{\circ}$ elle est blonde. Les huiles brune et noire sont obtenues de foies morts depuis plusieurs jours.

Les chiffres suivants donnent une idée de la composition chimique des diverses sortes d'huile de foie de morue :

\begin{tabular}{|c|c|c|c|c|c|}
\hline & Vierge. & Ambrée. & Blonde. & Brune. & Yoirc. \\
\hline Oléine & 988.700 & 988.675 & 988.695 & 987.999 & $988.95 \tau$ \\
\hline Margarine.......... & 8.060 & 8.066 & 8.089 & 9.264 & 8.323 \\
\hline Chlore............. & 1.122 & 1.122 & 1.116 & 1.018 & 1.005 \\
\hline Iode............... & $0.32 i$ & 0.327 & 0.322 & 0.310 & 0.201 \\
\hline Brome............. & 0.013 & 0.043 & 0.088 & 0.031 & 0.016 \\
\hline Soufre............. & 3.201 & 0.200 & 0.196 & 0.156 & 0.142 \\
\hline Phosphore.......... & 0.203 & 0.201 & 0.200 & 0.196 & 0.076 \\
\hline Acides...$\ldots \ldots \ldots \ldots$ & 0.000 & 0.439 & 0.897 & 0.924 & 0.838 \\
\hline Pertes... & 1.314 & $0.92 \dot{t}$ & $0.44 !$ & 0.102 & 0.43 \\
\hline
\end{tabular}

Pour la comparaison des huiles de foie de morue, de raie el de squale M. Delattre donne les chiffres suivants :

\begin{tabular}{|c|c|c|c|}
\hline & $\begin{array}{l}\text { Huile de foie } \\
\text { de morue. }\end{array}$ & $\begin{array}{l}\text { Iruile de foie } \\
\text { de raic. } \\
\text { - }\end{array}$ & $\begin{array}{l}\text { Huile de foic } \\
\text { de squale. }\end{array}$ \\
\hline$\ldots \ldots \ldots \ldots \ldots \ldots$ & 988.700 & 986.915 & 987.174 \\
\hline Margarine.............. & 8.060 & 11.017 & $10.12 i$ \\
\hline Chalore................ & $1.1: 2$ & 1.125 & 1.018 \\
\hline Iode.................... & 0.327 & 0.185 & 0.345 \\
\hline Brome.................. & 0.043 & 0.039 & $0.03 \mathrm{i}$ \\
\hline Soufre.................. & .0 .201 & 0.165 & 0.160 \\
\hline Phosphore. ............. & 9.203 & 0.286 & 0.206 \\
\hline Pertes................ & $1.34 \mathrm{f}$ & 0.241 & 0.942 \\
\hline
\end{tabular}

D'apris ces chiffres, l'huile de foie de raie contiendrait une proportion d'iode deux fois moindre que l'huile de foie de morue; mais par contre un tiers en plus de phosphore. Quant à l'huile de squale, elle serait plus riche en iode et en phosphore que celle de morue, contiendrait un peu moins de brome et de soufre. Aussi M. Delattre attribue à ce dernier produit une efficacité au moins égale et dans certains cas supérieure à l'huile de foie de morue (1).]

Quant aux caractères de coloration développés par des agents chimiques, les expériences suivantes, comparées à celles de MM. Girardin et Cobley, montrent que ces caracteres sont trop variables pour pouvoir servir à la distinction des huiles. J'ai opéré sur huit sortes d'huiles:

No 1 . Huile de foie de morue du docteur Jongh.

$$
\begin{array}{lllll}
\text { No 2. } & - & - & - & \text { brune, Méniel. } \\
\text { No 3. } & - & - & - & \text { blonde, Ménier. }
\end{array}
$$

(1) Devergie, Composition chimique et emploi médicul des huiles de foie de morue, de raie et de squale (Bulletin de l'Acad. de médecine. Paris, 1858-59, t. XXIV, p. 820). - Voy. aussi Devergie, Rapport sul un mémoire de MII. Despinoy et Garreau (de Lille) ayant pour sujet la composition et les propriétés des caux et extraits de foies de momes (Bulletin de l'Acad. de mérl. Paris, 1862-63, t. XXVIII, p. 35). 
$N^{\circ} 4$. Huile de foie de morue blanche, anglaise, Ménier.

No 5. - - - purifiée, de MM. Cabaret et Rivet, à Bruxelles.

No 6. - - - de raie, de M. Gobley.

No\% - - - de M. Faucher, à Batignolles.

No 8. - de poisson ordinaire du commerce.

Première expérience. J'ai versé sur un verre de montre 1 gramme de chacune des huiles ci-dessus, 3 gouttes d'acide sulfurique concentré, et j'ai agité immédiatement avec un tube de verre.

$N^{0} 1$. Couleur pensée un peu claire, passant au rouge et s'éclaircissant de plus en plus. Après dix minutes, couleur jaune brunâtre.

No 2. Couleur pensée magnifique, s'éclaircissant peu à peu et passant au rouge-cerise. Après dix minutes, couleur jaune noirâtre.

$N^{\circ} 3$. Couleur peusée claire et rougeâtre, s'affaiblissant et passant au rouge par l'agitation. Elle devient ensuite hyacinthe brunatre.

$N^{\circ} 4$. Couleur vineuse devenant promptement terne et finissant par devenir noirâtre.

$N^{\circ} 5$. Couleur vineuse violacée, s'éclaircissant après quelques instants, passant ensuite au rouge brunâtre et au noirâtre.

№ 6. Couleur vineuse violacée foncée, passant promptement au brunatre et finissant par devenir presque noire.

No 7. Couleur pensée claire, passant au rouge vineux, puis au rouge jaunâtre.

No 8. Couleur jaune brunâtre passant promptement au noir.

Deuxième expérience. Huile 6 gouttes, acide sulfurique concentré 2 gouttes; agitation immédiate.

No 1 . Couleur pensée rougeâtre, passant au rouge et ì l'hyacinthe.

No 2. Belle couleur pensée foncée, passant au rouge, puis à l'hyacinthe.

$N^{\circ} 3$. Couleur vineuse un peu violacée; passant presque immédiatement à l'hyacin the.

$N^{\circ} 4$. Couleur rouge-hyacinthe.

No 3 . Rouge violacé, passant immédiatement à l'hyacinthe.

No 6 . Couleur brune foncée, devenant immédiatement brune-hyacinthe, puis noire jaunâtre.

No 7 . Couleur jaune-hyacinthe, avec une nuance violacée sur les bords, devenant ensuite brunâtre, puis noire jaunâtre.

$N^{\circ}$ 8. Couleur hyacinthe jaunàtre devenant noirâtre.

Après vingt-quatre lieures, tous les essais précédents présentent une couleur' noirâtre avec un mélange de rouge ou de jaune verdâtre.

La même huile peut présenter tantôt une nuance, tantôt l'autre.

Troisième expérience. - I'raitement par le chlore.

No 2. Huile de foie de morue brune. Prend promptement une couleur noirâtre et se trouble.

No ${ }^{4}$. Huile de foie de morue blanche. Se trouble aussitôt et paraît se décolorer. En continuant le courant de gaz, le liquide redevient transparent et d'un jaune obscur ou noirâtre.

No 6. Huile de foie de raie Gobley. Brunit beaucoup, mais reste trans. 
parente. Abandonuée à elle-même pendant plusieurs jours, on ne la distingue plus du $n^{0} 2$.

№ 8. Huile de poisson commune. Brunit moins que la précédente, conserve une teinte jaune et reste transparente. Après plusieurs jours de repos, elle est devenue d'un brun noir.

Si l'on considere la coloration en violet par l'acide sulfurique comme le caractère distinctif de la meilleure huile de foie de morue, on mettra au premier rang l'huile brune du commerce; au deuxieme rang, l'huile vendue par le docteur Jongh ; au troisième rang, l'huile blonde du commerce, qui est peut-être la même que celle de MM. Cabaret et Rivet.

L'huile blanche anglaise paraît être de mauvaise qualité; peut-être n'est-ce pas de l'huile de foie de morue.

L'huile de foie de raie paraît être très-inférieure à l'huile de foie de morue brune.

On a voulu expliquer l'action restaurante de l'huile de foie de morue, dans le cas de consomption rachitique et de phthisie luberculeuse, par la présence de l'iode et du phosphore; mais nous venons de voir que ce dernier corps n'existe pas dans l'huile brune purifiée, qui est certainement la plus active. Quant à l'ịode, on ne peut douter qu'il ne contribue pour quelque chose à l'aclion médicatrice de l'huile. Mais le principe huileux par luimême, en fournissant à la respiration l'élément combustible propre à entretenir la chaleur animale, sans qu'il en coûte rien à un corps amaigri, peut contribuer beaucoup à la restauration presque immédiate mais malheureusement souvent passagère de l'individu. Le principe aromatique et âcre de l'huile de poisson ne doit pas être élranger non plus à son action sur l'éconoınie; aussi suis-je persuadé que l'huile simplement additionnée d'iode, proposée par M. Personne comme succédanée de l'huile de foie de morue, pourra rendre de grands services à la médecine, sans cependant remplacer complétement l'huile de foie de morue.

URDRE DES MALACOPTÉRIGIENS APODES.

Les malacoptérygiens apodes, ou qui manquent de nageoires ventrales, ont tous une forme allongée, une peau épaisse et molle qui laisse peu paraître leurs écailles; on les divise en plusieurs genres principaux, sous les noms de anguilles, gymnotes, donzelles, équilles, etc.

Les anguilles ont les opercules pelits, entourés concentriquement par les rayons, et recouverts, aussi bien qu'eux, par la peau qui ne s'ouvre que fort en arrière par un trou, ce qui, abritant mieux les branchies, permet à ces poissons de rester plus ou moins longtemps hors de l'eau, sans périr. Leur corps est long et 
grêle; leurs écailles, comme encroûtées dans une peau grasse et épaisse, ne se voient bien qu'après la dessiccation de celle-ci; ils manquent tous de nageoires ventrales et de cœcums, et ont l'anus placé assez loin en arrière. On les divise encore en anguilles proprement dites, ophisures, murènes, symbranches, etc.

Les anguilles proprement dites ont des nageoires pectorales et ont la dorsale et la caudale sensiblement prolongées autour du bout de la queue, de manière à y former, par leur réunion, une caudale pointue. On y trouve d'abord nos anguilles communes, dont la mâchoire supérieure est plus courte que l'inférieure et dont la nageoire dorsale commence à une assez grande distance en arrière des pectorales. Ces poissons, longs d'environ ร̌ว centimètres, mais que l'on dit pouvoir acquérir une taille beaucoup plus grande, habitent pendant la plus grande partie de leur vie les eaux douces de presque tous les pays, les mares et les étangs, aussi bien que les rivières; cependant ils viennent de la mer, et tous les ans, au printemps, on observe à l'embouchure des rivières des myriades de petites anguilles auxquelles on donne le nom 'de montée, qui viennent remplacer celles que la pêche ou la voracité des autres poissons ont détruites, et qui ne paraissent retourner à la mer que pour y déposer leur frai. Les anguilles nagent également bien en arrière et en avant, et leur peau est si glissante qu'on les saisit très-difficilement. Elles peuvent quilter l'eau et traverser les prairies, soit pour y chercher des limaces ou des vers, soit pour gagner d'autres cours d'eau ou pour se glisser dans les fontaines, les puits, les citernes, etc. Elles ont la vie fort dure, et on les voit remuer et palpiter pendant un certain temps, après avoir été écorchées et coupées par tronçons; leur chair est blanche, grasse, d'un goût très-agréable, mais elle est difficile à digérer.

Les congres diffèrent des anguilles communes par leur mâchoire supérieure plus longue que l'inférieure et par leur dorsale qui commence assez près des pectorales. Le congre commun, que l'on vend à Paris sous le nom d'anguille de mer, atteint 2 mètres de longueur el la grosseur de la cuisse.

Les murènes manquent tout à fait de pectorales, mais ont encore la dorsale et l'anale bien visibles; leurs branchies s'ou. vrent par un petit trou de chaque côté; leurs opercules sont très-minces et leurs rayons branchiostéges complétement cachés sous la peau; l'espèce la plus célèbre est la murène commune, poisson très-répandu dans la Méditerranée et dont les anciens faisaient grand cas. Ils en élevaient dans des viviers, et l'on a souvent cilé la cruauté de Védius Pollion, qui faisait jeler aux siennes ses esclaves fautifs. 
Les gymnotes ont, comme les anguilles, les ouïes en partie fermées par une membrane; mais cette membrane s'ouvre audevant des nageoires pectorales. L'anus est placé fort en avant; la nageoire anale règne sous la plus grande partie du corps et le plus souvent jusqu'au bout de la quene; mais il n'y a pas du tout de nageoire dorsale. Il y en a une espèce fort célèbre qui habite les rivières de l'Amérique méridionale : e'est le gymnote électrique, à qui sa forme allongée et tout d'une venue, et sa tête et sa queue obtuses, on tait donner aussi le nom d'anguille électrique. Il atteint $2^{\mathrm{m}}, \check{b}$ à 3 mètres de longueur, et donne des commotions électriques si violentes qu'il abat les hommes et les chevaux. L'organe qui produit ces effets règne tout, le long du dessous de la queue, dont il occupe la moitié de l'épaisseur. Il est formé de quatre faisceaux longitudinaux, composés d'un grand nombre de lames parallèles, très-rapprochées, aboutissant d'une part à la peau, de l'autre au plan vertical moyen du poisson, el recevant un très. grand nombre de nerfs.

ORDRE DES CIIONDROPTÉRYGIENS.

Les poissons chondroptérygiens ou cartilagineux, forment une série (1) peu nonbreuse, mais très-remarquable par ses formes variées et son organisation. Ils ont le squelette essentiellement cartilagineux, c'est-à-dire qu'il ne s'y forme pas de fibres osseuses, mais que la matière calcaire s'y dépose par petits grains discontinus; ils n'ont pas de sutures à leur crâne, qui est toujour's formé d'une seule pièce. Ils manquent d'os maxillaires et intermaxillaires, dont les fonctions sont remplies par les os analogues aux palatins, ou par le vomer. La substance gélatineuse qui, dans les poissons ordinaires, remplit les intervalles des vertèbres et communique de l'une à l'autre seulement par un petit trou, forme, dans plusieurs chondroptérygiens, une corde qui enfile toutes les vertèbres, sans presque varier de diamètre.

Les chondroptérygiens se divisent en deux ordres : ceux dont les branchies sont libres, comme dans les poissons ordinaires, et ceux dont les branchies sont fixes, ou attachées à la peau par leur bord extérieur, en sorle que l'eau n'en sort que par des trous de la surface. Le premier ordre ne forme qu'une famille dite des sturioniens; le second ordre forme deux familles : les sélaciens et les cyclostomes.

Les sturioniens tiennent encore d'assez près aux poissons or-

(1) Voir le tableau de la classification des poissons, p. 157. 
dinaires, par leurs ouïes, qui n'ont qu'un seul orifice très-ouvert et garni d'un opercule, mais sans rayons à la membrane. Ils ne forment que trois genres dont le principal est celui des esturgeons.

Les esturgeons ont aussi la forme générale des poissons osseux, et élablissent, par la conformation de leur squelette, le passage entre ceux-ci et les vrais chondroptérygiens; car plusieurs os de leur tête et tous ceux de l'épaule sont complétement durcis; leur mâchoire supérieure se compose des palatins soudés aux maxillaires, et l'on trouve dans l'épaisseur des lèvres des vestiges des intermaxillaires. Leur corps est plus ou moins garni d'écussons implantés sur la peau en rangées longitudinales; leur bouche est petite et dépourvue de dents; leur nageoire dorsale est située en arrière des ventrales el au-dessus de l'anale; enfin la caudale entoure l'extrémité de la queue el présente en dessous un lobe saillant. Ces poissons sont en général de grande taille et sont doués d'une force musculaire considérable; mais ils ont des habitudes paisibles el ne sont guère redoutables que pour les petits poissons. Au printemps, les esturgeons remontent par troupes nombreuses de la mer dans les fleuves, pour y déposer leurs œufs, et les jeunes paraissent gagner promptement la mer et y rester jusqu'à l'âge adulte. Leur fécondité est très-grande, car on assure avoir trouvé près de $1,500,000 œ u f s$ dans une femelle du poids de 139 kilogrammes, et dans une autre, pesant 1,400 kilogrammes, les $œ u$ fs seuls en pesaient 400. Nous avons dans toute l'Europe occidentale l'esturgeon commun (Acipenser Sturio, L.), long de plus de 2 mètres, à museau pointu, et pourvu de š rangées d’écussons forts et épineux. On le rencontre également dans les fleuves qui se jettent dans la mer Noire et dans la Caspienne, mais il y est accompagné d'autres espèces, et principalement du grand esturgeon (Acipenser Huso, L.) (fig. 908), dont les boucliers sont plus

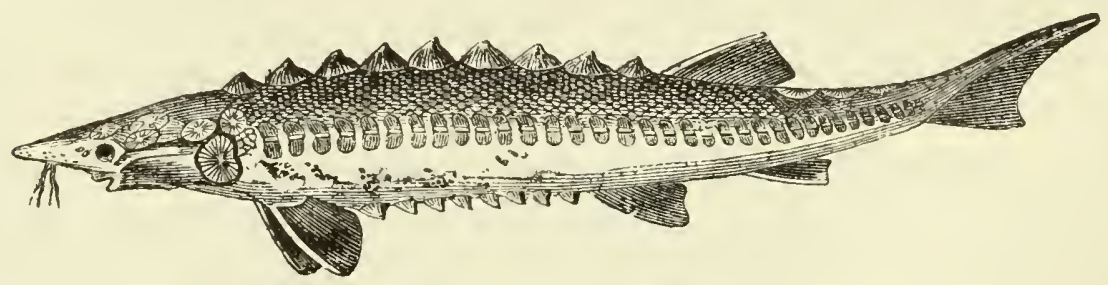

Fig. 908. - Grand esturgeon.

émoussés, les barbillons plus courts et la peau plus lisse que dans l'esturgeon ordinaire. Il atteint souvent 4 à 5 mètres de lon. gueur et plus de 600 kilogrammes de poids. C'est arec ses œufs pressés et salés que l'on prépare le caviar, mets très-recherché dans les pays du Nord, et avec sa vessie natatoire que l'on fait l' $i$ - 
chthyocolle ou colle de poisson. On trouve aussi dans les mêmes régions le Sewruga (Acipenser stellatus Pallas), le Sterlet (Acipenser Ruthenus L.) et l'acipenser Güldenstüdtii, qui contribuent à la production de cetle substance.

Ichthyocolle, ou colle de poisson. Cette substance se prépare surtout en Russie, avec la vessie aérienne du grand esturgeon et des autres Acipenser. On nettoie ces vessies, on les roule sur ellesmêmes, on les fait sécher, et, sur la fin de leur dessiccation, on leur donne la forme d'une lyre ou d'un cœur, comme on le voit dans le commerce : d'autres fois aussionse contente, aprèsqu'elles ont été netloyées et séchées en partie, mais non roulées, de les plier en carré, à peu près comme nous faisons d'une serviette, et l'on en achève la dessiccation après les avoir rapprochées à la manière des feuillets d'un livre, et fixées à l'aide d'un bâton qui les traverse. Ces trois modes de préparation, qui constituent les trois sortes de colle de poisson du commerce, en lyre, en cceur et en livre, donnent toujours des produits plus ou moins colorés; on les blanchit en les exposant à la vapeur du soufre. On doit les choisir blanches, demi-transparentes, sans odeur, se dissolvant dans l'eau bouillante presque sans résidu, et lui donnant, par le refroidissement, une forte consistance gélatineuse. Lorsqu'on les interpose en feuille mince entre l'œil et la lumière, elles présentent un chatoiement irisé semblable à celui de la nacre de perle.

Des trois sortes de colle de poisson que je viens de nommer, la plus chère et la plus estimée dans le commerce est celle en lyre, dite aussi petit cordon, à cause de sa petitesse, comparativement à celle on cour que l'on nomme communément gros cordon, après vient le gros cordon et enfin la colle de poisson en livre, qui est la moins estimée. Je ne crois pas que cette gradation soit bien raisonnée, car j'ai éprouvé, par expérience, que le gros cordon se dissolvait bien plus facilement dans l'eau que le petit, qu'il fournissait au moins autant de gélatine, et laissait plutôt moins de résidu qu'autant. Quant à la colle en livre, elle m'a paru moins facilement soluble que le petit cordon; mais, en définitive, elle ne laisse pas plus de résidu, et sa qualité est presque égale.

Celte dernière est à présent la seule qui arrive dans le commerce; les divers systèmes de colle roulée facilitant beaucoup la fraude (1).

La colle de poisson est très-usitée pour faire des gelées, et pour clarifier différentes liqueurs, comme la bière et le vin blanc. Elle possède à cet égard une propriété beaucoup plus marquée

(1) Voir pour la préparation de l'Ichthyocolle de Russie, J. Léon Soubeiran : Journal de pharmacie et de chinie, $\mathbf{4}^{\mathrm{e}}$ série, $\mathrm{X}, 43$. 
qu'aucune des colles ou gélatines obtenues par décoction de diverses substances animales. Cela tient à ce que, au lieu d'être un produit désorganisé, soluble dans l'eau, l'ichthyocolle est formée d'un tissu organique qui se gonfle et se divise seulement dans l'eau, en formant un réseau qui se resserre par suite de sa combinaison arec quelque principe astringent des liqueurs, entraînant toutes les impuretés dans sa précipitation.

Autres colles de poisson.

Colle de poisson anglaise. Cette colle est en lanières filiforrmes, longues de 5็ millim. environ, qui paraissent avoir été coupées dans de l'ichthyocolle en feuilles, d'une qualité supérieure. Elle est presque transparente, très-chatoyante à la lumière, trèsfacilement et complétement soluble dans l'eau, donnant une gelée transparente et incolore. C'est la plus belle et la meilleure des ichthyocolles naturelles.

[Pereira décrit une colle de poisson de l'Inde, qui paraît fournie par un Polynemus, très-probablement le Pol. plebeius (1).] Ce genre de poissons, qui est très-commun dans les mers tropicales et dans le Gange donne actuellement une assez grande quantitéd'ichthyocolle del'Inde; on utilise aussi les Bola etles Silures, particulièrement le Silums Raita. Les produits qu'on en obtient ont toujour's une légère odeur de poisson; ils laissent plus de résidu que la colle de Russie, donnent une gelée transparente, moins ferme que celle des Acipenser. On les reçoit en grande quantilé sur les marchés de Londres; ils servent surtout à la clarification de la bière (2).

Colle de poisson vitreuse. Cette substance, fabriquée arec les écailles de carpe, est la plus belle des colles artificielles que j’aie vues. Elle est en lames très-minces, incolores et transparentes comme du verre, à surface resplendissante, rayée de lignes parallèles rapprochées. Elle a la consistance et presque la ténacité de la corne, est quelque temps à se dissoudre dans la bouche, mais se dissout complétement dans l'eau bouillante, et forme une gelée aussi belle et aussi consistante que l'ichthyocolle. Il ne faut pas la confondre avec les gélatines de quadrupèdes, que l'on prépare aujourd'hui très-minces et fort belles, mais qui ne produisent jamais avec l'eau une gelée aussi abondante ni aussi tremblante.

Fausse ichthyocolle en 1yre. Cetle substance provenant de vessies de machoiran de Cayenne et de Para a tout à fait la forme de l'ichthyocolle en lyre, et est fabriquée comme elle avec une

(1) Voir Pharm. Journal, t. X, p. 600.

(2) Voir J. Léon Soubeiran: Ichthyocolle de l'Inde et de la Chine (Journal de pharmacie et de chirrie, $4^{\mathrm{e}}$ série, XI, 153.) 
membrane de poisson roulée, contournée et desséchée. Elle est plus grosse que le petit cordon, d'une couleur terne, grise ou jaune sale, d'un aspect corné, à peine chatoyante, très-difficile à diviser, et ne se dissolvant tout au plus qu'à moitié dans l'eau. Il convient de la rejeter.

Fausse culle de poisson en feuilles. Cette substance provient des vessies natatoires de moruequi nous arrivent par Dunkerque. Elle est en feuilles très-minces, longues de 22 à 27 centimèlres, larges de 6 à 8 ; elle est bosselée, opaque, d'un blanc terne et non chatoyante; elle se déchire facilement en tous sens, tandis que la véritable colle de poisson ne se déchire que dans le sens de ses fibres. Elle offre une saveur salée.

Elle se ramollil dans l'eau, se tuméfie et s'y divıse en grumeaux. Elle laisse un résidu considérable lorsqu'on la traite par l'eau bouillante, et la liqueuĩ ne se prend pas en gelée en refroidissant. On trouve souvent de cette fausse colle de poisson chez les épiciers de campagne.

Colle de machoiran de Cayenne. J'ai reçuanciennement, d'une personne qui occupait un poste supérieur à Cayenne, trois vessies de machoirans (1), qui sont très-épaisses, comme musculeuses et formées d'une cavité supérieure cordiforme, plus large que haute, séparée par un étranglement d'une seconde carité oblongue ou fusiforme. La plus petite de ces vessies, à l'élat de dessiccation, est longue de 22 centimètres, large de 10 à sa partie supérieure, et pèse 102 grammes. La seconde vessie présente une cavité supérieure large de 13 centimètres, haute de 11, une cavité inférieure longue de 153 , large de 7 , et est d'un poids total de 278 grammes. La troisième, dont je n'ai que la cavité cordiforme, volumineuse et très-déformée, pèse 460 grammes. Celle ichthyocolle m’a paru peu soluble dans l'eau et ressembler beaucoup, pour la qualité, à la fausse colle en lyre, décrite ci-dessus. Mais on trouve dans le commerce une très-belle colle fabriquée à Gayenne, que l'on suppose appartenir à la vessie natatoire d'un machoiran, et qui, si elle est tirée de ce poisson, ne peut provenir que de sa peau même, préparée et blanchie.:Cette colle, telle qu’elle se trouve lans la collection de l'École, est en une feuille très-mince, incolore, presque transparente, luisante à sa surface, faiblement nacrée, non irisée, longue de 90 centimèlres, large de 14, offrant la forme générale d'un poisson. Dans la substance mème de la feuille se trouvent imprimés, en lettres transparentes, les mots : P. Pouget, à Cayenne.

(1) Ces poissons appartiennent à la famille des siluroïdes, de l'ordre des malacoptéry giens abdominaux. 
Cette ichthyocolle, de même que la fausse colle en feuille cidessus, se déchire facilement en tous sens; mise à tremper dans l'eau, elle s'y gonfle considérablement et se dissout en grande partie par l'ébullition, en laissant cependant un résidu floconneux el opaque assez abondant.

\section{ORDRE DES SÉLACIENS.}

Les sélaciens forment plusieurs genres principaux qui sont les squales, les marteaux, les anges, les scies et les raies. Les squales ont un corps allongé, des pectorales médiocres, des ventrales situées en arrière de l'abdomen el des deux côtés de l'anus; une queue grosse el charnue; leurs yeux sont placés anx côtés de la tête, et leurs branchies aux côlés du cou ; an tolal, leur forme générale est celle des poissons ordinaires. Leurs os de l'épaule sont suspendus dans les chairs en arrière des branchies, sans s'articuler ni au crâne ni à l'épine ; leurs petites côtes branchiales sont apparentes, et ils en ont aussi de petites le long de l'épine qui esi entièrement divisée en vertèbres. Chez un grand nombre de ces poissons, il existe à la partie supérieure de la tête deux ouvertures nommées évents, qui servent à porter aux branchies l'eau nécessaire à la respiration, lorsque la guenle est remplie par une proie trop rolumineuse. Plusieurs sont vivipares, les autres font des cufs revêlus d'une coque dure et cornée ; aussi la fécondation a-l-elle toujours lieu arant la ponte.

On divise les squales en plusieurs sous-genres, tels que les roussettes, les requins, les milandres, les grisets, les pèlerins, les humantins, les aigullats, les leiches, etc.

Les roussettes ont le museau courl et obtus, les narines percées près de la bouche, conlinuées en un sillon qui règne jusqu'an bord de la lèvre, et plus ou moins fermées par un ou deux lobules cutanés; leurs dents sont formées d'une pointe au milieu et de deux plus petiles sur les côtés. Elles ont des évents et une nageoire anale répondant à l'intervalle des deux dorsales, qui sont elles-mêmes placées fort en arrière. La grande roussette ou chien ale mer (Scyllium Canicula) atteint près de $1^{\mathrm{m}}$, 50 de longueur, est très-vorace, et suit les vaisseaux pour saisir tout ce qui en tombe. Sa peau desséchée est connue dans le commerce sous les noms de peau de roussette, de chien de mer, on de chagrin, elle est toute couverte de petits tubercules cor .és, qui lui donnent la dureté d'une râpe, et qui la rendent propre à polir le bois, l'ivoire et même les métaux. Le foie de roussette cause de graves accidents à ceux qui en mangent. Il fournit, à l'aide du feu, une grande quantité d'huile. 
Les requins ont en dessous de leur museau proéminent des narines non prolongées en sillon, et une large gueule demi-cireulaire, munie de dents tranchantes et pointues, dentelées sur leurs bords. Ils manquent d'évents, ont la première dorsale bien avant les ventrales, et la deuxième à peu près vis-à-vis de l'anale. Le requin vrai (Carcharias verus) a 8 ou 10 mètres de long, un e gueule fortement fendue au-dessous du museau, el d'un contour égal environ au liers de la longueur le l'animal. Il est d'une force et d'une voracité extrêmes, et est l'effroi des navigateurs dans presque toutes les mers. Il avale les hommes tout entiers et fait sa nourriture habituclle des thons, des phoques et des morues.

La peau du requin sert aux mêmes usages que celle de la roussette. On en couvre aussi des malles, et l'on en fait des liens, des courroies, des outres à contenir de l'huile, etc.

Les scies ont la forme allongée des squales; mais leur corps est aplati en avant, leurs branchies sont ouvertes en dessous, comme dans les raies, et leur museau se prolonge en un long bec osseux, déprimé en forme de lame d'épée, et armé, de chaque côté, d'une série de grandes pointes tranchantes, implantées comme les dents d'une scie. Ce bec, qui leur a valu leur nom, est un e armepuissante arec laquelle ces poissons ne craignent pas d'atlaquer les plus gros cétacés. Les vraies dents de leurs mâchoires ont la forme de petits pavés.

Les raies forment un genre non moins nombreur que celui des squales. Elles se reconnaissent à leur corps aplali horizontalement el semblable à un disque, à cause de son union avec des pectorales très-amples et charnues, qui se joignent en avant avec le museau, et qui s'étendent en arrière jusque vers la base des ventrales. Les yeux etles évents sont à la face dorsale; la bouche, les narines el les orifices des branchies à la face rentrale. Les nageoires dorsales sont presque toujours sur la queue. On les divise en rhinobates, torpilles, raies proprement diles, pastenagues, etc.

Les torpilles $(f g$. \&10 et 911 ) ont la queue courte et encore assez charnue; le disque de leur corps est à peu près circulaire, le bord antéricur étant formé par deux productions du museau qui se rendent de côté pour atteindre les pectorales. Nous citerons la torpille commune, Torpedo Narlie, Resso ; liaja Torpedo, L.L'espace entre ces pectorales, la tête et les branchies, est rempli de chaque côté par un appareil extraordinaire (fig. 910), formé de petits tubes membraneux serrés les uns contre les autres, comme des rayons d'abeilles, subdivisés par des diaphragmes horizontaux en petites cellules pleines de mucosités, et animés par des nerfs abondants venant de la huitième paire. C'est dans cet appareil que réside la puissance électrique qui a rendu ces poissons si célèbres 
et qui leur a valu leur nom. Ils ne sont pas cependant aussi redoutables que le gymnole électrique dontj'ai parlé précédemment (page 192). On connaît un troisième genre de poisson électrique appartenant aux malacoptérygiens abóominaux et à la famille des

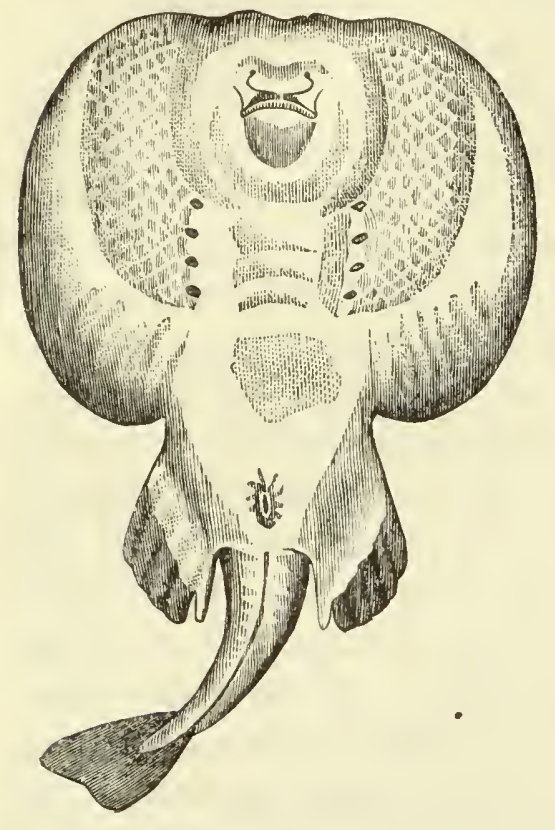

Fig. 910. - Torpille commune.

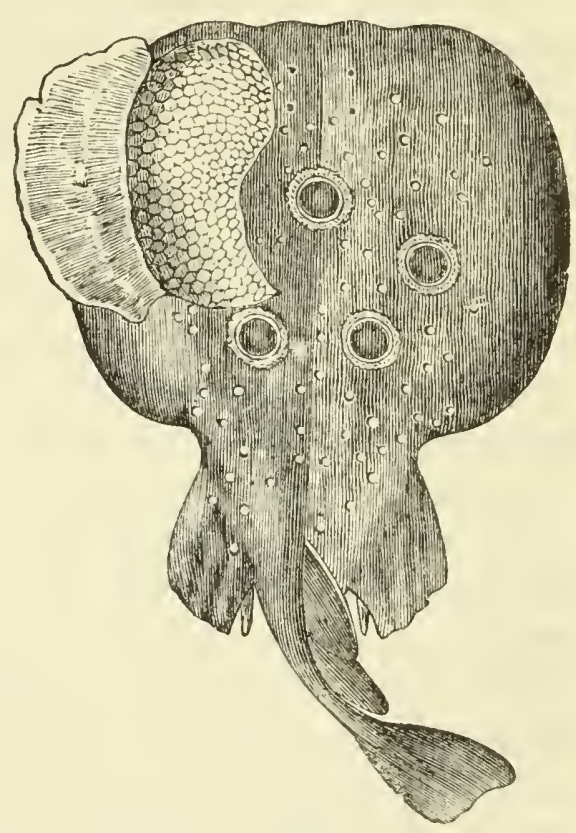

Fig. 911. - Turpille commune.

siluroïdes : c'est le silure ou malaptérure électrique, le raasch ou tonnerre des Arabes, qui habite le Nil et le Sénégal (1).

Les raies proprement dites ont le disque rhomboïdal, la queue mince, garnie en dessus, vers la pointe, de deux petites dorsales, et quelquefois d'un vestige de caudale. Nos mers en fournissent beaucoup d'espèces encore mal déterminées; l'une des plus estimées pour la table est la raie bouclée (Raja clavata, L.), qui se distingue par son âpreté et par les gros tubercules osseux, ovales et garnis chacun d'un aiguillon recourbé, qui hérissent irrégulièrement et en nombre très-variable ses deux surfaces.

L'huile de foie de raie, telle qu'on la prépare dans les pharmacies, est d'un jaune doré, transparente et de propriétés analogues à celles de l'huile de foie de morue; elle paraît contenir moins d'iode (voyez page 158).

Les pastenagues diffèrent des raies par leur queue armée d'un

(1) Voyez C. Matteucci, Traité des phènomènes électro-physiologiques dcs animaux, suivi d'études anatomiques sur le système nerveux et sur l'organe électrique de la torpille. Paris, 184'. - Jobert (de Lamballe), des Appareils électriques des poissons électriques. Paris, 1858, in-8 arec atlas de $11 \mathrm{pl}$. in.fol. Robin, Sur les phénomènes et la direction de la décharge par l'appareil électrique des Raies (Annales Sciences naturelles, $5^{\mathbf{e}}$ série, IV, 340). 
long aiguillon dentelé des deux côtés, ce qui en fait une arme très-dangereuse. C'est à ce genre qu'appartient le sephen de la mer liouge et de la mer des Indes, qui fournit à l'industrie cette peau dure et tuberculeuse appelée galuchat, du nom d'un ouvrier de Paris qui paraît l'avoir mis en usage. La plupart des sélaciens, tels que les roussettes, les requins, les humantins, les aiguillats, les leiches, etc., sont d'ailleurs pourvus d'une peau rude et tuberculeuse, dont on se sert pour faire des courroies, couvrir des malles, des étuis, des boîtes à bijoux, des garnitures d'armes, ou pour polir le bois, l'ivoire et les métaux. La plus grande confusion régnant dans le commerce entre ces peaux, chaque commerçant leur appliquant à sa fantaisie les noms de peau de requin, de chien de mer, de chagrin et même de galuchat, je me suis procuré celles que j'ai pu, afin de les décrire et d'en déterminer l'espèce autant que possible.

1. Peau de requin. Je n'ai pas trouvé cette peau dans le commerce; celle d'un jeune requin desséché, qui fait partie de la collection de l'École, est mince, couverte partout de très-petites écailles imbriquées, d'une couleur grise uniforme, à demi translucides, rayées dans le sens longitudinal, et à bord entier et circulaire. Ce bord est libre sur le corps de l'animal, ce qui donne à la peau de la rudesse au toucher, mais il est soudé sur les nageoires, qui offrent un toucher très-doux. Celte peau pourrait servir à couvrir des malles, des meubles ou des étuis; mais fort peu à polir les ouvrages de bois ou d'ivoire; c'est pour cela sans doute qu'on ne la trouve pas dans le commerce.

2. Peau de roussette mouchetée. Cette peau est ouverte par le ventre; elle a le museau court et arrondi; les évents placés tout près des yeux, un peu au-dessous et en arrière. Les branchies ont cinq ouvertures dont les deux dernières sont placées au-dessus des pectorales; celles-ci sont coupées carrément et les ventrales le sont obliquement. Les deux dorsales sont placées bien en arrière des ventrales, et l'anale répond à l'intervalle des deux dorsales. La caudale se compose de deux parties presque distinctes : une inférieure, grande et triangulaire, obscurément lobée en arrière; une terminale, courte, élargie, coupée carrément à l'extrémité, arrondie aux angles, faiblement échancrée au milieu, et formant deux lobes arrondis, peu marqués.

Tous ces caractères appartiennent à la première section des roussettes (Scyllium de Cuvier), mais j'en ignore l'espèce. Ces peaux sont longues de 70 à 73 centimètres, larges de 14 à 16 centimètres un peu en avant des pectorales, ce qui est le point de leur plus grande largeur. Toute la peau du dos, comprise entre les nageoires, et depuis l'extrémité du museau jusqu'à celie 
de la queue, est couverte d'une infinité de taches rondes et brunâtres, sur un fond blanchâtre. Le ventre, en étant dépourvu, est blanc. Les taches sont assez grandes ct distinctes sur les côtés du corps, principalement à la lace supérieure des pectorales, qui présente la disposition des taches du guêpard ou du serval. Ces taches diminuent de grandeur, se rapprochent et finissent presque par se confondre sur la ligne médiane du dos, qui est, à cause de cela, d'un gris noirâtre plus foncé que le reste du corps (1). Toute celte peau est couverte d'écailles tuberculeuses imbriquées, trèsfines et très-serrées; cornées, très-dures, transparentes. Chacune de ces écailles est triangulaire et comme formée de trois pointes épineuses soudées, dont les deux latérales sont courtes et élargies, et celle du milieu proéminente, plus longue et terminée par une pointe aiguë. Toutes ces écailles, dont la pointe est dirigée en arrière, donnent à la peau un reflet velouté et lui communiquent la rudesse d'une rìpe. Cette peau est d'un très-grand usage pour polir ; on en forme aussi, à ce qu'on m'a assuré, ce que je nomme du faux galuchat, en usant par le frottement les écailles, qui laissent sur le derme l'impression d'un réseau carré, lequel devient très-apparent en collant la peau ainsi préparée sur un papier vert, recouvrant lui-même les objets de gânerie auxquels on veut donner celte couverture. Mais je suis persuadé que ce faux galuchat est obtenu plutôl avec la peau d'aiguillat, dont il sera question ci-après.

3. Pean de leiche. Cette peau est celle que l'on vend le plus communément, sous le nom de peau de chien de mer, aux ébénistes, pour polir le bois. Elle est ouverte par le dos, longue de $\mathbf{1}^{\mathrm{m}}, \mathbf{4 5}$, large de $0^{\mathrm{m}}, 46$ en arrière des pectorales, et présente, dans son état de dessiccation, une forme à peu près rhomboïdale. La tête a dû être fort obtuse et le museau court; les narines sont placées à l'extrémité du museau et éloignées de la bouche : l'ouverture des yeux est placée en arrière de chaque narine : elle est assez grande et ovale-oblongue. Les évents en sont assez éloignés; les ouvertures branchiales sont au nombre de cinq; les deux dernières sont très-rapprochées, et la dernière touche aux nageoires pectorales. Toutes les nageoires à l'exception de la caudale, qui est plus grande, sont sensiblement égales et ont 13 à 14 centimètres de longueur. Les nageoires pectorales commencent à 24 centimètres à l'extrémité du museau; la première dorsale à 48, les deux ventrales à 86 , la deuxième dorsale

(1) Une peau de roussette, un peu différente des précédentes, est longue de 55 centimètres, large de $\mathbf{1 4}$, d'une teinte grise à peu près uniforme, offrant des taches très-nombreuses peu distinctes, à peu près également réparties partout, cependant toujours plus rapprochées sur le dos que sur les flancs. 
à 90 , et la caudale à $\mathbf{1}^{\mathrm{m}}, 10$; il n'y a pas d'anale. La caudale est entière, plus large au commencement, en dessous qu'en

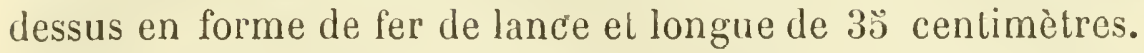

Toute cette peau est d'un gris brunâtre uniforme et présente l'aspect et le toucher d'une râpe. Elle est toute couverte d'écailles tuberculeuses, disposées en quinconce, 'très-rapprochées, mais laissant cependant un espace distinct entre elles. Ces écailles sont toutes égales, comme rhomboïdales, fixées au derme par l'angle antérieur, libres et terminées en pointe aiguë à l’angle postérieur. Elles sont demi-transparentes, de nature cornée, et présentent a leur surface 3 ou 4 sillons qui convergent vers la pointe.

4. Peau d'aiguillat. Elle est ouverte par le ventre, longue de 90 centimètres, mais l'extrémité de la tête et la queue manquent. Les évents sont situés de chaque côté, vers le sommet de la tête; les branchies ont $\mathbf{4}$ ou 5 ouvertures transversales, placées en avant des pectorales. La première nageoire dorsale est placée peu en arrière des pectorales, et la seconde dorsale est très-éloignée de la première, en arrière des ventrales. Il n'y a pas d'anale. Chaque nageoire dorsale est précédée par un aiguillon aplati, corné et aigu, long de 4 centimètres. La surface de la peau est comme polie et luisante, marquée d'un grain très-fin et uniforme; elle est d'un gris brunâtre sur le dos et d'un gris blanchâtre sur le ventre. Cette peau appartient évidemment au Spinax Acanthias (Cuv.), qui est assez commun sur nos marchés, mais dont la chair est dure, filandreuse et peu agréable au goût (1). La peau, vueà la loupe, paraît toute couverte de petites écailles épaisses, carrées, disposées en quinconce, d'une transparence opaline et nacrée, incisées ou dentées comme une petite coquille du côté antérieur; terminées à l'angle postérieur par une pointe très-obtuse, non redressée, ce qui prive cette peau de la rudesse qui distingue les précédentes, et fail dire aux ouvriers qu'elle ne mord pas. Mais la régularité de son grain et son éclat nacré la font rechercher des gaînier's et des armuriers, pour faire des étuis et des fourreaux d'épées. Je pense que c'est avec elle également que l'on fabrique le faux galuchat, dont j’ai parlé plus haut.

5. Peau de sagre (Spinax niger, Cuv.). Je n'ai qu'un très-petit carré de cette peau avec un de ses aiguillons; la peau entière n'a pu être retrouvée. Elle ne diffère de la précédente que par ses tubercules plus gros, par une rudesse plus marquée et par une couleur grise plus foncée; l'aiguillon est arrondi à la base, aplati seulement à l'extrémité, long de 6, כ̊ centimètres. Ce qui me fait altribuer cette peau au sagre, c'est que ce poisson a les tubercu-

(1) D'après M. Auguste Duméril, cette peau appartient au Centrophorus gra mulosus (note manuscrite de M. Guibourt). 
les du ventre plus gros et plus colorés que ceux du dos, et que l'aiguillon que j'en ai, ayant été détaché du bord de la peau, celle-ci ćtait par conséquent ouverte par le dos, qui en est, en effet, la partie la moins estimée. Cette peau sert aux mêmes usages que la précédente, mais elle est beaucoup plus belle et plus rare.

6. Galuchat ou peau de sephen. Cette peau, tirée du dos du Trygon Sephen, Clop., se trouve dans le commerce en morceaux roulés, longs de 40 à 60 et quelquefois 6 centimètres. Elle présente, sur un fond gris foncé, un nombre infini de tubercules très-serrés, proéminents, arrondis, blanchis par le froltement, et qui sont à l'intérieur blancs, opaques et nacrés. Ces tubercules grossissent en allant vers le milieu de la peau, dont le centre est toujours occupé par un amas de quelques tubercules beaucoup plus volumineux que les autres. On couvre, avec la peau de sephen, des poires à poudre ; on en fait des fourreaux ou des poignées de sabres et de poignards, etc. Quelques fabricants la blanchissent complétement ou la teignent de différentes couleurs; mais elle est, à mon avis, plus belle avec sa couleur naturelle, étant simplement à moitié polie par le frottement, qui met à découvert la blancheur nacrée de ses tubercules.

\section{ORDRE DES SUGEURS.}

Le dernier ordre des poissons, celui des suceurs ou des cyclostomes, comprend les plus. imparfaits des animaux vertébrés ; ils n'ont ni pectorales, ni ventrales ; leur corps allongé se termine en avant par une lèvre charnue et circulaire ou demıcirculaire; tous les corps des vertèbres sont traversés par un seul cordon tendineux, rempli intérieurement d'une substance mucilagineuse non étranglée. On n'y voit pas de côtes ordinaires; mais les petites côtes branchiales, à peine sensibles dans les squales et les raies, sont ici fort développées et unies les unes aux autres, pour former comme une espèce de cage, tandis qu'il n'y a point d'arcs branchiaux solides. Le principal genre est celui des lamproies, dont l'anneau maxillaire est entièrement circulaire et armé de fortes dents. Sa langue a deux rangées longitudinales de petites dents, et se porte en avant et en arrière comme un piston, ce qui sert à l'animal à opérer la succion qui les distingue. Ils ont une dorsale en avant de l'anus, et une autre en arrière, qui s'unità la nageoire de la queue.

Ils vivent dans l'eau des mers, des fleuves et des rivières, et doivent à leur forme cylindrique et à leur peau nue, lisse et visqueuse, une grande ressemblance avec les anguilles, et les serpents nus. Ils sont privés de vessie natatoire et tombent au fond 
de l'eau, aussitôt qu'ils cessent de se mouvoir. Ils ont l'habitude de se fixer, comme les sangsues, aux pierres (1) et aux autres corps solides, à l'aide du disque concave de leur ventouse. Ils attaquent par le même moyen de grands poissons et parviennent à les percer et à les dévorer. La lamproie marine (Petromyzon marinus, L.), qui atteint une longueur de 70 à 100 et même 160 centimètres, est très-estimée dans quelques pays, tandis qu'elle passe ailleurs ponr être pernicieuse.

\title{
DEUXIEME EMBRANGHEMENT
}

\author{
ANMLUX ANNELÉS
}

Les annelés se subdivisent en cinq classes : les insectes, les arachnides, les myriapodes, les crustacés et les cirrhipèdes.

\section{PREMIÈRE GLASSE}

\section{LES INSEGTES.}

Les insectes ont constamment six pieds; leur corps, dont le nombre des segments ne dépasse jamais douze, est partagé en trois portions principales; la téte, le thorax et l'abdomen; quelques-uns n'ont pas d'ailes, conservent toute leur vie la forme qu'ils avaient en naissant, et ne font que croître et chianger de peau. Les autres ont des ailes, mais ces organes et souvent meme les pieds ne paraissent pas d'abord, et ne se développent qu'à la suite de changements plus ou moins remarquables, nommés métamorphoses. La tête porle les antennes, organes du tact et peut-être de l'ouïe, les yeux et la bouche. La bouche est en général composée de six pièces principales, dont quatre latérales, disposées par paires, se meuvent transversalement ; les deux autres, opposées l'une à l'autre, dans un sens contraire à celui des précédentes, remplissent les vides compris entre elles; l'une est située au-dessus de la paire supérieure, et l'autre au-dessous de l'inférieure. Dans les insectes broyeur's ou qui se nourrissent de matières solides, les quatre pièces latérales font l'office de mâchoires, et les deux autres sont con-

(1) De là le nom de petromyzon qui leur a été donné par Artédi. Le nom de lamproie a la même signification, et vient de lambere petras. 
sidérées comme des lèvres. Les deux mâchoires supérieures ont reçu le nom de mundibules, et les deux inférieures, qui ont conservé celui de mâchoires, portent chacun un ou deux filets articulés, appelés palpes. La lèvre supérieure se nomme labre et l'inf'érieure lèvre; ;icelleci est formée de deux parties : l'une, plus solide et inférieure, est le menton; la supérieure, qui porte le plus souvent deux palpes, est la languette.

Dans les insectes suceurs, ou qui ne prennent que des aliments fluides, les divers organes de la manducation présentent deux sortes de modificalions générales : dans la première, les mandibules et les mâchoires sont remplacées par de petites lames en forme de scies ou de lancettes, composant, par leur réunion, une sorte de suçoir reçu dans une gaîne, soit cylindrique ou conique, et articulée en forme de rostre, soit mem braneuse ou charnue, inarticulée et terminée par deux lèvres, et formant une trompe. Le labre est triangulaire, voûté, et recouvre la base du suçoir. Dans le second mode d'organisation, le labre et les mandibules sont presque oblitérés; la lèvre n'est plus un corps libre, et ne se distingue que par la présence de deux palpes dont elle est le support; les mâchoires ont acquis une longueur extraordinaire, et sont transformées en deux filets tubuleux, réunis par leurs bords et formant une trompe roulée en spirale. A la base de chacun des filets est un palpe très-petit et peu apparent.

Le thurax ou corselet, qui fait suite à la tête, se compose de trois anneaux appelés prothorax, mésothorax et métathorax, presque toujours soudés entre eux et portant chacun une paire de pattes. Lorsqu'il existe des ailes, c'est sur l'arceau dorsal des deux derniers anneaux thoraciques qu'elles sont insérées.

Les ailes sont des pièces membraneuses, sèches, transparentes, attachées sur les côtés du dos du tlıorax. Les premières, lorsqu'il y en a quatre, ou lor'squ'elles sont uniques; sont fixées sur le mésothorax, et les secondes sur le métathorax. Elles sont composées de deux membranes appliquées l'une sur l'autre, et parcourues par des nervures qui sont des tubes trachéens. Dans les papillons, les ailes sont couvertes de très-petites écailles, semblables à de la poussière, qui leur donnent les couleurs dont elles sont ornées. Cette poussière s'enlève facilement avec le doigt; examinée au microscope, elle présente les formes les plus variées.

Beaucoup d'insectes, tels que les hannetons, les cantharides, etc., ont, au lieu des ailes antérieures ou supérieures, deux écailles plus ou moins solides et opaques, qui s'ouvrent et se ferment, et sous lesquelles les ailes sont repliées transversalement, dans l'élat de repos. Ces écailles, formant étui, ont reçu le nom d'élytres; les insectes qui les portent ont reçu le nom de coléoptères (1). Dans d'autres insectes, l'extrémilé de ces étuis est membraneuse comme les ailes; on les nomme demi-étuis ou hémélytres, et les insectes qui les portent hémiptères.

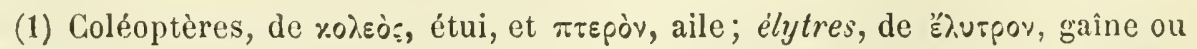
enveloppe. 
Les pieds sont composés d'une hanclic de deux arlicles, d'une cuisse, d'une jambe d'un seul article, et d'un doigt nommé habituellement tarse, divisé en 3 à 5 articulations, dont la dernière est ordinairement terminée par deux crochets.

L'abdomen, qui forme la troisième et dernière partie du corps, renferme les viscères, les organes sexuels, et présente 10 segments plus ou moins mobiles les uns sur les autres. Les parties re ia génération sont situées à son extrémité postérieure et sortent par l'anus. Les derniers anneaux de l'abdomen forment, dans plusieurs femelles, un oviducte plus ou moins compliqué et leur servant de tarière. Il est remplacé par un aiguillon dans les femelles de beaucoup d'hyménoptères. Des crochets ou des pinces accompagnent presque toujours l'organe fécondateur du mâle. Les deux sexes ne se réunissent ordinairement qu'une seule fois, et cet accouplement suffit, dans quelques genres, pour plusieurs générations successives. La femelle fait sa ponte et déposeses cufs de la manière la plus favorable à leur conservation, et de telle sorte que les petits, venant à éclore, trouvent à leur portée les aliments convenables. Il arrive très-souvent, par exemple dans les papillons, que le petit animal sorti de l'œuf ne ressemble en rien à un papilion, et présente seulement un corps trìs-allongé, partagé en anneaux, à tête pourvue de mâchoires et de plusieurs pelits yeux, ayant des pieds tris-courts, dont six écailleux el pointus, placés en avant, et d'autres, en nombre variable, membraneux, attachés aux derniers anneaux. Ces animaux, nommés chenilles, vivent un certain temps dans cet état, et changent plusieurs fois de peau. Enfin il arrive une époque où, de cette peau de chenille, sort un être tout différent, de forme oblongue, sans membres distinets, et qui cesse bientot de se mouvoir, pour rester longtemps, avec une apparence de mort et de desséchement, sous le nom de chrysalide. Après un temps plus on moins long, la peau de la chrysalide se fend, et le papillon en sort humide et mou, arec des ajles flasques et courtes; mais en peu d'instants ses ailes croissent et se raffermissent, et il est en état de voler. Il a six pieds, des antennes, une trompe en spirale, des yeux composés; en un mot, il ne ressemble en rien à la chenille d'où il est sorti.

Voilà ce qu'on appelle les métamorphoses des insectes. Leur premier état se nomme, d'un nom plus général, larve; le second, nymphe; le dernier, état parfait. Ce n'est que dans celui-ci qu'ils peuvent se reproduire.

Tous les insectes ne passent pas par ces trois états : ceux qui n'ont pas d'ailes sortent généralement de l'œuf avec la forme qu'ils doivent toujours garder; et, parmi ceux qui ont des ailes, un grand nombre ne subissent d'autre changement que de les recevoir : on les nomme insectes à demi métamorphoses.

l.es yeux des insectes sont de deux especes : a facettes ou composés, simples ou lisses. Les premiers, situés d'ordinaire sur les cotés de la tête, sont très-volumineux et présentent une cornée convexe, divisée en une multitude de petites facettes, dont chacune représente un œil complet, pourvu d'un enduit de matière colorée ordinairement noire, d'une 
choroïde fixée par son contour à la cornée, et d'un filament nerveux particulier. Le nombre de ces yeux est quelquefois prodigieux, car on en compte près de 9,000 dans le hanneton, plus de 17,000 chez les papillons, et l'on connaît des insectes (les mordelles, par exemple) qui en ont plus de $2 \ddot{0}, 000$.

Plusieurs insectes ont, outre ces yeux composés, des yeux simples ou lisses, nommés aussi ocelles, dont la cornée est tout unie. Ces yeux sont ordinairement au nombre de trois, et disposés en triangle sur le sommet de la tête. Dans la plupart des insectes aptìres et des larves de ceux qui sont ailés, ils remplacent les précédents et sont souvent réunis en groupe.

Le systime nerveux des insectes est généralement composé d'un cerveau formé de deux ganglions opposés, réunis par leurs bases, donnant huit paires de nerfs et deux nerfs solitaires, et de douze ganglions inférieurs réunis entre eux par des cordons longitudinaux. Les deux premiers de ces ganglions sont situés près de la jonction de la tête au thorax, et sont contigus longitudinalement. L'antérieur donne des nerfs à la lèvre inférieure et aux parties adjacentes; le second et les deux suivants sont propres à chacun des trois segments du thorax; les autres ganglions appartiennent à l'abdomen, de manière que le dernier ou douzième correspond au septième anneau de l'abdomen, suivi immédiatement de ceux qui composent les organes sexuels.

La circulation du sang dans les insectes paraît être très-incomplète et est peu connue. On voit bien, près de la surface du dos, un tube longitudinal qui exécute des mouvements alternatifs de contraction et de dilatation, analogues à ceux du cœur chez les animaux vertébrés; mais ce vaisseau dorsal ne fournit aucune branche. Le fluide nourricier y pénètre par des ouvertures latérales garnies de valvules qui empêchent le sang de refluer au dehors. Le vaisseau dorsal lui-même paraît être partagé en plusieurs chambres par d'autres valvules qui s'opposent au retour du sang vers les parties postérieures, et le poussent, au contraire, dans une artère unique qui le transporte dans la tête. De là, on suppose qu'il repasse dans l'abdomen par une sorte d'imbibition générale, et qu'il rentre daus le vaisseau dorsal par les ouvertures latérales dont il a été parlé. Ce fluide nourricier, quelle que soit d'ailleurs sa nature, a besoin d'être vivifié par le contact de l'oxygène atmosphérique, ou par la respiration. Celle-ci s'opère par des ouvertures nommées stigmates, situées de chaque côté de l'abdomen, et communiquant, par canal, avec deux vaisseaux aérifères principaux, nommés trachées, qui s'étendent parallèlement l'un à l'autre dans toute la longueur du corps. Ces deux trachées principales se subdivisent à l'infini en d'autres trachées de plus en plus petites, qui portent l'air dans toutes les parties du corps, et le mettent en contact avec le sang dont ces parties sont imbibées.

Il n'y a aucune classe d'animaux qui soit aussi nombreuse en espèces que celle des insectes; on en connaît plus de soixante mille, et la vie d'un homme suffirait à peine pour en faire une étude approfondie. Leur division en ordres repose principalement sur des considérations tirées de leur appareil buccal, de leurs organes de locomotion et 
de leurs métamorphoses. Le tableau suivant, emprunté à M. H. MilneEdwards (1), donnera une idée exacte des principaux caractères employés dans celle classifiction.

\section{INSECTES}

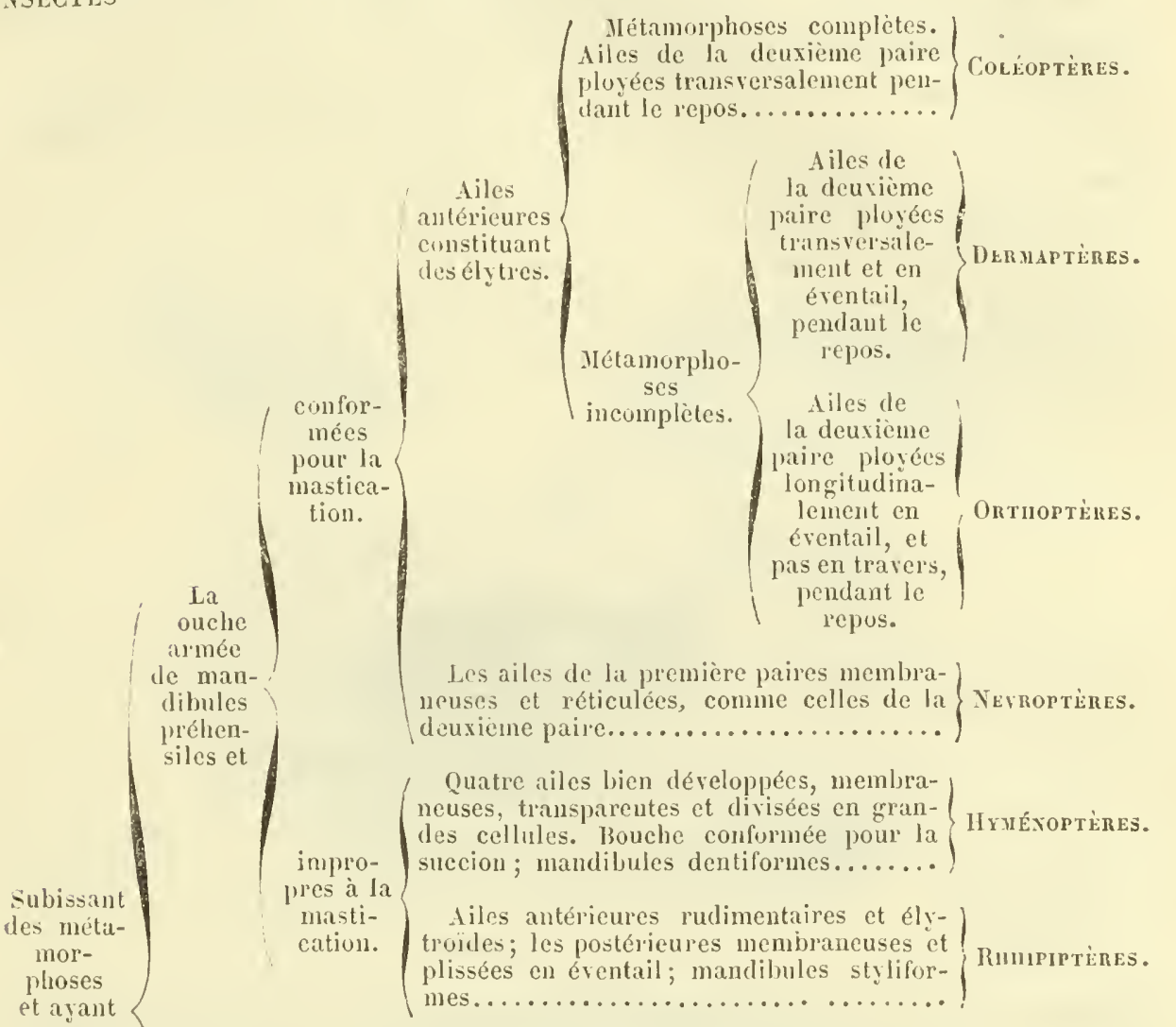

presque

loujours

din's

ailes.

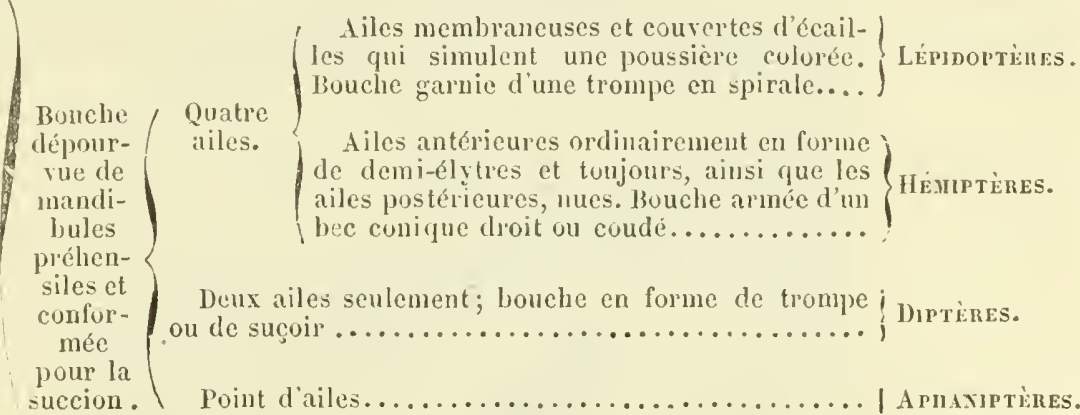

ve subissant pas de métamor- (Abdumen dépourvu d'appendices...... | A roploures. phuses, n'ayant jamais d'ailes.. $\left\{\begin{array}{c}\text { Abdomen garni de fausses pattes ou } \\ \text { d'appendices propres au saut............ Tursaroures. }\end{array}\right.$

\section{ORDRE DES COLÉOPTÈrRS.}

L'ordre des coléoptères comprend tous les insectes pourvus d'élytres et subissant une métamorphose comp̧lète. Leur tête offre des antennes

(1) Milne-Edwards, Eléments de zoologie. Paris, 1869. - Voyez aussi sur ce sujet Maurice Girard, les Insectes, Traité élémentaire d'Entomologie. Paris, $1873-1876,2$ vol. in-8, avec Atlas de 100 planches. 
de formes rariées, mais dont le nombre des articles est presque tonjours de onze; deux yeux à facettes ct pas d'yeux lisses; une bouche composée d'un labre, de deux mandibules de consistance cornée, de deux mâchoires portant chacune un ou deux palpes, et d'une lèvre composée de deux pieces, le menton et la languette et accompagnée de deux palpes insérés sur cette dernière piece.

Le segment antérieur du thoras, nommé prothorax ou plus commodément corselet, porte la première paire de pieds, et surpasse de beaucoup en étendue les deux autres segments. Ceax-ci s'unissent étroitement arec l'abdomen, et leur partie inférieure, ou la poitrine, sert d'attache aux deux autres paires de pieds, tandis que leurs bords latéraux et supéricurs donnent naissance aux élytres et aux ailes. Les élytres sont crustacées et, dans l'état de repos, se joignent sur la ligne

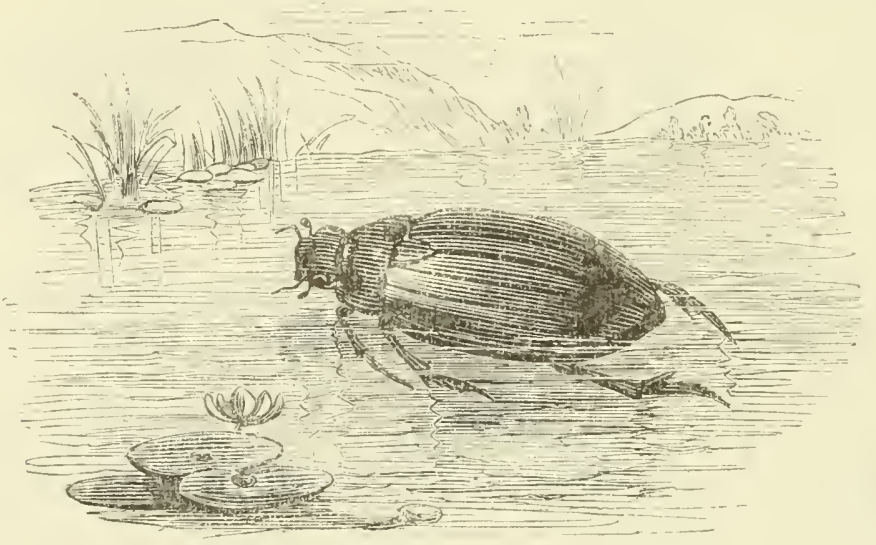

lig. 912. - Hydrophite.

médiane, par une ligne droite. Presque toujours clles cachent les ailes, qui sont grandes et plissées transversalement. Quelquelois les ailes

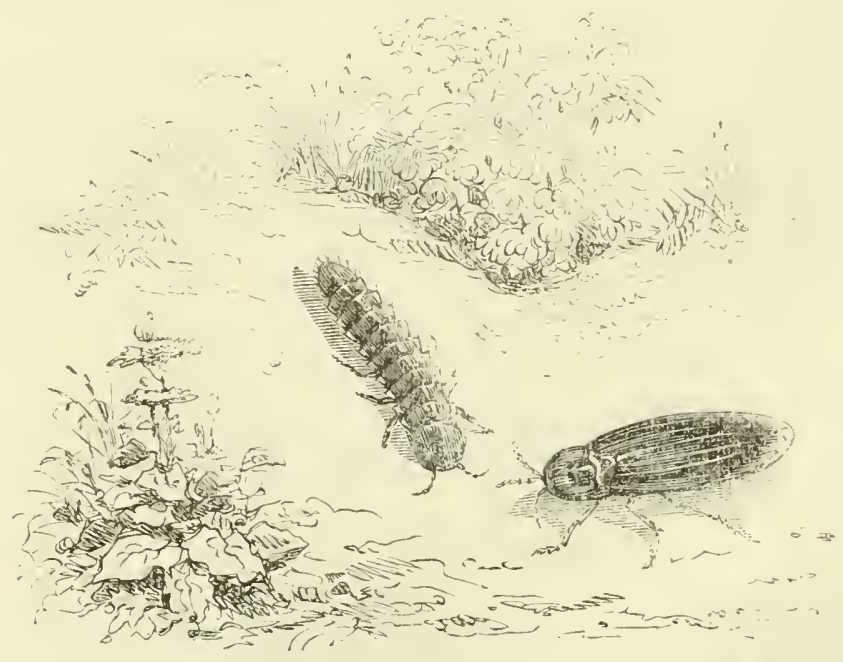

Fig. 913. - Lamps res màle et femelle.

manquent, mais les élytres existent toujours. L'abdomen est largement uni au tronc; il est composé de 6 à 7 anneaux, membraneux en dessus, 
solides en dessous. Le nombre des articles des tarses rarie depuis trois jusqu'à einq.

Les coléoptires subissent une métamorphose complète : leur larve ressemble à un ver, ayant une tête écailleuse, une bouche analogue à celle de l'insecte parfail, et ordinairement six yieds. La nymple est inactive et ne prend pas de nourriture. Elle est recouverte d'une peau membraneuse qui s'applique sur les parties situées au-dessus et les laisse apercevoir.

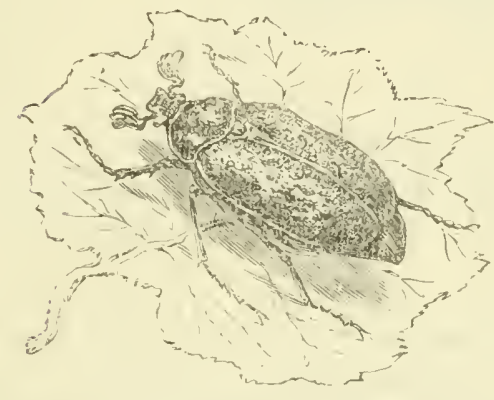

lig.g. 91'. - Le hameton foulon, mâle.

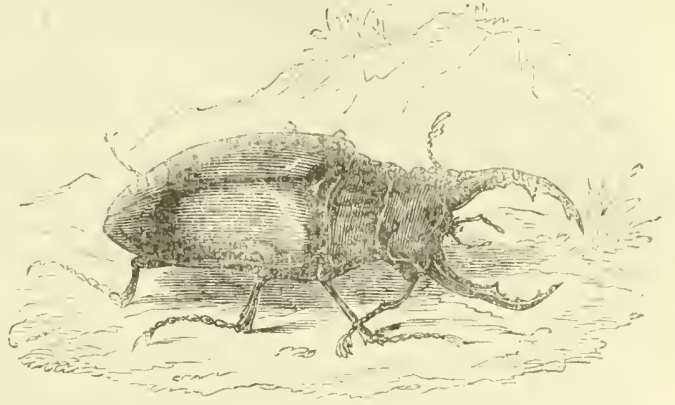

Fig. 915. - Cerf-volant, màle

On divise cet ordre en quatre sous-ordres, de la manière suivante:

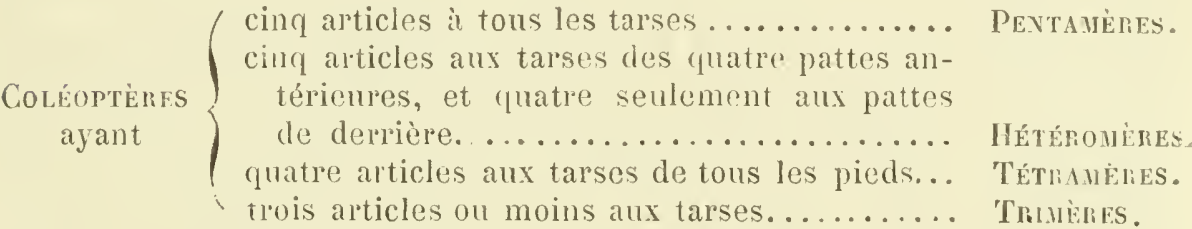

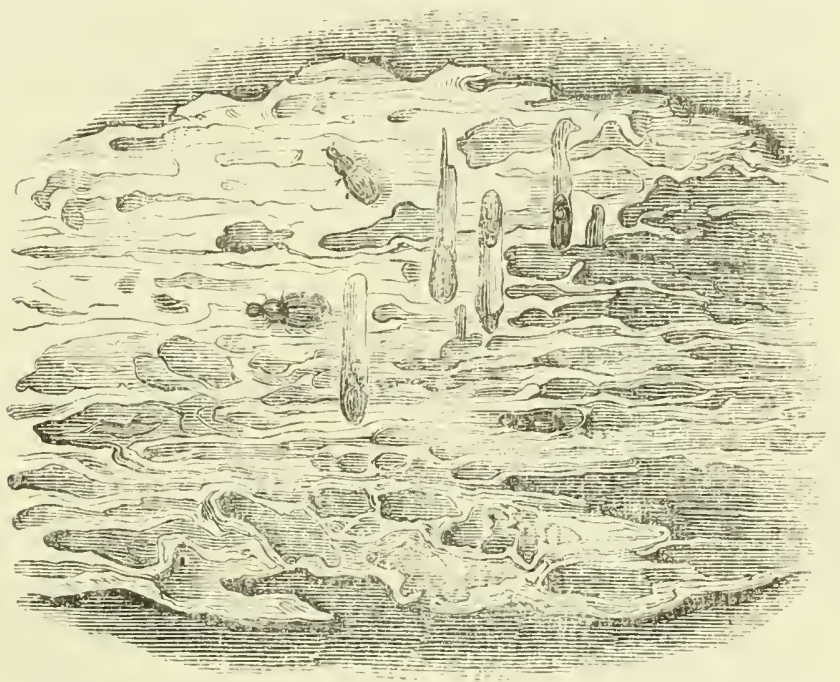

Fig. 916. - Scolıte graveur.

Les habitudes des coléoptères varient trop pour que nous puissions en rien dire de général. Le nombre en est immense, puisqu'on en connaît plus de cinquante mille espìces. 
Nous citerons comme exemples quelques espèces pour faire connaître les diverses formes : nous choisirons, parmi les pentamères, les hydro-.

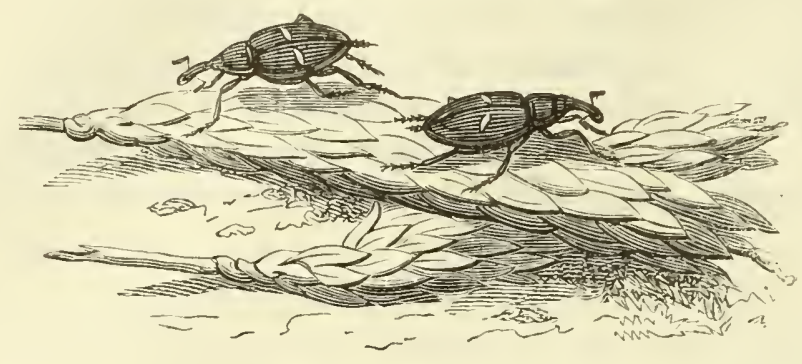

Fig. 97ł. - Charançun du blé.

phyles (fig. 912), le lampyre (fig. 913), le hanneton foulon (fig. 914), le cerf-volant (fig.915), et parmi les tétramères, le scolyte graveur (fig.916), et le charançon du blé ( $f g .917)$.

\section{Cantharide officinale.}

Le nom de cantharide est d'origine grecque ( $x \alpha v \theta \alpha p i ́ s)$; mais il est fort douteux que les anciens le domnassent à l'insecte qui le porte aujourd'hui. Ainsi Dioscoride, en consoillant de récolter les cantharides qui se trouvent dans les froments, et en disant que les meilleures de toutes sont celles qui ont des raies jaunes en travers de leurs ailes, désigne assez clairement le mylabre de la chicorée ; et, lorsqu'il ajoute que celles qui sont d'une seule couleur sont inertes, il est évident qu'il veut parler d'un insecte différent pe notre cantharide officinale. Il est probable que ce sont ces considérations qui ont délerminé Linné à donner le nom de cantharide à un autre genre de coléoptères, qui a formé depuis les deux genres malachie et téléphore, el à comprendre la cantharide officinale dans son genre Meloe, sous le nom de Meloe vesicatorius. Fabricius, divisant ensuite le genre Meloe, donna à la can-

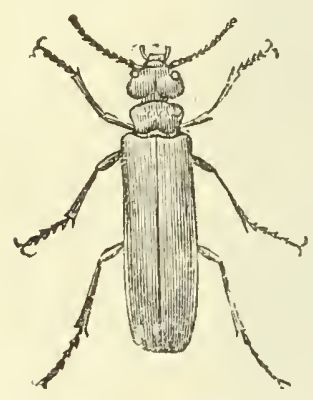

Fig. 918.- Cantharide.

tharide le nom de Lytta vesicatoria; enfin Geoffroy lui a rendu son nom officinal, Cantharis vesicatoria, aujourd'hui généralement adopté.

La cantharide (fig. 918) est un insecte coléoptère, hétéromère, trachélide; autrement, insecte à quatre ailes, dont les deux supérieures, nommées élytres, en forme d'étuis; à cinq articles aux quatre premiers tarses et seulement quatre aux deux derniers; à tête en cœur séparée du corselet par un rétrécissement brusque en forme de cou. Chacun des deux crochets des tarses est profondément divisé ou double ; les antennes sent filiformes, atteignant au moins la longueur de la moitié du corps, et sont com- 
posées de onze articles dont le premier est ovoïde et renflé, le second annulaire et très-petit, et les autres allongés; les élytres sont longues et flexibles. Le genre cantharide comprend plusieurs espèces qui diffèrent par leur grandeur, leur couleur et d'autres caractères peu importants: toutes sont vésicantes, mais à des degrés différents. Celle que nous employons, qui est la plus commune et la plus active est, d'un vert doré, sauf les neuf derniers articles des antennes et les tarses, qui sont d'un violet noirâtre. Elle a de 14 à 23 millimètres de longueur et 5 à 7 de largeur; son odleur est forte, vireuse et très-désagréable : cette odeur annnonce le voisinage des essaims, et aide à les découvrir lorsqu'on vent en faire la récolte. On ne connaît pas encore les conditions dans lesquelles les cantharides subissent leurs métamorphoses; on suppose seulement qu'elles sont analogues à celles que nous indiquerons pour les méloés. Les insectes parfaits paraissent sous le climat de Paris vers le solstice d'été : elles se rassemblent ordinairement en troupes sur les peupliers, les troënes, les rosiers et par préférence sur les frênes dont elles dévorent les feuilles; il est dangereux de reposer sous les arbres qu'elles habitent. La récolte des cantharides se fait le matin avant le lever du soleil, et lorsqu'elles sont encore engourdies par la fraîcheur et l'humidifé de la nuit. Une personne masquée et gantée secoue les arbres, au-dessous desquels on a étendu des draps où tombent les cantharides : on les fait mourir à la vapeur du rinaigre, contenues dans des nouets de linge ou étendues sur des tamis; enfin on les fait sécher dans une étuve. Elles perdent beaucoup de leur poids dans cette opération, au point que, après, il en faut environ 13 pour peser 1 gramme.

Les cantharides sont éminemment âcres et corrosives, et sont à présent presque le seul épispastique usité ; elles sont un poison prises intérieurement, même à une très-petite dose, ce qui fait qu'on ne doit administrer ainsi quelques-unes de leurs préparations qu'avec une extrême prudence. Leur action se porte surtout sur les voies urinaires, et est si intense qu'il suffit, pour la produire, de la simple application des cantharides sur le bras. Malgré ces propriétés si énergiques, les cantharides deviennent avec le temps la proie de plusieurs espèces d'insectes et d'acariens qui en détruisent les parties les plus actives", et ne laissent guère que les élytres et les autres parties vertes. Le moyen de les préserver de celte altération consiste à les renfermer, après les avoir entièrement desséchées, dans des vases hermétiquement fermés (1).

(1) Jour. de chim. médic., t. III, p. 49 et 435. Voir aussi sur ce sujet $\Lambda$. Fu Guibourr, Drogues, ze édit.

T. IV. -14 
Robiquet s'est occupé de l'analyse des cantharides, et nous a éclairés sur le siége de leur propriété vésicante. Voici quelquesuns de ses résultats (1).

$1^{\circ}$ Le principe vésicant des cantharides se dissout dans l'eau à l'aide de l'ébullition.

$2^{\circ}$ Les cantharides, épuisées par l'eau et desséchées, donnent dans l'alcool une teinture qui produit par son évaporation une huile verte nullement vésicante.

$3^{\circ}$. La décoction aqueuse évaporée donne un extrait que l'alcool sépare en deux parties : l'une, noire et insoluble; l'autre, jaune, visqueuse, très-soluble : toutes denx vésicantes.

$4^{\circ}$ La matière noire, parfaitement privée de matière jaune par l'action réitérée de l'alcool employé bouillant, ne conserve rien de vésicant.

$\check{\beth}^{\circ}$ La matière jaune, caractérisée par sa solubilité dans l'alcool et dans l'eau, perd sa propriété vésicante au moyen de l'éther sulfurique, qui en sépare une substance particulière, insoluble dans l'eau et dans l'alcool froid, soluble dans l'alcool bouillant, el qui s'en précipite, par le refroidissement, en paillettes cristallines.

$6^{\circ}$ Celtc dernière substance, absolument séparée de toutes les autres qu'elle a laissées inertes, se troure soluble en toutes proportions dans les huiles, qu'elle rend éminemment caustiques. On doil la cónsidérer comme le véritable principe vésicant des cantharides. (Depuis on lui a donné le nom de cantharidine; elle n'est pas azolée et a pour formule $\mathrm{G}^{10} \mathrm{H}^{6} \mathrm{O}^{4}$.) Elle se présente sous forme de petites lames incolores, inodores, répandant des vapeurs à $120^{\circ}$ el se volatilisant vers $210^{\circ}$.

$7^{\circ}$ L'infusion des cantharides fraîches contient du phosphate de magnésie qui s'y trouve dissous par deux acides : l'un, l'acide acétique; l'autre, l'acide urique.

[Depuis lors, la cantharidine a été isolée par divers dissolvants, au moyen du chloroforme par M. William Procter en 185 l (2), et toutrécemment au moyen de l'éther acétique par M. Galippe (3). Elle est dans ce dernier cas, en magnifiques cristaux, prismatiques à base rhombe.

Cette matière est soluble dans l'eau froide, qui en prend $0,1 \mathrm{~s}$ pour 100 de soni poids : l'cau bouillante en dissout 0,297 pour 100 : l'alcool à $830,0,862$ pour 100 ; la benzine bouillante, 3,38 ; l'acide

mouze, de la Cantharide officinale. Thèses de l'École supérieure de pharmacie de Paris, 1867.

(1) Robiquet, Ann. de chim., t. LXXVI, p. 302.

(2) Voir Journal de pharmacie et de chimie, $3^{\text {e }}$ série, $\mathbf{X X}$, p. 426.

(3) Voil Journal de pharmacie et de chimie, 4e série, XX, 212. 
chlorhydrique bouillant, 0,3. Elle se combine avec les bases pour former des cantharidates (1).]

Substitutions. Quoiqu'il existe un assez grand nombre de coléoplères parés d'une couleur verte dorée, plus ou moins semblable à celle des cantharides, il y en a peu qui puissent être confondus avec elles, à cause de leur grandeur ou de leur forme différente, et des caractères tirés de leurs antennes ou de leurs pattes. Si l'on admet cependant que ces insectes soient privés de leurs appendices, alors la confusion deviendra possible et l'on pourra prendre, par exemple, un callichrôme musqué (2), pour une cantharide un peu forte. Cet insecte est commun sur les saules vers le mois de mai; il appartient aux coléoptères tétra. mères et à la famille des longicornes; il est long de 27 millimètres, a les antennes filiformes el plus longues que le corps, les cuisses des pieds postérieur's allongées, les jambes très-comprimées. Il exhale une odeur de rose très-marquée. Privé de ses appendices et comparé à une cantharide, il en diffère encore par son thorax beaucoup plus volumineux el arrondi, presque du mêre diamètre que l'abdomen, et par ses élytres un peu coniques el plus larges à la partie antérieure qu'à l'autre extrémité, tandis que les élytres de la cantharide sont d'égale largeur partout, et présentent la forme d'un rectangle long, arrondi aux angles. L'euchlore de la vigne (3), diphucéphale soyeux (4), le mélyre vert (5), n’ont qu'une ressemblance plus éloignée avec les cantharides, et d'ailleurs ne s'y trouvent jamais mêlés; mais la cétoine dorée $(6)(f g .919)$ s'y rencontre souvent et en quantité assez considérable, quoique sa forme ramassée el ovalaire la rende très-facile à distinguer (7). Elle est longue de 16 à 22 millimètres et large de 10 à 12. Sa tête est très-petite, unie immédiatement à un corselel co-

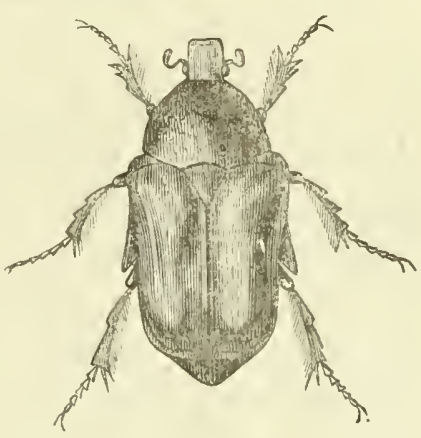

Fig. 919 , - Cétoine doréc. nique dont la base est aussi large que les élytres, et est accompagnée d'un écusson triangulaire très-apparent. Les élytres portent

(1) Voir Dragendorff, Untersuch aus den Pharmac. Institut. Dorpat; et Wiasing, Die Verbindungen dos Cantharidins mit Anorganschen Busen, thèse de pharmacie de Dorpat. Décembre, 1866. - Travaux résumés par 11. Mélıu, dans l'Anmaire pharmaceutique, 187i, p. 174. - Voir aussi Journal de pharmacie el de chimie, $4^{\mathrm{e}}$ série, XVIII, til.

(2) Cuvier, Atlas du Règne animal, pl. LXV, fig. 8.

(3) Ibid., pl. XlIII, fig. 7.

(') Ibid., fig. 3.

(5) Ibid., pl. XXXII, fig. 18.

(6) Ibid. pl. XLV, fig. 6.

(i) Voy. Gory et Percheron, Monoarap̧ize des cétoines. Paris, 1833. 
une nervure saillante près de leur bord interne, et sont marquées de quelques petites lignes transversales blanches dans leur partie postérieure. Le test vert qui recouvre la tête, le corselet et les élytres, est partout marqué de très-petites piquares ou de petites cicatrices, qui me paraissent analogues à celles qui, sur les anneaux du ventre et sur les membres, donnent naissance aux poils roux dont ces parties sont garnies. Cet insecte, qui n'est nullement vésicant, appartient à la famille des lamellicornes, des coléoptères pentamères; on le voit par toute l'Europe sur les fleurs de rosier, de sureau, de sorbier, d'ombellifères, etc. ; lorsqu'on le saisit, il laisse échapper par l'anus une liqueur fétide.

[D'autres espèces de cantharides ont des propriétés analogues, qui les ont fait utiliser comme vésicants. Nous citerons en particulier la Cantharide porntillée (Lytta adipersa, Klug) de Montevideo, qui vit sur le Beta vulgaris, var. Cicla. On la trouve en abondance du nois de décembre au mois de mars. Elle a 13 à 16 millimètres de longueur; elle est reconverte d'une sorte de poussière grise, et marquée d'un grand nombre de petits points noirs. Ses antennes sont noires et ses pattes rougeâtres. M. Courbon, qui a observé l'action de celte espèce, lui altribue une innocuité complète sur les organes génito-urinaires.]

Mylabre de la Chicoríe ( $f g .920)$.

Il est d'autant plus probable que cet insecte est celui qui a été désigné par Dioseoride comme la meilleure espèce de cantharide, qu'il n'a pas cessé d'être employé comme épispastique dans tout l'Orient et jusqu'en Chine. Il appartient, comme la cantharide, aux coléoptères hétéromères trachélides. Il se distingue générıquement des cantharides par ses antennes un peı terminées en massue, et par ses couleurs ternes ou non métalliques, et variées. Le mylabre de la chicorée est long de 14 à 16 millimètres, large de 5ँ; son corps est cylindrique, bombé et comme bossu, eouvert d'élytres jaunes, avec trois bandes transversales, faites en zigzag et de couleur noire. La première bande est assez près du corselet et est quelquefois réduite à l'état de taches isolées; la séconde dépasse la moitié des élytres, et la troisième est placée à l'extrémité. Les autres espèces de mylabre sont peu différentes de celle-ci.

M. Léon Ferrer a constaté la présence de la cantharidine dans un certain nombre de mylabres, entre autres dans le Mylabris punclata, de Pondichéry, qui a donné sur 30 grammes de poudre $(0,066$ de cantharidine); le Mylabris punctum, du même 
pays $(0,029$ du principe actif pour 100 grammes de matière); les Mylabris Lavaterce, Sidee, Cichorii, variabilis, maculata, etc. (1).

\section{Méloé proscarabée.}

Meloe proscarabccus, L. ( / g. 921). Insecte coléeptère, hétéromère, trachéiide, pourvu d'antennes à articles grenus et arrondis comme des grains de chapelet, et amincies en pointe à leur extrémité. La tête est plus large que le corselet, qui est carré; les élytres sont molles, courtes et ne recouvrent qu'une petite partie de l'abdomen qui est renflé : les ailes manquent.

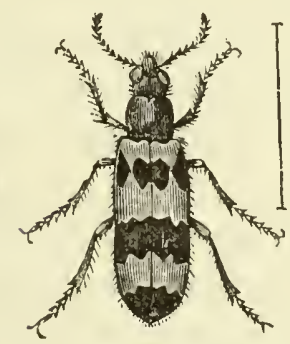

Fig. 920. - Mylabre de la chicorée.

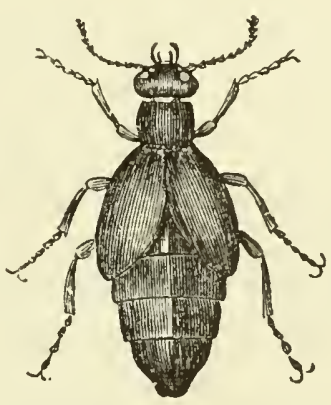

Fig. 921. - Méloé proscarabée.

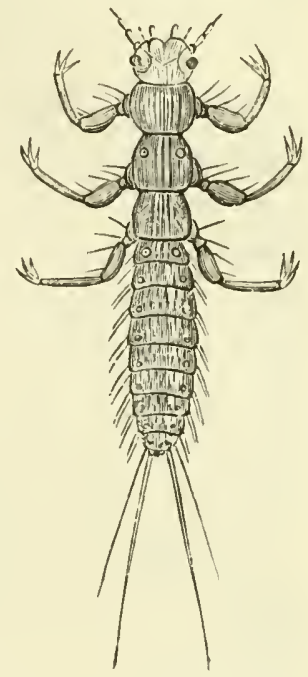

Fig. 9 22. - Larve de méloé.

Cet insecte est long de 28 millimètres, large de 11, de forme ovoïde-oblongue, d'un noir violet; il marche péniblement, à cause du poids de son abdomen. Il serait très-exposé, en raison de sa nudité presque complète, à la voracité des oiseaux et de quelques mammifères ou reptiles, s'il ne faisait suinter de ses articulations, au moment du danger, une humeur onclueuse, probablement caustique et d'une orleur repoussante, qui éloigne ses ennemis par le dégoût qu'elle leur inspire.

[Les meloés ont des métamorphoses extrêmement curieuses, dont les observations de Newport et de M. Fabre, d'Avignon, nous ont fait connaître les principaux délails. Avant d'arriver à l'élat de nymphe, la larve passe par quatre formes différentes. Telle qu'elle sort de l'œuf, elle est coriace, svelte, pourvue de 6 pieds terminés par trois ongles crochus, ei de mandibules acérées (fly. 922). A cetétal, elle s'accrcche aux poils de certains hyménoptères, et a été prise pour une espèce de poux, qu'on a décril sous le nom de pou de la Mellite ou de triongulin.

L'abeille la transporte avec elle jusqu'au moment de la ponte ;

(1) L. Ferrer, Essai sur les insectes vésicants. Thèse soutenue à l'École supérieure de pharmacie de Paris, 1859. 
à ce moment la larve descend sur le petil œuf qui nage au milieu du miel, s'y établit comme sur un radeau, en perce les enveloppes et se nourrit du contenu. Elle subit alors une transformation: elle devient molle, prend des formes lourdes, perd ses yeux, ses pattes et ses cirrhes : ses mandibules acérées s'excavent en cuiller de façon à pouvoir puiser le miel : elle vit ainsi pendant un temps assez long aux dépens de la provision amassée par l'hyménoptère. Une nouvelle modification extérieure se produit ensuite : clle devient une sorte de chrysalide, immobile, revêtue de téguments cornés sur lesquels se dessinent un masque céphalique, et des indices de pattes. Puis, cette enveloppe extérieure se rompant, il en sort une nouvelle larve assez semblable à la seconde forme. Pendant ces diverses transformations l'organisation intérieure s'est très-peu modifiée : il n'y a pas eu de métamorphose profonde : mais, à partir de ce moment, la larve devient une véritable nymphe, dans laquelle se forment et se développent les organes de l'animal, qui n'a plus qu'à sortir de sa dernière enveloppe pour devenir insecte parfait (1).]

Le méloé proscarabée et le méloé đe mai ont été autrefois employés en médecine. On en composait des exutoires et on les administrait à l'intérieur. Quoique moins active que celle des cantharides, leur action ne laissait pas d'être dangereuse. On a prétendu qu'ils étaient efficaces contre la rage.

\section{Coccinelle.}

Quelques coccinelles ont été recommandées comme antiodon-

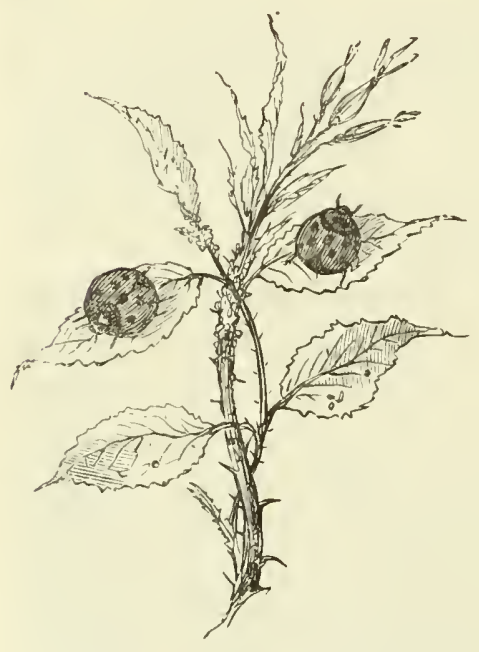

Fig. 923. - Coccinelle à 7 points. talgiques, particulièrement la coccinelle à sept points, Coccinella septempunctata (fig. 923). Cet insecte, connu sous le nom de bête à bon Dieu, replie ses pieds contre son corps lorsqu'on le saisit et fait sortir par les jointures de ses cuisses et de ses jambes une humeur jaunâtre d'odeur désagréable.

\section{Tréhala.}

Parmi les substances qui formaient la collection de matière médicale de M. Della Sudda, à l'exposition universelle de 18əั5̆, l'une de celles qui ont le plus fixé mon attention a été la matière nommée tréhala

(1) Voir Fabre, Hypermétamorphose, et mœur's des méloïdes (Ann. des sciences natur. Zoologie, t. VII, p. 298). 
ou trikala, yui était supposée venir de Trikala en Roumélie(1); mais, suivant M. Bourlier, pharmacien aide-major, qui a protité de son séjour à Constantinople pour se livrer à l'etude des productions naturelles de l'Orient, le tréhala (seul nom véritable) ne provient pas de la Roumélie, et serait originaire de Syrie. Il est aussi commun en Orient et d'un usage aussi répandu que le sont en France le salep et le tapioka: on s'étonne alors que cette substance alimentaire, remarquable à plus d'un titre, nous soit restée jusqu'ici complétement inconnue.

Le tréhala est une coque creuse évidemment maçonnée par un insecte. Il est de forme ronde ou ovale, du volume d'une grosse olive, plus ou moins, et présente, du côté interne, une couche de matière blanche, compacte, à surface intérieure unie, quelquefois rougeâtre, assez semblable, pour l'aspect, à l'endocarpe d'une pistache. Cette couche compacte est couverte, du côté extérieur, de grains grossièrement aq̃glomérés qui donnent au tréhala une surface tuberculeuse el le font ressembler à une praline blanche. Les plus petites coques, qui sont aussi les plus arrondies, paraissent presque entièrement fermées ou n'offrent qu'une fente longitudinale; mais les plus grosses sont largement ouvertes par un bout el présentent alors quelque ressemblance avec la cupule tuberculeuse d'un gland. Ajoutons que ces capsules sont souvent fixées sur un rameau grêle d'une plante demi-ligneuse, ou entremêlées de débris d'une feuille très-cotonneuse appartenant à une carduaccé; disons enfin que, bien que la plupart des coques soient privées de l'insecte qui les a construites ou habitées, un certain nombre le renferment encore. Cet insecte est un coléoptère tétramère voisin des charançons, et qui appartient comme eux à la famille des curculionides ou des rhynchophores.

Le tréhala n'a jamais paru en France avant l'Exposition de 1830 ; mais on le trouve décrit sous le nom de schakar el ma-ascher dans la pharmacopée persane de frère Ange, de Toulouse. Ia description, quoique suivie de celle d'un arbre impossible et dans laquelle plusieurs végétaux sont confondus, est assez exacte dans ce qui regarde le produit lui-même, pour qu'il ne reste pas de doute sur son identité avec le tréhala.

Je ne suivrai pas le frère Ange dans ce qu'il rapporte du fruit de l'arbre qui ressemble à un estomac d'homme et qui s'ouvre pour donner naissance à une fleur bleue, d'un aspect admirable ; ni du suc de l'arbre, laiteux et caustique, qui tue à la dose de 3 drachmes; ni de l'opinion que cet arbre estle rhododaphné, c'est-

(1) Voir le Catalogue de cette Collection dans Ie Journal de pharmacie et de chimie, année 1856, t. XXIV, p. 300, n. 145. 
à-dire le laurier-rose. La seule chose réelle, suivant la détermination que' $M$. le professeur Decaisne a bien voulu en faire, c'est que la plante qui porte le tréhala appartient par ses feuilles, dont les débris se trouvent fixés aux coques, et par ses capitules, dont j'ai pu lui remettre un fragment, au genre Echinops de la tribu des Cynarées. Cetle plante, ou une espèce très-voisine, encore inédite, se trouve dans l'herbier du Muséum d'histoire naturelle. Elle a éte récoltée par Olivier entre Ispahan et Téhéran; elle ne porte aucune marque de la présence du tréhala. Quant à l'insecte, c'est, ainsi que je l'ai dit plus haut, un coléoptère de la famille des rhynchophores, à laquelle appartient la calandre, qui cause de si grands dommages dans les greniers à blé; mais bien différent de celle-ci qui, renfermée dans le grain de blé qu'elle dévore, n'en laisse à l'homme que le son, l'insecte du tréhala récolte des quantités considérables de matière amylacée dont il construit sa demeure et qu'il abandonne à l'homme après sa mort. Les entomologistes les plus habiles, à Paris, MM. H . Lucas et Chevrolat; à Londres, M. Saunders, comprennent cet insecte dans le genre Larinus dont plusieurs espèces sont déjà connues pour vivre sur des plantes synanthérées, ce qui leur a valu les noms de Larinus Cynarc, Onopordinis, Cardopatii, Scolymi, elc. Mais aucune des larves de ces espèces ne manifeste l'instinct d'extraire l'amidon de la plante pour en construire sa demeure (1). Cette circonstance suffit pour établir que le Larinus du tréhala est une espèce nouvelle pour laquelle M. Chevrolat a proposé provisoirement le nom de Larinus subrugosus. Je me permettrai de proposer celui de $L a-$ rinus nidificans (2), emprunté au premier des vers dans lesquels

(1) J'ai longtemps hésité à croire qu'une aussi grande quantité d'amidon pût être tirée d'une plante à rameaux grêles et demi ligneux; mais, en examinant les fragments des rameaux qui accompagnent le thélıala, j'ai vu que presque tous, indépendamment de la perte probablement accidentelle de leur écorce cotonneuse, sont rongés d'un côté jusqu'au centre, et qu'ils offrent à l'intérieur les restes d'une moelle blanche devenant d'un bleu noir par l'iode. La larve du Larinus entame donc les rameaux de l'Echinops pour se nourrir du sucre, de la gomme et de l'amidon qu'ils contiennent; mais la plus grande partie de celle-ci est dégorgée pour servir à la construction du nid.

(2) Avant de savoir que M. Chevrolat avait nommé l'insecte du tréliala, ayant remarqué la disposition particulière des lignes ponctuées qui décorent les élytres, j'avais pensé à proposer le nom de Larinus lineopunctalus ou de Larinus deciespunctatus. Les élytres sont oblongues, de la même largeur que le corselet qu'elles ne dépassent pas; elles recouvrent exactement la partie postérieure de l'abdomen et sont chacune terminées par une pointe mousse un peu courbée vers la ligne médiane dn corps. Chacune des élytres est marquée de dix lignes ponctuées qui, partant du bord antérieur, suivent le contour de l'organe et se joignent en un circuit fermé avant d'arriver à l'extrémité; autrement dit, ce sont cinq lignes sirculaires qui se doublent en parcourant les deux côtés de l'élytre, et comme cet organe est allongé, les lignes intérieures, se rapprochant de plus en plus, finissent par ne plus laisser 
Virgile plaint les animaux de travailler pour l'utilité de l'homme bien plus que pour eux-mêmes:

Sic vos non vobis nidificatis, aves.

Ce qui peut aussi s'appliquer à l'insecte qui produit le tréhala.

Je reviens au tréhala : quoique les Persans lui dennent le nom de sucre des nids et qu'il renferme en effet un sucre cristallisable très-remarquable par ses propriélés, néanmoins le tréhala est de nature principalement amylacée, ainsi que le montre un commencement d'analyse que j'en avais faite, avant que M. Marcelin Berthelot se fût chargé de l'examen du sucre, dont personne mieux que lui ne pouvait établir les propriétés.

Le tréhala mis en contact avec l'eau se ramollit, se gonfle et finit par se convertir en une bouillie épaisse et mucilagineuse. En ajoutant beaucoup d'eau, la liqueur surnageante est faiblement sucrée; le dépôt, au lieu d'être pulvérulent et mobile comme une fécule pure, a toujours l'apparence d'une bouillie mucilagineuse. En examinant au microscope un peu de celte bouillie délayée dans l'eau et additionnée d'iode, on y trouve les parties suivantes :

$1^{\circ} \mathrm{Un}$ nombre considérable de globules très-petits, sphériques, transparents, incolores, analogues à ceux qui constituent en partie les tubercules d'orchis.

$2^{\circ}$ Des amas de granules amylacés, de moyenne grandeur, opaques, colorés en bleu-noir par l'iode, tenus réunis par un mucilage, sans aucun indice de cellule végétale.

$3^{\circ}$ D’autres granules amylacés, isolés, toujours opaques et comme composés eux-mêmes d'une matière grenue inégalement colorée en bleu par l'iode. Ces granules ont un diamètre égal à celui des gros grains d'amidon de blé; mais le bord en est rarement nettement circulaire, un peu ovale ou un peu elliptique; le plus souvent le bord est irrégulier, et d'autres fois encore les granules sont déchirés en fragments irréguliers, toujours opaques et d'un bleu noirâtre (1).

entre elles qu'un espace linéaire. J'ai préféré cependant, aux noms dérivés de ces lignes ponctuées qui peuvent appartenir à d’autres espèces, un nom basé sur l'industrie instinctive de l'insecte.

(1) J'ai trouvé parmi ces gl'anules : $1^{\circ}$ Un œuf coloré en jaune, pourvu de deux enveloppes au moins, dont l'extérieur était en partie lacéré. Cet œuf avait la forıne d'un citron allongé, terminé en mamelon à l'un des bouts.

$2^{\circ}$ Le squelette transparent d'un insecte, ou mieux d'un arachnide ì 6 pattes trapues partant du centre de la face inférieure du corps, comme les pattes d'un jeune sarcopte. Chacune de ces pattes avait 4 articles et portait à l'extrémité une longue soie. Le corps était en forme de fuseau, terminé antérieurement par un rostre conique. Cet arachnide est probablement celui qui détruit le 
J'ai pris quelques granules d'amidon du tréhala et je les ai fait bouillir dans une grande guantité d'eau distillée, pendant une demi-heure. Ils ont été peu altérés dans leur forme et se coloraient toujours en bleu noirâtre par l'iode.

Après deux heures d'une nouvclle ébullition, presque tous les granules étaient divisés par fragments très-irréguliers, toujours denses et se colorant en bleu foncé par l'iode.

L'amidon contenu dans la moelle de l'Echinops est en tous points semblable à celui du tréhala et se comporte de même par une longue ébullition dans l'eau.

La fécule de pomme de terre, que l'on traite de la même manière, se dissout et disparaît complétement; l'amidon de blé ne laisse qu'un flocon léger que l'iode colore faiblement d'une teinte violacée,

L'amidon de l'Echinops et du tréhala diffère donc beaucoup de la fécule de pomme de terre et même de l'amidon de blé, qui sont formés de couches concentriques dont les intérieures sont facilement solubles dans l'eau bouillante et dont les plus extérieures, quoique plus résistantes, finissent cependant par disparaître entièrement ou presque entièrement.

Mais il est analogue aux amidons d'orge, de sagou des Moluques et surtout de gomme adragante, qui, plus ou moins, sont formés d'une matière très-dense qn'une longue ébullition dans l'eau ne peut pas complétement diviser et encore moins dissoudre.

Je me hasarde à établir une certaine relation entre la nature de l'amidon de l'Echinops et la production du tréhala. Si cet amidon était facilement attaquable par l'eau ou, ce qui en est une conséquence presque nécessaire, s'il était facile à digérer, il est probable que le tréhala n'existerait pas. Mais cet amidon n'étant pas digéré par la larve du Larinus, celle-ci doit on ne pas l'avaler ou le rejeler par une sorte de dégorgement. De là a pu naître l'industrie d'en fabriquer un nid.

Je termine en faisant connaître approximativement les quantités d'amidon, de sucre et de gomme que contient le tréhala.

50 grammes de cette substance ont été traités à froid par la quantité nécessaire d'eau distillée : l'amidon lavé autant que possible et séché pesait 33,27 .

La liqueur filtrée a été réduite à un petit volume et étendue de

larinus mort dans sa coque; car il est rare qu'on l'y trouve entier. Dans nos collections, ce n'est plus un acaride qui attaque le tréhala, où il ne reste plus de matière animale à dévorer; c'est un anthrène dont le camphre nous débarrasse facilement. 
deux fois autant d'alcool à 88 centièmes. La gomme précipitée, lavée à l’alcool et séchée, pesail ¿, 33.

La liqueur alcoolique a été évaporée en consistance de sirop épais : après plusieurs jours, elle avait formé des cristaux durs et transparents d'un sucre que M. Berthelot a bien voulu se charger d'examiner.

Le sirop surnageant possédàit une amertume assez marquée : évaporé jusqu'à former une masse solide et transparente, il s'est transformé, plusieur's jour's après, en une masse cristalline et demi-opaque, à la manière du sucre d'orge. Il est certain que cette masse était encore formée, en grande partie, de sucre cristallisé. Le tout réuni pesait 14,40.

Le tréhala est donc composé approximativement de

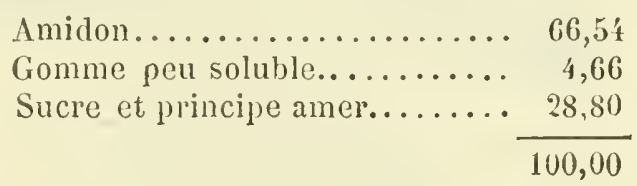

Il faut déduire des nombies précédents une quantité assez considérable de composés inorganiques représentés par 4,60 d'une cendre composée de :

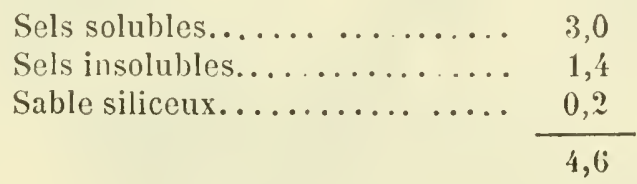

Les sels solubles sont composés de carbonate, chlorure et sulfate alcalins en quantilés approximativement égales, et d'une moindre quantité de phosphate.

La cendre insoluble dans l'eau, mais soluble dans l'acide chlorhydrique, élait formée de carbonate de chaux el d'une petite quantité de fer probablement phosphaté.

\section{ORDRE DES ORTHOPTÉRES.}

Sans entrer dans de longs délails sur l'organisation de cet ordre, nous citerons, parmi les espèces qu'il renferme, la mante religieuse (fig. 92\%), la sauterelle (fig. 920̈) et les blattes (fig. 926).

Les blattes forment un genre d'orthoptères coureurs à corps allongé plus ou moins aplati, à antennes glabres, à élytres se recouvrant obliquement à leur suture. La blatte des cuisines (Blatta orientalis, L. ( $f g .927$ ) est commune dans les boulangeries; elle répand une odeur fétide. Elle n'est pas venimeuse. Comme les 
autres espèces du genre, elle est omnivore et cause de grands degâls dans les provisions où elle se répand.

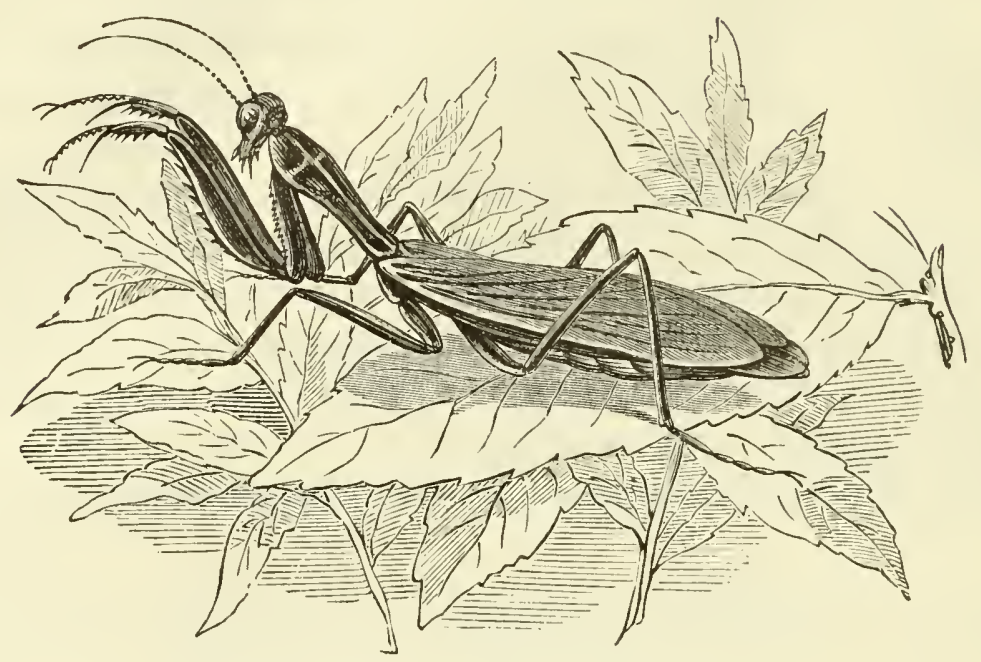

Fig. 924. - Mante religieuse.

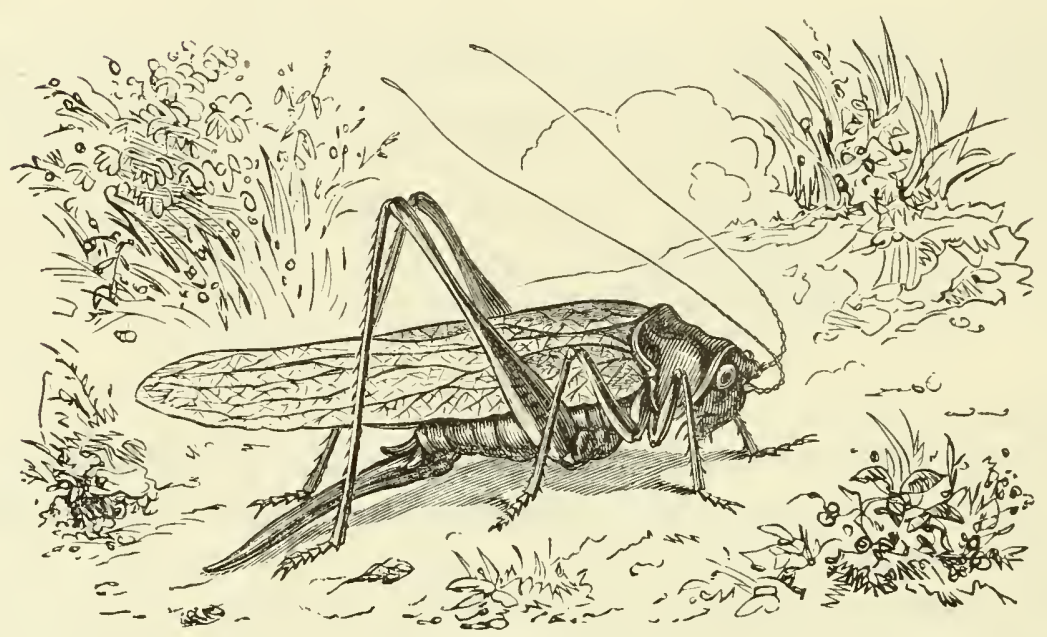

Fig. 925. - Sauterelle.

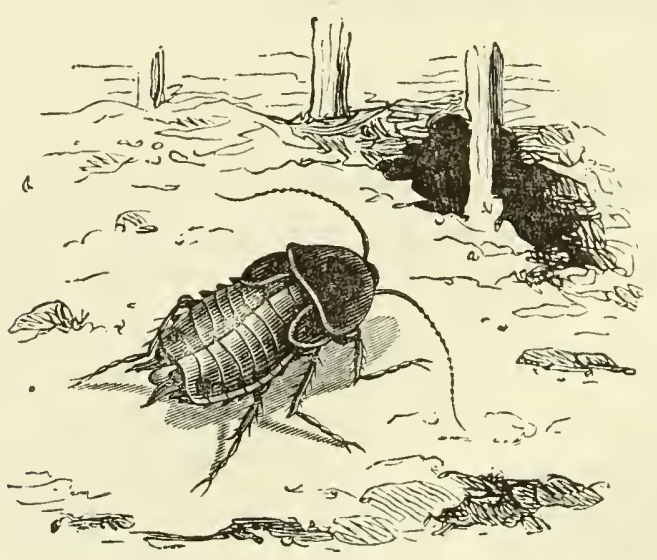

Fig. 926. - Blatte des euisines. 
ORDRE DES NEVROPTÉRES.

Les névroptères, généralement carnassiers, comprennent les libellules (fig. 927), les éphemères (fig. 928), les friganes et les termites, etc.

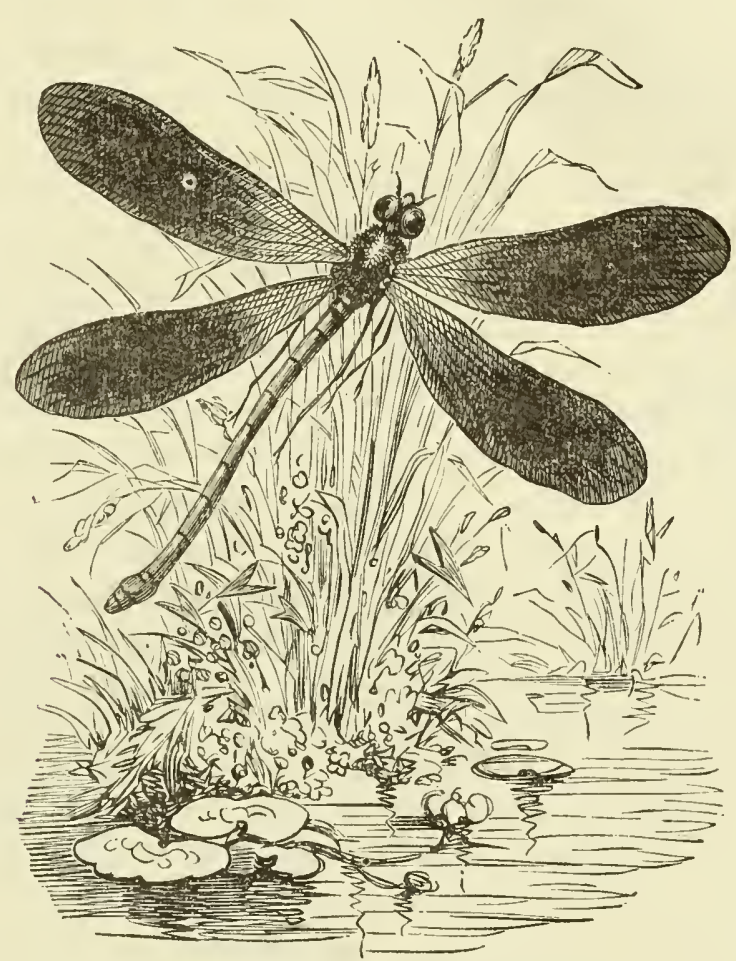

Fig. 927. - Libellule.

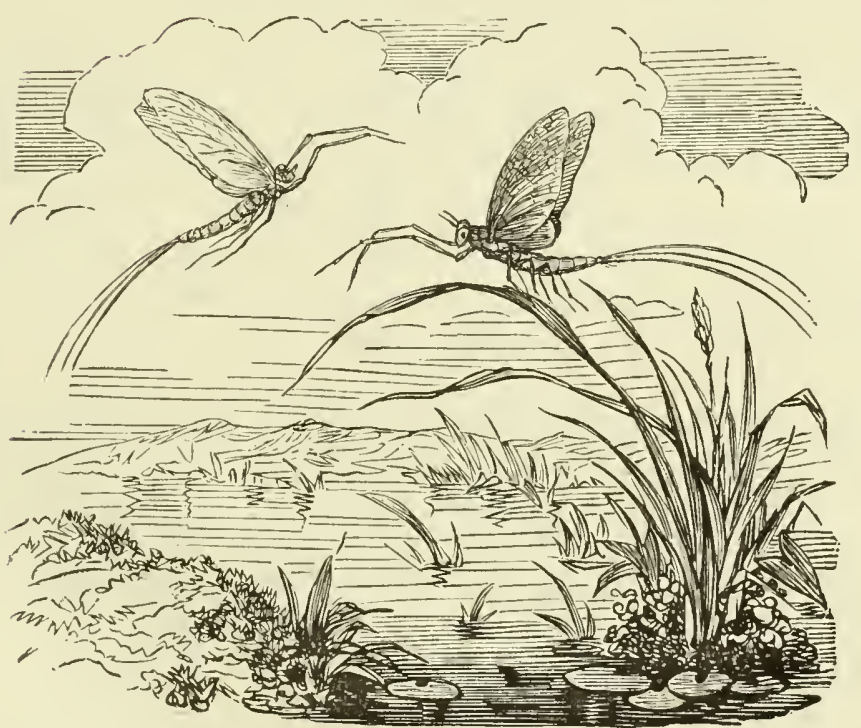

Fig. 928. - Éphémère commun. 


\section{ORDRE DES HYMÉNOP'TÉRES.}

Les hyménoptères (1) ont une bouche composée de mandibules et de mâchoires avec deux lìres, et quatre ailes membraneuses et nues. Les deux ailes supérieures, toujours plus grandes, ne présentent que des nervures longitudinales peu nombreuses, et les inférieures suivent, en s'écarlant du corps, les mouvements des supérieures auxquelles elles s'accrochent. Les femelles ont l'abdomen terminé par une torière ou un aiguillon.

Ils ont tous des yeux composés et trois petits yeux lisses; des antennes rariubles selon les genres et même selon les sexes de la même espèce, néanmoins filiformes ou sétacées dans la plupart. Les mâchoires et la lèrre inférieure sont généralement étroites, allongées, altachées dans une cavité profonde de la tête par de longs muscles; formées en demi-tube à leur partie inférieure, souvent repliées à leur extrémité, plus propres à conduire des sucs nutrilifs qu'à la mastication, et réunies plusieurs en forme de trompe mobile, mais non susceplible de s'enrouler. Il y a quatre palpes, dont deux maxillaires et deux labiaux. Le premier segment du thorax est très-court, et les deux autres sont confondus en un; les ailes sont croisées horizontalement sur le corps; l'abdomen est suspendu le plus souvent à l'extrémité du corselet par un étranglement; tous les tarses ont cinq articles non divisés; la tarière ou l'oviducte et l'aiguillon sont ordinairement composés de trois pièces longues et grêles, dont deux servent de fourreau ḋ la troisième, et dont la supérieure a une coulisse en dessous pour emboîter les deux autres.

Les hyménoptères subissent une métamorphose complète; la plupart de leurs larves ressemblent à un ver et sont dépourvues de pattes; mais, dans la famille des porte-scie, les larves ont six pattes à crochet, et souvent douze à scize autres simplement membraneuses; on a donné à ces larves le nom de fuusses chenilles. Les unes et les autres ontla tête écailleuse, avec des mandibules, des mâchoires et une lèvre à l'extrémité de laquelle est une filière pour le passage de la matière soyeuse qui doit former la coque de la nymphe. Le régime de ces larves varie beaucoup; plusieurs ne peuvent se passer de secours étrangers, et sont élevées en commun par des individus stériles réunis en société. Dans leur état parfait, les hyménoptères virent sur les fleurs. La durée de leur rie, depuis leur naissance, est bornée au cercle d'une année.

On divise les hyménoptères en deux sous-ordres, celui des térébrants, dont les femelles portent une tarière, et celui des porteaiguillon, où il n'existe pas de tarière, el où là femelle présente tonjours, près de l'anus, un appareil sécréteur destinć à proluire un liquide vénéneux que l'animal emploie pour sa défense. Quelquefois l'insecte se borne à lancer ce venin au dehors, comme le font plusieurs fourmis; mais presque toujours la petite

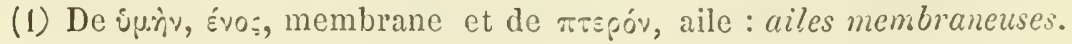


poche au venin communique avec un aiguillon destiné à verser le liquide délétère dans la plaie faite par l’instrument. Les mâles sont toujours privés de celte arme; mais les femelles, et souvent les individus stériles, en sont pourvus, et sa piqûre détermine une inflammation donloureuse.

Les IYYMÉNOPtÈres TÉRÉBRANTS contiennent, dans la petile tribu des gallicoles, le genre Cynıps, dont plusieurs espèces produisent les nombreuses galles de chêne, que j’ai décrites (1). Ces insectes ( $\mathrm{ig} .929)$ paraissent comme bossus, ayant la tête petite et le thorax gros et élevé. Leur abdomen est séparé du corselet par un étranglement trèsprononcé; il est comprimé en carène à sa partie inférieure et tronqué obliquement à son extrémité. Il renferme, chez les femelles, une tarière formée d'une seule pièce longue et très-déliée, roulée en spirale à sa base, et en partie logée entre deux valvules allongées, qui lui forment un demi-fourreau. L'ex-

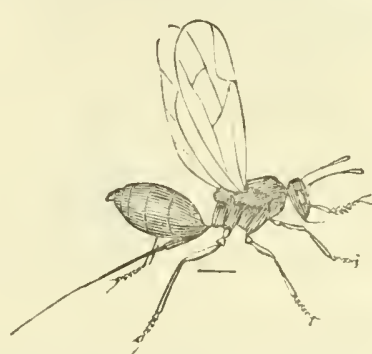

Fig. 929. - Iyménoptère térébrant (Diplolèpe). trémité de celte tarière est creusée en gouttière, avec dies dents latérales qui servent à élargir les entailles que l'insecte fait an végétal pour y placer ses œufs. Les sucs de la plante s'épanchent à l'endroit qui a été piqué el y forment une tumeur on excroissance, dont j'ai décrit plusieurs espèces. On trouve des galles analognes sur un grand nombre d'autres végétaux, tels que le rosier sauvage, le lierre terrestre, le chardon hémorrhoïdal, elc. Mais toules les galles ne sont pas dues à des cynips : telles sont celles de l'orme, du térébinthe et du Rhus semialata (2), qui sont produites par des pucerons $(A p h i s)$, de l’ordre des hémiptères.

Les hyMÉnoptères porte-AigullLon, indépendamment de l'aiguillon de trois pièces, caché et rétractile, dont sont ordinairement pourvus les femelles et les neutres, ont les antennes toujours simples et composées de treize articles dans les mâles et de douze dans les femelles; les palpes sont ordinairement filiformes et les quatre ailes toujours veinées. L'abdomen, uni au thorax par un pédicule, est composé de sept articles chez les mâles, el de six chez les femelles, les larves n'ont pas de pieds, et vivent des aliments que les femelles ou les neutres leur fournissent. On en forme quatre familles; savoir : les hétérogynes (ex.: les fourmis), les fouisseurs (ex. : les scolies), les diploptères (ex. : les guêpes), et les mellifères (ex. : les abeilles).

(1) Tome II, page $499 \cdot 505$.

(2) Tome III, page 498-503. 
Les Fouruis vivent en société, et nous offrent trois sortes d'individus, dont les mâles et les femelles sont ailés, et les neutres privés d'ailes; leurs antennes sont coudées, et celles des femelles et des neutres, qui ne sont que des femelles incomplètes, vont en grossissant vers l'extrémité ; la longueur de leur premier article égale au moins le tiers de la longueur totale. Les mâles et les femelles ont trois yeux lisses, disposés en triangle sur le sommet de la tête; ces yeux manquent chez les neutres, qui se font en outre remarquer par la grosseur de leur tête et par la force et la longueur de leurs mandibules.

Les fourmis neutres, que l'on nomme aussi ouvrières, constituent la partie la plus nombreuse de la société à laquelle elles appartiennent, et sont seules chargées des travaux nécessaires à la prospérité générale. Les unes se creusent une demeure souterraine, au bas d'un mur exposé au soleil, ou au pied des vieux arbres, tandis que d'autres réunissent en commun une masse énorme de débris ligneux, de feuilles desséchées, ou d'autres matières recueillies sur les végétaux, pour en construire une sorte de ville, où sont pratiquées une infinité de routes et de ruelles, avec des carrefours ou des places publiques. Les mâles et les femelles ne participent pas aux travaux, ne restent même dans la fourmilière que fort peu de temps lorsqu'ils sont parvenus à leur état parfait, et les premiers périssent aussitôt qu'ils ont fécondé les femelles. Celles-ci quiltent la demeure commune en même temps que les mâles; mais, après avoir été fécondées dans les airs, el s'être dépouillées de leurs ailes, elles sont ramenées dans la fourmilière par les ouvrières, et placées dans les chambres les plus retirées, où elles sont nourries par leurs gardiennes (1). Dès qu'elles pondent un œuf, une ourrière s'en empare et le transporte dans une autre chambre. Les larves reçoivent aussi, de la part des ouvrières, les soins les plus assidus; lorsque le temps est beau, on voil ces nourrices actives porter leurs élèves hors de la fourmilière pour les exposer au soleil, les défendre contre leurs ennemis, les rapporter dans leur nid à l'approche du soir, et les entretenir dans un état de grande propreté. Pendant que certaines ouvrières s'occupent de ces soins, d'autres vont récolter des sucs sucrés sur les fleurs et sur les fruits : mais elles sont surtout avides d'un suc particulier, qui suinte du corps des pucerons. Quelquefois même elles ne se contentent pas de prendre la gouttelette sucrée que le puceron leur abandonne lorsqu'il se sent caressé par leurs antennes; sourent elles portent ces insectes dans leur demeure,

(1) Les fourmis femelles périssent aux approches de l'hiver; il n'y a que les ouvrières qui passent cette saison engourdies sous la terre et qui, au printemps, assurent le salut de la nouvelle génération. 
et les y élèvent comme une sorte de bétail. Enfin, il y a des fourmis qui, non contentes d'avoir un bétail, se font aussi des esclaves, en allant prendre de force, dans d'autres fourmilières, des larves et des nymphes d'une espèce plus faible, les transportent dans leur propre demeure et appliquent les insectes qui en proviennent à tous les travaux de leur communauté.

Toutes les fourmis ne sont pas pourvues d'aiguillon.

La fourmi fanve des bois (Formica rufa, L.) (fig. 930) est de ce nombre. L’individu neutre ( $f g .931)$ est long de 8 millimètres,

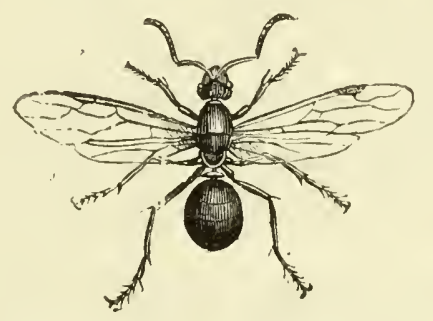

Fig. 930. - Fuurmi fanve lemelle.

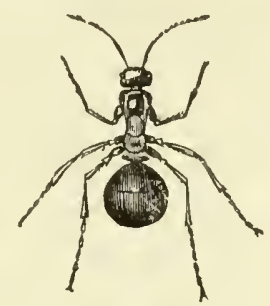

Fig. 931. - Fourmi fauve (individu neutre).

noilâtre, avec une grande partie de la tête, le thorax et l'écaille ou le pédicule fauves. Elle forme dans les bois des nids en pain de sucre ou en dôme, composés de terre et de débris ligneux. Elle laisse échapper un liquide acide qui forme des traces rouges sur les fleurs bleues. Elle coniient en outre une huile résineuse, àcre et odorante, qu'on peut obtenir, mélangée avec l'acide, par le moyen de l'alcool ; la teinture qui en résulte est l'eau de magnanimité d'Hoffmann, et passe pour aphrodisiaque.

L'acide libre des fourmis, ou l'acide formique, a été pris par quelques chimistes pour de l'acide acétique. Mais, dès l'année 1777, Arvidson et Oehrn, chimistes suédois, en avaient démontré la nature particulière, qui a été confirmée depuis par Gehlen et par Berzélius. Doebereiner a montré aussi que cet acide se formait par un grand nombre de réactions sur les principes organiques, et notamment lorsqu'on traite l'acide citrique, l'acide tartrique, le sucre, l'amidon, elc., par le peroxyde de manganèse et l'acide sulfurique. Cet acide, tel qu'on peut l'obtenir, est hydraté, liquide, volatil, non cristallisable ; la propriété qui le distingue le plus facilement de l'acide acétique est celle de réduire, à l'aide de l'ébullition, les oxydes et les sels de mercure et d'argent. Combiné aux bases et anhydre, il est formé de $\mathrm{C}^{2} \mathrm{H}^{3} \mathrm{O}^{3}$. L'acide liquide conlient un atome double d'eau en sus.

La fourmi rouge (Myrmica, Latr.), qui habite aussi dans ies bois, est pourvue d'un aiguillon, et pique assez vivement. Le pédicule de son abdomen est formé de deux nouds; le mulet est rougeâtre, avec l'abdomen lisse et luisant, et une épine sous le premier nœud du pédicule.

Guinourt, Drogucs, io édit.

T. $I V \cdot-13$ 


\section{Abeille domestioue.}

Apis mellifica, L. L'abeille est un insecte hyménoptère, principalement caractérisé par ses quatre ailes nues et transparentes; son corps velu, sa lèvre supérieure courte, ses antennes filiformes, moins longues que la tête et le corselet réunis; ses tarses postérieurs, dont le premier article est aplati en une palette carrée, concave sur une de ses faces. Cet insecte vit en sociétés nom. breuses, composées de trois sortes d'individus, savoir : des neutres ou ouvrières, dont le nombre est de 13 à 20,000 et quelquefois de 30,000; d'environ 6 à 800 mâles, nommés vulgairement bour dons ou faux bourdons (1), et communément d'une seule femelle, dont les anciens faisaient un roi, mais que les modernes désignent sous le nom de reine.

Cette femelle ( $f g .932, \mathrm{~B}$ ) est plus grande et plus forte que les
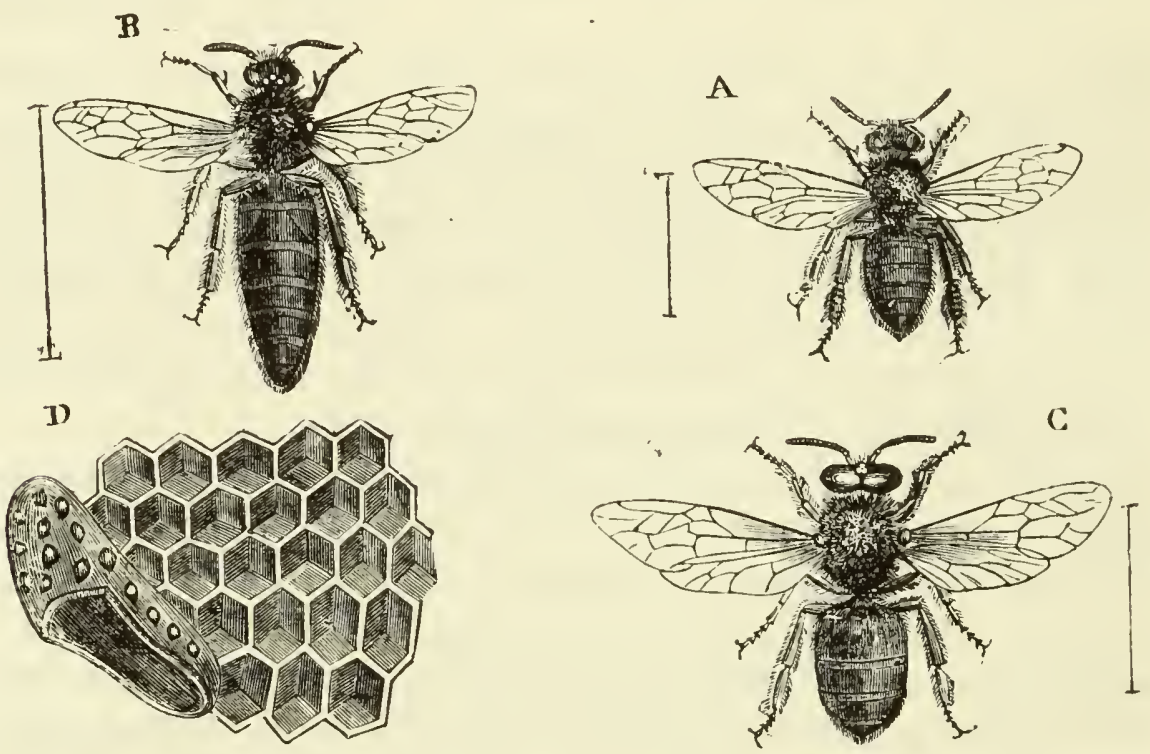

Fig. 932. - Abeilles (*).

màles, surtout lorsqu'elle est fécondée ; elle a la tête triangulaire, un peu moins large que le corselet; les ailes courtes; l'abdomen

(1) Il ne faut pas confondre ces abeilles mâles avec les vrais liou'dons, qui constituent une autre espèce d'insectes apiaires, beaucoup plus gros, vivant dans des habitations souterraines, en sociétés beaucoup moins noinlieuses que les abeilles, mais composées de même d'ouvirières, de mâles et de femelles

(*) La figure $932 \mathrm{D}$, indépendamment d'un certain nombre de cellules hexagones servant à contenir le miel, on à recevoir les œufs qui produiront des ouvrières, représente une cellule beaucoup plus grande, à parois plus épaisses et scrobiculées, dans laquelle la reine dépose un œuf destiné a produirc une femelle. Il n’y a qu un très-petit nombre de ces cellules dans chaque ruche. Les cellules destinées aux mảles sont semblables à celles qui reçoirent les ouvrieres; elles sont seulement un peu plus grandes. 
très-allongé et terminé par une pointe percée d'une ouverture qui donne issue à un aiguillon rétraclile, et permel l'introduction des parties génitales du mâle; ses jambes sont aplaties et concaves, non garnies de brosses à leur partie interne.

Les mâles ( $/ \mathrm{g} .932, \mathrm{C}$ ) sont plus gros et plus velus que les ouvrières; leur tête est arrondie, garnie d'yeux très-gros, qui se touchentsupéricurement, el de mandibules fort courtes bidentées, entièrement cachées par le poil de la face. Leur corselet est trèjlarge et très-velu inférieurement; leur abdomen est tronqué à la base, non percé à la pointe et dépourvu d’aiguillon.

Les ouvrières (fig. 932, A) sont les plus petits individus de lit peuplade; leur corps n'a que 14 millimètres de longueur au plus; elles ont des mandibules en cuiller, beaucoup plus longues que celles des males et de la femelle; leur front est beaucoup moins velu; leur tête triangulaire; leur abdomen court, conique, percé à l'extrémilé d'une très-petite ouverture pour la sortie de l'aiguillon. Leurs jambes de derrière sont Iriangulaires, élargies, lisses, présentant du côté extérieur un enfoncement qui a reçu le nom de corbeille; le premier article des tarses de ces jambes est aussi très-élargi, de forme carrée el creusé en goultière; enfin, des espèces de brosses couvrent toute la partie interne des jambes et du premier arlicle.

C'est au printemps el en ćlé surtout, qu'on roit les abeilles sur les fleurs, où elles rassemblent les malériaux des denx produils précieux qu'elles savent fabriquer et dont nous les dépouillons pour notre utilité. Avant que nous cussions appris à les réunir dans des demeures arlificielles, auxquelles on donne le nom de ruches, les abeilles vivaient en société dauns les bois, et se cachaient dans de grandes cavités pour se meltre à l'abri des intempéries de l'air. C'est ce qu'on observe encore dans les vastes forêts de la Russie, de la Pologne, en Italie et dans quelques-unes de nos provinces inéridionales.

A leur arrivée dans une ruche, les abeilles neutres, qui sonl les seules qui travaillent, commencent par en boucher tous les trous par où la lumière pourlail pénétrer et les insectes entrer, avec une matière particulière nommée propolis. Celle matière, qui est de nature résineuse, gluante el aromatique, parıîl provenir de l'enduit balsamique, qui défend contre l'humidité les bourgeons des arbres et arbrisseaux, et principalement ceux des peupliers, des bouleaux el des saules.

Cel ouvrage est à peine achevé, que les abeilles se meltent à construire leurs rayous (fig. 932, D), composés d'un graud nombre de lames verticales, distantes d'environ 33 millimètres, et formées, sur chaque face, d'une infinité de cellules hexagones, des- 
tinées à recevoir les œufs de la femelle et à contenir le miel qui excède les besoins de la ruche. La matière de ces rayons est la cire, substance sécrétée par des organes propres aux abeilles ouvrières, et qui aboutissent à huit poches situées sous les segments inférieurs de leur abdomen: les mâles et la femelle en sont privés.

Le miel est d'une origine toute différente : il provient des liqueurs sucrées contenues dans les nectaires des fleur's, qui ont ćlé pompées par les abeilles ouvrières, et qui sont restituées à la communauté, après avoir été élaborées dans leur estonac. Il est réservé pour la mauvaise saison : mais l'homme est là qui se l'approprie, et qui souvent ccuronne sa spoliation par la ruine enlière de la république.

La fécondation de l'abeille femelle s'opère dans l'air' elle parait n'avoir lieu qu'une fois, ou du moins on a cru s'être assuré que la femelle, après celte seule approche d'un des mâles, pourait produire des œufs fécondés pendant deux années.

[La femelle peut produire des wufs sans être fécondée. Mais alors ce sont toujours des mâles. Quand la fécondation a eu lieu, elle peut laisser passer dans son oviducte des œufs qui ne reçoivent point l'impression du liquide fécondateur renfermé dans la vésicule copulative, ou les soumettre à cette influence, et pondre ainsi, suivant les cas, des œufs mâles ou femelles. Ces faits trèscurieux ont été mis hors de doute par les observations de MM. Dzierzon, curé à Carlsmark, de Siebold et Leuckart.]

Dès que les œufs déposés dans les cellules sont éclos, les ouvrières nourrissent les larves d'une sorte de bouillie toujours élaborée dans leur estomac, mais différente du miel. On remarque aussi qu'elles prennent un soin particulier de celles qui doivent fournir des femelles, et qu'elles leur donnent une nourriture plus abondante, d'une nature différente, et sans doute propre à développer chez elles les organes de la génération; car les ouvrières ne sont que des femelles en qui ce développement n'a pas eu lieu. Peu de jours après que les larves sont nées, elles se filent une coque dans laquelle elles restent huit à dix jours à l'état de nymphes; après ce temṕs, elles en sortent abeilles parfaites.

Au moșen de cette génération, et ordinairement du 2 ò au 30 juillet, la ruche se trouve trop pleine, de sorte que les abeilles se divisent en deux parlis, ayant chacun une femelle à leur tête. La plus ancienne quille ordinairement la ruche, et va chercher une nouvelle demeure. Elle rassemble ses ouvrières autour d'une branche d'arbre, en un pieloton plus ou moins pesant, que l'on a l'adresse d'altirer peu à peu dans une ruche préparée d'avance. C'est ainsi qu'on les multiplie. 
Les abeilles fournissent trois produits à la pharmacie et aux arts: la propolis, le miel et la cire.

La propolis est de nature résineuse; elle est rougeâtre, odorante, soluble dans l'alcool, et saponifiable par les alcalis. On s'en sert dans les arts pour prendre des empreintes, et on l'emploie quelquefois en médecine sous la forme de fumigation, ou appliquée à l'extérieur comme résolutive. Elle présente la plus grande analogie, par son odeur, avec la matière résineuse qui recouvre les bourgeons de peuplier.

Le miel et la cire sont d'un usage bien plus étendu. La récolle s'en fait dans les mois de septembre et d'octobre; pour cela on frotte intérieurement de miel une ruche vide, on la renverse auprès de la ruche pleine que l'on veut couper, et l'on glisse celle-ci dessus de manière à recouvrir l'autre exactement; on retourne les deux ruches, de manière que la pleine se trouve en bas et renversée, et l'on frappe légèrement dessus. Les abeilles en sortent et se portent dans la ruche supérieure que l'on place ensuite sur l'appui. Alors, on coupe à l'aise la moitié ou les denx tiers au plus des rayons, et, celte opération faite, on remet les abeilles dans leur ancienne ruche de la même manière qu'on les en avait retirées.

Pour séparer le miel de la cire, on expose les gâteaux sur des claies au soleil. Le miel en découle et est reçu dans des vases placés au-dessous; ce miel, qui est le meillenr de tous, se nomme miel vierge.

On soumet ensuite les gâteaux à la presse, et l'on obtient unc quantité de miel plus coloré, d'une saveur et d'une odeur moins agréables. Enfin, on fond les rayons dans de l'eau pour les priver du reslant du miel, et l'on coule la cire dans des vases de terre ou de bois.

Le miel le plus estimé vient de Narbonne, dans le département de l'Aude. Il est blanc, très-grenu, aromatique et d'un goût trèsagréable. Quelques personnes, cependant, n'aiment pas son parfum, et il a l'inconvénient, lorsqu'il est mis au sirop, de se candir au bout de quelque temps.

Le miel le plus estimé, après celui du Languedoc, est celıi du Gâtinais (1); il est plus uni que celui de Narbonne, moins aromatique, communément blanc; c'est celui qu'on doit préférer pour

(1) Gatinnis, ancienne province de France, dont la partie septentrionale, appartenant à l'Ile-de-France et nommée Gâlinais français, comprenait toute la partie du département de Seine-et-IIarne située au sud de la Seine, et dont la partie méridionale, faisant partie de l'Orléanais et nommée Gâtinais orléunais, comprenait les arrondissements de Pithiviers, de Montargis et de Fien, dans le département du Loirct. 
meltre en sirop. Presque toutes les autres provinees de France donnent aussi des miels, mais qui ne sont pas renommés, si ce n'est ceux de Bretagne, par leur mauvaise qualité : ils sont en général très-colorés, coulants et pourvus d'une saveur résineuse désagréable, allribuće au sarrasin, que l'on cultive en abondance dans celle province.

Le miel, quoique élaboré par les abcilles, a conservé toute son

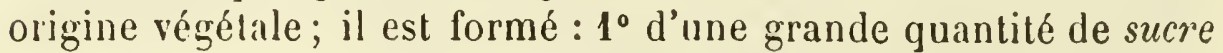
grenu ou glucose, semblable au sucre solide de raisin et au sucre solide qui résulte de l'action d'acides sur le sucre de canne ou l'amidon, et, comme eux, faisant dévier vers la droite le plan de la lumière polarisée; $2^{\circ}$ d'une pelite quantité de sucre de canne, qui dévie également vers la droite le plan de la lumière polarisée, mais dont l'action sur ce plan est intervertie vers la gauche par les acides, ce qui n'a pas lieu pour le glucose concrétionné ; $3^{\circ}$ de sucre incristallisable, analogue au sucre non cristallisable qui provient de l'action des acides sur le sucre de canne ou l'amidon, mais exerçant une déviation à gauche beaucoup plus marquée sur la lumière polarisée (1); $4^{\circ}$ d'un acide libre; $5^{\circ}$ d'un principe aromalique; $6^{\circ}$ de cire, dont il contient d'autant moins qu'il a été obtenu avec plus de soin. Le miel de Bretaggne contient, en outre, du couvain, qui en détermine la promipte fermentation et la destruction.

Falsification du miel. Depuis quelques années, le miel est souvent falsifié arec du glucose solidifié. Une apparence mate particulière et une saveur plus ou moins élrangère au miel, indiquent déja cette sophistication; mais on ne peut en devenir cerlain qu'en constatant la présence du sulfite de chaux, qui accompagne toujours le glucose, tandis que le miel n'en contient pas. Pour faire cet essai, on fait dissoudre, à froid, un peu de miel dans l'eau distillée. Si le miel est de belle qualité el que la liqueur soit transparente, on peut l'essayer immédiatement par le nitrate de baryte et l'oxalate d'ammoniaque, qui ne doivent pas la troubler. Mais, lorsque le miel est de qualité inférieure, quoique non falsifié, il fournit une liqueur trouble; alors il faut la tiltrer préalablement à travers un papier pur, qu'on lave d'abord soimême avec de l'acide chlorhydrique affaibli, et ensuite avec de l'eau distillée. Ce lavage préliminaire est nécessité par la propriélé que possède le miel de dissoudre avec une grande avidité tous les sels calcaires; en sorte que, si le papier en contenait les moindres traces, le miel les dissoudrait, et pourrait paraître falsilié lorsqu'il ne l'est pas.

(1) Soubeiran, Journ. de pharm. et de chimie, t. XVI, p. 25.2. 
l.a cire est la matière qui compose les rayons dans lesquels l'abeille dépose ses œufs et le miel qui doit servir à sa nourriture pendant l'hiver. On a cru longtcmps, d'après Réaumur, qu'elle était le produit du pollen des fleurs récolté par les abeilles ouvrières, rapporlé par elles à la ruche dans les petits cuillerons dont sont munies leurs pattes postérieures, et avalé alors par d'autres ouvrières qui, bientôt après, le rendaient sous la forme d'une bouillie liquide, avec laquelle elles construisaient leurs rayons. Cependant, dès l'année 1768, Bonnet, de Genève, annonça, d’après une Société de Lusace, que la cire était le produit d'une sécrétion qui s'opérait sous les anneaux du ventre; et Hunter (1), en 1791, avait déjà consigné la découverte qu’il avait faite des organes destinés à cette sécrétion. Depuis, Huber a vérifié cette déconver'se, et a d'ailleur's prouvé directement que le pollen des fleurs était inutile à la production de la cire, en renfermant un nouvel essaim d'abeilles, pendant cinq jours, dans leur ruche, et leur donnant seulement à discrétion du miel et de l'eau; au bout de ce temps, elles avaient fabriqué cinq rayons de la plus belle cire, d'un blanc parfait et d'une grande fragilité.

J'ai exposé précédemment comment on vidait les ruches, et les moyens de séparer le miel et la cire. Celle-ci fondue dans l'eau, pour la priver du miel qu'elle retient encore, est coulée dans des vases de terre ou de bois. On la nomme cire jaune.

On doit choisir la cire jaune d'un jaune pur et sans mélange de gris, ce qui est dù à du dépôt qui n'en a pas été séparé; mais il est indifférent que le jaune en soit pâle ou foncé ; car souvent on lui donne cette dernière nuance artificiellement, et elle ne lui communique d'ailleurs aucune bonne qualité. Il faut aussi que cette cire, machée dans la bouche, n'offre aucun goût de suif; elle doit, au contraire, avoir un léger goût aromatique assez agréable. Échauffée dans les doigts, elle s'y ramollit assez pour y être facilement pétrie ; mais elle doit conserver de la ténacité entre ses parties, et ne pas se diviser en grumeaux, qui adhèrent aux doigts, ainsi que cela a lieu quand elle est mélangée de cire de myrica.

Delpech, pharmacien à Bourg-la-Reine, a signalé une autre falsification que la cire jaune subit assez souvent dans le commerce. A yant fait dissoudre de cette cire altérée, dans de l'huile de térébenthine, elle a laissé un résidu blanc et pulvérulent, qui s'est trouvé être de la fécule de pomme de terre, dont la quantités'élevait au tiers du poids de la cire employée. Cette cire était d'une couleur jaune terne, moins onctueuse et moins tenace que la

(!) Hunter, Philosopnical Transactions, 1791. 
eire pure ; mais le meilleur moyen de s'assurer de la bonne qualité d'une cire consiste à la traiter par l'essence de térébenthine, qui doit la dissoudre entièrement.

La cire jaune doit sa couleur, son odeur et une certaine onctuosité qui lui reste encore, à des corps qui lui sont étrangers et qui proviennent des principes colorants et aromatiques des plantes; de même que cerlains principes végétaux amers, résineux, colorants ou aromatiques, communiquent leurs propriétés à plusieurs de nos humeurs et même à nos solides. On débarrasse la cire de ces propriétés étrangères en la fondant à une douce chaleur, et la faisant tomber par filets sur un grand cylindre plongé horizontalement dans l'eau, et tournant continuellement sur son axe. De cette manière, la cire se divise en grenailles ou en rubans ; on l'expose, ainsi divisée, sur un pré, à un pied d'élévation de terre, et étendue sur des châssis de toile. On l'arrose légèrement tous les soirs, et on la laisse ainsi exposée au soleil et à la fraîcheur des nuits, jusqu’à ce qu'elle soit parfaitement blanche. Elle est alors très-sèche et friable. On la fond en y ajoutant un peu de suif, pour lui restituer le liant qu'elle a perdu, et on la coule en petites plaques rondes. Il faut toujours choisir celle qui, par sa fragilité et l'absence de toute saveur de suif, paraît être la plus pure. La cire pure est blanche, solide, cassante, presque sans odeur et saveur; elle est un peu plus légère que l'eau, et pèse 0,966 . Flle devient molle et ductile à une chaleur de 35 degr'és, se fond à environ 70 degrés, et se congèle à 62,75 , sans offrir aucune cristallisation. Elle se volatilise et se détruit en partie à une chaleur approchant de la chaleur rouge.

La cire blanche est aujourd'hui très-souvent falsifiée avec de l'acide stéarique; on reconnaît cette falsification par l'alcool houillant, qui dissout, presque en toutes proportions, l'acide stéarique, et qui le laisse cristalliser en grande partie par le refroidissement, tandis que la cire est très-peu soluble dans l'alcool bouillant; de plus, en trempant un bon papier de tournesol bleu dans la dissolution alcoolique, et le laissant sécher à l'air, il arrive un moment où l'acide stéarique rougit le tournesol; la cire pure ne prodnit pas cet effet.

La cire est entièrement insoluble dans l'eau; clle est soluble dans les huiles fixes en toutes proportions, soluble dans les huiles volatiles à l'aide de la chaleur. L'alcool très-rectifié bouillant en dissout 0,0486 de son poids, d'après Boullay, et seulement 0,01, suivant M. Chevreul; il l'abandonne en se refroidissant. L'éther bouillant en dissout 0,25 , qu'il abandonne de mẻme en trèsgrande partie. D’ailleur's, la cire paraît formée de deux principes différents qui peuvent être isolés par le moyen de l'alcool. Lors- 
qu'on traite, en effet, la cire blanche par une grande quantité d'alcool bouillant, elle laisse environ 0,3 d'une substance qui est du palmitate de myricile $\left(\mathrm{C}^{92} \mathrm{H}^{29} \mathrm{O}^{4}\right)$, et donne, par l'évaporation de l'alcool, 0, lincte de la première par scs propriétés.

[Le palmitate de myricile, qu'on a nommé d'abord myricine, cst à peine soluble dans l'alcool bouillant, el s'en précipite entièrement par le refroidissement, sons l'action des bases alcalines, il se saponifie et se dédouble en acide palmitique et en alcool myricique. L'acide cérotique ou cérine est soluble dans l'alcool bouillant et lui communique par le refroidissement une consistance gélatineuse. Quand il est pur, il se volatilise sans décomposition. Il est saturé par les alcalis et forme des sels arec eux.]

La cire jaune on blanche entre dans la composition de presque tous les emplâtres ou onguents.

\section{ORDRE DES LÉPIDOPTÈRES.}

Les insectes de cet ordre présentent, à l'état parfait, quatre ailes recouvertes, sur les deux faces, de petites écailles colorées (1), semblables à une poussière farineuse, et qui s'enlèvent au toucher. Ils ont, pour pomper le miel des fleurs, qui est leur seule nourriture, une trompe roulée en spirale, entre deux palpes (les inférieurs) hérissés d'écailles ou de poils. Celte trompe est composée de deux filets tubulaires, représentant les mâchoires, et portant chacun, près de leur base extérieure, un très-petit palpe (supérieur) ayant la forme d'un lubercule.

Deux pelites pièces, à peine distinctes, semblent ĉtre des vestiges de mandibules. Les antennes sont toujours composées d'un grand nombre d'arlicles, mais sont de forme variable; les trois segments du thorax se réunissent en un seul corps; l'écusson est triangulaire, avec la pointe dirigée vers la tête. Les ailes ne présentent que des veines longitudinales. A la base de chacune des deux supérieures, est une picee en forme d'épaulette. L'abdomen, composé de 6 ou 7 anneaux, est attaché au thorax par une très-petite portion de son diamètre et n'offre ni aiguillon ni tarière. Ils n'ont pas d'individus neutres.

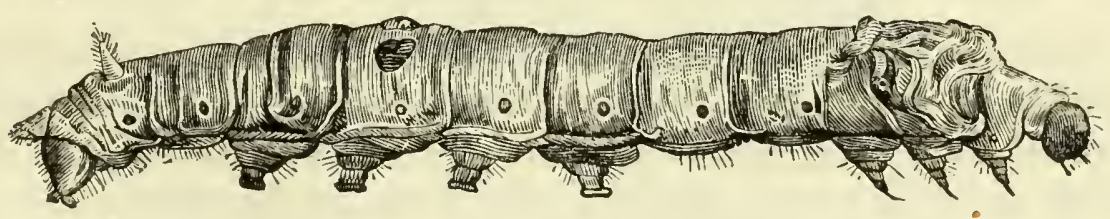

Fir.r. 933. - Chenille de bombyx du mùrier, dite ver à soie, dans son plus grand déreloppement, parvenue à son einquième âge.

Les larves des lépidoptires sont connues sous le nom de cherilles (fig. 933). Elles ont six pieds écailleux ou à crochets, qui répondent ì

(1) De là le nom de lépidoptères : de $\lambda \varepsilon \pi i \varsigma$, écaille, et de $\pi \tau \varepsilon \rho o ́ v$, aile. 
ceux de l'insecte parfait, et, en outre, de quatre à dix pieds membraneux, dont les deux derniel's sont silués prìs de l'anus, à l'extrémité du corps. Le corps de ces larves est en général allongé, presque cylindrique, mou, diversement coloré, tantôt nu ou ras, tantôt liérissé de poils, de tubercules, d'épines, et composé, la tête non comprise, de 12 anneaux, avec neuf stigmates de chaque côté. Leur lête est revêlue d'un derme corné ou écailleux, et présente, de chaque côté, six pelits grains luisants qui paraissent être des yeux lisses. Flle a, de plus, deux antennes trìs-courtes, et une bouche composée de dcux fortes mandibules, de deux mâchoires, d'une lèvre et de quatre petits palpes. Cette bouche, ainsi armée, leur sert à dévorer les feuilles des végétaux, et d'autres fois les fleurs, racines, bourgeons ou graines; d'autres, encore, rongent les draps et les autres étoffes de laine, les pelleteries, et sont pour nous des hôtes tris-pernicieux. Quelques-unes, enfin, se nourrissent de cuir, de graisse, de lard ou de cire.

Les chenilles changent ordinairement quatre fois de peau, avant de passer à l'état de nymphe ou de clırysalide. La plupart se renferment alors dans une coque formée d'un fil tris-fir, qui constitue la soie. Celte malière est élaborée dans deux vaisseaux intéricurs, longs et tortueux, qui viennent aboutir à la livre inférieure, sous forme d'un petit mamelon qui donne issue au fil de soie. D'autres chenilles se contentent de lier, avec de la soie, des feuilles, des molécules de terre, ou les pal'elles des substances où elles ont vécu, et se forment ainsi une coque grossière; d'autres, enfin, restent à découvert, et se suspendenl, au moyen d'un cordon de soie, à un corps solide. Beaucoup de ces nymphes, appartenant aux lépidoptìes diurnes, sont ornées de taches dorées qui ont donné lieu à la dénomination générale de chíysa-

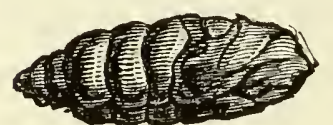

Fig. 934. - Chrysalide. lides. Toutes ces nymphes sont emmaillotiees ou en forme de momie; c'est-à-dire qu'elles sont enfermées sous une membrane assez dure, sous laquelle on distingue les parlies extérieures de l'insecte parfait (fig. 934). La durée de cet état d'insensibilité ou de mort apparente, est Irès-variable; tantot elle n'est que de quelques jours, el d'autres fois la clırysalide passe l'hiver, et l'insecte ne subit sa dernière métamorphose qu'au printemps ou dans l'été de l'année suivante. En général, les œuf́s pondus dans l'arrière-saison n'éclosent qu'au printemps.

L'ordre des lépidoplères se divise en trois familles également distinctes par les mœurs et la conformation, savoir : les DIURNEs, reconnaissables à leurs ailes élevées perpendiculairement dans l'état de repos; les crépcsculanes, dont les ailes sont horizontales pendant le repos, et les antennes en forme de massue allongée; et les nocturnes dont les ailes sont également horizontales ou inclinées en forme de toit, el dont les antennes diminuent de grosseur de la base à lia pointe.

Les premiers, qui comprennent le genre de papillons proprement dits (fig. 935 et 936), sont les plus remarquables par la vivacité 
de leurs couleurs; mais ils ne nous offrent aucune espèce que nous devions citer particulièrement.

Les seconds renferment le genre des sphinx, dont une grande

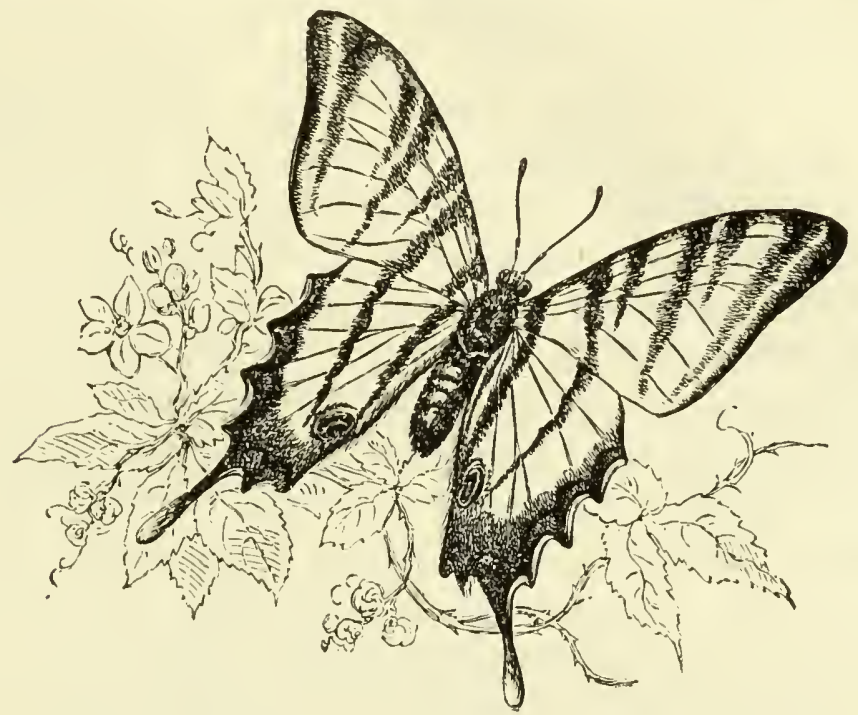

Fig. 935 et \$36. - Papillon podalyre (Papilio podalyrius).

espèce de notre pays est remarquable par l'image d'une tête de mort figurée sur son thorax.

La troisieme famille, formée par les phalènes de Linné, est aujourd'hui divisée en un grand nombre de genres, parmi lesquels nous cilerons le genre saturnie, dont une belle espèce, nommée

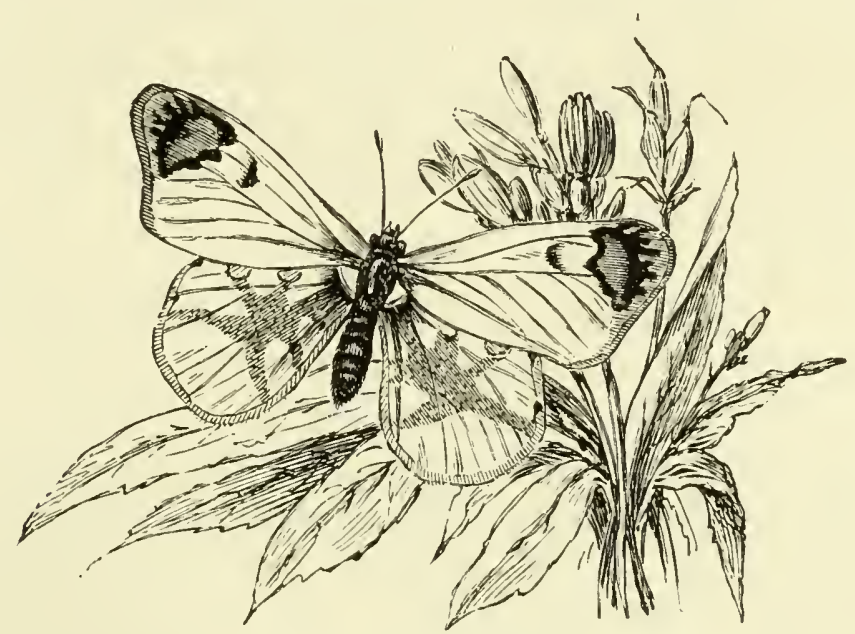

Fig. 936. - Papillon.

le grand paon de nuit (Saturnia pavonina), est le plus grand des lépidoptères d'Europe ; nous y trouvons aussi le bombix du mûrier, si connu sous le nom de ver à soie et la pyrale de la vigne, qui produit de si grands dégâts dans les pays de vignobles. Nous nous bornerons à faire l'histoire du bombyx du mûrier. 


\section{Bombyx du mîrier.}

Bambyx mori, L., insecle lépidoptère de la famille des nocturnes, dont les ailes sont blanchâtres, avec deux ou trois raies obscures transversales, et une tache en croissant sur les ailes supérieures. Il est originaire des provinces septentrionales de la Chine (la Sérique des anciens), où la manière de l'élever et celle d'en utiliser la soie sont connues depuis très-longtemps (1). Deux moines grecs en apportèrent les œufs à Constantinople, sous le règne de Justinien : à l'époque des premières croisades, la culture s'en répandit en Sicile et en Italie; mais ce ne fut guère que du temps de Henri IV que cette branche d'industrie acquit quelque importance dans nos provinces méridionales, dont elle forme aujourd'hui l'une des principales richesses.

Les œufs du bombyx du mûrier sont designés, par les agriculteurs, sous le nom de graine de ver's à soie. Ils sont un peu ovales ou ellipsoïdes et lenticulaires; ils se dessèchent à l'air, s'aplatissent encore davantage, et peuvent se conserver pendant assez longtemps en bon état, pourvu que la dessiccation n'ait pas élé Irop forte et qu'on les préserve aussi de l'humidité. Leur poids est donc variable et n'est pas exaclement le même pour les différentes races; cependant, en moyenne, il en faut environ 1300 pour peser un gramme, ou 44,000 pour faire une once métrique de $3\left\lfloor^{\mathrm{gr}}, 25\right.$. Ces œufs sont d'un jaune-jonquille lorsqu'ils viennent d'être pondus; dans l'espace de huit jours, ils deviennent bruns rougeâtres, puis d'un gris cendré, couleur qu'ils conservent jusqu'au moment où commence le travail de l'incubation, qui a lieu ordinairement du 15 avril au 15 mai, suivant la température moyenne du lieu où elle se fail.

Dans le midi de la France, on appelle les ver's à soie magniaux, magnians ou magnans, d'où est venu le nom de magnaneries donné aux établissements dans lesquels on les élève. Les diverses maladies des vers à soie, et particulièrement la pébrine ou gattine, qui sévit actuellement dans tous les pays séricicoles, ont été l'objet d'un grand nombre de travaux, parmi lesquels nous citerons particulièrement ceux de M.I. Cornalia, Pasteur, de Quatrefages, Chavannes (de Lausanne), Béchamp, etc. Je me bornerai à dire ici que les œufs, pour éclore, doivent être placés dans une étuve dont on élève progressivement la température de 15 à 27 ou 28

(1) D'après les chroniques chinoises, la femme de l'empereur Ho-ang-ti, nommée Si-ling-chi, chargée par ce prince de faire des essais pour utiliser le fil des ver's ì soie, trouva non-seulement la façon d'élever ces insectes, mais encore la manière de dévider leur soie et de l'employer pour la fabrication des étoffes. Cette découverte se faisait il y a environ 4540 ans. 
degrés, et où l'air est maintenu à un degré convenable d'humidité. Après huit ou dix jours de chaleur croissante, les œufs deviennent blanchatres et bientôt après les larves commencent à en sortir. Elles ont environ deux millimètres de longueur, pèsent moins que l'œuf qui leur a donné naissance et sont d'abord d'une couleur brune foncée el presque noire.

Le premier soin que réclament les petits vers à soie est celui d'ètre séparés de leurs coques. A cet effet, on les recouvre d'une feuille de papier criblée de trous, à traverslesquels les vers passent pour arriver à leur nourriture, qui consiste en feuilles de mûrier blanc, placées au-dessus. Ils vivent, à l'état de larve, environ trentequatre jours pendant lesquels ils augmentent rapidement de poids et de volume, et changent quatre fois de peau. A l'époque de chaque mue (1), ils s'engourdissent et cessent de manger; mais après avoir changé de peau, leur faim redouble et la quantité des feuilles qu'ils consomment augmente prodigieusement. On compte que, pour leslarves provenant d'une once ou de 31 grammes de graines, il faut de 3 à 4 kilogrammes de feuilles mondées, pendant le premierâge; 10 à 11 kilogrammes pendant le deuxième âge ; 3ö kilogrammes pendant le troisieme; 10: kilogrammes pendant le quatrième, et de 6 à 700 kilogrammes pendant le cinquième (2). C'est le sixième jour de ce dernier âge qu'a lieu leur plus grande faim, ou ce qu'on appelle la grande frèze. Les vers dévorent alors de 100 à 1 ว̆0 kilogrammes de feuilles dans un jour et font, en mangeant, un bruit qui ressemble à une forte averse. Le dixième jour, le ver à soie cesse de manger et s'apprête à subir sa première métamorphose. Il se vide d'excréments ei grimpe sur des branchages qu'on a eu soin de placer au-dessus des claies où il était, resté jusqu’alors; il cherche une place convenable à son établissement, et pose d'aljord, çà et là, quelques fils forts qu'il multiplie dans tous les sens de manière à former un lacis, auquel on donne le nom de banc, de banne ou de bourre de soie. C'est alors que, suspendus au milieu de ce lacis, ils construisent leur cocon, en tournant continuellement sur eux-mêmes en divers sens, et en agglutinant les unes contre les autres, en allant toujours nécessairement du dehors au dedans, les diverses partics du fil qui sort de leur filière. Le résultat de cette manœurre est la formation d'une enveloppe assez ferme, et de forme ovoïde ou

(1) Cliaque mue constitue th nouvel âge pour le ver ì soie. Le premier àge, dẹuis la naissance jusqu'à la première mue, dure ordinairement 5 jours; le second àge, de la première mue à la seconde, dure ́́ jours; le troisième âge, i jonrs; le quatrième âge, $i$ jours; le cinquième et dernier âge, 9 à 11 jours. Cette durée peut être abrégée ou retardée pal des circonstances dépendantes de la température, de la nourriture et d'autres causes.

(2) La figure 933 représente le ver à soie parvenu ì sou cinfuibuce âge. 
elliptique plus ou moins allongée, souvent un peu rétrécie par le milieu ( $f g .936)$. Cette enveloppe est formée par un seul fil qui a plus de mille mètres de longueur (1), et qui est tellement lénu qu'il en faut à peu près 3,7500 mètres pour peser un gramme. Ce fil si ténu n'est cependant pas un fil simple; il est formé par la soudure de deux fils provenant des deux réservoirs intérieurs collatéraux, et qui se sont réunis avant d'arriver au seul et unique conduit aboulissant à la lèvre inférieure de l'animal.

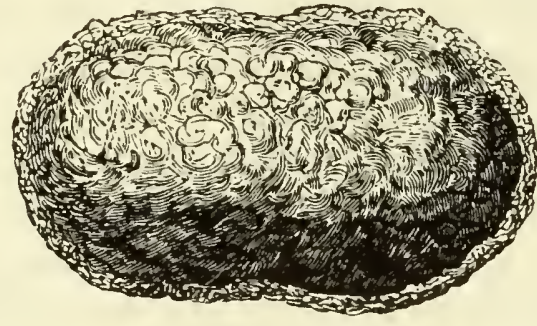

liig. 930. - Cocon.

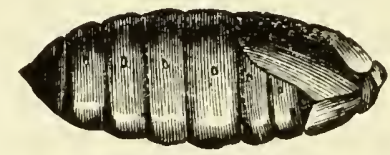

lig. 937. - Chrysalide.

Le ver à soie emploie trois à qualie jours pour filer son cocon; presque aussilôt après, il éprouve des changements successifs qui déterminent la séparation de la peau et de ses annexes d'avec la chrysalide formée en dedans. Enfin la peau est rejetée tout entière à l'extrémilé postéricure, et la chrysalide paraît à nu (fig. 937), d'une couleur presque blanche d'abord, devenant bientôt d'un rouge brun. A traver's son enveloppe, on voit se dessiner la lête, les antennes, les ailes et les palles du papillon. Linfin, au bout de 16 a 18 jours, le papillon, élant complétement formé, sort de la chrysalide et songe à percer le cocon. A cet effet, il en humecle une extrémilé, avec une humeur particulière qu'il dégorge et qui a la propriété de ramollir ou de dissoudre la soie. Il heurte ensuite la tête contre le point ramolli, le perce et passe peu à peu à travers l'ouverture. On a remarqué que les papillons males sortaient en plus grand nombre dans les deux ou trois premiers jours, et les femelles en plus grand nombre dans les jours suivants, de telle sorte qu'il y a en totalité un peu plus de femelles que de males. La femelle est plus furte (fig. 938), et son ventre est surtout très-volumineux en raison des œu's qu'il renferme. Elle est lourde, peu empressée de quiller sa place el ne vole pas; elle a les ailes blanches, les antennes peu développées et d'une couleur pâle. Le papillon mâle (fig. 939) est plus petit; son ventre est plus allongé et pointu; ses ailes colorées par un dessin plus prononcé, ses antennes plus grandes et noiratres. Il ne vole pas

(1) Le fil retiré d'un cocon n’a guère plus de 6 à 800 mètres; mais cela tient à ce que ce fil devient d'autant plus fin qu'on approche plus du centre, et quil se rompt bien avant que le cocon soit entièrement dévidé. 
dans les pays où la température n'est pas assez élevée; mais il est cependant très-vif et très-alerte. Il court en agitant ses ailes avec beaucoup de vivacité, surtout lorsqu'il sent une femelle. Il s'en approche arec ardeur, se place parallèlement à son côté, saisit

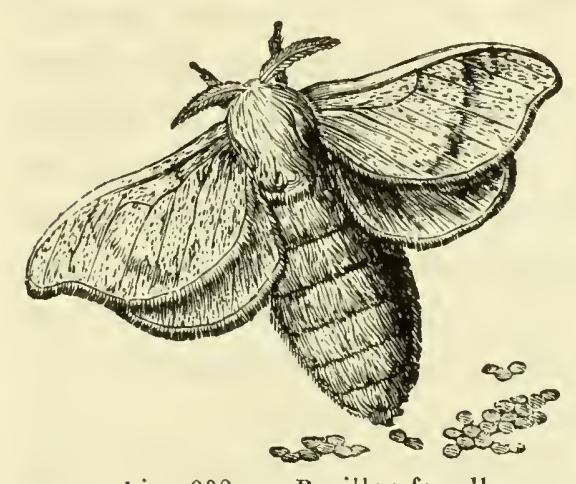

1 ig. 938. - Papillon femelle.

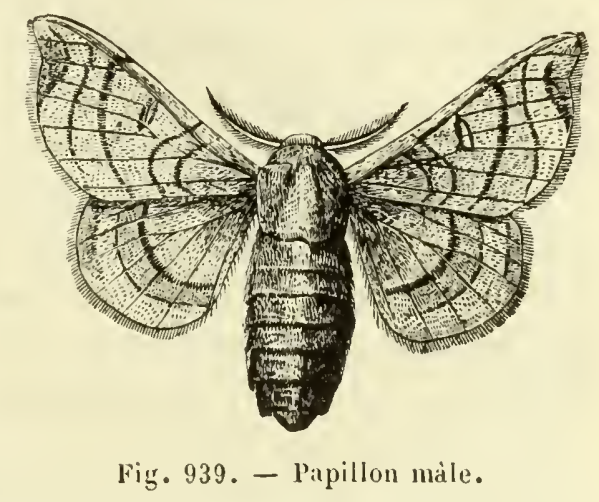

avec les crochets dont son anus est armé l'extrémité du ventre de la femelle et s'y cramponne. Il se retourne alors et se place sur la même ligne, la tête diamétralement opposée à celle de la femelle. L'accouplement dure quelquefois trois el qualre jours; mais ordinairement il se termine dans la même journée; d'autres fois on l'abrége, et l'on fait servir le mâle à plusieurs accouplements. La femelle, peu d'instants après qu'elle est séparée du mâle, s'oc. cupe de sa ponte. Elle dépose ses œufs humides et envisqués d'une mucosité très-tenace qui les fixe aux corps solides qui l'entourent. Souvent elle pond plus de cinq cents œufs. De même que le mâle, elle ne prend aucune nourriture; leur seule fonction, une fois arrivés à l'élat de papillon, est d'assurer la reproduction de leur espèce. Une fois ce grand but de la nature rempli, ils dépérissent, se dessèchent et meurent tous en quelques jours. Les œufs se conservent à l'air, naturellement ou artificiellement, jusqu'au printemps suivant.

Pour utiliser la soie des cocons, il faut empêcher l'insecte d'en sortir, car, le trou une fois fait, il devient impossible de les dévider. Dans les magnaneries, on ne laisse donc vivre que le nombre de chrysalides nécessaires pour assurer la récolte des oul's (1). On tue les autres en plaçant les cocons dans un four médiocrement chaud, ou, ce qui vaut mieux, dans un appareil nommé élou/foir, nù ils sont renfermés dans des caisses chauffées au moyen de la vapeur de l'eau. Chaque cocon est formé, comme nous l'avons dit, par un seul fil d'une longueur immense et d'une tinesse exlrême, yqu'il faut dévider. Pour faciliter cette opération, on est obligé de

(1) On compte qu'il faut environ 500 grammes de cocons pour retirer des papillons qui en naitront 30 grammes d'cufs. 
tremper les cocons dans de l'eau chaude, afin de ramollir la matière gluante qui colle entre eux les divers tours de ce fil; puis on réunit plusieurs de ceux-ci en un seul faisceau, qui, à l'aide de machines appropriées, est enroulé autour d'un dévidoir, et constitue un seul brin de soie filée. La soie connue sous le nom d'organsin se compose de trois ou quatre de ces fils réunis el tordus, et, dans la soie appelée trame, on fait entrer ordinairement depuis huit jusqu'à vingt de ces fils dans le même brin. Toule la coque ne peut se dévider de la sorte. D'ordinaire on ne retire que 500 grammes de soie de 5 à 6 kilogrammes de cocons. Il reste ensuite des pellicules que l'on carde avant de les filer, et qui donnent ainsi diverses matières, connues dans l'inclustrie sous les noms de filoselle, de fantaisie, etc.

On connaît deux espèces principales de soie : celle qui est naturellement blanche et la jaune. Nous possédons celle-ci depuis plus de deux siècles : on la blanchit en la soumettant au décreusage, opération qui consiste à lui enlever de la cire, une matière colorante et la substance glutineuse qu'elle contient; mais cette opération, si bien faite qu'elle soit, donne du blanc moins durable que celui de la soie blanche native, et de plus altère beaucoup la force de la soie: aussi accorde-t-on la préférence à la soie blanche native dont les Chinois ont eu longtemps l'exclusive possession : ce qui lui a fait donner le nom de soie sina.

Il n'y a guère que quatre-vingts ans que le gouvernement français, frappé des avantages qui résulteraient de l'importation du ver à soie sina, en fit venir de la graine de Chine, et la distribua a différents propriétaires. Celte opération parut manquée, quand on apprit, en 1808, que l'espèce s'était conservée chez quelquesuns d'entre eux; la culture en ful encouragée; et aux différentes expositions des produits de l'industrie française, on a pu se convraincíe que l'élucation de celle précieuse espèce élait définitivement établie en France (1).

La soie, distillée, dans une cornue, donne une huile ammoniacale très-félide, qui fait la base des gouttes céphaliques d'Angleterre.

ORIRE DES HÉMIPJÈRES.

Les hémiplères se rapprochent des coléoptères par la structure de leur squelette tégumentaire et par leurs ailes, qui sont au nombre de quatre et dont les deux supérieures sont en général plus consistantes que les inférieures; mais ils s'en éloignent beaucoup par la structure de leur bouche, qui est dépourvue de mât-

(1) Ann: de chion. et de phys., t. XIII, I) 233. 
choires el toujours conformée pour la succion, et par le peu d'importance de leurs métamorphoses, le jeune insecle ne changeant ni de forme ni d'habitudes, et acquérant seulement des ailes d̀ont il était d'abord privé.

On divise les hémiptères en deux sous-ordres, savoir : $1^{\circ}$ les IIÉTÉRoptères, dont les ailes supérieures sont coriaces et crustacées vers la base, et membraneuses à l'extrémité (1), et dont le bec nait du front; $2^{\circ}$ les номорте̇вes, dont les ailes supérieures ont partout la même consistance et diffèrent peu des inférieures, et dont le bec naît de la partie la plus inférieure de la tête et très-près de la poitrine.

Dans les hétÉRoptẻres, le corselet est grand et souvent triangulaire; les élytres et les ailes sont horizontales ou à peine inclinécs, le bec est en général gros el court. Ce groupe se subdivise en deux familles dont l'une est terrestre et l'autre aquatique.

La première porte le nom de GÉoCoRisES, ou de punaises terrestres, et comprend la punaise des lits, un des insectes les plus incommodes pour l'homme et l'un de ceux pour lequel il éprouve le plus de répulsion. Il est dépourvu d'ailes, a le corps mou, orbiculaire et très-aplati; le corselet très-élargi; la lête fort petite, pourvue de deux antennes brusquement terminées en forme de soie el d'un suçoir à trois arlicles distinels ( $/ g .940)$.

La seconde famille prend le nom de II DROCORISES, ou de punaises d'eau. Ils ont les antennes très-courtes et cachées sous les yeux, et les pieds antérieurs suuvent élargis, recourbés en avant en forme de pince, et leur servant à saisir d'autres insectes dont ils

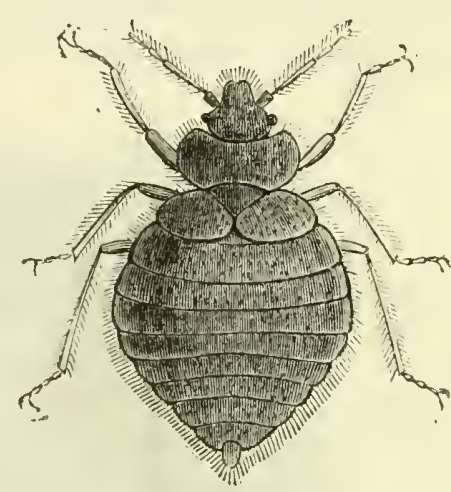

Fig. 940. - Punaise des lits. se nourrissent : tels sont les nèpes ( $/ \mathrm{g} .941)$ et les ranatas.

Le sous-ordre des HOMOPтĖRES se compose d'insectes qui vivent exclusivement du suc des végétaux. Leurs ailes antérieures sont tantôt coriaces, tanlôt membraneuses et semblables aux inférieures. Enfin les femelles ont, en général, une tarière à l'aide de laquelle elles percent l'épiderme des végétaux pour y loger leurs $œ u$ fs. On les divise en trois familles : les cicadaires (cigales et fulgores (fig. 93i); les aphidiens et les gallinsectes.

Les cigales, qui forment le type de la première famille, sont pourvues de trois yeux lisses et ont six articles aux antennes;

(1) Cette section comprend les véritables hémiptères, dont le nom veut dire

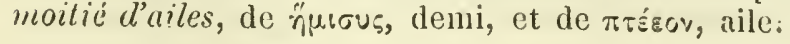


leurs élytres sont transparents et veinés, el les inâles portent, de chaque côté de la base de l'abdomen, un organe parliculier à l'aide duquel ils produisent une espèce de chant monotone. Ces

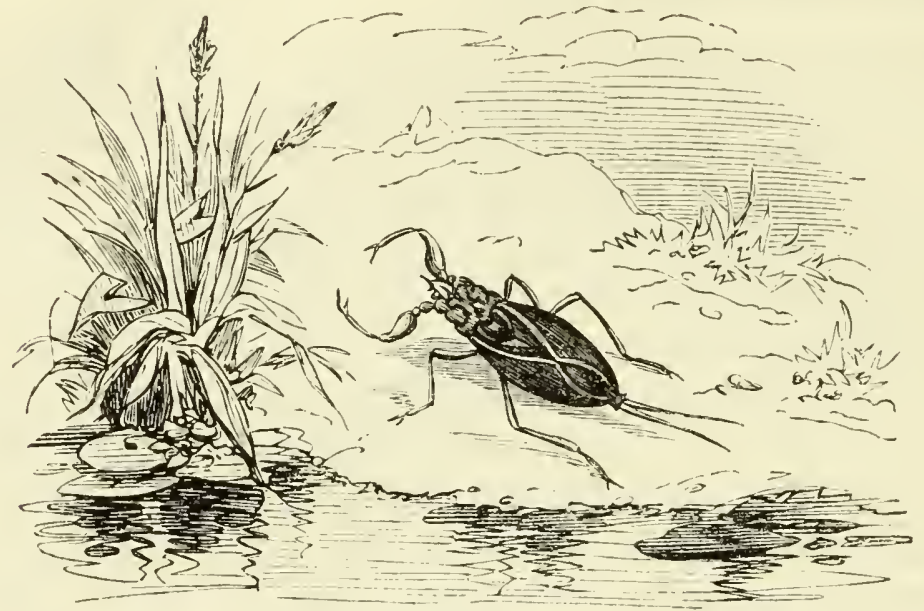

Fig. 941 - Nèpe.

insectes se tiennent sur les arbres; les femelles ont une tarière arec laquelle elles percent les petites branches de bois mort pour y déposer leurs œufs. Les jeunes larres quiltent celle relraite

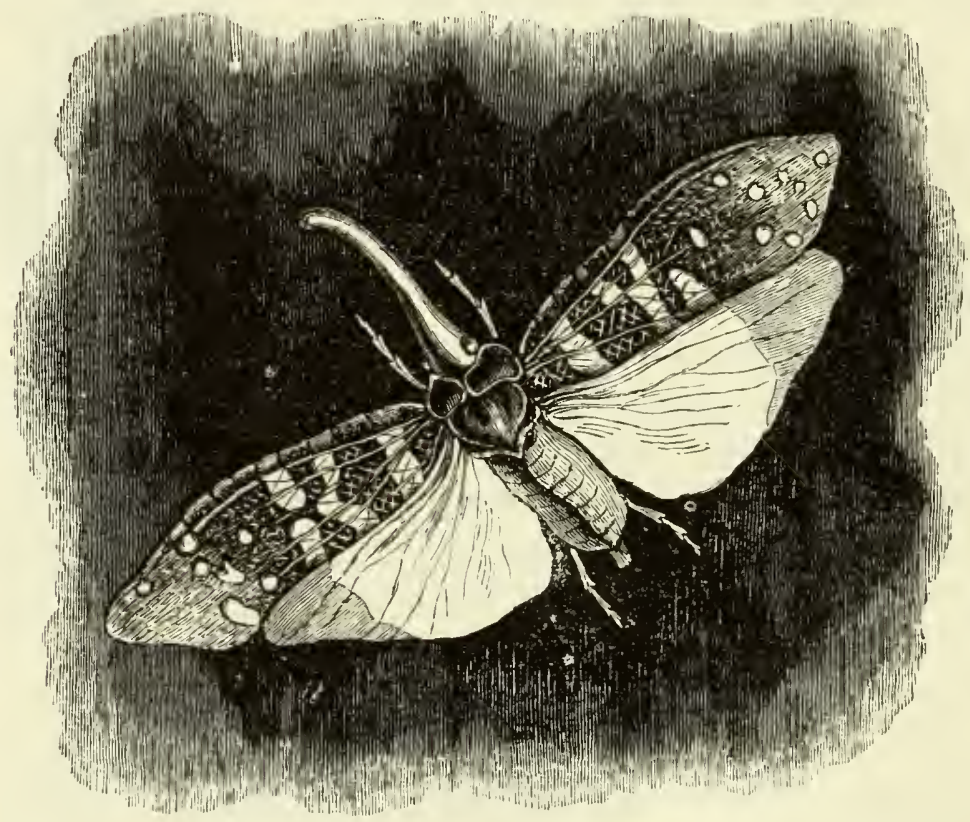

Fig. 942. - lulgore porte-chandelle.

pour's'enfoncer en terre où elles vivent en suçant les racines, et se changent en nymphes après être restées engourdies pendant l'hiver. Ces nymphes ont des rudimeuls d'ailes et les patles de devant très-développées, atin de pouvoir ouvrir la terre pour re- 
venir au jour et monter sur les arbres, où elles se dépouillent de leur enveloppe et prennent des ailes. Un insecte de ce genre, nommé la cigale de l'orne, vit en Italie sur l'ornier, ou frêne à la manne, et en fait exsuder le suc sueré par les blessures qu'il fait à son ćcorce. Mais on a eu tort de supposer que le produit de cette exsudation constiluait la manne du commerce, dont les larmes ou masses sont évidemment trop volumineuses pour avoir une pareille origine, et qui sont d'ailleurs certainement le produit d'incisions faites à la main (t. II, p. 583).

La famille des apnidiens se distingue de la première famille par les tarses, qui n'ont que deux articles, et par les antennes filiformes, plus longues que la tête, composées de 6 à 11 articles. Ce sont de lrês-petits insectes, dont le corps est mou et les élytres presque semblables aux ailes. Ils vivent sur les plantes et pullu. lent prodigieusement. On y trouve d'abord les psylles ou faux pucerons, qui ont 10 ou 11 articles aux antennes, dont les deux sexes ont des ailes et qui peuvent sauter; viennent, après, les pucrous proprement dits (fig. $9 \mathbf{4 3}$ et 944), qui ont les antennes fort

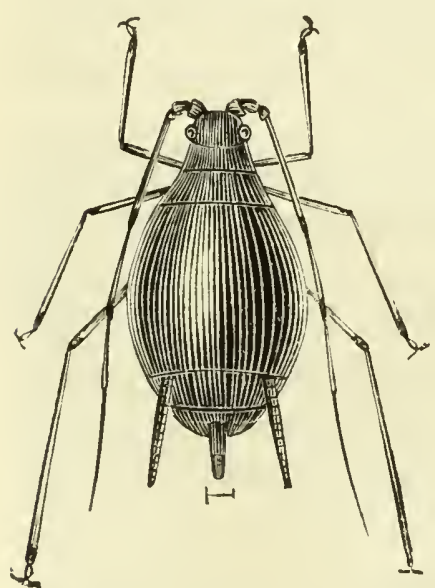

Fig. 943. - Puceron (Aphis).

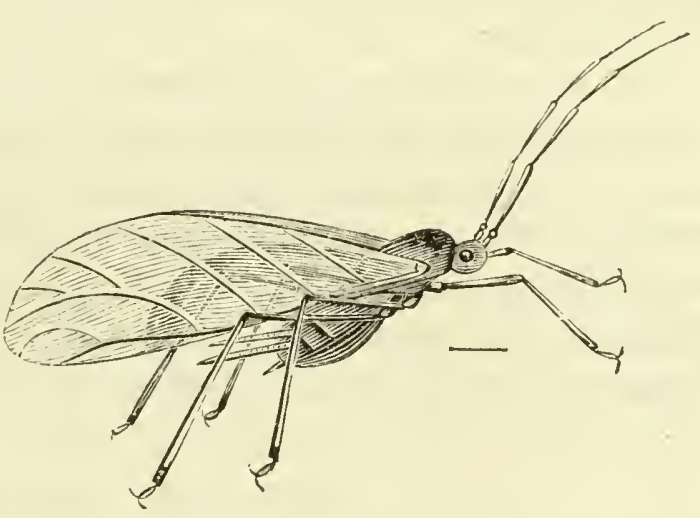

Fig. 944. - Puceron (Aphis).

longues et composées de 7 arlicles, et deux cornes ou deux mamelons à l'extrémité de l'abdomen. Ces insectes, fort singuliers par' leur ınode de génération, vivent en société sur les végélaux qu'ils sucent avec lcur trompe. Ils ne sautent pas et marchent lentement. Les deux cornes que l'on observe à l'extrémité ile l'abdomen sont des luyaux creux, d'où s'échappent souvent de pelites goulles d'une liqueur transparente el mielleuse, dont les fourmis sont très-frianues. Au printemps, chaque société ne se composte que de femelles aptères, ou n'ayant que des vestiges d’ailıs comme des nymphes. Ces pucerons produisent tous, sans accollplement préalable, des petits qui naissent vivants, sortant à roculons du ventre de leur mère. Plusieurs générations de femel- 
les se succèdent ainsi jusque vers la fin de la belle saison, époque à laquelle, seulement, naissent des mâles qui fécondent la dernière génération produite par les individus précédents, et consistant en femelles non ailées et qui ne sont plus vivipares. Ces femelles produisent donc des œufs qui restent fixés tout l'hiver aux branches des arbres, et d'où sortent au printemps de nouveaux pucerons femelles, devant bientôt se multiplier sans le secours des mâles.

Le puceron du rosier est très-commun dans nos jardins; il est vert avec des antennes noires. Le puceron du chêne est brun et se fait remarquer par son bec plus de trois fois plus long que son corps. Le puceron du hêtre est tout couvert d'un duvet blanc, cotonneux. Les pucerons de l'orme el des pistachier's (1), en piquant les feuilles ou les jeunes rameaux de ces végiéaux, y produisent des excroissances vésiculeuses dont plusieurs ont élé décrites au tome 1II, pages 499 et suivantes.

[Cilons encore parmi les pucerons, qui s'allaquent aux plantes, le Phylloxera vastatrix, récemment découvert par M. J. E. Planchon, sur les racines de la vigne, et qui est la cause de la maladie qui détruit cette plante dans diverses parties du midi et de l'oliest de la France.]

Les gallinsectes, qui forment la troisième famille des hémiplères, n'ont qu'un seul article aux tarses. Le mâle est dépourvu de bec et n'a que deux ailes; son abdomen est terminé par deux soies. La femelle est sans ailes et munie d'un bec, les antennes sont filiformes et composées le plus souvent de onze articles. Plusieurs espèces de gallinsectes ont eu, ou ont encore une grande importance commerciale, à cause de leur matière colorante rouge.

\section{Cochenile du Mexique,}

Coccus C'acti, L. Insecte hémiptère homoplère, de la famille des gallinsectes; il n'a qu'un arlicle aux tarses, avec un seul crochet

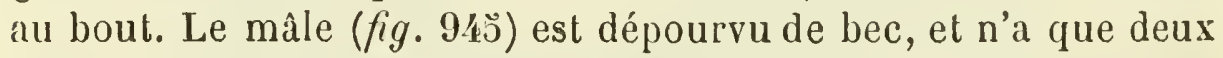
ailes qui se recouvrent horizontalement sur le corps; son abdomen est terminé par deux longues soies. La femelle ( $/ \mathrm{g} .941)$ est sans ailes et munie d'un bec; les antennes sont en forme de fil ou de soie, le plus souvent de onze articles.

La cochenille vit naturellement sur différents nopals du Mexique, mais n'y acquiert qu'une qualité inférieure à celle que les habitants savent lui donner par la culture. A cet effet, ils plantent

(1) Voir Derbes: Aphidiens du Pistachier Térébinthe (Annai. sc. nat. Zoologio, $5^{\mathbf{e}}$ série, $\mathrm{X}, 193$ et XV, 1). 
autour de leurs habitations les espèces de Cactus reconnues pour être les plus propres à la nourriture de l'insecte, et surtout le Cactus cochinillifer et le Cactus Opuntia, $\mathrm{L}_{\text {. }}$, qui est nommé raquette dans nos jardins, à cause de la forme singulière de ses feuilles. Ils vont chercher les cochenilles femelles dans les bois, avant

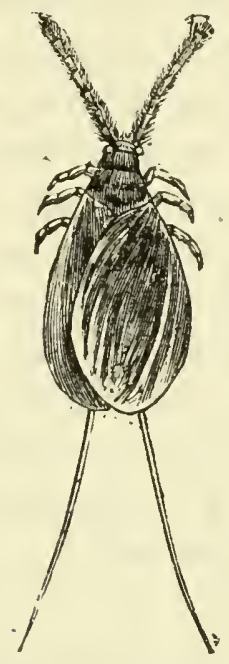

lig. 94 h. - Corhenille mâle.

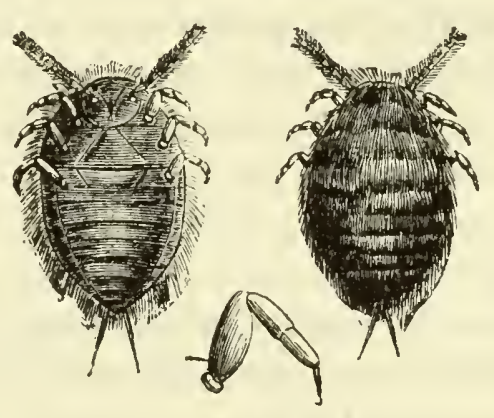

lig. 946. - Cochenille femelle.

qu'elles aient fait leur ponte, et les déposent au nombre de dix à douze dans de petits nids de bourre de coco, qu'ils fixent sur les épines des Cactus. L'insecte y opère sa ponte et meurl; mais, utile encore à sa famille, son corps lesséché et changé en coque lui sert de rempart contre les agents extérieurs; el ce n'est qu'après cette sorte d'incubation, que, les œufs étant éclos, les petits se répandent par milliers sur la plante, s'y altachent et y subissent toutes leurs métamorphoses. A la dernière, les femelles prennent l'état d'immobilité de leur mère ; les mâles acquièrent des ailes, s'approchent des femelles, les fécondent et meurent bientôt après. C'est à cette époque que l'on recueille les femelles, seules restées sur la plante, en les faisant tomber avec un pinceau sur un drap étendu à terre; mais on en laisse une certaine quantité qui produit une seconde généralion, el celle-ci une troisième: que l'on récolte encore la même année. La cochenille de la première récolte est la plus estimée, et celle de la dernière l'est le moins. On la fait mourir en la plongeant pendant un instant dans l'eau bouillante, et on la dessèche au soleil, dans des four's ou sur des plaques de fer chaudes.

On dit aussi qu'on la fait quelquefois sécher immédiatement dans les fours, sans l'avoir passée à l'eau bouillante, et c'est à cette différence de préparation qu'on attribue celle que l'on obsreve entre les cochenilles noire et grise du commerce; on sup- 
pose que la cochenille noire, qui est privée en grande partie de l'enduil blanchâtre et écailleux qui recouvre la grise, a été passée à l'eau bouillante, et l'autre pas; mais, comme la cochenille noire contient généralement plus de matière colorante que l’autre, et que ce résultat est directement le contraire de ce qui devrait arriver si elle était la seule qui eût été plongée dans l'eau, il est plus raisonnable d'attribuer la différence des deux cochenilles, et la qualité supérieure de la noire, à une variété de culture, et à ce qu'elle est encore plus éloignée de l'état sauvage que l'autre (1).

La cochenille noire du commerce ne ressemble guère à un insecle. C'est un petit corps orbiculaire, anguleux, de 2 millimètres de diamètre environ, privé de membres, noirâtre ou d'un rouge brun, arec quelques restes d'un enduit blanchâlre, silué dans l'intérieur des rides. Lorsqu'on la fait tremper dans l'eau, elle se gonfle et prend une forme ovoüde, aplatie en dessous; on distingue alors facilement les onze anneaux qui la composent; elle donne une poudre d'un rouge cramoisi, devenant d'un rouge brun très-foncé par l'eau ou la salive.

La cochenille grise ou jaspée dilfère de la précédente par l'enduit blanchâtre qui la recouvre presque entièrement, par la couleur moins foncée de sa poudre, et par la teinte moins intense qu'elle communique à l'eau. Elle est sujette à contenir du talc ou de la céruse, ainsi que l'a fait connaître M. Boutron (2), mais ce n'est pas à cette fraude seule qu'il faut attribuer la différence des deux cochenilles: car il est certain que la grise constitue une sorte distincte, indépendamment des substances étrangères que la cupidité peut y introduire.

Cochenille sylvestre. On nomme ainsi la cochenille qui croît naturellement dans les bois, an Mexique, et qu'on y récolte quelquefois, pour la verser directement dans le commerce. Cette sorte est d'une couleur rougeâtre, terne et non argentée. Examinée à la simple vue, elle paraît formée de deux sortes de parties : $1^{\circ}$ d'insectes isolés, beaucoup plus petits que ceux qui constituent les cochenilles noire et grise; $2^{\circ}$ de parlies agglomérées, globuleuses ou ovées, qui paraissent composées d'une matière furfuracée, blanche et rouge, entremêlée de poils. Cette substance, gonflée par l'eau, laisse alor's distinguer facilement, à l'aide de la loupe, un, deux ou trois insectes semblables aux précédents, munis de leurs pattes et quelquefois de leur bec, renfermés dans une matière blanche et pulpeuse ; souvent aussi on y découvre un certain nombre de petites cochenilles impercep-

(1) Voyez à ce sujet le Jour. de chim. méd., t. VII, p. 205, et Bazire, Note pour la culture de la cochenille (Journ. de pharm., t. XX, p. 615).

(2) Boutron, Journal de pharmacie, t. X, p. 46. 
libles qui paraissent nouvellement nées. Ces parlies agglomérées sont donc des espèces de nids ou de cocons, que l'insecte se forme pour se mettre à l'abri des intempéries de l'air. Elles ne domnent à l'eau qu'une couleur vineuse foncée, qui produil peu à la teinture; les insectes isolés fournissent une teinte rouge beaucoup plus belle et tiès-foncée, mais qui proluit encore beauconp moins que la teinture d'une pareille quantité de cochenille noire ou grise; aussi la cochenille sylvestre est-elle peu estimée et peu répandue dans le commerce.

[La cochenille est originaire du Mexigue, et les Espagnols de cette région ont fait longtemps tous leurs elforts pour empêcher l'insecte vivant d'être transporté hors de leurs pays. Cependant déjà en 1700 , on avait réussi à l'introduire dans la colonie française de Saint-Domingue. Plus récemment on en a introduit dans les Canaries, où elles sont l'objet d'un commerce considérable; en Algérie, où elles penvent bien prospérer, mais où leur culture est en ce moment presque abandonnée (1); dans les possessions hollandaises de l’Océanie, à Java, où elles donnent de 1ə00,000 à 200,600 livres par an (2).]

Nous devons à Pelletier et à M. Caventou une belle analyse de la cochenille, et la découverte de son principe colorant, auquel ils ont donné le nom de carmine. Voici un exposé te leur travail:

La cochenille, traitée par l'élher sulfurique bouillant, cède à ce véhicule une matière grasse odoran'e, d'un jaune orangé, qui, p:ar un examen subséquent, se trouve composée d'un peu de carinine, de stéarine et d'élaïne semblables à celles qui composent la graisse des mammifères; enfin, d'une malière olorante et acide qui paraît être à la matière gras se de la cochenille ce que l'acide butyrique est au beurre.

La cochenille, épuisée par l'éther, ayant été traitée par de l'alcool très-rectilié, l’a coloré en ronge jaunâtre; le liquide, refroidi et éraporé spontanément, a laissé précipiter une malière d'une très-belle couleur rouge, grenue, comme cristalline, soluble dans l'eau, mais ne se dissolvant pas entièrenent dans l'alcool trèsrectifié et froill, qui en séparait une matière brunûtre très-animalisie, semblable à celle que l'ean extraira tout it l'heure de la cochenille: la portion de matière rouge dissoute par l'alcool n'était pas encore de la carmine pure; car, la liqueur aỵant été mêlée de partie égale d'éther sulfurique qui en a précipilé la carmine pure, on en a ensuite reliré un peu de malière grasse semblable à celle déjà obtenue par l'éther.

(1) Voir le Catalogue de l'Exposition universelle de 186\%. Algérie, p. 80.

(2) L. Soubeiran, Journal de pharmacie et de chimie, te série, t. IX, p. 53. 
La cochenille épuisée par l'éther et l'alcool était toujours trèscolorée, la carmine qu'elle contient encore étant défendue de l'action du dernier de ces menstrues par la matière animale qui y est insoluble. Cette cochenille, bouillie dans l'eau, l'a colorće en rouge-cramoisi; el, lorsqu'elle ne lui a plus rien cédé, il n'est plus resté qu’une matière translucide, gélatineuse, brunâtre, dont quelques parties seulement étaient incolores. Les dernières décoctions, qui étaient incolores également, ne contenaient que de la matière animale semblable à celle qui n’avait pas été dissoute, et qui composait le squelette de l'insecte, à cela près cependant de l'altération qu'à dû lui causer sa dissolution même. Les premières liqueurs contenaient, en outre de la carmine et de la matière grasse.

La matière animale de la cochenille a paru à MM. Pelletier et Caventou différente de la gélatine, de la fibrine et des autres matières animales connues; ils pensent qu'elle peut être commune dans la classe des insectes, comme les premières le sont dans celles des mammifères et des autres animaux vertébrés. Quant à lat carmine, voici ses propriétés :

Elle est d'un rouge-pourpre éclatant, inaltérable à l'air, fusible à 50 degrés centigrades, décomposable à une chaleur plus élevée, et ne fournissant pas d'ammoniaque parmi les produits de sa décomposition.

Elle est très-soluble dans l'eau et incristallisable, beaucoup moins soluble dans l'alcool, insoluble dans l'éther.

Sa dissolution n'est pas précipitée par les acides, qui ne font que changer sa couleur du rouge-cramoisi au rouge vif et au rouge jaunâtre (elle est précipitée par les acides lorsqu'elle conlient de la matière animale que les acides précipitent). Les alcalis lui restituent sa couleur, et la font ensuite tourner au violet. L'alumine se conduit avec elle d'une manière singulière, et qui semble encore difficile à expliquer. Mise en gelée dans la dissolution de carmine, elle l'en précipite, s'y combine, et forme une laque d'un beau rouge à froid, qui, par l'action continue de la chaleur, devient cramoisie et violette; si, avant d'ajouter l'alumine à la dissolution de carmine, on a rougi celle-ci par un acide, la laque sera d'abord d'un rouge éclatant, mais la moindre chaleur la fera passer au violel; si, au contraire, c'est un alcali qu'on a d'abord ajoaté à la dissolution, la liqueur, qui était devenue violette par son action, redeviendra tout de suite rouge par celle de l'alumine, et la laque rouge qui se formera sera à peine altérée par une ébullition prolongée; de scrte qu’il semblerait que l'alumine mise en contact avec la carmine et un alcali agit comme un acide, et qu'elle présente au contraire l'énergie 
alcaline, lorsque c'est avec un acide et la carmine qu'elle se trouve mêlée.

La cochenille est très-employée dans la teinture, et pour fabriquer le carmin et la laque carminée (1). La cochenille n'est usitée en pharmacie que pour colorer différentes teintures, des opiats et des poudres dentifrices.

\section{Kermès animal, ou Graine d'Écarlate.}

Chermes Vermilio, G. Planch. ; Coccus Ilicis, L. (proparte). Insecte du genre de la cochenille, qui vit sur les feuilles d'une espèce de chêne vert nommé Quercus coccifera, et que l'on récolte dans le midi de la France, en Espagne, en Italie et dans le Levant. La femelle se fixe sur les feuilles de l'arbre pour y vivre immobile, y croître, y être fécondée et y déposer ses cufs qu'elle recouvre de son corps; après quoi elle meurt. Alors il ne reste plus de l'insecte qu'une coque rongeâtre, qui se remplit d'un suc rouge participant de la nature du végétal et de l'animal, et qui contient ses œufs. Celte coque croît encore, et, lorsqu'elle a acquis sun volume, et avant que les œufs soient éclos, on en fait la récolte. On tire par expression du kermès récent un suc rouge chargé d'une matière féculente, dont on fait un sirop en y ajoutant un pen de sucre : ce sirop, qui nous est apporté de Montpellier, doit être dépuré avant d'être mis en usage. Ou bien on fait sécher le kermès, après l'avoir exposé à la vapeur du vinaigre pour faire périr les œufs, et on le répand dans le commerce: il est alors sous la forme de coques rondes, lisses et d'un brun rougeâtre, de la grosseur d'un petil pois, contenant une poudre de la même couleur, composée des débris de l'insecte et de ses œufs.

[Le véritable kermès est facile à distinguer, par sa teinte rougeâtre et par la couleur rouge des petits qu'abrite la coque, de deux autres espèces vivant dans les mêmes régions et que beaucoup d'auteurs ont confondues avec lui. Nous les avons distinguées sous les noms de Chermes Emerici et de Chermes Bauhini. La promière de ces espèces est blane jaunâtre, couverte de dépressions ponctiformes; la seconde est noire, lisse et glabre (2).

Le kermès est peu employé en pharmacie acluellement. Son plus grand usage est encore dans la teinlure, où il peut, dans plusieurs cas, être substitué à la cochenilie. Sa couleur n'est pas aussi belle.

(1) Voyez Journ. de pharm., t. IV, p. 193.

(?) G. Planchon, le Kermès du chéne aux points de vue zoologique, commercial et pharmaceutique. Thèse de l'École supérieure de pharmacie de Montpel. lier, 1864. 
On connaît en Pologne une espèce de cochenille, nommée Coccus polonicus, qui étrit pour ce pays l'objet d'un commerce asse\% considérable avant l'introduction de celle du Mexique en Europe. La femelle de cet insecte a la forme d'un grain rougeâlre et se fixe sur les racines du Scleranthus perennis, et sur celles de plusieurs Polygonum. On dit qu'elle produit une aussi belle teinture que la cochenille; on en fait encore usage en Allemagne, en Pologne et en Russie.

\section{Circ de Chine ou Eve-Iar.}

[Sous le nom de cire de Cline, on connait en France un produit naturel ayant la blancheur et l'éclat du blanc de baleine, mais qui ne fond qu'à la température de $83^{\circ}$. Cetle substance est aussi connue en Angleterre sous le nom de cire blanche, cire d'insecte et de spermaceti végétal. Son origine a élé longtemps douteuse. On l'a atlribuée à des insectes de la famille des fulgoridées, le Flota limbata entre autres ; mais la matière cériforme fournie par ces insectes est facilement soluble dans l'eau et n'est point fusible par la chaleur, caractères qui suffisent à la distinguer nettement de la cire de Chine. On sait maintenant, grâce aux efforts de William Lockart, qu'elle est produite par une espèce de coccus. Les échantillons de cire qu'il a envoyés renfermaient cncore l'insecte, et M. Westwood a pu l'étudier et reconnaître que c'était une espèce nouvelle, à laquelle il a appliqué le nom de Coccus sinensis. Le squelelte desséché de l'insecte forme, d'après le savant naturaliste, une masse à peu près sphérique, creuse, souvent quelque peu rilée, brillante à l'intérieur, et d'une couleur foncée brune rougeâtre. Le diamètre varie de 3 à 4 dixièmes de pouce. Le point d'attache à la branche est marqué par une ligne linéaire. En outre, il se trouve dans la cire une quantité d'insectes plus petits et plus jeunes, ressemblant assez à de petits cloportes .

Les Chinois cultivent l'arbre sur lesquels vivent des Coccus et les y élèvent de manière à recueillir la cire. On sait maintenant que celte plante est le Fraxinus clinensis de Roxburg.

Au mois de mars ou d'avril, on cherche les coques qui renferment les petits, on les roule dans des feuilles de gingembre et on les suspend aux branches du frêne. Les œufs éclosent, se répandent sur les branches, et s'y fixent. Il se produit alors autour d'eux une production cireuse, blanche, qui augmente peu à peu, de manière à cnvahir toutes les branche:. On gralle alors le bois, et on détache la cire, qui se présente en morceaux plats, légers, tordus ou arrondis, irréguliers, d'un demi-pouce au plus de longueur. 
M. Brodie l'a étudiée au point de vue chimique, et lui assigne les caractères suivants. Lorsqu'elle est complétement pure, elle fond à $81^{\circ}$, ŏ. Elle est très-peu soluble dans l'alcool et dans l'éther, mais sc dissout très-facilement dans l'huile de naphte bouillante, et cristallise par le refroidissement. Elle peut être considérée comme un cérotate d'oxyde de cérotyle. Sa formule est $\mathrm{C}^{108} \mathrm{H}^{108} \mathrm{O}^{4}$. Traitée par l'liydrate de potasse fondu, elle donne de l'acide cérolique et de la cérotine.

La production annuelle est en Chine de 400,000 livres, ayant une valeur d'environ 600,000 francs. C'est dans ce pays surtout qu'elle se consomme. Elle y sert à la fabrication des bougies. Elle y est aussi employée extérieurement et intérieurement dans un assez grand nombre de maladies (1).

On extrait aussi d'une espèce de coccus du Mexique (Coccus Axine), une substance grasse siccative, nommée, par la Pharmacopée mexicaine de 1846, age ou axine, qui, d'abord oncluense, durcit par son exposition à l'air. Celte propriété l'a fait employer dans la chirurgie indienne comme notre collodion : on l'emploie aussi comme vernis pour protéger les instruments en acier contre la rouille. Elle se saponifie aisément et donne de l'acide laurostéarique, un peu d'acide stéarique ou d'acide palmitique, et enfin un acide gras spécial, l’acide axinique (2).

ORDLE DES DIPTERES.

Les diptères ont deux ailes membraneuses, derrière lesquelles on trouve presque toujours une paire de petits appendices ayant la forme de balanciers, et souvent aussi, à leur base, deux autres petites pièces membraneuses semblables à des valves de coquilles, et nommées ailerons ou cuillerons (fig. 947). La bouche des diptères est organisée pour la succion seulement. Elle présente ordinairement une trompe, tantot molle el rétractile, tantol cornéc et allongée, terminée par deux lèvres et offrant, à sa partic supérieure, un sillon longitudinal dans lequel est reçu un suçoir composé de soies cornées, très-aiguës.

Le nombre des diptères est très-considérable; on peut se faire une idée assez exacte de leur forme générale, par celle de la mouche domestique. Leurs pieds sont en généra! longs, grêles et terminés par un tarse de cinq articles, dont le dernier est souvent garni de pelotes vésiculeuses. Leur abdomen est souvent pédiculé et, chez la femelle, il est souvent terminé en une pointe qui peut

(1) Voir Hanbury, Pharmac., Juurn., XII, 476 et 48?, et Journal de pharmacie et de chimie, $3^{\mathrm{e}}$ série, XXIV, 136, et XXXVI, 371.

(2) Voir, pour les détails, Hoppe, Journ. fü, prakt. Chim., LXXX, p. 10?, et Journal de pharmacie et de chimie, $3^{\text {e }}$ série, XXXVIII, p. 15?. 
s'allonger comme un tuyau de lunette, et constitue une sorte de tarière. Tous ces insectes subissent des métamorphoses complètes; leurs larves sont dépourvues de pattes, ont la tête molle et la bouche munie de deux crochets. Tantôt elles changent plusieurs fois de peau et se filent une coque pour se transformer; tantôt

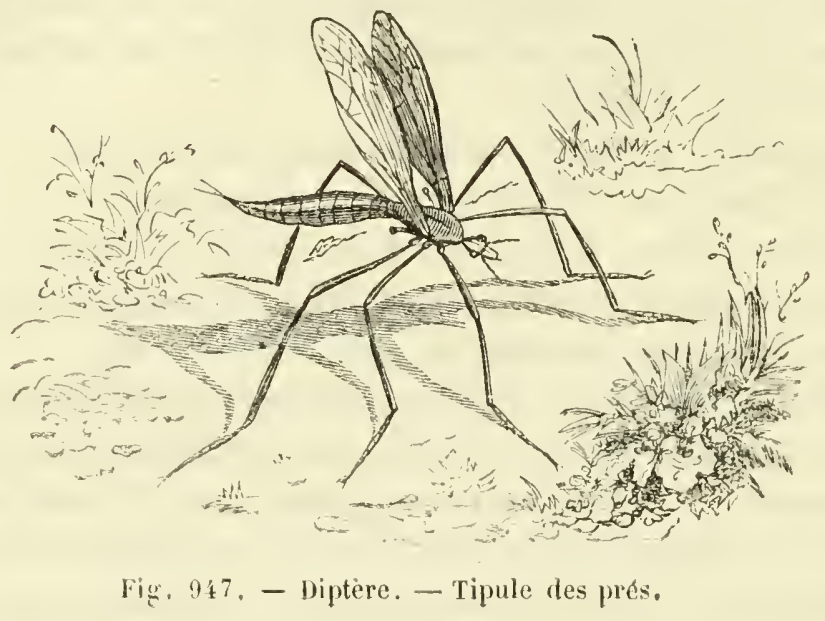

elles ne muent pas, et leur peau, durcie et racornie, devient pour la nymphe une coque solide, ayant l'apparence d'une gaîne.

Un issez grand nombre de diptères nous sont fort incommodes par leurs piqûres, ou nous portent préjudice, soit en piquant la peau des animaux domestiques pour vivre de leur sang ou pour

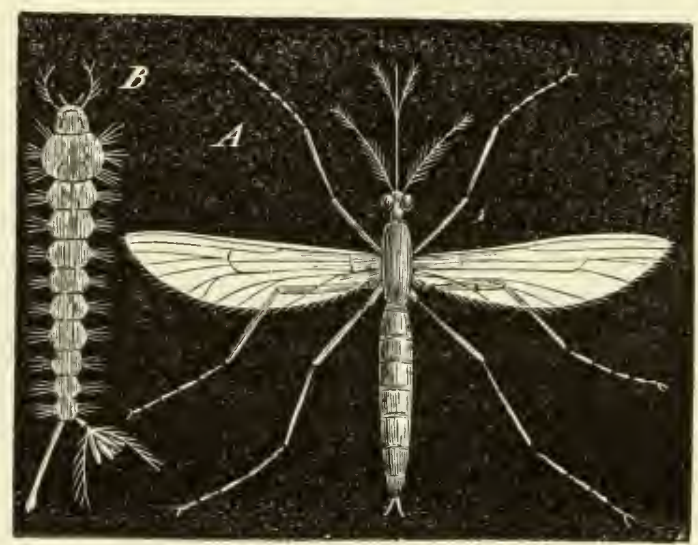

Fig. 9i8. - Cousin.

y déposer leurs œufs, soit en infectant, pour les mêmes molifs, les viandes que nous conservons. Ceux qui nous tourmentent le plus, personnellement, sont les cousins (Culex, L.) (fig. 948), qui sont répandus depuis la zone équaloriale, où on leur donne les noms de moustiques et de maringouins, jusque sous le cercle polaire. Ils habitent principalement le voisinage des eaux, à la surface desquelles les femelles déposent leurs œufs, et où leurs lar- 
ves vivent et subissent toutes leurs métamorphoses. Les insectes parfaits ont le corps et les pieds fort allongés et velus; les antennes très-garnies de poils et formant un panache chez les mâles; les palpes avancés, filiformes, velus, de la longueur de la trompe et composés de cing articles chez les mâles, plus courts et moins articulés chez les femelles; la trompe composée d'un tube membraneux, terminé par deux lèvres formant un petit renflement, el d'un suçoir de cinq filets écailleux produisant l’effet d'un aiguillon.

On sail combien ces insectes sont importuns et fâcheux ; avides de notre sang, ils nous poursuivent partout, entrent dans nos habitations, particulièrement le soir, s'annoncent par un bourdonnement aigu, et percent notre peau. que nos vêtements ne garantissent pas toujours. Ils distillent dans la plaic une liqueur venimeuse qui y détermine une vive irritation et de l'enflure. Dans les pays chauds, on se préserve de leurs atteintes en enveloppant sa couche d'une gaze; dans les pays froids, on les éloigne parle feu.

Les taons (Tabanus, L.) ressemblent à de grosses mouches un peu velues, et sont connus par les tourments qu'ils font éprouver aux chevaux et aux boufs, dont ils percent la peau et sucent le sang. Ils ont la tête aussi large que le thorax, presque hémisphérique el presque entièrement couverte par deux yeux à'un vert doré, avec des taches pourpres. Les ailes sont étendues horizontalement de chaque côté du corps; les cuillerons recouvrent presque entièrement les balanciers; l'abdomen est triangulaire et déprimé; les tarses ont trois pelotes. Ces insectes commencent à paraître vers la fin du printemps et volent en bourdonnant. Ils poursuivent même l'homme; mais les bêtes de somme, n'ayant pas les moyens de les repousser, sont plus exposées à leurs altaques.

[Dans diverses régions de l'A frique centrale, les voyageurs ont signalé un diptère du genre Glossine (G. morsitans, Westw..), qui est connu sous le nom de T'setsé. C'est un insecte plus grand que la mouche commune (fig.949), d'un jaune blanchàtre, dont la trompe ressemble à une soie cornée, à laquelle les pulpes servent de gaines (fig. 9ə0): Il est redoutable pour les bestiaux sur lesquels il s'élance avec la rapidité d'une flèche, el qui, une fois piqués, maigrissent à vue d'œil et meurent au bout de quelques jours:]

Les estres (AEstrus, L:) ont le port d'une grosse mouche trèsvelue, et leurs poils sont souvent colorés par zones, comme ceux des bourdons. A li place de la bouche, ils n'offrent que trois tubercules, ou de faibles rudiments de lit trompe el des palpes. 
Leurs antennes sont très-courtes el terminées par une palette arrondie, porlant une soie simple. Leur's ailes sout écartées; les cuillerons sont grands, et cachent les balanciers; les tarses sont terminés par deux crochets et deux pelotes.

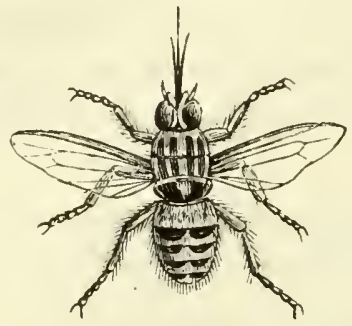

Fig. 949. - Tetsé.

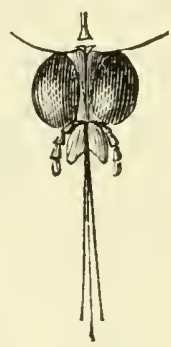

Fig. 950. - Trompe.

On troure rarement ces insectes à l'état parfait, le temps de leur apparition étant très-borné. Ils déposent leurs œufs sur le corps de plusieurs quadrupèdes herbivores, tels que le bœuf, le cheral, l'âne, le renne, le cerf, le chameau, le mouton, le lièrre même, qui paraissent tous craindre singulièrement l'insecte, lorsqu'il cherche à faire sa ponte. Chaque espèce d'œstre est ordinairement parasite d'une même espèce de mammifère, et choisit, pour placer ses œufs, la partie du corps qui convient le mieux à ses larves, soit qu'elles doivent y rester, soit qu'elles doivent passer de là dans un endroit plus favorable à leur déreloppement. C’esı ainsi que l'oestre du lıeuf (fig. 9öl) dépose ses œufs, un à

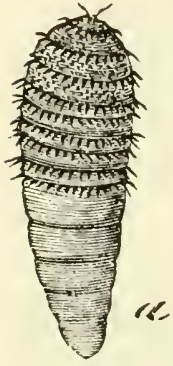

Fig. Ç̌l. - OEstride du bœuf.

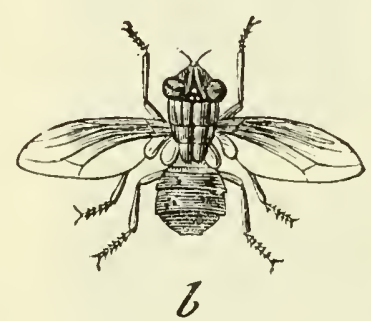

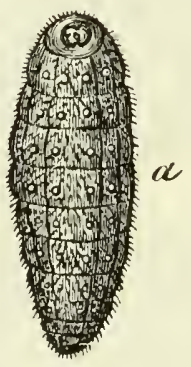

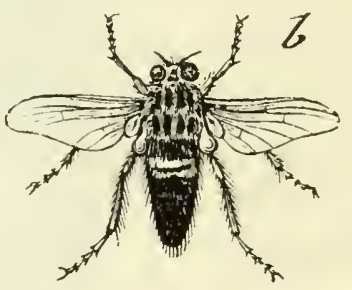

Fig. 952. - OEstride de la brebis.

un, sous le cuir des bœufs et des vaches âgés de deux ou trois ans au plus, et les mieux portants. Il s'y forme des bosses ou des tumeurs, dont le pus intérieur alimente la larve. Les chevaux y sont aussi sujels. L'oestre du cheval dépose ses œufs, sans presque se poser, se balançant dans l'air el par intervalles, sur la partie inlerne de ses jambes el sur les côlés de ses épaules, où la bouche du cheval va les prendre, pour leur ouvir la route de l'estomae. L'oestre hémorrlioilal place les siens sur les lèrres mêmes du cheval, d'où ses larres paryiennent, ainsi que les précédente:, 
dans l'estomac de l'animal, où elles vivent de l'humeur sécrélée par sa membrane interne. L'oestre du monton ( $f(g .952)$ place ses oufs sur le bord interne des narines de ce quadrupède, qui s'agite alors el fuit la tête baissée. La larve s'insinue dans les sinus maxillaires el frontaux, se fixe à la membrane qui les tapisse, au moyen de deux forts crochets dont sa bouche est armée, et y reste depuis le mois de juin on de juillet jusqu'au mois d'avril de l'année suivante. Iorsqu'il se trouve plusieurs larves dans les sinus d'un mouton, l'animal peut tomber frappé de vertige. Lorsque toutes ces larves ont acquis leur dernier accroissement, elles quittent leur demeure, par une des voies naturelles du quadrupède, se laissent tomber à terre et s'y cachent pour se transformer en nymphe sous leur propre peau, ainsi que le font les diptères de la même famille (celle des athéricères).

ORDRE UES APIANIPTĖRES, OU DES SUCEURS.

Cel ordre ne l'enferme qu'un seul genre, celui des puces (Pulex, L.), dont le corps est ovale, comprimé latéralement, revêtu d'une peau carlilagineuse, et divisé en douze segments, dont trois composent le thorax, qui est court, et les autres, l'abdomen. La tête est petite, trèscomprimée, arrondie en dessus, tronquée et ciliée en avant; elle a, de cliaque côté, un pelit œil arrondi, derrière lequel est une fossette où l'on découvre un pelit corps mobile, garni de quelques épines. Au bord antérieur, tout près du bec, sont insérées deux antennes composées de qualre articles. La bouche est en forme de bec ou de suçoir, et présente trois soies renfermées entre deux lames articulées dont la base est recouverte par deux écailles mobiles. Ce suçoir est ordinairement caché entre les lanches des pattes anlérieures, qui sont dirigées dans le sens de la têle. Comme les hanches de toutes les pattes sont trìs-développées, celles-ci paraissent composées de quatre parties : les jambes et les tarses ont tous cinq arlicles et sont Irès-épineux. Les pattes postérieures sont plus fortes et plus longues que les autres, el sont conformées pour le saut.

Dans la puce commune (fig. 95ั3), qui vit du sang de l'homme et de celui des animaux qui habitent avec lui, le male est beaucoup plus petit que la femelle, et se trouve renversé entre ses patles pendant l'accuuplement, durant lequel la femelle l'emporte avec elle dans les sauts qu'elle fait pour se soustraire aux dan-

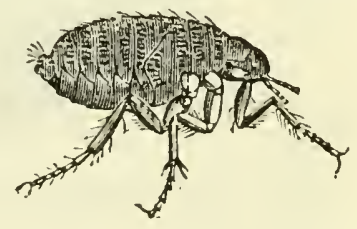

Fig. 933.- Puce commune. gers qui peuvent la menacer.

La femelle pond une douzaine d'œufs qui sont arrondis, un peu allongés, blancs, lisses, polis, assez semblables à la graine de 
perles. En secouant, pendant l'été, les coussins où les chiens et les chats dorment habiluellement, on en fait tomber un nombre considérable qu'il faut éviter de laisser glisser dans les fentes des parquets ou dans les encoignures des appartements où ils écloraient; il faut au contraire les détruire avec soin. Les larves qui en sortent ressemblent à de petils ver's sans pieds et très-vifs qui, après douze ou quinze jours, se filent une petite coque soyeuse où

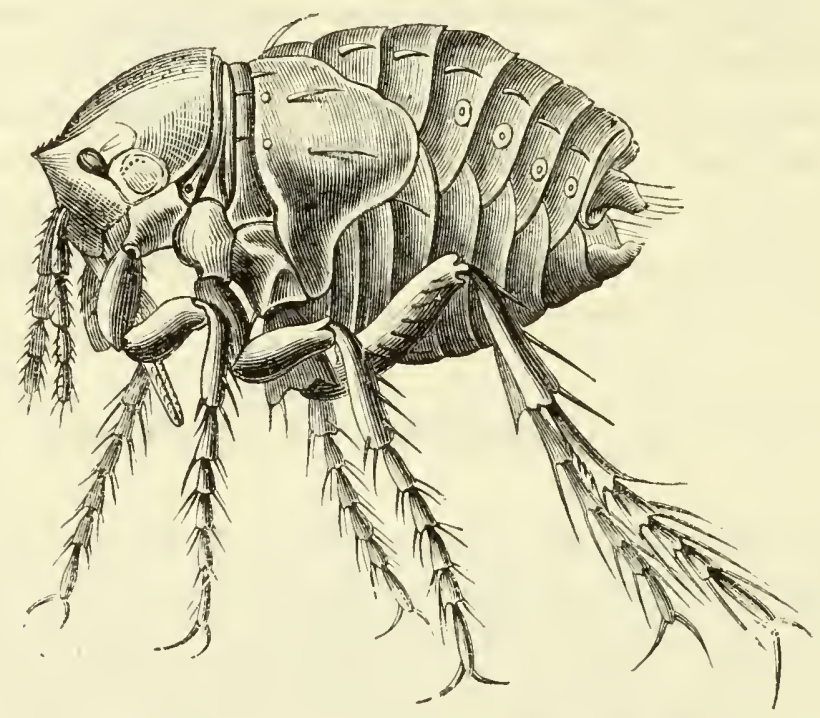

Fig. 954. -- Puce chique, d'après II. Kat'stein.

clles sc changent en nymphes. Elles en sortent à l'état parfait après un espace de temps à peu près égal.

On connaît en Amérique, sous le nom de chique (Pulex penetrans, ᄃ. .), une espèce de puce fort incommode $(/ g$. 9ö4). La femelle fécon-

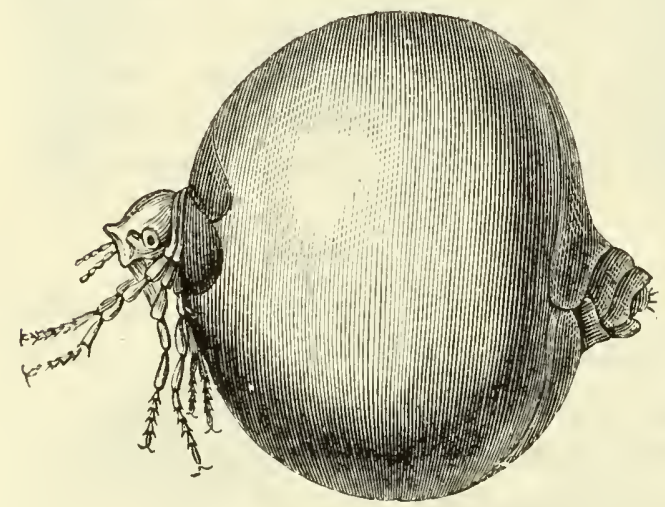

lig. 935. - Cilique gorgée, d’après Karstein. dée altaque seule l'homme; on la trouve ordinairement aux pieds, dans les régions sous-onguéales, aux talons. Elle se loge entre le derme et l'épiderme, ne laissant apercevoir que les deux ou trois derniers anneaux de son abdomen qui se gonfle rapidement et acquiert la grosseur d'un pois (fig. 9əัว̆). La famille nombreuse à laquelle elle donne naissance occasionne, par son séjour dans la plaie, un ulcère difficile à guérir et quelquefois mortel. On se préserve de ces accidents en entretenant la propreté des pieds et en les lavant 
avec une décoction de tabac. Les nègres savent aussi extraire avec adresse l'animal de la partie du corps où il s'est établi (1).

\section{ORDRE DES ANOPLOURES OU DES PARASITES.}

Les insectes de cet ordre vivent tous à la surface du corps des animaux; ils ont six pieds comme tous les vrais insectes et sont complétement aptères, ainsi que les aphaniptères et les thysanoures; ils n'ont que deux ou quatre petits yeux lisses; leur bouche est en grande partie intérieure et ne présente au dehors qu'un museau ou mamelon avancé, renfermant un suçoir rétractile, ou deux lèvres rapprochées avec deux mandibules en forme de crochets. Ils ne subissent aucune métamorphose.

C'est dans cet ordre que l'on trouve le genre des poux $(P$ ediculus de G.). Ils ont le corps aplati, presque transparent, distinct de la tête, et composé de 9 à 10 anneaux, dont les trois antérieurs, appartenant au thorax, portent les trois paires de pattes; les stigmales sont très-distincts. Ils ont pour bouche un mamelon très-petit, tubulaire, situé à l'extrémité antérieure de la tête et renfermant un suçoir; leurs antennes sont courtes, composées de cinq articles; leurs yeux sont au nombre de deux seulement, lisses et situés aux deux côtés de la tête; leurs pattes sont de longueur à peu près égale, et formées de plusieurs articles dont le dernier est armé d'un ongle très-fort qui peut se replier sur l'extrémité de l'article faisant saillie, ce qui permet à l'insecle de s'accrocher solidement aux cheveux de l'homme, ou aux poils des animaux dont il suce le sang.

L'homme nourrit trois espèces de poux :

Le pou de' la tête (Pediculus humanus capitis de Geer) est griscendré, taché de brunâtre. Il a le corps ovoïde-allongé, un peu atténué à l'extrémité, et les lobes de l'abdomen arrondis. Le mâle est plus petit que la femelle, pourvu à l'extrémité d'une petite pièce conique. La femeile est au contraire un peu échancrée à l'extrémité ( $/ g .9$ oั6); après l'accouplement, elle pond, en six jours de temps, une cinquantaine d'œufs qui éclosent en six autres jours, et les petits qui en proviennent ont pris tout leur accroissement, s'accouplent et pondent au bout de dix-huit jours; en sorte que, en supposant toutes les circonstances favorables, la seconde génération d'un e seule femelle pourrait s'élever à 2, 500 individus, la troisième à 123 , 000, etc. Cet insecte habite la tête des hommes malpropres et surtout des enfants; on le détruit par

(1) Voyez G. Bonnet, Mémoire sur la puce pénétrante ouchique (Archives de médecine navale, novembre 1857, t. VIII, p. 81 et sujv. et Annales sc. nat. zoologie, $5^{e}$ série, VIII, 104.

Guibourt, Drogues, 7• édit.

T. IV. -17 
les préparations de soufre, de mercure, l'eau de savon, les poudres ou décoctions de staphisaigre, de cévadille, de coque du Levant, de tabac, de jusquiame; mais surtout par une grande propreté.

Le pou du corps humain est blanc, étiolé, avec les yeux brunâtres et les hords de l'abdomen dentelés. Il pullule d'une manière effrayante dans certaines maladies, et peut amener le dépérissement de l'individu.

Le pou a u pubis, ou morpion ( dents par son corps large et arrondi, son thorax très-court et se confondant presque avec l'abdomen, et ses quatre pieds posté-

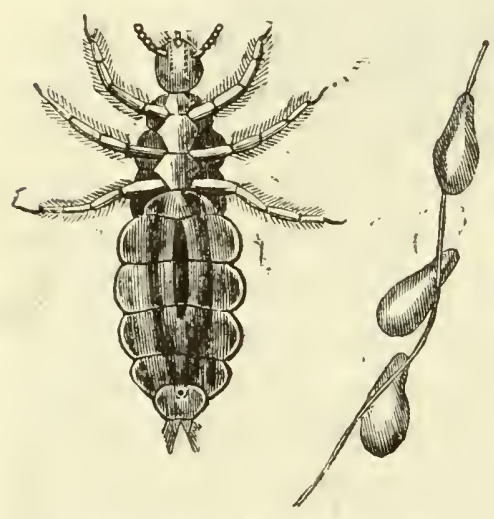

Fig. 956. - Pou femelle, vu du côté du ventre $(*)$

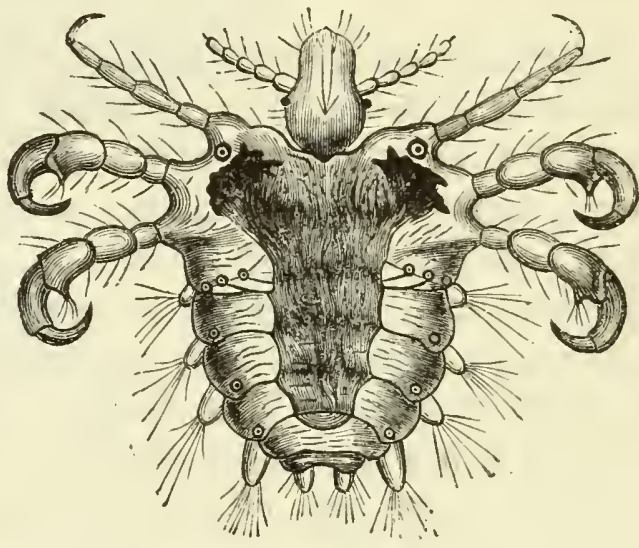

Fig. 957, - Pou du pubis.

rieurs très-forts. Il s'attache aux poils des parties sexuelles et aux sourcils; sa piqûre est très-forte. On s'en débarrasse par les moyens déjà indiqués, et surtout par des lavages avec une faible dissolution de deutochlorure de mercure.

Il existe, sans aucun doute, d'autres espèces de poux sur un grand nombre de quadrupèdes et sur les oiseaux, mais ils sont peu connus et il n'est pas certain que tous doivent être comptés au nombre des insectes aptères. La tique des chiens, ou ricin, et la smaridie des moineaux, entre autres, appartiennent aux arachnides trachéennes.

(*) $a$, œufs ou lentes fixées sur un cheveu. 


\title{
DEUXIÈME CLASSE
}

\author{
LES MYRIAPODES.
}

Latreille et Cuvier comprenaient encore les myriapodes parmi les unsectes, mais les myriapodes diffèrent des insectes par un corps tris-

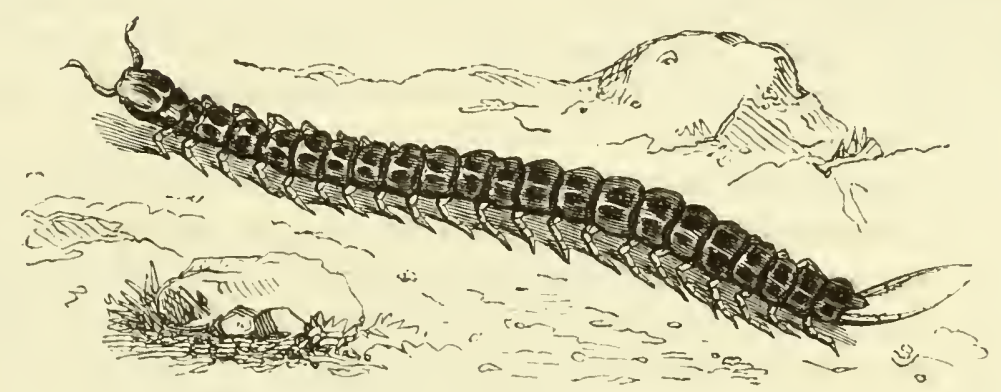

Fig. 958. - Scolopendre électrique.

allongé, toujours privé d'ailes, et composé d'un très-grand nombre d'an meaux dont chacun porte une paire de pattes. Cependant leur organi-

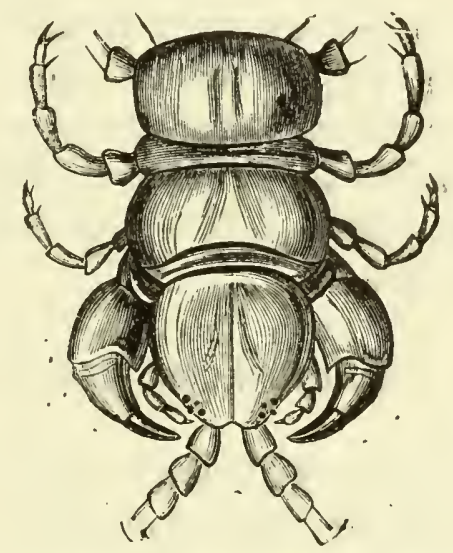

Fig. 959. - Extrémité antérieure de Scolopendra insignis (grandeur naturelle).

sation intérieure les rapproche des insectes. Cette classe comprend les scolopendres (fig. 958 et 959) et les iules de Linné, subdivisés aujourd'hui en un certain nombre de genres. 


\section{TROISIÈME GLASSE}

\section{LES ARACHNIDES.}

Les arachnides sont des animaux articulés, organisés pour viire dans l'air comme les insectes; mais qui en different parce qu'elles ont toutes la tête confondue avec le thorax, pas d'antennes, des yeux simples en nombre pair, quatre paires de patles et jamais d'ailes. Enfin le plus grand nombre respirent à l'aide de cavités pulmonaires et ont un système circulatoire complel.

Les arachnides pondent des œufs comme les insectes; un certain nombre les enveloppent dans un cocon de soie, et quelquefois la mère demeure avec sa jeune famille pour la proléger. Elles subissent toutes plusieurs mues avant d'arriver à l'état adulte, et quelques-unes éprouvent une sorte de mélamorphose, qui consiste en ce qu'elles n'ont que trois paires de pattes dans leur jeune âge et qu'elles n'acquièrent la quatrième paire qu'à un âge plus avancé.

On divise les arachnides en deux ordres fondés sur leur mode de respiration el de circulation. On nomme pulmonaires celles qui ont à l'intérieur plusieurs cavités garnies d’une multitude de lamelles, où leur sang, qui est blanc, reçoit l'action de l'air atmosphérique ; leurs yeux sont au nombre de huit ou de six. On nomme araignées trachéennes celles qui, respirant par des trachées, n'ont que des vestiges d’organes circulatoires; les yeux sont au nombre de quatre.

\section{ORDRE DES ARACHNIDES PULMONAIRES.}

Les arachnides pulmonaires forment deux familles :

$1^{\circ}$ Les aranéides, dont les palpes sont petits, en forme de pieds, et non terminés par une pince; on les nomme aussi pulmonaires fileuses. On y trouve les mygales et les araignées.

$2^{\circ}$ Les pédipalpes, dont les palpes sont très-grands et terminés par une pince, ou une griffe qui en fait un puissant organe de préhension. Cette famille comprend les phrines et les scorpions.

Les mygales sont remarquables par la force de leurs mandibules et de leurs pattes; leurs yeux, au nombre de huil, sont situés à l'extrémité antérieure du céphalothorax (1); leurs palpes

(1) On désigne ainsi le lobe antérieur du corps des arachnides, formé par la réunion de la tête et du thorax. 
partent de l'extrémilé des mâchoires et ressemblent à des pattes composées de six articles, dont la mâchoire serait le premier Chacun de ces palpes est terminé par un fort crochet replié en dessous ; on admet aussi que, chez les mâles, ces palpes portent a l'extrémité leurs organes générateurs. Leurs serres frontales, ou mandibules, sont terminées par un crochet mobile, replié inférieurement et offrant à son extrémité, toujours trèspointue, unc petile fente pour la sortie du venin contenu dans une glande renfermée dans la mandibule. L’abdomen est suspendu au thorax par un court pédicule; il renferme le canal intestinal et ses annexes, quatre poches pulmonaires communiquant avec l'extérieur par autant de petites ouvertures placées à la face inférieure, et, dans les femelles, deux ovaires conduisant à deux oviductes qui débouchent dans une même vulve placée assez près du pédicule. L'anus est à l'extrémité du ventre, entouré de quatre mamelons par lesquels s'échappe la soie élaborée dans des vaisseaux intérieurs très-compliqués.

C'est à ce genre qu'appartiennent les plus grandes aranéides. Dans l'Amérique méridionale, on en trouve une espèce, la mygale aviculaire ( $/$ g. 960), qui atteint quelquefois 5̌ millimètres de longueur et qui, lorsque ses pattes sont étendues, occupe un espace circulaire de 22 à 24 centimètres. On assure que ces énormes araignées sont assez fortes pour s'emparer des colibris et des oiseaux-mouches. Leur corps est entièrement velu et d'un brun noiratre. Elles établissent leur domicile dans les gerçures de l'écorce des arbres ou entre des pierres, et se construisent, pour demeure, un tube d'un tissu très-fin et Fig. 960. - Mygale aviculaire. serré. Elles passent pour venimeuses. On en trouve d'autres espèces plus petiles, dans le midi de l'Europe, qui se creusent, dans les lieux secs et montueux, des galeries souterraines dont elles tapissent l'intérieur d'un tissu soyeux, et dont elles ferment l'entrée à l'aide d'un couvercle à charnière, formé de fils de soie mélangés de terre gâchée.

Les araignées diffèrent des mygales parce qu'elles n'ont qu'une paire de sacs pulmonaires et de stigmates, par leurs palpes insérés sur le côté extérieur et près de la base des mâchoires, et par le nombre de leur's filières, qui est de six. On les divise en araignées sédentaires, qui font des toiles, ou jettent au moins des fils pour surprendre leur proie, et se tiennent tout auprès, ainsi 
que près de leurs œufs; et en araignées vagabondes, qui ne font pas de toile, saisissent leur proie à la course ou en sautant sur elle. A la première section appartiennent les araignées proprement dites, qui construisent dans l'intérieur de nos habitations, aux angles des murs, sur les plantes, etc., une toile grande, à peu près horizontale, à la partie supérieure de laquelle est un tube de soie, où elles se tiennent en embuscade, sans faire aucun mouvement. Au nombre des araignées vagabondes se trouvent les Iycoses de Latreille, dont une espèce a reçu le nom de tarentule (Lycosa Tarentula, Latr.) de celui de la ville de Tarente, en Italie, aux environs de laquelle elle est commune. Cette espèce jouit d'une grande célébrité. On a répandu l'opinion que sa morsure était mortelle pour l'homme; mais qu'on s'en guérissait en dansant longtemps au son de la musique. [Tout en tenant compte des exagérations, on ne peut guère se refuser à admettre que la piqûre de cette araignée ne puisse produire des accidents nerveux, augmentés probablement par l'imagination surexcitée du

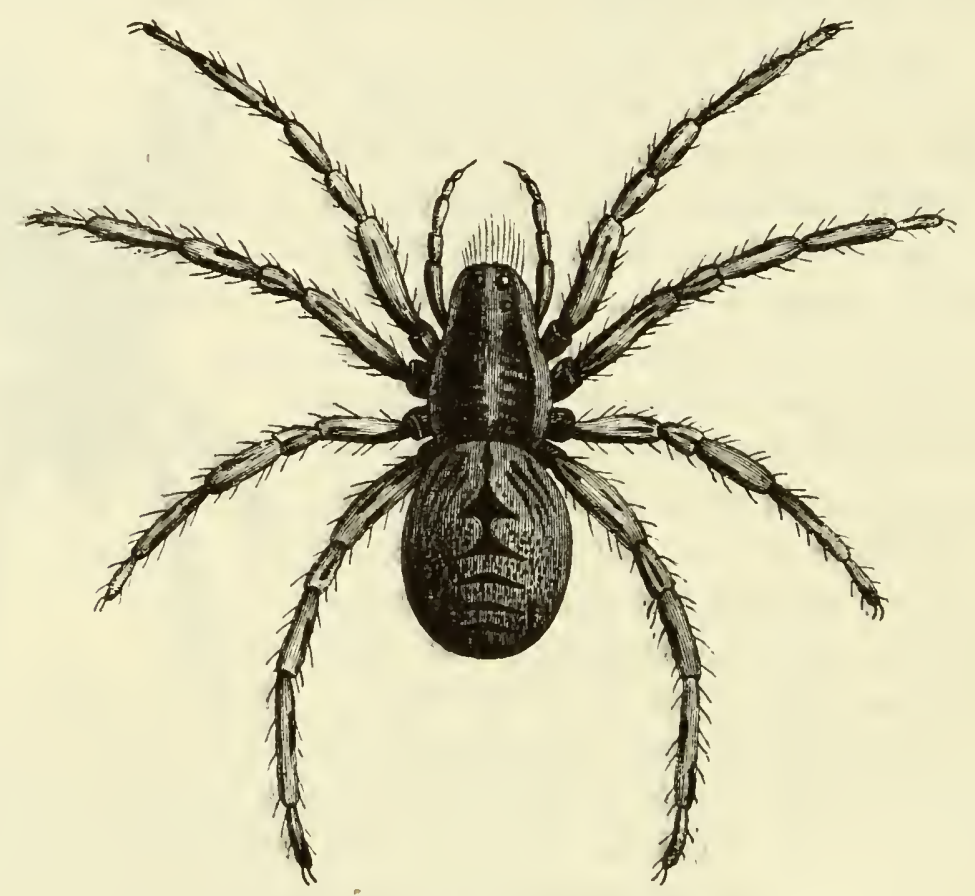

Fig. 961. - Tarentule (rue en dessus).

malade (1). Ces accidents se produisent surtout dans la Pouille; mais il paraît qu'on en a observé quelques cas en Espagne, où existe une espèce de tarentule (fig. 961 et 962) (2). En Abyssi-

(1) Voir sur ce sujet Ozanam, Etude sur le venin des arachnides et son empioi thérapeutique, suivie d'une dissertation sur le tarentisme et le tigretlier. Paris. 1856.

(2) Nunez, Étude-médicale sur le venin de la tarentule. Paris, 1866. 
nie, on attribue à la piqûre d'une tarentule la maladie nerveuse connue sous le nom de tigrettier.

Une autre araignée très-redoulée en Corse est le malmignatte (Latrodectus Malmignathus, Walk., fig. 963), auquel certains auteurs altribuent une piqûre aussi dangereuse que celle de la vi-

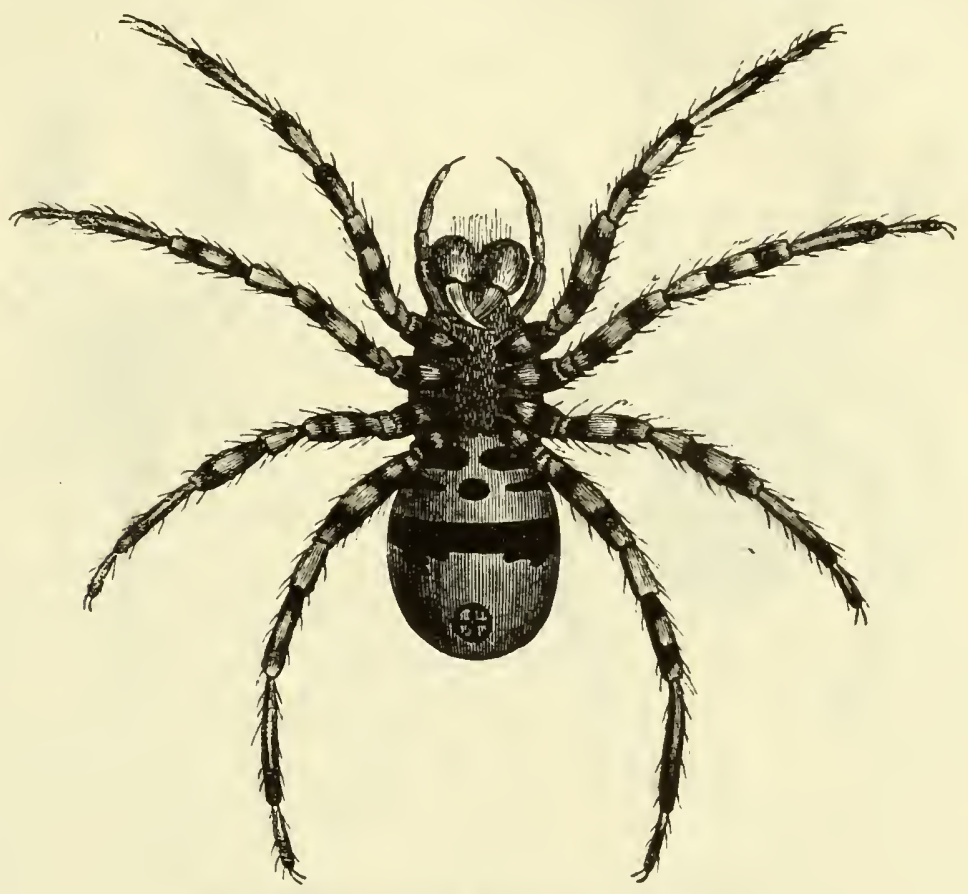

Fig. 962. - Tarentule (vue en dessous).

père (1). D'après M. Santi, cité par M. Cauvet (2), la piqûre, d'abord faible, s'exaspère au bout de trois heures, et le malade ressent un froid général très-vif, des sueurs froides, de l'angoisse, parfois du délire. Le pouls est agité; si le traitement par l'opium est incomplet, il reste une coloration ictérique, des douleurs névralgiques et un affaiblissement général, contre lequel les eaux thermales sont employées avec succès.

Les pédipalpes diffèrent beaucoup des aranéides, non-seulement à cause de leurs palpes très-grands et terminés par une pince ou une griffe, mais encore par leur abdomen à segments très-distincts et sans filières au bout. Les uns ont l'abdomen plus ou moins pédiculé, sans lames ni aiguillon à son extrémité; leurs stigmates, au nombre de quatre, sont situés près de l'origine du ventre et recouverts d'une plaque cornée ; leurs palpes sont terminés seulement par un crochet mobile : on en fait deux

(1) Cauro, Thèse inaugurale à la Faculté de médecine de Paris, 1833.

(2) Cauvet, Nouveaux éléments d'histoire raturelle médicale. Paris, 1869, t. I, p. 207. 
genres, les phrines et les téliphones. Les autres ont l'abdomen réuni au thorax dans toute sa largeur, offrant à la base de sa parlie inférieure deux lames mobiles en forme de peignes, et terminé par une queue noueuse, armée à l'extrémité d'un aiguillon

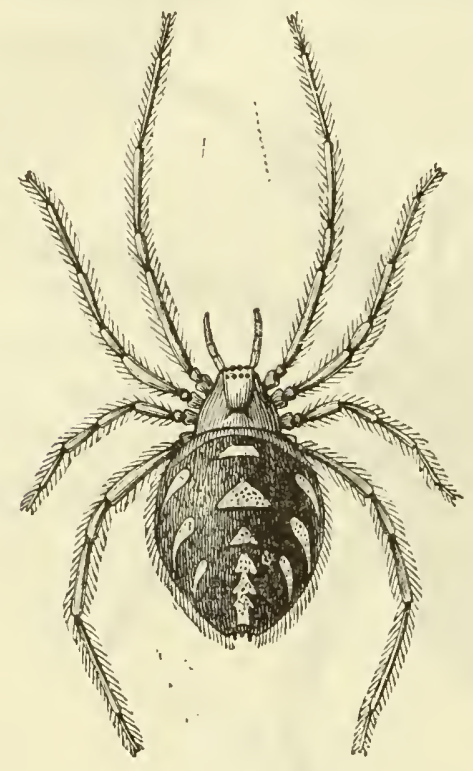

Fig. 963. - Malmignatte.

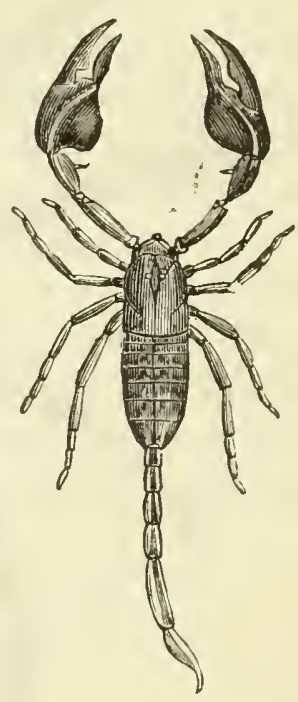

Fig. 964. - Scorpion roussâtre.

venimeux : leurs stigmates sont au nombre de huit, et disposés quatre par quatre, de chaque côté de la longueur du ventre. Leurs palpes sont très-forts, courbés en avant en arc de cercle,

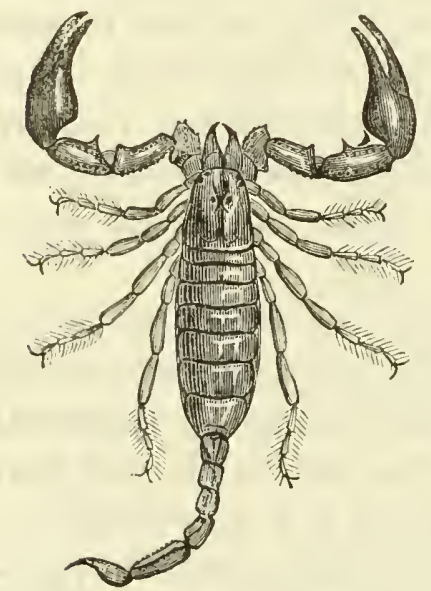

Fig. 965. - Scorpion flavicule, de grandeur naturelle. et terminés par deux doigts en forme de pince, dont l'extérieur est mobile. Ils forment le genre des scorpions, et sont redoutés pour la violence de leur venin. Le scorpion d' frique (Scorpio afer) est long de 13 à 16 centimètres, d'un blanc noirâtre, pourvu de huit yeux et de treize dents aux lames abdominales. Il habite aussi l'Asie et l'île de Ceylan. Le scorpion roussâtre (Scorpio occitanus, Amoreux, fig. 964) atteint seulement 5 š millimètres de longueur; il a huit yeux comme le précédent; les serres de ses palpes sont très-larges et. massives; la queue est plus longue que le tronc, munie au-dessus de chaque article d'une arête raboteuse; ses peignes sont à quatorze dentelures; il habite l'Algérie et l'Espagne, on le rencọtre aussi 
dans quelques rares localités du midi de la France. Sa piqûre est dangereuse (1).

Le scorpion d' Earope (Scorpio flavicaudus) (/ig. 96ə̆) de Geer se trouve dans le midi de la France ; il n'atteint guère que 27 millimètres de longueur. Il est d'un brun noirâtre, à serres anguleuses, à queue plus courte que le corps. Il n'y a que six yeux el neuf dentelures aux peignes. Il ne paraît pas que sa piqûre soit suivie de graves accidents.

\section{ORDRE DES ARACHNIDES TRACHÉENNES.}

Dans les arachnides trachéennes les organes respiratoires consistent en trachées qui reçoivent l'air par deux stigmates, et le distribuent dans tout l'intérieur du corps, afin de suppléer au défaut de circulation du sang; les yeux sont au nombre de deux ou de quatre, ou manquent tout à fait. On divise cet ordre en trois familles, sous les noms de faux scorpions, de phalangites el d'acarides. Ces derniers seuls vont nous occuper.

Les acarides ou les mites ont le thorax et l'abdomen réunis en une seule masse, sous un épiderme commun; le thorax est tout au plus divisé en deux, par un étranglement; leur bouche est conformée en suçoir, et leurs organes de mastication sont plus ou moins enfermés dans une gaîne ou une sorte de cuiller formée par la lèvre inférieure. Les palpes maxillaires sont libres, et leur extrémité est ordinairement armée d'un crochet ou d'une petite pince. Les uns ont quatre ou deux yeux; d'autres, un seul; et plusieurs en sont tout à fait privés. Ils naissent en général avec six pattes, et n'en acquièrent une quatrième paire qu'après leur première mue. La plupart de ces animaux sont très-petits et presque microscopiques; ils sont ovipares et pullulent beaucoup. Les uns sont errants sous les pierres, les feuilles, les écorces d'arbres, dans la terre, sous l'ean, partoụt où il peut se trouver des matières organiques en décomposition, et principalement dans la farine, sur la viande, les animaux desséchés dans les collections, le fromage, les vieux ulcères, etc. D'autres vivent en parasites sur la peau ou dans la chair des animaux vivants, et peuvent les affaiblir beaucoup par leur excessive multiplication. D'autres encore paraissent être la cause première de maladies contagieuses. Des habitudes aussi variées devaient amener de grandes différences d'organisation dans des êtres que leur petitesse rend en apparence assez semblables ; aussi le nom-

(1) Voir Jousset : Essai sur le venin du Scorpion (Journal de pharmacie et de chimie, $4^{\mathrm{e}}$ série, XIV, p. 148). 
bre de ceux qui sont connus est-il déjà fort considérable. Je mentionnerai seulement :

1. La tique des chiens ( $f g .966)$, que les Latins nommaient ricinus, et les Grecs, croton (xpózwv). Latreille aurait mieux fait de prendre l'un ou l'autre de ces noms comme appellation générique, que de former le mot ixode (visqueux), qui n'a aucun rapport avec cette petite arachnide. M. Duméril la nomme Croton Ricinus : elle habite les arbustes peu élevés, dans les bois, el s'attache aux oreilles des chiens, aux fanons des bœufs et aux chevaux; elle engage tellement son suçoir dans leur chair qu'il faut un assez grand effort pour l'en détacher : elle était auparavant très-aplatie avec les pattes fort distinctes; mais quand elle a été fixée pendant quelque temps comme parasite, son corps se gonfle comme une vessie; elle ressemble alors à une verrue arrondie ou ovale, portée sur un court pédicule, formé par la réunion de toutes les pattes insérées près du suçoir. Les piqueurs lui donnent le nom de louvelte.

2. Le lepte rouget $(/ g .967)$ qui est très-commun au mois d'a aût sur les graminées et d'autres plantes; on l'observe souvent aussi

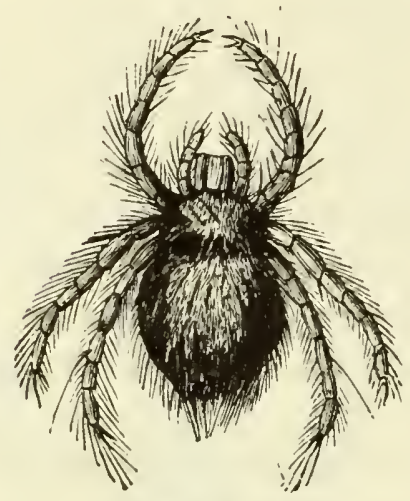

Fig. 966. - Tique.

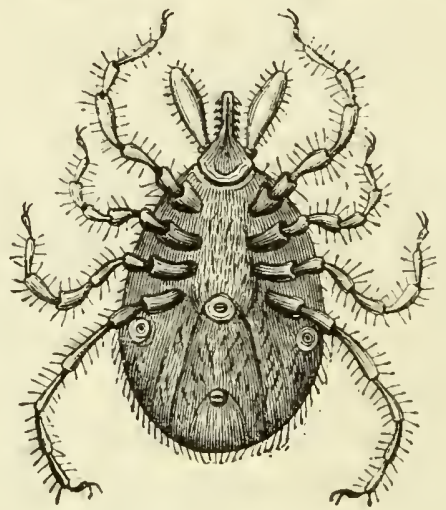

Fig. 967. - Rouget.

dans les jardins, au sommet des mottes de terre, au haut des échalas, sur les pommes des caisses d'orangers, etc., où il attend le moment de pouvoir s'accrocher aux passants. Il est à peine visible à la vue, lorsqu'il est isolé ; sa bouche consiste seulement en une sorle de bec sans machoires; il cause des démangeaisons fort vives et même de l'inflammation à la peau. L'alcool et le vinaigre camphré, et les préparations mercurielles le font périr. [L'ammoniaque liquide paraît être le meilleur remède contre les démangeaisons qu'il produit.

Ce petit animal n'est que l'état d'une espèce de Trombidium, le $T r$. autumnale. Dans cette période, il n'a que 3 paires de pattes, une quatrième paire existe chez l'insecte parfait. 
3. Argas de Perse (fig. 968) (Argas Persicus, Fisch). Cet animal est commun dans la ville de Miana en Perse, d'où le nom de punaise de Miana qu'on lui donne. Il n'a qu'une ressemblance trèséloignée avec notre punaise. Son corps est beaucoup plus bombé, la partie antérieure est très-obtuse, il n'a pas de tête distincte, enfin il a huit paltes au lieu de six. Son corps est granuleux et chagriné d'un rouge sanguin. Il attaque l'homme et produit des piqûres très-douloureuses, qu'on accuse mẻme, probablement à tort, d'amener la consomption et la mort.]

4. Mite domestique (Acarus domesticus), de Geer (1). Mite blanche à deux taches brunes, à corps hérissé de longs poils, ovale avec un rétrécissement au milieu, à pattes égales (fig. 969).

Ce petit être microscopique et le suivant auraient peu d'intérêt pour nous s'ils ne se trouvaient mêlés, jusqu'à un certain point, à l'histoire de la gale humaine. Il vit en grande quantité sur le vieux fromage, sur la viande sèche ou fumée, sur les oiseaux et les insectes desséchés des cabinets d'histoire naturelle; on l'aperçoit à peine à la vue simple. Il est d'un blanc sale, avec deux taches brunes internes, que l'on distingue à travers le corps. Sa partie antérieure est conique et se termine

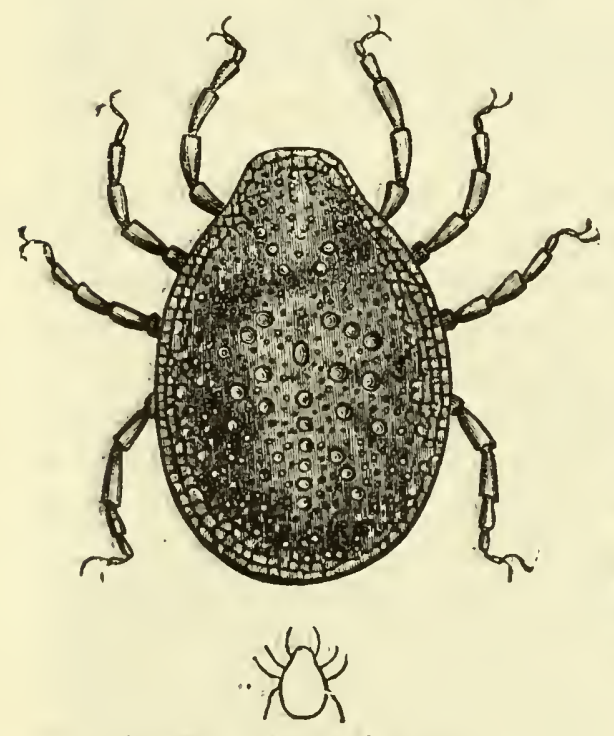

Fig. 968. - Argas de Perse.

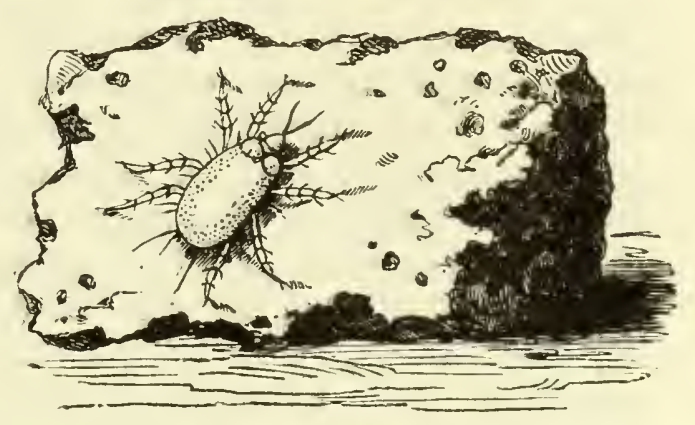

Fig. 969. - Mite du fromage.

par une petite tête à peine distincte du reste, munie d'un très-petit bec composé de deux pièces dentelées, et accompagné, à la base, de deux tentacules dirigés en avant. Les deux paires de pattes antérieures sont dirigées vers la tête et les deux autres vers le côté opposé; les unes et les autres sont articulées, de longueur à peu près égale, munies à l'extrémité d'une petite pelote ovale, qui sert à l'insecte à se maintenir sur les corps étrangers, dans toutes les positions. Il court avec beau-

(1) Geer, Insect., t. VII, pl. V, fig. 1 à 8. 
coup d'agilité : c'est lui que j'ai trouvé dans la vermoulure des cantharides nouvelles (1).

5. Mite de la farine (Acarus farince), de Geer (2). Mile allongée, blanche, à tête roussâtre, à grosses pattes coniques égales, roussâtres.

Cet acarus est plus petit que le précédent, à corps ovale et allongé; sa tête est grosse, conique, et s'avance en forme de museau. Ses pattes diminuent peu à peu de volume et se terminent en pointe mousse, sans pelote transparente, mais avec un petit crochet à l'extrémilé ; les cotés du corps et les pattes sont garnis d'un certain nombre de poils assez longs, et celui qui sort de l'avant-dernière articulation de chaque patté est plus fort que les autres. Cet acarus a une démarche trèslente; je l'ai observé, en quantité innombrable, dans des cantharides qui avaient été mouillées d'acide pyroligueux, dans le but de les conserver (3). Il se répand avec une grande facilité sur le corps humain, sans y produire la gale. Supposant anciennement que cet acarus était le même que celui trouvé par Galès, dans les vésicules de la gale, j’en avais conclu qu'il n'était pas essentiel à la production de cette maladie, laquelle pouvait exister sans lui. J'ajoutais que, si on le suppose amené d'ailleurs, il s'attachera aux pustules et s'y multipliera, comme dans tous les lieux humides où se trouvent des matières animales en décomposition. Je regarde encore cette conclusion comme l'expression de la vérité ; seulement il faut y ajouter que, indépendamment de cet acarus accidentel, il en existe un autre essentiel à la production de la gale humaine, qui avait été vu avant Galès, qui lui a échappé et que d'autres, plus habiles, ont retrouvé depuis.

6. Mite rhomboïlale. Puisque je me suis trouvé amené à parler des mites développées dans les cantharides vermoulues, je donnerai ici les caractìres et la figure de la troisième espèce mentionnée dans le Mémoire précité, p. 441; ne l'ayant pas trouvée décrite dans de Geer ni ailleurs, je puis supposer qu'elle est nouvelle (4). Mite parfaitement visible à la vue simple, munie de huit pattes semblables à celles du sarcopte de Galess, ou de la mite de farine; mais elle a une marche bien plus rapide, sans cependant avoir la vélocité de l'acarus domestique. Elle est presque entièrement dépourvue de poils; sa tête, qui est très-mobile (fig. 970), est armée de deux forts tentacules, semblables à des pieds courts, épais, contractiles et terminés chacun par un doigt mobile et par un autre appendice plus petit, qui en forme une sorte de main. Dans sa jeunesse, cette mile n'a que six pieds. Ses deux tentacules, qui sont alors presque soudés avec la tète, sont trìs-peu mobiles.

sarcopte de la gale, de Galès. Je reviens sur cet acarus dont

(1) Guibourt, Jour. de chimie médic., t. III, 1827, p. 440, second insecte.

(2) Geer, Insect., t. VII, pl. V, fig. 15.

(3) Guibourt, Journ. de chimie médic., t. III, p. 438-440.

(4) Bory de Saint-Vincent (Annales des sciences naturelles. Paris, 1828, t. XV p. 125) a décrit un acarus assez semblable à celui-ci, mais d'une espèce évidemment distincte. D'ailleurs les circonstances dans lesquelles l'acarus de Bory de Saint-Vincent a été observé sont essentiellement différentes : il naissait par milliers sur le corps d'une femme qui avait l'apparence de la santé, mais qui mourut quinze jours après. 
l'histoire se trouve liée à celle de la gale humaine. Galès, qui était à la fois pharmacien en chef de l'hôpital Saint-Louis et docteur en médecime, a publié, en 1812, une dissertation sur la gale (1), accueillie d'abord avec une grande faveur; mais quil'a laissé en bulte, plus tard, à la plus grave des accusations. Dans celte thèse, après avoir rendu pleine justice aux observateurs qui l'avaient précédé, et principalement à Abynzoar, médecin arabe du douzième sic̀cle; à Moufet, naturaliste

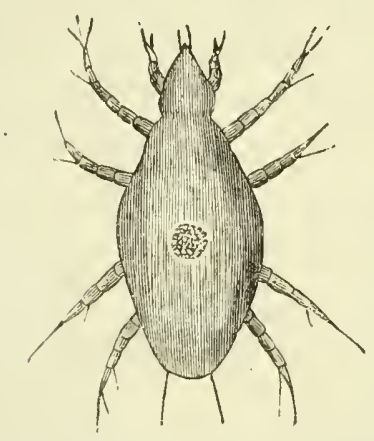

Fig. 970. - Hite rhomboïdale.

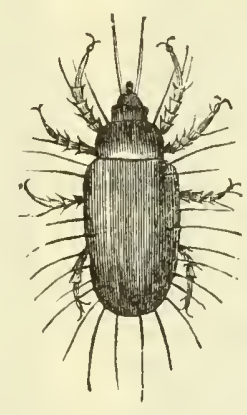

Fig. 971. - Sarcopte de la gale, d'après Galès.

anglais; à Cestoni, à Linné et à de Geer, Galès rend compte de ses propres observations sur l'insecte de la gale, et annonce en avoir plus de 300 , ayant constamment la même forme, à cela près de la grosseur et du nombre des pattes, qui était tantôt de six, tantôt de huit. Galès n'a donné aucune description de l'insecte observé par lui, el s'est borné à en faire dessiner la figure que je reproduis ici $(f g .971)$. Il est évident que cel insecte diffère totalement de celui décrit par tous les auteurs, et l'on trouve également qu'il offre la plus grande ressemblance avec la mite de la farine décrite el figurée par de Geer.

7. Mite de la gale, ou Acarus scabiei de De Geer; Acarus exulce. rans, L. ; Acarus humanus subcutaneus, Geoffr.

" ])ans les ulcères produits par la gale sur les mains el les autres parties du corps humain, on trouve de très-petites mites qui sont l'unique cause de cette maladie. Linné, qui d'ahord leur avait donné le nom d'Acarus humanus subcutaneus, mais qui ensuite les a regardées à tort comme ne formant qu'une espèce avec celles de la farine et du vieux fromage, en parle de cette manière: "Cette mite habite sous la peau humaine, où elle cause la "gale; elle y produit une pelite vésicule d'où elle ne s'éloigne "guère. Après avoir suivi les rides de la peau, elle se repose et " excite une démangeaison. Celui qui y est accoutumé peut la "voir à l'œil simple, au-dessous de l'épiderme, et il est facile de a l'ôter avec la pointe d'une épingle. Elle est très-petite, de forme " arrondie, et sa tête n'est presque pas visible; la bouche et les " pattes sont rousses ou jaunâtres; le ventre est ovale, d'appa-

(1) Galès, Essai sur le diagnostic de la gale, etc. Paris, 1812, in- $^{\circ}$. 
"rence aqueuse; le dos est marqué de deux lignes courbes bru"nes."

a Les huit pattes de notre mite sont en général assez courtes; les pattes antérieures sont grosses, de figure conique, divisées en plusieurs articulations, ayant des poils dont quelques-uns sont assez longs. Elles portent à l'extrémilé une longue partie déliée, droite et cylindrique, terminée par une pelite vessie arrondie que la mite appuie sur la place où elle marche. Cette partie déliée est mobile sur le reste de la jambe avec laquelle elle fait des angles différents, à la volonté de l'animal. Les quatre pattes postérieures sont placées à une certaine distance des premières, et sont encore plus courtes; mais elles sont terminées par une partie déliée, fort longue et de couleur brune, qui m'a paru être un peu courbée, et à l'extrémité de laquelle je n'ai pu distinguer de boule vésiculeuse. "(De Geer.)

Nous avons vu plus haut comment Galès, oubliantlesinstructions de ses devanciers, n'avait pas su trouver l'acarus de la gale et en avait pris un autre pour lui. Pendant vingt-deux ans, les médecins français, égarés par les conseils de Galès, ne furent pas plus heureux, et en vinrent à penser que l'acarus de la gale n'existait pas. Mais, en 1834, M. Rennuci, élève en médecine, natif de Corse, où la gale est commune, ayant fait connaître la manière de trouver l'Acarus scabiei, il fut alors facile de l'étudier. M. Raspail en a

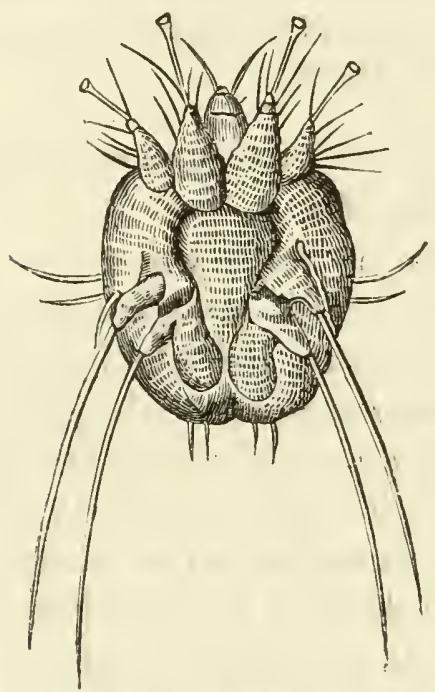

Fig. 9.72. - Sarcopte de la gale, d'après Raspail.

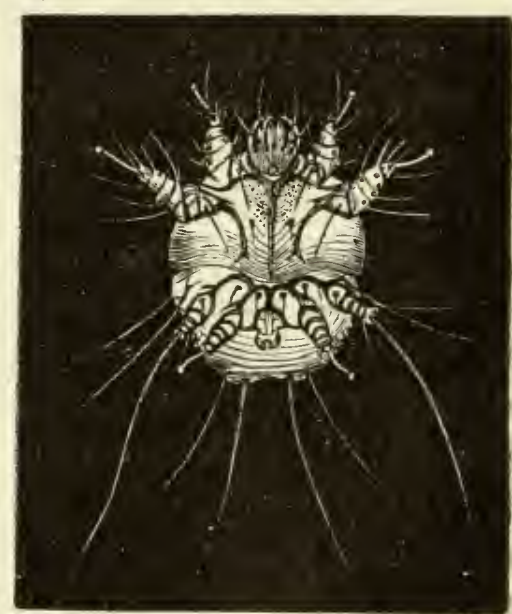

Fig. 973. - Surcopte mále (face ventrale)

publié une autre figure (fig. 972) (1) el en a donné une description plus complète, mais identique, dans ses parties essentielles,

(1) Raspail, Nouveau système de chimie organique. Paris, $1838,2 \mathrm{e}$ édition, pl. XV, fig. 1, 2. 3. 
avec celle de De Geer. Enfin M. le docleur Bourguignon a vu, en 1850 , ses recherches sur la gale humaine honorées d'une récompense par l'Académie des sciences. Il s'est surtout livré à l'examen microscopique le plus complet de l'Acarus scabici, et en a

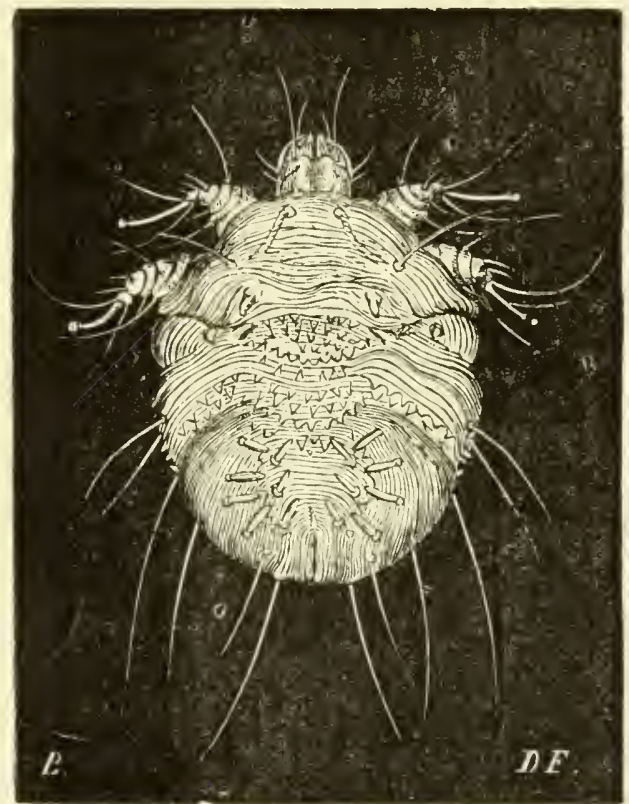

Fig. 974. - Sarcopte lemelle (face dorsale)

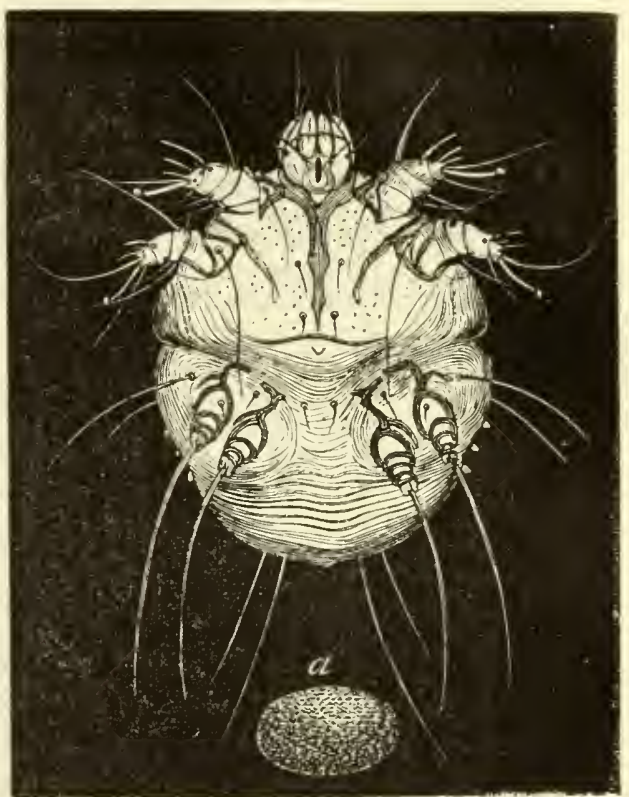

Fig. 975. - Sarcopte femelle (face ventrale).

dessiné un très-grand nombre de figures (1). M. Cauvet (2) a résumé les dernières données de la science sur l'histoire naturelle du sarcopte de la gale, d'après les travaux de Ch. Robin (3), Bourguignon Lanquetin (4), elc. Nous nous contentons de reproduire les figures ( $/ \mathrm{hg} .973$ et 974$)$, qu'il a reproduites et de renvoyer aux détails dans lesquels il est entré.

On a observé des Acarus sur divers animaux attaqués de gale, tels que le cheval, le chameau, le mouton, le chat, les oiseaux de basse-cour (כ), le chien et le renard. Chacun de ces Acarus paraît propre à l'espèce qui le porte, et est très-probablement lia

(1) Bourguignon, Traité entomologique et pathologique de la gale chez l'homme (Collection des mémoires présentés à l'Académie des sciences par des savants étrangers, $\mathrm{t}$. XII).

(2) Cauvet, Nouveuux élëments d'list. natur. médicale. Paris, 1869, t. I, p.. 214.

(3) Robin, in Diclionnaire de méclecine, $12^{\mathrm{e}}$ édition, par Littré et Robin. Paris, 1873 , p. 1378 , art. SARcopte.

(4) Lanquetin, Notice sur la gale et l'animalcule qui la produit. Paris, 1859, in-8.

(5) Voyez Reynal et Lanquetin, de la Maludie parasitaire des oiseaux de basse-cour, transmissible à l'homme et au cheval (Mém. de l'Acad. de médec. Paris, 1863, t. XXVI, p. 215. 
cause de la maladie et celle de sa transmission. Des expériences faites notamment par Walz, sur les Acarus du mouton et du renard, paraissent prouver, de plus, que ces insectes ne sont pas transmissibles d'une espèce de quadrupède à l'autre, ni du quadrupède à l'homme; ou plutôt qu'ils ne s'y propagent pas, et qu'ils y meurent bientôt après. D'un autre côté, un très-grand nombre de faits élablissent que le contact d'un cheval, d'un chien, d'un chat, d'un chameau galeux, peut développer dans l'homme une maladie de la peau qui a beaucoup d'analogie avec , celle qui lui a donné naissance.

\section{QUATRIÈME CLASSE}

\section{LES CRUSTACES.}

La classe des crustacés comprend tous les animaux articulés et à pattes articulées, qui sont pourvus d'un cœur et de branchies, pour respirer dans l'eau. Les crabes et les écrevisses forment le type de ce groupe; mais on range un grand nombre d'animaux dont la structure est beaucoup moins compliquée et dont la forme extérieure est différente. Les derniers crustacés sont même si imparfaits qu'ils ne peurent vivare que fixés en parasites sur d'autres animaux, et que beau. coup de naturalistes les ont rangés parmi les vers intestinaux.

Le squelette tégumentaire des crustacés offre en général une consistance considérable et une dureté pierreuse dues à la présence d'une grande proportion de carbonate calcaire. On peut considérer cette enveloppe solide comme une espèce d'épiderme qui se détache et tombe à certaines époques. On comprend, en effet, la nécessité de cette mue, chez des animaux dont tout le corps est enfermé dans une gaîne solide qui, ne pouvant croître comme les organes intérieurs, opposerait à leur développement un obstacle invincible, si elle ne tombait au moment où elle est devenue trop petite pour les loger commodément. En général, les crustacés sortent de leur ancien test sans y occasionner la moindre déformation, et, lorsqu'ils le quiltent, toute la surface de leur corps est déjà revêtue de sa nouvelle gaîne; mais celle-ci est très-molle et n'acquiert la solidité qu'elle doit avoir qu'au bout de quelques jours.

Les crustacés sont tous ovipares. Les femellesse distinguent en général des mâles par la forme plus élargie de leur abdomen. Après avoir pondu leurs oufs, elles les porient pendant un certain temps, suspendus sous cette partie du corps, ou même renfermés dans une espèce de poche formée par des appendices appartenant aux pattes. Quelquefois les petits naissent dans cette poche et y restent jusqu'à ce qu'ils aient subi leur première mue. En général, les jeunes n'éprouvent pas de véritable mélamorphose, et acquièrent seulement quelquefois un plus grand nombre de pattes. 
M. Milne Edwards divise les crustacés en trois groupes naturels d'après la conformation de leur bouche, savoir :

$1^{\circ}$ Les Crustacés masticateurs, dont la bouche est munie de mâchoires et de mandibules propres à la masticalion.

$2^{\circ}$ Les crustacés suceurs, dont la bouche est composée d'un bec tubuleux armé de suçoir's.

$3^{\circ}$ Les crustacés xiphosures, dont la bouche ne présente pas d'appendices qui lui appartiennent en propre, mais est entourée de pattes dont la base fait l'office de mâchoires.

Les Chustacés masticateurs comprennent le plus grand nombre de ces animaux et ceux dont l'organisation est la plus compliquée. M. Milne Edwards les a divisés en neuf ordres d'après les caractères suivants.

\section{CRUSTACÉS MASTICATEURS.}

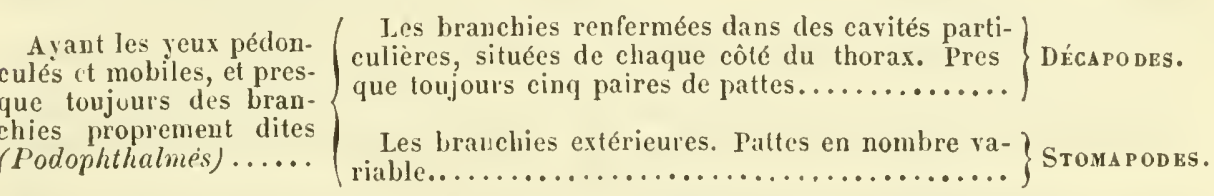

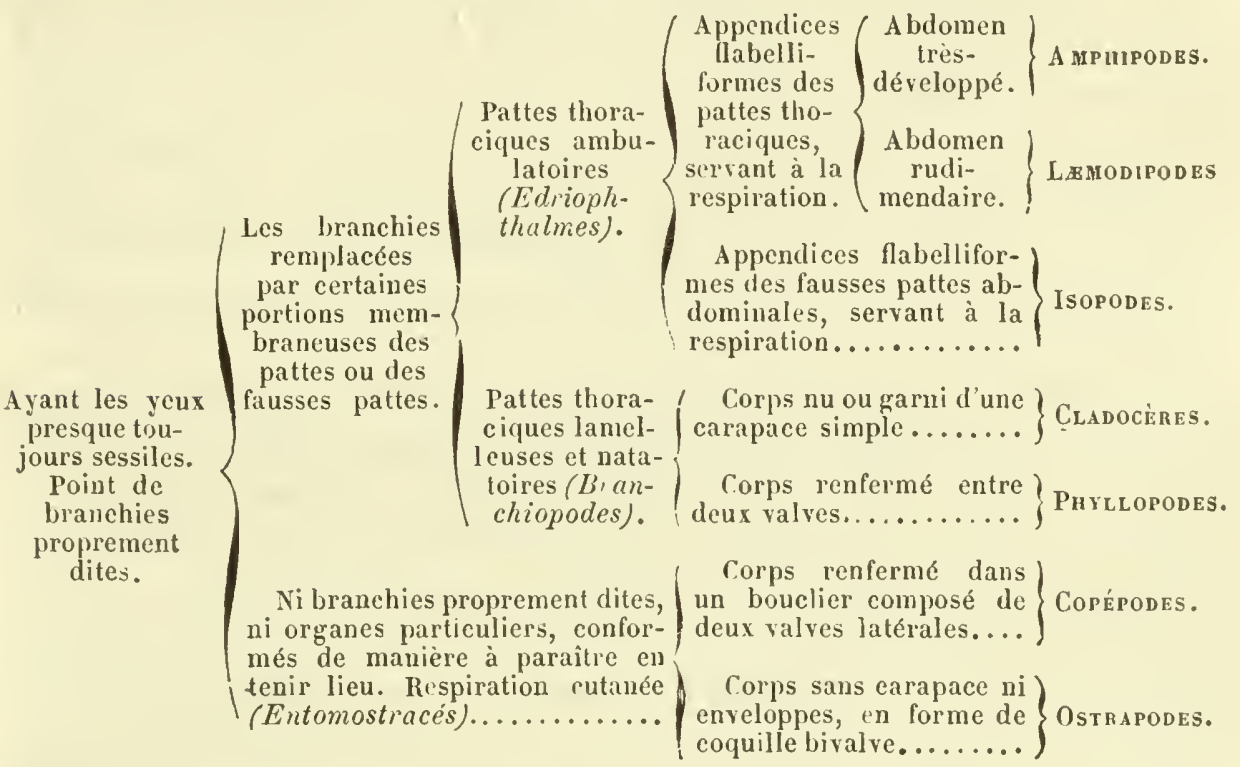

ORDRE DES DÉGAPJDES.

Les crustacés décapodes forment rois tribus distinguées par la conformation de l'abdomen et par la position des ouvertures destinées au passage des cufs.

La première tribu, qui a reçu le nom de DÉCA PODES BRACHYURES. se compose des crustacés connus vulgairement sous le nom de cancres ou de crabes, dont l'abdomen est presque rudimentaire, et qui ne sont en apparence composés que d'un large thorax en forme de gâteau aplati, portant, à la partie antérieure, les yeux,

Gurbount, Drogues, 7 e édit.

T. IV. -18 
la bouche et les antennes, et renfermant l'estomac, le foie, les branchies, le cœur et les organes de la génération qui sont doubles dans les deux sexes, et qui s'ouvrent par deux ouvertures percées dans le bouclier inférieur. Ils ont cinq paires de pattes, dont celles de la première paire se terminent par une forte pince très-solide, en forme de main. Les crabes les plus communs sur nos côtes sont le crabe commun (Cancer Monas, L.), et le tourteau ou poupart (Cancer Pagurus, L.), dont la chair est assez estimée; il pèse quelquefois $2 \mathrm{kilog} .500$ gram.

La deuxième tribu, celle des DÉCAPODES AnOMOURES, tient le milieu entre les brachyures et les macroures, par leur abdomen qui, sans être un organe puissant de natation, comme cela a lieu dans la dernière tribu, n'est cependant pas réduit à un état aussi rudimentaire que chez les brachyures. On y trouve des animaux fort singuliers, du genre des pagures, généralement connus sous les noms de bernard-l'ermite, de soldat, etc. Ils ont l'abdomen gros, contourné sur lui-même et tout à fait membraneux, tandis que le reste de leur corps est revêtu d'un tégument crustacé, comme à l'ordinaire. Celte conformation, qui rend leur abdomen très-sensible et facile à blesser, les délermine à se loger dans la coquille vide de divers mollusques gastéropodes; ils s'y cramponnent à l'aide de leurs pattes postérieures qui sont courtes, et traînent parlout avec eux celte demeure, dans laquelle ils peuvent à volonté se retirer en entier.

Les déCapodes MaClioures qui forment la troisième tribu, se reconnaissent au grand développement de leur abdomen qui se termine toujours par une grande nageoire composée de cinq lames disposées en éventail. Ils sont essentiellement nageurs, et en frappant l'eau arec leur puissante queue ils se lancent en arrière avec une ơnande vitesse. Leur corps est allongé et presque toujours comprimé latéralement. Ils ont des antennes très-lon. gues, et le dessons de leur abdomen est garni de fausses pattes natatoires. Nous y trouvo's le genre des langoustes et celui des écrevisses.

Les langoustes (Palinurus), sont de très-gros crustacés macroures, caractérisés par deux antennes extérieures très-fortes, beaucoup plus longues que le corps tout entier, sétacées, hérissées de poils et de piquants, et portées chacune sur un grand et gros pédoncule formé de trois articles épineux. Elles ont en outre deux antennes intérieures beaucoup plus faibles, mais cependant encore assez longues, formées de trois articles, et terminées par deux petites branches multi-articulées. Toutes leur's pattes sont monodactyles; seulement celles de la première sont plus grosses et plus courtes que les autres. La carapace est hérissée de poin- 
tes; les yeux sont ronds et portés sur des pédoncules étroits, trans. versaux, qui semblent partir du même point au milieu du front.

Ces animaux se tiennent dans les profondeurs de la mer, et se rapprochent des rivages rocailleux dans les mois de mai, juin, juillet, pour s’accoupler el déposer leurs œufs. L'espèce la plus connue sur nos côtes est la langouste commune (Palinurus Locusta, Oliv.), qui atteint jusqu'à 50 centimètres de longueur avec un poids de 3 à 6 kilogrammes, lorsqu'elle est chargée d'œufs. Son teste est épineux, garni de duvet, avec deux fortes dents dentelées au-devant des yeux. Le dessus du corps est d'un brun verdâtre ou rougeâtre, et la queue est tachetée dẹ jaunâtre; sa chair est très-estimée.

Les écrevisses ont les antennes extérieures aussi longues que le corps, sétacées, portées sur un pédoncule formé de trois gros articles, et les antennes intérieures beaucoup plus courtes, bifides et sétacées. Leur bouche est garnie de six paires de membres non développés ou atrophiés, dont ceux de la première paire portent le nom de mandibules et ceux de la dernière le nom de pieds-mâchoires, à cause de leur conformation plus rapprochée de celle des autres pieds, eł de leur dentelure intérieure, qui en fait de véritables organes masticateurs. Les pieds thoraciques sont au nombre de dix, dont ceux de la première paire sont beaucoup plus forts que les autres, inégaux, terminés par une forte pince osseuse, en forme de tenailles dentelées, dont le mordant extérieur est fixe el l’intérieur plus petit et mobile. Ces pieds étant très-lourds et beaucoup plus gros à l'extrémité qu'à leur point d'altache, sont.très-sujets à sc rompre, principalement un peu audessus de la seconde articulation, et ils peuvent se reproduire, surtout lorsqu'ils sont rompus en cet endroit. On a même cru remarquer que, lorsque les pattes sont coupées plus près de l'extrémité, la partie qui excède le point où doit se faire la reproduction tombe avant que celle-ci commence à s'opérer. Les quatre dernières paires de pieds sont plus minces et à peu près égales ; cependant la seconde et la troisième sont encore terminées par de petites pinces dont le doigt extérieur est mobile. La quatrième et la cinquième paire ne portent qu'un ongle simple, pointu et crochu; la carapace est allongée, demi-cylindrique, atténuéc en avanl en un rostre pointu, tronquée en arrière et marquée au milieu d'un sillon transversal. L’abdomen est grand, formé de six articles, recourbé en dessous, muni de cinq paires de fausses pattes servant à la natation, et terminé par cinq grandes lames ciliées, dont les deux latérales sont formées chacune de deux pièces distinctes, transversales. Leurs yeux sont demi-sphériques, ct d'un diamètre qui ne dépasse pas celui de leur pédoncule. 
L'écrevisse de mer ou homard (Astacus maritimus, Fabr.; Cancer Gammarus, L.), acquiert jusqu'à כొ0 centimètres de longueur'; il se tient sur les côtes de l'Océan. de la Manche et de la Méditerranée, dans les lieux remplis de rochers. Sa carapace est unie, terminée antérieurement par un rostre pourvu de trois pointes de chaque côté; ses pinces sont très-grosses, de nature calcaire, inégales, l'une ovale avec des dents fortes et mousses, l'autre oblongue avec de petites dents nombreuses. Il est d'une couleur bruneverdâtre avec les filets des antennes rougeatres. Son test devient d'un beau rouge par la cuisson, comme ceux de la langouste et de l'écrevisse; sa chair est très-estimée.

L'écrevisse de rivière (Astacus fluviatilis, Fabr. ; Cancer Astacus, L.) ( fig.976) se trouve dans les eaux douces de l'Europe et du nord de l'Asie. Elle se tient ordinairement sous les pierres, dans les

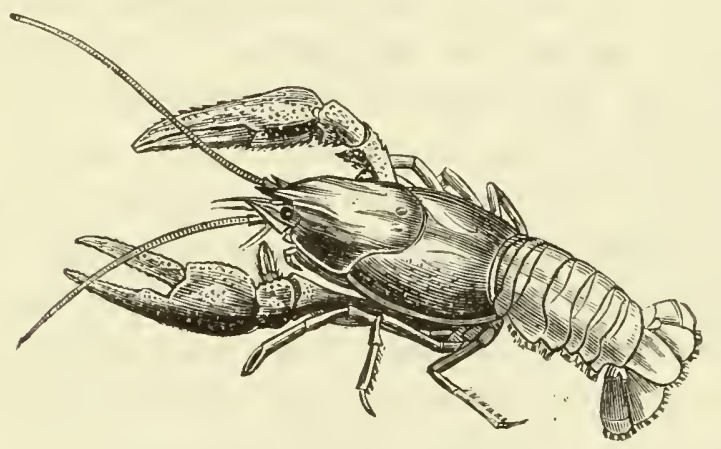

Fig. 976. - Écrevisse de rivière. cavités des berges, et ne paraît en sortirque pour chercher sa proie. Elle vit de mollusques, de petits poissons, de larves d'insectes et de chairs corrompues qui flottent dans les eaux. Son existence peut se prolonger vingt ans et au dela, et sa taille augmente proportionnellement à son àge. Chaque année, vers la fin du printemps, elle se dépouille de son test, et, quelques jours après, la nouvelle enveloppe crustacée est presque aussi solide que la précédente et plus grande, quelquefois d'un cinquième. C'est aux approches de la mue qu'on trouve dans l'estomac de l'écrevisse les deux concrétions calcaires nommées pierres ou yeux d'écrevisse, et comme elles disparaissent peu après, à mesure que le nouveau test se durcit, on croit avec fondement qu'elles servent à sa reproduction (1).

Les plus belles pierres d'écrevisse nous viennent d'Astrakan, sur la mer Caspienne. Pour se les procurer, on met les écrevisses pourrir en tas, ou mieux on les pile grossièrement et on les agite

(1) J'ajoute a cette raison l'observation que les pierres d'écrevisse plongées dans l'eau bouillante prennent une couleur rosée qui est une dégradation de la couleur rouge que leur test acquiert par le même moyen. Souvent, cependant. la première, au lieu d'être rosée, est violette, bleue ou verdàtre; mais j'attribue cet effet à ce que, la plupart du temps, on sépare les pierres d'écrevisse de l'animal par la putréfaction de celui-ci, et que cette opération doit nécessairement influer sur la matière colorante contenue dans les pierres. 
dans l'eau afin d'en séparer les pierres qui tombent au fond. On lave ces pierres et on les fait sécher.

Les pierres d'écrevisse sont formées de couches concentriques superposées; elles sont convexes d'un côté, creuses de l'autre, avec un rebord saillant tout autour, ce qui leur donne une sorte de ressemblance avec un oil, et leur a valu le nom vulgaire d'yeux d'écrevisse. Leur diamètre varie de 9 à 18 millimètres, et leur poids de 5 à 15 décigrammes. Elles sont formées de couches concentriques de carbonate de chaux, dont les parties sont liées à l'aide d'un mucus animal. On les emploie comme absorbantes en pastilles, et comme dentifrices en opiat.

On dit qu'on fabrique de fausses pierres d'écrevisse. Quoique je n'en aie jamais vu, il me semble qu'il doit être facile de reconnaître les véritables, en raison de la difficulté d'imiter leur texture lamelleuse, jointe à leur aspect éclatant, qui a quelque chose de la porcelaine sans en avoir la transparence. De plus, les véritables pierres d'écrevisse se dissolvent dans le vinaigre, et laissent à leur place une matière gélatineuse qui garde leur forme.

Sous le nom vulgaire de crevettes, on connaît plusieurs espèces communes sur les côtes d'Europe et recherchées comme

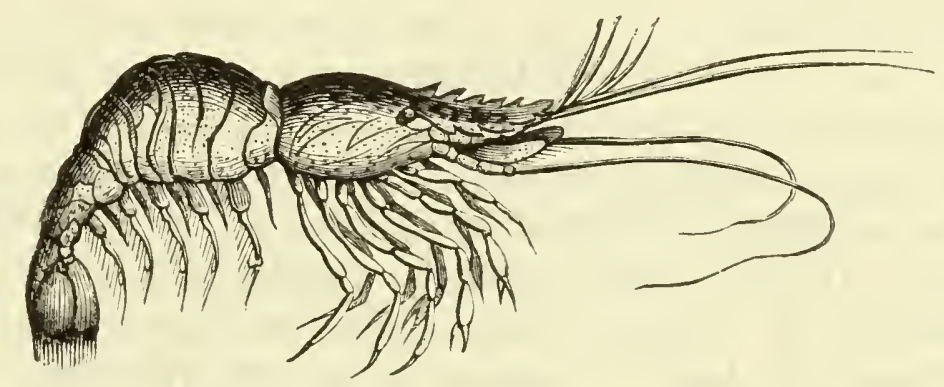

Fig. 977. - Palemon ou crevette.

aliment; c'est la crevette proprement dite ( $(\mathrm{gg} .977)$ ou la solicoque (Palcemon Squilla, Fabr.), le bouquet ou porte-scie (Palcemon serratus, Fabr.).

ORDRE DES ISOPODES.

Cloporte.

Oniscus Asellus, L.; Oniscus murarins et Oniscus Asellus, Cuv• ( $f$. 978). Cirustacé isopode, grisâlre, aplati, ovalaire, convexe en dessus, concave en dessous. Son corps est formé de qualorze articles, en y comprenant la têle : celle-ci porte deux yeux granulés, deux grandes antennes à sept ou huit articles, deux mandibules sans palpes et trois paires de inâchoires; les sept articulations qui suivent la tête portent chacune une paire de pieds terminés 
par un crochet simple; les cinq qui viennent après supportent des écailles membraneuses sous lesquelles sont déposés les nufs dans la femelle, et les organes respiratoires dans les deux sexes; le dernier anneau porte deux appendices plus ou moins allongés qui laissent suinter, quand on y touche, une humeur gluante dont on ignore l'usage. La femelle garde ses œufs sous les écailles

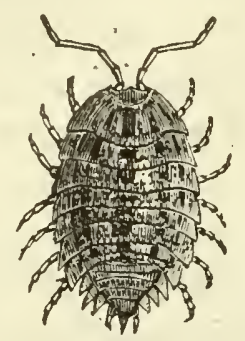

Fig. 978. - Cloporte.

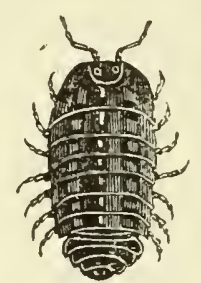

Fig. 979. - Armadille.

de la queue et entre les pattes; ils y éclosent, et les petits ne paraissent au jour qu'arec la forme qu'ils conservent toute leur vie; seulement ils n'ont que dix ou douze pattes et changent plusieurs fois de peau.

Le cloporte habite les caves et les autres lieux humides de nos maisons. On l'emploie le plus habituellement à l'élat récent pour les préparations magistrales, et on le prend à mesure du besoin. Il passe pour diurélique, et peut l'être en effet, en raison des particules salpêtrées au milieu desquelles il vit, et qui s'attachent à son corps. On peut aussi employer l'espèce des bois, qui est peu différente de celle des caves. Quant aux cloportes que l'on trouve desséchés dans le commerce, et qui viennent surtout d'Italie, ce sont des armadilles (Oniscus Armadillo, L.) (fig. 979), qui diffèrent des cloportes par leur corps poli, brillant, très-convexe, susceptible de se rouler en boule lorsqu'on les touche, et ayant les appendices de la queue a peine distincts. La poudre de cloporte entre dans les pilules balsamiques de Morton.

C'est aux crustacés isopodes que l'on rapporte les animaux fossiles auxquels on a donné le nom général de trilobites, qui devaient cependant différer des isopodes que nous connaissons par des pattes membraneuses propres à la natation. C'est seulement dans les couches de sédiment les plus anciennes du globe, composant les terrains dits cambriens et siluriens, et principalement dans les schistes argileux, que l'on trouve des tribolites. C'est à peine si l'on en rencontre quelques traces dans le terrain houiller : ils avaient tous cessé d'exister avant l'apparition des premiers animaux vertébrés. 
ORDRE DES LINGATULES.

Les lingatules ( $f g .980)$ ont été prises pour des belminthes jus-

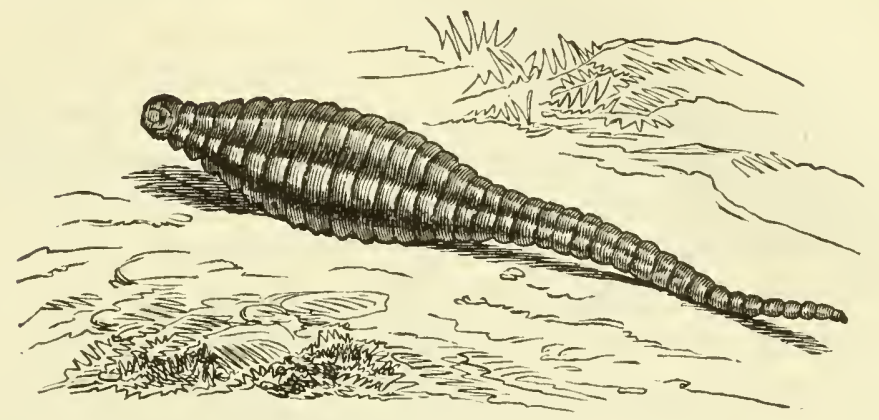

Fig. 980. - Lingatule.

qu'au moment où M. Van Beneden étudia leur développement et proposa de les classer à la suite des crustacés cyclopigènes.

\section{CINQUIÈME CLASSE}

\section{LES CIRRIPÉDES.}

Les cirripèdes forment la cinquième classe des annelés articulés qui comprennent les balanes (fig. ( 81$)$ et les anatifes ( $f g .982)$.

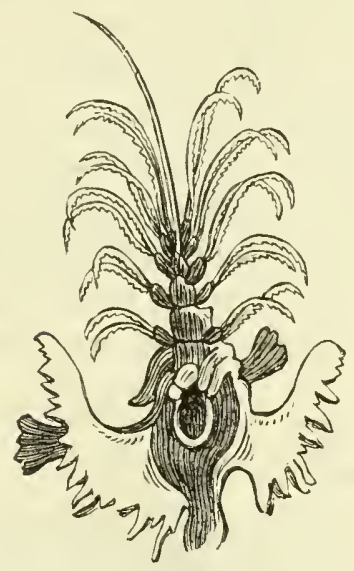

Fig. 981. - Balane telline (l'animal grossi sorti de son test).

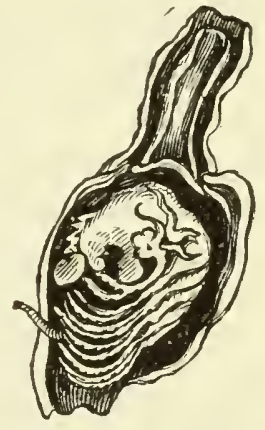

Fig. 982. - Anatife lisse (coupe verticale montrant l'animal). 


\section{SIXIÈME CLASSE}

\section{LES ANNELIDES.}

"Les annélides, dits aussi vers à sang rouge, ont leur sang généralement coloré en rouge, comme celui des animaux vertébrés, et circulant dans un systìme double et clos d'artères et de veines. Ils respirent par des organes qui tantôt se développent au dehors, tantot restent à la surface de la peau ou s'enfoncent dans son intérieur. Leur corps, plus ou moins allongé, est toujour's divisé en anneaux nombreux, dont le premier, qui se nomme tête, est à peine différent des autres, si ce n'est par la présence de la bouche et des principaux organes des sens. Ja mais ces animaux n'ont de pieds articulés; mais le plus grand nombre portent, au lieu de pieds, des soies ou des faisceaux de soies roides et mobiles. Ils sont gétéralement hermaphrodites, et quelques-uns ont besoin d'un accouplement réciproque. Leurs organes de la bouche présentent tantot des mâchoires plus ou moins fortes, tantot un simple tube; ceux des sens extérieurs consistent en tentacules charnus et en quelques points noirâtres que l'on regarde comme des yeux, mais qui n'existent pas dans toutes les espèces."

Cuvier a divisé la classe des annélides en trois ordres, d'après les différences observées dans leurs organes respiratoires.

ORDRE DES TUBICOLES.

Les premiers ont des branchies en forme de panaches ou d'arbuscules, attachées à la tête ou sur la partie antérieure du corps, dont la partie postérieure est renfermée dans un tube solide qui leur sert d'habitation; aussi leur donne-t-on le nom de tubicoles. Les uns, comme les serpules, habitent un tube calcaire homogène, résultant probablement de leur transsudation, comme la coquille des mollusques, mais auquel ils n'adhèrent point par des muscles; d'autres se construisent un tube en agglutinant des grains de sable, des fragments de coquilles, ou des parcelles d'argile, au moyen d'une membrane qu'ils transsudent sans doute aussi (par exemple les térébelles); d'autres enfin ont un tube entièrement membraneux ou corné.

ORDRE DES DORSIBRANCHES.

Les annélides du second ordre ont sur la partie moyenne du cor $\mathrm{s}$ ou tout le long de ses côtés, des branchies en forme d'arbres, de houppes, de lames ou de tubercules. On Jeur a donné le nom de norsibrancHes. Ils habitent dans la vase ou nagent librement dans la mer. T'el est l'arénicole des pêeheurs, très-commun dans le sable des bords de la mer, où les pêcheurs vont le chercher pour s'en servir comme d'appât; il est long de 30 centimètres, de couleur rougeâtre, avec treize paires de branchies. 
ORDRE DES ABRANCHES.

L.es annélides du troisième ordre n'ont pas de branchies apparentes, et respirent, ou par la surface de la peau, ou par des cavités intérieures. On les nomme abRanches, et on les divise en deux familles, suivant qu'ils sont pourvus de soies ou que leur corps est entièrement nu. Les premiers, sous le nom d'aBRANCHES sétig̀̀REs, comprennent les lombrics et les naides; les autres, nommés aBranches NUS ou HIRUdinés, renferment les sangsues, dont nous nous occuperons plus particulièrement.

\section{Ver le terre ou Lombric.}

Lumbricus terrestris, L., annélide abranche sétigère, dépourvu d'yeux, de tentacules et de cirrhes. Il a le corps mou, rouge, cylindrique, quelquefois long de 30 centimètres, composé de plus de cent vingt anneaux contractiles, et muni en dessous de huit rangées de petites pointes, à l'aide desquelles il rampe sur la terre. Il est hermaphrodite avec rapprochement d'individus. Un bourrelet ou renflement placé vers le liers antérieur du corps, sensible surtout au temps de l'amour, sert à deux individus à se fixer l'un à l'autre pendant la copulalion. Les œufs descendent entre l'intestin et l'enveloppe extéricure, jusqu'autour du rectum où ilséclosent, les petits sortant vivants par l'anus (Montègre). I.éon Dufour dit au contraire que les lombrics font des œufs analogues à ceux des sangsues.

Le ver de lerre perce en tous sens l'humus humide dont il avale beaucoup. Il mange aussi des, racines, des fibres ligneuses, des parties animales, etc. Au mois de juin, il sort de terre la nuit, pour's'accoupler.

Le ver de terre était employé autrefois en pharmacie pour préparer une huile médicinale par décoction. Celte composition est complétement lombée en désuétude.

\section{Annólides hirudinés ( 1 ).}

Les annélides qui composent les familles des hirudinés ont le corps nu, très-rarement appendiculé, contractile, formé d'un très-grand nombre d'anneaux, et terminé à chaque extrémité par une ventouse dilatable et préhensible. La ventouse buccale est

(1) De hirudo, sangsue. Cette famille répond au genre hirudo de Linné. Jusqu'ici tous les auteurs ont écrit hirudinées; mais le genre féminin ayant été affecté, d'un accord unanime, aux familles du règne végétal, et le masculin ì celles du règne animal (édentés, cétacés, gallinacés, crustacés, etc.), j’ai cru pouvoir écrire hirudinés. Ce nom n'est d'ailleurs, en effet, qu'un des adjectifs du nom de la classe annélides, auquel il peut être nécessaire de le joindre. 
étroitement unie avec le corps ou en est séparée par un étranglement. La bouche, située dans la ventouse antérieu re, avec ou sans mâchoire, est quelquefois munie d'une petite trompe cylindrique et extensible. Les mâchoires sont au nombre de trois, ra rement de deux, denticulées ou non; des points oculaires, au nombre de deux à dix, sont placés à la partie supérieure de la ventouse buccale. La ventouse anale est simple, nue, raremen $t$ armée de petits crochels, tantôt oblique, tantôt exacternent terminale. Les branchies sont nulles.

A. Moquin-Tandon, auquel on doit une excellente monographie des hirudinés (1), les a partagés en quatre sections, de la manière suivante :

1. Corps à anneaux très-distincts, opaque, à sang rouge. Ventouse buccale unilabiée : Albioniens.

2. Corps à anneaux très-distincts, opaque à sang rouge. Ventouse buccale unilabiée : Bdelliens.

3. Corps à anneaux peu distincts, transparent, à sang incolore: Siphoniens.

4. Corps sans anneaux distincts, transparent, à sang incolore : Planćriens.

$2^{\mathrm{e}}$ section. HiRudinés BdElliens. - Les annélides de cette section comprennent la sangsue officinale, et les genres qui s'en rapprochent le plus. Ils ont le corps généralement opaque, composé d'anneaux plus ou moins distincts; la ventouse buccale n'est pas séparée du corps par un étranglement: elle est en forme de bec de flûte et bilabiée; leur sang est rouge, et leurs œufs sont multiples. A. Moquin-Tandon les divise en sept genres, de la manière suivante :

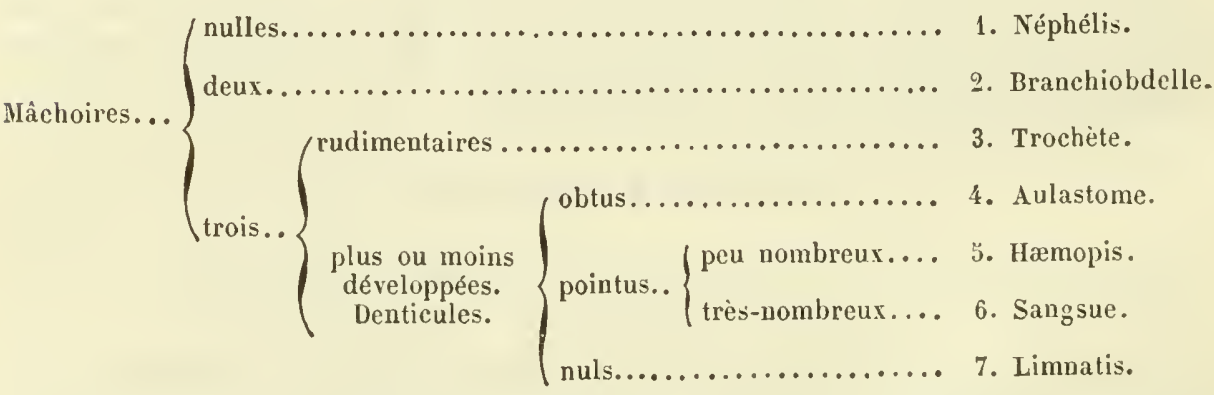

1. Branchiobdelle de l'écrevisse. Cet annélide est le plus petit de tous les hirudinés. On le trouve sur les branchies de l'écrevisse, il marche à la manière des chenilles arpenteuses ;

(1) Moquin-Tandon, Monographie de la famille des Hirudinés. Paris, 1846, 1 vol. in- $8^{\circ}$, avec un atlas de 14 planches coloriées. 
il a le corps un peu transparent. Il construit, pour ses œufs, une capsule pédiculée qu'il fixe aux branchies de l'écrevisse.

2. Néphélis octoculée ou sangsue vulgaire (fg.983). - Hirudo octoculata, Bergm.; - Hirudo vulgaris, Mull. ; - Erpobdella vulgaris, Lam. ; - Nephelis tessulata, Savigny ; - Nephelis vulgaris, Moquin.

Corps allongé, assez déprimé, rétréci graduellement en avant,

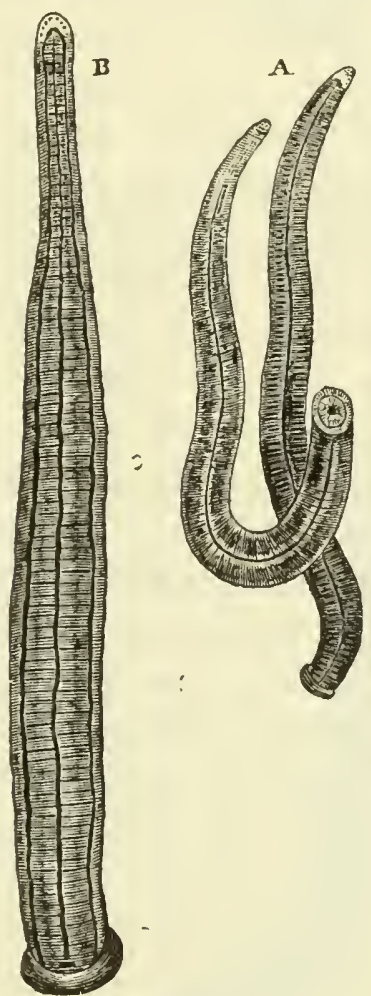

Fig. 983. - Néphélis octoculée $\left({ }^{*}\right)$. composé de 96 à 99 anneaux égaux, très-peu distincts, portant les orifices sexuels entre le $30^{\mathrm{c}}$ et le $32^{\mathrm{e}}$ anneau et entre le $34^{\mathrm{e}}$ et le $3 \check{\jmath}^{\mathrm{e}}$. ces orifices étant situés non sur les anneaux, mais dans leurs intervalles. - Ventouse antérieure peu concave, à lèvre supérieure formée de trois segments. le terminal grand et obtus. - Points oculaires, très-distincts, au nombre de huil, les quatre antérieurs disposés en croissant sur le premier segment, les quatre postérieurs rangés sur les côtés du troisième segment (fig. 984). Dans l'état d'exlension de

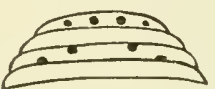

Fig. 984

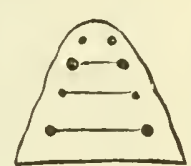

Fig. 985.

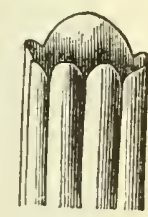

Fig. 986. Points oculaires. Points oculaires. OEsophage.

la lèvre supérieure, la disposition des points oculaires change et devient telle que la représente la figure 983. - Bouche grande, måchoires nulles, œsophage à trois plis (fig. 986). - Estomac tubulaire, droit, sans brides ni poches latérales; intestin et rectum semblables, à peine distincls de l'estomac. - Anus assez grand, semi-lunaire, très-apparent, placé sur le côté dorsal du dernier anneau. - Ventouse anale moyenne, obliquement terminale.

Cet annélide habite l'Europe, dans les fontaines, les ruisseaux et les fossés qui contiennent de l'eau. Il ne peut quitter l'eau sans mourir au bout de quelques minutes. 11 ne se contracte pas

(*) A, d'après Moquin-Tandon, Atlas de la Monographie des hirudinés. - B, la même, d'après l'Atlas du Dictionnaire des sciences naturelles. 
en olive comme les sangsues; mais roule son corps à peu près comme les lombrics. Il ne peut sucer le sang d'aucun animal vertébré, la nature lui ayant refusé les organes propres à entamer la peau. Il se nourrit de planaires, de monocoles et d'animaux infusoires. On en connaît un grand nombre de variétés, distinguées par leurs couleurs. Il est tantôt d'un brun noir et presque opaque, tantôt rougeâtre, couleur de chair, cendré gris, ou verdâtre. Quand la couleur n'est pas trop obscure, on voit, à travers la peau, le vaisseau abdominal et les deux vaisseaux latéranx, ainsi que leurs branches transversales. Il dépose ses capsules depuis le mois de mai jusqu'au mois d'octobre, sur des plantes aquatiques ou sur des corps solides submergés. La manière dont se forment ces capsules est très-singulière. De même que les lombrics, les hirudinés sont endrogynes, mais ont besoin du rapprochement de deux individus pour devenir féconds. Dans les néphélis, particulièrement, l'organe mâle est situé entre le $31^{\mathrm{e}}$ et le $32^{\mathrm{e}}$, anneau, et l'organe femelle entre le $34^{\mathrm{e}}$ et le $35^{\mathrm{e}}$. Au temps de l'amour, celte partie du corps, qui porte le nom de ceinture (1), se gonfle et se couvre d'une matière visqueuse servant à l'adhérence des individus. Deux individus se rapprochent ventre à ventre et en sens inverse, de

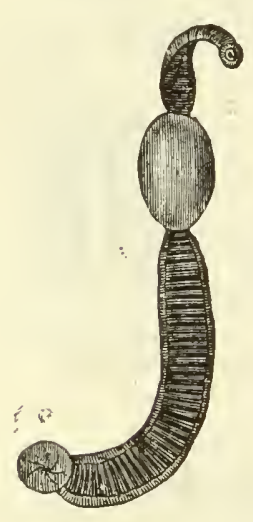

Fig. 987. Ceinture. telle sorte que l'organe mâle antérieur de l'un correspond à l'organe femelle postéricur de l'autre. Après la fécondation, la ceinture se gonfle encore plus en son milieu, se rétrécit à ses extrémités, et exsude, par toute sa surface, une matière visqueuse qui se condense en une capsule ovoïde ( $/ \mathrm{g}$. 987). Lorsque cetie capsule est formée, la sangsue la remplit d'une matière gélatineuse, demi-transparente, dans laquelle aucun germe n'est encore visible; puis elle cherche à s'en séparer. A cet effet, elle se fixe par sa ventouse anale, rétrécit fortement toute la partic de son corps comprise dans la capsule et antérieurement, et en sort à reculons, au moyen des mouvements qu'elle imprime à ses anneaux. Aussitôl qu'elle a quitté la capsule, les deux ouvertures se ferment, et l'on voit à leur place un épaississement brunâtre qui tombera plus tard, comme un opercule, pour laisser sortir les jeunes sangsues.

D’après Moquin-Tandon, chaque néphélis peut produire successivement cinq à huit capsules pareilles; mais je ne puis ad-

(1) La ceinture comprend un plus grand nombre d'anneaux que ceux qui séparent les organes sexuels; dans la néphélis octoculée, la ceinture comprend 15 à 17 anneaux, dont 8 avant l'ouverture de l'organe mâle et 9 après. 
mettre qu'on dise qu'elle les ponde, tant leur formation diffire de la ponce d'un ouf proprement dit.

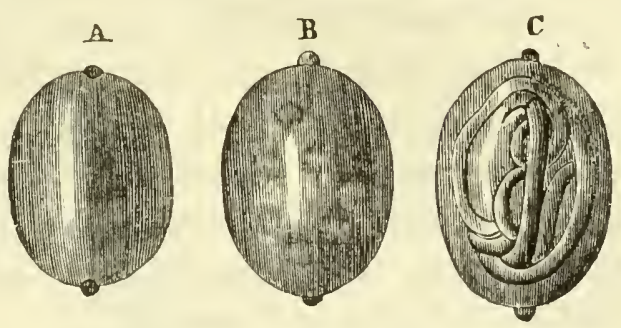

Fig. 988. - OEufs $(*)$.

Les capsules de néphélis sont longues de 4 à 6 millimètres, Ølarges de 3 à 4. Rayer les a représentées comme étant parfaitement

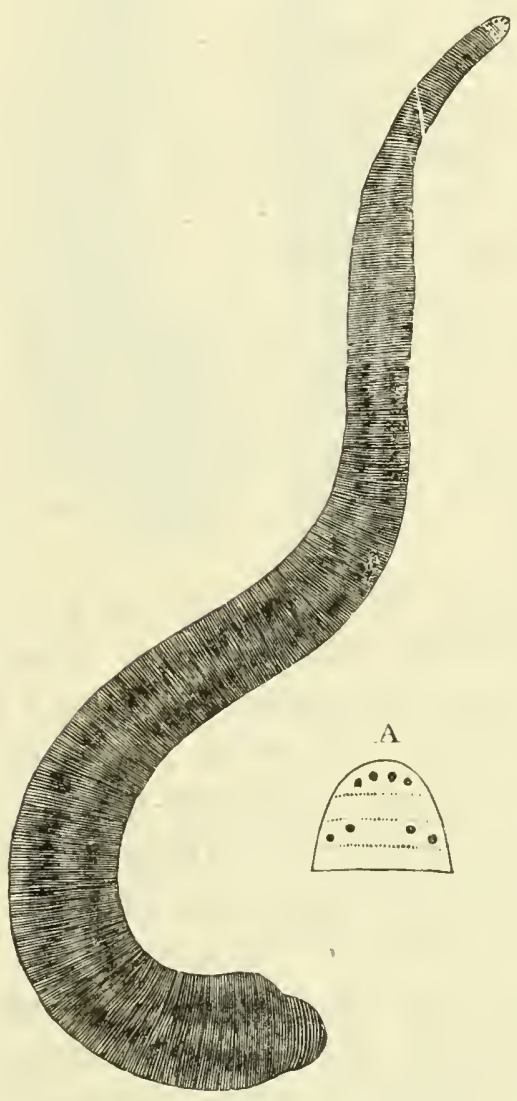

Fig. 989. - Trochète verdàtre.

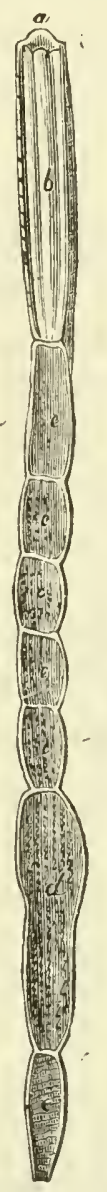

Fig. 990. - Estomac de la trochète verdâtre.

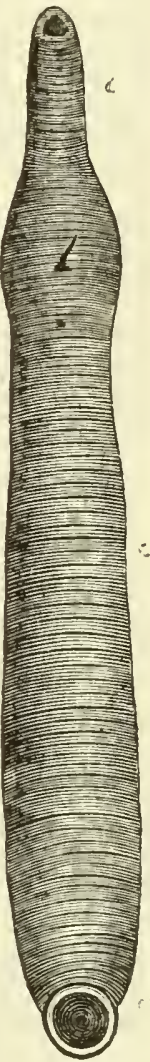

Fig. 991, Trochète verdâtre.

ovoïdes ( $f g .988$ ), el Moquin comme étant aplaties et ayant les bords irréguliers el sinués. L’enveloppe en est transparente, de

(*) A, eapsule de néphélis fortement grossie, dans laquelle les ovules ne sont pas encore visibles. - B, autre capsule dans laquelle trois ovules sont visibles. - C, autre capsule contenant plusieurs petites sangsues déjà développées. 
nature cornée, d'abord assez claire, puis d'une couleur jaune ou roussâtre. Elle est enduite d'une humeur visqueuse qui la fait adhérer aux corps sur lesquels elle a été déposée. Aux deux extrémités du grand diamètre, on voit une petite callosité brune, l'une ronde et déprimée, l'autre saillante et formant quelquefois une sorte de pédicule. On sait que ces capsules avaient d'abord été prises par Linné pour un insecte hémiptère aquatique qn'il avait désigné sous le nom de Coccus aquaticus, et que c'est Bergmann qui lui en a fail connaître l'origine et l'espèce.

3. Trochète verdâtre (Trocheta subviridis, Dutrochet) ( $f \mathrm{~g} .989$ et 983). Corps allongé, déprimé, très-extensible (1), composé de 140 anneaux fort étroits, inégaux, peu distincts, portant les orifices sexuels entre le $32^{\mathrm{e}}$ et le $33^{\mathrm{e}}$ et entre le $37^{\mathrm{e}}$ et le $38^{\mathrm{e}}$ anneau. Ventouse orale très-concave, à lèvre supérieure formée de trois segments, dont le terminal est grand et obtus. - Points oculaires apparents, les quatre antérieurs disposés en croissant sur le premier segment, les quatre autres rangés en lignes transverses, sur les côtés du troisième segment (fig. 989, A). Bouche grande, offrant trois mâchoires très-petites, tranchantes, non édenticulées. - OEsophage oblong, tubulaire, à trois plis. Estomac tubulaire, membraneux, divisé par quatre replis intérieurs, en cinq compartiments placés bout à bout (fig. 990). Intestin dilaté en avant, séparé de l'estomac et du rectum par des replis semblables aux prćcédents. - Anus très-grand et trèsapparent, ouvert sur le dos du dernier anneau. - Ventouse anale moyenne, obliquement terminale.

La trochète verdâtre a le dos d'un gris olivâtre un peu veloulé, avec deux bandes longitudinales noirâtres, peu apparentes, rapprochées de la ligue médiane. Le ventre est un peu plus pâle que le dos, sans bandes ni taches. Il y en a plusieurs variétés dont une brune, une d'un rouge-brun très-vif, et une couleur de chair, toutes trois sans bandes. A l'époque de la reproduction, la ceinture se gonfle beaucoup ( $/$ g. 991), et paraît plus pâle que le reste du corps; elle commence au $23^{\mathrm{e}}$ anneau, et cn comprend 18. La trochète forme ses capsules comme les néphélis et en sort de la même manière. La capsule isolée est d'un brun foncé, assez épaisse, non transparente, pointue aux deux extrémités, longue de 9 à 14 millimètres, large de 6 à 8 .

Les trochètes habitent les rigoles des prairies, les petites sources, et, dans les lieux humides, des canaux souterrains où elles poursuivent les lombrics qu'elles dévorent. Elles sortent également de l'eau pour déposer leurs capsules, comme la

(1) Fortement tendu, il peut acquérir jusqu'à 20 centimètres de longueur. 
plupart des autres genres. Elles sont impropres à la succion.

4. Aulastome vorace, Aulastoma Gula, Moq-Tand. ; - Hirudo Sanguisuga, Muller; - Hirudo vorax, Johns; - Hcomopis nigra,

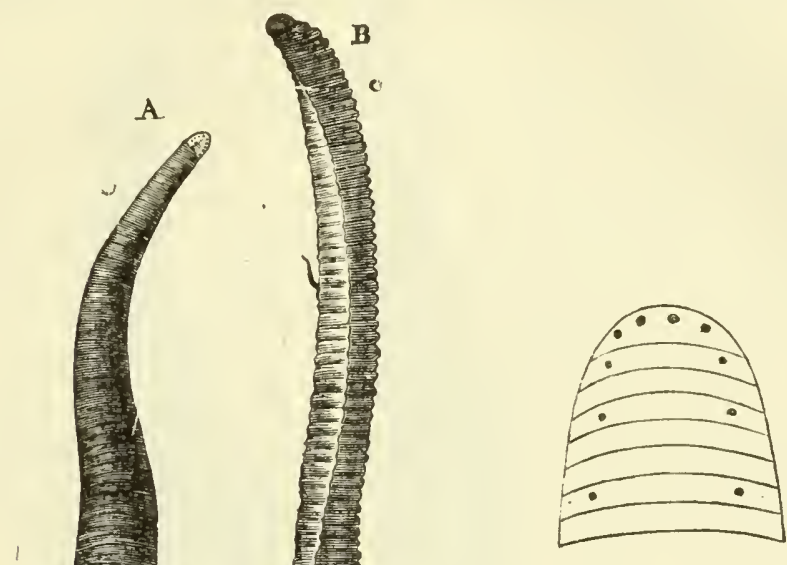

Fig. 993. Points oculaires.

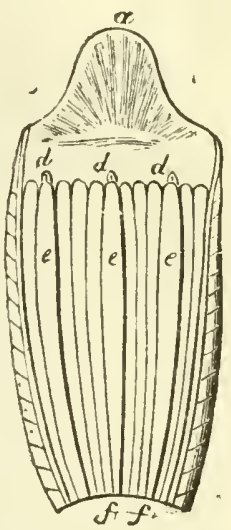

Fig. 994. - Ventouse buccale et œsophage ouverts , très gros$\operatorname{sis}\left({ }^{* *}\right)$.

Fig. 992. - Aulastome vorace (").

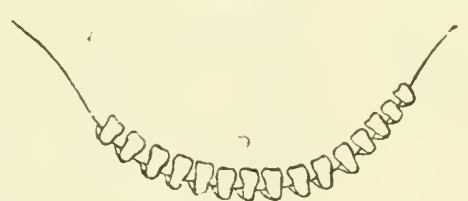

Fig 995. - Mâchoire $\left({ }^{* * *}\right)$.

Sav.; - Pseudobdella nigra, Blainv. ; - Hirudo vorax, Huzard (1). Corps allongé, se contractant difficilement en olive, composé de 9ă anneaux très-distincts et égaux (fig. 992), portant les ori-

(1) Huzarā, Journ. pharm., t. XI, pl. I, fig. 5, 6, 7, 12, et pl. II, fig. 16. La description et l'anatomie de l'hiduro vorax, faites par M. Huzard fils, sont très-exactes; seulement il faut remarquer que le nom de sangsues de cheval faussement donné dans le commerce à cet annélide, est cause que M. Huzard l'a d'abord confondu avec un ou deux autres annélides, qui sont l'Homopis sanguisorba, Sav., et une variété noire de la sangsue médicinale.

(*) A, d'après l'atlas de Moquin-Tandon. - B, d'après l'atlas du Dictionnaire des sciences natu'elles.

$\left(^{* *}\right) a$, lèrre supérieure vue en dessous ; $d, d, d$, mâchoires; $e, e, e$, gros plis œesophagiens placés en arrière des mâchoires; $f, f$, petits plis œesophagiens.

(***) Une mâchoire considérablement grossie, garuie de ses denticules. 
fices sexuels entre le $24^{\mathrm{e}}$ et le $25^{\mathrm{e}}$ anneau, et entre le $29^{\mathrm{e}}$ et le $30^{\mathrm{e}}$. Points oculaires au nombre de 10, disposés, comme dans

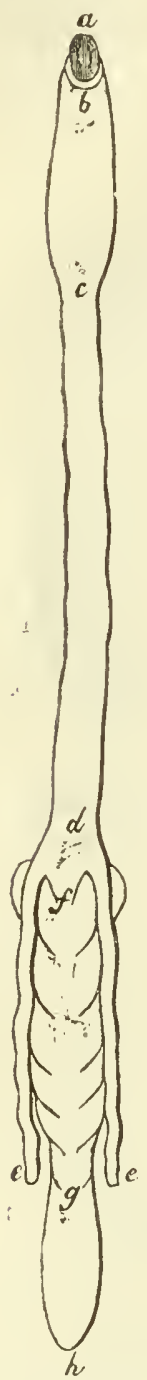

Fig. 990 . OEsophage $\left({ }^{*}\right)$.

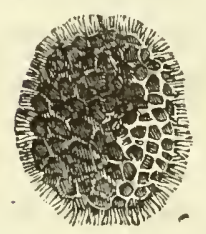

Fig. 997. Cocon. la sangsue officinale, sur une ligne elliptique, les quatre postérieurs plus isolés el plus petits (fig.993). Ventouse antérieure peu concave, à lèvre supérieure avancée en demi-ellipse. Bouche grande, pourvue à la gorge de trois mâchoires égales, très-petites, ovales, non comprimées, à denticules peu nombreux, distincts el émoussés ( $/ \mathrm{g}$. 994 el 99 5ั). - OEsophage en forme de sac oblong ( $/$ ig. 994 et 996), sillonné par douze plis longitudinaux. - Estomac ayant la forme d'un long tube à peine marqué de légers renflements, muni intérieurement de deux appendices très-étroits, en forme de cœcums, et terminé par une sorte d'entonnoir $(f)$ qui s'ouvre dans l'intestin (1). - Anus semi-lunaire, très-apparent. Ventouse anale assez petite, obliquement terminale.

L'aulastome vorace habite dans toute l'Europe et est commune dans les étangs de Gentilly, à la porte de Paris. Elle est d'un brun noir foncé ou d'un noir olivâtre uniforme, velouté, marqué çà et là de quelques points noirs peu apparents. Le ventre est olivâtre, quelquefois cendré ou jaunatre, le plus souvent sans taches, toujours plus clair que le dos. Les ventouses sont très-lisses en dessous, l'antérieure médiocrement grande, très-dilatable. Ventouse anale petite, d'un gris d'ardoise, surtout quand elle se dilate.

Les aulastomes sont demi-terrestres; elles sortent fréutumment de l'eau et vont se cacher sous les pierres qui sont autour des mares et des étangs. Elles aiment beaucoup les lombrics qu'elles avalent tout entiers avec une grande voracité; elles peuvent les prendre par la moitié du corps et les engloutir en une seule fois, les deux moitiés rapprochées, ou bien elles les coupent par morceaux, lorsqu'ils sont trop volumineux. Elles avalent de même les naïs, les larves aquatiques, les petits pois-

(1) Dans les embryons le tube de l'estomac est lobé sur toute sa longueur, et les deux appendices inférieurs sont de véritables poches, comme dans les hamopis et les sangsues.

(*) $a$, orifice de la ventouse buccale; $b c$, œsophage; $c d$, estomac; $e, e$, appendices filiformes de l'estomac; $f g$, intestin; $h$, rectum. 
sons, les néphélis, les trochètes, les sangsues, et meme les in-

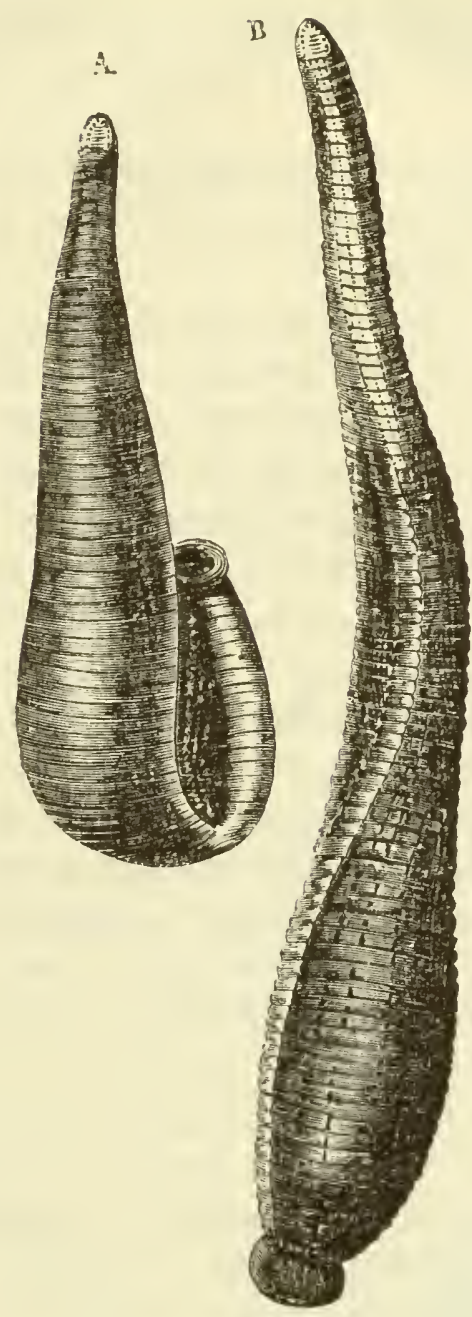

Fig. 998. - Hamopis cheraline $(*)$

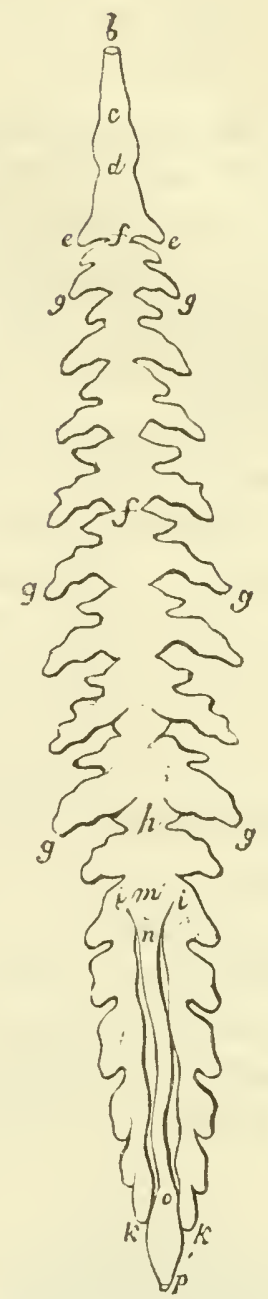

Fig. 999. - Canal digestii de l'Homopis Sanguisugn (**).

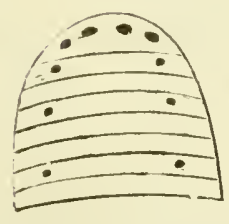

Fig. 1000 . Points oculaire:

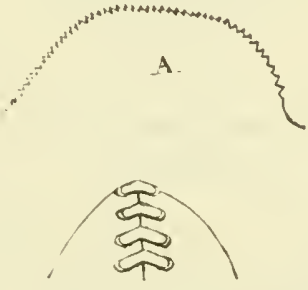

B

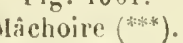

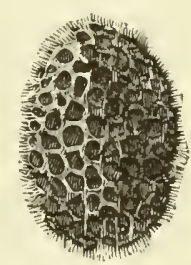

Fig. 1002 . Cocon.

$\left(^{*}\right)$ A, Variété olivâtre. - B, Variété fauve.

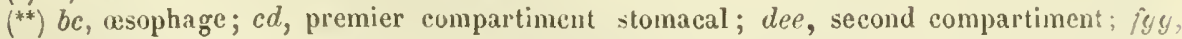
truisième, quatrième...., dixième compartiments; $k k k$, onzième et dernier compartiment $i k$, $i k$, ses deux grandes poches en forme de caeums; $m$, son entonnoir; no, intestin; " $p$. rectumiou cloaque.

${ }^{\left({ }^{* *}\right)}$ A, machoire très-grosse; B, portion de måchoire cousidérablement grossie, présinutant sil carène de plusieurs denticules placés sur elle comme à cheval. 
dividus de leur propre espèce. Elles ne peuvent mordre la peau humaine. Elles déposent dans la terre humide des cocons à tissu spongieux, très-lâche, semblables à ceux des sangsues, mais un peu plus petits ( $/ \mathrm{g}$. 1002).

כ. Hremopis ehevaline, Hcemopis Sanguisuba, Moq. Tand. Hirudo sanguisorba, Lam. - Hermopis sanguisorba, Sav . - Hipjobdella sanguisuga, Blainv. (fig. 998).

Corps allongé, composé de 95 à 97 anneaux égaux, peu distincts, portant entre le $24^{\mathrm{e}}$ et le $2 \mathrm{~J}^{\mathrm{e}}$ l'organe mâle, et entre

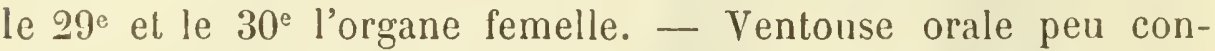
cave, à lèvre supérieure très-avancée, formée de 3 segments. 10 points oculaires disposés sur une ligne elliptique ( $\mathrm{fg} .1000$ ), de la même manière que dans l'aulastome et dans la sangsue officinale. - Bouche grande; 3 mâchoires égales, petites, ovales, non comprimées, à denticules pen aigus (fig. 100). - OEsophage très-court communiquant sans élranglement à la première et à la seconde poche de l'estomac (fig. 999), dont les autres poches sont séparées par des étranglements, et de plus divisées en deux lobes principaux; la dernière poche est très-grande et terminée par deux sacs qui se prolongent jusqu’à l'extrémité du corps; l'intestin est tubulaire el terminé par un rectum court et oroüde. - Anus petit, arrondi, à peine visible. - Ventouse anale assez grande, obliquement terminale.

L'hæmopis chevaline a le dos roussâtre ou olivâtre, avec ou sans rangées de petites taches noirâtres; les jords sont à peine saillants, avec une bande étroite orangée, jaunâtre ou brune rougeâtre, rarement de la couleur du dos; le ventre est d'un noir d’ardoise ordinairement plus foncé que le dos (1). Ventouses lisses. l'antérieure peu grande, l'anale de moitié plus grande que l'antre, mince el de la couleur du ventre. A l'époque de la reproduction, la ceinture est assez marquée; elle commence au $23^{\circ}$ anneau et finit au $37^{\mathrm{e}}$ ou $3 \mathcal{E}^{\mathrm{e}}$. Les cocons sont ovoïdes, plus petits et plus courts que ceux de la sangsue médicinale (fig. 1002).

L'hæmopis chevaline habite les eaux vives de l'Europe, principalement en Espagne et en Porlugal. Elle est très-abondante aussi sur tout le littoral de l'Afrique. Elle suce le sang des vertébrés; mais, ne pouvant attaquer que leurs membranes muqueuses,

(1) On en connait un certain nombre de variétés, dont une fuuve, a le dos avec six lignes longitudinales interrompues, on formées de petites taches noirâtres, les bords orangés et le ventre gris foncé (fig. 995, B); une autré olicâtre, ayant le dos et le ventre vert-olive, sans aucune tache et les bords jaunâtres (fig. 998, $\boldsymbol{A}$ ); une autre noire, ayant le dos noir olirâtre, unicolore; les bords semblables et le ventre un peu plus foncé; une quatrième très-noire dont le dos est très-noir, unicolore, les bords à peine plus clairs et le ventre olivàtr's foncé; ; etc. 
elle s'introduit dans le pharynx et les fosses nasales des chevaux, des bœufs, des chameaux, de l'homme même, et les tourmente cruellement. Elle est longue de 8 à 10 centimètres et large de 10 à 15 millimètres.

6. Sangsue médicinale, Hirudo medicinalis, L. Le corps d'une sangsue médicinale, dans un état d'extension moyenne, est allongé, plus convexe du côlé du dos que de celui du ventre, qui est déprimé ou un peu aplati; il s'atténue sensiblement en avant et beaucoup moins en arrière où il est arrondi : il en résulte que sa plus grande épaisseur est vers le tiers ou le quart postérieur; mais il peut devenir presque linéaire par une grande extension, de même qu'il prend la forme d'unc olive ou d'une amande, dans sa plus grande contraction. La facilité avec laquelle la sangsue médicinale prend cette forme, surtout quand on la comprime modérément en tous sens, dans le creux de la main, est à la fois un caractère spécifique propre à la faire reconnaître et un indice de bonne santé.

Le corps d'une sangsue est composé de 95 anneaux égaux, bien distincts, saillants sur le côté. L'extrémité supérieure est terminée en une pointe obtuse, et présente, du côté de la face ventrale, un orifice ovale et oblique, dit ventouse buccale, couvert supérieurement par trois segments ou anneaux incomplets (non compris dans le nombre des anneaux du corps), qui en constituent la lèvre supéricure; tandis que la lèvre inférieure est formée par le premier

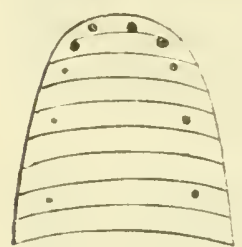

Fig. 1003 . Points oculaires.

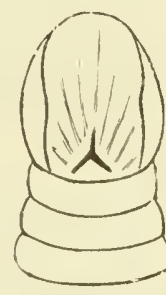

Fig. 100 '. Ventouse.

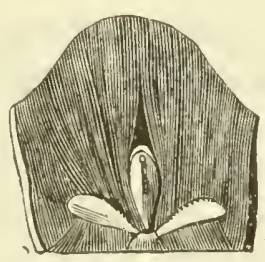

Fig. 100 s.

Ventouse buccale onverte pour montrey les trois mâchoires.

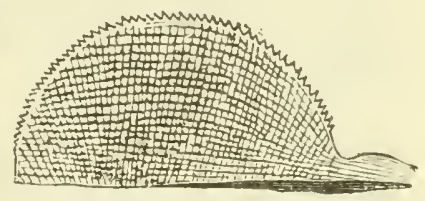

Fig. 1006.

Coupe longitudinale d'une mâchoire jsolée, considérablement grossie, montrant les denticules fui la courounent.

anneau complet du corps, sans qu'il y ait aucun étranglement marqué au-dessous. Les points oculaires sont au nombre de dix, dont six rapprochés sur le premier segment de la lèvre supérieure, deux sur le troisième segment et deux sur le troisième anneau : les quatre points postérieurs sont plus petits que les autres ( $f \mathrm{~g}$. 1003). Le fond de la ventouse présente trois petites fentes disposées en étoile ( $\mathrm{fg} .1004)$, au fond desquelles se trouvent trois màchoires égales, grandes, bombées, dont le sommet est hérissé de 
denticules très-nombreux et très-aigus (/ig. 100ミ̆ et 1006). Le tube digestif sera décrit plus tard. L'organe mâle est situé entre le $24^{\circ}$ et le $2 \partial^{e}$ anneau, l'organe femelle entre le 29 et le $30^{\circ}$. L'anus est très-petit et à peine visible. La ventouse anale est moyenne, obliquement terminale.

L'utilité incontestable des sangsues, pour le traitement d'un grand nombre de maladies; la grande consommation qu'on en fait toujours, malgré l'abandon presque complet de la doctrine dite physiologique; leur prix élevé, enfin la nécessité pour le pharmacien de ne rien ignurer d'important dans ce qui regarde lat vie, les fonctions, les maladies, la reproduction et la conservation de ces précieux annélides, m'engage à les considérer ici sous ces divers points de vue. Ce que je vais en dire sera tiré en partie de l'excellente monographie qu'en a publiée Moquin-Tandon (1).

Système cutané. La peau des sangsues est molle, extensible dans toutes ses parties et adhérente aux couches musculaires sur lesquelles elle repose; elle se compose de trois parties, qui sont: l'épiderme, le pigment et le derme.

L'épiderme est mince, lisse, transparent, blanchâtre et unicolore. Il se renouvelle à des intervalles de temps très-rapprochés, s'il faut en juger par le nombre et la fréquence des dépouilles que l'on trouve dans l'eau où l'on conserve les sangsues en captivité. Ces dépouilles ont été prises, par la plupart des auteur's, pour des mucosités exsudées du corps des sangsues, et qui leur causaient une grande mortalité en corrompant l'eau; mais j'ai montré que ces prétendues mucosités étaient l'épiderme même de l'annélide, sur lequel on observe très-facilement l'impression de ses anneaux (2).

"Cet épiderme se détache d’abord de l'extrémité antérieure, et la sangsue en sort comme d'un fourreau, en le repoussant peu it pen vers l'autre extrémité. Souvent même celte enveloppe forme anneau au milieu du corps de la sangsue et paraît l'étrangler. Cet épiderme, détaché de tout le corps, adhère encore quelque temps à l'extrémité postéricure; la sangsue le traîne avec elle en nageant, et paraît éprouver un vif sentiment de douleur, lorsqu'on l'en détache brusquement. Ainsi celte mucosité qui nage dans l'eau, au lieu d'être le produit d'une exsudation morbide des sangsues, est le résultat d'une fonction inhérente à leur constitution. Seulement il est probable que cette fonction ne s'accomplit pas aussi farilement dans les conditions ou nous plaçons les sangsues que dans l'état de nature, et que plusieurs y succombent. Déjà plusieurs pharmaciens, sans s'être rendu compte

(1) Morquin-Tandon, Monographie de la famille des hirudinées. Paris, 18:ti, avec atlas de 14 planches gravées et coloriées.

(2) Guibourt, Journal de climie médicule, 183\%, p. 611. Antérieurement, cependant, Carena avait fait la même observation. 
de la nature de ces débris, mais pensant qu'il importail aux sangsues d'en être débarrassées, ont proposé de mettre dans l'eaı de la mousse, du sable de rivière, ou différents corps durs, dont le frottement en ficilitât la séparation. "

Le pigment est situé sous l'épiderme; il est traversé probablement par les extrémités nerveuses qui viennent s'épanouir à sa surface, car il possède une sensibilité très-vive; examiné au microscope, il paraît formé d'un lissu granuleux peu épais et dirersement coloré. Dans la sangsue médicinale, sa couleur est toujours plus foncée sur le dos que du côlé du ventre.

Le derme est la partie la plus épaisse de l'enveloppe cutanée; il recoit des ramifications nerveuses, ainsi que de petits vaisseaux sanguins dont une grande partie le traversent pour aller former une sorte de réseau à sa surface; à des intervalles égaux, le derme s'amincit, devient peu apparent, et présente comme des interruptions circulaires très-étroites. Ces solutions de continuité imparfaites, recouvertes seulement par l'épiderme, facilitent beaucoup les mouvements de l'annélide et en forment les articulations. l.espace compris entre ces interruptions en constitue au contraire les anneaux.

Cryptes mucipares. On trouve dans le derme une infinité de trèspetites cellules folliculaires, formant à l'extérieur de petites Éminences disposées par bandes circulaires, avec plus ou moins le régularité. Selon la volonté de l'animal, ces petites éminences paraissent un moment d'une manière très-sensible, et bientôt après elles s'aplatissent et ne sont plus appréciables. Ces petites cellules intérieures, auxquelles on donne le nom de cryptes, s'ouvrent à l'extérieur par un pore véritablement microscopique, desliné à donner issue à l'humeur visqueuse et transparente, qui luIrifie toute la surface de la peau. Mais, indépendamment de ces cryptes, il existe, sur les deux côtés du ventre, des glandes beaucoup plus volumineuses et plus compliquées, qui ont élé prises, tantòt pour une dépendance des organes spermatiques, tantôt pour des organes respiratoires, mais qui paraissent en réalité ne sécréter qu'un liquide muqueux plus clair et plus aqueux que celui des cryples mucipares; aussi leur donne-t-on le nom de glandes de la mucosité. Ces glandes sont au nombre de 34 (17 de chaque côté du corps), situées au-dessous des couches musculaires el entre les poches de l'estomac (1). Leur partie la plus profonde consiste en une ou deux anses plus ou moins sinueuses, communiquant par un conduit avec une poche arrondie située immédiatement sous le derme; celle poche s'ouvre à son tour,

(1) Voir la figure $1008, r r r$. 
à l'extérieur, par une petite ouverture, et toutes ces ouvertures sont régulièrement éloignées les unes des autres, d'un intervalle de こ̌ anneaux.

Muscles. Immédiatement au-dessous de la peau, se trouvent trois couches musculaires placées l'une au-dessous de l'autre. La première couche (muscles circuluires) est composée de fibres circulaires, réunies au nombre de 5 ou 6 par anneau : elle parait être une dépendance de la peau. La seconde couche (muscles diagonaux) est composée de deux plans de faisceaux de fibres obliques, qui forment par leur entre-croisement une sorte de grillage régulier. La troisième couche (muscles longitudinaux) est composée de fibres longitudinales, parallèles et fasciculécs, unies entre elles par un mince tissu cellulaire, et qui s'étendent d'une extrémité à l'autre de l'animal. On remarque en outre, en dedans du plan formé par les fibres longitudinales, des fibres transverses qui nées du côté du dos, par une partie élargie, se portent vers la ligne ventrale, en formant des brides qui séparent et supportent les sinus de l'estomac.

A l'extrémilé antérieure du corps, les deux plans de fibres, diagonales et longitudinales, semblent se confondre, et il en résulte un tissu contractile, non distinct du derme, et

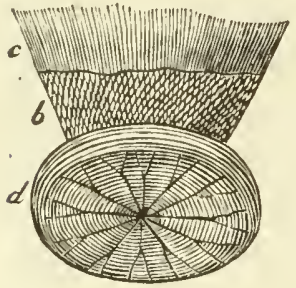

Fjg. 1007. - IIuscles. qui constitue les deux lèvres ou les bords de l'ouverture antérieure, susceptibles de prendre toutes les formes,

A l'extrémité postérieure, il y a aussi une sorte de confusion des deux plans de fibres musculaires, mais elles prennent une nouvelle disposition. En effet, les fibres longitudinales, rapprochées à cause de l'absence des viscères, partent d'un point central pour s'irradier à la circonférence du disque; tandis que les fibres diagonales, devenues tout à fait circulaires, forment le disque lui-même, dont toutes les parties peuvent s'appliquer exactement et sans aucun vide à la surface des corps étrangers (fig. 1007).

Système nerveux. Le système nerveux de la sangsue est, à peu de chose près, ce qu'il est dans les lombrics et dans les entomozoaires. Placé sur la ligne médiane abdominale, dans le tissu cellulaire qui sépare l'intestin de la couche musculaire sous-cutanée, il est composé d'un certain nombre de ganglions placés à la file, et fournissant, outre le double cordon de communication en avant et en arrière des uns avec les autres, des filets transverses pour l'enveloppe extérieure. Ces ganglions sont au nombre de 21 ou 2?, non compris un grand ganglion cesophagien contenu dans la lèvre inférieure, ayant la forme d'un anneau qui entoure 
le commencement de l'œsophage, et paraissant formé de quatre ganglions réunis, dont deux postérieurs et un peu supérieurs dits sus-csophagıens, et deux antérieurs et cun peu inférieurs dits souscesophagiens. Ces deux derniers réunis, ayant la forme d'un très-gros ganglion un peu échancré cn avant, sont accolés postérieurement à un troisième renflement arrondi, qui doit être considéré comme le premier ganglion de la chaîne médullaire (Moquin-Tandon). Chacun des ganglions suivants est de forme lo. sangique, les deux angles antérieur et postérieur fournissant le double cordon qui continue le système nerveux d'une extrémité à l'autre, et les deux angles latéraux donnant naissance aux filets qui vont se distribuer aux diverses parties du corps. Tous ces ganglions diminuent progressivement de grosseur, au point de finir par être peu apparents; le dernier, seul, qui fournit des filets au disque postérieur, est sensiblement plus volumineux que ceux qui le précèdent (Voy. fig. 1002).

Sensibilité, sens du toucher. La peau des sangsues jouit d'une vive sensibilité : au moindre attouchement, l'animal se contracte; le plus léger frottement avec la barbe d'une plume fait roidir les cryptes granuleux du derme, et l'animal paraît tout couvert de tubercules; l'acide le plus faible, le vinaigre affaibli,

(*) $a$, ventouse buccale; $b$, premier ganglion de la chaîne médullaire; eee, ganglions intermédiaires; $d$, ganglion anal; fff, chaîne médullaire; ggg, nerfs qui partent des ganglions ; $i$, asophage; $k k, k k$, compartiments de l'estomac; $m$, dernier compartiment; $m n$, $m n$, ses grandes poches en forme de coecuns; $p p$, intestin; $q$, rectum ou cloaque; rrr, poches de la nucosité; $s$, bourse de la verge; $x$, fourreau de la verge; $z$, verge; $t$, un épididyme; AAA, A. cordons spermatiques; BHB, testicules; D, matrice; EE, ovaires ; $w$, vulve, d'après Mloquin-Tandon, Atlas.

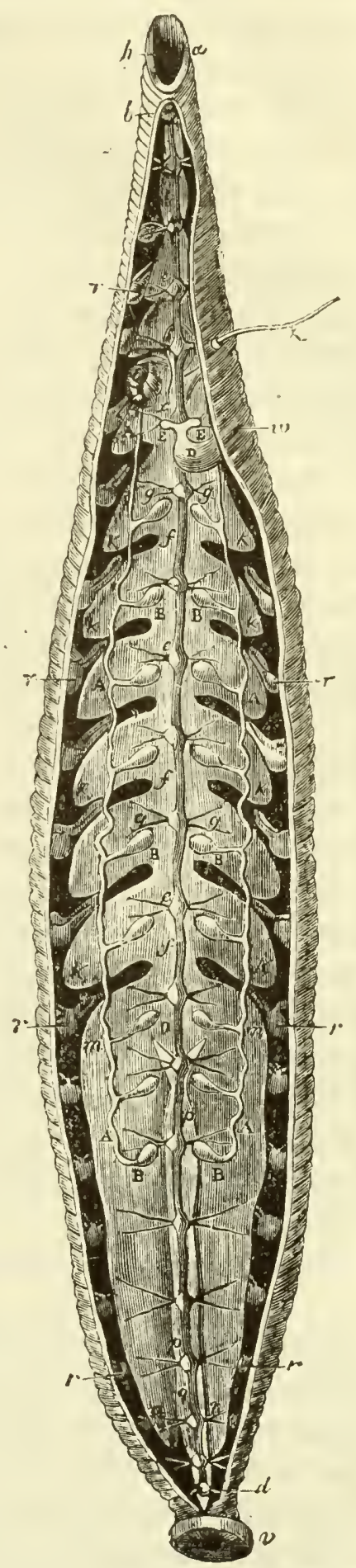

Fig. 1008. - Anatomie de la sangsue médicinale; individu de très-forte taille, conché sur le dos et ouvert $\left({ }^{*}\right)$. 
l'eau salée, leur occasionnent des impressions très-vives, attestées par des mouvements énergiques et subits; quelque peu de nitrate d'argent dissous dans l'eau, dont la présence serait à peine :oupçonnée par notre langue, détermine chez les sangsues la plus riclente agitation.

Plusieurs auteurs, qui se sont spécialement occupés de l'histoire naturelle des sangsues, n'ont admis dans ces annélides d'intre sens du toucher que celui qui vient d'être décrit, lequel, n'étant que l'effet de la sensibilité du système cutané, est un sens purement passif, ou une sorte d'irritabilité dont aucun animal n'est dépourvu. Mais il est un autre toucher, un toucher explorateur, qui consiste dans la faculté de diriger, par un acte de la volonté, un organe spécial vers les objets extérieurs, dans la vue de les reconnaître ou de les saisir; tels sont la main de l'homme, la trompe de l'éléphant, les tentacules des mollusques, etc. Lit même faculté existe dans les sangsues, dont l'organe explorateur est la lèvre supérieure. En effet, cel organe leur sert de palpe, pour reconnaître les nouveaux lieux où elles se trouvent, les individus de leur espèce qui les avoisinent, la peau des animaux qu'elles peuvent attaquer et l'endroit le plus propice pour y mordre. Cet organe supplée, chez les sangsues, à l'absence ou à l'imperfection des autres sens.

SeNS de L'ouïe, de L'odorat et du goùt. L'anatomie la plus délicate n’ayant fait découvrir aucun organe qui pût remplir la fonction de l'ouĩe, on est d'accord pour refuser aux sangsues la faculté de percevoir les sons. On a cru remarquer cependint que ces annélides prenaient la fuite lorsqu'un bruit d'une certaine intensité se produisail dans leur voisinage; mais rien n'empêche de croire que l'ébranlement de l'air et de l'eau suffise pour les avertir qu'un danger peut les menacer. Le sens de l'ouie, ainsi considéré, ne serait qu'une modification du toucher ou de la sensibilité générale dont le siége se trouve sur la surface cutanée.

On ne connaît de même aux sangsues aucun organe spécial pour le sens de l'odorat, et il est très-probable qu'elles en sont privées. Quelques expériences, qui ont montré que les sangsues pouvaient vivre sans inconvénient dans un air chargé des émana tions du musc, du castoréum, de l'ail et de l'assa-fœtida, tandis que la vapeur de l'acide chlorhydrique ou de l'ammoniaque les tue, ne prouvent en aucune façon qu'elles soient pourvues de la fitculté de distinguer les odeurs (1).

(1) On a remarqué cependant que les sangsues ont de la répugnance ì piquep, chez l'homme malade, les régions qui ont été couvertes par des emplàtres odorants, et que les sangsues d'un étang se dirigent de tous les côtés rers. 
Nous admettons plus facilement que les sangsues aient le sens du goût, parce qu'il nous semble que cette faculté doit appartenir à lous les animaux pourvus d'organes d'appréhension ou de succion, pour leurs aliments. La membrane qui tapisse l'intérieur de la bouche nous paraît d'ailleurs très-appropriée à la perceplion des saveurs. Ce qui démontre, du reste, que les hirudinés possèdent, en général, le sens du goût, c'est leur préférence marquée pour tel ou tel aliment: les glossiphonies recherchent le sang des mollusques fluviatiles; la piscicole, celui des poissons d'ear douce; les pombdelles, celui des poissons de mer; une autre attaque de préférence la torpille; celle-là, les cyprins, etc. La sangsue médicinale, posée sur la peau de l'homme qui vient d'expirer, s'arrête le plus souvent sur le point dè mordre, ou bien commence à sucer, mais se détache bientôt de la blessure, jugeant sans doute que le sang ne peut plus lui convenir (1).

Sens de la vue. La sangsue médicinale porte sur la lèvre supérieure, et sur les anneaux qui en sont le plus rapprochés, dix points noirs disposés en fer à cheval, qui sont considérés comme des yeux rudimentaires. De Blainville, n'ayant pu y découvrir, au microscope, ni vaisseaux ni nerfs, a pensé qu'ils étaient impropres à la vision.

C.ependant M. Charpenlier (2) a remarqué que les sangsues évitent la lumière, surtout lorsqu'elle est vive, et qu'elles recherchent les endroits les plus obscurs. Lorsque le soleil donne, elles s'abritent derrière tous les objets propres à donner de l'ombre, ou se creusent des trous dans la terre, et s'y tiemnent cachées pendan l'ardeur du jour. Au contraire, pendant la nuit ou le matin, quand il fait frais, on les voit en grand nombre sortir de leurs trous; mais elles y rentrent précipitamment lorsqu'on s'approche du bassin. Comment expliquer ces faits si les sangsues élaient privées de la vue?

SuivantThomas, si l'on présente une chandelle allumée devant un vase rempli de sangsues livrées au repos ou au sommeil, à peine ont-elles ressenti l'influence de la lumière qu'elles se détachent du vase, et s'agitent en tous sens.

11. D'usaux a fait une autre expérience : il a entouré de papier noir un bocal contenant des sangsues, à l'exception d'un seul point par où la lumière pénétrait. Toutes sont venues se fixer autour de l'ouverture, et y sont retournées après en avoir été dé-

les jambes d'une personne qui vient d'entrer dans l'eau. On attribue ces faits et quelques autres au sens de l'odorat, et l'on suppose que la peau elle-même, les cryptes cutanés ou la lèrre supérieure, peuvent être le siége de l'olfaction.

(1) Vitet, Traité de la sangsue médicinale. Paris, 1809, in-8.

(2) Charpentier, Monographie des sangsues médicinales et officinales. Paris, 1838 . 
tachées. M. Dusaux a pensé que les sangsues étaient attirées par la lumière, et il en a conclu qu'elles voyaient. M. Dusaux supposait donc aux sangsues une tendance pour la lumière opposée à ce que pensait $\mathbf{M}$. Charpentier, mais il en tirait la même conséquence. J'ai montré que le résultat obtenu par M. Dusaux était conforme à ceux observés par M. Charpentier, parce que, dans une chambre éclairée par une seule petite ouverture, la partie la plus obscure est évidemment la paroi même où se trouve placée l'ouverture. Seulement la tendance qu'ont les sansgues à fuir la lumière qui les fatigue est un phénomène du même genre, en sens inverse à celui qui porte la plupart des êtres organisés, et notamment les végétaux, à se diriger vers elle, qui les vivifie sans que la présence ou l'absence des yeux y soit pour rien. J'ai fait d'ailleurs une expérience qui, favorable d'abord, en apparence, au sens de la vue chez les sangsues, a fini par montrer qu'elles en sont dépourvues.

"Un bocal contenant des sangsues se trouvait placé le soir dans une pièce peu éclairéc, elles se tenaient presque toutes dans un repos parfait, la ventouse buccale attachée à la paroi supérieure du vase, la partie inférieure du corps plongée dans l'eau. En approchant une lumière très-près du groupe immobile, toujours, au bout d'une minute environ, on voyait les sangsues détacher leur ventouse supérieure et s'éloigner de l'endroit éclairé (c'est l'expérience de Thomas). En plaçant ensuite une carte, servant d'écran, devant la moitié supérieure de la sangsue, et en n'éclairant que la partie postérieure, l'animal restait en repos. En faisant l'inverse, toujours, au bout d'une minute, l'extrémité supérieure se détachait; mais, en éloignant la lumière à la distance de 10 à 12 centimètres, l'effet n'avait plus lieu. C'était la chaleur communiquée au verre par la proximité de la flamme qui avait agi sur les sangsues. J'en ai acquis la preuve en éloignant la lumière de 7 décimètres à un mètre, et en réunissant les rayons lumineux seuls sur l'extrémité supérieure de la sangsue, à l'aide d'une large lentille : bien que, de cette manière, les points prétendus oculaires fussent plongés dans une vive lumière, les sangsues y furent toutes successivement insensibles. "

[On a observé cependant aboutissant à chacun des yeux de la sangsue un filet nerveux émanant directement du cerveau. Il est bien difficile d'admettre que des points oculaires ainsi organisés ne servent pas à la vision.]

Système circulatoire. Les sangsues n'ont pas de cœur proprement dit: leur système circulatoire se compose principalement de quatre troncs longitudinaux qui vont d'une extrémité àl'autre; l'un ventral et un autre dorsal, séparés par le tube digestif, et deux autres latéraux. Il présente de plus des vaisseaux courts et 
des branches spéciales, fournis par les quatre troncs principaux, et qui produisent des rameaux, des ramuscules et des anastomoses.

Les anatomistes ne se sont pas accordés sur la désignation parliculière de ces vaisseaux : les uns ont considéré la vaisseau dorsal comme une veine, el les deux vaisseaux latéraux comme des artères. Cuvier, de Blainville et Brandt, ont adopté l'opinion contraire, et regardent le vaisseau dorsal comme une artère, et les autres comme des veines. De Blainville pense que le sang, puisé par les radicules veineuses dans toutes les parties du corps, doit passer dans les troncs latéraux pour se porter de là dans le vaisseau dorsal, d'où ensuite, par ses ramifications, il est dirigé vers tous les points du corps. D'autres conçoivent la circulation d'une manière différente; mais tous regardent comme une preuve qu'elle existe les pulsations lentes et régulières que l'on peut observer, même à l'œil nu, dans les quatre gros vaisseaux (1). Cette circulation continue lorsque la sangsue est coupée en deux tronçons, état sous lequel elle peut vivre assez longtemps, mais sans pouvoir régénérer la partie manquante.

Le sang des sangsues est d'une couleur rouge, et présente au microscope des globules d'une extrême petitesse $(0,0004$ de millimètre). D'après M. Derheims, il contient une quantité à peine appréciable de fibrine et plus de matière colorante que le sang des mammifères.

Respiration. Un assez grand nombre d'auteurs ont regardé les glandes muqueuses placées sur les côtés de la face ventrale et le long des deux gros vaisseaux latéraux comme des organes respiratoires analogues aux trachées des insectes; mais on s'accorde à penser aujourd'hui que la respiration a lieu à travers la peau, sur toute la surface du corps.

Il est prouvé d'ailleurs quc les sangsues ont besoin, pour vivre, de la présence de l'oxygène. Thomas (2), ayant mis un certain nombre de ces annélides sous l'eau, dans un vase qui contenait à sa partie supérieure un certain volume d'air, reconnut, au bout de deux jours, que le volume de cet air était diminué, et qu'il était devenu impropre à la combustion. On remarque aussi que les sangsues retenues captives dans un vase plein d'eau restent volontiers au fond de ce liquide lorsqu'il vient d'être renouvelé et qu'il est pourvu de toute la quantité d'oxygène qu'il contient habituellement, mais qu'elles se tiennent en très-grande partie hors de l'eau lorsque cet oxygène a été absorbé par la respiration

(1) Ces pulsations sont au nombre de 8 à 10 par minute.

(2) Thomas, Mémoire pour servir à l'histoire naturelle des sungsues. Paris, 1806. 
ou par la décomposition putride de leurs excrétions (1). On sait enfin que les sangsues meurent en très-grande quantité, étant tenues en captivité dans l'eau, dans les temps orageux; ce que j'ai toujours attribué à la putréfaction immédiate des substances animales qu'elles répandent dans l'eau, et à la suppression complète de l'oxygène qui en est la suite.

Quelque indispensable que soit l'oxygène à la respiration des sangsues, on conçoit cependant que, dans des animaux aussi imparfaits, cette fonction puisse être momentanément suspendue sans leur causer un dommage considérable. Thomas rapporte avoir conservé pendant deux jours des sangsues plongées dans du gaz azote, de l'hydrogène ou de l'acide carbonique; mais ce qui est plus singulier, c'est que la sangsue médicinale puisse vivre plus d'un jour sous la cloche d'une machine pneumatique. Elle s'y meut comme à l'air libre, fixe tour à tour son disque et sa lèvre supérieure sur les parois de la cloche, et peut même, d'après Thomas, y sucer le sang des animaux(2).

Système digestif. Les organes digestifs des sangsues s'étendent, sans aucune circonvolution, depuis la ventouse antérieure jusqu'à l'anus, qui est situé sur la face dorsale du dernier anneau, tout près du disque postérieur. On y comple la bouche, l'œsophage, l'estomac, l'intestin el l'anus.

L'ouverture de la bouche se confond avec la ventouse antérieure qui est formée, ainsi que nous l'avons déjà dit, d’une lèvre supérieure oblongue, obtuse à l'extremité, à trois segments on anneaux complets, et d'une lèvre inférieure constituée par le premier anneau complet du corps. La paroi interne de cette

(1) Parce que ces substances en fermentation dans l'eau absorbent l'air qui $y$ était contenu, et privent par lì ces animaux d'un principe qui leur était nécessaire (Vauquelin, in G. Rochette, Essai médical sur les sangsues. Parí, 1803, p. 18).

(2) J'ai tenu, une fois, pendant vingt-quatre heures, quatre sangsues sous le l'écipient d'une machine pneumatique : deux étaient placées sans eau, dans un petit vase de terre; les deux autres étaient $m$ ises daus un vase contenant de l'eau préalablement bouillie. Les quatre sangsues ont paru souffrir de cette opération, mais elles l'ont supportée et elles ont vécu ensuite comme si elles 11'y avaient pas été soumises. Une des sangsues placées dans l'air a rendu de lair par la bouche pendant le jeu des pompes. Les deux sangsues placées sous l'eau n'ont rendu aucune bulle d'air, ni par leurs ouvertures naturelles, ni par la surface du corps, ce qui m'a paru montrer que ni les vésicules nuqueuses, ni les cryptes du derme ne peuvent être considérées comme des organes pulmonaires. Mais ces deux sangsues, qui étaient suspendues par leur disque postérieur, la tête en bas, et qui ont conservé tout le temps la même position, unt offert, dans la partie la plus élevé du dos et dans un endroit répondant à l'extrénité d'un des cuecums, une bosse considérable qui était due à la dila. tation d'un gaz intérieur; car elle a disparu immédiatement par la rentrée de l'uir dans la cloche. Cette expérience me parait montrel' que les sangsues peuvent renfermer de l'air dans leur canal intestinal. 
ventouse est légèrement sillonnée (fig. 1012). Tout au fond, se trouvent trois plis longitudinaux qui, à l'état de repos, ont leurs bords rapprochés et cachent les mâchoires. Mais lorsque la sangsue veut mordre, ces plis s'effacent et laissent paraître les máchoires, qui sont égales, rapprochées par leurs extrémités

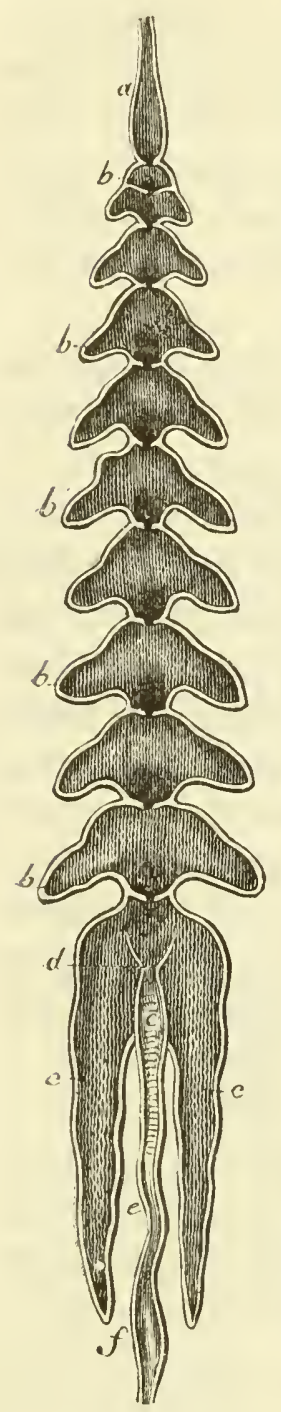

Fig. 1009.

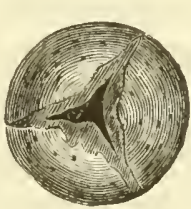

Fig. 1010 . Ventouse.

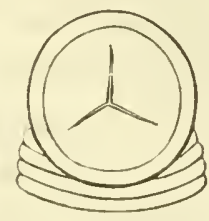

Fig. 1011. Ventouse.

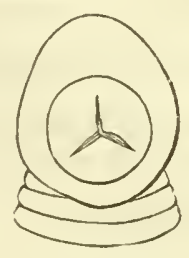

Fig. 1012 . Ventouse.

Fig. 1013. - Portion du corps d'une sangsue ou se trouvent le: organes générateurs $(*)$.

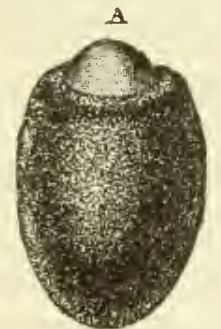

Fig. 101.1. - Cucon de la sangsue médicinali.
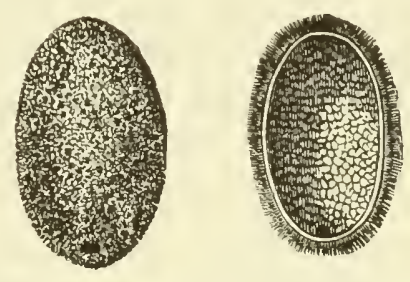
)Esophage buceal.

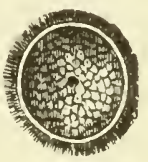

postérieures, très-divergentes par devant, comme trois rayons partant d'un même point; leur bord, convexe et tranchant, présente une rangée de soixante denticules environ (fig. 1005, 1006), qui, vues perpendiculairement, par un très-fort grossissement, ressemblent à des équerres placées comme à cheval sur le borl tranchant la mâchoire.

L'oesophage commence immédiatement après les mâchoires:

(*) $a$, orifice mâle; $b$, verge; $c$, orifice femclle. 
( $(f g .1008, a)$; il est petit, resserré et membraneux, pourvu de quelques rides longitudinales peu marquées. L’estomac, qui vient après, est composé de onze chambres séparées par des diaphragmes presque entiers, et munies, à commencer par la seconde, de deux poches latérales $(b, b, b)$ moins sinueuses que celles des hæmopis. Dans l'état de plénitude, ces poches s'appuient les unes sur les autres. La dernière chambre présente une partie moyenne $(d)$, en forme d'entonnoir, qui communique avec le commencement de l'intestin, et deux poches latérales $(c, c$, en forme de cœcums, qui se prolongent presque jusqu’à l'extrémité de la sangsue. L'intestin $(e, e)$ a la forme d'un tube sinueux, qui se continue avec le rectum $(f)$ et aboutit à l'anus.

Succion, déglutition, digestion. Dans l'état de repos, lorsqu'une sangsue tient sa ventouse buccale appliquée contre une surface plane, cette ventouse présente un cercle parfait (fig. 1010), du centre duquel partent trois lignes rayonnantes formant entre elles trois angles de 120 degrés, et répondant à l'entrée des plis dans lesquels sont cahées les mâchoires. Mais si les mouvements du corps étranger, la chaleur, le toucher ou l'odorat, éveillent dans la sangsue le sentiment de la faim, on la voit allonger la partie antérieure du corps, donner à sa ventouse la forme d'une lance émoussée à l'extrémité (fig. 1011) et palper la surface dn corps qui excite sa convoitise, afin de choisir l'endroit où il lui convient le mieux de pratiquer sa triple morsure. Le choix fait, la sangsue applique sa ventouse, en l'arrondissant un peu ( $/ \mathrm{g}$. 1.006), opère un mouvement de succion qui donne à la partie de la peau circonscrite par les lèvres, et forcée de suivre le mouvement, la forme d'un mamelon, écarte les plis du pharynx, dresse ses mâchoires, et, les faisant jouer à la manière de trois scies, parvient à faire trois incisions linéaires, convergeant en un centre commun (fig. 1012). Dès lors, le sang afflue dans l'œsophage, d'où, par des mouvernents ondulatoires, alternatifs et régulier's, la sangsue le fait passer dans son estomac; elle ne s'arrête que lorsqu'elle en a épuisé la source; et si c'est sur l'homme qu'elle agit el quon lui laisse toute liberté, elle ne lâche prise ordinairement que lorsqu'elle a rempli de sang tous les compartiments de son estomac. Alors elle tombe dans une sorte de torpeur, et meurt quelquefois de cet excès de réplétion (1). Les sangsues, dans cet état, meurent même presque toujour's, lorsqu'elles sont réunies en grand nombre dans une petite masse d'eau, qui se corrompt

(1) Voici le résultat d'expériences faites par M. Alphonse Sanson, pour déterminer la quantité de sang que peurent prendre les sangsues médicinales.

Dans le commerce, on distingue, d’après leur grosseur, ces annélides en cinq catégories, dont on fixe ainsi le poids : 
par le sang qu'elles y répandent; mais, rendues à la liberté, dans des marais naturels, elles dégorgent, si cela leur est nécessaire, une partie du sang qu'elles ont pris, et en digèrent le reste lentement, dans un espace de temps qui paraît s'étendre de six à douze mois.

REPRoduction. Les sangsues sont hermaphrodites, ou plutôl androgynes, c'est-à-dire qu'elles sont pourvues des deux sexes, mais que le concours de deux individus est nécessaire à la fécondation, l'organe mâle de l'un s'unissant à l'organe femelle de l'autre, el réciproquement. Ces organes s'ouvrent au dehors, assez près de l'extrémité antérieure, dans un renflement particulier analogue à celui qu'on voit chez les lombrics; mais ce renflement n’apparaît dans les sangsues qu’à l'époque de la reproduction.

Vers cetle époque, on voit souvent sortir par l'orifice de l'organe mâle, situé à la partie inférieure du vingl-quatrième anneau, un corps filiforme, très-extensible et blanchâtre, qui n'est autre chose que la verge $(f \mathrm{~g}$. 1011). A l'intérieur, cet organe est renfermé dans un fourreau qui, après être descendu, en se rapprochant de l'axe du corps (fig. 980, $m$ ), se recourbe ver's le haut et se termine par une bourse pyriforme placée vis-à-vis du cin-

POIDS

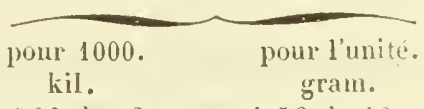

\begin{tabular}{|c|c|c|c|}
\hline igsues & vaches & 4,500 à 12 & 4,58 à \\
\hline & grosses, ou de $1^{\text {er }}$ choix....... & $2,500 i$ & 2,50 a \\
\hline & grosses moyennes, ou de $2^{e}$ choix & 1,125 à & 1,12 à \\
\hline & petites moyennes, ou de $3^{\mathrm{e}}$ choix & 0,625 a & 0,62 \\
\hline & filet $\ldots \ldots \ldots \ldots \ldots \ldots \ldots$ & 0,450 & 45 \\
\hline
\end{tabular}

Les sangsues vaches étant peu actires et rejetées du service médical, M. Sanson a pris dix sangsues de chacune des autres sortes, et en a déterminé le poids arant et après leur avoir laissé librement sucer le sang des malades :

10 SAygSUES.

Grosses.........

Grosses moyennes.

Petites moyennes.

Filet.............

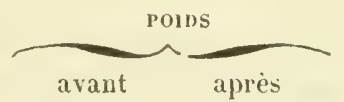

la succion. la succion. gram. gram. $30 \quad 190$ 12,50 i 5

\begin{tabular}{|c|c|c|}
\hline \multicolumn{2}{|c|}{ SAXG } & du sang \\
\hline 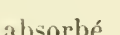 & pour & de \\
\hline De. & I sangsue. & la sang-ue. \\
\hline $\begin{array}{l}\text { gram } \\
160\end{array}$ & $\begin{array}{l}\text { gram. } \\
16\end{array}$ & 533 \\
\hline 83,50 & 8,35 & 6,95 \\
\hline $3: 3$ & 3,30 & $4, i 0$ \\
\hline 19 & 1,90 & 3,80 \\
\hline
\end{tabular}

11 est essentiel qu'un médecin connaisse ces résultats, afin de pouvoir apprécier, d'après le nombre et la qualité des sangsues demandées ou fournies, la quantité de sang qu'elles doivent tirer. Il faut tenir compte d'ailleurs du sang qui coule après la chute des sangrues, et dont on facilite le plus sourent l'écoulement par l'application de cataplasmes. La quantité en est très-variable; on estime qu'elle égale, en moyenne, le sang dont les sangsues se sont gorgées. 
quième ganglion ventral, et qui a été comparée à la prostate. A droite et à gauche de cet organe, que Moquin-Tandon nomme bourse de la verge, on observe deux corps ovoüdes d'un blanc assez mat, marqués de dépressions et d'anfractuosités $(t)$, que l'on considère aujourd'hui comme des épididymes; à la partie postérieure de ceux-ci, sont deux cordons spermatiques, sous forme de canaux filiformes (AAA,AA), sinueux et très-déliés, qui descendent jusqu'aux deux tiers du corps, et qui portent du côté intérieur, à une distance régulière de cinq en cinq anneaux, de petites poches pédiculées (B, B, B), que l'on regarde comme des testicules.

L'organe femelle est beaucoup moins étendu et moins compliqué. L'ouverture extérieure, ou la vulve $(w)$, est située entre le vingt-neuvième el le trentième anneau. A l'intérieur, cet orifice communique avec un canal très-court (vagin), qui se termine par un renflement assez considérable (D), qui est la matrice. A l'autre extrémité, cet organe porte un conduit dirigé vers le haut et par'tagé ensuite en deux rameaux, dont chacun porte un ovaire (E, E):

Dans l'accouplement, deux individus se rapprochent, ventre contre ventre et en sens inverse, de telle sorte que la verge de l'un rencontre la vulve de l'autre. L'accouplement dure plus de trois heures, pendant lesquelles ces annélides demeurent dans: un repos absolu. On suppose que le temps de la gestation est de trente à quarante jours, et c'est ordinairement dans les mois de juillet et d'aoûl qu'on peut en observer les produits; mais on en trouve également dans d'autres saisons.

M. Le Noble, médecin de Versailles, qui le premier nous a fail connaître les cocons de la sangsue médicinale, raconte que, au mois de novembre 1820, 2,000 sangsues ayant été mises dans un réservoir disposé à cet effet, sur la fin du printemps et au commencement de l'été suivant, on commença d'y apercevoir le jeunes sangsues accolées au dos et au ventre des anciennes et nageant avec elles, et, que, dans le courant d'acût, on remarquia des trous, à parois très-lisses, pratiqués dans l'argile dont on avait garni les côtés du réserơoir, et qu’on trouva dans chacun d'eux un cocon de forme ovoïde et du volume d'un petit cocon de ver à soie. A celte meme époque, M. Collin de Plancy fit connaître qu'en Bretagne, les paysans repeuplenl leurs réservoirs de sangsues, en y déposant des cocons qu'ils vont chercher, dans les mois d'avril et de mai, dans la vase des marais fangeux. M. Charpentier, pharmacien à Valenciennes, a récolté ces mêmes cocons sur les bords de ses réservoirs, vers la fin de mois de juillet, et surtout dans le mois d'août.

Chacun des cocons de la sangsue médicinale ( $f g$. 1014) représente un ovoïde dont le plus grand diamètre varie de 11 à 28 mil- 
limètres, et le plus petit de 11 à 18 . On y distingue : $\mathbf{1}^{\circ}$ une enveloppe extérieure fauve, d'apparence spongieuse, épaisse de 3 à 4 millimètres, de manière à former des espèces de prismes creux, tiès-perméables à l'air et à l'eau ; $2^{\circ}$ une capsule blanchâtre, formée d'un tissu mince, mais dense et assez résistant, offrant, à chaque extrémité du grand diamètre, une petite saillie brune, par l'une desquelles la capsule devria s'ouvrir pour livrer passage aux petites sangsues. Les deux enveloppes paraissent être de même nature et se rapprocher beaucoup de la composition du mucus animal.

La plupart des observateurs, qui ont suivi le développement des cocons de sangsues, s'accordent à dire que l'enveloppe spongieuse est d'une formation postérieure à celíe de la capsule membraneuse, qui serait d'abord formée ou même pondue par l'annélide; car plusieurs ont cru que celle capsule sortait toute formée de la vulve de l'animal. Mais il n'est pas probable que les choses se passent ainsi, d'après M. Charpentier' (1).

"Quand la sangste ra former son cocon, elle commence par préparer une substance qui ressemble it de la glaire d'œuf battu, et qui doil se convertir en tissu spongieux et entourer la capsule. Cette substance s'échappe sans doute par les parlies générales (2) ì l'état de mucus, et est convertie en mousse écumeuse au fur et à mesure qu'elle sort. Tant que dure l'opération, l'animal a constamment la tête penchée vers les parlies génitales.

"Cette opération terminée, la capsule se forme arec un mélange de mucus et d'albumine qui est sans doute aussi secrété, à l'élat liquide, par les organes générateurs. Les premières portions s'infillrent et se répandent tout autour dans la mousse extérieure, et la convertissent en tissu spongieux; le reste sert à former la capsule. Celle-ci recourre tout l'espace occupé par la ceinture, et la sangsue en est enveloppée, comme d'un corselet.

"Le tissu spongieux et la capsule étant formés, la sangsue remplit celle-ci de la pulpe gélatineuse qui contient les germes encore imperceptibles des êtres qui en sorliront. Alors, au moyen de la contraction el de l'extension successive de ses anneaux, elle se débarrasse de son cocon et en sort à reculons, la tête la dernière. Au même moment les deux bouts de la coque se ferment à la manière d'une bourse à cordons ; mais non hermétiquement. Il y reste toujours une ouverture d'un millimètre environ, que l'on peut reconnaître à l'aide d'une épingle."

(1) Charpentier, Monographie des sangsues méllicinales. Paris, $18: 38$.

(2) D’après Wedecke, cité par $\Lambda$. Moquin-Tandon, la mousse écuneuse soltirait de la bouche et serait déposée sur la capsule après sa formation, ce qui expliquerait pourquoi Rayer a vu des capsules de sangsue qui n'en étaient pas entièrement recouvertes. Telle est celle représentée fig. 986, A.

Guibourt, Drogues, 7 e édit.

T. IV. -20 
Les sangsues, pour fabriquer et déposer leurs cocons, se retirent dans des trous qu'elles pratiquent elles-mêmes dans la berge des ruisseaux ou des étangs, ou dans d'anciennes galeries de taupes ou de rats, où l'on trouve quelquefois plus de trente co. cons réunis. Suivant M. Charpentier, c'est dans les premiers jours du mois d'août, c'est-à-dire trente à quarante jours après la formation des cocons, que l'on voit sortir les premières petites sangsues; de sorte que, à partir de l'accouplement, qui a lieu vers la fin de mai ou dans les premiers jours de juin, il s'est écoulé environ soixante-dix jours. Le nombre des sangsues produit par chaque cocon varie considérablement; on en trouve depuis trois jusqu'à vingt-quatre; la moyenne paraît être de onze à douze. Les jeunes sangsues, au moment de l'éclosion, sont longues de 2 centimètres, filiformes, transparentes, d'une conleur un peu cendrée ou rougeâtre : les yeux se distinguent très-bien sur la ventouse orale. Au bout de quelques jours paraissent les bandes colorées du dos, et peu à peu elles prennent la livrée qui les caractérise.

VARIÉTÉS DE L'ESPÈcE. La sangsue médicinale présente un trèsgrand nombre de variétés qui résultent d'une coloration différente de son pigment et de la disposition des lignes ou des taches que l'on observe-sur le dos ou sur le ventre. Quelques-unes de ces variétés ont été élevées au rang d'espèces par plusieurs naturalistes; mais elles paraissent se mélanger toutes indistinctement, pour la fécondation; elles fournissent alors des variétés intermédiaires de plus en plus difficiles à déterminer.

1. Sangsue médicinale grise (Hurido medicinalis grisea, fig. 1015). Dos olivâtre, plus ou moins gris et plus ou moins foncé, avec quatre bandes bien distinctes, deux de chaque côlé, outre une bande plus latérale encore, bordée de noir ou de brun; ventre vert foncé, tout maculé de noir. On en rencontre un grand nombre de sous-variélés quui diffèrent par leur's lignes continues ou interrompues, sans taches ou marquées de taches noirâtres ( $/ \mathrm{g} .1007$ a 1020). Ces sangsues habitent la plus grande partie de l'Europe, et principalement la France, l'Allemagne et la Hongrie. Elles sont les plus estimées de toutes.

2. Sangsue médicinale verte (Hirudo medicinalis viridis). Fond d'un vert plus ou moins clair, avec six bandes de couleur trèsvariable, quelquefois décomposées en taches assez régulières. Ventre vert jaunâtre, bordé par une ligne noire, sans aucune tache intermédiaire (fig. 1016 à 1023).

3. Sangsue médicinale noire (Hirudo medicinalis nigrescens). Dos noirâtre ou olivâtre noir, présentant des bandes réduites à 
des mouchetures noires et brunes à peine visibles (1), ou des bandes noires interrompues par des taches plus claires, en forme

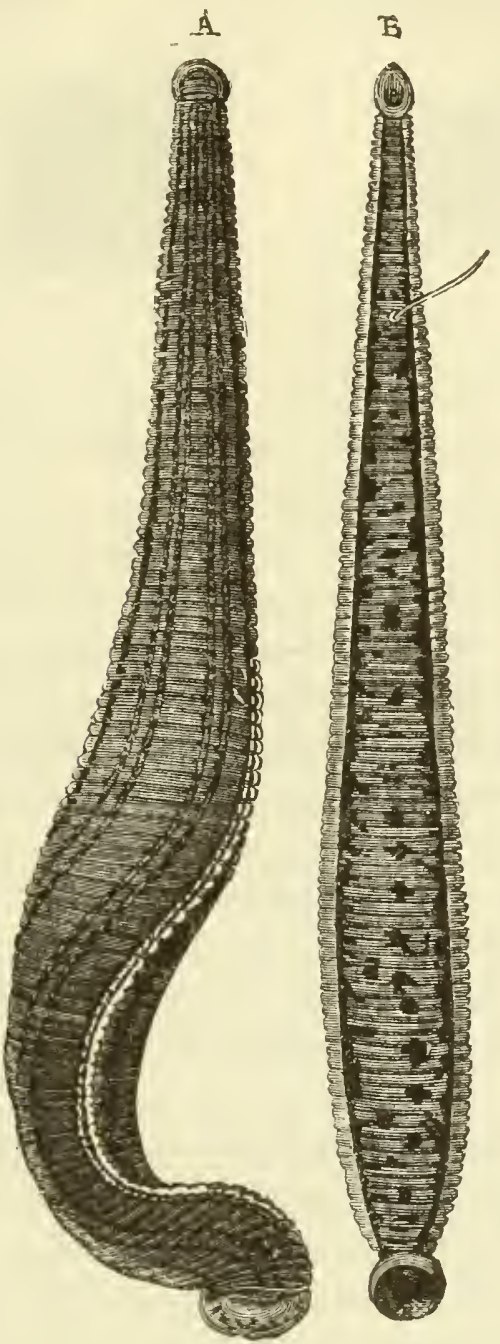

Fig. 1015. - Sangsue médicinale grise $\left({ }^{*}\right)$.
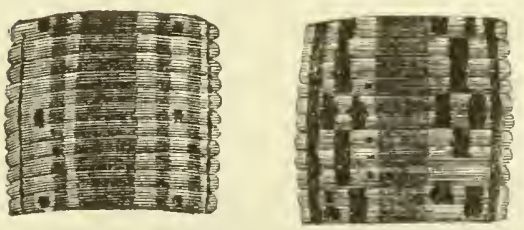

Fig. 1017 et 1018 . - Troncons de variété de sangsue médicinale, vus par le dos.

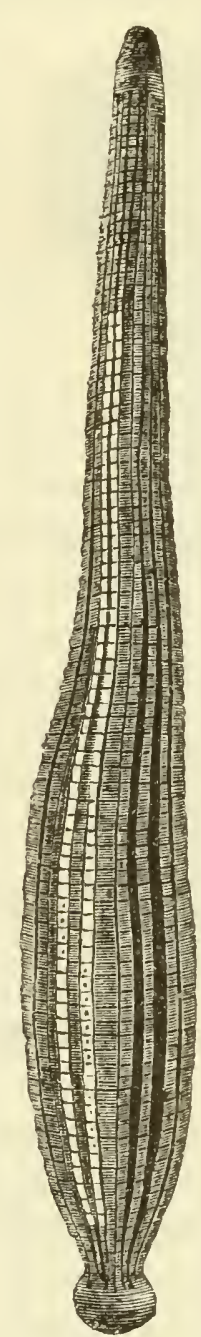

Fig. 1016. - Sangsue médicinale verte.
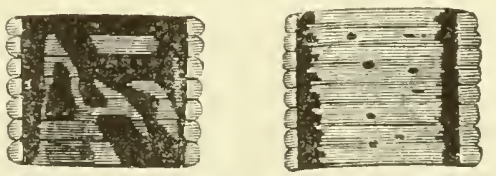

Fig. 1019 et 1C20. - Troncons de variété de sangsue médicinale, vus par le rentre.

de croissant (Moquin-Tandon, pl. VII, fig. 19). Le ventre est d'un vert-noir très-foncé, sans taches. Cette variété de sangsue est

(1) Huzard, Jour. de pharm., t. XI, pl. II, fig. 15. - Moquin-Tandon, pl. VII, fig. 18.

(*) A, vue par le dos; $-B$, vue par le rentre. 
très-aclive et attaque fréquemment; dans les ma rais, les jambes des bœufs el des chevaux. Il est très-facile de la confondre avec l'hæmopis noire et l'aulastome vorace, dont on ne la distingue
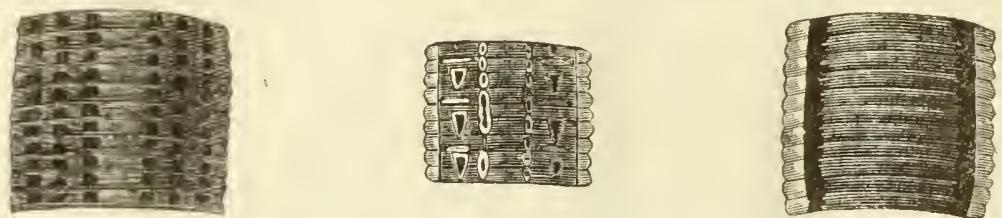

Fig. 1021, 1021 et 1023. - Sangsuc médicinale verte.

guère que parce que celles-ci ne se contractent pas en olive, n'offrent aucun indice de bandes dorsales et ne montrent aucune aptitude pour mordre la peau de l'homme.

4. Sangsue médicinale jaune (Hirudo medicinalis flava). Dos olivâtre plus ou moins jaune; rentre d'un jaune très-pâle et verdâtre. On en connaît deux sous-variétés : l'une, nommée Hirudo chlorogastra, a des bandes dorsales roussâtres très-apparentes; l'autre (Hirudo chlorina) a les bandes dorsales presque nulles, et le ventre et le dos également d'un jaune verdâtre pâle (NoquinTandon) (1).

ร. Sangsue médicinale fauve ou blanchâtre. Dos couleur de chair, ou mieux, d'un fiuve un peu rosé et très-pâle, n'offrant ni bandes ni taches, ou présentant quelques taches linéaires disposées en séries longitudinales (Moquin-Tandon) (2). Ventre trèspâle.

6. Sangsue médicinale fauve (Moquin -Tandon) (3). Dos fauve, marqué de six bandes longitudinales de couleur brunâtre, quelquefois simples; d'autres fois les bandes les plus latérales comprennent entre elles une série de taches oblongues, de même couleur. Ventre pâle, quelquefois un peu verdâtre, sans taches.

7. Sangsue médicinale obseure. Dos brun, tantôt clair et rosé avec de larges lignes brunes, tantôt plus foncé et obscur, avec des bandes composées de mouchetures noirâtres, disposées en séries longitudinales.

8. Sangsue médicinale truitée, ou marquetée (Hirudo medicinalis tessellata, Blainv.; - Hirudo troctina ou interrupta, MoquinTandon). Dos d'un beau vert ou quelquefois sali par une teinte roussâtre; bandes remplacées par des taches isolées, arrondies ou carrées, placées de cinq en cinq anneaux. Ces taches sont roires avec un bord orangé, ou orangées avec un bord noir; quelquefois celles du milieu sont toutes jaunes, et les intermé-

(1) Moquin-Tandon, pl. VII, fig. 16 et $1 \%$.

(2) Id., pl. VlII, fig. 1 et 2.

(3) Id., pl. VHII, fig. 3 et 4 . 
diaires tout à fait noires (fig. 1018), elc. Les bords sont d'un jaune orangé ou d'un roussâtre brillant. Le ventre est verdâtre, ou gris jaunâtre, rarement roussâtre, tantôt immaculé, tanlôt marqué de larges taches noires; ses bords sont ornés d'une bande longitudinale disposée en zigzag.

Moquin-Tandon forme de cette sangsue une espèce particulière. Elle est employée depuis longtemps en Angleterre et dans les hôpitaux de Paris. M. Huzard, qui l'a décrite le premier, la croyait originaire d'A mérique; mais elle vient de l'Algérie et de toute la Barbarie. On lui donne dans le commerce le nom de sangsue dragon; on la regarde comme médiocre pour l'usage médical.

9. Sangsue de Verbano (Hirudo verbana, Car.). Corps déprimé ; dos d'un vert sombre avec des bandes brunes transverses, nombreuses, terminées par une tache ferrugineuse, dont la réunion constitue de chaque côté une ligne longitudinale interrompue. Ventre vert, peu ou pas tachelé.

Cette sangsue se trouve sur les bords du lac Majeur et dans les environs de Nice. Elle est employée en médecine.

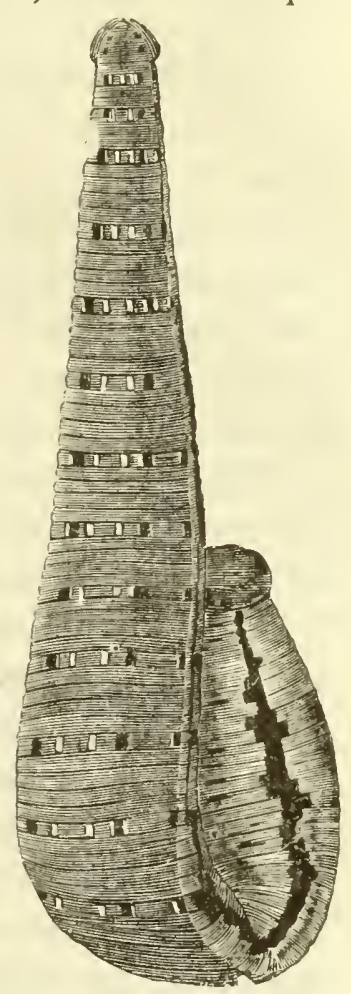

Fig. 1024. - Sangsue midicinale truitée, ou marquetée.

\section{Sangsue du Sénégal (Hirudo mysome-} las). Corps plus aplati que celui de la sangsue médicinale; dos d'un vert olivâtre, ou d'un noir jaunâtre, avec trois bandes longitudinales jaunâtres, bordées de noir; bords jaunes; ventre jaune avec des taches noires irrégulières; bouche et ventouse anale noires. Points oculaires peu apparents.

On regarde celle sangsue comme une espèce distincte; elle ne prend guère que la moitié du sang que sucerait la sangsue médicinale. On trouve d'autres espèces de sangsues dans les eaux de l'Amérique septentrionale, en Chine, au Japon, à Ceylan, etc.

[On a récemment apporté à Londres l'Hirudo quinque-striata, Schmarda, sangsue d'Australie, marquée sur un fond jaune de כ̆ lignes dorsales d'un vert foncé. Mais l'expérience a montré que cette espèce était beaucoup moins utile que nos sangsues ordinair ( (1).]

Commerae des sangsues. Il y a soixante ans, le prix des sangsues variant de 1 วั à 60 francs le mille, la France en produisait une

(1) Voyez Plarmaceutical Journal and Transactions, $2^{\mathrm{e}}$ série, XI, 36. 
quantité plus que suffisante pour sa consommation; le superflu passait à l'étranger. Mais, bientôt après, la consommation dépassa tellement la production, que la France fut obligée d'en faire venir de Belgique, d'Espagne, d'Italie, de Bohême et d'A frique.En 1835, époque à laquelle les renseignements suivants m'ont été fournis par Gallois, qui élait alors le premier de nos négociants en sangsues, bien que le prix des sangsues se fût élevé de 150 à 250 francs ie mille, la pêche active avait cessé en France, excepté dans l'ancienne Bretagne et dans la Sologne qui fournissaient encore une petite quantilé de sangsues au commerce. Partout ailleurs la peche était purement locale, et son produit n'atteignait pas les besoins de la population.

L'Espagne était également épuisée; la Toscane en fournissait encore, mais d'une qualité inférieure; la Boheme ne nous en envoyait plus : les marais de la Hongrie eux-mêmes commençaient à être dégarnis, et la maison Gallois, dont les vastes réservoirs étaient établis aux Vertus, près de Paris, et qui avait une succursale à Palota, près de Pesth, en Hongrie, était obligée de tirer ses sangsues des frontières de la Russie et de la Turquie. Les sangsues qui arrivaient de ces contrées étaient rassemblées d'abord dans des réservoirs établis à Palota, et y restaient jusqu'aux demandes transmises de Paris. Alors on les pêchait dans les réservoirs; on les renfermait dans des sacs de toile qui en contenaient de 25 à 30 kilogrammes; on rangeait ces sacs les uns à côté des autres sur des hamacs superposés, placés dans une voiture de la forme d'une tapissière, et la poste les transporlait jusqu'à Paris, en douze ou quinze jours de temps.

Jamais cependant les sangsues n'arrivaient directement à Paris : dans les temps chauds et orageux, on était obligé de les rafraîchir deux fois pendant la route, et on le faisait toujours au moins une fois. A cet effel, on avait établi à Kehl de grands baquets dans lesquels on en plaçait de plus petits. Les uns et les autres étant remplis d'eau, c'est dans les petits baquets que l'on vidait les sacs. Toules les sangsues saines s'échappaient des petits baquets et tombaient dans les grands; toutes celles qui restaient au fond des. baquets intérieurs étaient mises de côté comme ne pouvant supporter le reste du voyage. On lavait les sacs, on les remplissait de. nouveau et on les transporlait aux Vertus, où était fondé le principal établissement de Gallois.

Là les sangsues étaient distribuées dans de grands réservoirs à eau courante, dont les bords étaient plantés de roseaux. Elles y séjournaient ordinairement pendant un mois; mais, à l'époque où je les ai visitées, les demandes excédant les arrivages, elles étaient repêchées après cinq ou six jours de repos seulement, ce 
qui nuisait à leur qualité, beaucoup étant encore malades par suite de la fatigue du voyage.

Je me suis informé auprès de Gallois si les sangsues se reproduisaient dans ses réservoirs; si elles s'y nourrissaient et s'y développaient; enfin s'il tirait parti de leur reproduction. $11 \mathrm{~m}$ 'a répondu que très-rarement il avait aperçu de jeunes sangsues que l'on pouvait croire nées dans son établissement; que ces petites sangsues meltaient au moins huit ans pour parvenir à l'état adulte; que cependant il ne pouvait pas dire que ce fûl là la vraie durée de leur croissance, parce que les sangsues adultes, apporlées du dehors, au lieu de se nourrir et d'augmenter dans ses réservoirs, y maigrissaient et y perdaient de leur poids. Enfin, il m'a dit que, quant à lui, il jugeait impossible de compter sur la reproduction et la nourriture des sangsues, dans des réservoirs artificiels, pour servir aux besoins du commerce ; parce que les frais d'entretien et de nourriture, jusqu'au moment où les sangsues seraient propres à l'usage médical, l'emporteraient de beaucoup sur le prix de celles qui sont apportées de l'étranger (1).

Depuis que ces renseignements m'ont été donnés, et malgré une diminution considérable dans le nombre des sangsues employées (2), l'épuisement des marais, en Europe, n'a cessé d'augmenter; les pêcheries de la Hongrie, de la Bosnie, de la Valachie et du bas Danube sont devenues de jour en jour plus insuffisantes, et maintenant c'est la Turquie d'Europe et l'Asie Mineure, la Russie méridionale, la Géorgie, l'Arménie, qui fournissent la plus forte partie des sangsues du commerce. Ces sangsues sont expédiées par les bateaux du Levant, principalernent à Trieste el à Marseille, qui reçoit en outre les sangsues d'Afrique.

(1) Extrait d'un rapport sur une lettre de M. Fleury, fait à l'Académie de médecine, le 29 septembre 1835.

(2) D'après les tableaux d'importation publiés par l'administration, il serait entré en France, approximativement :

En 1827, 33,635,000 sangsues.

$1829,44,581,000$

$1831,36,444,000$

$1832,57,\{01,030$

$1833,41,654,000$

$1835,22,560,000$

$1837,25,768,000$

$1839,22,411,000$
En 1841, 17,479,700 sang'sues.

$1843,17,6 \notin 8,000$

184 , $15,225,000$

$1845,13,8 \div 3,500$

$1846,12,721,500$ -

$1847,11,790,800$

$1448,9,685,600-$

$1849,11,109,000$ -

Il est curieux de remarquer l'énorme différence qui a eu lieu dans la consommation des sangsues en 1832 et 1819 . Est-on mort du choléra plus en 1832 qu'en 1849? en est-on mort moins? Je laisse à de plus habiles à le décider.Voyez (hevallier, Note sur le commerce des sangsues (Annales d'hygiène, 1845, t. XXXIV, p. 41). - Soubeiran, Rapport sur le commerce des sangsues (Bulletin de l'Académie de médecine, 1848, t. XIII, p. 6:3). 
Kehl et Strasbourg reçoivent toujours celles qui viennent de la Hongrie ; llambourg transmet à la Hollande et à l'Angleterre un certain nombre de sangsues originaires de la Russie propre el de la Pologne.

Gorgement des sangsues. Il y a quelques années, le commerce des sangsues était entaché d'une fraude très-préjudiciable à la santé publique. Ces annélides étaient tous plus ou moins gorgés de sang. Cet abus avait pris naissance d'abord, parce que, les sangsues devenant de plus en plus rares dans les marais, il ne suffisait plus, pour obtenir une pêche productive, que les pêcheurs agitassent la vase et entrassent dans l'eau, les jambes nues ou entourées de flanelle, ou jetassent dans l'eau de petites couvertures de laine, auxquelles les sangsues s'attachent volontiers; alors on a eu recours à des appâts de chair saignante ou à des linges imbibés de sang caillé. Ensuite le commerce en gros des sangsues s'étant fait au poids, et, dans la vente au détail, les grosses sangsues ayant une valeur plus grande que les petites, les commerçants ont eu tout bénéfice à augmenter le poids et la grosseur des sangsues en les gorgeant de sang. La fraude était arrivée au point que, en 1840 , il était presque impossible de trouver à Paris des sangsues vierges, c'est-à-dire qui ne fussent pas gorgées.

L'École de pharmacie se préoccupa de cet état de choses, et, malgré les réclamations des marchands en gros, qui prétendaient que le gorgement des sangsues se faisait naturellement dans les marais, ou qu'il élait nécessaire pour que les sangsues pussent supporter la fatigue du transport, elle saisit, à plusieurs reprises, des quantités considérables de sangsues gorgées et fit condamner les détenteurs. Aujourd'hui il est parfaitement établi :

$1^{\circ}$ Que les sangsues naturelles ne contiennent que très-rarement une petite quanlité de sang rouge, et que la seule chose que l'on trouve habituellement dans leur estomac est un liquide verdâtre provenant de la digestion de leur nourriture antérieure, et qu'elles rejettent quelquefois dans l'eau où l'on les conserve;

$2^{\circ}$ Que le gorgement des sangsues, loin d'être utile pour leur transport, est une cause de mortalité et de perte pour le commerce ;

$3^{\circ}$ Que, quelle que soit l'origine du sang contenu dans l'estomac des sangsues, on ne doit délivrer, pour l'usige médical, que celles qui en sont privées; on doit conserver les autres dans des marais ou réservoirs artificiels, jusqu'à ce qu'elles aient digéré le sang qu'elles renferment.

Il suffit d'ailleurs, pour reconnaître si une sangsue est pure ou gorgée, de la serrer fortement. entre le pouce et_l'index, par l'é- 
tranglement qui sépare le corps de la ventouse postérieure; au besoin, on la maintient plus sûrement, en entourant cette partie d'un linge. On presse alors le corps de la sangsue entre deux doigts de l'autre main, et on l'y fait glisser doucement, comme dans une sorte de laminoir, à partir de la ventouse anale jusqu'à l'extrémité antérieure. Lorsque la sangsue ne contient pas de sang, on ne voit rien apparaître à cette extrémité; mais, lorsqu'elle a été gorgée, le sang contenu dans les cavités de l'estomac reflue vers l'œsophage et forme un renflement qui s'étend quelquefois du quart jusqu'à la moitié de la longueur de l'animal. Une pression plus forte le fait même sortir par la bouche.

Gorgement des sangsues. Les pharmaciens, les herboristes, les médecins dans les localités où il n'existe pas de pharmaciens, les hôpitaux, les commerçants en gros, ont besoin de conserver chez eux une provision de sangsues proportionnée à leur consommation. A Paris, qui est devenu un des centres principaux de ce commerce, les délaillants trouvent un grand avantage à ne tenir chez eux qu'un petit nombre de sangsues, et alors ils se contentent de les mettre dans un vase de verre ou de grès, couvert d'une simple toile, et contenant 5 ou 6 litres d'eau pour cent ou deux cents sangsues. On place ee vase dans un lieu frais, à l'abri de la gelée, des rayons du soleil, des odeurs fortes ou des émanations de laboratoire, et l'on change l'eau tous les jours en été, et tous les deux jours en hiver, en prenant les précautions suivantes :

$1^{\circ}$ L'eau doit être de source, de rivière ou de pluie, et non de l'eau de puits ou de citerne, qui est en grande partie privée de l'air nécessaire à la respiration des sangsues.

$2^{\circ}$ L'eau doit être à la même température que celle où se tronvent les sangsues; elle peut être un peu plus élevée lorsque la température est basse; elle ne doit pas être plus froide.

$3^{\circ}$ On vide complétement le vase aux sangsues, en en versant le contenu sur un tamis de crin lâche, ou sur une passoire dont les trous soient assez petits pour que les sangsues ne puissent pas s'y engager. On lave exactement le vase à l'intérieur ainsi que le linge qui le recouvre.

$4^{\circ}$ On sépare avec soin des sangsues saines celles qui sont mortes el même celles qui paraissent malades, ce qu'on reconnaît à l'enflure et au changement de couleur des extrémités, ou à des nodosités séparées par plusieurs étranglements.

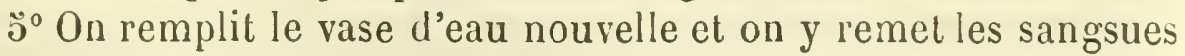
saines, à la main; cela vaut mieux que de remettre d'abord les sangsues dans le vase et de verser brusquement l'eau par-dessus. J'ai vu plusieurs fois périr un grand nombre de sangsues, rien 
que pour les avoir soumises au choc de l'eau sortant d'un robinet, à une température de quelques degrés plus basse que celle de l'air ambiant.

Pour éviter cet inconvénient, el pour remédier aussi à la mortalité des sangsues, provenant de beaucoup d'autres causes, principalement durant les chaleurs de l'été, je me suis bien trouvé, pendant longtemps, de l'emploi d'un grand vase de faïence contenant, au fond, une couche de sable de rivière, recevant un courant d'eau modéré, mais continuel, par un tuyau plongeant dans ce sable, et perdant l'eau par un autre tube placé à la partie supérieure (1).

Les sangsues, ainsi que je l'ai dit précédemment, changent trèssouvent d'épiderme, et cette opération, qui ne se fail pas sans peine lorsque les sangsues sont conservées dans de l'eau pure, en fait périr un grand nombre. Pour y remédier, M. Chatelain (2) a conseillé de meltre au fond des vases où on les conserve de l'argile plastique réduite en pâte, dans laquelle les sangsues aiment beaucoup à s'introduire et à séjourner; MM. Derheims et Desaux ont employé la mousse, d'autres le charbon, la tourbe, etc. Le sable de rivière, que j'ai conseillé plus haut, me paraît préférable pour les pharmaciens.

Les sangsues, tenues en captivité, sont sujettes à plusieurs autres maladies qui paraissent causées par l'accumulation en trop grand nombre dans une petite quantité d'eau, le renouvellement insuffisant de l'eau ou de la lerre argileuse qui les renferme, le défaut de propreté des vases ou des sács, l'état de plénitude ou de gorgement, principalement en été, le transport prolongé, surtout à l'époque de la gestation, enfin le contact de celles qui sont mortes ou déjà affectées de maladies. On remédie à ces maladies tet à la morlalité qúi en est la suite, en prenant le contre-pied des circonstances défavorables qui viennent d'être énumérées. On s'est très-bien trouvé, en pareil cas, d'ajouter à l'eau dans

(1) Guibourt, Journ. pharm., t. XII, p. 19.

(2) Un grand nombre de pharmaciens se sont occupés de l'histoire naturelle, de la reproduction et de la conservation des sangsues, et ont publié des observations importantes qui ont formé peu à peu un corps de doctrine dont tous ont profité. Je citerai entre autres M. Brossat, à Bourgoin (Isère); M. Desaux, à Poitiers; M. Trémolière, à Marseille; M. Châtelain, pharmacien en chef de la marine à Toulon; M. Derheims, à Saint-Omer (Bulietin de l'Académie de médecine, t. VII, p. 981); M. Fleury, à Rennes; M. Charpentier, à Valenciennes; MM. Chevallier, Bouchardat et Soubeiran, à Paris. Je ne dois pas oublier M. Joseph Mar'tin, négociant en sangsues, à Paris, et possesseur de vastes réservoirs à Gentilly, qui s'est honoré par la résistance qu’il a opposée au gorgement frauduleux des sangsues, et qui a publié le résultat de ses observations. sur le commerce de ces annélides dans un ouvrage intitulé : Histoire pratique des sangsues. Paris, 1845. 
laquelle on conserve les sangsues du charbon pulvérisé. On a également conseillé de désinfecter les vases et les toiles à l'aide du chlorure de chaux, et de passer les sangsues, une ou deux fois, dans une eau additionnée d'une très-faible quantité du même chlorure.

Les sangsues peuvent aussi mourir d'inanition. Que l'on suppose, dans une pharmacie, des sangsues non gorgées, déjà éminemment propres au service médical, et mises tous les jours au seul régime de l'eau. Au commencement, elles sont grosses autant que le comporte leur âge, vigoureuses, fermes et ramassées en olive; peu à peu elles diminuent de rolume, s'allongent, deviennent plates, flasques et presque sans force. C'est un peu avant de parvenir à cet état, qu'elles étonnent par la grande différence observée entre leur peu de volume, lorsqu'on les appl:que sur la peau, et celui qu'elles acquièrent après la succion. Enfin, l'abstinence continuant, la sangsue tombe au fond de l'eau et ne se relève plus. On la distingue de celles qui sont morles de maladies par l'absence de toute nodosité et par sa flaccidité. C'est ordinairement vers le deuxième mois que les sangsues non gorgées sont réduites au seul régime de l'ean, que cette mort commence à se montrer. Quelques pharmaciens ont proposé de remédier aux effels de l'abstinence en ajoutant à l'eau du sucre pur ou caramélisé, ou même du sang; mais M. Derheims et de Blainville ont montré l'inutilité de ces additions, la sangsue adulte n'empruntant ancune nourriture au liquide au milieu duquel elle se trouve (1). On peut dire encore que le sang ajouté à l'eau dans laquelle on conserve les sangsues s'y putréfie rapidement et cause la mort de ces annélides. Mais si les sangsues ne se nourrissent pas de sang étendu d'eau, elles boivent avec avidité le sang pur et récent avec lequel on les met en contact (2). C'est même un des moyens dont on se sert pour les gorger. Tout en. condamnant fortement ce moyen de fraude, jadmets cependant que, dans le cas d'inanition complète, on puisse fournir aux sarigsues un peu de sang pour les ranimer. J'ai conseillé anciennement. de les mettre dans de l'argile humectée, où elles paraissent trouver quelques parties nutritives.

J'ai dit précédemment que les temps orageux étaient très-défavorables aux sangsues, ce que j'attribuais à la putréfaction instantanée des matières organiques et à la disparition de l'oxygène contenu dans l'eau (page 300). Je me suis assuré qu'on soustrayait les sangsues à l'influence désastreuse de l'électricité atmosphérique, en plaçant le vase qui les contient dans une cave souter-

(1) Voir également Journal de chimie médicale, t. VIII, p. 606. 1832.

(2) Journ. pharm., t. XXIV, p. 314. 
raine; mais lorsqu'on les y laisse longtemps, elles deviennent flasques, molles et peu actives, de sorte que leur séjour dans une cave humide et obscure ne doit être que momentané.

A Paris, les marchands de sangsues en conservent des quanlités considérables dans des magasins frais, profonds, mais aérés, dallés, abondamment pourvus d'eau, et où l'on ne voit que des baquets couverts de toiles et des sacs suspendus à l'air.

La toile qui recouvre les baquets présente au milieu une large ouverture circulaire qui permet de voir l'intérieur, et par laquelle cependant les sangsues ne peuvent sortir; cette ouverture étant garnie tout autour d'une bande de toile pendante el effilée par le bas, ce qui empêche les sangsues de s'y fixer.

Les sangsues qui arrivent dans ces magasins sont d'abord versées dans les baquets pleins d'eau pour faire le triage des mortes, des malades, et faire la séparation des grosseurs. Les sangsues reconnues bonnes et marchandes sont enfermées dans des sacs qui en contiennent deux ou trois kilogrammes, et suspendues à l'air libre; mais il faut, à tour de rôle, les remettre à l'eau pendant un jour sur deux ou trois. Les sangsues malades ou gorgées sont placées dans de l'argile détrempée, où elles doivent être examinées tous les deux ou trois jours et changées tous les quinze ou vingt jours, en été (Martin).

Enfin les principaux négociants en sangsues, plusieurs pharmaciens éloignés de Paris et obligés de conserver chez etix un grand nombre de sangsues, et divers hôpitaux, ont pris le parti de faire établir des bassins, des réservoirs ou canaux, traver'sés par un courant d'eau modéré, couverts d'une couche d'argile au fond, et plantés sur le bord de plantes aquatiques, où les sangsues, se trouvant presque revenues à leur état naturel, se conservent en bon état de santé, et peurent même se multiplier, ainsi que je le dirai plus loin.

Application des sangsues. A l'exception de la plante des pieds et de la main, les sangsues peuvent être appliquées sur toute la surface du corps. Cependant, comme leurs morsures laissent des traces apparentes, il faut, autant que possible, surtout chez les femmes, ne pas les poser sur les parties découvertes, comme le visage, le cou, la partie supérieure de la poitrine, l'avant-bras et le dos de la main. Il faut éviter aussi le trajet des gros vaisseaux et des gros troncs nerveux.

On peut encore appliquer les sangsues sur quelques membranes muqueuses facilement accessibles, comme les gencives, la vulve ou le col de l'utérus; mais il faut user de grandes précautions pour empêcher ces animaux de se glisser trop avant dans les organes. 
La place sur laquelle on veut poser les sangsues doit être rasée, si elle est couverte de poils, et elle doit être privée de sueur par le lavage à l'eau chaude ou par un bain local. Si elle a été couverte de cataplasmes, on la lave pareillement à l'eau liède; sielle a été couverte d'embrocations huileuses ou d'emplâtres résineux et odorants, on la lave au savon ou à l'alcool rectifié d'abord, puis à l'eau.

Quelques personnes ont conseillé d'humecter la peau avec de l'eau sucrée, du jaune d'œuf ou du lait; ces précautions sont non-seulement superflues, mais elles peuvent être contraires. D'autres prescrivent de faire jeimer les sangsues en les laissant deux ou trois heures hors de l'eau arant de les appliquer. Je conseille, au contraire, de les laisser dans l'eau, et de les laver même dans l'eau pure, au moment de les appliquer. La seule précaution à prendre, c'est que les sangsues et la peau soient très-propres.

Quelques personnes prétendent encore activer la morsure des sangsues, en les roulant dans la main ou dans un linge chaud, en leur pinçant la ventouse anale, en les renfermant dans une pomme creuse, etc. Tous ces moyens sont plus nuisibles qu'utiles. La meilleure manière de faire mordre les sangsues, lorsque la surface est étendue, consiste à les poser en tas sur la place même, et à les recouvrir l'un linge sec dont on maintient les. bords appliqués sur la peau, avec la paume de la main. Lorsque la place est plus circonscrite, on prend un verre à patte, de dimension convenable; on pose dessus un linge sec, dans le creux duquel on met les sangsues, et l'on renverse le tout sur la place où celles-ci doivent prendre. Les sangsues, ne pouvant s'attacher au linge sec, se fixent immédiatement sur la peau, el, aussitôt qu'une a mordı, toutes les autres suivent.

Pour placer les sangsues, une à une, dans la bouche ou dans l'intérieur de la vulve, on a imaginé un grand nombre de petits instruments dont le meilleur paraît être un petit lube de verre poli aux deux bouls, dans lequel on place la sangsue. Celle-ci est poussée par l'extrémilé postérieure, à l'aide d'un piston, el est forcée de s'approcher de l'endroit où elle doit mordre. Sans ce piston, la sangsue pourrait rester très-longtemps immobile dans le tube. Les Chinois se servent, pour le même usage, d'un tube de bambou, que l'on pourrait suppléer par une tige de sureau évidée de sa moelle.

Lorsque les sangsues ont mordu, il faut les laisser tranquilles et se borner à les supporter avec une serviette, pour empêcher que leur poids ne fatigue les plaies. Il faut aussi les laisser tomber naturellement. Si cependant il était utile d'en arrêter 
la succion, par exemple lorsqu'il n'en reste plus qu'une ou deux, qui s'opposent aux soins subséquents réclamés par le malade, on les fait tomber en leur mettant sur le milieu du corps une pincée de sel.

A près la chute des sangsues, on entretient ordinairement l'écoulement du sang pendant une heure ou deux, en étuvant continuellement les plaies arec une éponge imbibée d'eau tiède, ou en les recouvrant toutes d'un large cataplasme de farine de lin, ou mieux encore, lorsque l'indication s'y trouve, en mettant le malade dans un bain. Au bout du temps indiqué, il ne reste guère que deux ou trois piqûres saignantes, que l'on peut abandonner à elles-mêmes, si le malade peut supporter cet accroissement de perte de sang sans inconvénient; ou que l'on arrête en appliquant exactement sur chaque piqûre mise à découvert un petit morceau d'agaric de chêne épais et velouté et en exerçant une compression par-dessus, à l'aide d'une compresse de linge et d'un bandage. La poudre de Lycoperdon Bovista, une couche de gomme arabique pulvérisée, de poudre de tan, de cachou ou du quinquina, recouvertes d'une compresse, peuvent conduire au même résultat; la colophane, le sangdragon, les terres absorbantes sont moins efficaces. Il faut le moins possible avoir recours aux sels et acides minéraux, tels que le nitrate d'argent, qui est cependant très-efficace, les sulfates de cuivre et de fer, l'eau de Rabel, etc. (1).

Dégorgement et réapplication des sangsues. Une fois gorgées de sang, les sangsues tombenl dans un état de somnolence qui les rend impropres, pendant longtemps, à rendre de nouveaux services. Anciennement on les jetait presque toujours comme inutiles; aujourd'hui qu'elles sont devenues rares et d'un prix élevé, on néglige encore trop souvent de les conserver. Toutes les sangsues qui ont servi devraient être cédées, à prix modique, à des personnes chargées de les recueillir et de les livrer à d'autres, qui s'occuperaient, sous la surveillance de l'autorité, des moyens de les rendre propres de nouveau à l'usage de la médecine.

Il n'y a rien de nouveau dans celte pratique. Depuis longtemps, dans les campagnes et dans les petites villes, on a vu des ménages conserver les sangsues qui leur avaient servi, sans autre soin que de les changer d'eau très-souvent, et, au bout d'un certain temps, les employer de nouveau pour eux ou les louer à leur's voisins. Cet usage est surtout très-répandu au Brésil et dans les

(1) J'ai souvent été appelé auprès de malades chez lesquels l'écoulement du sang n'avait pu être arrêté; je suis toujour's parrenu à l'arrêter immédiatement avec l'agaric de chêne et la compression. 
colonies, où les sangsues, qui sont apportées d'Europe, sont partout d'un prix très-élevé. On cite comme un exemple déjà ancien de l'utilité de cette pratique, que, en 1825, dans l'hôpital militaire de Bayonne, la réapplication des sangsues a réduit à 1,212 francs la dépense pour l'achat des sangsues, qui s'était élevée à 3,000 francs en 1824. En 1826, à l'hôpital de Pampelune, la réapplication des sangsues a produit une économie de 3,05̆6 francs. En trois années, de 184วั à 1847, l'Hôtel-Dieu de Paris, tout seul, a produit de cette manière, à l'administration des hôpitaux, une économie de 61,690 francs.

Deux manières de procéder peuvent être employées pour atteindre cette économie, et pour diminuer d'autant la consommation des sangsues et les craintes que l'on a pu concevoir sur leur complète disparition. On peut rendre, autant que possible, les sangsues à leur vie naturelle et attendre qu'elles aient digéré le sang qu'elles ont pris ; ou bien on peut, par des moyens particuliers, opérer le dégorgement immédiat des sangsues et les appliquer de nouveau, presque sans retard, à l'usage médical.

Le procédé dı dégorgement naturel peut certainement être employé, même sur une assez grande échelle, ainsi que le prouvent les faits suivants :

En 1823, les officiers de santé de l'hôpital militaire de Bayonne ont placé dans un bassin 9,245 sangsues, provenant des applications de juin et juillet. Vers la fin de l'année, ils ont pu remettre en service 7,4łŏ sangsues, qui ont été jugées de bonne qualité.

Le $\mathbf{1}^{\text {er }}$ avril 1831, dans un bassin alimenté par un filet d'eau et où se trouvaient plusieurs plantes aquatiques, M. Chatelain a fait jeter 12,000 sangsues gorgées de sang. Après quatre mois et demi de séjour, le bassin fut vidé, et l'on en retira 4,600 individus se contractant en olive et très-propres à faire un bon service; cependant leur digestion n'étail pas encore terminée.

Dans un bassin de $2^{\mathrm{m}}, 50$ carrés, et de 30 centimètres de profondeur, en partie rempli d'argile blanche onctueuse, mise en consistance de pâte molle, M. Bouchardat et Soubeiran ont déposé successivement 6,כ00 sangsues. Le sol et l'argile avaient une pente convenable, pour que l'eau, coulant par intervalle à la surface, pût s'écouler par un trop plein grillé, placé à la partie la plus déclive; de cette manière, l'argile élait humectée, mais non couverte d'eau, excepté dans la partie basse. Chaque jour on enlevait les sangsues qui étaient venues mourir à la surface. L'expérience commencée au mois de décembre fut terminće au mois de juin; les sangsues retirées de l'argile étaient très-vires; 
elles teignirent l'eau immédiatement en vert. Après deux ou trois jours, elles étaient supérieures en qualité aux meilleures sangsues du commerce; elles prenaient toutes très-promptement et restaient plus longtemps attachées sur les malades. Cependant ce procédé a été abandonné pour le dégorgement immédiat (1).

Bien des procédés ont été conseillés pour le dégorgement immédiat des sangsues : MM. Petit-Ferdinand et Olivier ont proposé de pratiquer une petite ouverture sur le dos (vers l'origine des deux grandes poches digestives, après le soixante-deuxième anneau), et de faciliter la sortie du sang par une légère pression. Ce procédé me paraît peu praticable, surtout en grand, et doit être préjudiciable pour les sangsues.

M. Tournal, de Narbonne, a imaginé de dégorger les sangsues en les retournant comme un doigt de gant à l'aide d'un petit stylet, à pointe mousse, en bois, que l'on appuie contre la ventouse anale et que l'on pousse de bas en haut jusqu'à le faire sortir, toujours revêtu de la ventouse, par la bouche. En continuant encore de rabattre la sangsue sur le petit morceau de bois, on finit par la retourner entièrement, la peau revêtant à l'intérieur, dans toute sa longueur, le morceau de bois, et le canal intestinal se trourant tout à fait à l'extérieur: on lave alors l'animal, et on replace les organes dans leur situation normale. Suivant M. Tournal, la sangsue ne paraît pas être trèsaffectée par cette curieuse opération, et elle est propre à servil immédiatement. Moquin-Tandon pense, au contraire, que les sangsues ne peuvent être retournées sans déchirures profondes, dont elles doivent souffrir pendant longtemps. Il est évident, d'ailleurs, que ce procédé ne serait pas praticable en grand.

D'autres personnes ont conseillé de faire dégorger les sangsues en les plaçant sur de la cendre, du charbon, de la sciure de bois, du sel; dans de l'eau salée, dans de l'eau mèlée de vin rouge ou blanc, etc. On les lave ensuite dans de l'eau pure, et on les change d'eau tous les jours, ainsi qu'il a été dit précédemment pour les sangsues vierges.

M. Joseph Marlin prescrit de faire dégorger les sangsues en les pressant entre les doigts, depuis l'extrémité postérieure jusqu'à l'antérieure, ainsi qu'on le pratique lorsqu'on veut reconnaître le gorgement des sangsues. Seulement il faut pousser la. pression jusqu'à faire sortir le sang par la bouche. Mais il est dif. ficile d'arriver à ce résultat sans causer des déchirures intérieu-

(1) Journal de phamucie et de chimie, t. XI, p. 345. 
res, auxquelles les sangsues succombent tôt ou tard. C'est cependant ce procédé qui est usité aujourd'hui dans les hôpitaux de Paris; mais, combiné avec l'immersion dans de l'eau salée chaude, qui donne au sang plus de fluidité, et dispose les sangsues à le rendre plus facilement.

A l'Hôtel-Dieu de Paris, un homme est chargé spécialement de la pose des sangsues dans les salles d'hommes, et une femme remplit la même fonction dans les salles de femmes. ILes sangsues prescrites sont envoyées de la pharmacie, au lit de chaque malade, dans un pot de terre couvert d'une toile percée d'un trou, duquel part un petit conduit de toile ouvert, et qui n'arrive pas au fond du pot. Les sangsues retirées du pol sont appliquées tout de suite, puis, le pot ayant été recouvert, à mesure qu'elles tombent, on les remet dans le pot par le conduit de toile resté ouvert. C'est dans ces mêmes pots qu'elles retournent à la pharmacie, où elles sont comptées, puis soumises au dégorgement. Pour assurer la régularité de ce service et intéresser.les employés ¿ sa réussite, on accorde une prime de 1 centime aux infirmiers, par chaque sangue gorgée qu'ils rendent en bon état, et une autre prime de 2 centimes à l'homme chargé du dégorgement, pour chaque sangsue rendue au service et qui produit un effet utile.

Le dégorgement a lieu le jour même que les sangsues ont été posées. A cet effet, on en prend une douzaine que l'on jette dans une eau salée faite avec seize parties de sel marin et cent parties d'eau, chauffée à $\mathbf{4 0}$ ou $\mathbf{4}$ degrés. On presse successivement ces sangsues légèrement entre les doights; elles rendent ainsi sans effort tout le sang qu'elles ont pris. Les sangsues dégorgées sont mises en repos dans des pots avec de l'eau fraîche que l'on renouvelle tous les jours. Au bout de huit à dix jours, elles sont trèsaptes à être appliquées de nouveau; elles prennent aussi vite que les meilleures sangsues du commerce et tirent autant de sang. Les sangsues qui ont ainsi fourni une seconde piquire sont dégorgées encore une fois; si elles sont en bon état, on les fait servir de nouveau; si elles paraissent fatiguées, on les porte dans de petits marais (Bouchardat et Soubeiran).

[M. Ebrard préfère à l'emploi de l'eau salée, de l'eau aiguisée (1) de $1 / 4$ ou de $1 / 8$ de vinaigre. $]$

On a pu craindre que l'application de sangsues qui ont sucé, il y a peu de temps, le sang d'une personne malade, aurait de graves inconvénients ; mais depuis que l'emploi des sangsues dégorgées a lieu dans les hôpitaux de Paris, sur une grande échelle,

(1) Ebrard, Monograplie des sangsues médicinales. Paris, 1857, p. 391.

Gubont, Diogues. ic ili!.

T. IV. -21 
on n'a eu aucun exemple d'accident produit par leur emploi. Antérieurement, le docteur Pallas avait démontré, par des essais entrepris sur lui-même, l'innocuité des blessures de sangsues déjà employées, qui avaient été lavées et conservées pendant que!ques jours dans de la terre humide. Il n'a pas même craint de s'appliquer des sangsues qui s'étaient repues sur un bubon de l'aine el sur les bords d'un ulcère syphilitique: ces annélides prirent très-bien, et leurs piqûres guérirent avec facilité comme des morsures ordinaires. Néanmoins l'administration des hôpitaux de Paris, pour prévenir toute récrimination, n’a jamais fait employer au dehors des hôpitaux établis spécialement pour les maladies cutanées et syphylitiques, les sangsues qui avaient été appliquées sur les malades de ces établissements.

Multiplication des sangsues en France. - On se plaint depuis trèslongtemps de la disparition des sangsues en France, et l'on attribue avec raison cette disparition à la pêche immodérée qui en a été faite depuis trente ans; mais lorsque nous tirions annuellement de l'étranger 30,40 , ou 50 millions de sangsues, était-il donc possible de mettre des restrictions à la pêche intérieure? Aujourd'hui que l'importation se trouve réduite à 10 millions, il sera certainement plus facile d'imposer des conditions à la pêche et d'arriver à repeupler nos marais.

En 1830\%, M. Fleury, pharmacien à Rennes, avait proposé au ministre du commerce :

$1^{\circ}$ De prohiber la pêche des sangsues dans le temps de la ponte ;

go De ne laisser prendre que celles qui auraient atteint une grosseur et un poids déterminés;

$3^{\circ}$ De mettre les lieux où vivent les sangsues sous la surveillance des gardes champêtres;

$4^{\circ}$ D'exiger les pêcheurs une légère rétribution pour la permission qui leur sera accordée.

Chargé de faire un rapport sur 'ces propositions à l'Académie de médecine, mes conelusions, adoptées par l'Académie, ont élé :

$1^{\circ}$ Que les moyens proposés par M. Fleury, pour s'opposer à la destruction des sangsues et pour en repeupler nos marais, paraissaient insuffisants, n'étant appliqués qu'au petit nombre de celles qui y restent, et qu'ils étiient d’ailleurs d'une exécution difficile;

2. Que la meilleure manière de s'opposer efficacement à cette destruction, serait de rendre à leur vie naturelle en France, dans des lieux désignés à cel effet, les sangsues qui sont importées de l'étranger, après leur usage dans les hôpitaux, qui les livreraient presque pour rien a l'administration. 
La question ayant été soumise de nouveau à l'Académie, par suite d'une communication de M. Joseph Martin et de lettres de renvoi émanées de M. le ministre de l'agriculture el du commerce et de M. le préfet de police, l'Académie a adopté, sur un rapport très-approfondi de Soubeiran, les propositions suivantes:

$1{ }^{\circ}$ Défendre la vente des sangsues gorgées dans toute la France, et soumettre les vendeurs à une pénalité sévère,

$2^{\circ}$ Obliger ceux qui font le commerce des sangsues à désigner sur leurs factures la variété de sangsues dont ils font livraison;

$3^{\circ}$ Interdire la pêche des sangsues pendant les mois de l'accouplement et de la ponte, en laissant à chaque préfet le soin de fixer l'époque de la pêche dans son département;

$4^{\circ}$ Interdire la pêche et la vente des sangsues pesant moins de 2 grammes ou plus de 6 grammes;

$\breve{J}^{\circ}$ Autoriser cependant la vente ou la pêche de ces sangsues, par exception, quand elles seront destinées à peupler les réservoirs; mais ne l'autoriser que sur une décision du préfet, faisant connaître la quantité de ces sangsues et leur destination;

$6^{\circ}$ Par une mesure transitoire, interdire la pêche des sangsues, en France, pendant six ans;

$7^{\circ}$ Faire une obligation aux hôpitaux de déposer les sangsues, qui ont servi, dans des réservoirs assez vastes pour qu'elles puissent s'y dégorger el s'y multiplier (1).

Je me permettrai quelques observations sur ces conclusions.

$1^{\circ} \mathrm{Il}$ est évident d'abord que la défense de vendre les sangsues gorgées ne peut s'entendre que de celles destinées à être appliquées immédiatement, car il est utile au contraire d'encourager la vente des sangsues qui ont seivi, puisque c'est sur elles principalement que l'on doit compter pour la reproduction des sangsues en France. Il devrait donc être permis à des hommes pourrus d'une médaille, de parcourir les villes pour y acheter les sangsues gorgées et les livrer aux éleveurs.

2 Le minimum et le maximum de poids fixés pour les sangsues marchandes sont l'un et l'autre trop élevés. Il résulte en effet du tableau du poids des sangsues emprunté à M. Martin, que les yrosses sangsues, diles de premier choix, pèsent de 2 à 3 grammes, ''t qu'au-dessous se trouvent les moyennes dont le poids varie de $1^{\mathrm{gr}}, 12$ à 2 grammes, et qui peuvent ètre d'une grande utilité en médecine; puis les petites sangsues, pesant de $0^{\mathrm{gr}}, 60 \mathrm{a} 1$ gramme; enfin les sangsues filet, dont le poids est inférieur à 5 déci-

(1) Soubeiran, Rapport (Bulletin de l'Académie de médecine. Paris, 1847-48, t. XIII, p. 613). 
grammes. J'ajoute que, si l'on empêchait la vente de toutes les sangsues au-dessous de 2 grammes, on retirerait plus de la moitié des sangsues du commerce, et que le prix de celles qui resteraient s'en trouverait nécessairement doublé : je dis enfin qu'audessus de $3^{\mathrm{gr}}, \mathfrak{5}$ les sangsues commencent à être moins estimées, et que celles de 4 grammes sont déjà considérées comme inférieures pour la succion. Le résultat de ces observations est que l'on derrait défendre la vente et la pêche, par conséquent, des sangsues au-dessous de 1 gramme el au-dessu's de b̆ grammes. Si ces dernières sont peu estimées pour l'usage médical, elles paraissent être les plus propres à la reproduction. Il y a donc une double raison pour les laisser dans les marais.

$3^{\circ}$ Je trouve très-difficile d'admettre que l'on proscrive dans une loi la pêche et la vente des sangsues an-dessous et au-dessus d'un poids donné, et qu'on en permette cependant la pêche et la vente pour peupler les réservoirs. Je pense qu'il vaut mieux les laisser où elles sont; elles grossiront certainement plus vite et produiront davantage. Il vaut mieux fonder la population des réservoirs et marais artificiels, au moyen des sangsues de bonne qualité qui ont servi à l’usage médical.

$4^{\circ}$ Je ne trouve ni juste ni politique, d'interdire complétement la pêcbe des sangues en France pendant un nombre quelconque d'années, de priver la population qui s'y livre du salaire que cela lui procure et de lui faire perdre l'habitude d'une occupation qu'il faudra ensuite rétablir. Je pense que ce sera bien assez de limiter la pêche aux sangsues comprises entre les poids de 1 à 5 grammes.

$\breve{J}^{\circ}$ Quant aux hôpitaux, dont un certain nombre ont organisé un service pour faire resservir immédiatement leurs sangsues une ou denx fois, je ne crois pas qu'on doive les priver du bénéfice immédiat qui en résulte pour eux; mais je crois qu'on peul exiger que les sangsues qui auront servi trois fois, ou peutêtre seulement deux fois (1), soient livrées par les hôpitaux aux éleveurs de sangsues. Voici les conseils que l'on peut donner à ces derniers. Je les extrais du rapport de Soubeiran (2).

"Les réservoirs, pour la multiplication des sangsues, doivent avoir de 60 à 70 mètres carrés (Faber); l'encombrement les fait périr; il faut d'ailleurs qu'elles puissent y trouver une nourriture suffisante.

"On préférera les réservoirs naturels, si l'on peut y installer les sangsues à peu de frais. Il est cependant plus difticile d'em-

(1) Il est donteux qu'une sangsue, qui a été dégorgée deux fois par la pression, puisse faire immédiatement une troisième piqûre bien utile.

(2) Soubeiran, Buletin de l'Académie de médecine, Paris, 1847-48, t. XIII, p. 6?9. 
pêcher les sangsues d'en sortir, et leurs ennemis d'arriver jusqu'à elles. En tous cas, il faut commencer par les mettre à sec, afin d'enlever avec grand soin les aulostomes voraces qui peuvent s'y trouver.

"Le fond de l'étang doit êlre formé par une terre douce et argileuse, pour que les sangsues puissent s'y enfoncer. Les fonds de tourbe sont aussi favorables. On peut encore avoir recours aux prairies basses; après avoir creusé le sol, on en couvre le fonds avec 30 centimètres de terre des marais.

" L'eau doit être assez peu profonde pour que le soleil puisse la réchauffer ; cependant il est nécessaire d'avoir sur guelques points des endroits profonds de 2 à 3 mètres, qui servent de refuge aux sangsues pendant les gelées de l'hiver et pendant les sécheresses de l'été. Sur d'autres $€$ ndroits, le sol doil se relever en îles couvertes d'herbes sur lesquelles les sangsues puissent se promener.

"Une eau trop courante ne vaut rien; mais il est bon qu'elle se renouvelle lentement. Les sangsues peuvent également réussir dans une eau stagnante, pourvu qu'il y pousse en abondance des plantes aquatiques qui la purifient. Ce qu'il faut surtout chercher à réaliser, c'est un niveau constant, sans lequel les cocons déposés sur les bords sont détruits par la sécheresse ou les inondalions.

"Les bords de l'étang doivent s'élever en un talus peu incliné, afin que les sangsues puissent librement sortir de l'eau pou: déposer leurs cocons. M. Faber conseille d'établir sur le bord du marais, au niveau des plus basses eaux, un terrain plat de 1 a 2 mètres de largeur; de charger ce terrain d'une couche de terre tourbeuse sur laquelle on cultive des plantes aquatiques. C'est là que les sangsues iront se loger au moment de la ponte.

"Il est utile que la partie occupée par l'eau soil le siége d'une abondante végétation. Les plantes purifient l'eau par l'oxygène qu'elles exhalent au soleil; elles abritent les sangsues el leur' facilitent le moyen de se débarrasser de leur épiderme, aux époques de la mue. Les masselles, l'acore, les iris, la prêle des marais, la phellandrie, le caltha, sur les bords; les potamogeton, les myriophylles, les chara, au milieu des eaux, sont les régétaux les plus fivorables.

"Il reste une dernière précaution à prendre, c'est d'empécher l'arrivée des ennemis des sangsues; s'il est à peu près impossible de leur venir en aide contre ceux qui habitent les marais, au moins faut-il les garantir des ennemis du dehors, qui sont principalement les canards domestiques et sauvages, 
les hérons, les taupes, les musaraignes. A cet effet, les réservoirs doivent être entourés d'un petit mur ou d'une enceinte de planches enfoncées en terre de soixante centimètres. Il faut également faire la chasse aux oiseaux sauvages dans la saison où ils se montrent.

"Enfin se présente la question de la nourriture. Si les marais ont été peuplés avec des sangsues gorgées, on peut se dispenser, pendant quatre ou cinq mois, de leur donner aucune nourriture; mais, ce terme passé, et lorsque le marais contient des sangsues jeunes ou non gorgées, principalement au printemps, lorsqu'on veut pousser à la reproduction, il est nécessaire de jeter aıx sangsues de petits poissons, des salamandres, des grenouilles surtout dont elles sont très-friandes. On peut aussi, avec mesure, étendre du sang coagulé sur des planches que l'on fait flotter sur l'eau. On cesse aux mois de juillet et d'août, lorsque les cocons sont formés, et, deux mois plus tard, on peut livrer une partie des sangsues adultes, non les jeunes, à la consommation. ")

[Depuis une vingtaine d'années, l'hirudiniculture a pris une extension considérable. Elle se pratique soit dans des marais ou étangs nalurels, soit dans ce que l'on appelle barrails, soit dans des bassins artificiels d'un mètre environ de profondeur, soit enfin dans des fossés en zigzags. Pour établir des barrails, on choisit des terrains voisins d'une rivière et plus bas que son niveau ordinaire : on les divise en plusieurs parties d'un ou deux hectares, qu'on entoure d'une espèce de digue en terre longée d'un fossé intérieurement et extérieurement. Au moyen de vannes on peut faire passer l'eau de l'extérieur à l'intérieur ou réciproquement. Au printemps le barrail se trouve recouvert sur toute son étendue de 20 à 30 centimètres d'eau, el on y jette alors les grosses sangsues qui doivent servir à l'ensemencement. Vers le 15 juin, on fait écouler les eaux et on laisse le sol à sec : les sangsues font alors leur ponte el déposent leurs cocons sur toute la surface du marais.

Dans les fossés en zigzags, les parties entourées d'une sorte de digue, comme les barrails, ne sont pas entièrement inondées, mais seulement des fossés qui vont en zigzags d'un bord à l'autre de ces parties.

Dans les marais et les barrails les sangsues sont nourries aux dépens d'animaux vivants (chevaux, ânes on rarement bétail) qu’on y fait pénétrer à certaines époques, et que les sangsues se, hâtent de venir piquer. - Dans les barrails, les bassins et les fossés, les procédés de nourriture varient. Les uns emploient des planchettes portant du sang en caillot: d'autres pêchent les sangsues de temps en temps pour les plonger dans du sang 
liquide; ou encore pour les enfermer dans des sacs où l'on introduit la jambe d'un cheval vivant. - D'autres enfin remplissent de sang liquide des boyaux de veau et les répandent dans les fossés. Mais aucun de ces procédés ne vaut le premier que nous avons indiqué; c'est le plus naturel et celui qui réussit le mieux (1).

Pour les personnes qui veulent élever les sangsues en petit, M. Vayson de Bordeaux a imaginé un petit marais domestique, qu'on appelle vaysonnier. Un vase en terre cuite, sous forme de cône tronqué renversé, a sa base inférieure percée de petits trous qui ne peuvent laisser passer les sangsues : on le remplit de terre bourbeuse et l'on y place ces animaux : l'ouverture supérieure est fermée avec une toile grossière. Si on veut expédier les sangsues, on emballe le vase dans une caisse après avoir humecté la terre. Si on veut au contraire les garder sur place, on met le fond du vase dans un baquet dont l'eau a un décimètre de hauteur et on l'y abandonne. La terre se délaye à la partie inférieure, tandis qu'elle reste presque sèche à la surface: les sangsues peuvent aussi choisir la zone qui leur convient le mieux, et non-seulement s'y conserver, mais encore s'y repròsuire.]

\section{SEPTIÈILE CLASSE}

\section{LES ENTOZOAIRES.}

[Sous le nom d'entozocires ou réunit généralement des annelés dont la plus grande partie vivent en parasites dans le corps d'autres animaux. Ils appartiennent it un certain nombre de types, distincts les uns des autres, auxquels la plupart des naturalistes donnent aujourd'hui la valeur de véritables classes, et que nous décrirons sticcessivement sous les noms généralement usilés de Vémutoides, Trémı́todes, Turbellariés el Cestoides.

Pendant longtemps on a complétement ignoré de quelle manière ces animaux pouvaient naitra et se développer dans le corps d'êtres vivants; et quelques naturalistes avaient recours, pour expliquer leur apparition, à l'admission d'une génération spontarice. On sait maintenant quelles sont les conditions dans lesquelles la plupart d'entre eux se développent, et les phases successives par lesquelles ils doivent passer avant d'arriver à l'état adulte.

(1) Voir sur ce sujet et pour tout ce qui concerne les modes de conservation et l'élève des sangsues, Ebrard, ouvrage cité, et Vayson, Guide pratique des éleveurs de sangsues. 1855. 
Ces êtres singuliers, en sortant de l'œuf, ne ressemblent en rien aux parents qui leur ont donné naissance: sous leur première forme, ils sont agames, el ne peuvent se reproduire que par voie de scissiparité ou de gemmation.Quand ils ont ainsi donné une nouvelle génération d'individus, tantôt semblables à eux-memes, tantôt différents, ils périssent; et ce sont leurs descendants qui forment, soit en se transformant eux-mêmes, soil par voie de gemmation, des individus sexués ressemblant à ceux qui ont produit les $\propto$ ufs. Il y a donc production successive de généralions, agames et sexuées, alternant entre elles de façon à ce que l'une d'elles ne ressemble ni à celle qui la précède ni à celle qui la suit, la forme adulte ne se retrouvant semblable à ellemême qu'après un nombre de générations agames, variable suivant les différents cas. C'est ce qui explique le nom de génération alternante qu'on a donné au mode de reproduction de ces êtres. On les a aussi appelés diquénèses.

Les zoologistes ont donné des noms aux états successif's sous lesquels se montrent ces animaux. M. Van Beneden (1) a proposé entre autres ceux de Scolex pour la forme agame, et de Progloltis pour l'état parfait; et comme les Scolcx peuvent avoir deux formes différentes, il a distingué la forme première sous le nom de Protoscolex. Il arrive aussi trèssouvent que les individus sexués naissant d'un Scolex restent attachés entre cux: M. Van Beneden a proposé de désigner ces sortes d'agrégalions du nom de Strobile. Nous aurons à nous servir dans le cours de cette élude de ces diverses dénominations.

Une particularité aussi curicuse du développement de ces entozoaires, c'est que, pour passer d'une forme à l'autre, il leur faut un changement complet de milieu. Tel d'entre eux qui existe à l'état agame dans le tissu musculaire d'un animal ne pourra prendre la forme sexuée que dans le tube digestif d'un animal différent. C'est ainsi que nous. verrons le cysticerque du porc, qui n'est que le Scolex du ténia, ne se. développer en ver rubané possédant les organes de la génération, que s'il passe avec la viande du porc dans l'intestin de l'homme ou d'un animal.

Ces points bien établis, nous allons étudier les divers groupes d'entozoaires, en indiquant seulement ceux qu'on a rencontrés chez l'lomme.

\section{NÉMATOÏDES.}

Les Nématoïles sont ainsi nommés à cause de l'apparence de leur corps cylindrique, le plus souvent grêle et presque filiforme. Ils n'ont d'aulre appendice que deux petites soies qui jouent le rôle de pénis. Leurs téguments sont assez épais et striés transversalement. Sous la peau se trouve une couche de fibres musculaires, et l'intérieur du corps est occupé par une grande cavité viscérale. La bouche et l'anus sont toujours distincts et termi-

(1) P. Gervais et Van Beneden, Zoologie méclicale. Paris, 1859, t. JI, 216. 
naux. Les sexes sont séparés: le mâle est plus souvent plus petit que la femelle. Les organes génitaux se présentent sous la forme de longs tubes repliés aboutissant, les uns à des pièces copulatrices clures et cornées placées à l'anus ou pròs de l'anus; les autres à la vulve située en avant de l'anus, et plus ou moins rapprochée de la tête.

Nous ne parlerons pas des anguillules, dont quelques espèces vivent dans les plantes, et y produisent des maladies spéciales, telles que la nielle du blé, causée par l’Anguillulina tritici: nous passerons tout de suite à l'étude des némaloïdes parasites de l'homme. Ils sont assez nombreux et se rapportent aux genres Anchylostoma, Strongylus, Ascaris, Occyuris, Tricocephalus, Spiroptera, Filaria et Trichina.

L'AxGiylostone duodénal est un petit ver long de 8 à 10 millimètres, cylindrique, transparent dans son quart antérieur, jaunâtre, rougeâtre ou brun, dans le reste du corps (fig. 102əั et 1026).

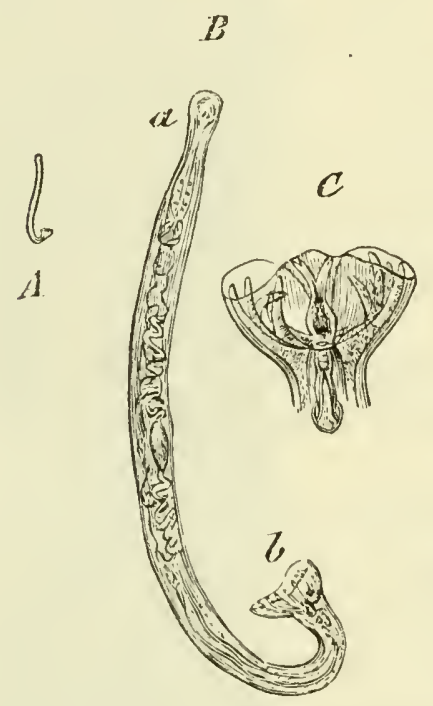

Fig. 1020ั. - Anchylostumum dusdenile màle $(*)$.

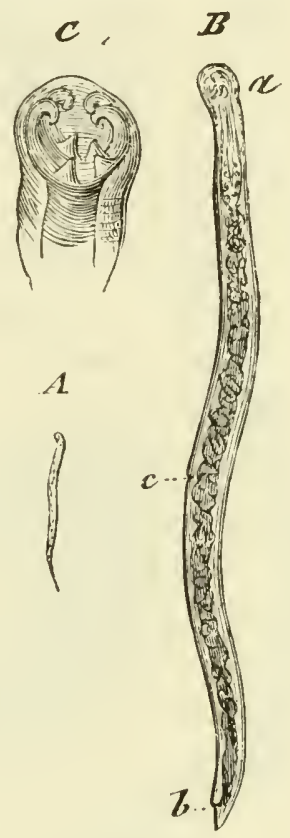

lig. 1020. - Ansinlosionum duodenale femelle $\left({ }^{* *}\right)$.

Il habile le duodénum et le jćjunum. On l'a observé en Italie, et surtout en Égypte où, d'après M. Griesinger, il produirait la maladie connue sous le nom de chlorose d'Egypte. Celte opinion se

$\left({ }^{*}\right) \mathbf{A}$, de grandeur naturelle; - B, le mème grossi ; $a$, extrémité céphalique; $b$, extrémité caudale; - C, extrémité caudale fortement grossie pour montrer la disposition de la capule et des rayons qui la soutiennent.

$\left({ }^{* *}, \mathbf{A}\right.$, de grandeur naturelle; - B, la mème grossie; $-a$, extrémité céphalique ; $b$, extrémité eandale; $c$, orifice vulvaire; $c$, extrémité céphalique fortement grossie pour montrer Ia disposition de l'armature buccale. 
troure confirmée par les observalions de MN. Grenier, Monestier et de M. Wücherer, qui tendent à attribner une maladie analogue nommée malceur, cachexic afrucaine, à la présence de ce même ver dans les inteslins.

Le genre Strongylus contient deux espèces parasites de l'homme. La plus commune est le strongle géant (Strongylus gigas, Rud.), gui produit dans le rein de graves désordres et détruit à peuprès complétement la substance de cet organe. Il occasionne de violentes douleurs, des hématuries et des pỉénomènes comparables à ceux des calculs rénaux. On l'a trouvé chez le chien, le cheval, le bœuf chez quelques animaux sauvages, et de temps en temps chez l'homme.

Ses caractères sont les suivints ( $/ \mathrm{g} .1027$ et 1028): son corps est rouge, presque cylindrique, un peu rétréci aux extrémités; finement strié transversalement. La bouche, placée à l'extrémité antérieure, est petite et entourée de six papilles. Le mâle porte à l'extrémité du corps une bourse enlière, ayant en son milieu une résicule renflée membraneuse, d'où sortent deux spicules longs et filiformes. La femelle n'a pas celte bourse terminale, et sa vulve s'onvre très-près de la bonche. Les dimensions de ce nématoïde sont considérables. Le mâle peut avoir 40 centimètres de longueur sur ò nillimètres de large : la femelle a de 60 centimètres à 1 mètre de longueur et peut acquérir la grossemr du petit doigt.

La seconde espèce de strongle (Strongylus longevaginatus, Diesing) a été observée en Transylvanie dans le parenchyme pulmonaire d'un enfant.

Les Ascarides ont un corps alténué en avant : la bouche est entourée de 3 papillestrès-marquées et très-saillantes : les mâles ont deux spicules pour pénis.

L'ascaride lombricoüde (Ascaris lumbricoides, L. (tig. 1029) rappelle par sa forme générale les lonibries terrestres, et on a même pensé pendant longtemps que ce n'était qu'un état particulier de ce ver de terre. Il alteint parfois jusqu'à 40 centimètres; mais sa longueur habituelle chez l'homme est de 16 à 22 centimètres. Son diamètre varie de 2 à ŏ millimètres. Les individus mâles sont plus petits et moins communs que les femelles dans le rapport de 1 à 4. Il est épais, aninci aux deux extrémités, blanchâtre, demi-transparent. Le mâle est recourbé à son extrémité postérieure : ses spicules sont presque droits et aplatis. Il est long de 16 à 17 centimètres et large de 3 millimètres environ. La femelle est plus grande; elle peut atteindre 30 centimètres de long sur 4 à ŏ millimètres de large.

Ce ver est très-fréquent chez les enfants; il vit habituellement daus l'intestin grêle et descend rarement dans les gros intestins, 
d'où il est rejeté au dehors. Il remonte quelquefois dans l'cstomac

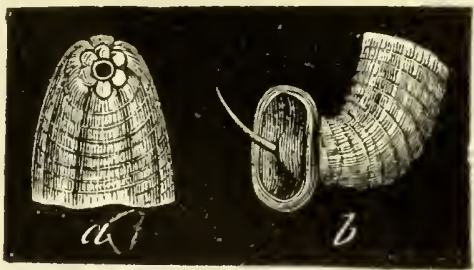

Fig. 1025. - Strongle.

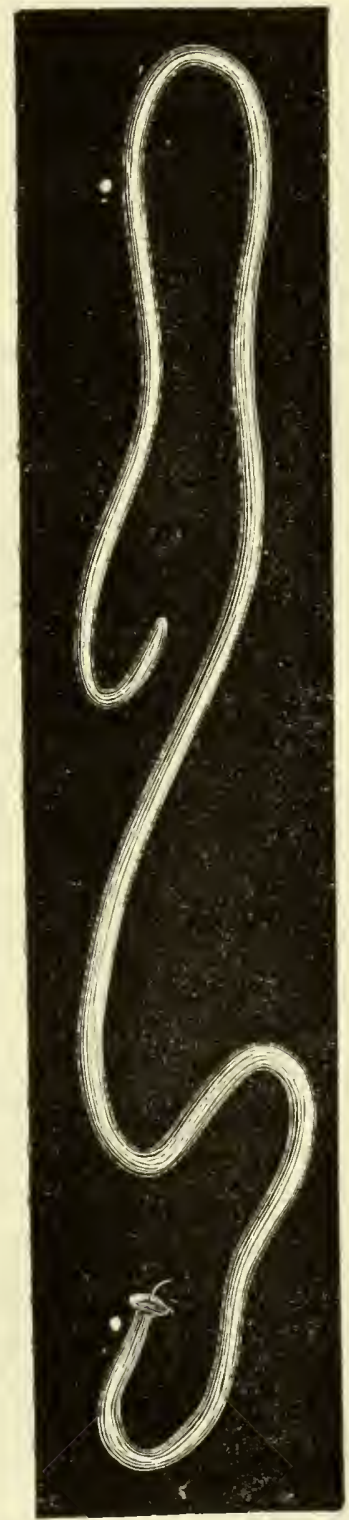

Fig. 1027. - Strongle.

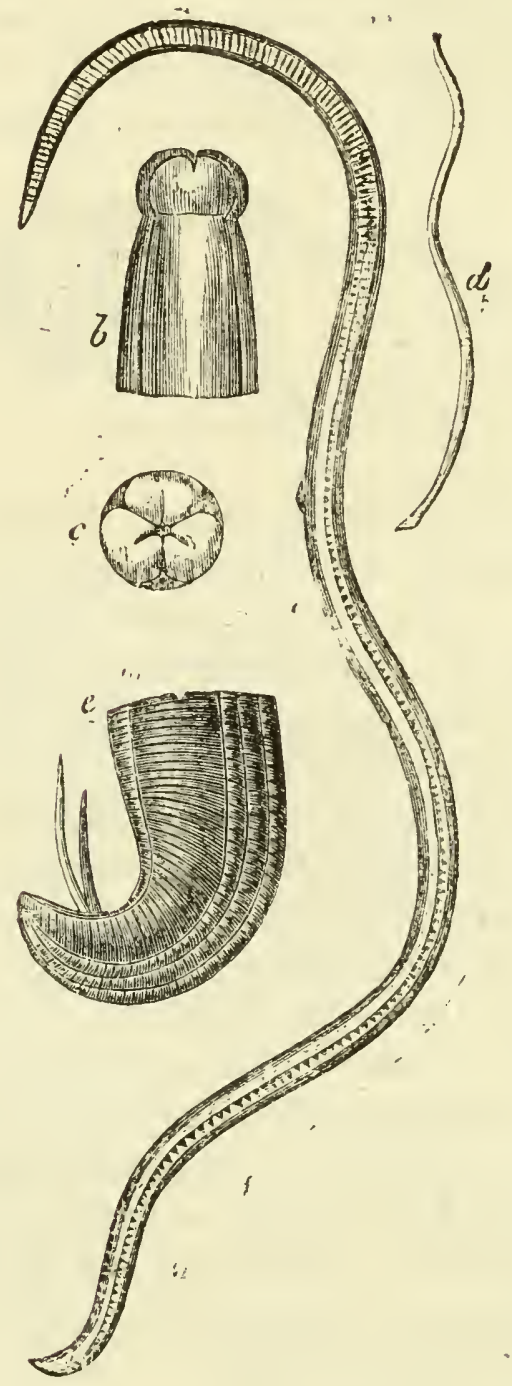

Fig. 1029. - Ascaride lombricoïde $\left({ }^{*}\right)$

et jusque dans l'œsophage, d'où il peut être expulsé par la

(*) $a$, ascaride lombricoïde de l'homme, indiridu femclle; $b$, $c$, extrémité antérieure grossie; $d$, individu màle; $e$, son extrémité postérieure grossie. 
bouche ou par les narines. On l'a également trouvé dans d'autres viscères, en rapport:avec l'intestin; mais ce n'est qu'accidentellement. Ne pouvant facilement en être expulsé, il peut y produire des accidents graves. - t)uand il est dans l'intestin grêle, il peut en être chassé par l'usage de la mousse de Corse, du semen-contra, de l'huile de ricin, du calomel, etc., etc.

D'après M. Davaine (1), l'œuf de l'ascaride lombricoïde ne se développe pas dans l'intestin : il est expulsé et reste même assez longtemps sans que l'embryon se développe. Ce dernier ne sort probablement de sa coque, que lorsqu'il est ramené au milieu des sucs intestinaux. Les œufs, entraînés par lcs eaux pluviales, peuvent rester longtemps dans les mares, les puits ou les ruisseaux, sans cesser de vivre; et c'est en buvant à ces sources que l'homme peut introduire dans son intestin les germes de ces

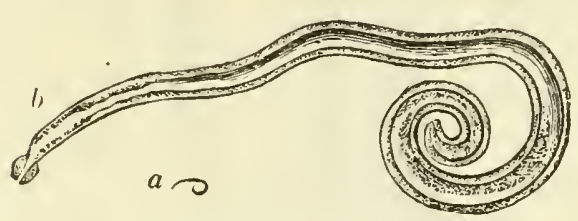

Fig. 1030. - Oxyure màle. helminthes. Aussi sont-ils beaucoup plus communs dans les campagnes que dans les villes où on a l'habitude de boire des eaux filtrées.

Nous ne mentionnerons que pour mémoire l'ascaride ailé (Ascaris alata), espèce douteuse dont on n'a observé que deux femelles dans l'intestin grêle de l'homme.

A côté des ascarides, il faut placer les Oxyunes, caractérisés par trois lobes peu saillants autour de la bouche, le spicule unique, court et falciforme du mâle, et l'alténuation de la partie terminale du corps de la femelle. C'est dans ce genre que l'on comprend aujourd'hui l'Ascaride vermiculaire de Rudolphi (Oxyurus vermicularis, Bremser), très-commun dans le rectum chez les enfants, et parfois aussi chez les adultes; il cause souvent des démangeaisons insupportables ål'anus. Le mâle (fig. 1030) est long de 3 à 4 millimètres seulement, linéaire, obtus à son extrémité antérieure, contourné en spirale à l'autre extrémité; la lemelle (fig. 1031) est longue de 8 à 10 millimètres, atténuée en une pointe très-tine. On a observé ce ver dans toute l'Europe et en Afrique. On le détruit par des lavements d'infusions d'absinthe ou de semen-contra; par des frictions d'onguent mercuriel à l'anus; quelquefois par de simples lavements d'eau froide.

Les 'Trichocéphales ont le corps très-allongé formé de deux

(1) Davaine, Recherches sur le développement et la propagation du tricocéphale de l'homme et de l'ascaride lombricoïle (Comptes rendus de l'Académie des sciences, XLVI, 21 juin 1858), et Traité des entozoaires et des malndies vermineuses de l'homme ou des animaux domestiques. Paris, 18.99 fig. 65. 
parties : l'antéricure, filiforme, très-amincie en avant ; l'autre, moins longue, subitement renflée, et se terminant en pointe obtuse. L'anus se trouve à cette extrémité. Le mâle a un spicule simple, contenu dans une gaine renflée ou vésiculeuse, la femelle

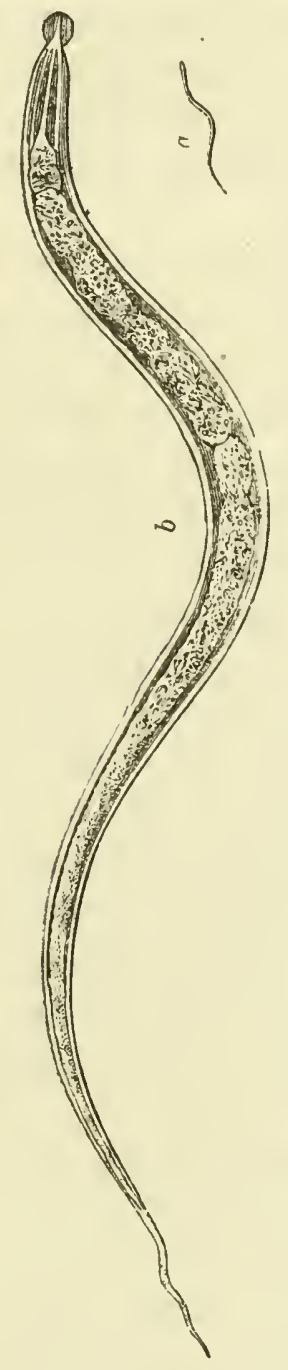

Fig. 1031. - Oxyure femelle.

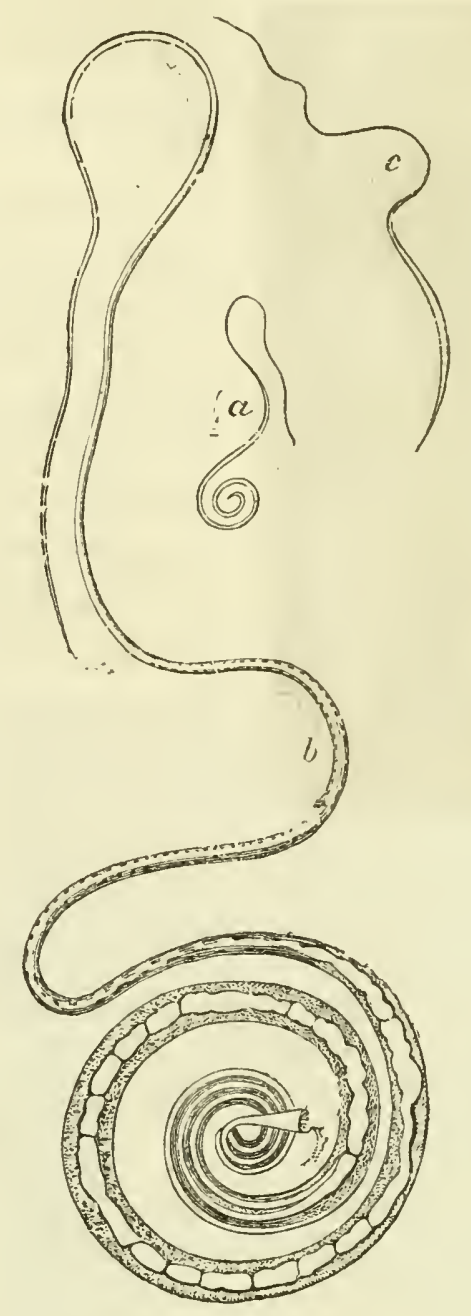

Fig. 1032. - Trichocéphale (").

a la vulve placée au point de jonction des deux parties du corps.

Le plus connu des Trichocéphales est le Tr. dispar, Rudolphi, qui est un des vers les plus communs dans le gros intestin de l'homme, plus rare dans l'intestin grêle.

Ce ver se distingue surtout par son cou capillaire terminé par un corps assez gros. Le mâle a environ 37 millimètres de longueur; la femelle de 40 à 50 millimètres. La partie épaisse du corps n'en occupe que le tiers. Dans le mâle cette partie (fig. $1032 a, b)$ est roulée en spirale. La femelle a la partie posté-

$\left(^{*}\right) a$, måle de grandeur naturelle; $-b$, måle grossi; $-c$, femelle de grandeur naturelle. 
rieure plus droite et simplement percée à l'extrémité. Les œufs, qu'elle pond, ne se développent point dans l'intestin : comme ceux des ascarides lombricoïdes, ils sont expulsés avec les fèces, et ne germent que lorsqu'ils sont reportés dans le tube inteslinal probablentent par les boissons. Leur forme extérieure est

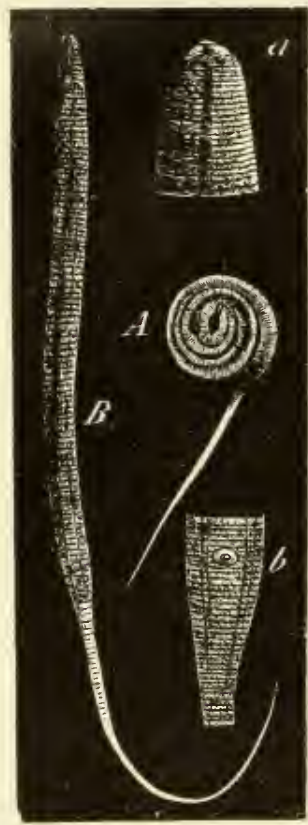

Nig. 1033. - Filaria medinensis à l'état embryonnaire (*). très-caractérisée : ils sont oblongs, revêlus d'une coque résistante, prolongée à chaque extrémité en un goulot court, arrondi, translucide.

Le genre SpIroptère contient une espèce (Spiroptera hominis, Rud.) encore incertaine et sur la quelle nous n'avons pas à insister.

Les Filaires sont des vers très-allongés, cylindriques filiformes, dont les mâles ont, deux pénis inégaux plus ou moins tordus. Une de leurs espèces est célèbre sous le nom de dragonneau, de ver de Médine ou de Guinée. C'est le Filaria medinensis'fig. 1033), Gmelin. On ne connaît que la femelle, qui présente les caraclères suivants : corps blanc, épais de 2 millimètres, pouvant acquérir jusqu'à 7 s̆ centimètres, et, d'après certains auteurs, $1^{\mathrm{m}}, \breve{0} 0$, et même 3 mètres de longueur, terminé en crochel; bouche ronde portant d'après les uns quatre épines disposées en croix, selon d'autres trois petits nodules arrondis. Corps terminé en crochet un peu atténué.

Ce ver est très-commun dans les régions chaudes de l'ancien continent; il est rare en Amérique, où on ne l'observe qu'à l'île de Curaçao. Il s'insinue sous la peau des diverses parties du corps, aux cuisses, aux jambes, au scrotum, au bras, à la poitrine, mais surtout à la cheville des pieds. On ne sait pas exactement de quelle manière il s'introduit dans l'organisme. On a cependant r'emarqué qu'il envahissail les membres inférieurs des gens qui marchent dans les endroits humides, la région dorsale des Indiens qui charrient de l'eau sur leurs épaules, enfin les direrses parties du corps des personnes qui se b igguent daus le Nil ou le Sénégal. On en conclut qua le rer se trouve dans l'eau, à l'état jeune, et qu'il altaque la peau par les conduits sudorilères ou la gaine des poils. Une fois sous les téguments, le ver s'accroît et peut délerminer au bout de quelques mois la production de tumeurs

(*) A, individu cnroulé, peu de temps suns toute après la sortic de l'ouf; - B, individu étendu; - a, portion cepphalique; - b, anus situé vers le point de réunion du corps et de lia p.ortion caudisle. 
douloureuses, el d'abcès au milieu desquels on doit aller chercher le ver pour l'extraire. On le saisit pour cela arec précaution et on le retire tout doucement en l'enroulant autour. d'un petit bâton. Il faut bien prendre garde de ne pas le rompre: car il peut en résulter de graves accidents, dus soit à la présence dans les chairs des embryons dont la filaire est en général touie pleine, soil à la putréfaction du corps de la mère.

Une autre espèce de filaire existe assez communément chez les nègres entre la sclérotique et la conjonctive de l'œil : c'est le Filaria oculi, qui peut acquérir de 1 pouce $1 / 2$ à 2 pouces de longueur el cause souvent des douleurs très-vives.

Le dernier des nématoïdes, dont il nous reste à parler, a acquis dans ces derniers lemps une grande célébrité par les graves maladies dont il est la cause et dont l'opinion publique s'est assez vivement préoccupée; c'est la trichine, Trichina spiralis (fig. 1034), que M. R. Owen avait déjà fait connaître en 1835, mais dont l'histoire n'est bien établie que depuis quelques années. T'el qu'on le rencontre dans les muscles, c'est un petit ver cylindrique, filiforme, ressemblant un peu à un ver de terre, de 1 millimètre à peu près de longueur, de $0^{\mathrm{m}}, 003$ à $0^{\mathrm{m}}, 00$ d'épaisseur. Sa peau est assez épaisse, transparente, homogène, ridée transversalement. L'extrémité buccale est un peu plus effilée que l'autre : à cet état, les trichines ont un tube digestif assez simples'ouvrant par une fente terminale; mais pas d'organe sexuel. On les rencontre parfois libres, cheminant dans les fibres musculaires, mais elles finissent presque toujours par s'enkyster. A l'endroit où elles s'élablissent, les fibres du muscle changent de nalure, ses stries disparaissent; il devient granuleux, le sarcolemme s'épaissit tout autour,

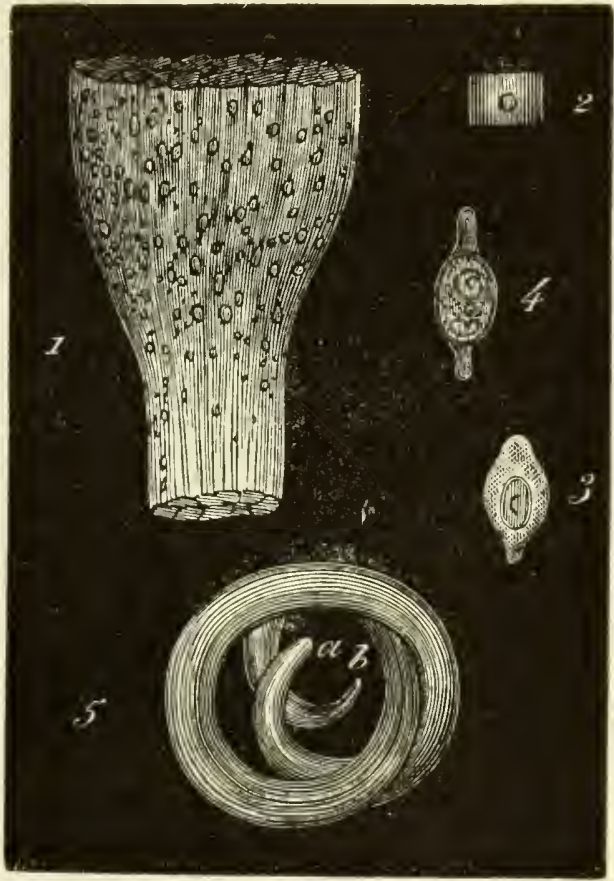

Fig. 103 '.- Trichina spiralis, d'après.R. Owen $\left(^{*}\right)$ el le ver se trouve entouré d'une enveloppe à deux parois, ayant

(*) 1, portion de muscle (cubital antérieur) couverte de kystes de trichines (plusieurs de ces kystes ont été dessinćs trop grands); -2 , ḳste isolé ; -3 , kyste grossi 20 fois contenant une matière calcaire ; -4 , kiste contenant deux vers; -5 , trichine grossie 200 fois; - $a$, extrémité eéphaliquue; - $b$, extrémité catudale. 
la forme d'un ooil humain, de la grosseur d'un petit grain de sable ou d'une petite tele d'épingle. Plus tard les parois de ce kyste s'encroûtent de sels calcaires; et c'est alors seulement qu'on peut les apercevoir facilement à l'œil au milien des fibres rouges

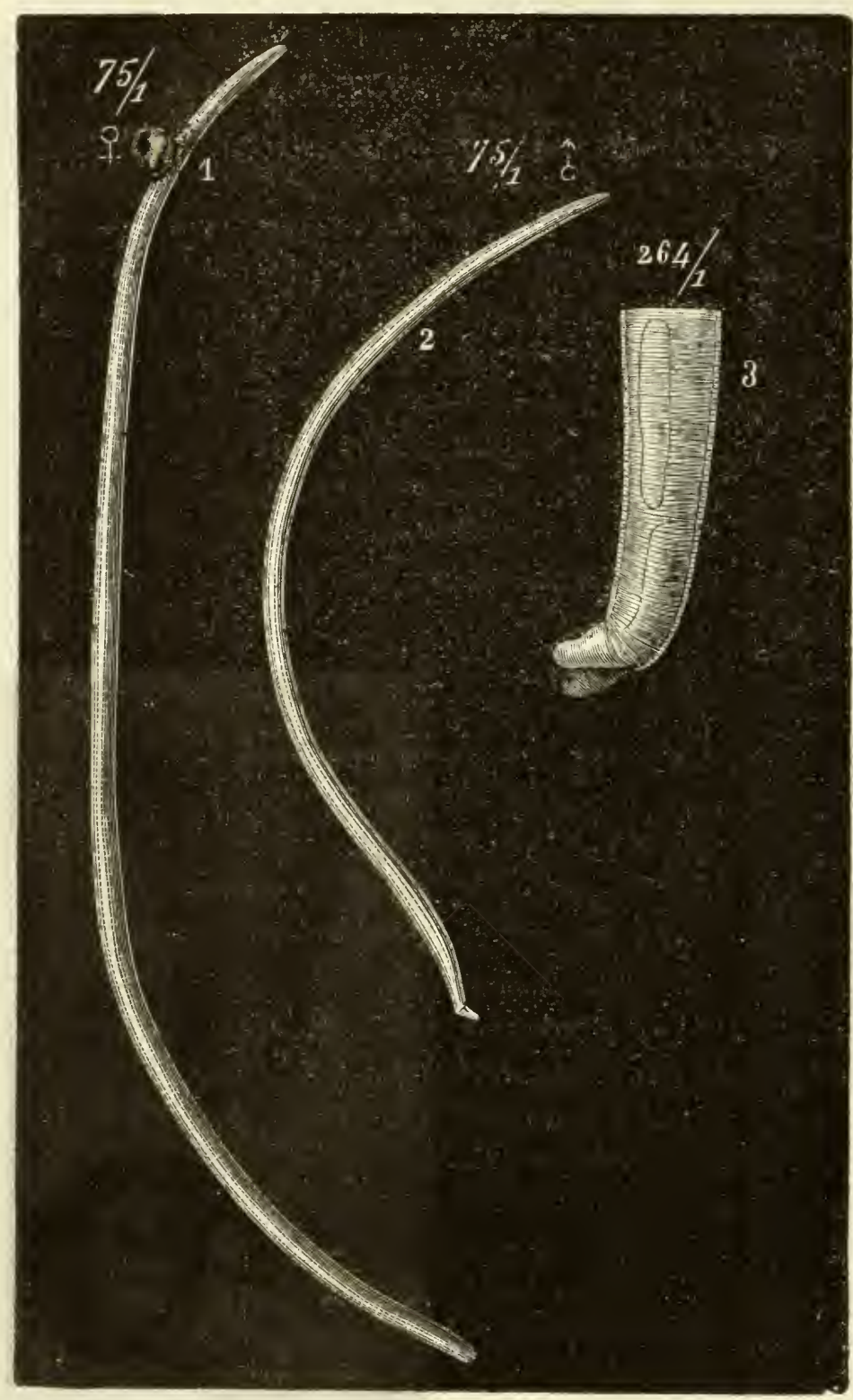

lig. 1035. - Trichina spiralis $(*)$.

du muscle. La trichine est roulée en spirale sur elle-même dans l'intérieur de cette poche, elle y reste très-longtemps vivante, mais elle n'y alteint jamais l'étal sexué : cc n'est que lorsque les

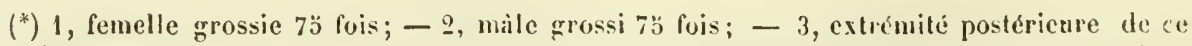
Icrnier, vuc de còté, grossic $266^{\circ}$ fois pour montrer les prolongements qui forment la pince (opulatrice postérienre. 
sucs intestinaux agiront sur sa coque extérieure et qu'elle se trouvera dans le tube digestif qu'elle accomplira cette évolution. M. Virchow, à Berlin, Leuckart, à Giessen, ont fait connaître d'une manière positive ces phases curieuses de la vic de la trichine. Si l'on fait avaler à un lapin, par exemple, un morceau de viande contenant des kystes de trichines, ces vers se trouvent débarrassés par les sucs digestifs des muscles et des enveloppes qui les contiennent: une fois libres, ils grandissent, acquièrent des organes de la génération qui viennent s'ouvrir chez le mâle à côté de l'anus, entre deux appendices coniques, et chez la femelle au tiers supérieur de la région antérieure du ver. Les mâles ont alors un millimètre environ de longueur: les femelles, qui sont beaucoup plus nombreuses, ont 3 ou même 4 millimètres. Ces animaux se fécondent, et quatre ou six jours après, les femelles donnent naissance à un grand nombre de petits embryons vivants. Les parents meurent alors et sont expulsés au dehors. Quant aux petils, ils perforent les parois intestinales et se répandent dans les muscles, où ils vont s'enkyster. C'est dans cette période, qu'ils causent dans l'organisme des désordres considérables, qui peuvent se terminer par la mort.

Les faits que nous venons d'indiquer ont permis d'expliquer la nature de certaines affections morbides à forme souvent épidémique, observées surtout dans le nord de l'Allemagne. On sait maintenant que le point de départ de toutes ces maladies a été l'indigestion de viandes contenant dans leurs fibres un grand nombre de trichines enkystées. C'est surtout la viande de porc, mangée crue à l'état de jambon ou de saucisson, qui a ainsi produit la trichinose. Aussi le meilleur moyen d'éviter ces accidents est de faire cuire ou de fumer arec soin la chair de ces animaux. Dans ces conditions, les trichines meurent dans leur kyste et sont complétement inertes (1).

\section{$2^{\circ}$ TRÉMATODES.}

Les Trématodes soṇt des animaux inarticulés, vermiformes ou discoildes, mous, ayant un canal digestif à une seule ouverture. Iis ont en général des ventouses, ou organes d'adhérence. Les sexes sont souvent réunis sur le même individu. Les organes de la génération sont très-complexes. Les œufs sont elliptiques et le plus souvent pourvus d'un opercule.

On distingue dans les trématodes deux groupes distincts: les

(1) Voy. A. Delpech, Rapport sur les trichines et la trichinose (Bull. de l'Académie de médecine. Paris, 1865-66, t. XXXI, p. 659, et Annales d'hygiëne. 18t6, $2^{\mathrm{e}}$ série, t, XXVI, p. 21). - Voy. aussi Thudichum, Public Health. Seventh Report of the medical Officer of the Privy Council, 1864. London, 1865. 
polystomes, qui ont en général plus de deux ventouses, vivent en parasites externes et ont dès leur naissance la forme qu'ils conserveront toujours ; les distomes, qui n'ont pas plus de deux ventouses, sont digénèses, et vivent la plupart dans le corps d'autres animaux. Ce sont les seuls dont nous ayons à nous occuper.

Les faits de génération alternarte n'ont encore été observés que chez les distomes non parasites de l'homme; mais il est probable que tous les animaux de ce groupe passent par des phases analogues. Quand l'embryon d'un distome sort de l'œuf, il a le corps cilié comme celui d'un infusoire. A son intérieur se développe une espèce de sac mobile, pourvu d'une ventouse rudimentaire, qui lui sert à se fixer sur certains mollusques, ou sur des insectes

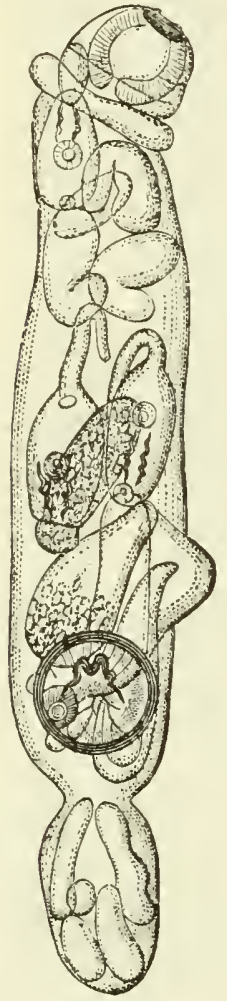

Fig. 1036. - Sporocyste du Distoma echinatum, trèsgrossi.

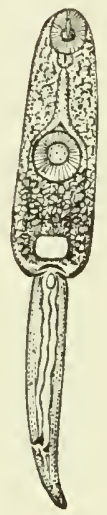

Fig. 1037. - Cercaire du Distoma retusum, trèsgrossi.

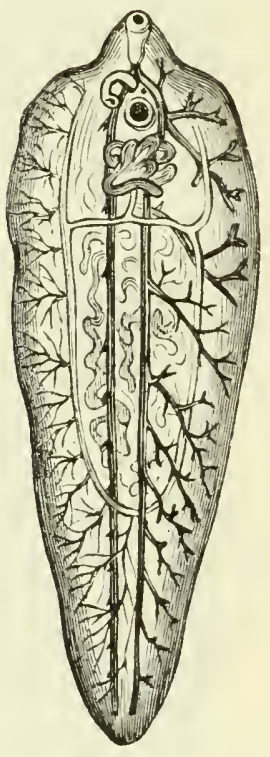

Fig. 1038. - Distome hépatique.

aquatiques. Bientôt cet animal (fig. 1036) produit par une sorte de bourgeonnement interne des êtres d'une forme toute différente, ayant déjà l'apparence du distome adulte terminé par une queue simple (fig. 1037) ou bifide. Ces animaux ont été décrits à cet état sous le nom de cercaires, et rangés dans. le groupe des infusoires: mais on sait maintenant que ce ne sont que des sortes de larves de distomes. En effet, à un moment donné, ils pénètrent 
dans l'intérieur d'un mollusque ou d'un autre animal aquatique; ils s'y enkystent après avoir perdu leur queue; ils ont ainsi toute l'apparence du distome adulte. Mais, pour acquérir les organes sexuels, ils doivent attendre de nouvelles conditions : il faut que l'animal, dans lequel ils se trouvent, soit avalé par un vertébré, et que, parvenus de cette manière dans l'organe qui leur convient, ils puissent atteindre la dernière phase de leur développement. Ils produisent alors des œufs qui, expulsés au dehors, vont recommencer le cycle d'évolutions que nous venons d'indiquer.

Les distomes qu'on a rencontrés dans le corps de l'homme sont : la douve et le distome lancéolé, qui se trouvent tous deux dans le foie : le Distoma heterophies, de l'intestin; le Fascicularia ocularis, Moq., et le Festucaria lentis, Moq., qu'on a rencontrés dans l'œil; enfin le Thecosoma hematobium, Moq., découvert dans la veine porte. Nous ne parlerons que des deux premiers.

Douve hépatique (Distoma hepaticum). Cet helminthe a le corps ovale-oblong, aplati comme une feuille, plus large en avant où il se rétrécit en une sorte de cou, qui porte à son extrémité la bouche entourée d'une sorle de cupule. La ventouse ventrale se trouve un peu en arrière de la bouche, et entre les deux ventouses l'orifice des organes sexuels. Ses dimensions sont de 18 à 31 mil. de long sur 4 à 13, 5 de large (fig. 1038).

Ce ver est parasite des ruminants : on le trouve aussi chez le cheval, l'âne et le cochon, et quelques autres animaux encore; rarement chez l'homme, où il vit généralement dans les conduits et la vésicule biliaires, quelquefois aussi dans l'intestin.

Distome lancéolé (Distoma lanceolatum). Ce distome, plus petit que le précédent, est lancéolé ; trois ou quatre fois plus long que large, demi-transparent, lisse. La ventouse buccale est plus grande que dans l'espèce précédente. Il vit à peu près dans les mêmes conditions que la douve. A cause de ses moindres dimensions il peut pénétrer plus avant dans les canaux biliaires.

\section{$3^{0}$ TUBELLARIÉS.}

Les turbellariés sont des vers dont le corps est mou, déprimé, sans divisions annulaires, dépourvus d'appendices latéraux quelconques et de ventouses. Ces animaux se lient d'une manière assez intime aux sangsues; quelques-uns d'entre eux ont une bouche et un anus distincts et situés aux deux extrémités du corps; mais, chez d'autres, l'orifice anal se trouve vers le milieu de la face ventrale, et il en est beaucoup chez lesquels la cavité digestive ne communique à l'extérieur que par une ouverture unique. Le canal alimentaire est souvent garni de prolongements 
latéraux plus ou moins ramifiés : la circulation s'opère à l'aide d'un système de vaisseaux très-analogues à ceux des sangsues. Chez la plupart on n'a pas reconnu de système nerveux; mais, chez d'autres, il se compose de deux cordons longitudinaux terminés antérieurement par une paire de ganglions sous-œsophagiens. La plupart sont androgynes. Ils ne sont pas parasites comme les véritables vers intestinaux; on les trouve dans la mer et dans les eaux douces, où ils rampent à la manière des li maces. On les divise en planaires, cérébratules et mémertes.

\section{$4^{\circ}$ CESTOÏDES.}

Les cestoïdes ou vers rubanés sont caractérisés, ainsi que l'indique leur nom, par l'aspect aplati de leur corps. Ils ont une tête très-petite, munie de deux ou quatre ventouses et parfois de crochets disposés en couronne: une portion très-mince, qu'on appelle leur cou, puis un corps élargi formé d'un nombre consi-

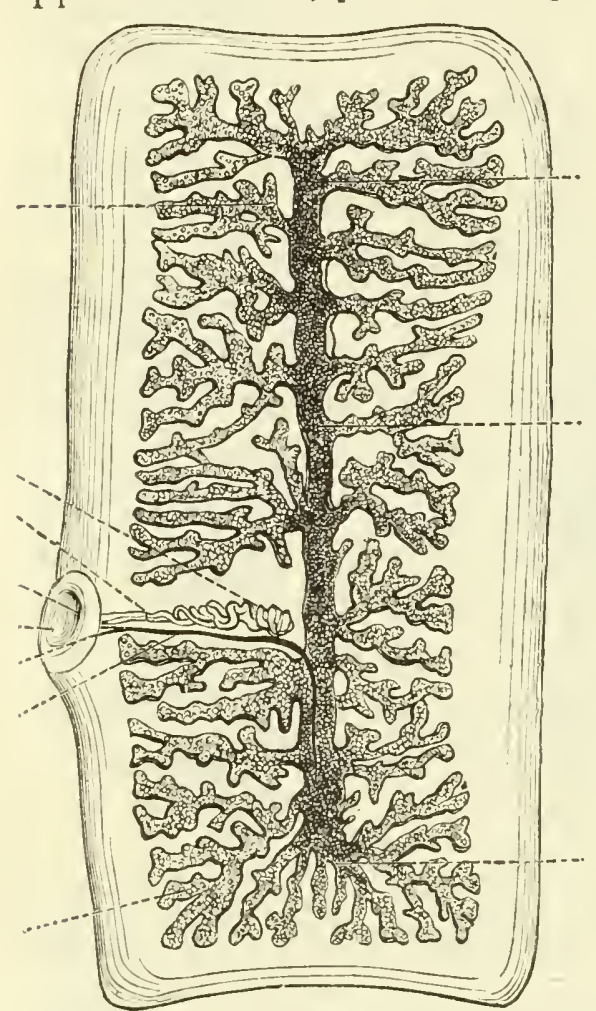

Fig. 1039. - Teria solium $\left({ }^{*}\right)$. dérable d'articles pouvant se détacher les uns des autres dans la dernière période de leur vie. Ils n'ont pas de tube digestif, pas d'organes de circulation, un appareil excréteur (?) formé de 4 vaisseaux longitudinaux anastomosés entre eux. Quant aux organes de la génération, ils sont très-complexes. Chacun des anneaux est hermaphrodite et contient dans sa cavité un testicule et un canal déférent aboutissant au pénis, un organe produisant la résicule germinative, un autre le vitellus, une matrice, et un vagin s'ouvrant à côté de l'orifice dı mâle ou dans un cloaque commun (fig. 1039).

Les cestoïles sont digénèses el passent successivement par les états de scolex, strobile, et progloltis. Ces phases successives ont été surtout étudiées pour le ténia, et nous les décrirons avec détails à propos de ce ver. Les helminthes de ce groupe que nous avons à signaler rentrent tous dans les genres Thenia et Botryocéphale.

(*) $a$, testicule; $b$, spermiducte; $c$, orifice du pénis; $d$, matrice remplie d'œufs ; $e$, ragin, $f$, cloaque sexucl. 
Le plus connu est certainement le Tienia Solium., L. vulgairement désigné sous le nom de ver solitaire.

On avait remarqué depuis longtemps ce ver à l'état adulte, et on avait décrit les principaux traits de son organisation, mais il n'y a guère qu'une quinzaine d'années que les observations de Küchenmeister, suivies de celles de Leuckart, de Siebold, Van Beneden (1), Humbert (de Genève), etc., etc., ont montré par quelles phases successives passe ce curieux animal.

Quand un œuf de ténia, libre ou enfermé encore dans les ar. ticles rejetés avec les foces, est avalé par le cochon, et arrive ainsi en contact des sucs intestinaux, l'embryon, qui existait déjà dans l'œuf, sort de l'enveloppe cornée qui l'entourait. Il est alors court, sans articulations, muni de six crochets, au moyen desquels il peut se frayer un passage à travers les tissus. C'est le premier état du ver, le protoscolex. Dès qu'il s'est établi dans une partie du corps de l'animal, le plus souvent dans les muscles ou le tissu cellulaire, il se produit dans son intérieur par une sorte de gemmation un nouvel etre, qui s'enkyste au milieu des tissus: c'est le Scolex. On aperçoit alors dans le petit kyste une fine vésicule ( $f g .1040,1041$ et 1042), logeant dans son intérieur une partie invaginée comme un doigt de gant, qui, lorsqu'elle se déroule au dehors, présente une sorte de cou terminé par une petite tête. Cette partie céphalique rappelle tout à fait par son apparence celle que nous décrirons dans l'état parfait du ténia; elle est, comme elle, armée de ventouses et de crochets. La vésicule mesure environ 1 วั millimètres de diamètre. - Elle était décrite sous le nom de cysticerque du cochon (Cysticercus cellulosce), et regardée comme un helminthe particulier, avant qu'on eût aperçu que ce n'était qu'un des états du ver solitaire. Ce sont ces vésicules, et leur kyste, qui constituent ce qu'on connaît sous le nom de ladrerie du porc.

Les cysticerques restent à cet état, tant qu'ils sont logés dans les muscles ou le tissu cellulaire du cochon. Mais si la chair du porc vient à être avalée par l'homme, de nouvelles transformations vont s'opérer, la vésicule terminale va disparaître, et le Scolex, constitué par la partie céphalique, va donner naissance par voie de génération agame à une série de nouveaux individus possédant chacun les deux sexes: ce sont les articles du ver rubané, les proglottis, qui, agrégés ensemble, forment le ver solitaire dans son état ordinaire, l'état strobilaire de M. Van Beneden ( $f g .1043$ ).

Dans cette période, le ver solitaire présente les caractères sui-

(1) P. Gervais et Van Beneden, Zoologie médicale. Paris, 1859, t. II, p. 229. 
vants : il est très-long, plat, d'une blancheur opaline, devenant d'un blanc opaque dans l'alcool. Il a une consistance gélatineuse ou parenchymateuse et se déchire très-facilement. Sa longueur
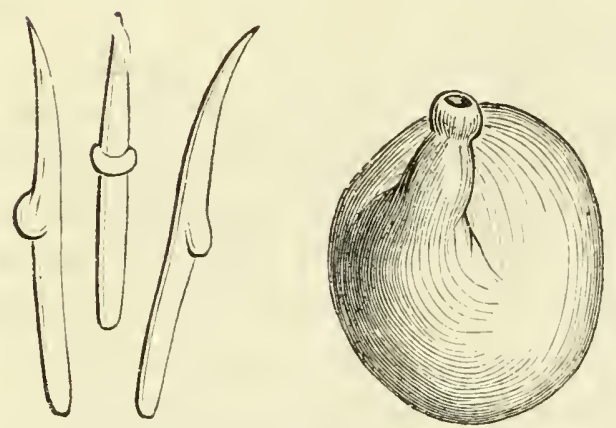

Fig. 1040 et 1041. - Cisticerque du cochon et trois de ses crochets.
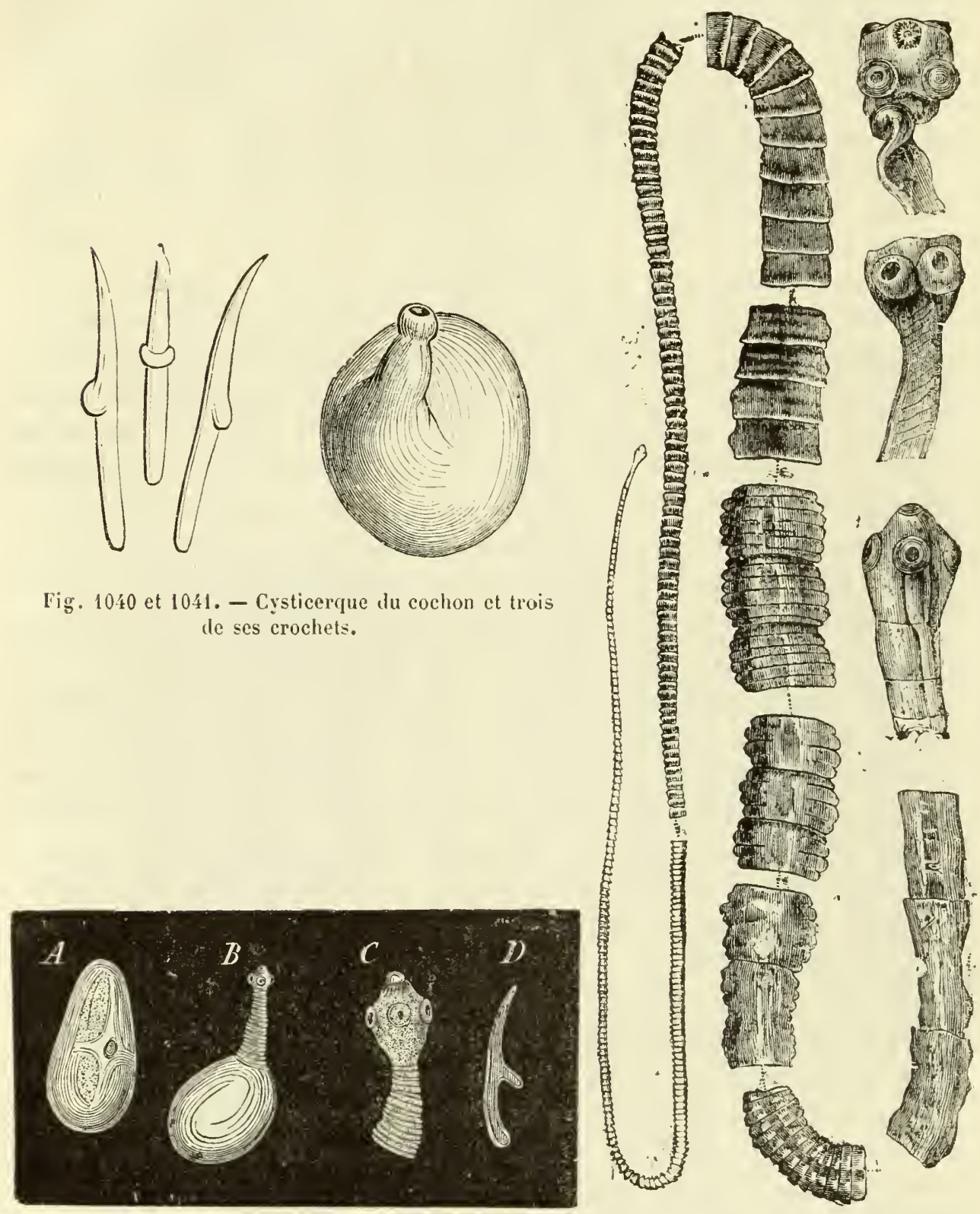

rig. 1042. - Cysticerque $\left({ }^{*}\right)$.

Fig. 10ł3. - Tánia solimm (état strobilaire).

et le nombre de ses anneaux sont très-variables. Il est fréquemment long de 1 à 3 mètres; on prétend même en avoir vu de 10 mètres. Sa tête est fort petite (fig. 1043), et cependant bien dis-

$\left(^{*}\right) A$, animal retiré dans son ampoule; $B$, animal développé; $C$, tète et cou isolés; $D$, ur des crochets. 
tincte par suite de l'extrême étroitesse du cou. Elle est presque carrée à cause de ses quatre suçoirs latéraux, et présente au sommet un rostre très-court et très-oblus. Ce rostre est entouré d'une couronne de crochets. Le véritable cou est très-court, quoique

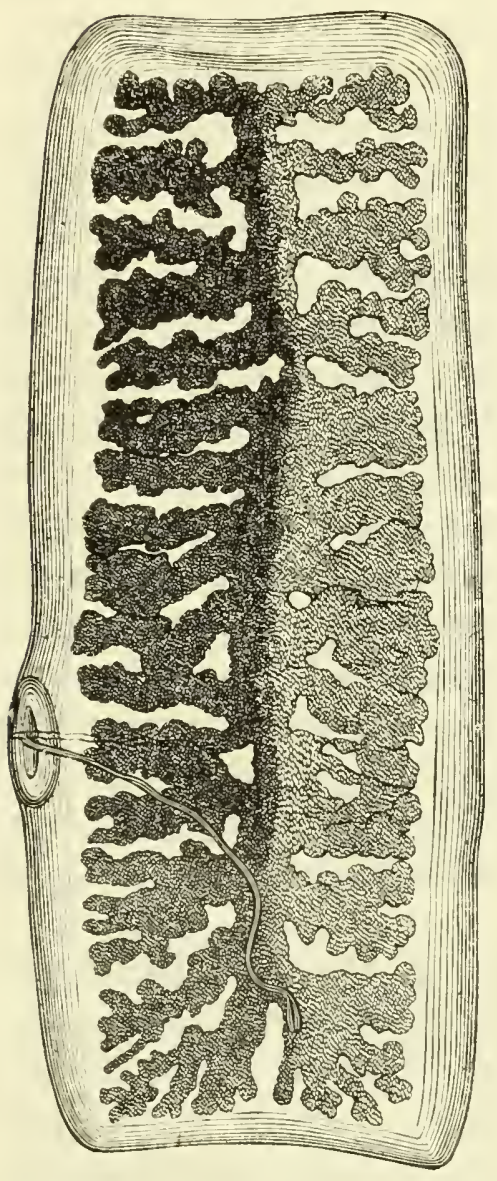

Fig. 104^. - Tænia solium (proglottis).

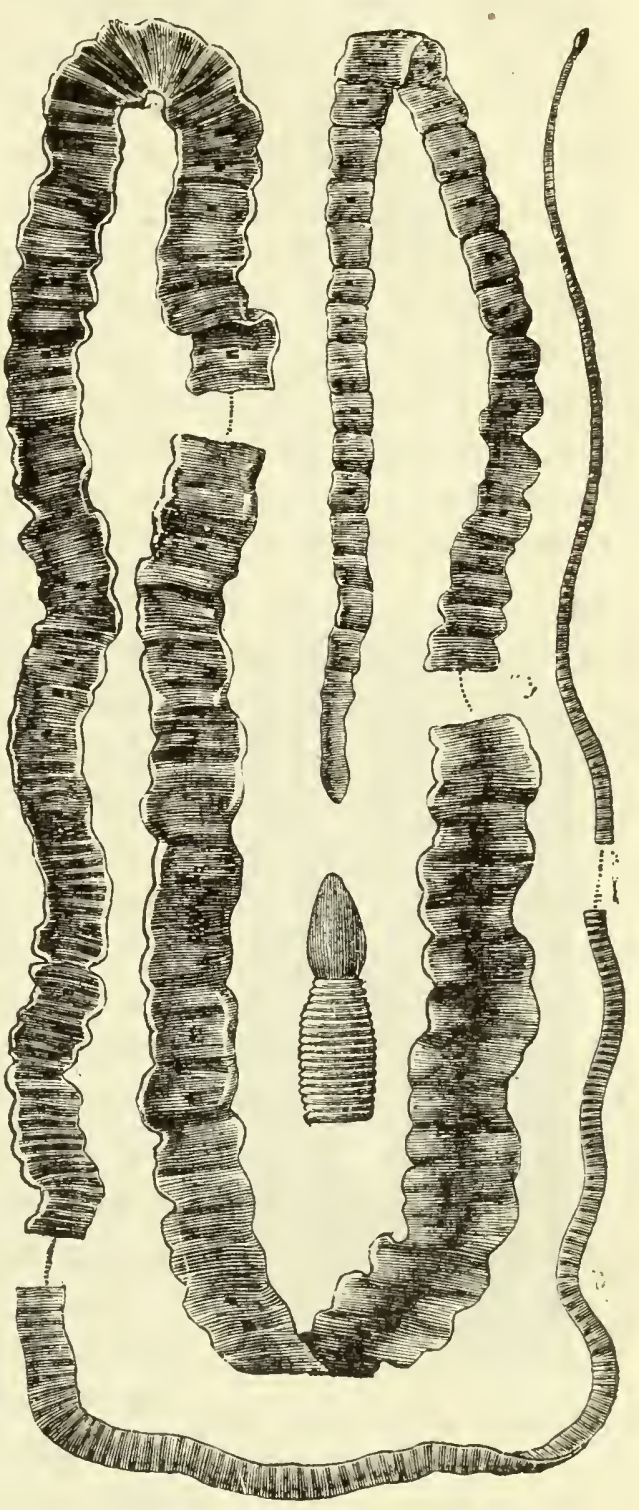

Fig. 10 \{ว. - Bothiocéphale.

cinq ou six fois plus long que la tête : ce qui le fait paraître trèslong, c'est que les premiers articles du corps, qui commencent immédiatement après, sont d'abord peu distincts, aussi grêles que le cou, sur une longueur assez considérable, et n'augmentent en largeur que très-lentement. Dans le second tiers du corps, les articles sont bien formés, sub-carrés, plus étroits en avant, terminés en arrière par une sorte de bourrelet droit; plus bas, les arti- 
cles s'allongent au point de devenir deux ou trois fois plus longs que larges; leurs extrémités sont à peu près droites: leurs côtés sont renflés au milieu, et souvent l'un ou l'autre élargi par un petit mamelon percé d'un orifice arrondi. (Dans cette partie, le corps du ténia a 7, 9 ou même 13 mill. de large.) Les mamelons, dont il vient d'être parlé, et dans lesquels se trouve l'orifice des organes sexuels, sont assez inégalement rangés de chaque côté du corps; car il y en a souvent alternativement deux d'un côté et un de l'autre, et, d'autres fois, trois ou plus sans interruption d'un seul côté, puis un de l'autre.

On a cru pendant longtemps qu'il n'y avait qu'un seul ténia à la fois dans le canal intestinal, mais on a vu des malades en rendre presque simultanément 2 ou 3 ; on cite même une femme qui en a rendu 18 dans l'espace de quelques jours. Pendant longtemps aussi, on a regardé les articles séparés du ténia ( $f g .1044)$ comme des animaux particuliers qu'on appelait des vers cucurbi-

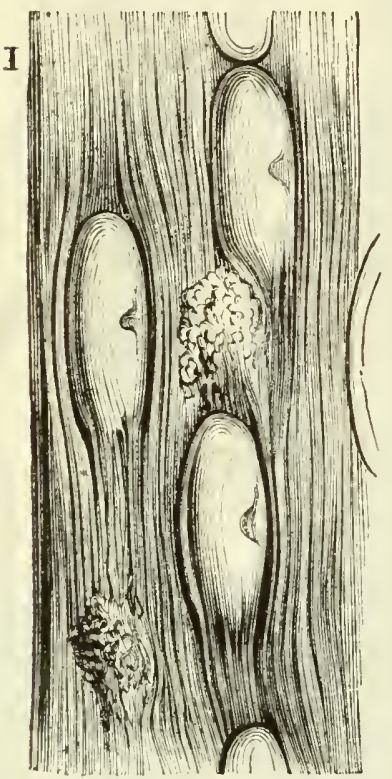

Fig. 1046. - Cysticerques dans les muscles de l'homme.

tains. Ces cucurbitains sont presque entièrement remplis par la matrice, qui présente un aspect rameux et contient une quantilé considérable d'œufs, presque globuleux, un peu plus longs que larges.

Le ténia est un des vers les plus communs dans le tube digestif de l'homme. Il est surtout répandu dans les régions où on mange du cochon à l'état cru, jambon ou saucisson. On l'a observé dans presque toutes les parties du monde. Dans certains pays d'Afrique, en Abyssinie, par exemple, presque tous les habitants en sont atteints.

On a accusé le ténia de déterminer chez l'homme des accidents fort graves, et de le conduire souvent au marasme et a la mort. Mais on a acquis la certitude que des individus, qui cependant en étaient affectés, avaient vécu pendant longtemps dans un état de santé aussi parfait que ceux qui en sont exempts et sans qu'on pût soupçonner en rien la présence de ce ver dans leur tube digestif. Généralement cependant les hommes qui ont un ou plusicurs ténias dans leurs intestins, éprouvent un certain affaiblissement, de la dyspepsie, de la boulimie, etc., qui leur font désirer d'en être délivrés. Les médicaments qui réussissent le mieux sont: l'huile animale de Dippel, l'écorce de racine de grenadier, l'huile de fougère mâle, le cousso d'Abyssinie, le 
mousséna, le kamala, aidés de l'action purgative subséquente de l'huile de ricin.

On a trouvé accidentellement chez l'homme le ténia dans son état de cysticerque (fig. 1046); mais le cas est rare (1), et ce n'est qu'autant qu'il y aurait un nombre considérable de ces hydatides et qu'ils comprimeraient des organes importants, qu'ils pourraient amener des accidents sérieux.

Un des organes, où on l'a rencontré dans ces derniers temps, est le corps vitré de l'œil. La conséquence inévitable de sa présence est la désorganisation graduelle de cette partie; aussi faut il dans ce cas se hâter de l'extraire aussitôt qu'on l'a constaté.

Une autre espèce de ténia dont on ne connaît chez l'homme que l’état vésiculaire ou le Scolex est l'échinocoque (fig. 1019). On le trouve dans divers organes: poumons, rate, pancréas et foie, plus rarement dans le cerveau. L'embryon des échynocoques, une fois fixé dans les tissus, ne produit pas un seul scolex comme celui des Trenia solium, mais une génération de simples vésicules, qu'on a appelées des acéphalocystes ( $f g .1047)$. Ces vésicules en produisent d'autres, tantôt semblables à elles-mêmes, tantôt munies d'une tête couronnée de ses crochets et portant latéralement des ventouses circulaires (fig. 1048). Ces Scolex, d'abord adhérents à la membrane génératrice, s'en détachent pour nager dans le liquide qu'elle renferme. Ils restent à cet état, et se résorbent même peu à peu en ne laissant que leurs crochets, si les conditions de leur existence ne viennent pas à changer. Mais si le chien avale un des organes dans lesquels ils se trouvent, ils se transforment dans son canal digestif en un petit ténia, qui n'a pas plus de trois millimètres de longueur, et dont nous donnons ici la figure (fig. 1049). Ce strobile présente cette particularité que le dernier segment est déjà adulte lorsqu'il n'y a encore que deux ou trois anneaux de formés. La matrice est sinueuse et le remplit presque complétement; les œufs en sont sphériques.

Ce ver habite dans son état d'bydatide, à part les organes de l'homme, ceux de la plupart des animaux domestiques. C'est dans le chien, qu'il prend la forme adulte, on le nomme Terria Echinococcus.

Nous ne mentionnerons que pour mémoire le ténia ccenure (Tcenia Canurus),' qui, à l'état de Scolex, se loge dans le cerveau du mouton et, en comprimant cet organe, produit la maladie connue sous le nom de tournis.

D'autres ténias se trouvent encore chez l'homme, mais plus ra-

(1) Sichel fils. Note sur un cas de cysticerque ladrique intra-ocu!aire (Journal de pharmacie et de chirurgie. $4^{\mathrm{e}}$ série, XV, 396). 
rement que le ver solitaire : ce sont les T'crnia flavopunctata, Weinl, le Trenia nana, Sieb., T'cnia elliptica, Batsch, qui onl tous la tête armée ; enfin, le T'cenia inerme ou médiocanellé ( $T$ 'cenia mediocanellata, Küch.), dont l'extrémité antérieure est dépourvue de crochets.

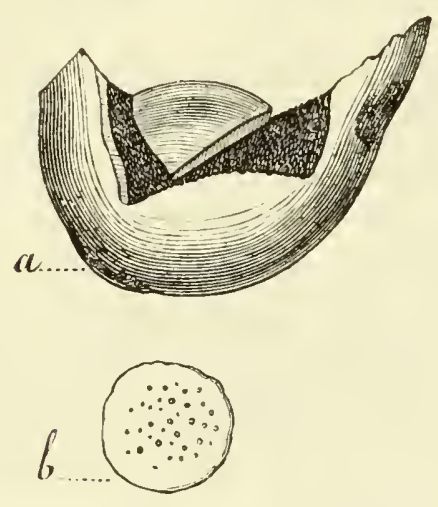

Fig. 1047. - Acéphaloẹste.

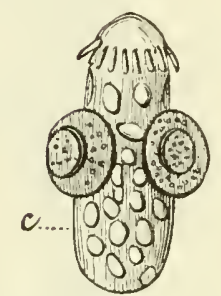

Fig. 1048. - Scolex de l'échinocoque.

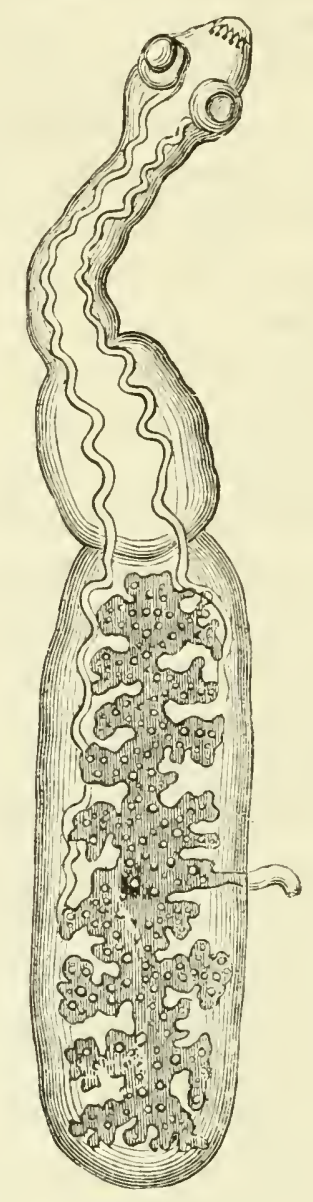

Fig. 1049. - Ténia échinocơue du chien.

Le genre botriocéphale ne nous intéresse que par une seule espèce, le téria large ou Bothriocephalus latus (fig. 10/3̆). Il a la tête oblongue, pourvue pour tous suçoirs de deux fosseltes longitudinales opposées l'une à l'autre. La tête est peu apparente, d'abord à cause de sa petitesse, ensuite parce que le cou n'est pas beaucoup moins large. La partie antérieure du corps est moins filiforme que dans le ténia et s'élargit plus promptement. Les articulations sont beaucoup plus rapprochées. Les anneaux sont par conséquent plus courts, beaucoup plus larges que hauts, et plus réguliers. Ils se distinguent aussi très-nettement de ceux du ver solitaire, en ce que l'ouverture des organes génitaux se trouve sous le milieu inférieur des anneaux et non sur les bords latéraux.

Tous les zoologistes décrivent chacun des anneaux du Bothriocéphale comme portant en son milieu deux orifices, l'un situé dans 
le voisinage du bord supérieur del'anneau et désigné sous le nom d'orifice mâle, l'autre occupant le centre de l'anneau et qui a reçu le nom d'orifice femelle. Or, lorsqu'on examine altentivement un de ces anneaux, on voit que le marnelon supérieur porte, non pas une, mais deux ouvertures, l'une qui permet à la verge de saillir au dehors, l'autre, fente étroite et allongée, qui communique avec un long tube vaginal et que l'on peut désigner, pour ce motif, sous le nom de vulve; ce mamelon dépend donc à la fois de deux appareils sexuels : quant à l'orifice central, il représente l'ouverture de l'utérus et donne issue aux œufs.

Il résulte de ce qui précède : $1^{\circ}$ que l'appareil femelle du Bothriocéphale diffère considérablement de celui du Ténia, puisqu’il possède deux orifices; qo que chez le Bolhriocéphale il y a une ponte régulière, tandis que chez le Ténia, les œufs̀ ne peuvent être mis en liberté que par la séparation des anneaux. On s'explique ainsi comment les Bothriocéphales peuvent atteindre des dimensions considérables et comment des malades peuvent en posséder sans pourtant rejeter de proglottis, ce qui fait souvent méconnaître la présence du parasite (1).

Le bothriocéphale a de 2 à 9 mètres de longueur sur 12 à 1 ŏ mill. de largeur, mais on en a cité qui avaient des dimensions beaucoup plus considérables.

Il est loin d'être aussi répandu à la surface du globe que le T'cenia solium. On le trouve au contraire limité dans certaines régions déterminées : il est très-commun à Genève, dans les. pays baignés par la Baltique, en Russie et en Pologne, à l'est de la Vistule. On ne le connaît point à l'état de cysticerque : et l'on ignore les conditions de son existence avant qu'il soit porté dans le lube digestif de l'homme.

La présence des divers entozoaires, dans le corps humain, est parfois assez difficile à diagnostiquer : un des meilleurs moyens de la constater est l'examen des œufs, qui peuvent être expulsés au dehors. Aussi ne saurions-nous mieux faire que de terminer les indications qui précèdent par le tableau suivant, emprunté à M. Davaine (2).]

(1) Voir Sommer et Landois (Zeitschrift für Wiss. Zoologie, t. M Mil, mars, 1872).

(2) Consulter, pour les entozoaires, P. Gervais et Van Beneden, Zoologie médicale. Paris, 1859. - Davaine, Traité des entozoaires et des maladies vermineuses. Paris, 1860. - Virchow, Darstellung der Lehere von den Trichinen. Berlin, 1864. - Leuckart, Untersuchungen über Trichina spiralis. Leipzig et Heidelberg, 1860. - Kestner, Élude sur le Trichina spiralis. Paris, 186t. Siebold, Ueber den Generationswer.hsel der Cestoden (Zeiltschrift für wissenschaftliche Zoologie, 1850, II, 198).- Küchenmeister, Die in und an dem Kilrper des lebenden Menschen vorkommenden Parasiter. Leipzig, 1855. 
Tableau des ovules qui peuvent se rencontrer dans les garde-robes, pour servir au diagnostic de la présence des ver's dans l'intestin ou dans les voies biliaires.

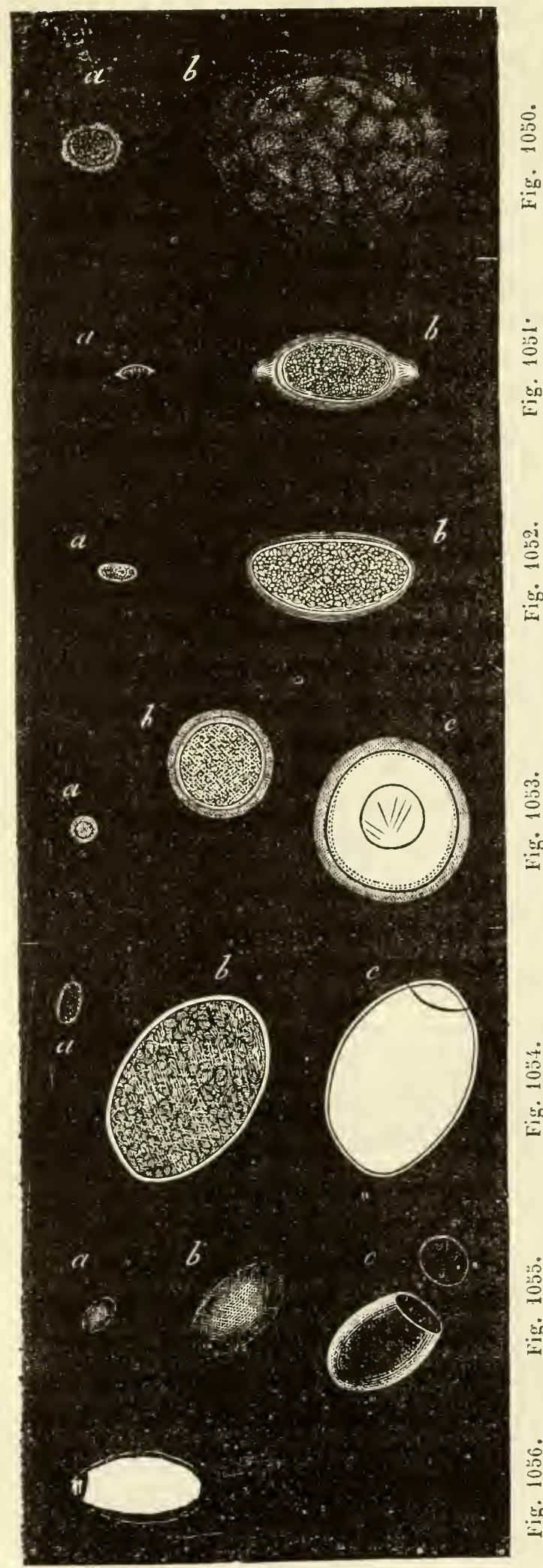

Tous les ovules de la première colomne sont au grossissement de 70 a 107 diamètres; ceux de la seconde et de la troisième colonne sont au grossissement de 340 diamètres.

1050. Ascaride lombricoüde. - a, ovule grossi 107 fois; $b, 340$ fois, - Ces ovules expulsés avee les féces sont d'un jaune brunâtre, mûriformes; sourent leur coque n'est plus visible à travers l'enveloppe extérieure albumineuse? (enveloppe transparente chez l'œuf pris dans l'oviducte) qui s'est imbibée des liquides intestinaux après la ponte, et - qui est ainsi devenue plus on moins opa$\overrightarrow{20}$ que. - Longueur, $0 \mathrm{~mm}, 07 \mathrm{~s}$; largeur, $0^{\mathrm{mm}}, 0 \not 38$.

Ces ovules sont expulsés arec les garde-robes ehez les individus atteints d'ascarides lombricoïles adultes. On les trouve facilement.

1051. Trichocéphale dispar. - a, orule grossi 70 fois: $b, 340$ fois. - Longueur, $0^{\mathrm{mm}}, 053$; largeur, 0 mm, 02.4 . oi On les trouve très-ficilement et très$\stackrel{20}{\subseteq}$ conmminément dans les selles.

1052. Oxyure vermiculaire. - $a$. $\therefore$ ovule grossi 70 fois; $b, 340$ fuis. - Longueur, $0^{\mathrm{mm}}, 053$; largeur $0 \mathrm{~mm}, 028$. - Je l'ai cherché vainement dans les selles chez les individus atteints d'oxyures.

1053. Tenia solium arme. - $a$, orule grossi 70 fois; $b, 3.40$ fois; $c$, même grossissement, traité par la solution de potasse caustique conceutrée. - Diamètre, $0^{\mathrm{mm}}, 033$. - J'ignore encore si les œufs De téuia se présentent dans les selles - lorsque ce ver est intact; il doit en ètre - ainsi dans les cas de Tania fenestrata; - j'en ai trouvé chez un individu qui rendit des fragments déchires. De nourelles olservations sont nécessaires pour qu'on sache ce que la recherche des orules peut donner d'éclaireissements au diagnostic.

103̈i. Bothriocéphale large. - $a_{2}$ ovule grossi 70 fois; $b, 340$ fois ; $c$, traité par l'acide sulfurique concentré qui fait apparaître l'opercule. - Longueur, $0^{\mathrm{mm}}, 068$; largeur, $0^{\mathrm{m} m}, 044^{\prime}$. Mêmes remarques que pour le Tæria solium.

1055. Distome lancéolé. - a, ovule grossi 107 fois; $b, 340$ fois; $c$, traité par la potasse caustique qui rend la séparation de l'opereule plus facile. Couleur brun noirâtre; longueur , $0 \mathrm{~mm}, 04$; largeur, $0_{\mathrm{mm}}, 02$. - Ces ovules se rencontrent chez le mouton dans les ma- tières fécales; ils indiquent avec certitucle la présence du distome lancéolé dans les canaux biliaires ou dans l'in- testin. S'ils se rencontraient dans les - garde-robes chez I'lomme, ils seraient également un signe certain de la présence du distome lancéolé dans les roies biliaires ou digestives.

1056. Distome hépatique. - a, orule grossi 107 fois et traité par la potasse eaustique pour en séparer l'opercule. - Longueur, $0^{\mathrm{mm}}, 13$; largeir, $0^{\mathrm{mm}}, 09$. so - Mêmes remarques que pour le distome lancéolé. 


\title{
TROISIEME EMBRANCIEMENT
}

\author{
ANIMAL MOLIUSQUES.
}

L.es mollusques n'ont point de squelette osseux ni de canal vertébral. Leur système nerveux ne se réunit pas en une moelle épinière; mais seulement en un certain nombre de masses médullaires dispersées en différents points du corps, et dont la principale est située en travers de l'œsophage. Les organes du mouvement et des sensations n'ont pas la même symétrie de nombre el de position que dans les animaux vertébrés, et la variété est plus frappante encore pour les viscères, pour la position du cœur et des organes respiratoires, et pour la structure même de ces derniers; car Jes uns respirent directement l'air atmosphérique, et les autles le puisent dans l'eau douce ou salée.

Le sang des mollusques est incolore ou légèrement bleuatre, et il circule dans un appareil vasculaire compliqué, composé d'artìres et de veines. Un cœur, formé d'un seul v'entricule, et, en général, d'une ou de deux oreillettes, se Irouve sur le trajet du sang artériel et envoie ce liquide dans toules les parties du corps, d'où il revient à l'organe de la respiration par l'intermédiaire des veines. Quelquefois, cependant, on rencontre à la base des vaisseaux qui pénètrent dans ce dernier appareil, des cœurs pulmonaires qui accélèrent le cours du sang dans les vaisseaux de la petite circulation. La circulation se fait ainsi à peu près comme chez les crustacés et d'une manière inverse de ce qui a lieu ehez les poissors.

"L'irritabilité est très-grande chez la plupart des mollusques et se conserve longlemps apris qu'on les a divisés. Leur peau est nue, trèssensible, ordinairement enduite d'une humeur qui suinte de ses pores. On n'a reconnu à aucun d'organe particulier pour l'odorat, mais on suppose que la sensation des odeurs est perçue par toute la surface de la peau. Presque tous sont privés d'yeux; mais les céplıalopodes en ont d'au moins aussi compliqués que ceux des animaux à sang chaud. I's sont aussi les seuls où l'on ait découvert des organes de l'ouïe, et où le cerveau soit entouré d'une boîte eartilagineuse particulière.

"Les mollusques ont presque tous un développement de la peau qui recouvre leur corps à la manière d'un manteau, et qui en a reçu le nom ; mais sourent aussi ce prolongement de la peau se rétrécit en un simple disque, ou se rejoint en tuyau, ou se creuse en sac, ou s'étend enfin el se divise en forme de nageoires.

"On nomme Mollusques nus ceux dont le manteau est simplement membraneux ou charnu; mais il se forme le plus souvent dans son 
épaisseur une ou plusieurs lames de substance plus ou moins dure, qui s'y déposent par couche et qui s'accroissent en étendue aussi bien qu'en épaisseur, parce que les couches internes, qui sont les plus récentes, débordent toujours les anciennes.

"Lorsque cette substance dure, en raison de son peu de développement, reste cachée dans l'épaisseur du manteau, on laisse encore aux animaux qui présentent ce caractère, le nom de Mollusques nus; mais le plus souvent elle acquiert assez d'étendue pour que l'animal puisse se contracter sous son abri. On lui donne alors le nom de coquilles (testa), et à l'animal celui de Testacé.

"Les variétés de formes, de couleur, de surface et d'éclat des coquilles sont infinies. La plupart sont de nature calcaire; mais il y en a de simplement cornées. Dans les deux cas, elles se composent toujours d'une matière déposée par couches, ou transsudée par la peau sous l'épiderme, comme les ongles, les poils, les cornes, les écailles ou même les dents. Le tissu des coquilles differe selon que cette transsudation se fait par lames parallèles ou par filets verticaux serrés les uns contre les autres.

"Les mollusques offrent toutes sortes de mastication et de déglutition; leur estomac est tantôt simple, tantôt multiple, souvent muni d'armures particulières; leurs intestins sont diver'sement prolongés; ils ont toujours un foie considérable.

"Les mollusques présentent toutes les variétés de génération. Plusieurs se fécondent eux-mêmes; d'autres, quoique hermaphrodites, ont besoin d'un accouplement réciproque; beaucoup ont les sexes séparés. Les uns sont vivipares, les autres ovipares. Les œufs de ceux-ci sont tantôt enveloppés d'une coquille, tantôt d'une simple viscosité. "

La forme générale des mollusques, étant assez proportionnée à la complication de leur organisation intérieure, peut servir de base à leur division naturelle en cinq classes (1), dont les caractères se trouvent exposés dans le tableau suivant.

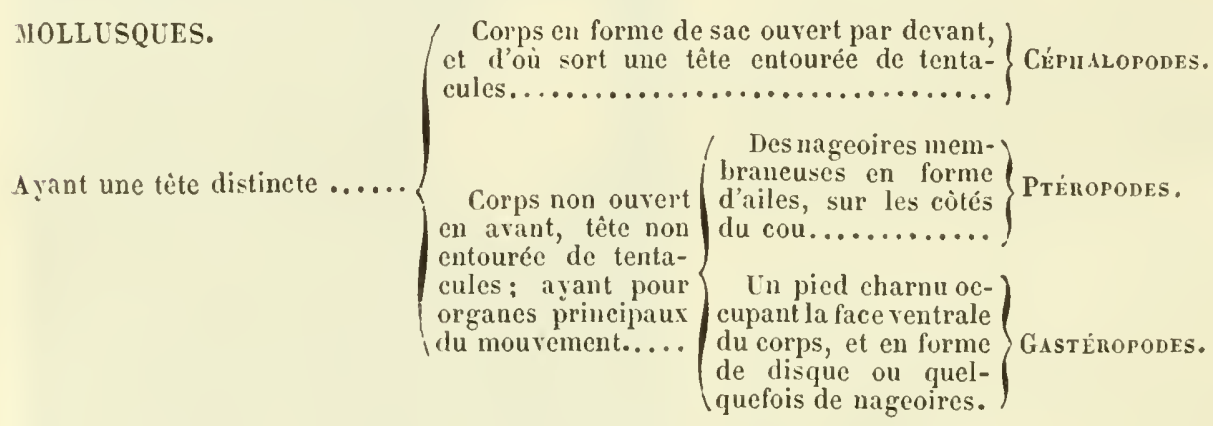

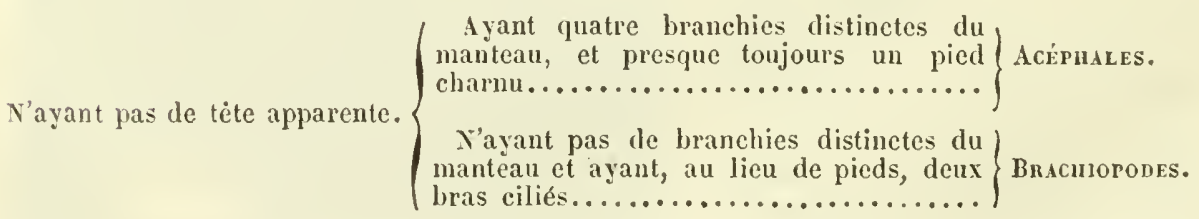

(1) Cuvier admettait, sous le nom de cirrhipodes, une dernière classe de mollusques qui ont été depuis réuuis aux crustacés. 


\section{PREMIÈRE GLASSE}

\section{LES MOLLUSQUES CÉPHALOPODES.}

Ces animaus sont tous aquatiques et marins. Leur manteau forme un sac musculeux qui enveloppe tous les viscères. Dans plusieur's, les côtés du manteau s'étendent en nageoires charnues. La têle sort de l'ouverture du sac; elle est ronde, pourvue de deux grands yeux et couronnée par des appendices charnus, coniques, plus ou moins longs, susceptibles de se fléchir en tous sens, très-vigoureux, et dont la surface est le plus souvent armée de suçoirs par lesquels ces animaux se fixent avec beaucoup de force aux corps qu'ils embrassent. Un entonnoir charnu, placé à l'ouverture du sac, donne passage aux excrétions.

Les céphalopodes ont deux ou quelquefois quatre branchies, placées dans leur'sac, une ou deux de chaque côté, en forme de feuille de fougire; la respiration se fait au moyen de l'eau qui entre par l'ouverture du sac, et sort par l'entonnoir charnu dont il vient d'être question. Entre les bases des pieds, est percée la bouche dans laquelle sont deux fortes mâchoires de corne, semblables à un bec de perroquet. Entre les deux mâchoires est une langue hérissée de pointes cornées; l'œsophage se renfle en jabot et conduit à un gésier charnu auquel succède un troisième ventricule membraneux et en spirale, dans lequel le foie, qui est très-grand, verse la bile par deux conduits. L'intestin est simple et peu prolongé; le rectum s'ouvre dans l'entonnoir.

Les céphalopodes à deux branchies ont une excrétion particulière, d'un noir très-foncé, qu'ils emploient à teindre l'eau de la mer pour se cacher. Cette excrétion est produite par une glande et réservée dans un sac particulier, diversement situé, selon les espèces.

La peau de ces animaux, surtout celle des poulpes, change de couleur pal place, avec une rapidité bien supérieure à celle du caméléon. Les sexes sont séparés. L'ovaire de la femelle est dans le fond du sac; deux oviductes conduisent les œufs au dehors, au travers de deux grosses glandes qui les enduisent d'une matière visqueuse et les rassemblent en espèces de grappes. Le testicule du mâle, placé comme l'ovaire, donne dans un canal déférent qui se termine à une verge située à gauche de l'anus. Une vessie et une prostate y aboutissent également. Swammerdam et 'Needham avaient trouvé dans l'appareil génital mâle des corps singuliers dont, jusqu'à présent, on n'avait connu ni la véritable structure ni la distinction. On les avait tour à tour considérés comme des zoospermes d'une taille gigantesque et comme des vers parasites. MM. Milne Edwards et Peters ont étudié ces corps anormaux chez un grand nombre de céphalopodes et en ont fait connaître la conformation. On $\mathrm{y}$ distingue toujours un étui en forme de silique, composé de deux tuniques et contenant dans son in- 
térieur un long tube contourné comme un intestin, rempli d'une matière blanche opaque, et en connexion avec un appareil membraneux plus ou moins translucide. Ce tube intestiniforme est un réservoir spermalique contenant des milliers de zoospermes, et l'appareil auquel il est attaché sert à faire éclater l'étui et à déterminer la sortie du réservoir lui-même. La structure de cet instrument d'éjaculation varie suivant les espèces. M. H. Milne Edwards propose d'appeler ces corps des spermatophores, et les compare à des grains de pollen qui renferment aussi des corpuscules fécondateurs et qui éclatent de même pour s'en décharger, lorsqu'ils sont parvenus de l'appareil mâle sur l'organe femelle.

Les céphalopodes sont très-voraces. Comme ils ont de l'agilité et de nombreux moyens de saisir leur proie, ils détruisent beaucoup de poissons et de crustacés. Leur chair se mange; leur encre est usitée en peinture; la coquille interne d'une espèce (la sìche) est employée en pharmacie.

Les céphalopodes ne forment que deux ordres et qui sont pen nombreux en genres. Les uns n'ont que deux branchies, sont pourvus d'une poche à encre et ont leurs bras ou tentacules couverts de suçoirs. On les nomme céPHaLOPODES DIBRANGHIaUX ou AGÉTABUlifÉres, et on y trouve les poulpes, les argonautes, les calmars el les sèches. Les autres, nommés tétrabrancintaux, ont quatre branchies, sont privés de sécrétion atramentaire et ne portent pas de suçoirs sur leurs tentacules. Tel est le nautile.

ORDRE DES DIBRANCHIAUX OU ACÉTABULIFÉRES.

Les poulpes (Octopus) (1) n'ont que deux petits grains coniques de substance cornée, aux deux côtés de l'épaisseur du dos; leur sac, de forme ovale, est dépourvu de nageoires, et leurs pieds sont au nombre de huit, tous à peu près égaux, très-grands à proportion du corps, réunis à la base par une membrane qui les rend palmés. L'espèce vulgaire (Octopus vulgaris, Lam., Sepia octopodia, L.) habite la Méditerranée el l'Océan. Elle a le corps ovale et entièrement lisse, les pieds quatre ou cinq fois plus longs que le corps, tous grêles et effilés dans leur moitié terminale, garnis, sur toute leur longueur et du côté interne, de deux rangs de ventouses al-

(1) Aristote avait donné à ces animaux le nom de Polypes ( $\pi 0$ únous, plusieurs pieds) qui leur convient parfaitement; mais, dans les temps modernes, ce même nom ayant été appliqué aux hydres d'eau douce, et ensuite à une classe tout entière d'animaux rayonnés, Lamark a fait adopter pour les polypes d'Aristote le nom de Poulpes, qui n'est qu'une contraction du mot grec. Il a formé pour nom générique latin le mot octopus, qui signifie huit pieds. (Voyez Lamarck, Histoire naturelle des animaux sans vertébres. Paris, 1845, t. XI, p. 360.) 
ternes. Elle est longue, en tout, de 60 à 65 centimètres; mais il existe dans l'océan Pacilique des poulpes qui ont 2 mètres de long et qui sont un objet de terreur pour les pêcheurs de la Polynésie. Pline parle aussi d'un poulpe dont les bras avaient 10 mètres de long, ce qui est probablement très-exagéré.

Le poulpe musqué ou élédon d'Aristote (Octopus moschatus, Lam.) diffère du précédent par des bras encore plus longs à proportion, plus grêles et réunis à leur base par une membrane plus haute; mais son caractère principal réside dans un seul rang de ventouses très-rapprochées, sur chaque bras. Il est commun dans la Méditerranée; il exhale une forte odeur de musc, même après avoir été desséché.

Les argonautes (Argonauta Argo, L.) ( $/ g$. 1057) sont des poulpes à huit pieds non palmés à la base, et à deux rangs de suçoirs, dont la paire de pieds la plus voisine du dos se dilate à son extrémité en une large membrane. Ils n'ont pas dans le dos les deux petils grains cartilagineux des poulpesordinaires: mais on les trouve toujours dans une coquille très-mince, cannelée symélriquement et roulée en spirale, dont le dernier tour est si grand proportionnellement qu'elle a l'air d'une chaloupe dont la spire serait la poupe. Aussil'animal s'en sertil comme d'un bateau, et, quand la mer est calme, on en voit des troupes naviguer à la surface, en se servant de six de leurs tentacules comme de rames, et relevant les deux

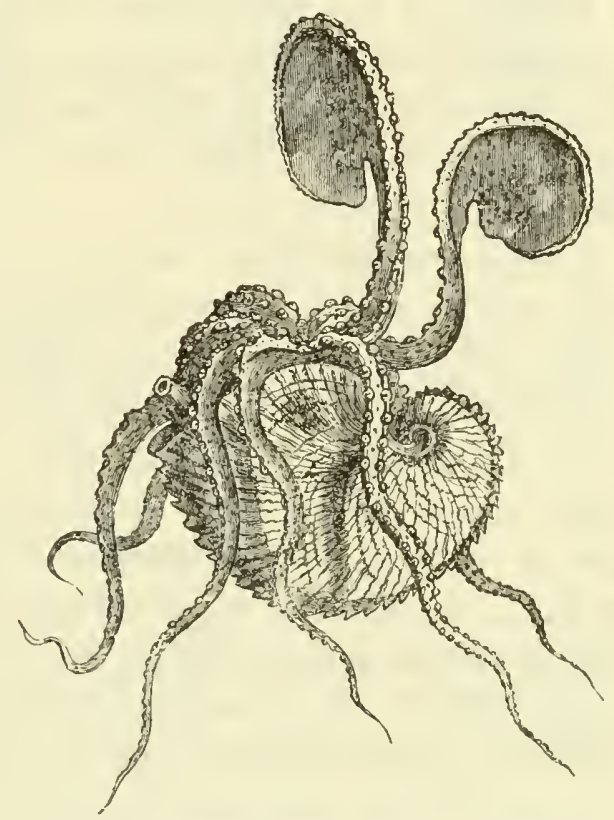

Fig. 1057. - Argonaule dans sa coquille. qui sont élargis, pour en faire des voiles. Si les vagues s'agitent ou qu'il paraisse quelque danger, l'argonaute retire tous ses bras dans sa coquille, s'y concentre, et redescend au fond de l'eau. te corps de l'argonaute ne pénètre pas jusqu'au fond des spires de sa coquille et ne paraît y tenir par aucune attache musculaire, ce qui a fait penser à plusieurs naturalistes qu'il ne l'habite qu'en qualité de parasite, comme le bernard-l'hermite habite la sienne. Cependant, comme l'on trouve toujours l'argonaute dans la même coquille et qu'on ne rencontre jamais dans celleci un autre animal, bien qu'elle soit très-commune, il est probable qu'elle lui appartient en propre. Les anciens connaissaient 
ce singulier céphalopode, et le nommaient nautile ou pompile (1).

Les Calma (Loligo, Lam.) ont dans le dos, au lieu de coquille, une lame de corne, en forme de lancette; leur sac s'élargit à l'extrémité postérieure el foìme deux nageoires latérales, figurant ensemble un rhombe ou une ellipse. Outre huit pieds égaux assez courts, chargés de deux rangées de suçoirs, leur tête porte encore deux bras beaucoup plus longs, armés de suçoirs seulement vers le bout, qui est élargi. Leur bourse à encre est enchâssée dans le foie.

Les sìches (Sepia, Lam.) ont les dix bras des calmars, dont deux, beaucoup plus longs que les autres, sont pourvus de suçoirs seulement à l'extrémité. Leur sac est élargi tout autour par une nageoire charnue peu développée; leur coquille est interne, ovale, épaisse, bombée, composée d'une infinité de lames calcaires très-minces, parallèles, jointes ensemble par des milliers de petites colonnes creuses qui vont perpendiculairement de l'une à l'autre. La bourse à l'encre est détachée du foie et située plus profondément dans l'abdomen. Les glandes des oviductes sont énormes; les œufs sont déposés attachés les uns aux autres, en grappes rameuses, ce qui leur a fait donner le nom de raisins de mer.

L'espèce répandue dans toutes nos mers (Sepia officinalis, L.)

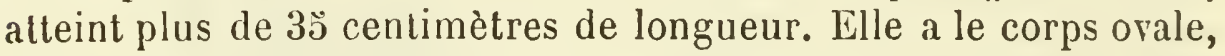
large, déprimé, bariolé en dessus de lignes onduleuses blanches (fig. 1058), sur un fond grisâtre, et tacheté de petits points pourprés. La bouche renferme deux mâchoires cornées de couleur noire, en forme de becs de perroquet ( $f$ ig. 1029, a et $\left.a^{\prime}\right)$, que l'on trouve souvent disséminés dans les masses d'ambre gris (pag. 120 et 121). La coquille, qui porte vulgairement le nom d'os de sèche, est ovale, plate, mais bombée sur ses deux faces. Le côté interne ( fig. 1029, $b^{\prime}$ ) est formé de couches calcaires très-friables, succes sivement plus grandes et dont les plus nouvelles recouvrent toutes les autres. Les couches les plus externes, les plus grandes par conséquent, sont beaucoup plus dures et en partie cornées. Elles forment, au-dessus des autres $(f g .10 \preceq 9, b)$, une sorte de manteau demi-transparent, un peu élargi en forme d'ailes, vers l'extrémité postérieure, et terminé par une pointe assez aiguë. On trouve dans la couche de calcaire grossier de Grignon (Seineet-Oise) un assez grand nombre de ces pointes calcaires, accompagnées d'une portion de lame convexe qui les supporte. Cuvier avoue avoir cherché, pendant plus de dix années, ce que ces pointes pouvaient être, lorsqu'il les a reconnues pour appartenir àla partie inférieure de coquilles de sèches.

(1) Pline, IX, c. XxIX. 
L'os de sèche est employé à l'intérieur comme absorbant e comme dentifrice. On le donne aux oiseaux de volière dans le double but d'user leur bec, qui, sans cela, pourrait ac-

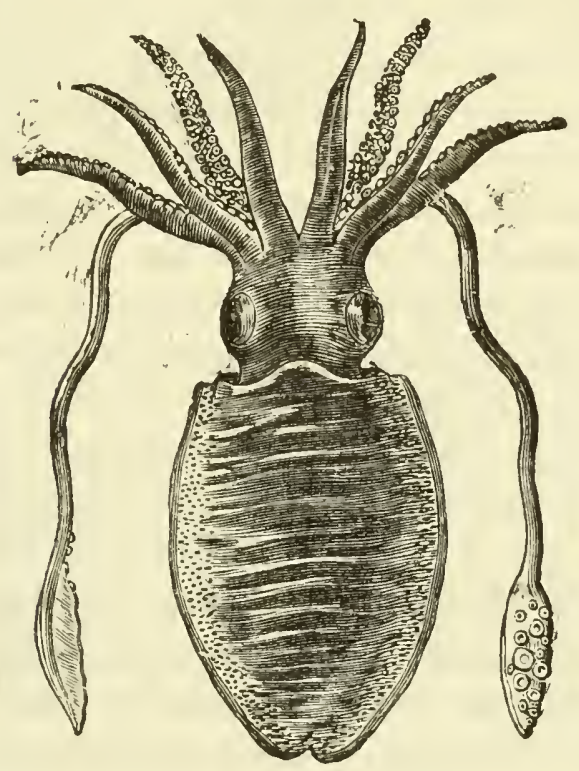

Fig. 1058. - Sèche (*)
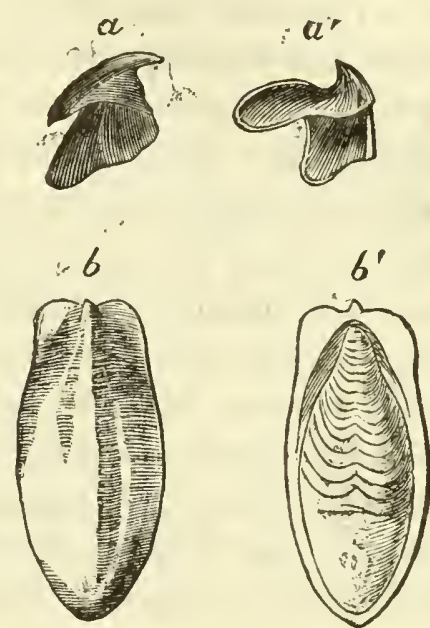

Fig. 1059. - Nâchoire et coquille de sèche $\left(^{* *}\right)$.

quérir une longueur incommode, et de leur fournir l'élément calcaire de leurs os, de leurs plumes et de la coquille de leurs œufs.

ORDRE DES TÉTRABRANGHIAUX.

Le nautile (Nautilus Pompilius, L.) (1) a le corps enfermé dans la dernière chambre d'une grande coquille tournée en spirale et divisée par des cloisons transversales en plusieurs cavités. Chacune de ces cloisons est percée d'un trou, et le conduit qui en résulte, qui est nommé siphon, s'étend jusqu'à l'extrémité postérieure de la coquille et est rempli par un tube membraneux qui part de l'extrémité postérieure du corps de l'animal. Celui-ci diffère beaucoup des poulpes et de la sèche: sa tête supporte un grand disque charnu qui a quelque analogie avec le pied des gastéropodes; ses tentacules sont petits, très-nombreux, rétractiles,

(1) Ce n'est pas le nautile de Pline, comme nous l'avons vu page 351.

$\left(^{*}\right)$ D’après Férussac et Alc. d'Orbigny, Hist. nat. des Céphalopodes acétabulifères. Paris, 1836-1848.

$\left(^{* *}\right) a a^{\prime}$, mâchoires eornées; $b$, coquille ou os de sèche, còté externe; $b$, le mème, cóté nterne. 
non garnis de suçoirs; ses yeux sont pédonculés; il n'a ni poche à encre ni nageoires; enfin, ses branchies sont au nombre de quatre."

On trouve à l'état fossile un grand nombre de coquilles qui présentent une structure très-analogue à celle des nautiles. Ce sont les ammonites, appelées communément cornes d'Ammon, à cause de la ressemblance de leurs volutes avec celles de la corne d'un bélier. Ces animaux vivaient anciennement dans les mer's, et leurs dépouilles se rencontrent par toute la terre, dans les terrains secondaires; mais ils ont disparu depuis très-longtemps de la surface du globe, et les terrains supérieurs à la craie n'en offrent aucune trace. Ils varient beaucoup pour la forme et encore plus pour la grandeur; car les uns ne sont guère plus gros qu'une lentille, et d'autres ont plus de $\mathbf{1}^{\mathrm{m}}, 30$ de diamètre. On rapporte également aux céphalopodes un grand nombre d'autres coquilles fossiles connues sous les noms de bélemnites, baculites, turrilites, nummulites, etc. Des nummulites sont de très-pelits corps fossiles de forme lenticulaire, qui forment presque à eux seuls des bancs immenses de pierre à bâtir. Mais on les trouve aussi dans nos mers actuelles, et, en les observant à l'état vivant, on a reconnu que ce sont des animaux d'une structure très-singalière, qui ont plus de rapports avec les polypes qu'avec les céphalopodes.

\section{DEUXIÈME CLASSE}

\section{LES MOLLUSQUES GASTÉROPODES.}

Les gastéropodes constituent une classe très-nombreuse de mollusques dont on peut se faire une idée par la limace et le colimaçon. Ils rampent généralement sur un disque charnu placé sous le ventre, mais qui prend quelquefois la forme d'une lame verticale propre à la natation, lorsque l'animal vit dans l'eau. Le dos est garni d'un manteau plus ou moins étendu et de formes diverses, qui produit une coquille dius le plus grand nombre des genres. La tête, placée en avant, se montre plus ou moins, et n'a que de petits tentacules placés au-dessus de la bouche; leur nombre varie de 2 à 6 , et ils manquent quelquefois. Les yeux sont très-petils, tantot adhérents à la tete, tantôt portés à la base, au côté ou à la pointe des tentacules : ils manquent aussi quelquefois. La position, la structure et la nature de leurs organes respiratoires varient et donnent lieu à les diviser en plusieurs familles; mais ils 
n'ont jamais qu'un cœur aortique, c'est-à-dire placé entre la reine pulmonaire et l'aorte.

Plusieurs sont absolument nus, d'autres n'ont qu'une coquille cachée; mais le plus grand nombre en porte une qui peut les recevoir et les abriter. Cette coquille peut être symétrique de plusieurs pièces, sy- . métrique d'une seule pièce, ou non symétrique. Dans les espèces où cette dernicre coquille est très-concave et où elle croît très-longtemps, elle forme nécessairement une spirale oblique.

Que l'on se représente, en effet, un cone oblique dans lequel se placent successivement d'autres cones toujours plus larges dans un certain sens que dans les autres, il faudra que l'ensemble se roule sur le côté qui grandit le moins. Cette partie, avortée ou oblitérée sur laquelle se roule le cone, se nomme la columelle (on peut la comparer à la vis d'un escalier tournant), et elle est tantot pleine, tantôt creuse. Lorsqu'elle est creuse, son ouverture, placée près de celle de la coquille, se nomme l'ombilic.

Les tours de la coquille peuvent rester à peu près dans le même plan, ou tendre loujours vers la base de la columelle : dans le premier cas, la spire est plate, et les coquilles s'appellent discoides; dans le second, la spire est d'autant plus aiguë que les tour's descendent plus rapidement et qu'ils s'élargissent moins. Ces coquilles sont dites turbinées.

Quand les tours restent à peu près dans le même plan, et lorsque l'animal rampe, il a sa coquille posée verticalement, la columelle en travers sur le derriere de son dos, et sa tête passe sous le bord de l'ouverture opposée à la columelle. Quand la spire est saillante, c'est obliquement, de gauche à droite, qu'elle se dirige dans presque toutes les espèces. Un petit nombre seulement ont leur spire saillante à gauche, lorsqu'elles marchent, et se nomment perverses (il eût suffi de dire inverses).

Il y a des gastéropodes à sexes séparés, et d'autres qui sont hermapurodiles, et dont les uns peuvent se suffire à eux-mêmes, tandis que les autres ont besoin d'un accouplement réciproque.

On divise les gastéropodes en huit ordres, dont les principaux caractères sont tirés de la disposition des branchies, comme on peut le voir dans le tableau suivant: 
GASTÉROPODES.

Ayant des poumons................... Putrones.

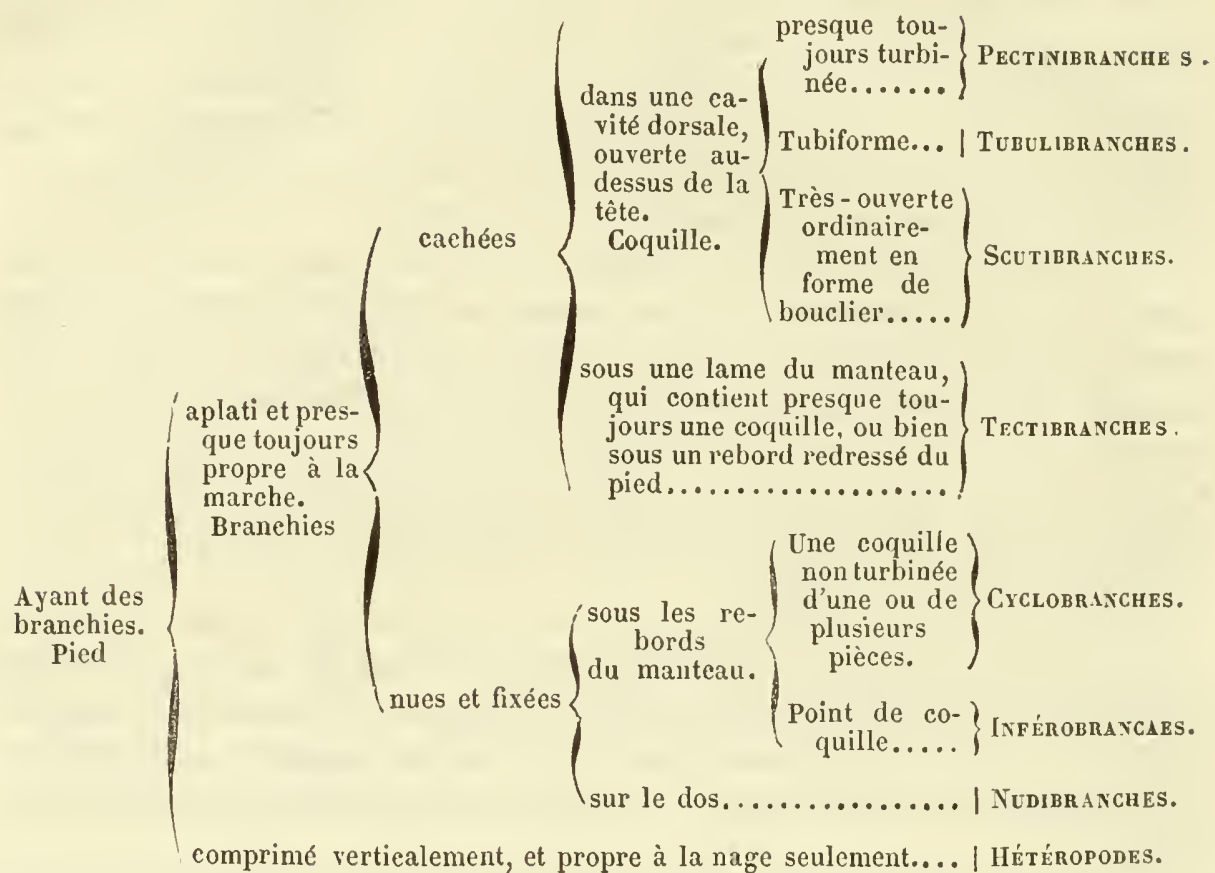

ORDRE DES PULMONÉS.

Les Pulmonés se distinguent des autres mollusques en ce qu'ils respirent l'air élastique par un trou ouvert sous le rebord de leur manteau, et qu'ils dilatent ou contractent à leur gré. Aussi n'ont-ils pas de branchies, mais seulement un réseau pulmonaire qui rampe sur les parois de leur cavité respiratoire. Les uns sont terrestres, d'auties vivent dans l'eau, mais sont obligés de venir de temps en temps à la surface, ouvrir l'orifice de leur cavité pectorale pour respirer. Tous sont hermaphrodites.

Les Pulmonés terrestres ont presque tous quatre tentacules; ceux d'entre eux qui n'ont pas de coquille apparente formaient, dans Linné, le genre des Limaces, qui se divise aujourd'hui en limaces proprement dites, arions, limas, vaginules, testacelles et parmacelles; ceux dont la coquille est complète et apparente entraient presque tous dans le genre des Escargots (Helix) de Linné. On les divise aujourd'hui en escargots proprement dits, vitrines, bulimes, maillots, grenailles et ambrettes.

Escargot des vignes, limaçons ou colimaçon des vignes (Helix pomatia, L.). Mollusque gastéropode, pulmoné, terrestre, pourvu d'une coquille univalve, globuleuse, tournée en volute, de 3 à 4 centimètres de diamètre. Elle est formée de cinq tours de spire 
obtus, dont le dernier est fort grand relativement aux quatre autres, et relevé en bourrelet sur les bords de son ouverture, laquelle est entamée par la saillie de l'avant-dernier tour, ce qui lui donne un peu la forme d'un croissant plus large que haut. Celte coquille est d'un gris roussâtre, avec des bandes plus pâles et des stries transversales fines et rapprochées ( $/ \mathrm{ig} .1030)$.

Le corps de l'animal est à peu près demi-cylindrique dans toute sa partie antérieure, qui peut s'étendre hors de la coquille;

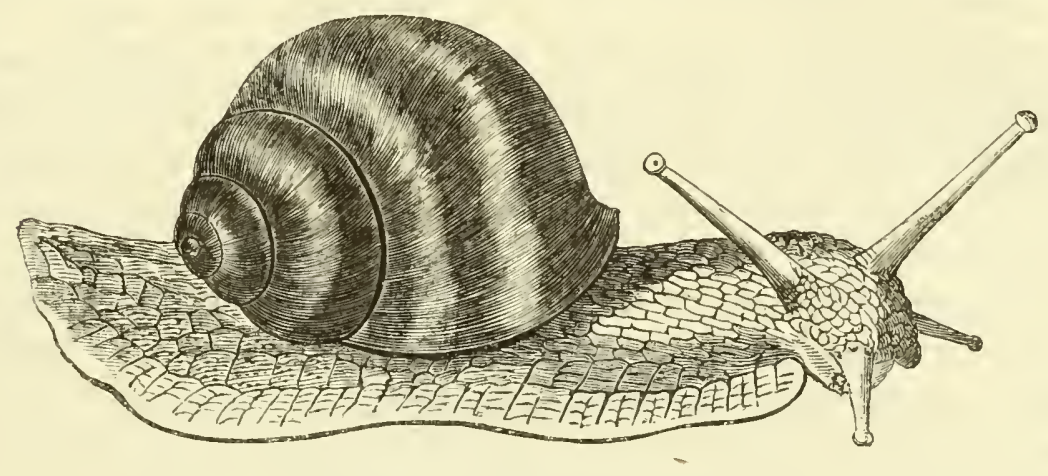

Fig. 1060. - Escargot des vignes.

mais il est muni inférieurement et en arrière d'un large disque musculeux ou pied, au moyen duquel il rampe sur la terre. Tous les viscères sont contenus dans la coquille et forment une masse tournée en spirale que l'on dirait sortie, comme une hernie, de la partie du dos occupée par le manteau, entraînant avec elle la peau considérablement amincie. Une partie du manteau forme encore cependant, au point de jonction des deux parties du corps, tout autour de l'ouverture de la coquille, une sorte de bourrelet ou d'anneau, auquel on a donné le nom de collier, et dans l'épaisscur duquel sont percés l'orifice arrondi de la cavité pulmonaire et celui de l'anus. La tête est peu distincte de la partie antérieure du corps. Elle est pourvue de quatre tentacules cylindriques, obtus, rétractiles, dont les deux antérieurs sont plus petits; les deux postérieurs portent chacun, à leur extrémité, un point noir que l'on regarde comme un æeil.

La bouche est accompagnée d'une autre paire d'appendices fort courts et obtus, et elle est armée d'une mâchoire supérieure dentelée, qui sert à ronger les herbes et les fruits, auxquels les limaçons causent beaucoup de dégâts. Les organes de la génération, mâle et femelle, se terminent à l'extérieur par un orifice unique, situé au côté externe et postérieur du grand tentacule droit.

Aux approches de l'hiver, l'escargot s'enfonce dans la terre ou se retire dans un trou. Il ferme alors l'ouveriure de sa coquille 
avec une exsudation calcaire qui le met à l'abri du froid et de la perte de son humidité, et il passe ainsi l'hiver dans un engourdissement complet, jusqu'au retour de la belle saison. C'est pendant que son ouverture est ainsi murée qu'on le récolte pour le faire servir d'aliment, ou pour la préparation de bouillons et de sirops pectoraux. Il contient une très-grande quantité de mucilage et une huile sulfurée qui noircit les vases d'argent dans lesquels on le fait cuire. On lui substitue quelquefois l'escargot des jardins (Helix hortensis, L.), l'escargot des haies (Helix aspera), celui des forêts (Helix nemoralis, L.), et quelques autres encore qui diffèrent du premier par un volume moins considérable, par une livrée à couleurs plus prononcées et très-variées, et parce que l'ombilic ou l'ouverture de la columelle est plus ou moins caché par le rebord externe de celle-ci. Dans le midi de la France, on connaît sous le nom de tapada (Helix naticoides, Cham.) un gros limaçon à peine contenu dans une coquille ovoïde, de 27 millimètres de diamètre, à columelle solide et torse, n'offrant pas d'ombilic par conséquent, composée de trois tours et demi de spire, dont le dernier est tout à fait disproportionné aux autres à cause de son grand volume. Ce colimaçon ne paraîl que dans la saison la plus chaude, ne fréquente que les terrains secs et exposés au soleil. Il est très-sensible au froid, et passe presque dix mois de l'année caché sous terre.

On trouve dans les terrains de sédiment, principalement dans ceux qui sont supérieurs à la craie, un nombre considérable de coquilles fossiles appartenant à la classe des Gastéropodes; telles sont principalement des planorbes, des lymnées ( $/ \mathrm{g}$. 1061), des

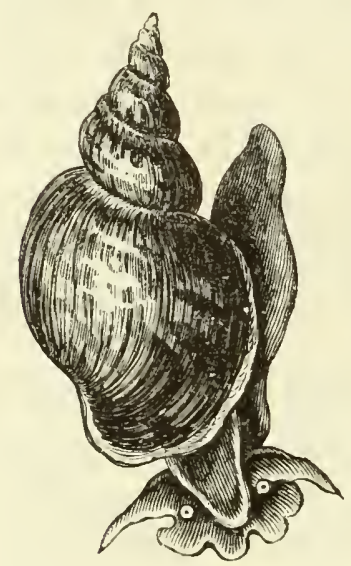

Fig. 1061. - Lymnée des étangs.

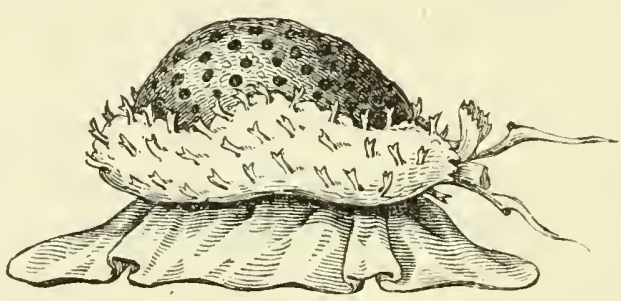

Fig. 1062. - Porcelaine.

toupres ou trochus, des turritelles, des paludines, des ampullaires, des cônes ou cyprées, des porcelaines (fig. 1062), des volutes, des olives, des buccins, des cérithes, des rocher's ou murex, des fuseaux, des 
pleurotomes, etc. Je suis obligé de renvoyer, pour la connaissance de ces coquilles, aux Traités de conchyliologie et de géologie (1).

\section{TROISIÈME CLASSE}

\section{LES MOLLUSQUES ACÉPHALES (2).}

Ces mollusques n'ont pas de tôte apparente, mais seulement une bouche cachée dans le fond ou entre les replis d'un manteau. Celui-ci est presque toujours ployé en deux et renferme le corps, comme un livre est renfermé dans sa couverture; mais souvent aussi les deux lobes se réunissent par devant, et le manteau forme alors un tube. Une coquille, composée de deux battants ou valves, recouvre ce manteau en totalité ou en partie, el présente à sa partie supérieure une charnière garnie d'un ligament élastique, dont le jeu fait bâiller les valves toutes les fois que deux muscles attachés à l'une et à l'autre ne se contractent pas pour les tenir fermées. Les branchies ont la forme de grands feuillets striés régulièrement en travers; leur nombre est toujours de quatre, el elles sont placées entre la face interne du manteau et le corps de l'animal. La bouche est à l'une des extrémités du corp̣s, et présente, de chaque côlé, deux feuillets triangulaires qui servent de tentacules. L'estomac, le foie et les autres viscères sont logés entre la bouche et l'anus, et au-dessous du cœur qui est situé sur le dos. Enfin, la partie inférieure du corps se prolonge presque loujours en une masse charnue, nommée pied, qui sert aux mouvements et qui porte quelquefois ì sa base un faisceau de filaments nommé byssus, à l'aide duquel l'animal se fixe aux corps sous-marins. Tous les acéplates se fécondent eux-mêmes. Ón les divise en six familles, sous les noms d'ostracés, de mytilacés, de camacés, de cardiacés et d'enfermés.

La famille des ostracés se compose d'un assez grand nombre de mollusques biralves qui mancuent de pied ou qui n'en ont qu'un fort petit, et qui, pour la plupart, sont fixés par leur coquille ou par leur byssus aux corps sous-marins. Leur manteau est ouvert en arrière aussi bien qu ${ }^{\circ}$ en avant, et ses deux lobes ne se réunissent par autune parlie de leurs bords, pour former des ouvertures particulières, comme cela a lieu dans les autres acéphales. Cette famille peut être divisée en deux tribus, suivant

(1) Voyez G. P. Deshayes, Description des animaux sans vertèbres découverts dans le bassin de Paris. Paris, 1857-1865, 3 vol. in- $4^{\circ}$, avec atlas de $196 \mathrm{pl}$.

(2) Cette classe ne comprend que les acéphales testacés de Cuvier, ses acéphales sans coquille formant aujourd'hui, à la suite des mollusques, et sous le nom de Molluscoides, un sous-embranchement intermédiaire entre les vrais mollusques et les zoophytes. 
qu'il existe un seul muscle adducteur allant d'une valve à l'autre, ou deux de ces muscles, l'un placé près de l'anus, l'autre audevant de la bouche, ainsi que cela a lieu chez presque tous les autres acéphales. C'est dans la première tribu que se trouvent les huitres dont on fail une si grande consommation pour la nourriture de l'homme, et qui sont l'objet d'un commerce trèsimportant pour plusieurs points maritimes de la France.

Les huitres forment un des genres les plus simples et les plus distincls parmi les acéphales; elles ont le corps placé dans la coquille de manière que l'extrémité, où se trouve la bouche, ou l'antérieure, correspond presque au sommet et au ligament qui unit les deux valves, et que l'extrémité anale ou postérieure est opposée et dans la partie la plus large. La forme générale du corps est un peu ovale, plus élargie et plus arrondie en arrière qu'en avant, où le corps se rétrécit en s'approchant du sommet, où il est comme tronqué par une ligne droite. C'est presque sur cette courte ligne seulement que les bords du manteau sont réuni, en formant une sorte de capuchon ou de cavité antérieure où se trouve la bouche; au delà, ils sont entièrement libres dans toute leur circonférence. Les bords sont formés-des deux rangées de papilles tentaculaires, comme frangées, qui sont le siége le plus actif de la sensibilité.

Les organes de locomotion sont presque nuls; car on ne trouve aucune trace de ce faisceau de muscles qui se voil au-dessous du corps de beaucoup de mollusques acéphales, et auquel on a donné le nom de pied. Mais, en compensation, on troure un muscle adducteur très-puissant, dont on voit l'impression presque au centre des deux valves de la coquille, lorsqu'elles en ont été séparées.

La coquille des huîtres est généralement irrégulière, plus développée et plus arrondie d’un des côtés de la charnière que de l'autre, ce qui tient souvent aux circonstances extérieures ou à la gêne qu'elle éprouve d'un côté. La valve inférieure, par laquelle l'animal adhère souvent au rocher ou au banc qui la porte est toujours plus épaisse et plus concave que l'autre; c'est elle qui contient l'animal, la valve supérieure qui est plate, mince, mobile, souvent plus pelite que l'autre, pouvant être considérée comme un opercule. On observe assez souvent, dans la valve inférieure, entre la charnière et l'impression du muscle adducteur, un espace assez considérable où la lame la plus récente est détachée de celles qui l'ont précédée, et forme une cavité sans communication extérieure, et qui contient une eau limpide et d'une fétidité remarquable, dont on ignore l'usage.

La bouche est située, ainsi qu'il a été dit plus haut, sous l'espèce de capuchon produit par la réunion de deux lobes du man- 
teau. Elle est formée par un rebord fort mince, accompagné seulement de deux paires de tentacules lamelleux. A la suite de cette bouche, qui est grande et très-dilatable, vient l'estomac qui n'est qu'une poche creusée dans le foie, avec une membrane interne très-mince, adhérente. De cet estomac partent une sorte de cœcum et le canal intestinal qui, après deux ou trois circonvolutions dans le foie, se porte sur le muscle adducteur et se termine par un orifice en forme d'entonnoir libre à l'extrémité, et placé exactement dans la ligne médiane et dorsale. (Voir figure 1063).

Les organes de la respiration sont formés par deux paires de grandes lames branchiales, placées, de chaque coté du corp̀s,

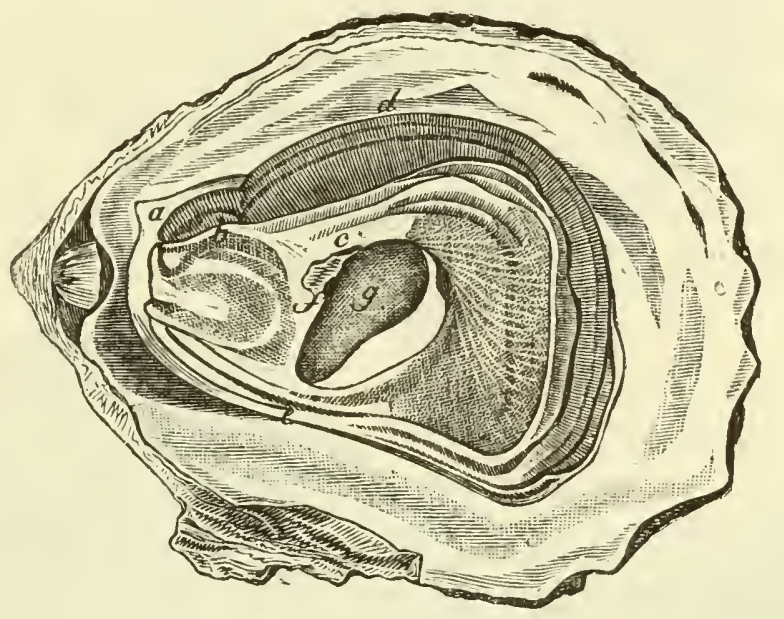

Fig. 1063. - Huître comestible $\left({ }^{*}\right)$.

entre la masse viscérale et le manteau; le cœur est situé en avant du muscle adducleur, entre la masse viscérale et lui, bien séparé dans son péricarde, facile à distinguer par son oreillette qui est d'un brun noir.

[Les huîtres sont hermaphrodites, mais les produits sexuels mâles et femelles ne se forment pas simultanément. Pendant les trois premières années de sa vie, l'huître est mâle et ne donne que de la liqueur fécondante. A partir de la troisième ou de la quatrième, elle est mâle depuis le mois de septembre jusquau mois de juin, et donne pendant ce temps le liquide qui doit agir sur les œufs, qui se produisent en juin et juillet.] Les œufs, quand ils sont rejetés, sont sous la forme d'un fluide blanc, ayant l'apparence d'une goutte de suif, dans lequel on aperçoit, à l'aide du microscope, une quantité innombrable de petites huîtres qui ne

(*) a, partie supérieure du manteau, couvrant Ia bouche et les palpes ou tentacules labiaux; $b$, $c$, le manteau; $d$, les branches; $e$ portion des lobes du manteau entre lesquelles l'anus vient déboucher; $f$, une portion du cœur placé à la partie antérieure du muscle des valves, $g$. 
tardent pas à s'attacher aux corps sous-marins ou aux individus de la même espèce. Ces nouvelles huîtres, en se développant, étouffent pour ainsi dire les anciennes, et c'est ainsi que se forment ces immenses bancs d'huîtres que l'on trouvesur nos côtes, et qui, malgré la destruction incessante qu'on en fait depuis plusieurs centaines d'années, se mblent ne jamais s'épuiser.

On trouve des huitres dans toutes les mers, mais jamais à de très-grandes profondeurs, ni à une grande distance des rivages. Ce sont les golfes formés par l'embouchure des grandes rivières et ceux où les eaux sont les plus tranquilles, qu'elles recherchent davantage. Leur nourriture ne peut guère se composer que d'animaux infusoires ou même de matières organiques suspendues ou dissoutes dans l'eau de la mer.

On connaît un assez grand nombre d'espèces d'huîtres, dont la plus intéressante pour nous est l'huître commune. Ostrea edulis, L. ( $/$ g. 1063, 1064, 1065), qui est si abondante sur les côtes de la Manche et de l'Océan, principalement dans la baie de Cancale, entre le bourg de ce nom, Saint-Malo et Granville, et sur la plage

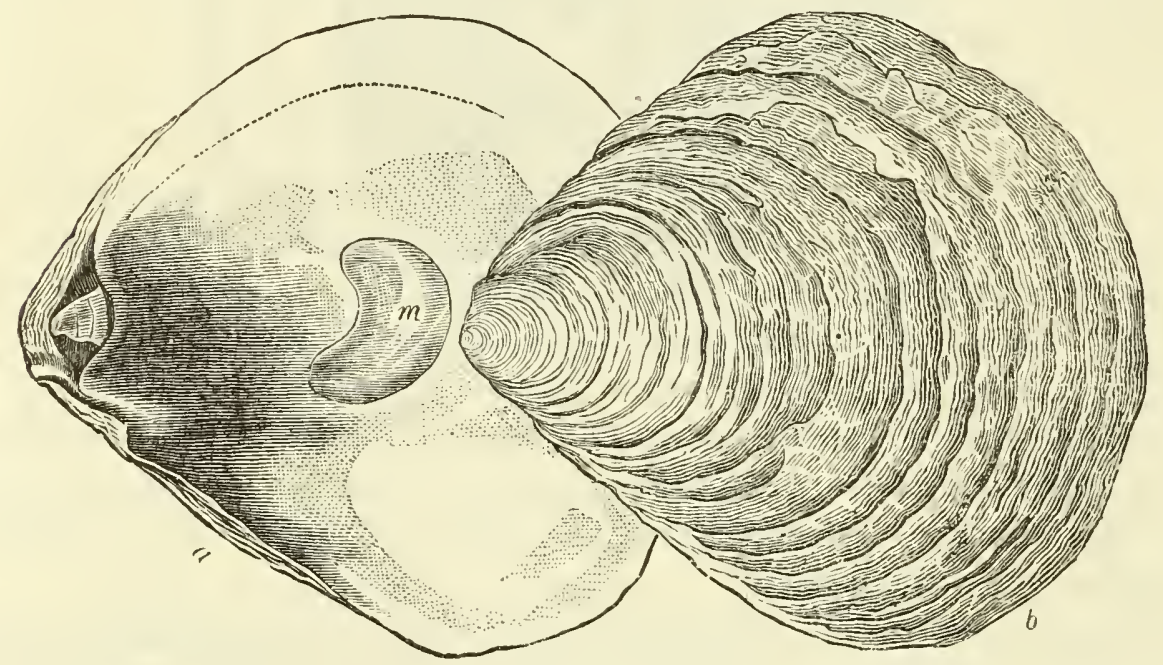

Fig. 1054. - Huitre comestible (*).

de Marennes, non loin de Rochefort et de l'île d'Oléron. La pêche des huîtres commence ordinairement à la fin de septembre et finit en avril ; elle est sévèrement interdite pendant les autres mois, parce que c'est l'époque du frai et qu'on suppose que l'huître est alors de moins bonne qualité. Elle est exécutée au moyen de la drague, espèce de grand râteau en fer que l'on promène au fond de la mer, suivi d'une poche qui reçoit les huîtres, et traîné par un bateau allant à toutes voiles. Mais l'huître, quand elle sort de

(*) $a$, valve creuse ou principale, vue dn côté intérieur; $m$, impression laissée sur la valve par le muscle adducteur; $b$, valve plate ou operculaire, vue du côté extérieur. 
la mer, sent ordinairement la vase, est dure et d'assez mauvais goût. Avant de la livrer à la consommation, on la dépose et on la laisse séjourner pendant un certain temps dans des réservoirs, dits parcs, creusés dans le sol ou dans la pierre, dans lesquels on peut, à volonté, conserver l'eau de la mer qui y est entrée à la

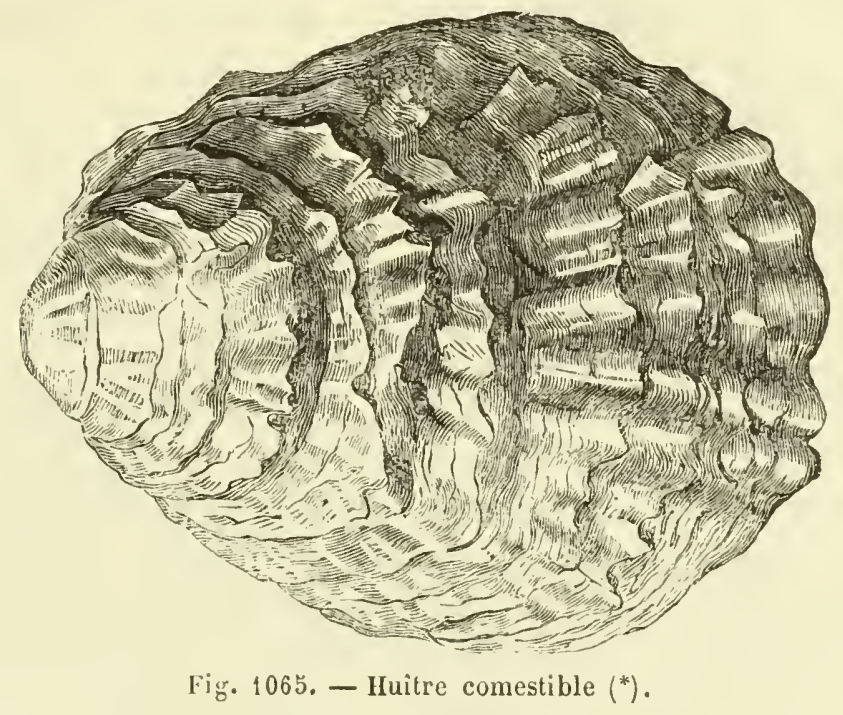

marée haute, ou la faire écouler. Les huîtres engraissent dans ces bassins, y deviennent plus tendres et d'un goût plus délicat. On cherche surlout à leur faire acquérir une couleur verte qui les fait estimer bien au-dessus des autres. En France, les principaux parcs d'huîtres sont établis à Marennes, Courseulles, Saint-Vast, le Havre, Étretat, Dieppe, etc.

On trouve dans les calcaires du lias, immédiaternent inférieurs à ceux du terrain jurassique, une fort belle coquille fossile nommée gryphée arquée, qui caractérise d'autant mieux cette formation qu'on ne la trouve nulle part ailleurs. Cette coquille, qui est généralement d'un gris d'ardoise, comme le calcaire argileux qui la renferme, ressemble assez, pour la îorme, à un nautile allongé, ou à un petit navire dont la poupe arrondie serait relevée en demi-tour de spire. Elle est fermée par un opercule plat qui répond à la valve supérieure des huîlres. Quant à la demi-spirale qui termine la valve inférieure, elle provient de l'exagération d'un caractère que l'on observe même dans l'huître commune, et qui consiste en ce que, l'animal s'éloignant avec l'âge de l'extrémilé de la coquille uù il était contenu dabord, ce sommet paraît s'allonger en forme de talon ou de crochet un peu proéminent.

(*) Valve principale du côté extérieur. Elles ne présentent pas toutes des cannelures aussi prononcées. 
C'est à la famille des ostracées qu'appartient l'aronde perlière (Avicula margaritifera, Brugn., Pintadina margaritifera, Lam.), qui produit les deux substances connues sous les noms de naere de perle ou de perles. L'animal a le corps très-petit, comparé à la grande étendue de sa coquille, et très-comprimé; il se prolonge en un pied assez petit, garni d'un byssus. Le manteau est fendu dans toute sa circonférence, si ce n'est le long du dos, et garni à son bord libre d'un double rang de cirrhes tentaculaires très-courts; la bouche est entourée de lèvres frangées; outre les deux paires d'appendices labiaux, il y a un gros muscle adducteur postérieur et un muscle antérieur extrêmement petit.

La coquille de l'aronde présente à peu près la forme d'un cercle, dont un quart serait agrandi et converti en partie du carré circonscrit ( $f g .1066,1067,1068$ ). Elle est rude, grossière, non cannelée, d'un aspect crétacé à l'extérieur' feuilletée, blanche, brillante et de la plus belle nacre dans la plns grande partie de son épaisseur et principalement à sa surface interne. Les valves sont de grandeur égale; mais la supérieure ou l'operculaire est plus plate que l'inférieure qui contient l'animal, et qui, cependant, est encore peu prolonde. La charnière est rectiligne et maintenue par un ligament qui va d'une extrémité à l'autre de la base de la coquille, mais en prenant une épaisseur et une force plus considérables à sa partie mitoyenne. A l'une des extrémités de cette base, celle où la coquille présente le plus d'épaisseur et où se trouve la cavité qui contient l'animal, le côté adjacent présente, un peu au-dessus de l'angle, du côté de la bouche, un sinus assez profond et une échancrure pour la sortie du byssus. Le fond de ld cavité offre une suite de petits points d'attache, disposés en $\mathrm{S}$, dont le dernier résulte de l'impression un peu plus grande du muscle adducteur antérieur : entre ce point et le bord opposé de la coquille, se présente l'impression beaucoup plus élendue du muscle postérieur.

L'aronde aux perles et ses variétés habitent principalement la mer Rouge, le golfe Persique, le détroit de Manaar, qui sépare Ceylan de la presqu'île de l'Inde, et les côtes du Japon. Dans le nouveau monde, on la trouve en plusieurs lieux du golfe du Mexique et dans la mer de Californie; mais la plus belle nacre vient du golfe de Manaar, où il existe plusieurs bancs d'aronde, dont le plus considérable occupe une étendue de 20 milles, visà-vis de Cordatchy. Pour ne pas détruire les jeunes arondes, le banc est partagé en sept parties, qui sont exploitées successivement chaque année. La pêche commence en février, pour finir en avril. Les barques des pêcheurs s'y rendent de différents points des îles et du continent. Chaque barque est montée, non 
compris le patron, par vingt hommes, dont dix rameurs et dix plongeurs. Ceux-ci se partagent en deux bandes qui plongent et se reposent alternativement. Chacun est pourvu d'un filet pour mettre les arondes perlières, d'une corde à laquelle est attachée une pierre qui doit accélérer sa descente, et d'une autre corde d'appel, dont une extrémité reste dans la barque. Au moment où le plongeur veut descendre, il prend entre les doigts du pied droit la corde à la pierre, et il saisit la corde d'appel de la main droite, en même temps qu'il se bouche les narines avec la gauche. Arrivé au fond de l'eau, il arrache les coquilles avec sa main droite, el les met dans son filet. Au bout de deux minutes, quelquefois de quatre, très-rarement de six, il se fait remonter. Chaque plongeur peut plonger sept à huit fois dans la matinée, et rapporte à chaque fois une cinquantaine de coquilles. Toutes les coquilles sont déposées à terre, dans des lieux réservés, où on les laisse un temps suffisant pour faire mourir les animaux, ce dont on s'aperçoit à l'ouverture spontanée des coquilles. Alors on cherche attentivement dans celles-ci et dans les lobes mêmes du manteau les perles qui peuvent s'y trouver, on choisit les plus belles coquilles pour la nacre et on abandonne le reste.

Les commerçants distinguent sans doute un assez grand nombre de sortes de nacre, d'après leur couleur et leur origine. Voici les seules que je possède :

$1^{\circ}$ Nacre vraie de Ceylan $(f g .1066)$. Valve operculaire, plate,

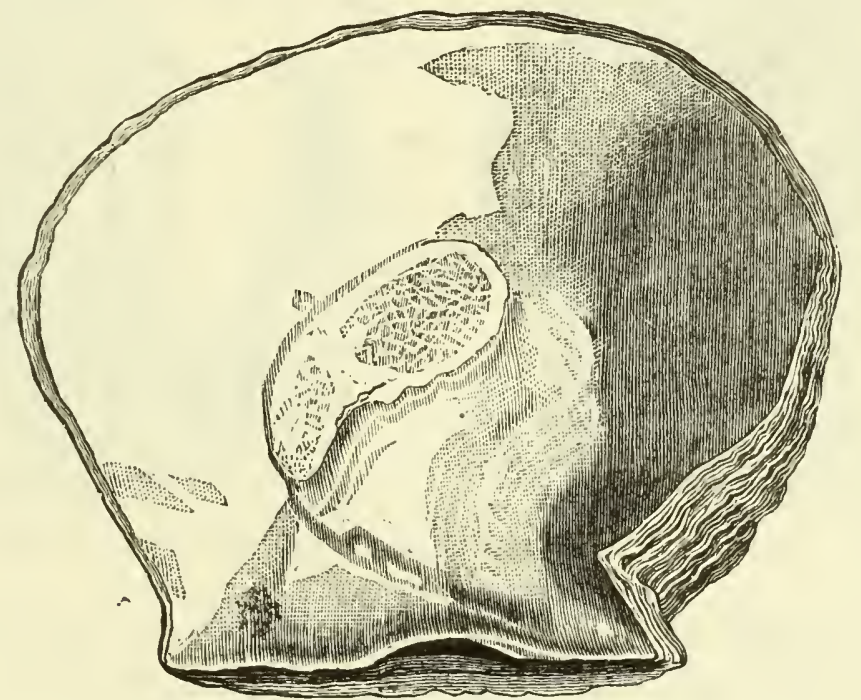

Fig. 1066. - Nacre vraie de Ceylan.

fort mince dans une grande partie de son étendue, couverte à l'extérieur d'une incrustation calcaire qui paraîl être étrangère à l'aronde; la substance propre de la coquille, y compris sa sur- 
face intérieure, est du blanc nacré le plus éclalant, à l'exception du bord feuilleté des lames qui est d'un jaune fauve partout uù il a été baigné par l'eaı de la mer. La charnière a 17 centimètres de longueur; la hauteur, du milieu de la charnière au bord opposé, est de 19 centimèlres; la plus grande largeur transversale en a 23. Sur l'intérieur de la coquille se trouvent deux signatures de commerçants, J.-J. Pott et Caillot.

$2^{\circ}$ Vacre bâtarde. Valve plate, disposée comme la précédente, et que je suppose operculaire comme elle : charnière de 11 centimèlres; hauteur et largeur 18 centimètres. La surface extérieure est uniformément bombée, entièrement feuilletée et marquée de bandes alternatives, grises et verte noirâtre, qui se dirigent en rayonnant, du sommet ou de l'angle aigu et le plus épais de la coquille, vers toute sa circonférence.

La surface intérieure est d'un blanc nacré un peu grisâtre, entouré, sur toute la circonférence, par un cercle assez large d'un vert cuivré. Cette aronde forme certainement une espèce distincte. L’impression du muscle adducteur est énorme de grandeur et rapprochée du sommet.

$3^{\circ}$ Vacre de Nankin. J'ai deux valves de cette nacre qui, en raison de leur épaisseur et de leur profondeur, doivent être deux

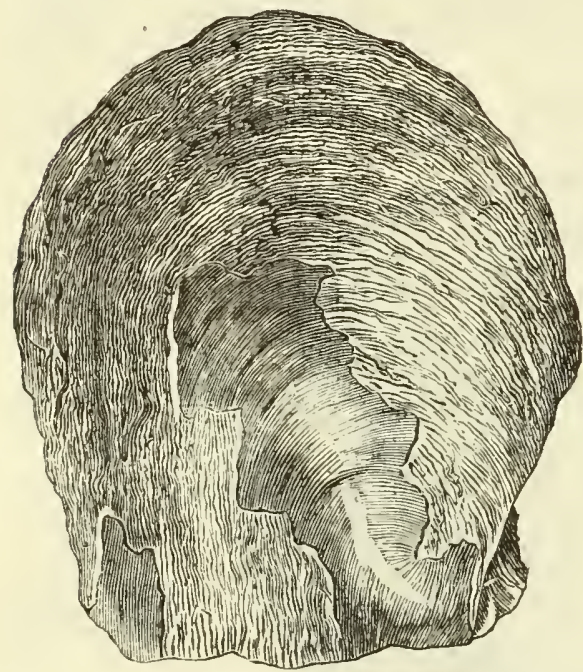

Fig. 1067. - Nacre de Nankin.

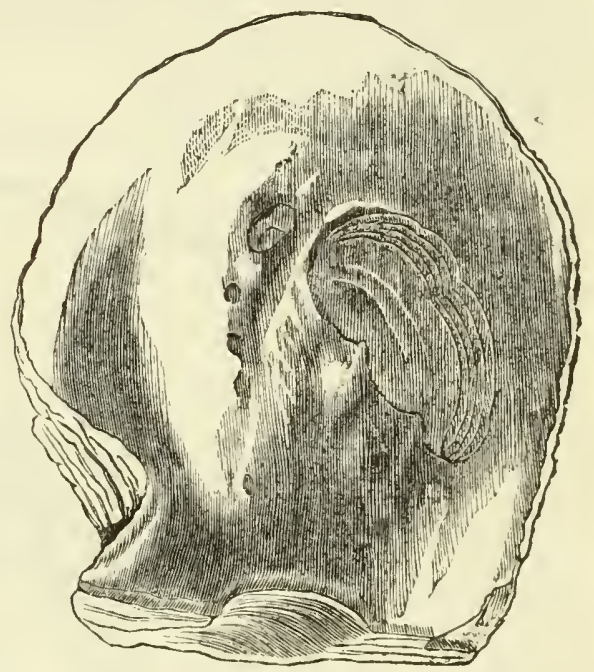

Fig. 1068. - Nacre de Nankin.

valves principales ou inférieures; mais elles sont conformées en sens contraire l'une de l'autre, ce qui indique que cette aronde, comme d'autres mollusques d'ailleur's, peut se présenter droite ou inverse.

La première de ces coquilles ( $/ \mathrm{g} .1067$ et 1068), dont le sommet est à la gauche du spectateur, lorsque la valve inférieure est placée comme on le voit ( $f g .1068)$, a 8 centimètres de charnière, 
12 centimètres de hauteur et 10 de largeur, ce qui en forme encore une espèce distincte; cependant, sauf les dimensions, elle offre tous les caractères de la première espèce : incrustation superficielle calcaire el lames concentriques très-nombreuses, jaunâtres dans toutes les parties mouillées par l'eau marine, d'un blanc nacré à l'intérieur. Mais ce blanc n'est pas pur, il présente une teinte jaunâtre uniforme.

La seconde coquille, étant placée comme la précédente, présente son sommet à la droite du spectateur; la charnière, au lieu de faire un angle droit avec le bord aminci de la coquille, forme un angle aigu; la nacre de la surface interne est violacée sur le bord.

$4^{\circ}$ Nacre noire de Californie. Valve plate ou operculaire, dont le sommet se trouve à droite du spectateur, lorsque la coquille est vue du côté intérieur, la charnière placée comme base. Longueur de la charnière 7 centimètres; hauteur de la coquille 14 centimètres; largeur $12,0 ّ$; incrustation extérieure blanchâtre; lames concentriques complétement noires à l'extérieur; nacre intérieure du blanc argenté le plus pur vers le sornmet, mais prenant peu à peu une teinte qui devient d'un vert olive très-foncé à la circonférence.

Les perles sont des corps de même nature que la nacre des coquilles. Elles se composent de couches concentriques de nacre, et elles se produisent lorsque cette matière, au lieu de s'étendre en couches plates sur celles déjà déposées, constitue de petits amas isolés comme des gouttelettes, ou adhérents à la coquille par un pédicule. Leur formation dépend d'une maladie ou, au moins, d'une activité anormale dans la sécrétion de la nacre. Aussi toutes les circonstances qui peuvent stimuler cette sécrétion, comme la présence d'un grain de sable entre la coquille et le manteau, ou une blessure faite à la coquille, tendent-elles à en déterminer la formation.

Les perles les plus estimées viennent de l'Inde et du golfe Persique. Elles sont d'autant plus recherchées et d'un prix plus considérable, qu'elles sont plus parfaitement rondes, polies, brillantes, blanches, demi-transparentes, et réfléchissant les brillantes couleurs de l'opale. Celles qui sont d'une forme irrégulière et comme mamelonnées, sont nommées perles baroques : ce sont généralement les plus volumineuses qui présentent cette forme; celles qui sont d'un volume extraordinaire, se nomment parangones; enfin, les perles les plus menues que l'on réservait autrefois pour l'usage de la médecine, portent le nom de semence de perles. Elles sont tout à fait inusitées à présent.

Plusieurs autres mollusques acéphales, dont la coquille est Guibourt, Drogues, $7 \circ$ édit.

T. IV. -24 
nacrée, peuvent produire des perles qui ont été quelquefois l'objei d'exploitations peu importantes et non continues. Tels sont: $1^{\circ}$ l'aronde oiseau ou l'hi rondelle (Avicula IFirundo, L.), que l'on trouve dans la Méditerranée. Cette espèce se distingue de l'aronde perlière, ou pintadine, par l'obliquité de sa coquille sur la charnière, qui se prolonge considérablement et inégalement au delà des deux bords de la coquille, de manière à figurer d'un côté un rostre très-allongé. $2^{\circ}$ Le marteau commun (Ostrea Malleus, L.), dont la charnière se prolonge à peu près également des deux côtés de la coquille, de manière à figurer le T d'un marteau, tandis que les valves, très-allongées dans le sens transverse, en représentent le manche. On trouve cette coquille dans l'archipel des Indes. $3^{\circ}$ Les jambon neaux (Pinna, L.), dont les deux valves égales ont la forme d'un éventail à demi ouvert el recourbé d'un côté, et sont étroitement réunies par un long ligament placé sur leur côté rectiligne. Une des espèces de ce genre, assez commune dans la Méditerranée, et connue sous le nom de pinne noble (Pinna nobilis, L.), est remarquable par son byssus formé de fils déliés, longs et brillants comme de la soie, dont on a fabriqué pendant longtemps des étoffes précieuses et d’un prix très-élevé; mais cette industrie est à peu près perdue aujourd'hui.

$5^{\circ}$ La mulette du Khin (Unio margartifera, Brugu.). Grande coquille épaisse et d'une belle nacre, que l'on trouve dans le Rhin, la Loire el quelques autres rivières. On en retire des perles assez belles et qui sont utilisées. C'est probablement à cette espèce qu'il faut rapporter ce que dit Valmont de Bomare des perles de Lorraine pêchées dans la Vologne, dont le duc Léopold s'était réservé la propriété, et dont une abbesse de Mons s'était fait faire un collier. Une mulette bien connue est celle nommée moule des peintres, qui sert à recevoir les couleurs dont les artistes se servent.

Les perles sont très-recherchées des femmes pour leur parure; mais on en fabrique un très-grand nombre de fausses avec de petites ampoules de verre enduites intérieurement de colle de poisson chargée d'essence d'Orient, tirée des écailles de l'ablette (page 181), et ensuite remplies de cire fondue. Ces fausses perles imitent très-bien les véritables, et leur fabrication forme aujourd'hui un art assez important.

Les moules (Mytilus, L.) forment un genre très-nombreux et fort connu de mollusques bivalves, qui ont une coquille close, très-solide et comme fibreuse ; à valves bombées et plus ou moins triangulaires. Un des côtés de l'angle aigu forme la charnière et est muni d'un ligament étroit et allongé. La tête de l'animal est cachée dans l'angle aigu; l'autre côté de l'angle aigu, qui est 
l’antérieur et le plus long, laisse passer le byssus. Le troisième côté, opposé à l'angle aigu, est arrondi et remonte vers la charnière à laquelle il se joint par un angle obtus. Près de ce dernier, se trouve l'anus, vis-à-vis duquel le manteau forme une ouverture particulière. Les bords du manteau sont adhérents, et ils sont garnis de tentacules branchus vers le côté arrondi, parce que c'est par là qu'entre l'eau nécessaire à la respiration. Il y a un petit muscle transverse en avant de l'angle aigu, et un grand en arrière près de l'angle oblus. Le pied est linguiforme, canaliculé et terminé par un byssus de couleur noirâtre. La coquille est aussi généralement d'une couleur noirâtre oı très-foncée à l'extérieur. tandis qu'elle est blanche et nacrée à l'inlérieur.

La moule commune (Mytilus edulis, L.) est répandue en abondance extraordinaire le long de toutes nos côtes, où elle est l'objet d'une pêche considérable. Dans la Manche, on la parque à la manière des huîtres, afin de l'atlendrir et de lui donner une meilleure qualité. Dans les environs de la Rochelle, on l'élève en domesticité et on la multiplie dans des espèces d'étangs salés artificiels, nommés bouchotes.

Les moules plaisent généralement comme aliment; mais elles déterminent quelquefois une sorte d'empoisonnement dont la cause n'est peut-être pas encore bien connue. On a longtemps attribué cet effet malfaisant à un petit crabe, nommé pinnothère, qui se trouve fréquemment dans l'intérieur de la coquille des moules; mais ce petit crustacé, n'étant pas venimeux par luimême, ne saurait communiquer celte qualité au mollusque. D'autres ont attribué la qualité malfaisante des moules au frai des astéries ou étoiles de mer, qui se répand dans la mer pendant les mois de mai, juin, juillet et août ; ce qui concorde avec l'opi. nion vulgaire que les moules ne sont vénéneuses que pendant les mois dans le nom desquels il n'entre pas d'r. Ce frai, nommé qual, est si caustique et si vénéneux, d'après de Beunie, qu'il enflamme et fait gonfler, avec une démangeaison considérable, la main qui le touche immédiatement. Cette opinion paraît donc très-probable, malgré l'observation presque constante que, dans un même repas, les moules ne sont malfaisantes que pour un petit nombre de personnes, et que ces personnes en sont habituellement incommodées en toutes saisons. On sait, en effet, que la disposition particulière desindividus influe beancoup sur l'effet des substances ingérées dans l'estomac; on conçoit, d'un autre côté, que l'appréhension causée par un empoisonnement antérieur puisse réveiller des accidents analogues, même lorsque l'aliment qui l'a causé une première fois est exempt de tout principe délétère. 
Les accidents causés par les moules se montrent ordinairement trois ou quatre heures après le repas. Les sensations deviennent obtuses; l'attention ne peut se porter sur rien; les yeux et le visage se gonflent et deviennent ardents; la gorge se resserre; la parole devient embarrassée ; le gonflement et l'irritation se propagent au cou, à la poitrine, au ventre, enfin sur tout le corps; la peau présente des plaques rouges et des ampoules blanchâtres qui changent de place à chaque instant, et qui ne peuvent être comparées à aucune autre éruption cutanée. Celle-ci est accompagnée d'une grande démangeaison, de délire, d'une inquiétude singulière, de roideur, et quelquefois d'une grande difficulté de respirer. Tous ces symptômes disparaissent ordinairement lorsque l'estomac s'est débarrassé par le vomissement de la substance délétère qui les causait. Le meilleur moyen de les arrêter est donc d'administrer un vomitif. On a conseillé aussi le vinaigre et l'éther. J'ai essayé ce dernier sans en éprouver aucun soulagement.

\section{QUATRIENE EMBRANCHEMENT}

\section{A IMAUX RAYONNES OU ZOOPIYTES.}

Cette quatrième grande division des animaux comprend un nombre considérable d'êtres dont l'organisation, toujours manifestement plus simple que celle des trois embranchements précédents, présente aussi plus de diversité et semble ne s'accorder qu'en ce point, que les parties y sont disposées autour d'un axe, sur deux ou plusieurs rayons, ou sur deux ou plusieurs lignes allant d'un pôle à l'autre. Le système ner. veux n'y est jamais bien évident, et il n'y a jamais non plus de véritable système de circulation. Quelques genres, tels que les holoturies et les oursins, ont une bouche, un anus et un canal intestinal distincts; d'autres ont un sac intestinal, avec une seule issue tenant lieu de bouche et d'anus; un plus grand nombre ne présentent qu'une cavité creusée dans la substance même du corps, et s'ouvrant quelquefois par plusieurs suçoirs. Enfin, il en est beaucoup où l'on n'aperçoit aucune bouche, et qui ne peuvent guère se nourrir qu'au moyen d'une absorption opérée par leurs pores.

Les animaux composés, dont on voit déjà des exemples parmi les derniers mollusques, sont multipliés dans certains ordres de zoophytes, et leurs agrégations forment des ironcs et des expansions qui affectent 
toutes sortes de figures. Cette circonstance, jointe à leur simplicitó d'organisation et à la disposition rayonnante de leurs organes, qui rappelle celle des fleurs des végétaux, leur a valu le nom d'animaux. plantes ou de zoophytes, par lequel on ne veut indiquer que ce rapport apparent; car les zoophytes, jouissant de la sensibilité, du mouvement volontaire, et se nourrissant, pour la plupart, de matières qu'ils avalent et qu'ils sucent, sont bien certainement à tous égards des animaux.

M. H. Milne Edwards divise les zoophytes en deux sous-embranchements faciles à caractériser par leur conformation générale : les premiers, qu'il nomme Zoopliytes radiaires, ont leurs organes disposés ordinairement autour d'un axe, et ont une forme plus ou moins distinctement étoilée; les seconds, appelés Zoophytes giobuleux, ont le corps plus ou moins splérique, au moins dans le jeune âge, car les progrès du développement peuvent les rendre tout à fait irréguliers.

Les zoophytes radiaires sont les animaux rayonnés les olus parfaits et ceux dont l'organisation est la plus compliquée. On les divise en échinodermes et en polypes.

\section{PREMIÈRE CLASSE}

\section{LES ÉCHINODERMES.}

Les ÉchiNodermes ont une peau épaisse, souvent très-dure, et garnie d'appendices tentaculaires servant à l'animal à ramper sur le sol. On y trouve les familles des astéries, des encrines,

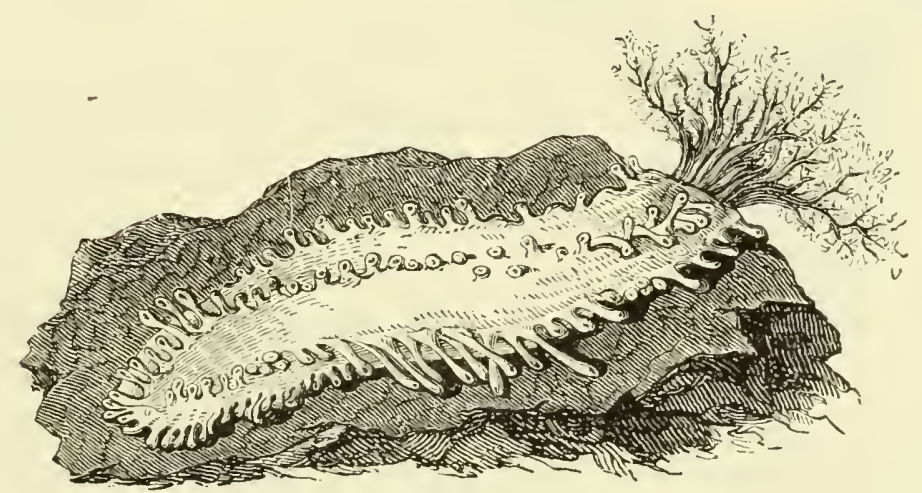

Fig. 1069. - Holothurie.

des oursins, et des holotharies ( $/ \mathrm{hg}$. 1069), qui peuvent être divisées elles-mêmes en un grand nombre de genres et d'espèces.

[C'est dans le genre des holothuries que se trouvent quelques espèces comestibles: l'Holothuria tubulosa, Gmel., recherchée 
par les pauvres gens de Naples; l'Holoth. guamensis ou guams des îles Mariannes, enfin, l'Holoth. edulis, Less., on trépangs, dont on fait un assez grand commerce dans les mers de Chine. Ces trépangs vidés et desséchés au soleil, après avoir été plongés quelques minutes dans l'eau bouillante, sont expédiées en Chine, où on les estime beaucoup : ils passent pour avoir des propriétés aphrodisiaques. On les appelle aussi edible see slug (limace de mer comestible) ou encore bêche de mer.

Les oursins sont également mangés dans divers pays: à Naples, l'Echinus granularis, Lamk. ; en Corse, I'E. Melo; en Provence et sur les côtes de la Méditerranée; les $E$. lividus, Desor, et esculentus, L.

Les animaux qui forment le groupe des polypes étaient autrefois divisés en polypes proprement dits et en aCALÈrues, contenant les méduses, les pélagies, les rhyzostomes, les béroés, les cestes, les physalles, les physsophores et les diphyes. Mais, en étudiant le mode de développement de ces animaux, on s'est aperçu qu'un certain nombre d'acalèplies commençaient par être des polypes, et qu'il y avait d'ailleurs de très-grands rapports d'organisation entre les divers genres de ces deux groupes. On les réunit donc en une seule classe à laquelle nous conserverons avec M. Van Beneden et P. Gervais le nom de polypes.]

\section{DEUXIÈME CLASSE}

\section{LES POLYPES.}

Ainsi limités, les polypes ont le corps tantôt mou, tantôt en partic encroûté d'une matière cornée ou pierreuse, par laquelle ils adhèrent aux corps étrangers. Ils ont le corps cylindrique, ovalaire ou disciforme, et n'offrent d'ouverture qu'à une de leurs extrémités, laquelle est entourée d'une couronne de longs tentacules. La bouche occupe l'axe du corps et sert en même temps d'anus: elle communique avec une grande cavité abdominale, terminée en cul-de-sac. Ils se multiplient de deux manières: tantôt ils produisent des œufs qui se détachent et sont expulsés au dehors, pour aller au loin se fixer et se développer; d'autres fois, il naît sur la surface de leur corps des espèces de bourgeons qui deviennent de nouveaux polypes semblables ou dissemblables à leur mère. Il en résulte des masses de formes trèsvariécs, dans lesquelles toute une suite de générations se trouve agrégée et semble vivre d'une vie commune. Souvent le corps 
de ces animaux est composé en entier d'un tissu demi-transparent, d'une grande délicatesse; mais, chez la plupart, la partie inférieure de leur gaîne tégumentaire se solidific et acquiert l'aspect de la pierre. Ces enveloppes solides forment tantôt des tubes, tantôt des cellules; elles sont quelquefois distinctes, mais d'ordinaire elles constituent par leur réunion une masse à laquelle on donne le nom de polypier, qui sert à les caractériser et dont le volume peut devenir très-considérable, quoique chacune de ses parties soit de dimensions fort petites.

Lorsque certains de ces animaux sont placés dans des circonstances favorables à leur développement, par exemple dans les mers voisines des tropiques, ils pullulent au point de recouvril d'immenses bancs sous-marins, qu'ils tapissent de leurs générations de polypiers amoncelées les unes sur les autres, et il ne leur faut pas un très-grand nombre d'années pour les élever au niveau de la surface de l'eau. Alors, le sol formé de leurs débris cesse de s'élever, mais bientôt apparaît une nouvelle série de phénomènes: des graines apportées par les vents ou déposées par les vagues, y germent el la couvrent d'une riche végétation, jusqu'à ce qu'enfin le sol devienne une île habitable. Dans l'ccéan Pacifique, on rencontre une foule de récifs ct d’iles qui n'ont pas une autre origine.

[On peut diviser les polypes en cTÉxopiones, contenant les cestes et les liéroés; discopHores ou polypo-Ménusirnes, contenant les siphonophores, autrefois nommés acalèphes hydrostatiques (fig. 1070), les méduses, les sertulaires et les hydraires; les zoantuaires et les CTÉNocères.]

Leszoantuaires sont ainsi nommés à cause de leur ressemblance arec certaines fleurs; leur peau est épaisse et opaque, et leur corps a ordinairement la forme cylindre tronqué dont une extrémité adhère au sol, et dont l'autre est garnie d'un grand

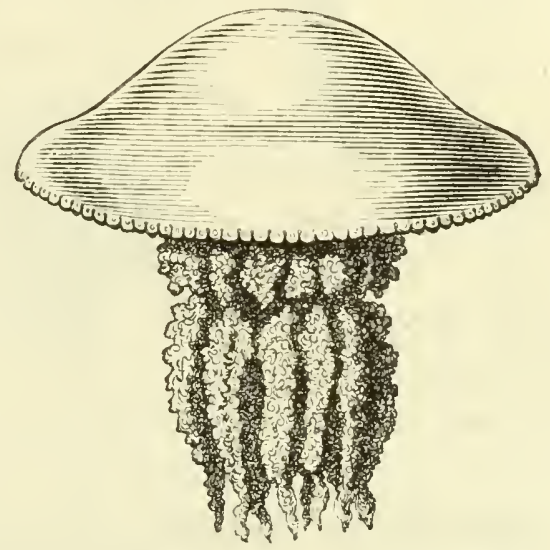

Fig. 1070. - Acalèphes. - Rhizostonc. nombre de tentacules effilés. Au milieu de la couronne, formée par ces appendices, se trouve la bouche qui, par l'intermédiaire d'un court œsophage, conduit dans une vaste cavité stomacale. Parmi les zoanthaires, il y en a dont les téguments conservent toujours une consistance charnue: telles sont les actinies ou anémones de mer, qui vivent isolées sur les rochers, el qui sont ornées des plus belles couleurs. Mais il y en a d'autres qui sécrè- 
tent en abondance du carbonate de chaux; ce sel se dépose dans la partie inférieure du corps et constitue autant de petits polypiers pierreux, dont quelques-uns restent isolés, comme les actinies; mais la plupart des autres (millepores, caryophyllies, astrées, méandrines, etc.), que Linné réunissait sous le nom de madrépores, forment, par leur réunion, des masses considérables, et ce sont eux principalement qui concourent à la formation des îles dites de corail, dont il a été question plus haut.

Dans le groupe des cténocères ou alcyoniens, le corps de chaque polype est, en général, beaucoup plus allongé, et les tentacules quile terminent sont larges, foliacés et au nombre de huit seulement. Presque tous ces polypes sont agrégés et forment un polypier solide dont un est bien connu sous le nom de corail rouge.

Les polypes de l'ordre des mydraires sont beaucoup plus simples que ceux des deux ordres précédents. Ils sont formés d'un sac gélatineux en forme de tube, et dont l'ouverture est garnie

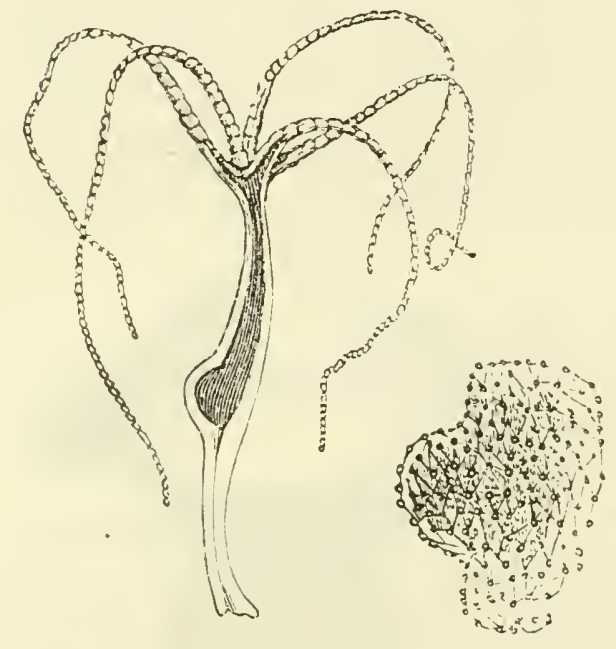

Fig. 1071. - Hydre et son bourgeon grossi.

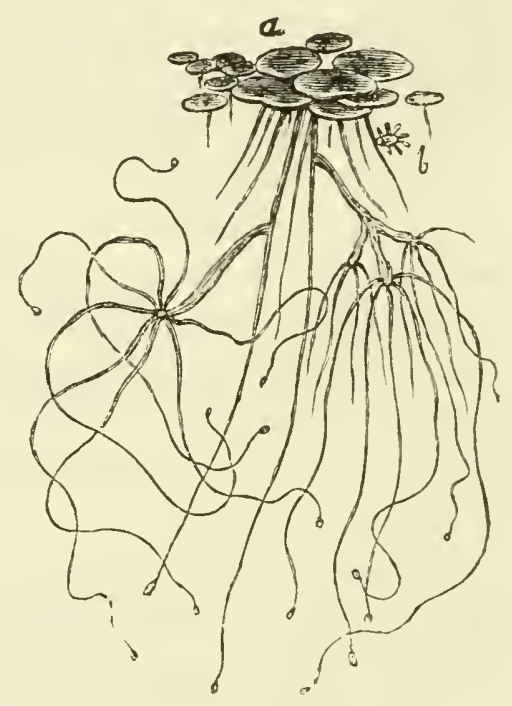

Fig. 1072. - Ilydres firécs à des lentilles d'eau douce $\left(^{*}\right)$.

de tentacules filiformes d'une très-grande sensibilité. Le microscope ne fait apercevoir dans leur substance qu'un parenchyme transparent rempli de granules un peu plus opaques. Néanmoins ils nagent, ils rampent, ils marchent même, en fixant alternativement leurs deux extrémités comme les sangsues; ils agitent leurs tentacules qui sont quelquefois fort longs, et s'en servent pour saisir leur proie, qui se digère à vue d'œil dans la cavité de leur corps. Ce qu'il y a de plus surprenant, et ce qui

(*) $a$, lentilles; $b$, petits naissant. 
montre bien l'homogénéité de toute leur substance, c'est qu'on peut retourner le tube qui les forme comme un doigt de gant, mettre en dehors la surface intérieure, et vice versâ, sans nuire en rien à leur existence, la nouvelle surface intérieure faisant fonction d'estomac, tout aussi bien que la première. Mais la propriété la plus merveilleuse de ces animaux est celle de reproduire constamment et indéfiniment les parties qu'on leur enlève, en sorte qu'on peut les multiplier à volonté par la section. Leur multiplication naturelle se fait, soit par le moyen de bourgeons qui se montrent à la surface du tube et qui s'en délachent après avoir produit un individu semblable à la mère, soit par de petits corpuscules qui sortent de leur parenchyme à l'automne, se conservent au fond de l'eau pendant l'hiver et ne se développent qu'au printemps.

On trouve ces singuliers animaux dans les eaux dormantes, la plupart du temps fixés par la base de leur tube à la face inférieure des lentilles d'eau, et s'agitant la tête en bas dans l'eau. Ils sont très-sensibles à l'action de la lumière qu'ils recherchent activement. On leur donne communément les noms d'hydies (fig. 1071, 1072), de polypes à bras et le polypes d'eau douce.

\section{TROISIÈME CLASSE}

\section{I.ES INFUSOIRES.}

Le zoophytes non radiaires comprennent deux classes d'êtres qui n'offrent guère d'autre rapport entre eux que celui d'être placés sur la dernière limite de l'animalité. La première classe, qui renferme les infusolnes nonogìnes du Cuvier, nous offre des animaux tout à fait microscopiques, qui se développent cu abondance dans l'eau chargée de matières organiques en décomposition. Leur corps est gélatineux, tantôt arrondi, tantôt allongé ou aplati, souvent couvert de petits cils, et offrant à l'intérieur un nombre ordinairement considérable de petites cavilés qui paraissent remplir les fonctions d'autant d'estomacs. La manière dont ces infusoires se propagent a donné lieu à beaucoup de controverses, et plusieurs naturalistes ont admis qu'ils pouvaient se former par l'organisation spontanée de matières provenant de substances organiques en décomposition.

Ce n'est pas ici le lieu d'exposer cette question de la génération spontanée, sur laquelle on a beaucoup discuté dans ces dernièrres années. Nous nous bornerons à renvoyer les lecteurs, curieux 
de se mettre au courant de cette question, aux nombreux mémoires de MM. Pasteur, Joly, Pouchel, etc., dont la plupart ont élé communiqués à l'Académie des sciences.

Nous nous bornerons à dire quelques mots des animaux inférieurs qu'on a trouvés dans l'intérieur du corps humain, ou au milieu des liquides de l'économie, ceux qu'on peut appeler entozoaires infusoires; ce sont des paramécies, des cercomonades, des trichomonades, des virgulines et des vibrions.

Les paramécies sont des infusoires aplatis et oblonss dont le corps finement cilié est pourvu d'une bouche antéro-latérale, et, d'après M. Davaine, d'un anus situé à la parlie inférieure et postérieure du corps. On en a observé une espèce, la paramécie du côlon (Paramecium coli, Malmstem), entre les villosités de la muqueuse du côlon.

Les cercomonades, caraclérisés par un cil vibratile à la partie antérieure et par une queue en arrière, fournissent une espèce aux entozoaires. M. Davaine l'a décrite sous le nom de Cercomonas

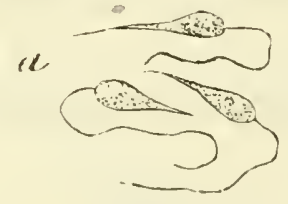
hominis, et en a distingué deux variétés : l'une, qu'il a trouvée dans les selles des cholériques; l'antre, dansles déjections d'un individu atteint de fièvre typhoïde (fig. 1073).

Les trichomonades se distinguent des cercomonades, par l'absence de l'appendice caudal. On en connaît une espèce (Trichomonas vaginalis) Duj.), observée par M. Donné (1) dans les mucosités vaginales de la lemme (fig. 1074).

Les virgulines, petits infusoires

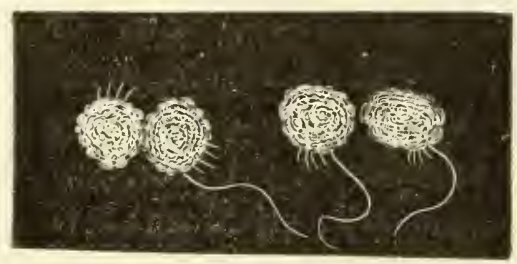

lig. 1074. - Trichomonades. allongés, munis d'un petit appendice caudal, ayant en tout $0^{\mathrm{mm}}, 05$, se trouvent assez abondamment dans le tartre.

Enfin, les vibrions, animaux microscopiques de $0^{\mathrm{mm}}, 008$ à $0^{\mathrm{mm}}, 013$; ayant le corps cylindrique, atténué aux deux extrémités, droits ou flexueux, ont été trouvés par myriades dans les selles des cholériques (V'ibrio Rugula, Müll.). Les Vibrio Baccillus, Müll., et V.lineola, Müill.), existent dans le mucus buccal; et les $V$. cyanogenus, Fuchs, et xanthogenus, Fuchs, colorent parfois le lait en bleu ou en jaune.

(1) Donné, Cours de microscopie. Paris, $18 \mathbf{i}^{\prime}$. 


\section{QUATRIÈIE CLASSE}

\section{LES SPONGIAIRES.}

La quatrième classe est celle des spongrares, c'est-à-dire des corps qui offrent la structure des éponges. Ces corps ressemblent beaucoup à la portion commune de certains polypes agrégés, tels que les alcyons; mais jusqu'à présent on n'y a rien trouvé d'analogue à la partie individuelle de ces animaux. Ce sont des masses qui vivent dans la mer, fixées aux rochers, et qui n'offrent aucun signe de sensibilité ni de contractilité. On sait seulement que, suivant les observations de M. Grant, elles vivent, parce qu'elles absorbent continuellement une quantité considérable d'eau par les pores répandus sur toute leur surface, et que ce liquide est ensuite expulsé par d'autres ouvertures plus grandes, sous forme de courant. Une espèce de charpente, composée tantôt d'aiguilles calcaires ou siliceuses, tantôt de filaments cornés, soutient ces masses et forme un tissu dont l'intérieur présente une multitude de lacunes communiquant entre elles. A certaines époques, de petits corps arrondis se développent dans ce parenehyme, tombent dans les canaux dont il est percé et sont expulsés au dehors avec l'eau qui les traverse. Ces corpuscules sont les germes reproducteurs de l'éponğe; ils sont donés d'abord de la faculté de se mouvoir, et, après avoil nagé pendant quelque temps, ils se fixent et se transforment en une petite éponge semblable à celle dont ils proviennent (Grant).

Dans toute la classe des zoophytes, je ne traiterai en particulier que de deux substances qu'elle fournit à la pharmacie, le corail rouge et l'éponge.

\section{Corail rouge.}

Le corail ( $(\mathrm{g} g \cdot 107 \mathrm{a})$, de même que la plupart des autres polypiers solides, a longtemps été considéré comme une plante dont l'axe était de nature calcaire, mais dont l'écorce vivante pouvait produire des fleurs régulières. C'est Peyssonnel qui a montré le premier, en 1727, que les prétendues fleurs de corail, observées par Marsigli en 1703, sont de véritables animaux rayonnés qui sécrètent la substance calcaire sur laquelle ils sont portés. Pallas décrivit ensuite le corail, et lui donna le nom d'Isis nobilis; Gmelin et Solander en firent une gorgone; enfin Lamarck en forma un 
genre particulier sous le nom de Corallium, el l'appela Coral. lium rubrum (1).

Le corail affecte la forme d'un petit arbrisseau, d'environ 50 centimètres de hauteur, fixé aux corps sous-marins par une sorte d'empâtement analogue à la griffe des fucus. De cet empâte-

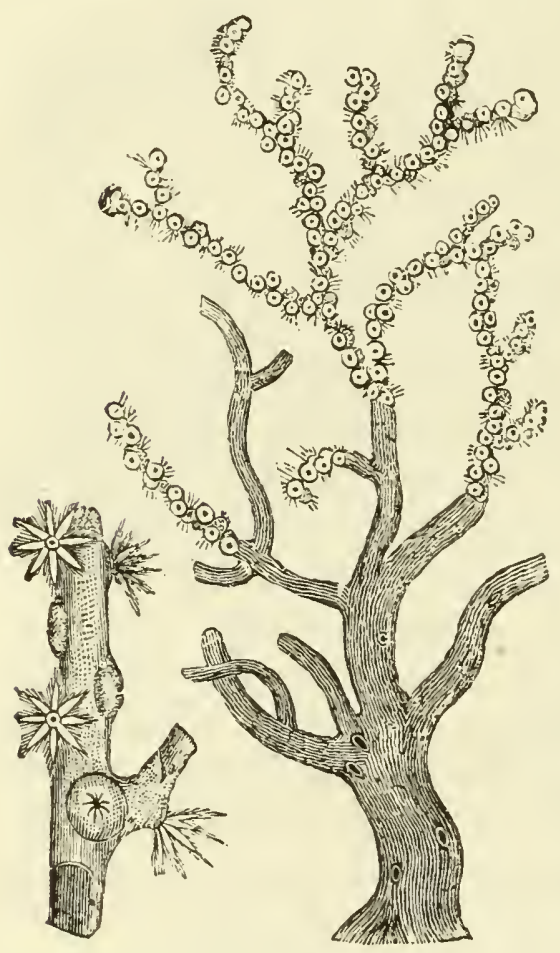

Fig. 1075. - Corail rouge. ment sort la tige, qui est ordinairement ronde, mais quelquefois comprimée, épaisse de 20 millimètres environ dans sa partie la plus grosse, mais se divisant bientôt en un certain nombre de rameaux irréguliers. Dans le corail vivant, ces rameaux sont recouverts d'une sorte d'écorce blanchâtre, charnue, lisse et polie, mais dont la surface est parsemée d'un grand nombre de cellules proéminentes contenant autant de polypes. Ceux-ci sont très-mous, tout à fait blancs et pourvus d'une bouche entourée de huit tentacules qui ressemblent àssez à des pétales étalés régulièrement, allongés, pointus, incisés sur les bords. La substance charnue qui leur est commune est sillonnée par une multitude de vaisseaux communiquant avec la cavité digestive des polypes, et sà partie interne sécrète du carbonate de chaux mêlé à une matière colorante rouge, et qui constitue l'axe pierreux du corail.

Cet axe pierreux ne se trouve dans le commerce que débarrassé de son écorce vivante. Il conserve la forme générale d'un arbrisseau ramifié et non articulé, formé par une substance compacte, d'un rouge vif et un peu rosé, qui en fait une des plus élégantes productions de la nature. Sa surface est toute couverte de stries longitudinales, serrées, parallèles, mais souvent sinueuses, et s'étendant, en suivant toutes les ramifications, d'une extrémité à l'autre de l'axe. La substance interne est tellement compact`, que la cassure brute ou polie n'y fait découvrir aucune trace d'organisation; mais lorsqu'on fait agir dessus un acide affaibli, l'énergie différente avec laquelle la substance du corail est attaquée y fait découvrir une organisation rayonnée, dontles stries correspondent à celles de la surface.

(1) Voir Lacaze-Duthiers, Histoire naturelle du Corail. Paris, $18 C 4$. 
La dureté du corail surpasse celle du spath d'Islande, mais est inférieure à celle de l'aragonite. Il est susceptible d'un beau poli, et l'on en fabrique des bijoux qui sont d'un prix d'autant plus élevé que sa couleur est plus vive et plus brillante.

Le corail abonde dans la Méditerranée et dans la mer Rouge, fixé aux rochers, à une profondeur très-variable; on ne le trouve pas à moins de $3^{\mathrm{m}}, 30$ et on le pêche jusqu'à 200 mètres. On le pêche principalement près de la côte d'Afrique, dans le détroit de Messine et dans l'Archipel grec, en promenant, au fond de la mer, des morceaux de bois garnis de filasse, que l'on tire fortement, lorsqu'on sent la filasse embarrassée dans le corail. Il y a aussi des plongeurs qui ne font pas d'autre métier que d'aller le chercher.

Différents auteurs ont émis sur la nature du principe colorant du corail des idées que M. Vogel, de Munich, a rectifiées, en montrant que ce principe était l'oxyde rouge de fer, et non une substance organique, puisqu'il n'est pas décoloré par le chlore, qu'il est insoluble dans l'eau, l'alcool et l'éther; qu'il noircit par l'acide sulfhydrique et qu'il disparaît en se dissolvant dans les acides azotique, sulfurique et chlorhydrique, dans lesquels alors les réactifs indiquent, comme seul principe colorant possible, l'oxyde de fer (1). Suivant M. Vogel, le corail rouge est composé de :

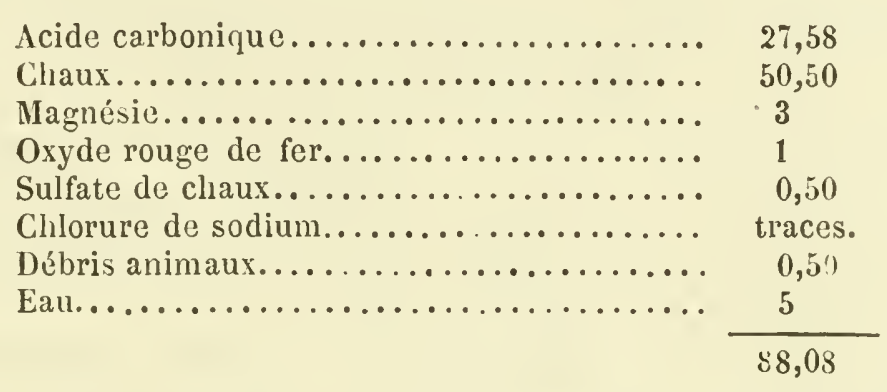

Le corail rouge n'est plus guère employé en pharmacie que comme dentifrice. La teinture et le sirop qu'on en préparait autrefois, après l'avoir fait dissoudre dans le suc de berbéris, ne sont plus usités.

(1) Ce qui pourrait faire douter de l'exactitude de cette conclusion, c'est la facilité avec laquelle le corail se décolore par certains agents réductifs, et reprend ensuite sa couleur au contact de l'air. Ainsi j'ai vu des boucles d'oreilles de corail, blanchies par l'application d'un cataplasme de farine de lin, reprendre leur couleur primitive après quelques jours d'exposition à l'air. On sait aussi qu'une forte transpiration fait perdre au corail une partie de sa couleur. Les corps gras et les liuiles volatiles le décolorent également. Nul doute que l'oxyde de fer ne fasse une partie essentielle de la matière rouge du corail; mais il est possible qu'il ne la compose pas à lui tout seul. 
On comprenait autrefois au nombre des drogues médicinales deux autres productions polypiaires nommées, l'une corail blanc, l'autre corail noir. La première est une oculine (Oculina virginea, Lamk.), c'est-à-dire un polypier à animaux inconnus, contenus dans des loges stelliformes régulières, arrondies, plus ou moins saillantes et mamelonnées, éparses à la surface d'un polypier calcaire, solide, compacte, arborescent et fixé. Il est d'un blanc de lait. On le trouve dans la mer des Indes et dans la Méditerranée; il existe aussi à l'état fossile dans le terrain de Paris.

Le corail noir ou antipathe, est un polypier branchu formé par une substance dure, élastique et cornée, disposée en couches concentriques distinctes. L'écorce molle a été détruite par la dessiccation, et les animaux qu'elle contenail sont inconnus. La souche soluvent entourée d'une incrustation calcaire grise, à structure radiée, que je crois appartenir au polypier, car les rameaux présentent quelquefois des concrétions semblables qui sont recouvertes par une couche de matière cornée.

\section{Éponges.}

Les éponges sont des êtres placés au plus bas degré du règne animal, composant des masses plus ou moins considérables, de formes très-variables et irrégulières, de structure fibreuse et comme feutrée, et de consistance molle; elles sont percées d'un grand nombre de conduits sinueux, de pores et d'orifices plus grands, nommés oscules. On n'y rencontre aucun polype ou animal rayonné distinct, ainsi qu'on en observe encore dans les alcyons ; mais seulement une sorte de mucilage animal qui enveloppe toutes les parties de leur tissu fibreux, et dont on les débarrasse par le lavage, avant de les livrer au commerce.

Cette description, ainsi conçue en termes généraux et telle que l'admetlait Lamarck, peut encore renfermer des corps d'une organisation bien différente, ainsi que cela résulte principalement des observations de M. Grant (1). Les uns, ce sont les moins nombreux, je pense, sont formẹs d'une substance tendineuse percée de pores ou de conduits de forme irrégulièrement rayonnée, et soutenue par des faisceaux d'aiguilles simples ou tricuspidées auxquelles on donne le nom d'acicules, et qui en forment comme le squelette. Ces acicules sont de nature calcaire ou siliceuse, suivani les espèces.

C'est dans ces spongiaires spécialement que l'on a observé la production des ovules tombant dans les conduits qui la traver-

(1) Grant, Annales des sciences naturelles, 1827, t. XI, p. 150. 
sent et rejetés au dehors, avec le courant d'eau. M. Flemming a imposé à ces spongiaires les noms de calcéponges (Calcispongia) et de haléponges (Halispongia), suivant la nature calcaire ou siliceuse de leurs acicules. On trouve, parmi les calcéponges, les éponges comprimée, bothryoîle et ciliée de différents auteurs; et parmi les haléponges, les éponges papillaires, paniformes, cendrée, arborescente, coulée, dichotome, elc. Ces fausses éponges, desséchées, sont dures et cassantes; celles qui sont calcaires font effervescence avec les acides; celles qui sont siliceuses rayent le verre; elles se gonflent peu par l'eau et y restent dures au toucher. Elles ne sont d'aucun usage dans la vie domestique.

Les autres spongiaires, qui sont les seuls auxquels on conserve aujourd'hui le nom d'éponges, présentent un squelette cartilagineux, formé de fibres très-déliées, transparentes, flexibles, élastiques, douces au loucher, anastomosées les unes avec les autres et formant un tissu, tantôt d'une grande finesse, tantôt grossier et traversé en tous sens par des canaux tortueux, d'un diamètre plus ou moins considérable. Dans l'état de vie, toutes les parties de ce tissu sont entourées d'une enveloppe muqueuse, qui manque le plus souvent dans les individus secs. Jusqu'à présent, on n'a pu observer, dans les vraies éponges, ni corps reproducteurs ni courants. Plusieurs observateurs cependant ont cru trouver de la sensibilité dans l'espèce de bave muqueuse qui les recouvre à l'état vivant, et on dit avoir vu un mouvement alternatif de contraction et de dilatation à l'ouverture de leurs tubes; mais ces faits sont révoqués en doute par M. Grant.

La forme des éponges varie à l’infini : tantôt elles sont sessiles on non pédiculées, arrondies, simples ou lobées; d'autres fois, elles sont rétrécies à la base, élargies par le haut en forme de toupie ou de sabot, et souvent creusées au centre en forme d'entonnoir ou de creuset; d'autres fois encore elles sont manifestement pédiculées, aplaties et flabelliformes, ou bien foliacées, ou bien encore ramifiées et ayant la forme d'un arbrisseau, etc. Lamarck en a décrit 141 espèces, et beaucoup d'autres ont été distinguées par divers naturalistes; mais il n'y en a qu'un petit nombre qui soient fournies par le commerce et usitées dans la vie domestique. Celles dont nous nous servons nous viennent principalement des côtes de la Syrie, de l'Anatolie, des îles grecques et des côtes d'Afrique. Il en vient aussi de la Havane et des îles de Bahama, mais qui sont d'une qualité très-inférieure.

1. L'éponge la plus estimée est l'éponge fine douce de Syrie (éponge usuelle, Lamk.), Spongia mollissima, Schmidt (1), qui est

(1) M. Fristedt a déterminé spécifiquement un certain nombre d'éponges du 
exclusivement réservée pour la toilette. Telle que le commerce la présente, elle est d'un jaune tirant sur le fauve, légère, généralement turbinée, quelquefois arrondie par le haut, mais le plus souvent creusée en forme de coupe ou d'entonnoir. La partie extérieure est fine, veloutée, douce au toucher, percée d'une infinité de petits trous ronds, de dimension presque semblable. Les grands trous y sont très-rares. La partie pleine de l'éponge, vue à la loupe, paraît formée d'une infinité de fibres anastomosées, dont quelques-unes, plus longues que les autres et plus libres, se roulent au dehors sous forme d'une petite mèche tortillée, qui se dresse au bord de chaque trou. Ce sont toutes ces petites mèches qui donnent à l'éponge son aspect et son toucher velouté. L'intérieur de la coupe ou de l'entonnoir est, au contraire, percé de grands trous, très-nombreux, disposés d'une manière plus ou moins apparente, en lignes rayonnantes. Les trous du fond pénètrent généralement jusqu'à la base et laissent voir le jour au travers.

Cette éponge est souvent moins grosse que le poing; mais elle acquiert quelquefois un volume considérable; elle se gonfle beaucoup dans l'eau et en retient une grande quantité. Son prix varie de 100 à 140 francs le kilogramme; les plus grosses et les plus belles, en forme d'entonnoir, que l'on réserve pour servir de montre aux marchands, ou pour les cabinets, se vendent séparément à la pièce, 200 francs, 50 francs et au delà (1).

L'éponge fine douce de Syrie, examinée au microscope, ne présente rien autre chose que des fibres cylindriques, ramifiées à l'infini et anastomosées les unes avec les autres, sans aucune régularité; car les espaces circonscrits sont quelquefois trèspetits et triangulaires; d'autres fois, ils sont plus grands et en forme de losange; mais le plus souvent ils sont très-grands et tout à fait irréguliers, les rameaux qui les forment faisant de grands circuits avant de s'anastomoser avec d'autres. Ces rameaux sont de grosseur à peu près égale, et conservent cette grosseur d'une extrémité à l'autre de l'éponge. Ils sont pleins et non tubuleux comme on le dit. Ils sont formés de fibrilles très-serrées et agglutinées, flexueuses, et qui se continuent sans inter-

commerce. Il rapporte : $1^{\circ}$ les éponges fines et douces de Syrie, au Spongia mollissima, Schmidt; $2^{\circ}$ les éponges fines de l'Archipel au Spongia Zimocca, Sclımidt; $3^{\circ}$ les éponges grossières du nord de l'Afrique au Spongia equina, Schmidt $; 4^{\circ}$ les éponges dites de Dalmatie, au Spongia adriatica, Schmidt. Quant aux éponges de Bahama, l'auteur n'a pas pu en indiquer l'origine. (Voir Wiggers et Huseman, Jahresbericht der Pharmacognosie, année 1869, p. 160.]

(1) Voyez Leroy de Méricourt, Considérations sur l'hygiène des pécheurs d'éponges (Annales d'hygiène, 1869, $2^{\circ}$ série, t. XXXI, p. 2i4́). 
ruption d'un rameau à l'autre. Ces fibrilles sont très-faciles à voir aux endroits où les rameaux sont rompus. Quant aux extrémités naturelles des rameaux par lesquelles ceux-ci doivent croître et sallonger, elles ont une terminaison nelte et arrondie. On observe aussi, mais bien moins fréquemment pour l'éponge fine douce que pour les autres, que les rameaux principaux peuvent donner naissance, dans l'intervalle de deux ramifications, à un rameau latéral, d'un diamètre plus petit; de sorte que, suivant ce que je pense, les éponges doivent croître à la manière des plantes, par l'allongement lerminal des axes et par le développement de bourgeons latéraux. Il y a toujours entre ces deux classes d'êtres cette grande différence, que l'axe de la plante, tirant sa principale nourriture de la racine, diminue en diamètre de sa base à l'extrémité; tandis que l'axe des éponges, tirant la sienne probablement de tous les points de la surface, conserve partout la même force et le même diamètre. Les éponges du commerce, que j'ai observées, ne m’ont présenté ni acicules, ni rien que l'on puisse prendre pour des organes reproducteurs. L'éponge fine douce, simplement lavée à l'eau et séchée, conserve une odeur très-marquée et non désagréable d'iode affaibli.

2. Éponge fine dure, dite éponge grecoue. Celte éponge se trouve principalement dans les parages de l'île de Rhodes et des îles de l'Archipel, mais elle vient aussi de la côte de la Syrie. Elle présente généralement une base très-étroite qui s'élargit en forme de sabot, de plateau mamelonné, de coupe ou d'entonnoir ; mais elle est très-souvent oblique sur son pied et déjetée d'un côté. Elle est d’un jaune fauve plus ou moins foncé et rude au tcucher, ce qui la rend peu agréable pour l'usage de la toiletle. Elle ne paraît pas différer de l'éponge fine douce, quant à son organisation.

3. Éponge blonde de Syrie, dite de Venise (éponge commune, Lam.) ( $\mathrm{ig}$. 1076). Cette éponge a la forme arrondie d'un champignon, et peut acquérir jusqu’à 30 ou 40 centimètres de diamètre. Elle est d'un blond pâle dans sa masse et d'une couleur d'ocre jaune au pied. Elle est très-poreuse, légère, lorsqu'elle a été lavée, et d'une structure grossière. Elle est caractérisée par sa surface qui présente, d'espace en espace : $1^{\circ}$ des trous ronds, assez grands pour y mettre le doigt; $2^{\circ}$ des amas un peu proéminents de trous beaucoup plus petits; $3^{\circ}$ des espaces déprimés, presque privés de trous et qui présentent à la loupe un lacis inextricable de fibres blondes. Le bord des trous grands et petils, et les suraces déprimées, présentent de petites élevures pointues, dures au toucher, formées de fwres dressées et entrelacées. Les grands trous sont dirigés vers la base de l'éponge; mais, comme ils 
deviennent très-sinueux, à leur partie inférieure, on ne voit pas le jour au travers. Vue au microscope, la seule différence que cette éponge présente avec l'éponge douce de Syrie consiste dans l'extrémité des rameaux qui, au lieu d'être arrondie, se termine par une pointe plus ou moins marquée.

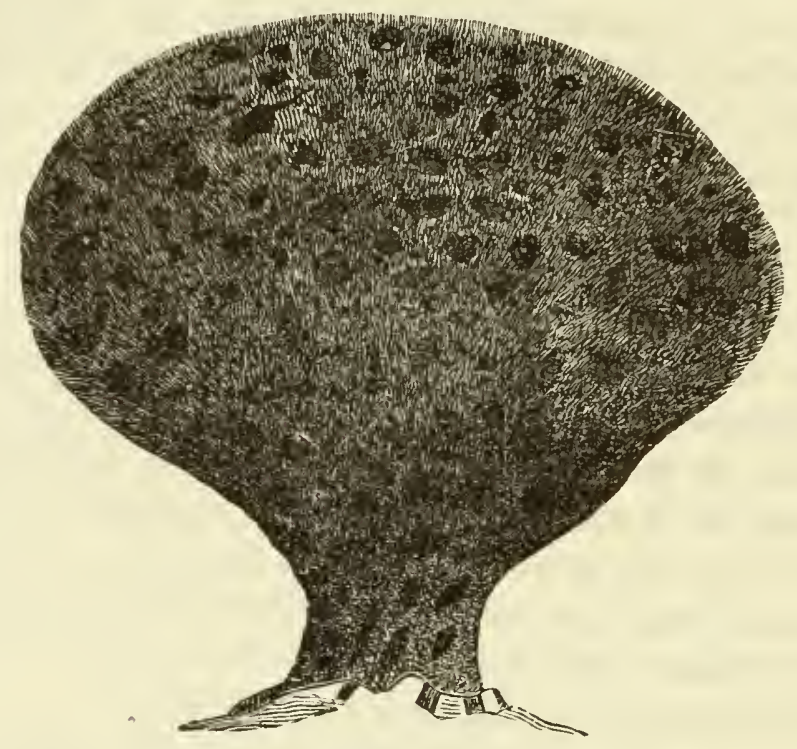

Fig. 1076. - Éponge blonde de syrie.

L'éponge blonde de Syrie sert à tous les usages domestiques. C'est la plus estimée, pour cet emploi, à cause de sa légèreté, de la régularité de sa forme et de la solidité de sa texture. Son volume considérable oblige souvent à la couper en plusieurs parts, pour en diminuer le prix et pour la facilité de son emploi.

4. Éponge blonde de l'Archipel, dite aussi éponge de Venise. Cette éponge est évidenment de la même espèce que la précédente; la disposition des trous et des espaces pleins, sur la face supérieure, est exactement la même. Mais elle est moins épaisse, aplatic, quoique bombée à la partie supérieure et de forme oblongue. Elle atteint quelquefois 60 centimètres de dia mètre. En raison de sa moindre épaisseur, les grands trous de la surface pénètrent plus facilement jusqu’à la racine, et quelques-uns la traversent de part en part. A l'état brut, elle est très-chargée de sable, et elle cause un grand déchet par le lavage. Elle sert aux mêmes usages que la précédente (1).

כั. Éponge de Gerby ou Zerby. Cetle espèce est une éponge

(J) D'après M. Blanc, négociant en éponges à Paris, cette variété d'éponge et la précédente croissent dans les mêmes parages; seulement celle dite de Syrie, habitant des endroits où la mer est tranquille, s'étend librement dans tous les sens et prend la forme arrondie d'un champignon; tandis que celle dite cle l'Archipel, se trouvant au milieu de courants, s'élève moins et s'étend davantage dans le sens horizontal. 
commune qui vient de l'île Zerby, près de la côte d'Afrique, dans la régence de Tripoli. Elle est volumineuse, souvent de forme irrégulière, mais généralement arrondie. On la reconnaît facilement à sa surface hérissée de fibrilles, et à la couleur rouge de sa racine qui tranche avec la couleur blonde de la partie supérieure. J'ai deux échantillons de celte éponge sous les yeux. L'un est à peu près carré, percé sur tous les côtés de trous moyens, trèsirréguliers, en partie cachés par des expansions membraneuses et par des pointes fibreuses très-développées. La face supérieure est en outre percée de plusieurs grands trous surmontés de lames déchiquetées, inclinées vers le centre de l'ouverture. Un des trous traverse directement la masse, qui est d'ailleur's toute caverneuse dans son intérieur.

Le second échantillon a la forme arrondie et un peu turbinée par le bas de la grosse éponge de Syrie; il est un peu plus serré que le premier, mais encore très-caverneux à l'intérieur, et il a la face supérieure toute percée de trous irréguliers, déchiquetés sur les bords; les plus grands trous seulement ont une forme ronde et sont entourés d'un bord frangé, proéminent, rapproché du centre de l'ouverture et ressemblant jusqu'à un certain point à des coronules. Cette sorte d'éponge est très-répandue aujourd'hui dans le commerce, parce que, étant très-volumineuse pour un poids peu considérable, elle paraît avantageuse au consommateur. Mais elle est en réalité bien inférieure pour la qualité aux éponges du Levant.

6. Éponge hrune de Barbarie. D’après M. Blanc, déjà cité, cette éponge vient de $S f a x$, sur la côte d'Afrique; elle doit une partie de ses caractères particuliers à ce qu'elle a été séchée dans son état naturel, ou sans avoir été lavée, de sorte qu'elle est imprégnée de la bave muqueuse qui la recouvre à l'état de vie. Elle est de forme arrondie ou aplatie, dure, pesante, d'un tissu grossier, d'une couleur de polypore amadouvier dans les parties où le tissu est à découvert, mais chargéc par places d'une sorte de boue noirâtre, due à sa matière gélatineuse desséchée. Elle exhale une odeur de pourri, mélangée de celle d'iode.

Cette éponge, mise à tremper dans l'eau, lui donne un aspect trouble et roussâtre, et lui communique son odeur repoussante, dont elle garde toujours une partie cependant. Elle prend la forme turbinée des éponges de Zerby, ou la forme un peu aplatie des grosses éponges de l'Archipel; elle conserve sa couleur d'agaric, et présente un tissu grossier percé de grands trous perpendiculaires et de trous moyens, dont l'ouverture est toute déchiquetée, à la manière des éponges de Zerby. Les extrémités de ces déchiquetures, étant toujours imprégnées de bave mu- 
queuse, reprennent, en se desséchant, une couleur noire et une consistance cornée. Cette éponge est celle de toutes qui résiste le mieux dans les lessivages, même à l'eau alcaline; aussi estelle principalement employće par les peintres en battiments et pour le service des écuries.

It m'a paru intéressant de rechercher si la bave muqueuse desséchée qui recouvre celte éponge ne présenterait pas quelques indices des polypes que Lamarck persistait à y supposer malgré les expériences réitérées qui ont semblé démontrer qu'elle n'en devait renfermer aucun (1). J'en ai done détaché quelques fragments que j'ai fait tremper dans l'eau, et dès la première fois que je les ai soumis au microscope, j'y ai découvert au milieu d'une pulpe gélatineuse, comme granulée, quelquefois d'apparence fibreuse, compacte et peu transparente, un nombre assez

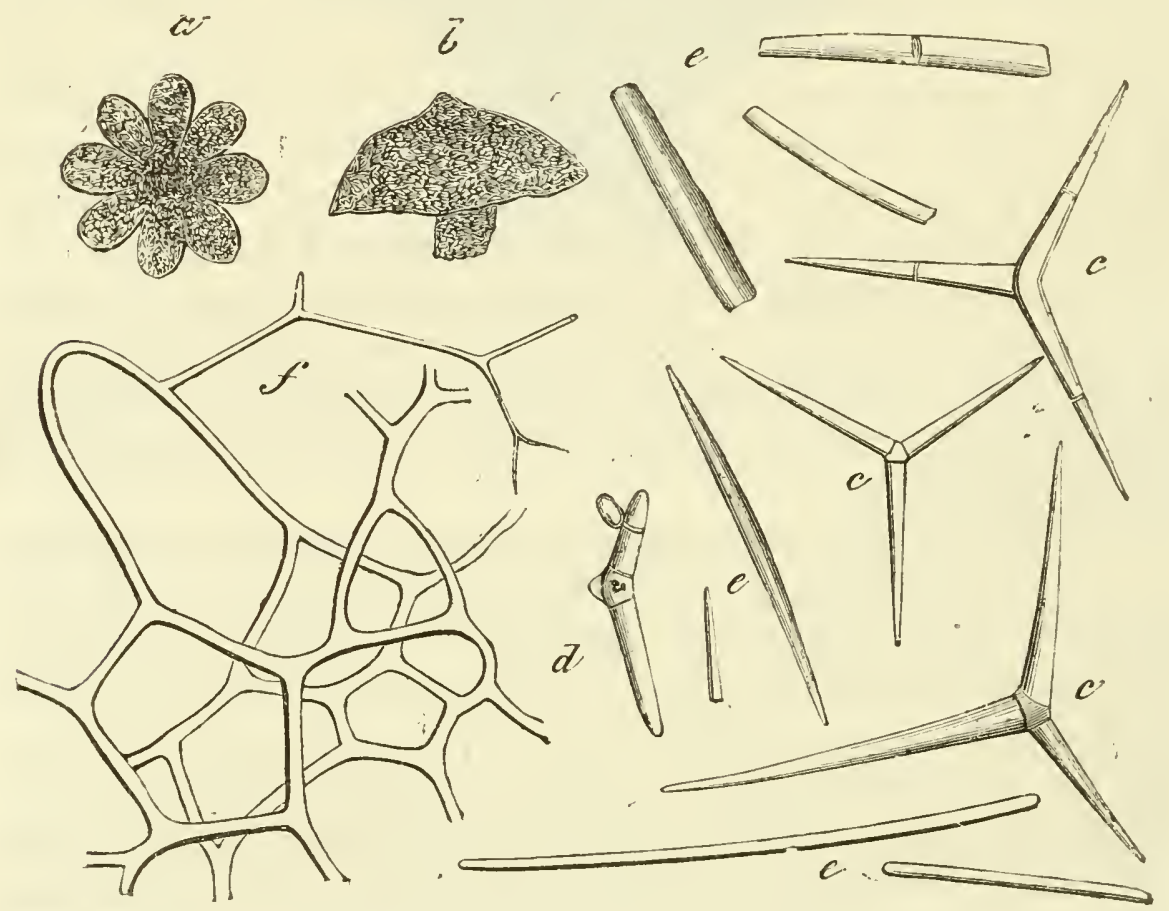

Fig. 1077. - Éponge brune de Barbarie.

considérable de corps arrondis, dont deux se trouvaient placés de manière à figurer une rosace à huit lobes arrondis, telle que je l’ai fait représenter dans la figure 1077, a. 11. J.-B. Baillière, éditeur de cet ouvrage, qui se trourait à ce moment chez moi, les a vus, et je dois invoquer son témoignage, parce que, les ayant

(1) Lamarck, raisonnant uniquement par analogie, soutient que toutes les espèces d'éponges possèdent des polypes distincts qui sortent de dessus la surface, et qui resscmblent beaucoup it ceux des alcyons. (Grant, Annales des sciences naturelles, 1827, t. XI, p. 181.) 
cherchés le soir du même jour, dans le même fragment gélatineux, ces corps, devenus opaques, ne présentaient plus de forme distincte, à l'exception d'un des deux qui, présentant le flanc, avait pris la figure d'un champignon arrondi, porté sur un trèscourt pédicule. Le même corps, retrouvé le lendemain et dessiné par un artiste, se trouve réprésenté même figure, lettre $b$. 11 m'a été impossible ce jour-là d'apercevoir aucune rosace; mais le lendemain, j'en ai encore rencontré une; aucun des autres corps opaques et arrondis ne présentait plus de forme distincte.

Sans doute que cette observation devra être confirmée par d'autres ; mais l'analogie évidente que ces rosaces à huit rayons, portées sur un court pédicule, présentent avec l'halliroé à côtes de Lamouroux, m'autorise à penser qu'elles constituent un animal rayonné qui doit être propre à l'éponge brune de Sfax.

La pulpe gélatineuse présentait, en ontre, un très-grand nombre de corps solides ayant la forme d'une étoile à trois rayons arliculés ei coniques (même figure $c$ ). T'antôt ces rayons élaient d'égale grandeur et terminés par une pointe aiguë ; d'autres fois, ils étaient inégaux, et quelquefois aussi un ou deux d'entre eux avaient la forme d'un bouton ou d'un petit cylindre arrondi à l'extrémité (lettre $d$ ).

Ces corps rayonnés, quoique formés principalemeut de carbonate de chaux, et se dissolvant avec effervescence par l'acide nitrique, sont évidemment organisés et diffèrent des acicules calcaires observés par M. Grant, par leurs articulations et par leurs stries superficielles transversales, semblables à celles observées sur les fibres mêmes qui composent le tissu des éponges. Outre ces étoiles à trois pointes, le champ du microscope offrait des corps filiformes (e) de longueur variable, non articulés, cylindriques, tronqués aux extrémités, présentant une apparence d’axe ou de canal central (tandis que les fibres mêmes de l'éponge n'en offrent aucun), résistant en partie à l'action de l'acide nitrique.

Quelles que soient les différences observées entre ces corps coniques ou cylindriques, articulés ou non, simples ou rayonnés, et les tibres qui forment le squelette persistant des éponges, je suis porté à considérer les premiers cornme le premier âge des fibres qui constituent l'éponge, lesquels ioivent se former, en effet, dans le même parenchyme qui renferme les polypes.

Le tissu fibreux de l'éponge brune de Sfax, même bien lavé à l'eau, examiné au microscope, présente un mélange de tissu parenchymateux fixé aux fibres spongiaires. Ces fibres sontentrelacées et anastomosées de la même manière que celles de l'éponge commune de Syrie, représentées $f$. Mais elles sont plus fortes, plus colorées, et terminées, dans les endroits où elles ne 
sont pas rompues, par des pointes aiguës. Ce qu'il y a de singu. lier, c'est qu'une addition d'acide nitrique fait disparaître toutes les extrémités pointues, et laisse les fibres terminées carrément. Les fibres deviennent aussi plus transparentes, en perdant sans doute quelques particules calcaires. Ces faits me confirment dans l'opinion que les étoiles calcaires à trois rayons et les fibres isolées qui se montrent dans l'enveloppe gélatineuse de l'éponge ne sont que le premier âge des fibres du squelette.

Les mers de l'Amérique fournissent au commerce une quantité assez considérable d'éponges, de formes et de nature trèsvariées, mais qui sont généralement de très-mauvaise qualité. Voici quelques-unes de celles que je me suis procurées :

7. Éponge dure de la Iavane (1). Ciette éponge a été confondue avec l'éponge fine de Syrie, sous le nom d'éponge usuelle. Elle présente, en effet, tout à fait la configuration hypocratériforme ou infundibuliforme de l'éponge fine de Syrie; mais elle a la couleur fauve et la rudesse de l'éponge grecque. Elle est rare et peu usitée.

8. Éponge dure de Bahama. Cette éponge cst attachée au rocher par une assez large base; mais elle s'élargit tout de suite encore plus, et présente une forme conique, avec des côtes longitudinales et un sommet trongué. Elle représente à peu près un biscuit de Savoie. La partic proéminente des côteș longitudinales et le sommet tronqué laissent voir des trous espacés, qui ont 3 à 4 millimètres de diamètre; tout le reste de la surface, et surtout les parties creuses, sont régulièrement percées de trous fort petits et réguliers. La surface de l'éponge est unie et comme rasée ; la substance en est dure, élastique, mais résistante, et elle se gonfle peu par l'eau; elle a une couleur fauve assez foncée; rue au microscope, elle paraît formée de rameaux cylindriques semblables à ceux de l'éponge douce, mais beaucoup plus courts et renfermant entre eux des espaces beaucoup plus petits. Celte éponge, malgré sa finesse, et à cause de sa dureté, est tout à fait impropre à la toilette.

9. Éponge laineuse à clochetons. Cette éponge, à l'état brut, présente une masse aplatie, blanchâtre, compacte, quel'on prendrait pour un morceau de poisson desséché. Mlise dans l'eau, elle s'y gonfle immédiatement, énormément, et prend la forme d'une rnasse composée de tubes à parois laineuses, épais, dressés, séparés par le haul, figurantles clochetons d'une cathédrale. Elle est singulièrement douce et molle au toucher, comme la toison

(1) Je ne puis dire exactement d'oi viennent les éponges d'Amérique; dans le commerce, on ajoute indifféremment il leur nom, corrame indication d'origine, le nom de la llavane ou de Bahama, 
d'un mouton. Elle est facile à déchirer, et serait probablement d'un usage peu profitable.

10. Éponge tubereuleuse a'Amérique. Cette espèce forme une masse arrondie, toute hérissée à sa surface de tubercules coniques, réunis entre eux par une partie plate, comme palmée, creusée en forme de croissant. Ces tubercules cachent presque complétement les ouvertures, qui sont inégalement réparties, rarementrondes, le plus souvent irrégulières, avec quelques trous ronds, assez grands pour qu'on puisse y introduire le doigt. Le pied de l'éponge est rouge, ainsi qu'une partie dè l'intérieur, mais toute la partie superficielle est d'une couleur blanchâtre, mate et comme opaque, ce qui, joint à une consistance très-ferme, semble indiquer une proportion assez considérable de principes inorganiques.

11. Éponge commune de la Ilavane ou de Bahama. Cetle éponge est assez abondante dans le cornmerce. Elle est arrondie ou cylindrique, souvent déchirée ou comme cariée au centre de la partie supérieure, et quelquefois creusée de manièreà figurer un creuset cylindrique à paroi épaisse. La surface extérieure présente de larges tubercules terminés par une portion de surface plane. Cette éponge, parsa teinte blonde ou fauve, sa demi-transparence et son élasticité, paraît être de la même nature que celle du Levant. Mais elle est très-caverneuse à l'intérieur, retient peu l'eau, se déchire el s'use avec une grande facilité. Elle est de trèsmauvaise qualité.

Composition chimique. La compositien élémentaire des éponges et la manière dont elles se comportent avec les agents chimiques, fournissent de bonnes raisons corroboratives en faveur de leur admission dans le règne animal. En effet, leur fibre élastique se ramollit au feu comme les poils et la corne, et fournit à la distillation une quantité considérable de carbonate d'ammoniaque; elle se dissout très-facilement dans les lessives alcalines et dans les acides minéraux concentrés, et leur dissoluté dans les acides précipite par la noix de galle. Mais, indépendamment du carbone, de l'hydrogène, de l'azote et de l'oxygène que les éponges contiennent, comme toutes les matières animales, elles renferment une quantité notable d'iode, dont une portion existe à l'état d'iodure soluble dans l'eau, mais dont la plus grande partie paraît combinée directement à leur propre substance, et ne s'en sépare que lorsque le tissu fibreux se trouve décomposé par le calorique. C'est à cet iode, sans aucun doute, que l'éponge doit la propriété qui lui a été reconnue il y a longtemps d'être un remèdę très-utile contre le goître. On l'employait, à cet effet, soit en décoction aqueuse, soit plus ou moins torréfiée, soit complé- 
tement calcinée. J'ai montré que la forme souslaquelle l'éponge est le plus active est celle d'éponge torréfiée jusqu'au brun noir, et jusqu'à réduction aux 75 centièmes de son poids. Les éponges que l'on doit préférer pour cette opération sont les éponges fines du Levant, non lavées, et privées autant que possible du gravier, des coquillages et des autres débris qui peuvent s'y trouver (1). Les éponges tines et douces servent aussi à préparer les éponges à la cire et à la ficelle, employées par les chirurgiens pour dilater l'ouverture des plaies que l'on veut empêcher de se fermer.

(1) Voy. Guibourt, Pharmacopée raisonnée, p.i07.

FIN DU QUATRIEME ET DERNIER YOLUME. 


\title{
TABLE DES MATIÈRES
}

\author{
DU TONE QUATRIÈME.
}

\section{TROISIENE PARTIE.}

ZOOLOGIE.

Calactères des animaux............................ 1

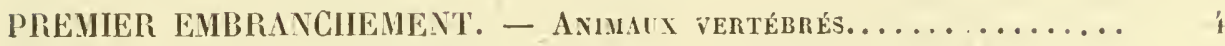

Première classe. - Les mannè̉res................. 千

Ordre des bimanes, l'homme...................... s

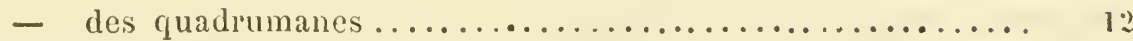

- des carnassiers............................... 13

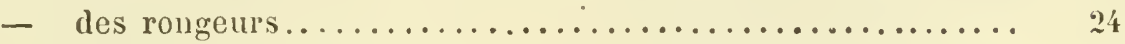

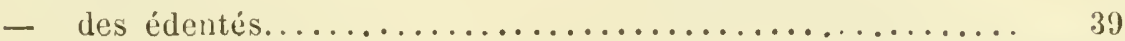

- des marsupiaux ........................... \$1

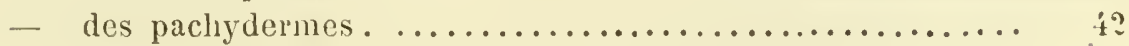

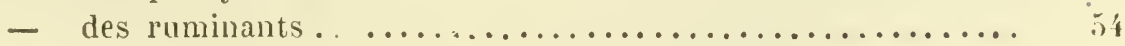

- des cétacés................................... 110

Deuxième classe. - Les orseaux................... 123

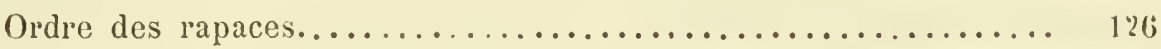

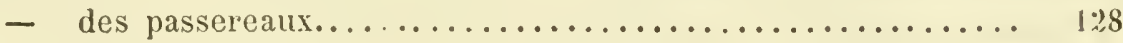

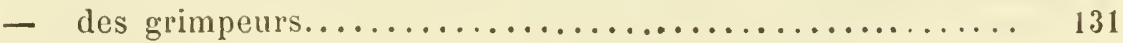

- des gallinacés.............................. 131

- des échassiers............................... 132

- des palmipèdes.............................. 135

Troisième classe. - Les reptiles................... 142

Ordre des chéloniens.............................. I't3

- des sauriens.................................. 148

- des crocodiliens............................. 148

- des ophidiens............................. 151

Quatrième classe. - Les batraciens.................... 163

Cinquième classe. - Les polssons..................... 168

Ordre des acanthoptérygiens..................... 172

- des malacoptérygiens abdominaux................. 175

- $\quad$ - $\quad$ subrachiens .................. 1i9

- $\quad$ - apodes....................... 187

- des chondroptérygiens ou cartilagineux............. i89

- des sélaciens.................................. 19i

- des suceurs................................ $: 00$ 
DEUXIËME EMBRANCHEMENT. - ArimaUX ANNELÉS ........... 201

Première classe. - Les insectes....................... 201

Ordre des coléoptères.......................... 205

- des orthoptères............................. 219

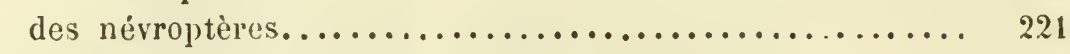

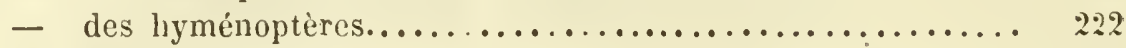

- des lépidoptères............................ 233

- des hémiptères............................. 240

-- des diptères............................... 251

- des aphaniptères ou suceurs................... 255

- des anoploures ou parasites..................... 257

Deuxième classe. - Les myria rodes........................ $\$ 59$

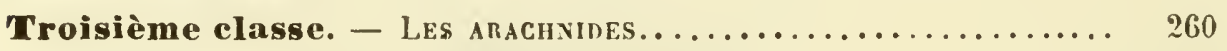

Ordre des arachnides pulmonaires.................... 260

- des arachnides trachéennes ...................... 265

Quatrième classe. - Les crustacés................... 272

Ordre des décapodes.............................. 273

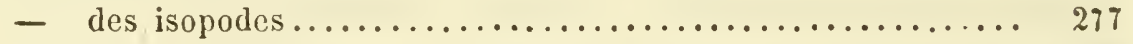

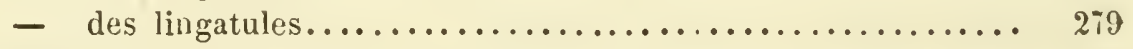

Cinquième classe. - Les cinntpèdes................... 279

Sixième closse. - Les annél.dins...................... 280

Ordre des tubicoles.............................. 280

- des dorsibranches......................... 280

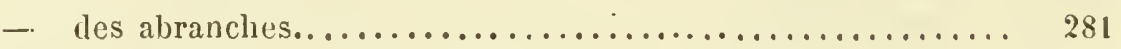

Septième classe. - Les entozonilies................... 327

Ordre des nématoïdes............................ 328

- des trẻmatodes................................... 337

- des turbellariés................................. 339

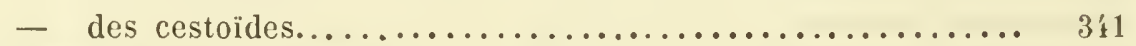

TROISIÈME EMBRANCHEMENT. - AniMAux MollusQues.......... 349

Première classe. - Les nollusques CÉPHalopones.............. 351

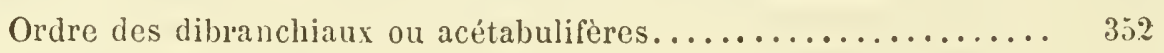

- des tétraoranchiaux......................... 355

Deuxième classe. - Lris woliusques gastéropodes........... 356

Troisième classe. - Les nollusques acéphales............... 361

QUATRIEME EMBRANCHEMENT. - ANIAAUX RAYONNES OU ZOOPHYTES.. $3 \mathrm{i}_{3}$

Première classe. - Les échinoderues................... 374

Deuxième classe. - LEs polipes....................... 375

Troisième classe. - Les infusolres.................... 378

Q uatrième classe. - Les spoxgialres................... 379

FIN DE LA TABLE DU TOME QUATRIÈME. 


\title{
TABLE GÉNÉRALE DES MATIÈRES
}

\author{
CONTENUES DANS LES QUATRE VOLUMES.
}

Not.. Les noms qui ne se trouveront pas aux noms généraux racines, bois, fleurs, sucs, résines, elc., devront être cherchés au nom de l'espèce.

$\boldsymbol{\Lambda}$

Abaremo-temo, III, 330.

Abeilles domestiques, IV, 226.

Abelmosch, III, 647.

Abelmoschus communis, 11I, biT.

- esculentus, III, 648.

Abies alba, II, 247,

- balsamea, 1I, 246.

- canadersis, II, 247.

- excelsa, II, 2't?.

- vigra, II, 247.

- pectinata, II, 245.

- taxifolia, II, 215.

$\Lambda$ biétine, II, 255.

Abiétinées, II, 237.

Ablette commune, IV, 176 .

- meunier, IV, 176.

Abranches xus, IV, 281.

- sétigíres, IV, :82.

Abrasin, II, 361 .

Abricutier, III, 31't

- de Briançon, III, 314.

- de Saint-Domingue, III, 281 .

Abrus precatorius, III, $3: 27$.

Absinthe grande, III, 45 .

- petite, maritime, III, 4 i.

- pontique, III, 44.

Abuta rufescens, III, 739.

Acrcia Adansonii, III, 39'-410-411.

- adstringens, III, 330.

- ogyptiaca, III, 393.

- albida, III, 440.

- Angico, III, 330-352.

- arabica, III, 350-393-440-441.
Acacia crpensis, 11I, 4千5.

- Catechu, III, 403.

- decurrens, III, 440-145.

- Erhenbergiana, III, 440.

- farnesiana, III, 396.

- guadalupensis, III, 35?.

- gummifera, III, 440-143.

- horrida, III, 352-4́6.

- indica, III, 396.

- jurema, III, 330.

- leucophlcea, III, 453.

- Neboued, III, 4t1.

- nilotica, III'390-400-439.

- nostras, III, 31 i-400.

- quadrangularis, III, 33..

- Senegal, III, 398.

- Seyal, III, 352-395440

- tenuifolia, 352.

- tortilis, III, 139.

- vera, III, 390-392.

- Verek, III, 398-440-411.

Acajou (noix d'), III, 49:2.

- (gomme d'), III, 492.

- à planches, III, 596.

- de Cuba, III, 596.

- de Haïti, Ill, 596.

- de Ilonduras, III, 596.

- mahogoni, III, 596.

- du Sénégal, III, 595.

- femelle, III, 59)(i.

Acalèphes, IV, 374 .

Acanthoptérygiens, IV, 172.

Acarides, IV, 265.

Acarus domesticus, IV, 267.

- exulceruns, 269. 
Acarus farinis, IV, 268.

- scabiei, IV, 269-271.

Acarna gummifera, III, 28.

Accipitres, IV, $1: 6$.

Acer campestie, III, 606.

- eriocirpum, III, 608.

- nigrum, III, 607,

- platanoides, JII, 606.

- psencioplatanus, III, 606.

- rubrum, III, 608,

- saccharinum, III, 60G.

Acerdèse, I, 300.

Acérées, III, 598.

ACÉRINÉES, III, 598.

Achaîlı, II, 13.

Ache des chiens, III, 21?,

- des marais, III, 20.5.

- des montagnes, III, 205.

Achillen Ageratum, j1.

- herba-rola, III, 48.

- Millefolium, III, 51.

- moschata, III, 47.

- ptarmicu, III, 52.

Achirite, I, 233.

Achmite, I, 473.

Acleras Sapota, II, 597.

Achyranthes lanatu, II, 451.

Acide abilétique, II, 255.

- angélicique, III, 209.

- arsénieux, 1, 125.

- bézoardique, IV, 106.

- borique, 1, 84 .

- carbonique, I, 112.

- chrysophanique, II, 59-44?.

- eugénique, IIl, 273.

- enxanthique, IV, 100.

- fumarique, III, 702.

- margaritique, II, 356

- molybdique, I, 208.

- myronique, III, 698.

- palmique, II, 356.

- polygalique, III, 665.

- purréique, IV, 100.

- silicique, I, 75.

- sulfureux, I, 118.

- sulfurique, I, 118.

- titanique, I, 206.

Acipenser Huso, IV, 190.

- Sturio, IV, 190.

Aconit antlore, III, 77 I.

- féroce, III, 773.

- napel, III, 791.

- salutifère, III, 772.

- tue-loup, III, 772.

Aconitum Anthora, 11I, 771.

- ferox, III, 773.

- lycoctonum, III, 761.

- Napellus, III, 772.
Aconitum neubergense, III, 773.

- stoerkianum, III, 7::3.

- tauricum, etc., III, 氵氵3.

Acole vrai, II, 89.

Acorus Calamus, II, 89.

Acrochordes, IV, 15:.

Acrosticum Huacsaro, II, io.

Actoea racemosa, III, 762 .

- spicata, III, 762.

Actinies, IV, 3 ;6.

Actinote, I, 426, 43 .

Adansonia digitata, III, 651 .

Adenanthera paconima, III, 380 .

Adiantum Capillus-Teneris, II, 7 .

- peda!um, II, if.

- tenerum L. II, 76 .

Adinole, I, 48\%.

Egagres, IV, 7 i .

- (bézoards de l'), IV, 103.

Egagroplite de bœuf, IV, 10:?

- de mouton, IV, $10 \%$.

- marin, IV, 102.

Egle Marmelos, III, 6 ?6.

Aérolithes, I, 258.

Arva lanato, II, 451.

Aschynite, I, 316.

Esculus Hippocastanum, III, 600.

Ethusa Cynapium, 1II, 21?.

- Meum, III, 212.

Agulurjin, III, 337.

Agalloche, III, :3:37.

Agapanthées, II, 153.

Agaric blanc, II, 44.

- de clî̀ne, II, 45.

Agaric comestible, II, 39 .

Agaricus, L., II, 39.

- aurantiacus, II. 41 .

- bulbosus, I, 39.

- campestris, II, 39.

- muscarius, II, 39-4i.

- necator, II, 39.

- pyrogallus, II, 39.

- vermucosus, II, :39.

Agate, I, 78 .

- onyx, I, 79.

Agathophyllum aromaticum, II, 400.

Agathophytum Bonus-Henricus, II, 417.

Agathotes Chirayta, Don, II, 555.

Agave cubensis, II, 183.

Agave de Cuba, II, 183.

Agneau de Scythic, II, 73.

Agneaux, IV, 81 .

Agrues castus, II, 482 .

Agouti, IV, 2.).

Agrimonia Eupratoria, III, 300.

Agrostema Githago, IH, i6'.

Agrégation (états d'), 1, 1.

Agustite, I, 419. 
Alınai, II, .50?.

Aigles, IV, 127 .

Aigremoine, III, 300 .

Ail, II, 155 .

Airclle canneberge, III, 8 .

- myrtille, III, 7 .

- ponctuéc, III, 7.

Aizoon canariense, II, 4iS.

Ajuga chamcepitys, II, 450.

- Iva, II, 480.

- reptans, IH, 480 .

Alacoaly, III, 538.

Alaterne, III, 5 '?.

Albâtıe, 1, $\$ 13$.

- gypseux, I, 403.

Albatios, IV, 135.

Albioniens, IV, 28:.

Albite, 1, 473, 480.

Albizzia anthelminthica, III, 331.

Albumen (Gartn.), II, 15.

Alchemilla vulgaris, IlI, 300 .

Alchemille vulgaire, III, 300.

Alcoea rosea, III, 6is.

Alcool, III, 589.

Alcornoque, III, 32! .

Alcyoniens, IV, 376.

Alectoria crinalis, II, 36.

Alectors, IV, 132.

Aleurites Ambinux, II, 36?.

Algarobo, III, 3999.

Algarovilla, III, 3999.

Algues, II, 23.

- alimentaires, II, 32 .

Algazel, IV, 76.

Alizarine, III. 82.

Alizier, III, 29$) ?$.

Alkanna tinctoria, II, 51 .

Alkekenge, II, 509.

Allanite, I, 313.

Alleluia, 574.

Allium ampeloprasum, II, Jisi.

- ascalonicum, II, 156.

- Cepa, II, 156.

- Porrum, II, 156.

- sntivum, II, 155.

- schanoprasum, II, 156.

- scorodoprasum, II, 156.

- Victorinlis, II, 156.

Allopliane, I, 357.

Allyle, II, 1,56.

Aloe soccotrinn, Ir, 159.

- spicata, etc., II, 159.

Aloès (bois d'), III, 33\%?

Aloès, II, 159.

- de la Barbarle, II, 163.

- caballin, II, 163.

- du Cap, II, 161.

- fétide, II, 161.
Aloès hépatique, II, 16il.

- de l'Inde, II, 16 I.

- socotin, II, 169.

Aloexyllum Agallochum, III, 339.

Aloine, II, $16 \mathrm{t}$.

Aloïnées, II, 153.

Alose, IV, 178.

Alouchi, III, 533.

Alouettes, IV, 130.

- de mer, IV, 131.

Alpaca, IV, 57.

Alpinia Cardamomum, II, ?13.

- Golanga, II, 200.

- officinarum, II, 201.

Alsine medir, II, 458.

Aisinées, III, 660.

Althcea offininulis, III, 645.

Althera rosea, III, 648 .

Alumine fluatéc alcalinc, I, 161 .

- fluo-silicatée, I, 337.

- hydratée, I, 33:

- ferrifère, I, 332 .

- hydro-silicatée, I, 3.5.

- mellitatée, I, 33:.

- uative, 1, 328.

- plıospliatée, I, 335.

- - cuprifère, I, 336.

_ - magnésifère, I, 337.

- plombifère, I, 336 .

- silicatée, I, 340.

- sous-sulfatéc alcaline, I, 466.

- sous-sulfatée lydratée, I, 33 '.

- sulfatée, 333.

- hydiatée, I, 334.

- trisulfatée lıydratée, I, 334.

- 11'i-liydratée, I, 332 .

Aluminite, I, 33'.

Aluminium, I, 327.

Alun ammoniacal, I. 469.

- de cuivre, I, 470.

- fibreux, I, 470.

- de liége, I, 469.

- de manganèse, I, 470.

- de plume, 470 .

- de Pome, I, i6s.

- saturé d'alumine, I, 466.

- soluble, I, 467 .

- de soude, 470.

Alunite, I, 466 .

Alunogène, I, 334 .

Ayxie aromatique, II, 578 .

Amandes amères, III, 31:.

- douces, III, 31\%.

Amandier rommun, III, 311 .

Amanites, II, 42.

A uaranthacées, II, 450.

A uaryllibél:s, 187.

Amaryllis Belladona, $18 \mathrm{~T}$. 
Ambligonite, I, 444.

Ambre blanc du Brésil, IIl, 461.

- - de Cayenne, III, 460.

Ambre gris, IV, 118.

- jaune, 1, 109 .

Ambréine, IV, 121.

Ambroisie du Mexique, II, 446.

Amentacées, II, 279.

Amétliyste, I, $i 8$.

- orientale, I, 330.

Amiante, I, 432.

Aniantoïde, I, 432 .

Amidon, 115.

- d'avoine, II, 1:? .

- de blé, II, 1 I8.

- de maïs, II, 122.

- d'orge, II, 120 .

— de riz, II, 1:1.

- de seigle, II, 120 .

Ammi inodore, III, 222.

Ammi majus, III, 221.

Ammi officinal, III, 221.

Ammoniaque (chlorlydrate d'), I, 181.

Anmoniaque sulfaté, I, 187.

Ammonites, IV, 356 .

Ammonium, I, 483.

- chloruré, I, 48́t.

Amonacées, II, 198.

Amome en grappe, II, 212.

- vulgaire, III, 22?.

Amomum Afzelii, II, 2:3.

- angustifolium, II, 219.

- Carclamornum, II, 213.

- Clusii, II, 222.

- Curcuma, II, 208.

- Danielli, II, 223.

- exscapum, II, 214.

- ylobosum, II, 21 i.

- Grana-paradisi, II, 221.

- macrospermum, II, 221.

- madagascariense, II, 219.

- maximum, II, 218.

- medium, 1I, 218.

- Meleguetta, I, 21't.

- racemosum, II, 21 .

- repens, II, 213.

- sylvestre, 1I, 226.

- villosum, II, 215.

- xanthioiltes, II, 21 j.

- Zedoaria, II, 210.

AupélidéES, III, 579.

Ampélite, I, 489-507.

- graphique, I, 507 .

Ampelopsis quinquefolia, III, 580 .

Amphibule, I, 426, 431 .

- alumineux, I, 134 .

- vert, I, 436.

Amphibolite, I, 489 .
Amphigène, I, 471.

Auplipodes, IV, 274.

Amplisbènes, IV, 152.

Ampullaires, IV, 360 .

Amygdalées, III, 289-3I1.

Amygdaline, III, 313.

Anygdaloide, I, 489.

Amygdalus communis, III, 311 .

- Persica, III, 313.

Ayy RIDÉES, III, $48 \%$.

Amyris Agullocha, III, 525.

- commiphora, III, 516.

- gilearlensis, III, 506.

- Kataf, III, 511.

- syluatica, III, 537 .

- toxifera, III, 537.

Arrabasis tamariscifolia, II, $\mathbf{4} 48$.

Anacalde orientale, III, 493.

Anacardiées, III, 487.

Anacardium longifolium, III, 493.

- occidentale, III, 491.

Anacyclus officinarum, III, 56 .

- Pyrethrum, III, 5'.

Anagallis coruleu, Il, 458 .

- phanicea, II, 458.

Anagénite, I, 189.

Analcime, I, 472.

Anamirta Cocculus, III, 740.

- racemosa, III, 740.

Ananas, 1I, 189.

Ananassa sativa, II, 189.

Anarrhique, IV, 181.

Anas mollissima, III, 651 ; IV, 137.

Anastatica hierochunticn, 1II, 68;.

Anchois vulgaire, IV, 178.

Anchusa italica. II, 514.

- officinalis, II, 514.

- tinctoria, II, 517.

Anchylostome duodénal, IV, 329.

Ancolie vulgaire, III, 767.

Anda Gomesii, II, 362.

Anda de ['ison, II, 362 .

Anda-açu, II, 36?.

Andalousite, I, 343.

Andassu, II, 362.

Andira anthelminlhica, III, 336.

- inermis, III, 33:.

- racemosa, Ill, 335-356.

- retusa, III, 333,

- stipulacea, III, 335 .

Ardromerla polifolia, III, 3.

Andromèdes, III, 3 .

Andropogon citratus, II, 101.

- eriophorus, II, 99.

- ischomum, II, 100.

- iwarnncusa, II, 101.

- lanigerum, II, 99.

- muricatus, II, 100. 
Andropogon Nardus, II, 101.

- à odeur de citron, II, 99.

- Parancura, II, 101.

- schcenanthus, II, 99.

Androsème, III. 624 .

Androsamum officinale, III, 625.

Ane, IV, 53.

Axénonées, III, 751 .

Anémone des bois, III, 756 .

- des fleuristes, III, 756 .

- des prés, III, 756 .

Anemone coronariu, III, 756 .

- nemorosa, III, 750 .

- pratensis, III, 756.

- Pulsatilla, III, 756.

Anémones, III, 755.

- de mer, IV, 376 .

Aneth, III, 226 .

Anethum graveolens, III, 226.

Angelica Archangelica, III, 207.

- sylvestris, III, 210.

Angelica-tree, III, 211.

Angelin, III, 335 .

- amargozo, III, 336.

- de la Guyane, III, 336.

Angélique du Brésil, III, 210.

- officinale, III, 207.

Angica, III, 352.

Angico, III, 330, 35?.

Angles dièdres, etc., I, 13.

Angracum fragrans, II, 235.

Anguilles, IV, 187.

- de mel', IV. $18 \mathrm{~s}$.

- électrique, IV, 189.

Anguis fragilis, IV, 151.

Angusture fausse, II, 565 ; III, 560.

- vraie, III, $55 \%$.

Anhingas, IV, 136.

Anhydrite, I, 491 .

Aniba guianensis, III, 535, 537.

Aniimum, III, 455 .

Animal au musc, IV, 57.

Animaux (définition des), I, 1.

- (tableau des), IV, 3.

Animaux articulés, IV, 2, 3.

- invertébrés, IV, 1.

- nollusques, IV, 2, 3.

- rayonnés, IV, $3,373$.

- vertébrés, IV, 2, 3, 4 .

Animé de Cartlıgo, III, 461.

- dure orientale, III, 457.

- occidentale, III, 456.

- orientale, III, 456.

- tendre d'Amérique, III, 460.

- tendre orientale, III, 460.

- - du Brésil, III, 461.

- - de Hollande, III, 461.

Anis de la Chine, III, 746.
Allis étoilé, III, 746.

- vert, III, 29:2.

ANNÉLIDES, $1 \mathrm{~V}, 280$.

Anolis des Antilles, IV, 151 .

Anolis bullaris, IV, 151.

Anoma Morunga, III, 387.

ANoNaGÉES, III, 742.

Anones, III, 744.

Axoploune, IV, $25 \%$.

Anortite, I, 427.

Anserine, 11I, 305.

- vermifuge, II, 446.

Antennaria dioiea, [II, 35.

- margarilacea, III, 36.

Anténois, IV, 81 .

Anthemis arvensis, III, 53.

- Cotula, III, 54.

- nobilis, III, 52.

- Pyrethrum, III, 56.

Anthère, II, 10.

Antoplyllite, I, 426, 427.

Anthore, III, 771.

Antliracite, 1, 91 .

Anthriscus Cerefolium, III, 215.

Anthrosidérite, I, 290.

Antiar, II, 328 .

Antiaris toxicaria, II, 328 .

Aritilope Bulsalis, IV, 75.

- cervicapra, IV, 75.

- Dorcas, IV, 75.

- Gazella, IV, 76.

- Gnu, IV, 76.

- leucoryx, IV, 76.

- Oryx, IV, 76.

- picta, IV, 76.

- rupicamra, IV, 76.

- Saiga, IV, 75.

- strepsiceros, IV, 76 .

Antilopes, IV, 75.

- à cornes courbes, IV, 75 .

- à cornes droites, IV, 15.

- des Indes, IV, 75.

Antimoine (régule d'), I, 133.

- natif, I, 129.

- oxydé, I, 131.

- oxysulfuré, I, 132.

- sulfuré, I, 130.

Antimonickel, I, 245.

Antipatle, IV, 382.

Antirlinum Asarina, II, 38?.

- majus, II, 490.

Antofle, III, 273.

Antoplyylite, I, 389 .

Antimolite, I, 427.

Apatite, I, 419.

Aphanèse, I, 228.

Apinaniptéres, IV, 255.

Aphanite, I, 489 . 
Aplièrèse, I, 2:31.

Aplludens, IV, 213.

Aplirodite, I, ;93.

Apis mellifica, IV, 226.

Apium graveolens, 11I, $20 \mathrm{~J}$.

- Petroselinum, III, 220.

A plosporées, II, 24.

Aplotaxis Lappu, III, 32.

A POCYNACÉES, $11,574$.

Apopliyllite, I, 427 .

Aquilaria Agallocha, Ill, 338.

- secundariu, III, 338.

Aquilegia rulgaris, III, 767.

Aracacha esculenta, III, 218.

Arachide, 11J, 384.

Arachis hypogoen, III, 384.

Arichuides, IV, 260.

Arachnides pulmonaires, IV, 260.

- tracliéennes, IV, 265.

Aracouchini, III, 5:34.

Alagonite, J, 415.

- coralloide, I, 416.

Alaignées, IV, :61.

Araliu mudicuulis, II, 183; III, 198.

Aralie nudicaule, III, 198.

Araliacérs, III, $197,198$.

Araritia, 111, 3'6.

- rosa, III, 34í.

Artor exccecins, III, 338.

- insarice, I1I, 535.

- radulifera, III, 597.

Arbousiel, III, 5 .

Arbre à la vaclie, II, \$28.

- à l'huile du Japon, II, 36 I.

- à pain, II, 326 .

- à suif de la Chine, II, 361 .

- au corail, III, 380 .

- aveuglant, II, 345.

Arbutus Unedo, III, 5.

- Uva ursi, III, 5.

Alcanson, 11. 262.

Archangelica officinalis, III, 207.

Arctium Bardana, III, 18.

Arclium Lappo, III, 18.

Arcloslaphylos Uva-ursi, III, 5.

Ardea, IV, 13 '.

- mijor, IV, 137.

- Garzeta, IV, 137.

Arec, II, 130.

Areca Catechu, II, 130 ; III, 405, 109.

Arénicole des pêcheurs, IV, 280.

Argali de Siberie, IV, 80.

Argania Sideroxylon, II, 596.

Argas de Perse, IV, 267.

Argas persicus, $1 \mathrm{~V}, 267$.

Argemone mexicana, III, 706.

Algent, 1, 151 .

- antimonié, I, 153 .
Argent antimonié sulfuré, I, l.,f.

- - sulfuré noil", I, 158.

- arséniulé, I, 154.

- (aurures d'), I, 147.

- biomuré, I, $\mathbf{1} 61$.

- carbonaté, I, 161.

- cliloro-bromuré, I, 160.

- chloruré, I, 160 .

- corné, I, 16 \%.

- de chat, I, 47\%.

- (Extraction de l'), I, 16?.

- gris, 161 .

- ioduré, I, 15?.

- natif, I, 152.

- rouge, I, 156.

- sélénié, I, 155.

- sulfo-antimonié, I, 156.

- sulfo-arséniuré, I, 156.

- sulfuré, I, 155.

- sulfuré stibio-cuprifère, I, 1.is.

- tellulé, I. 15 f.

Argent telluré anrifère, I, 1:,0.

- (titres de l'), I, 16i).

-- vitieux, I, 155.

Argentine, III, 305 .

Argile, I, 489.

- ocreuse pâle, I, 363.

- - rouge, I, 303.

- plastique, I, 360 .

Argiles apyres, 1, 356 .

- effervescentes, I, 362.

- ferrugincuses, I, 363.

- fusibles, I, 36?.

- marneuses, 1, 262.

- pures, I, 356.

- smectiques, I, 362 .

Arailolite, I, $\{90$.

Argilophy re, I, 490.

Argonautes, IV, 353.

Alguel, III, 363.

Argyreia speciosa, II, 520.

Argyrides, 1, 151.

Argyrose, I, 155.

Al'gyrythrose, I, 156 .

Arica-b(a)ti, III, 165.

Arille, II, 15.

Arions, IV, 359.

Arisama triphyllum, II, 88.

Aristoloche clématite, II, 37 í.

- Iongue, II, 374.

- petite, II, 374 .

- ronde, II, 373.

- serpentaire, II, 375.

Aristolochia anguicida, II, 330 .

Aristolochia nrborescens, II, 380.

- bilobata, II, 380.

- Clemalitis, II, 37 i.

- cordiflora, JJ, 380. 
Aristolochin cymbifera, II, $3 i 9$.

- foctida, II, 380.

- fragrantissima, II, 380.

- geminiflora, II, 380.

- gramliftora, II, 379.

- indica, II, 381.

- longa, II, 37't.

- maxima, II, 390 .

- olloratissimrr, II, 350.

- officinalis, II, 377.

- Pistoloclia, II, 375.

- pseudo-serpentaria, II, 379.

- rotunda, II, 373.

- Serpentaria, II. 335.

Aristolochiées, II, 372.

Arkose, I, 490.

Armadille, TV, 278.

Armeniaca brigantiaca, III, 31 .

- vulgaris, III, 31 i.

Armoise vulgaire, III, 43.

Arnebin tinctoria, II, 518.

Arnica montann, III, 33.

A RoİdÉEs, II, 85.

Aromadenitron elegans, III, 746.

Aronde oiseau, IV, 371 .

- perlière, IV, 366-369.

Arquérite, I, 167.

Arracacha (fécule d'), III, 218.

Arrête-bœuf, III, 324.

Arrow-root des Antilles, II, 226.

- de Taĩti, II, 186.

- de Travancore, II, 228.

Arroche des jardins, II, $4 \mathbf{1 3 .}$

Arsenic natif, I, 123.

- jaune du commerce, I, 128.

- rouge, I 128.

- sulfuré jaune, I, 125.

- sulfuré rouge, I, 123.

Arsénicite, I, 422.

Artanthe adunca, II, 279.

- elongata, II. 278.

- lancifolia, II, 279.

Artemisia dbrotanum, III, 43.

- Absinthium, III, 41, 45.

- campestris, III, 41 .

- chinensis, III, 48.

- Cina, III, 40.

- Diacunculus, III, 39.

- eriantha, III, 46.

- gallica, $\cdot$ III, 4 !.

- glacialis, III, 45.

- judaica, III, 39 .

- Lercheana, III, 41.

- maritima, III, 42.

- monog!ma, III, 40.

- Moxa, III, 48.

- mutellina, III, 46.

- pauciftora, III, 40.

Guibourt, Drogues, 7e édit.
Artemisia pontica, III, 't'.

- Sieberi, III, 39.

- spicatu, III, 46.

- vulgaris, III, 43.

Arthanita, II, 458.

Artichaut cultivé, III, 19.

- cardon, III, 19.

- d'Espagne, III, 26?.

Articulés, IV, 2, 3.

Alitocarpées, II, 326.

Arlocurpus incisa, II, :3:6.

- integrifolia, II, 327.

Arum Colocasia, II, 88.

- Dracunculus, II, 8i.

- esculentum, II, 88.

- muculatum, II, 86.

- muscivorum, II, 89.

- seyuinum, II, 88 .

- triphyllum, II, s8.

- vulgare, II, 86.

Arum serpentaire, II, si.

Arundo Donex, II, 96.

Anticoliexs, IV, 25.

Asa foetida, III, 237.

Asagrce officinalis, III, $15 \%$.

Asarine, II, 382.

Asarum exropaeum, 380.

- canalense, II, 380.

Asbeste, I, 432.

Ascaride lombricoïde, $\mathbb{N}, 330$.

- vermiculaire, IV, 332.

Ascaris alata, VI, 332.

- lumbricoides, IV, 330.

Asclépiade, II, 573.

AsclépIadéEs, II, 572.

Asclepias asthmatica, II, 572.

- Contrayerva, II, 534.

- currussavica, II, 572; III, 96.

- gigantea, II. 574.

- Vincetoxicum, II, 573.

Asclérine, 1, 502.

Asellus, IV, 180.

Ash cinchona, III, 168, 175 .

Aslyy crown bark, III, 148, 172.

Asmonich, III, 185.

Asparagine, II, 170.

Asparaginées, II, 167.

Asperge, II, 169.

Asparagus officinalis, II, 16!).

Asphalte, I, 103.

Asphodélées, II, 153.

Aspic de Cléopâtre, IV, 162.

Aspidium alhamanticum, II, 69.

Aspleninm Adiantum-nigrum, II, 73.

- Ceterach, II, 77.

- ruta-muraria, II, 77.

- Scolopendrium, II, 78.

- trichomanes, Il, 77. 
Astacus fluvintilis, IV, ?76.

- marinus, IV, 276.

Astéries, IV, 374.

AstéroïdéEs, III, (:0.

Astragrilus aristatus, III, i1:3.

- creticus, III, 447.

- glycyphyllos, III, 3:8.

- gummifer, III, 447.

- massilitnsis, III, ‘47.

- tragacantha, III, 447.

- verus, III, 447.

Astrées, IV, 376.

Astronum fraxinifolium, III, $35 s$.

Atakamite, I, 236.

Athamantha cretensis, III, 235.

- macedonica, III, 236.

Atractylis gummife: $\Omega$, III, 28 .

Atriplex hortensis, II, 4 43.

Atropa Mandagora, II, 501 .

- Bellarlona, II, 50?.

Atropine, II, 50 ?.

Aubépine, III, 293.

Aubergine, II, ;06.

Aubier, II, 7.

Augite, I, 426, 430 .

Auklnndin Costu゙, III, 3 I.

Aulostoma Gulo, IV, 287.

Aulastome rorace, IV, 287.

Aune noir, III, 542.

Aunée officinale, III, 60.

Aurantiacées, III, $6: 9$.

Aurantium vulgare, III, 632 .

Auroclis, IV, 85.

Aurone des champs, III, il.

Aurone mâle, III, 43.

Aurures d'argent. I, 1i7.

Australia yellow-wood, III, ¿97.

Autoul (écol'ce d'), II, 447.

Autour, IV, $12 \%$.

Autruches, IV, 133.

Awa, II, 276.

Avenu sativa, II, 112 .

Aventurine, 1,78 .

Avet, II, 245.

Averrhoa Caramóola, III, 5i .

- Bilimbi, III, 574.

Avicula Hirundo, IV, 370.

- margaritifera, IV, 366 .

Avila, III, 263.

Avocatier, II, 402.

Arocètes, IV, 134.

Aroine, II. 112.

Avoira, II, 132.

Axine, IV, 252.

Axinite, I, 426 .

Axis, IV, $7 \%$.

Axolot du Mexique, IV, 167.

Axonge, IV, 49.
Aya-pana, III, 64.

Aye-Aye, IV, 25.

Azédalac bipinné, III, „93.

Azerolier, III, 293.

Azolitmine, II, 65.

Azur, I, 248.

Azurite, 1, :33.

\section{B}

Babingtonite, I, 426 .

Bablah d'Égyte, III, 393.

Bablahs, III, 390.

Buctyrilobium Fistula, III, :T3.

Baculites, IV, 356.

liadiane, III, 7 i6.

Bagassa guianensis, 1I, 3:6.

Baguenaudier, III, 371.

Baie, II, 13.

Baie de genièvre, II, 2io.

Batérine, J, 308.

Baikalite, I, 429.

Balana Mysticetus, IV, 115.

- Physalus, IV, 118.

Balance de Nicliolson, I, 千ٔ7.

Balance liydrostatiquue, I, 47.

Balanites agyptiaca, III, 287.

Brilurthium chrysotrichum, II, if.

Balata (suc de), II, 600 .

Balauste, III, : 80 .

Balbusards, IV, 137.

Baieines, IV, 121 .

- (fanons de), IV, II?.

Balénoptères, IV, 115.

Balibabulah, III, 398 .

Ballota nigra, II, 476.

Ballote fétide, II, 476.

Bai.samifuées, II, 304 .

BALSAMINÉES, III, 578.

Balsamite odolante, III, 50.

Balsamita suaveolens, III, 50 .

Balsamocarpon brevifolium, III, ino.

Balsamodendron africanum, III, 51 .5.

- Ehrenbergianum, III, 512.

- gileadense, III, 506.

- Myrrha, III, 512.

- Muckul, III, 516.

Bulsamodendron opobaisnmum, III, $\vdots 06$.

- Roxburghii, III, 516 .

Bambou de l'Inde, II, 97.

Bambusa arundinacea, II, 97.

Bamia, III, 6i8.

Bananiers, II, 197.

Bany, II, 38:.

Banksia abyssini:a, III, 308.

Baobab, III, 651.

Laphia nitida, III, 3ł?. 
Bar-wood, III, 345.

Barbai'ea vulgaris, III, 689.

Barbarée, III, 689.

Barbatimâo, III, 330 .

Barbeau, III, 24.

Barbeau commun, IV, 175.

Barbotine, III, 41.

Barbues, IV, 179.

Barbus, IV, 131.

Bal'deau, IV, 53 .

Bardane, III, 17.

Bardiglio, I, 402.

Barégine, I, 513, 515.

Barges, IV, 134.

Baronez, II; 73.

Barosma betulina, III, 556 .

- crenata, III, 555.

- crenulata, III, 556 .

- serratifolia, III, 556 .

Barringtoniḱes, III, 268.

Barras, II, 262.

Bar's commun, IV, 172.

Barsowite, I, 426.

Baryte carbonatée, 1, 442.

Baryte sulfatée, I, 439 .

Baryum, I, 438.

Basalte, I, 490.

Basanite, I, 490.

Basicérine, I, 312.

Basilic, II, 461 .

Bassia butyracea, II, 598.

- latifolia, II, 598.

- longifolia, II, 597.

- Parkii, II, 598.

Bassorine, III, 45 .

Bastard cabbage-tree, III, 332.

Batata de Purga, II, 534 .

Batatas edulis, II. 520 .

Batraciens, IV, 163 .

- anoures, IV, 164.

- branchifères, IV, 164.

- urodèles, IV, 164.

Baudissérite, I, 381 .

Baulite, I, 473.

Baume blanc, III, 474, 476.

Baume, blanc, de Son Sonaté, III, 481.

- du Caire, III, 565.

- de Canada, II, 2:5.

- focot, III, 621 .

- de Giléad, III, 505.

— de Gurjun, III, 468.

- des jardins, II, 465.

- de Judée, III, 505.

- de Ia Mecque. III, 505.

- de Liquidambar, II, 305.

- Marie, III, 620.

- du Pérou, III, 471.

- brun, III, 76 .
Baume du Pérou en cocos, III, 'iti.

- noir, 111, 477.

- - sec, III, 476 .

- de Saint-Thomé, II, 255.

- de San-Salvador, III, 477.

- de Tolu, III, 474.

- vert, III, (i20.

Baumier du Canada, II, 246.

- de la Mecque, III, 510.

BDElliens, IV. 282 .

Bdellium d'Afrique, III, 51...

- de l'Inde, III, 515-514.

- opaque, III, 514-516.

Beaumonite, I, 429.

Beaver, IV, 25.

Bébeerine, II, 400.

Bebeeru, II, 399.

Bécasses, IV, 134 .

Beccabunga, I, f8'.

Becs-croisés, IV, 130.

Bec-de-grue, III, 576.

Becs-en-ciseaux. IV, 135.

Bers-fins, IV, 129.

Becs-ouverts, IV, $13 \dot{\text {. }}$

Bédéguar, III, 295.

Behen blanc, III, 25.

Behen rouge, II, 445 ; III, 25.

Bé-lalıé, III, 18 t.

Bela-ayé, III, 18 t.

Bélemmites, IV, 356 .

Bélier, IV, 81 .

Belladone, II, 50 ?.

Belle-de-nuit, II, 451 .

Bellis perennis, III 62.

Ben, III, 386.

- ailé, III, 387.

- aptère, III, 388 .

- disperme (fig.), III, $38 i$.

Benjoin, II, 602.

- de Boninas, II, 605.

Benoîte, III, 305.

BERBÉRIDÉES, III, 732.

Berberis vulgaris, III, 732.

Bergamote, III, 631.

Béril de Saxe, 1, 419.

Béroés, IV, 374-376.

Belthiérine, I, 292.

Bertholletia excelsa, III, ?6!).

Berzélite, I, 422.

Beta Cicla, II, 444.

Beta vulgaris, 414.

Betel, II, 277.

Bétoine, 444.

Betonica officinalis, $4 i$.

Bette, II, 47 ?.

Betterave, 44 .

Beurre, IV, 90.

- de Bambouc. II, 598. 
Beurre de cacao, III, 65\%.

- de Galam, 598.

- de ghée,

- de sliea, 595 .

Bevaro, IV, 25.

Bézoards animaux, IV, 103.

- de l'segagre, IV, 103.

- de bœuf, IV, 100.

- de chamean, IV, I00.

- ellagique, IV, 105.

- factice, IV, 107.

- fauve, IV, 105.

- lithofellique, IV, 103.

- minéral, I, 421.

- occidentaux, IV, 109.

- oriental, IV, 103.

- d'oxalate de chaux, IV, 110.

- de phosphate calcaire, IV, 108.

Biber, IV, 25.

Bière, III, 588 .

Bièvre, IV, 25 .

Bigaradier, III, 63:?.

Bignonia Catalpa, 5 í8.

- Chica, II, 550.

- leucoxylon, II, 548.

- longissimu, 11, 518.

- radicans, II, 550 .

Bignoniacées, II, 546.

Bile de bœuf, IV, 9S.

Buinane, IV, 8.

Bish, III, 77'.

Bislingua, II, 169.

Bismuth arsénié, I, 191.

- carbonaté, I, 19;.

- natif, I 191.

- oxydé, I, 19 '.

- silicaté, [, 19'.

- sulfuré, I, 192.

- - cuprifère, I, 193.

- - plombo-antimonifère, I, 193.

- - plombo-argentifère, I, 193.

- telluré, I, 191.

Bison d'Amérique, IV, 85.

Bistorte, II, 42'.

Bitangor maritima, III, 619.

Bittera febrifuga, $\mathbf{I J}, 569$.

Bitume, I, 10\%.

- élastique, I, 105.

Bitume glutineux, I, 103 .

- de Judée, I, 1 ค3.

Bivaro, IV, 25.

Biverio, IV, 25.

Bixa orei "ana, III, 676.

Bixactées, III, $6 \pi 6$.

Black-rose wood, III, 348.

Blaireau, IV, 17.

Blanc de baleine, IV, 112-117.

Bianquatte (soude), IV, 449.
Blanquette, II, 179.

Blase ten Chima, III, 17 .j.

Blatte. IV, 21\%.

Blıuspath, I, 33 .

Blé, II, 108.

- (ergot du), II, 5 f́.

- (farine de), 109.

- de sarrasin, II, f:3.

Bleischimmer, I, 176-17:?.

Blende, I, 365.

Bleu de cobalt, I, 256.

- de 'Thénard, I, 256.

- en liqueur, III, 485.

Bluet, III, 24.

Boas, IV, 153.

Boa-tan-paijang, III, 65 ?

Bocco, III, 555.

Boco, III, 354 .

Bocoa prounsensis, III, 355.

Boerhaavia diandra, III, 99

- hirsuta, II, 450.

Bœuf commun, IV, 82.

- musqué d'Amériqque, IV, 80.

Bœufs, JV, 8?.

- (ægograpile du), IV, 102.

- (bezoards du), IV, 100.

- (bile de), IV,' 98.

Bois, II, 8.

- d'acouma. II, 596.

- d'aloès, III, 337.

- - citrin, III, 339 .

- - musqué, III, 339.

- d'amarante, III, 3 í.

- amer de Bourbon, II, 5is.

- de Surinam, III, 568.

- d'Amboine, III, 597.

— d'anis, II, 396.

- d'arc, II, 325.

- d'amourette, II, 328.

- d'argan, II, 596.

- bagasse, II, 326.

- Bagot, III, 349.

- de balata, II, 595 .

- de baumier, III, 510.

- de betterave, III, 350 .

- bitumineux, I, 100.

- de boco, III, 354.

-- de Brésil, III, 310.

Bois caca, IJI, 462.

- de Caliatour, III, 345.

- cam, III, 34\%.

- Campêche, III, 3il.

- - cèdre, II, 219.

- Dlanc, II, 402; III, 53 i.

- - de Virginie, II, 4112.

- chair, II, 596.

- chandelle, III, 537-538.

- de chat, III, 539. 
Bois chatousieus, III, 3iC.

- de citron, III, 536.

- - de Cayenne, II, 101.

- - du Mexique, III, „38.

- de corail, III, 3 iti.

- - de tendie, III, 3 i6.

- de Colomandel, II, 601.

- de couleuvre, II, 563.

- de crabe, II, 400.

- diababul, III, 351 .

- d'écaille, III, 553 .

- d'épi de blé, III, 356.

- de fer, II, 59j; III, 355.

- de Fernambouc, III, 340.

- de Féroles, III, 537 .

- fossile, I, 100.

- de Gayac, 547-5.52.

- gentil, II, 388 .

- de girofle, II, 400 .

- de Gonzalo-Álvès, III, 5:38.

- de grenadi!le, III, 35́.

- viai, III, 553.

- d'hispanille, III, 537.

- de jasmin, III, 537.

- jaune de l'Australie, III, 597.

- - du Brésil, II, 325.

- - de Cayenne, II, 401.

- - de Maurice II, 578.

- - de Para, Il, 3:6.

- - des teintmriers, II, 325.

- de lettres, II, $3: 8$.

- de licari, II, 401; III, 53i.

- de maclura, II, 325.

- Marie, III, 618 .

- des Moluques, II, 359.

- musqué, III, 340.

- de naghas, II, 397.

- de nalle, II, 595 .

- néphrétique, IlI, 3,2 .

- de Nicaragua, III, 3 '́l.

- i odeur di sassafras, II, 39i.

- d'oliviel d'Amérique, II, 33 . .

- de palissandice, III, 3'4.

- palmiste, III, 332 .

- de pilnacoco, III, 35 t.

- de pavane, II, 359.

- de perdrix, III, 355-356.

- de poivre, II, 401.

- purgatit, II, 3j\%.

- de Résolu, II, 326.

- de Rhodes, II, 545.

- de rose du Brésil, III, 350.

- - des Canaries, II, 5í5.

- - de Cayenue, II, 401.

- $\quad$ - de Chine, III, 350.

- - - des ébénistes, III, 319.

- - faux, JII, 350.

- $\quad$ - femelle, II, 402.
Bois rose mâle, II, 40I; III, 537 .

- rouge de l'Inde, III, 597.

- Rozéphir, III. 351.

- de Saint-François, III, 356.

- de Saint-Martin, III, 356.

- de Sainte-Lucie, III, 316.

- de Sainte-Marthe, III, $3 \dot{4}$.

- de Sappan, III, 341.

- satiné, III, 507.

- - de Cayenne, III, 537.

— - de l'Inde, III, 597.

- - de Para, III, 59\%.

- violet, III, 350 .

- de vouacapon, III, 356.

- de zèbl’e III, 539.

Bol d'Arménie, I, 363.

Boldine, II, 39:.

Boldo, II, 39I.

Boldoa fragrans, II, 391.

Bolet, II, 431 .

- comestible, II, 43.

Boletus, II, 43.

- betulinus, II, 43.

- erluli, 1I, 43.

- fomentarins, II, 45.

- igniarius, II, 45.

- ungulatus, II, 45.

BoMBACÉES, III, Gíj.

Brmbax Gossypium, III, 635.

- jentandrum, III, 650.

- pyramidale, III, 650.

Bombyx du mûrier, $\mathbb{T}, 230$.

Bombyx mori. IV, 231.

Bon-Henri, II, 447.

Bonite des tropiques, IV, 175.

Bonne-dame, II, 4 千 3 .

Bonnet d'électeur, III, 26:.

Bonplandia trifoliatu, III, 5.s?.

Boochgaan-tam-paijany, III, $65_{3}^{2}$.

Boracite, I, 38:.

Borago officinalis, II, 513.

Borax, I, 45.9.

Borbori, III, Ti3.

Bonraginées, II, 511.

Borr-borri, III, it3.

Bos Taurus, IV, 8\%.

Boswellia Bum-Drijiane', III, jls.

- Carteri, III, jIs.

- payzrifera, III, 518.

- sacra, III, 518.

- serrata, III, 518.

Botriocéphale de l'homme, IV, 5 it.

Botrioceplalus latus, IV, 546.

Botryolite, I. 425.

Botryopsis platyphylla, III, it0.

Botrys, II, 445.

Boulangérite, I, 175-17\%.

Bouquetin, IV, 79. 
Bouquetin de Crète, IV, 80 .

Bourdon, IV, 226.

Bouc, IV, 78.

Boucages, III, 223.

Bouc-estain, IV, 79.

Bouillon-blanc, II, 484.

Bourgène, III, 54?.

Bourgeon oll bouton, II, ?.

Bournonite, I, 176-179.

Bourrache, II, 513.

Bouton, II, 9 .

Bouton d'or, III, 757.

Bouvreuils, IV, 130 .

Bow-wood, II, 325.

Bowdichia major, III, 329.

- virgilioides, III, 329.

Box-berry, III, 4 .

Brai sec, II, ?62.

Branchiobdelle de lécrevisse, IV, ?8?.

Brassica asperifolia, III, 693.

- Eruca, III, 694.

- Erucastrum, IlI, 694.

- Napus, III, (i93.

- nigra, III, 694.

- oleracea, III, 692.

Bratrachite, I, 388-389.

Braunite, I, 300.

Brayere anthelminthica, III, 308.

Brecciole, I, 491.

- volcanique, I, 500.

Brèche, I, 490 .

Brême commune, IV' 176.

Brevipennes, IV, 133.

Brewstérite, I, 4:8-441.

Brochantite, I, 237.

Brochet, IV, 176 .

Blonelucées, II, 18?.

Bromelia Ananas, II, 190.

Bromus catharticus, 1I, 94.

- purgans, II, 9't.

Brongniardite, I, 176-180.

Bronzite, I, 389.

Brookite, I, 206.

Brosmes, IV, 179.

Brotera corymbosa, III, 2 .

Broussonetia papyrifera, II, 324.

- tinctoria, etc., II, 325.

Bruants, IV, 130.

Brucite, I, 363, 379, 387.

Bruyère, III, 2.

Bryone, III, 257.

Bryonia alba, III, 257.

- dioica, III, 25 .

Bubale des anciens, IV, 75 .

Bubon Galbanum, HI, 246.

- macedonicum, HI, 236.

Buccins, IV, 360.

Bucco, III, 555 .
Bucholzite, I, 342.

Buchu, IIJ, 555.

Buena hexantra, III, 48i.

Buffalo, IV, 85 .

Buffle, IV, 86.

- du Cap, IV, 86.

Bugle, II, 480.

Buglose, II, 514 .

Bugrane, III, 325.

Buis, II, 371.

Bulbe, II, 9

Bulbosine, II, 42.

Bunium Bulbocastonum, III, 224.

Bruntkupferers, I, 219.

Buranhem, II, 596.

Bursera balsamifera, III, 528.

- gummifera, III, 525-527.

BurséliacéEs, III, 487.

Busards, IV, 127.

Buses, IV, 127.

Busserole, III, 5.

Bustamite, 1, 426.

Butea frondosa, JII, 408-42i.

- superba, III, 426.

Butua, III, 739 .

Buxine, II, 372.

Buxinées, II,371.

Buxus sempervirens, II, 371.

BYTTTÉRIACÉES, III, 645.

\section{i}

Caama, IV, 75.

Caapeba, III, 740 .

Cabaret, II, 380.

Cubaage tree, III. 332.

Cabelliau, IV, 180.

Cabeza de Negro, II, 14?.

Cabiai, IV, 25.

Cabiuna, III, 348.

Cabureiba, III, 477.

Cacao, III, 65 '

- caraque, III, 656.

- Maragnari, III, 657.

- minor, IlI, 655.

- Soconusco, etc., III, 656.

- Trinité, III, 656.

Cachalot, IV, 112.

Cachan lahuen, III, 554.

Cacholong, I, 83.

Cachou, III, 401.

- amylacé, III, 411.

Cachou blanc enfumé, III, 414.

- brun, en gros pains, HI, 415.

- brun siliceux, III, 416.

- cubique résineux, III, 419.

- de l'ares, III, 406-409. 
Cachou de Ceylan, III, 410.

- de Colombo, III, 410-413.

- de Pégu, III, 403-\$16.

- lenticulaire, III, 419.

- en boules, III, 409.

- en écorce d'arbre, III, 402-414.

- en masses, III, $\mathbf{4 1 6 ,}$

- terne et parallélipipède, III, \&1 .

Cactées, III, 251.

Cactus cochinillifer, III, 45t; IV, 210.

- opuntia, IV, 246.

Cade, II, 2 i0.

Cadmium, I, 375.

- sulfuré, I, 375.

Casalpinia brasiliensis, III, 3'1.

- coriaria, III, 398.

- echinata, III, 3i0.

- Srlupar, III, 3i1.

Cassalpiviées, III, 32.3.

Café, ]II, 99.

Caïlcedıa, III, 595.

Caille-lait blanc, III, 8í

- jaune, III, S4́.

Cailles, IV, 132.

Caillou de Rennes, I, 503.

Caïmans, IY, 148.

Caïnca, III, 9 ; .

Cajeput, III, 2:

Cake camboge, III, 615.

Calaba des Autilles, III, 6I8.

Caladium esculenlum, II, 88 .

Calageri, III, 6.j.

Calagirah, III, 65.

Calaguala, II, 70.

- faux, II, 73.

Calambac, III, 3 ; 7 .

- blanc, III, 340.

- faux, III, 340.

Calament de montagne, II, 469.

Calamine blanclıe, I, 372 .

- élecirique, I, 371.

- rouge, I, 373.

- terreuse, I, 370

Calımintha officinalıs, II, 469.

Calamites, II, 85 .

Calnmus aromaticus, II, 89.

- Draco, II, 135.

- scipiorum, II, 135.

- verus, II, 555.

- viminalis, II, 135.

Calaos, IV, 130.

Calcaire à cérites, I, 41 ?.

- oolitique, I, 411 .

Calcédoine, I, 78.

Calcéponge, IV, is.3.

Calciphyıe, I, 491 .

Calcispongia, IY, 383.

Calcium, 1, 395.
Calcium fluoruré, I, 39.).

Cialebasse, III, 261.

Calebassier, II, 546.

Calédonite, I, 189.

Calcndula areensis, III, 3:3.

- officinalis, III, 33.

Cialice, II, 10.

Calla palustris, II, 89.

Callichrome musqué, IV, 211.

Callicocen ipecasuanh", III, 85.

Calmars, IV, 35 i.

Calop'iylium Colaba, III, 618.

- inophyllum, III, 6I9.

- Tacamahace, III, 6:0.

Calotropis gigantea, II, 574.

Calschiste, I, 491.

Calyptranthes aromati:a, III, 27:3.

Calysaya ammilla, III, 141.

- anaranjarla, 1II, 1 í1.

- blanca, III, $1+1$.

- dorada, III, 141.

- de Plancha, III, 140.

- de Santa-Fé, III, 153.

- léger du commerce, 143-15S.

- morada, III, 143.

- negra, III, 141.

- pallida, III, 143.

- verde morada, III, 143.

- zamba, III, 1'il.

Calystegia sepium, II, 522 .

Cam-wood, III, 342.

Camagnoc, II, 350 .

Cambogia gutta, III, 611, 616.

Ciaméléon d'Égypte, IV, 149.

- à nez bificle, IV, 150 .

Cianéléoniens, IV, 149.

Camelin Sesanqua, III, 63\%.

Camelina sutiva, III, 699.

Cameline cultivée, III, 689.

Camelopardalis Girafa, IV, 74.

Camiri, II, 36 i2.

Camomille d'Allemagne, III, 50.

- des champs, III, 53.

- commune, III, 50 .

- puante, III, 54.

- romaine, III, 52 .

Campagnols, IV, 25.

Campanulacées, III, 13.

Camphora officinarum, II, 415.

Camphorosma monspeliac", II, 445.

Camphre de Bornéo, II, \&16.

- du Japon, II, 415 .

Camplurée de Montpellier, II, 445.

Camplnier de Borıéo, III, 643.

- de Sumatra, III, 643.

Canal médullaire, II, 8.

Cananga, I[I, 743.

Canards, IT, 136. 
Canarium balsamiferum, 1II, 52t.

- commune, III, 5?'.

- sylvestre, III, 536 .

- zephyrinum, III, 52'.

Cancrime, III, 454.

Canchalaryua, III, $55 \mathrm{i}$.

Candite, I, 386.

Cancer Astacus, IV, 2:6.

- Gammarus, IV, 276.

- Pagurus, IV, 274.

- Manas, IV, 274 .

Caneficier, III, 372.

Canella alba, III, (i2l.

- axillaris, III, 6:3.

Canellacées, III, 621 .

Canello, III, 750 .

Caniram, II, 563.

Canis familiaris, IV, 18 .

- Lupus, IV, 18.

Canna coccinea, II, 228.

Cunna discolor, II, 229.

Cannabinées, II, 330 .

Cannabis indicr, II, 331,

- sutiva, II, 331).

Canyacées, II, 198.

Canne à sucre, II, 103 .

- de Provence, II, 96.

Canieluacées, III, 621 .

Cannella alba, III, 62I.

Cannella axillaris, III, 6:i.

Cannel-coal, I, 96.

Canelle blanche, III, 6:1.

- de Cayenne, II, 40 S.

- de Ceylan, II, 404.

- de Chine, II, 409.

- de l'Inde, II, 407.

- de Jara, II, 411.

- de Malabar, II, 407.

- de Sumatra, II, 11 .

- giroflée, II, 400, 41千.

- mate, II, 407.

Cannello, III, 750.

Cantharide officinale, IV, 208.

Cantharidine, IV, 210.

Cantharis vesicaloria, IV, ?03.

Can keu, II, 217.

Caoutchouc, I!, 3 i7.

- minéral, 1. 105.

Capillaire du Canarla, II, Tí.

- commun, II, 77.

- de Montpellier, II, i7.

- du Mexique, II, 76 .

- noir, II, 77.

Capock, III, 650.

Caporcianite, I, 428 .

Capparidées, III, 6:9.

Capparis suinosa, III, 679.

Capra Agagrus, IV, 7 .
Capra Hiscus, IV, i8.

- Ibex, IV, 7!.

Câprier, III, 179 .

Caprification, II, 319).

Cappifoliacées, 111, 193.

Capsicum anuum, II, 510.

Capsicum frutescens, II, j!).

Capsule, II, 1 '.

Capucine (grande), III, 57 \%s.

Caquetta burk, III, 153.

Carabaya bark, III, 143.

Caracal, IV, 23.

Caractères climiques, I, 56.

- pliysiques, I, 7.

Caragne, III, 534 .

- d'Amboine, III, 532.

Carapa, III, 59.3.

- guineensis, III, 594 .

- guyanensis, III, 593.

- Touloucouna, III, 5ý́.

Carbone pur, I, 85 .

Carcapulli, III, 610, 616.

Carchurias verus, IV, 195.

Corlamine pratensis, III, 634 .

Caldamome ailé de Java, II, '2IS.

- d'Abyssinie, II, 220.

- de Banda. II, 221 .

- de Ceylan, II, 213.

- de Clusius, I1, 2:2.

- ensal, II, 213.

- fausse maniguette, II, $21 \mathrm{~S}$.

- Galanga, II, 226.

- grand, II, : 13.

- - de Girtner, II, 221.

- - de Madagascar, II, 219.

- long, dı Malaba1, 213.

- moyen, II, ?13.

-. noir, II, 214 .

- ovoïde de la Chine, II, '2! 8.

- petit, du Malabai, II, 2l:3.

- poilu, de la Chine, II, ¿15.

- lond, de la Chine, II, 217.

- a semences polies, II, 222 .

- xantlioïde, II, 215 .

Carde poirée, II, 4't'.

Cardèle cultivée, III, G.6.

Cardinale bleue, III, 10.

Cardopatium corymbrosun, III, 23.

Carduus marianus, III, 20 .

Caret, IV, 1 it.

- (écaille de), IV, $14 \pi$.

Carex arenaria, 1I, 9:, 1 sí.

Cargua-Cargua, III, 165.

Cariama, IV, 13'.

Cari vallandi, II, 185.

Carica ligitata, III, 267.

- Papayja, III, 266.

Cariopse, II, 1:3. 
Carissa Nylopicron, II, 578. Carlina gummifera, III, 28.

- subaccaulis, III, 26.

Carline oflicinale, III, 26.

Carmine, IV, $24 \%$.

Carvassiers, $\mathrm{II}, 13$.

- ampuibies, IL, 23.

Cafinivores, IV, 1 '́

Caroba, II, 547.

Carotte, III, 203.

- sauvage, IV, 236.

Caroube de Judée, III, 3\%6, 499 .

Caroubier, III, 376.

Carouge, III, 376.

Carpe, IV, 175.

Corpinus Betulus, II, 28 ?.

Carpobalsamum, III, 510 .

Carrageen, II, 3:.

Carrelet, IV, 179.

Carlhagena haid Cinchona-bark, III, 174.

Carthame, II, 195, III, 21.

Carthanus corymlosus, III, 29.

- lanatus, III, 23.

- tinctorius, I1, 19., III, 21.

Carton fossile, I, 432.

Carum Bullso castanum, III, 29't.

Carum Carvi, III, 22 '.

Carvi, III, 224.

Caryophyletes, III, 659 .

Caryophyllies, IV, 376.

Caryophilline, III, 273.

Caryophyllas aromaticus, III, 27I.

Casca l'Anta, II, 57 .

- pretiosa, II, 4113.

Cascarilln ahnmada, III, I76.

- amarillı, III, 1 16-165.

- - del Rey, III, 146.

- blanca, III, 176.

- boba amarilla, III, 152.

- bobri de hojas moradas, III, 167.

- carabaya, III, 168.

- Chahuarguera, III, 147.

- colorada, III, 147, 173.

- - de Cuzco, III, 158.

- - de hacaranda, III, 169.

- - del Roy, III, 147.

- - de Sunta-Anna, III, 158.

- con hojas de lucuma, III, 151.

- con hojas de Pallon, III, Ii9.

- cor hojas de Roble, III, 17 .

- con hiöjas redondas, III, 149.

- con hrjas rugosas, III, 17 .

- con hojas un poco villosas, 149.

- crespilla, III, 148, 173.

- de la Corlillera, III, 164.

- delgada, III, 178.
Cascarilla lle Piray, III, 16 \%.

- de Santa-Cruz, III, 16'.

- Echenique, III, 159.

- estoposa de Hualasco, III, 151.

- fina delgarla, III, 178.

- fina de Uritusinga, III, 1't't.

- lajartijada, III, 151.

- Lampigna, III, 15?.

- lustrosa, III, 160.

- macrocarpa, III, 182.

- magnifolin, III, 179.

- morada, III, 16:5.

- motosolo, III, 16 '.

- mila, III, 174.

- raranjada de Sunta-Fe, III, 152.

- negrilla, III, 171.

- parecida é la amurilla, III, 1:8.

- - í la tnena, III, 148.

- pata de gallaretr, III, 168.

- pata de gallinazo, III, 150, 161, 175.

- pelluda, III, 172.

- peruviana, III, 160.

- provinciana de Huanuco, III, 163.

- quepo, IlI, 159.

- roxa verdaderi, III, 169.

- verda, III, 164.

Cascarillo morado, III, 105.

- pallido, III, 148.

Cascarille blanchatre, II, 366.

- officinale, ll. 36'.

- noiråtre et poivrée, II, 366 .

- rougeâtre et térébinthacéc, II, 366.

Cascati, III, 416.

Caséum, IV, 90.

Cashcuttie, Ill, 416.

Casoars, IV, 133.

Cassab el darrib, II, 557.

Cassave, II, 351.

Casse, III, 372.

- (petite) d'amérique, III, 373.

- du Brésil, 374.

Cassia acutifolia, III, 36?, 364.

- celliopica, III, 36?, 36i.

- augustifolia, III, 363, 367.

- brasilimna, III, 37 í.

- catharlica, III, 368.

- Fistula, III, 372.

- lanceolata, III, 383, 367.

- leniliva, III, 362, 36'.

- ligrea, II, 111.

- ligustrina, III, 368.

- marylandica, III, 368.

- moschata, III, 371.

- obovata, III, :3:11, 365 .

- occidentalis, III, 368.

Cassicans, IV, 131.

Cassiées, III, 3:3. 
Cassier, III,

Cussine Gonguba, III, sit.

Cassiques, IV, 130.

Cassis, 11J, 251 .

Cassitérite, I, 196.

Cassure, J, 43.

Cassuvium pomiferum, III, 491.

Ciastor, IV, 25.

Castoréum, IV, 25.

- d'Amérique, IV, 29.

- rouge olangé, IV, 31 .

- de Russie, IV, 32-34.

Castoriexs, IV, 25.

Catu yambra, III, 4:5.

Cataire, II, 47 '.

Cotalpa, II, 518.

- bignomioides, II, 548.

- longissima, II, 5is.

Cate, III, 402.

Cathnotocarpus Fistula, III, 373.

Caulophyllum thalictroides, III, ;33.

Caviar, IV, 190.

Cécilies, IV, $16 \dot{1}^{.}$

Cédrat, cédratier, III, 628.

Cèdre du Liban, Il, 2is.

- rouge, II, 2i?.

- de Virginic, II, 2 '2.

Cédrcl odorant, III, 597 .

Cedrela febrifuga, III, 595.

- odorata, III, 597.

Cédrélacées, III, 595.

Cédron, IV, 571.

Ceiba pentundra, III, 650 .

Céleri, III, 206.

Cellule végétale, II, 1 .

Cendres vertes, I, 236.

Cenomyce rangiferina, IV, 71 .

Centaureu Behen, III, 24.

- Calcitrapu, III, 24.

- Centarrizm, III, 23.

- Cyanus, III, 28.

- Jucea, III, 24.

Centaurée (petite), II, 553.

Centaurées, III, 23.

Centhranthus ruber, III, 83.

Cephalanthus, III, 192.

Cephoelis Ipecacuunha, III, 85.

Cerasus avium, III, 315.

- caproniana, III, 316.

- Lauro-cerasus, III, 318.

- Manaleb, III, 316.

- Padus, III. 317.

- virginiana, III, 317.

Ceratonia Siliqua, III, 376.

Cerbères, IV, 153.

Cercaires, 1V, 338.

Cercomonades, $1 \mathrm{~V}, 37 \mathrm{~s}$.

Cereus peruvianus, III, 251.
Careus serpentinus, III, 251.

Cerf commun, IV, 71 .

- de la Louisiane, IV, $7 \dot{\text { f }}$

- du Canada, IV, 73.

- du Cap, IV, 75.

Cerfenil cultivé, III, 215.

- musqué, III, 215.

- peigne-de-Vénus, III, 2।6.

- sauvage, III, 216.

Cerf-volant, IV, 208.

Cérine, I, 313 ; IV, 233.

Cerisier, III, 315.

Cérite, 1, 313.

Cérithes, IV, 360 .

Cérium, I, 310.

- carbonaté, I, 312.

- fluoruré, I, 311.

- oxyfluoruré, J, 31:.

- pliospliaté, I, 312.

- - lanthanifère, I, 312.

- silicaté, I, 313.

- titano-silicaté, I, 313.

Cérosie, II, $10 \%$.

Ceroxylon andicola, II, 13i.

Céruse, I, 186.

Cervus Alces, IV, (j9.

- Dama, IV, 71.

- Elaphus, IV, 71.

- Turanrlus, 1V, 70.

Cestes, IV, 37i, 3:6.

Cestoïdes, IV, $3 \mathbf{4} 0$.

Cétacés, IV, 110.

- herbivores, IV, 111.

- soufleurs, IV, 111.

Ceterach nfficinarum, $\mathrm{II}, 7 \mathrm{7}$.

Cétine, IV, $112,117$.

Cétoine dorée, IV, 211.

Celraria islundicu, II, 55.

Cétrariı, II, 5 i.

Ceylanite, ], 386.

Ceyx, IV, 130.

Cluabasie. I, 428.

Chacal, IV, 18.

Chacaca, III, 750 .

Chacrille, II, 364 .

Charophyllum orloralum, III, 216.

- sativum, III, 215.

- sylvestre, III, 216.

Chalcopyrite, I, 218.

Chalkolite, I, 213.

Clialumeau, I, 5i.

Chamaras, II. 479.

Cliamædrys, II, 478.

Chamflauciées, III, 26 ?.

Chamæléon, blanc, III, $2 i$.

- noir, III, 28.

Cliamæpitys, II, 480.

Cliaineaux, IV, 56. 
Chameaux (bézoards des), IN, 100 .

Chamois, IV, 76 .

Chamoisite, I, 291.

Champignons, II, 36.

- de Malte, II, 73.

Chanvre cultivé, II, 330 .

Charbon animal, IV, 88 .

Chardon à foulon, III, 66 .

- aux ânes, III, 20.

- bénit, III, 23.

- étoilé, III, 24.

- Marie, III, 20

- roland, III, 213.

Chardonneret, IV, 130.

Chardonnette, III, 20.

Charme, Il, 282.

Châtaignier, II, 284 .

- du Brésil, III, 269.

Chats, IV, 23.

Chats-huants, IV, 128.

Chaume, II, 7.

Chausse-trape, III, 24.

Chaux antimonitée, I, $\{22$.

- arséniatée, 1, 421.

- boro-silicatée, I, 425.

- carbonatée concrétionnée, I, \{1?.

- contrastante, I, 406.

- cuboìde, I, 407 .

- - ferrifère, I, 4I3.

- - grossière, $1,41: 2$.

- - carbonatée inverse, 1, 405.

- - lente, I, 413.

- - manganésifèrc, I, 413.

- - métastatique, I, $40 \mathrm{~s}$.

- - mixte, I, 406.

- - prismatique, I, 415.

- - rlomboédrique, 404.

- - spathique, I, 40i.

- iluo-phosphatée, I, 418.

- liydio-phosphatée, I, 420.

- phospliatée, I, 4ls.

- silicatée, I, 425.

- sulfatée anhydre, I, 401.

- sulfatée hydratée, I, 40\%.

- titano-silicatée, I, 424.

- tungstatée, I, 423.

Chavica officinurum, II, 276.

- Roxburghii, II, 276.

Chaya, II, 450.

Chaya-vair, III, 8?.

Cuétroptères, IV, 1'́ .

Chélidoine (grande), III, i0 i.

- (petite), III, 705.

Chelidonium majus, III, 70'.

- Glaucium, III, 705.

Chélonées, IV, 146.

Chelonia imbricata, IV, 14i.

Chéloniens, IV, 1'3.
Chêne à la galle, II, 289 .

- au kermès, II, 289.

- blanc, II, 285.

- gravelin, II, 286.

- jaune, II. 288.

- liége, II, 287.

- noir d'Amérique, II,

- rouvre, II, 285.

- vélani, II, 286.

- vert, II,

Chenilles, IV, 234.

CHÉxopodées, II, 443.

Chenoportium ambrosioides, II, 4 if.

- anthelminthicum, II, Áti.

- Bonus-Henricus, II, 4ii.

- Botrys, II, 445.

- Quinoa, II, 446.

- Vulvaria, II, 446.

Chermes Vermilio, IV, 2'9.

Cherris, II, 332.

Chevaine, IV, 176.

Clieval (viande de), IV, 49.

Cheval, IV, 48.

Chevaliers, IV, 13 '.

Chevêclies, IY, 128.

Chèvrefeuille, III, 193.

Chèvres, IV, 77.

- domestiques, IV, is.

- d'Angora, IV, 79.

- mambrines, IV, 79 .

- de Syrie, IV, 79.

- du Thibet, $1 V, i 9$.

Chèrre de Cachemire, IV, 79.

Cherreuil, IV, it.

Chevrotains, IV, 57 .

- porte-musc, IV, 57 .

Chia, II, 473.

Chica, II, 550.

Cinconacées, iII, 12.

Chicorée crépue, III, 17.

- endive, III, 16 .

- sauvage, III, 15.

Chien de mer, IV, 196.

- domestique, IV, 18.

Chiendent des boutiques, II, 9i.

- des Indes, II, 100.

- pied-de-poule, II, 95.

China Abomalies, III, 167.

-. Calisaya, III, 140.

- flivarlura, III, $17 \mathrm{f}$.

- - fibrosa, III, 153.

- Guamalies, III, 167.

- Huanuco, III, 161.

- Huamalies, III, 167.

- Jaën, III, 175.

- officinalis, III, 145.

- pseudo-loxa, III, 148-172.

- pseudo-regia, Ill, 148. 
China regia, 111, 140.

- mubiginusa, III, 165.

- rubra, III, 169.

- tenn, IlI, 175.

- tena, III, 175.

Chincliilla, IV, 25.

Chinchillexs, IV, 25.

Chiococca anguifuga, III, 97.

- densifolin, III, 97.

- racemosa, III, 97.

Clique, IV, 256.

Chimophila umbellatı, III, 2.

Chimpansé, IV, 13.

Chiscocca anguifuga Mart, III, 9\%.

Chirayta, II, 5.5.).

Chironia angularis, $55 \mathrm{~s}$.

- chilensis, II, 5.5

- Centaurium, II, 553.

Chlorlydrate d'ammoniaque, I, '千8't.

Chlorlydrate de magnésie, I, 377.

Chlorite, I, 396.

- écailleuse, I, 397.

- liexagonale, I, 396 .

- schisteuse, I, 397.

Chloromélane, I, 292.

Chloropale, I, 289.

Cllorophane, I, 400 .

Chlorophoite, I, 289.

Chlorospinelle, I, 386.

Chloroxylum Swieteria, III, 5.37.

Chondodendron tomentosum, III, Tio.

Chondrilla graminea, Ill, 17.

Chondroptérygiens, IV, 189.

Chondrodite, I, 397 .

Chondrus polymorphus, II, 32.

Choristoporées, II, 24 .

Chouan, II, 417.

Choucaris, IV, 129.

Cllouette, IV, 128-137.

Chou bouillonné, IIl, 692.

- cabus, III, 69?.

- caraībe, II .

- fleur, III, 693.

- palmiste, II.

- pommé, III, 692.

- potager, III, 692.

- l'ave, III, 693.

- vert, III, 692.

Chrichtonite, I, 286-321 .

Christianite. I, 428.

Chrome, I, 209.

- oxydé, I, 209.

Cliromides, I, 201.

Clirysalides, IV, $23 i$.

Chrysobolanées, III, 287.

Chrysobalanus Icaco, III, 287.

Clnysobél'yl, I, 3:22.

Cln lysocolle, I, 233-458.
Chrysolithe, 1, 419.

Chlysolithe des volcans, I, 397 .

Chrysolithe orientale, I, $32 \%$.

Chrysopale, I, 3:2.

Chrysophyllum glycyphlceum, II, 596.

Chrysoprase, I, 79.

Churrus, II, 3:32.

Chynlen (racine de), III, 76.5.

Cibotium Buromez, II, Tí.

- Chamisoi, II, 7 t.

- glaucum, II, 74.

- Menziezii, II, 74.

Cichorium Endivia, III, 16.

- Intylus, III, 15.

Ciconia alba, IV, 137.

Cicutaire aquatique, III, 2I8.

Cicuta major, III, 216.

- virosa, III, 218.

Cicutaria aquatica, III, 218.

Cidre, III, 587 .

Cierge du Pérou, III, 216.

Cigales, IV, 2 \&l.

Cigale de l'orne, IV, 243.

Cigognes, IV, 134-137.

Ciguë des jaldins, III, 2 19.

- officinale, III, 216.

- (petite), III, 219.

- vileusc, III, 218.

Cinabre, I, 167.

Cinchonu, III, 109.

Cinchonı acarlemica, III, l'ti.

- affinis, III, 16:3.

- amygdalifoliu, III, 159.

- angustifolin, III, 152.

- anstralis, III, 161.

- boliviana, III, 143.

- Bonplandiana, III, 14́x.

- Calisaya, IlI, 1'́n.

- - Josephiana, III, I'́n.

- morala, III, 140.

- vera, III, 140.

- Chrhuarguera, 111, 14́.

- Condaminea, III, 1'́x.

- coccinea, III, 144.

- conglomerata, III, 173.

- cordifolia, III, Iif.

- - vera, III, 1ix.

- - rotundifolia, III, $17 \mathrm{i}$.

- crispa, III, 145.

- decurrentifolia, III, Ii6.

- Delondriana, III, 159.

- eliptica, III, 143.

- erythrantha, III, 1'tx.

- glandulifera, III, 171.

- Goudatiana, III, 17 .

-- heterophylla, III, 178.

- Lirsuta, III, 177.

- Humboldtiana, III, 1:2. 
Cinchona lanceolato, III, 15?.

- laccifera, III, 182.

- larcifolia, III, 15\%.

- lucumafolia, III, 150.

- luter, III, 174.

- macrocalyx, 1'́s.

- macrocarpa, III, IS:

- magnifolia, III, 179.

- micrantha, III, 16:).

-- Mutisii, III, 176.

- crispa, III, 176.

- - micropliylla, III, 176.

- - rugosa, III, 176.

- nitida, III, 160.

- oblongifolia, III, 179.

- obtusifolia, III, 14 '́.

- officinaiis, IlI, 141-16C-165.

- ovalifolia, III, 182.

- ovata, III, 168.

- - erythroderma, III, 169.

- rufinervis, III, 168.

- vuigaris, III, 168.

- Pahudiana, III, 173.

- Pallon, III, 145.

- parabolica, III, 177.

- peruviana, III, 161.

- pitayensis, III, 156.

- pubescens, III, 165.

- pelleteriana, III, 165.

- purpurea, III, 16is.

- purpurea, III, 165.

- quercifolia, III, 177.

- crispa, III, 177.

- rotundifolia, III, 17'́

- rufinervis, III, 168.

- rugosa, Ill, 177.

- scrobiculata, III, $\mathbf{1 5 8 .}$

- - genuina, III, 158 .

- Delondriana, III, 158.

- subcordata, III, 175.

- suberosa, III, 179.

- succirubra, III, 169.

- Taron-Taron, III, 191.

- Triance, III, 156.

- Tucujensis, III, 174.

- umbeliulifera, III, 173.

- undulata, III, 171.

- Urilusinga, III, 14 4.

- villosa, III, 172.

- violacea, III, 144.

Cinnamodentron corticosum, III, 623.

Cinnamomum aromaticum, II, 409.

- Cassia, II, 409.

- Culiliwan, II, 414.

- iners, II, 413.

- Malabathmm, II,

- perpetuoflorens, II, 408-411.

- Sintoc, II, 414.
Cinnamomum zeylanicum, II, 40 '.

Cimq fragnents précieıx, I, 35.1.

Cipipa, II, 351.

Cipolite, I, 491.

Cire d'abeille, IV, 229-231.

- de carnauba, II, 134.

- de Chine, IV, 250.

- du Japon, III, 490.

- de myrica, II, 281.

- fossile de Moldavie, I, 106.

Cirntpènes, IV, 279.

Cissamipelos Caapeba, III, 739.

- ebracteata, III, 739.

- glaberrima, III, 739 .

- mauritiana, III, 739.

Cisiampelos Pareira, III, 739.

Cissus, III, 579.

Cistinées, III, 673.

Cistus crelicus, III, 674.

- ladaniferus, III, 67x.

Citres, III, 6:27.

Citronnelle, II, 43.

Cituonnelle de la Martinique, II, 99.

Citronnier des Juifs; III, 628.

Citrons, III, 629 .

Cutrus Aurantium, III, 63'.

- Bigaradia, 11I, 632.

- Ceclra, III, 628.

- Limelta, III, 631,

- Limon, III, 629.

- medica, III, 627.

- vulgaris, III, 632.

Civette, II, 156.

- viaie, IV, 19.

Civettes, IV, 19.

Clalocères, IV, 273.

Classification minéralogique, I, 6:.

- des animaux, IV, 3.

- des corps simples, 1, 66.

- des végétaux, II, 16.

Clatliracées, II, 38.

Clavalier jaune, 11I, 562 .

Clavelli cinnamoni, II, 408.

Claviceps purpurea, II, 5í.

CléHATIDÉES, III, 751.

Clematis erecta, III, 75 .

- Flammula, III, 754 .

- recta, III, 75 f.

- Vitalba, III, 753.

- Viticella, III, 754 .

Clématite bleue, III, 754.

- droite, III, 754 .

- des haies, III, 753.

- odorante, III, 75't.

Cleome gigantea, III, 679.

- heptaphylla, III, 679.

- polygona, III, 679.

Clivage, I, 13. 
Cloisons, II, 12.

Cloporte, IV, 277.

Clostre, II, 2.

Clupea Alosa, IV, 1 is.

- Encrasicholus, IV, 178.

- latulus, IV, 178.

- Harangus, IV, 178.

- Sardina, IV, 178.

Cnicus benedictus, III, 2:.

Coarse camboge, III, 608.

Coatis, IV, 16.

Coatli, HI, 353 .

Cobalt arséniaté, I, 253.

- arsenical, I, 250.

- arsénité, I, 254.

Cobalt arséniuré, I, 250.

- - ferrifère, I, 251.

- gris, I, 252.

- oxydé, I, 253.

- sulfaté, I, 254.

- sulfo-arséniuré, I, 25?.

- sulfuré, I, 251.

Cobaye, IV, 25.

Cobilis barbatula, IV, riti.

- fossilis, IV, Ii6.

Cobra capello, IV, 16 ?.

Coca, III, 602.

Coccias, IV, 25.

Coccinelle. IV, 214.

Coccoloba uvifera, III, 434.

Cocculus palmatus, III, 735.

- rufescens, III, 739.

- suberosus, III, 740.

- toxicoferus, II, 570.

Coccus Axine, IV, 251.

- cacti, IV, 2 i4.

- ilicis, II, 289 ; IV, 219 .

- Lacca, II, 320.

- manniparus, II, 585.

- polonicus, II, 250.

- sinensis, IV, 250.

Coccolite, I, 429.

Cochenille de Pologne, IV, 250.

- du Mexique, IV, 244.

- grise, IV, 246.

- jaspée, IV, 246.

- noire, IV, 246.

- sylvestre, IV, 246.

Cochlearia armoracia, III, 685.

- officinalis, III, 684.

Cochlospermum Gossypium, III, 4j3-635.

Cochons, IV, 45 .

Cocorlis, IV, 13 .

Cocos nucifer'a, II, 131.

Cocotier, II, 131.

Codagapala, II, 578.

Coddam-Pulli, III, 610-616.

Coclocline polycarpa, III, i43.
| Coffea arabica, III, 99.

- mauritiana, III, 99.

Cognassier, III, 289.

Coing, III, 289.

Colchicacées, II, 143.

Colchicum autumnale, II, 143.

- illyricum, II, 147.

- variegatum, II, 148.

Colchique d'automne, II, I13.

Coléoptéres, IV, 205.

Colibris, IV, 130.

Colimaçon, IV, 358.

Colle de Flandre, IV, 88.

- de peau d'âne, IV, 5 '́ .

- de poisson, IV, 191.

- de poisson anglaise, IV, 192.

- de poisson vitreuse, IV, 19 ?.

- de poisson fausse, IV, 19:.

Collet, II, 5 .

Collyrite, 1, 356.

Colocase d'Égypte, II, 88.

Colocasia antiquorum, II, 88.

Colombars, IV, 132.

Colombo (racine de), III, 735.

- faux, III, 737.

Colophane, II, 262.

- d'Amérique, II, 264.

Colophonite, I, 349 .

Coloquinte, III, 259.

Coluber Esculapii, IV, 15.).

- Naja, IV, 162.

- natrix, IV, 154.

- viperinus, IV, 154.

Colus, IV, 75.

Coluteu arborescens, III, :3i1.

Colza, III, 693-696.

Combattants, IV, 134 .

Conbrétacées, III, 282.

Composées, III, 11.

Concombre cultivé, III, 260.

- d'âne, III, 258.

- sauvage, III, 258.

Condaminea tinctoria, III, 18?.

Condori, III, 380 .

Condrodite, I, 387.

Condroptérygiens, IV, 171-199.

Condurite, I, 226.

Cône, II, 15.

Cônes, IV, 360.

Congre commun, IV, 188.

Conifères, II, 236.

Conirostres, IV, 130.

Conium maculaturn, III, 216.

- Arracacha, III, 218.

Connaracées, III, 487.

Consolida regalis, III, 768 .

Consoude (grande), II, 515.

- royale, III, 768 . 
Contrayerva officinal, II, 316 .

Convallaria maialis, II, 167.

- Polygonatum, II, 167.

Conversion d'une analyse quantitative en formule, I, 69.

Convolvulacéts, II, 519.

Convolvulus arvensis, II, 52?.

- Batatas, II, 520.

- hivsuís, II, 522-539.

- Jalapa, II, 524.

- Mechoacamra, II, 533.

- officinalis, II, 525.

- orizabensis, II, 527 .

- purpureus, II, 521.

- Scammoni, II, 539.

- scoparius, II, 545 .

- sepium, II, 522.

- Soldanella, II, 522 .

- speciosus, II, 535.

- syriacus, II, 538.

- Turpelhum, II, 535.

Copalıu du Brésil, III, 467.

- de Caycune, III, ‘67.

- de Colombie, III, 468.

Copaïfera bracleata, III, 347.

- coriacea, III, 467

- Langsclorfii, III, 467.

- officinalis, III, 46\%.

- publiflorn, III, 347.

Copal, III, 455.

- d'Akkralı, III, 465.

- d'Angola, III, 465

- de Benguela, 111, 166.

- du Congo, III, 405.

- dur, III, 457.

- demi-dur, III, 460.

- fossile, I, 109 .

- santo, III, 523 .

- de Sierra-Leone, III, 465.

- tendre, III, 461.

- - de Nubie, II, 303.

Copalchi, II, 367.

Copépodes, IV, 273.

Copernicea cerifera, II, 134.

Coptis Teeta, III, 767.

Coque, II, 1 f.

Coque du Levant, III, 740 .

Coquelicot, III, 712.

Coquelourde, III, 756.

Coqs de bruyère, IV, 132.

Corail blanc, IV, 382.

- noil', IV, 382.

- rouge, IV, 376-380.

Coralline blanclıe, II, 29.

- de Corse, II, 30.

Corallina officinalis, II, 29.

Corallium rubrum, IV, 390.

Colbeaux, IV, 130.
Corca-pulli, III, (16.

Corchorus olitorius, IIl, Gil.

Cordia Mixu, 1I, 512.

Cordiérite, I, 330, 395.

Corette potagère, III, 611.

Coriandre, III, 236.

Coriandrum sativum, III, 2302.

Coriaria myrtifolin, III, 369-60.3.

Coriamiées, III, 598.

Corindon, I, 328.

- granulaire, I, $3: 31$.

Corypha cerifera, II, 131.

Cormorans, IV, $136-137$.

Cormaline, I, 79.

Cornées, III, 196.

Cornécnne, I, 491 .

Cornes de cerf, IV, i?.

Cornichon, III, 261 .

Cornichons de cerf, IV, 7:.

Colnouiller mâle, 11I, 196 .

- sanguin, III, 196.

Cornus mas, IlI, 196.

- sanguinea, III, 196.

Corolle, II, 10.

Corossoliers, III, 74́.

Corps cassants, I, 10.

- ductiles, I, 10.

- inorganiques, I, 24.

- isomorphes, I, 17.

- malléables, I, 10.

- organisés, I, 34.

- simples, I, 63,66 .

Coqueta bark, III, 15i.

Corroyère, III, 603.

Cortex Winteranus, III, $6: 1$

Cortex China ruber, III, 169.

Corydale, III, 702.

Corydaline, III, 702.

Corydalis hulbosa, III, 702 .

- capnoides, III, 702.

- tuberosa, III, 702.

Corylus Avellana, II, 28:3.

Costus, III, 28.

- amer, III, 18't.

- arabicus, III, 30.

- speciosus, III, 30.

Coton, III, 649.

- herbacé, III, 6i9.

Cottingas, IV, 129.

Cotylédons, II, 16.

Cotylet, III, 255.

Couagga, IV, 54 .

Couaque, II, 351 .

Coucous, IV, 131.

Coudous, IV, 76 .

Coudrier, II, 283.

Cougourde, III, 261.

Cougourdette, III, 26 ?. 
Couguar, IV, 23.

Couis, II, 5 i6.

Couleur des corps, I, 51.

Couleurrée, III, 257.

Couleurres, IV, 153.

- à collier, IV, 15 .

- vipérine, IV, 15́.

Coumarou, III, 356 .

Coumarouna odorata, III, 356-37\%.

Courbaril, III, 357.

Coure-vite, IV, 134 .

Courge, III, 261.

Courlis, IV, 134.

Couroucous, IV, 131.

Couroupita guianensis, III, 269.

Coury, III, 406-110.

Cousin, IV, 25:.

Cousso, III, 307.

Coutarea latifolia, III, 189.

Couzéranite, I, 426.

Couvelline, I, 218.

Cowdee gum, II, 268.

Crabe commun, IV, 275.

Craie, I, 401-411.

- de Briançon, I, 391.

Cran de Bretagne, III, 685.

Crapaud commun, IV, 167.

Crassulacées, III, 251.

Crotcogus Azarolus, III, 293.

- oxyacantha, III, 293.

C:uveiro da terra, III, 273.

Crayon des charpentiers, 1, 507 .

- noir, I, 507.

- rouge, I, 2i0.

Crème de tartre, III, 59:.

Crémomètre, IV, 93.

Crescertia Cujete, II, 546 .

Cresson alénols, III, 684́.

- de fontaine, III, 683.

- des jardins, III, 68'.

- de Pala, III, 56-684.

- des prés, III, 684.

- sauvage, III, 68í.

Cristal de roche, I, 75 .

Cristallisation (systèmes de), I, 30 .

Crocodiles, IV, 148.

Crocodiliens, IV, 148.

Crocoisme, I, 182.

Crocus metallorum, I, 13'.

Crocus sativus, II, 193.

- vernus, II, 193.

Cronstedtite, I, 292.

Crotales, IV, 155.

Croton Cascarilla, II, 364.

- Eluteria, J, 365.

- lacciferum, II, 320.

- Malambo, 1I, 368.

- molucanum, II, 362.
Croton pseudo-china, II, 367 .

- Ricinus, IV, 266.

- sebiferum, II, 361 .

- tigiuum, II, 359.

- tinctorium, II, 314.

Crozophora tinctoria, II, 314.

Crucifenes, III, 681 .

Ciustacées, IV, 272.

Cryolite, I, 461.

Cruptocarya pretios\%, II, 403.

Cryptocarye aromatique, II, 40?.

Cryptolite, I, 3 เ2.

Cténocènes, IV, 376.

Citénopholies, IV, 376.

Cube, I, 18.

Cubeba canina, II, ? ७े.

- Clusii, II, 275.

- officinalis, II, 274.

Cubèbes, II, 274 .

Cubébin, II, 275.

Cubilose, II, 36.

Cucubalus Behen, III, 25.

Cucumis Citrulus, III, 261.

- Colocynthis, III, 259.

- Melo, III, 261.

- sativus, III, 26').

Cucurbita aurantia, 11I, 262.

- Lagenaria, III, 261.

- maxima, IJI, :61.

- Melopepo, III, 26?.

- ovigera, III, 262.

- Pepo, III, :26.2.

- piliformis, III, 26?.

Cucurbitacées, III, 255 .

Cuichunchillı, III, 95.

Cuir de montagne, I, 4?6.

Cuivre, 1, 214.

- (extraction du), I, :39.

- arséniaté, I. :27.

- - aphanèse, I, 223.

- - érinite, I, 228.

- - eucliroïte, I, :28.

- - Iyroconite, I, 229.

- olivénite, I, 227.

- arsenical, I, 215.

- arsenité, I, 226.

- carbonaté anlıydre, I, 23í.

- - bleı, I, 234.

- vert, I, 235.

- dioptase, I, 233.

- gris, I, 221.

- - antimonifère, I, 221.

Cuivre gris arsenical, I, 223.

- - mercurifère, I, 2:2.

- - de Saint-Wenzel, I, 223.

- hydraté silicieux, I, 233.

- hydrosilicaté, I, 233.

- natif, I, 21i. 
Cuivre oxydulé, I, 22'.

- oxydé, I, 226.

- oxychloruré, I, 237.

- phosphaté anhydre, I, 231.

- octaédrique, I, 231,

- prismatique, I, 232.

- pyriteux, I, 218.

- - bronzé, I, 219.

- panaché, I, $2: 0$.

- sélénié, I, 216.

- - argentifère, I, :16.

- sous-sulfaté, I, 237.

- sulfaté, I, 238.

- sulfuré, I, 217.

- - hépatique, I, 217.

- - argentifère, I, 218.

Culex, IV, 252.

Culilawan, II, 414.

- des Papous, II, 414.

Cultrirostres, IV, 134.

Cumin, III, 225.

- noir, III, i68.

Cuminum Cyminum, III, 225.

Cupressinées, II, 236.

Cupressus sempervirens, II, 238.

Cupuliféres, II, 282.

Curare, II, 569.

Curcas multifida, II, 358.

Curcas purgatif, II, 357 .

Curcuma de Java, II, 207.

- long, 1I, 207.

- oblong, II, 207.

- rond, II, 207.

Curcuma aromutica, II, 208.

- domestica, etc., II, 208.

- tinctoria, II, 208.

- Zedoaria, II, 211-212.

- Zerumbet, II, 210.

Cururu-ape, III, 600.

Cusparia febrifuga, III, 556 .

Cusso d'Abyssinie, III, 30 ?

Cuticule, II, 5.

Cuzco bark, III, 165.

Cyanite, I, 341.

Cyclanien europaum, II, 458.

Crclostome, IV, 205.

Cydonia vulgaris, III, 289.

Cymophane, I, 322.

Cynanchum Argel, III, 363.

Cynara Scolymus, III, 19.

- Cardunculus, III, 19.

Cynarées, III, 17.

Cynips, IV, 283.

- galla tinctorice, II, 290.

- rosa, III, .

Cynocéphales, IV, 13.

Cynodon dactylon, II, 95.

Cynoglosse, II, 516 .

Gubourt, Drogues. $7 \bullet$ edit.
Cynoglossum officinale, II, 516

Cynomorium coccineum, II, 8 i.

Cynorrhodon, III, 294.

Cypéracées, II, 90.

Cyperus esculentus, II, 91.

- longus, II, 91.

- Papyrus, II, 92,

- rotundus, II, 91.

Cyprées, IV, 360.

Cyprès, II, 238.

Cyprinus alburnus, IV, 176.

- curatus, IV, 175.

- Barbus, IV, 175.

- Brama, IV, 176.

- Carpio, IV, 175.

- Dobula, IV, 176.

- Gutio, IV, 176.

- Proxinus, IV, $176^{\circ}$

- Tinca, IV, 175.

Cysticerque, IV,

Cysticercus cellulosa, IV,

Cytinus hypocislis, II, 84.

Cytisus Laburnum, III, 358.

\section{1}

DACTYLOPTÈRES, IV, 173.

Docdalea, II, 44.

Daim, IV, 71.

Dalbergia latifolia, III, 348-350.

DAlbergiées, III, 322.

Dalhia III, 62.

Daman d'Afrique, IV, 36-44.

Dammar aromatique, II, 268.

- austral, II, 267.

- batu, II, 266.

- des Ciélèbes, II, 268.

- friable, II, 303.

- puti, II, 266.

- sélan, II, 303.

Dammara alba, II, 266.

- orientalis, II, $266^{\circ}$.

- selanica, II, 303.

Danburyte, I, 428.

DAPHNACÉES, II, 387.

Daphne alpina, II, 390.

- Gnidium, II, 387.

- Laureola, II, 389.

- Mezereum, II, 388.

- Thymelaea, II, 388.

Dasyures, IV, 41 .

Datholite, I, 425.

Dattes, II, 123.

Dattes du désert, 1II, 287.

Dattier, II, 128.

Datura arborea, II, 498.

- fastuosa, II, 498.

T. II. - 27 
Datura ferox, II, 497.

- loevis, II, 498.

- Metel, II, 498.

- Stramonium, II, 497.

Daucus Carota, III, 203-236.

Daucus de Crète, III, 235.

- vulgaire, III, 236.

Datuphinelles, III, 768.

Dauphins, IV, 111.

Daurade ou dauradille, II, 77 .

Dauw, IV, 5 í.

DÉCAPODES, IV, 273.

- ANomocties, IV, 271 .

- blachyures, IV, 273.

- macrolres, IV, 274.

Delphinium Ajacis, Ill, 769.

- Consolida, III, 768.

Delphinium Staphisagria, III, 769.

Delphinus globiceps, IV, 116.

- Phoccena, IV, 112.

Delvauxine, I, 280.

Dentelaire, II, $456^{\circ}$.

Dentirostues, IV, 129.

Départ, I, 146.

Dermaptéres, IV, 205.

Desman, IV, 15-39.

Descloziite, I, 182.

Destrugesia albida, III, 446.

Diagomètre de Rousseau, II, 591 .

Diallage métalloïde, $\mathrm{I}, 389$.

- verte, I, 390.

Diallogite, I, 308.

Diamant, I, 85 .

- d'Alençon, I, 78.

Dianthus Caryopleyllus, III, 660.

Diaspore, I, 332.

Dichroite, I, 395.

Dictame des Barbades, II, 227.

- blanc, III, 556 .

- de Crète, II, 468.

Dictamnus albus, III, 556.

Dicypellium caryophyllatum, II, 401.

Didelphes, IV, 41.

Didymium, I, 310, 311.

Dika (beurre de), III, 573.

Dindon, IV, 132.

Dieffenbachia seguina, II, 88

Digitale pourprée, II, 500 .

Digitalis purpurea, II, 506 .

Digitigrades, IV, 17.

Diopside, I, 426, 430 .

Dioptase, I, 233.

Diorite, I, 491 .

Dioscorea, II, 186.

DiosconéEs, II, 185.

Diosma crenata, III, 555 .

jIOSMÉEs, III, 545.

Diospyros Ebenum, II, 601.
Diospyros melanoxyıon, II, 601. - reticulata, II, 601 .

Diphyes, IV, 374.

Diphucéphale soyenx, IV, 211.

DI PLÉCOLOBÉES, III, 681.

Diplotaxis tenuifolia, III, 694.

DipsacéEs, III, 66.

Dipsacus fullonum, III, 66.

Diptéres, IV, 251.

Dipterix odorata, III, $356,37 \%$.

Dipténocarpées, III, 642.

Dipterocarpus levis, III, 468-643.

- trinervis, III, 468-643.

- tuberculosus, III, 417.

Dipyre, I, 426.

Disclasite, 1, 427.

Diss (ergot du), II, j4.

Discophones, IV, 376.

Disthène, I, 341.

Distoma hepaticumi, IV, 339.

- hetorophies, IV, 339.

- lanceolatum, IV, 339.

i)istomes, IV, 338 .

Distylium racemosum, III, 50 .

Dividivi, III, 398.

Doctor-gum, III, 489.

Dodécadère pentagonal, I, 2'́ .

- rlomboidal, I, 2 '.

- triangulaire, I, 25.

Dolérite, I, 491.

Dolicos pruriens, III, 38:.

- urens, III, 38\%.

Dolomie, I, 413-492.

Domite, I, 492.

Dompte-venin, II, 573.

Dorade de la Chine, IV, 175.

Dorema ammoniacum, III, 243.

Doronicum pardalianches, III, 35.

Doronic, III, 35.

Dorsch, IV, 181.

Dorstenia Urasiliensis, II, 316.

- contrayervn, II, 317.

Douce-amère, II, 505.

Doucette, III, 79.

Douve (grande), III, 757.

- (petite), III, 757.

Dracocephalum moldavicum, II, $\mathbf{4 7 5}$.

Dracontium pertusum, II, 89.

Dragonneau de Médine, IV, 334.

Drèche, III, 588 .

Divemmi, III, 403 .

Dromadaire, IV, 57.

Dromes, IV, 134.

Drupe, II, 13.

DRYADÉES, II, 288-301.

Dryandra cordata, II, 361.

- vernicia, II, 361.

Drymis chilensis, III, 750. 
Drymis granaiensis, III, 750 .

- mexicana, III, 750.

- IVinteri, III, 748.

Dryobanalops aromntica, II, 417.

- Camphora, II, 417; III, 643.

Ducs, IV, 128.

Ductilité, I, 11.

Dufrénoysite, I, 175-176.

Dulcine, II, 587.

Dunkle ten China, III, 148-17:.

Dunkle Jean China, III, 149-17\%.

Dureté des corps, I, 8.

Dusodyle, I, 97-106.

Dysluite, I, 386.

Dzigguetaı, IV, 5 f.

\section{E}

East Indian satin-wood, III, 590.

Eau, I, 509.

- d'Acqui, I, 518.

- d'Aix, en Savoie, I, 519.

- d'Aix-la-Chapelle, I, 520.

- d'Aix en Provence, I, 521.

- d'Amélie, I, 522.

- d'Ax, I, 522.

- de Bade ou Baden, I, 522.

- de Bade en Argovie, I, 523.

- de Baden, en Autriche, I, 524.

- de Bagnères-de-Bigorre, I, 524.

- de Bagnères-sur-l'Adour, I, 524.

— de Baguères-de-Luchon, I, 525.

- de Bagnoles, I, 526.

- de Bagnols, I, 526.

- de Bains, I, 527.

- de bains d'Arles, I, 527.

- de Balaruc, I, 527.

-- de Baréges, I, 520.

— de Batli, I, 529.

- de Bonnes, I, 530.

- de Bourbon-Lancy, I, 531.

- de Bourbon-l'Archambault, I, 531.

- de Bourbonne-les-Bains, I, 533.

- de Bussang, I, 534.

- de Cannstadt, I, 534.

- de Carlsbad, I, 535.

- de Cauterets, I, 536.

- de Cauvallat, I, 537.

- de Challes, I, 537.

- de Chateldon, I, 538 .

- de Chatel-Guyon, I, 533.

- de Cihaudesaigues, I, 539.

- de Cheltenham, I, 539.

- de Contrexeville, I, 540.

- de Cransac, I, 540 .

- des Créoles, III, 602.

- de Dax, I, 54?.
Eau d'Eger ou Egra, I, 54 ?.

- d'Ems, I, 542.

- d'Encausse, I, 543.

- d'Enghien, I. 544.

- d'Epson, I, 545.

- de Forges-les-Eaux, I, 545.

- de For'ges-sur-Brüs, I, 5 í.

- de Graville-l'Heure, I, 546.

- de Gréoulx, I, 546.

- d'Hamman-Mescoutine, I, 547.

- d'Heilbrunn, I, 547.

- de Hombourg, I, 548.

- de Kreutznach, I, 549.

- de Lamalou, I, 550.

- de la Maréquerie, I, 550.

- de la Motte-les-bains, I, 550.

- de Louesche, I, 551.

- de Luchon, I, 552.

-- de Lucques, I, 552.

- de Luxeuil, I, 553.

- de mer, I, 511.

- du Mont-Dore, I, 557.

- de Néris, I, 558.

- de Passy, I, 559.

- de llombières, I, 562.

- de Pougues, I, 563.

- de Provins, I, 564.

- de Pullna, I, 564.

- de Pyrmont, I, 565.

- de Rennes-les-bains, I, 565.

- de Roisdorff, I, 566.

- de Ruyat et Chamalières, I, 567.

- de Saint-Allyre, I, 567.

- de Saint-Amand, I, 568.

- de Saint-Galmier, I, 569.

- de Saint-Nectaire, I, 570.

- de Saint-Pardoux, I, 572.

- de Saint-Sauveur, I, 572.

- de Sedlitz, I, 572.

- de Scidschutz, I, 573.

- de Seltz ou Selsters, I, 574.

- de Soultz-les-Bains, I, 575.

- de Soultzbach, etc., I, 575.

- de Spa, I, 576.

- de Tarascon, I, $5 \% 6$.

- de Tœplitz, I, 577.

- de Tongres, I, 57 i .

- d'Uriage, I, 377.

- d'Usal, I, 5 ĩ8.

- de Vals, I, 578.

- de Vernet, I, 579.

- de Vic-sur-Gère, 1, 579.

- de Vic-le-Comte, I, 580.

- de Vichy, I, 580.

- de Wiesbaden, I, 581 .

ÉbÉNACÉES, II, 600.

Ébène Maurice, II, 601 .

- noir du Brésil, III, 3jú. 
Étsène noire de Portugal, II, 601.

- rouge du Brési', II, 601.

- verte, III, 549.

- - de Cayenne, II, 548.

- rerte-brune, II, 549.

Ecaille de caret, IV, 14 i.

Ecbalium agreste. III, 258.

Échalote, II, 156.

Échasses, IV, 134.

Écinssiens, IV, 13\%.

Échidnés, IV, 11.

Éclinocoque, IV, 345.

Échinodernes, IV, $37 \%$.

Echinus esculentus, IV, 3i'.

- granulis, IV, 374.

- lividus, IV, 374.

Echium vulgare, II, 513.

Éclogite, I, 492.

Éclaire, III, 704.

Écorce, II, 8.

- amère de Madagascar, III, 154.

- à odeur de muscade, III, 623.

- de cascarille, III, 364.

- de copalchi, II, 367.

- de culilawan, II, 414.

- éleutérienne, II, 36t.

- de giroflier de Cayenne, III, 62.3.

- de josse, III, 191.

- de koss, III, 191.

- de massoy, II, 397.

- de Panama, III,

- de Paraguatan, III, 18:.

- pichurim, II, 397.

- précicuse, II, 403.

- de storax, II, 309.

- de Winter, III, 622-i47.

Éclevisses, IV, 275.

- de mer, IV, 276.

- de rivière, IV, 276.

Écuine de mer, I, 393.

Écureuils, IV, 25.

Edelforsite, I, 425.

Edingtonite, I, 428.

ÉnevTés, IV, 39.

Édredon, III, 651 .

Effraic, IV, 137.

Effraies, IV, 128.

Églantier sauvage, III, 29'.

- des jardins, III, 294.

Égrefin, IV, 181.

Eider, III, ;IV, 137.

Eisenkies, I, 260.

Eisen-apatit, I, 305.

Eisenpecherz, I, 277.

Eisen-silikat, I, 289.

Eisstein, I, 461 .

Ekébergite, I, 427 .

Elacoccoca verrucosc. II, 361.
Elaiomètre de Gobley, II, 59\%.

Elceis quineensis, II, 13?.

Élan, IV, 62.

Elaphis Esculapi, 1V, 155.

Elaphrium elemiferum, III, 523 ,

Elaphrium tomentosum, III, 529-53:.

Élasmose, I, 150.

Élasticité, I, 10.

Élatérite, I, 105.

Ėlectricité des minéraux, I, 53.

Electrum de Schlangenberg, I, 1'is.

Élédon, IV, 353.

Élémi de l'Aguayra, III, 526.

- du Bengale, III, 525 .

- du Brésil, III, 522.

- de Manille, III, 523.

- du Mexique, III, 523.

- en pains, 1II, 522.

Éléphant d'Afrique, IV, 43.

- des Indes, IV, 43.

Elephantasia macrocarpa, II, 142.

Elettari, II, 213.

Elettaria Cardamomum, II, 21:3.

- major, II, 214.

Ellébore blanc, II, 148 .

- fétide, III, 760 .

- à fleurs vertes, III, 760.

- noir, III, 757-760.

Embira, III, 745.

Emblica officinalis, II, $36 \mathbf{1}$

Embolite, I, 160.

Émeraude, 1, 3:5.

- du Brésil, I, 353.

- du Pérou, I, 3:30.

- orientale, I, 330 .

Émeri, I, 331.

Empleurum serrulalum, III, 556.

Emydes, IV, 145.

- clause, IV, 146.

- d'Europe, IV, 145.

Emys clausa, IV, 146.

- europiea, IV, 145.

- lutaria, IV, 146.

Encens, 11I, 516.

- de Cayenne, III, 531.

- de Suède, II, 25 .

- de Russie, II, 257.

Encre de sympathie, I, 2.6.

Encrines, IV, 374.

Endive, III, 16.

Endocarpe, II, 11.

Endosperme, II, 15.

Engelhardtia spicata, II, 30.3

Entozonires, IV, 327.

Épaulard, IV, 114 .

Eperlan, IV, 178.

Éphémères, IV, 221 .

Epicia, II, 247. 
Épiderme, II, 5.

Epidote, I, 427.

Epinard, II, 443.

- sauvage, II, 147.

Épinarde, IV, 174.

Épine blanche, III, 293.

- d'Espagne, III, 293.

- noire, III, 314.

- - d'Égypte, III, 40 4.

Épineux jaune, III, $56 \%$.

Épine-vinette, III, 732.

Épinoches, IV, 173.

Épistilbite, I, 429.

Eponges, IV, 383.

- arborescente, IV, 383.

- blonde de l'Al'clipel, 1V, 387.

- - de Syrie, IV, 386.

- botryoïde, IV, 383.

- brune de Barbarie, IV, 388.

- cendrée, IV, 383.

- ciliée, IV, 383.

- commune, IV, 386.

- - de la Havane, IV, 391.

- comprimée, IV, 383.

- de Gerby, IV, 387.

- de Sfax, IV, 388.

- de Venise, IV, 386-387.

- Zerby, IV, 387.

- diclotome, IV, 383.

- dure de Baliama, IV, 391.

- fine douce, IV, 384 .

- fine dure, IV, 386.

- - de la llavane, IV, 390.

- grecque, IV, 384.

- laineuse à clochetons, IV, 391.

- oculée, IV, 383.

- paniforme, IV, 383.

- papillaire, IV, 383.

- tuberculeuse, IV, ,991.

- usuelle, IV, 384.

Épurge, II, 342.

ÉQuisétacées, II, 8:.

Equisetum hyemale, II, 8't.

Equus Asinus, IV, 53.

- Cabullus, IV, 49.

Érable blanc, III, 607.

- champêtre, III, 606.

- nois, III, 607.

- plane, III, 606.

- rouge, III, ens.

- sycomore, III, 606 .

- à sucre, III, 606.

- de Virginie, III, 608.

Erbium, I, 314-325.

Erdmandel, II, 92 .

Ergot du blé, II, 54 .

- du diss, II, 54.

- du seigle, II, 46 .
Ergotatia arbotifaciens, II, 50.

Ergotine, II, 48.

Erica, III, 2.

Ericacées, III, 2.

Erinite, I, 228.

Eriodendion anfractuosum, III, 650.

Erithalis fruticosa, III, 5.37.

Erodium moschalum, III, 577.

Erpobclella vulgaris, IV, 28.3.

Eruca sativa, III, 691.

Erva Toustão, II, 450 .

Ervum Lens, III, 380.

Eryngium campestre, III, 213.

- maritimum, III, 214.

Emyophorus javana, III, 650.

Erysimurn Barbarea, III, 68?.

- officinale, III, 688.

Erythroa Centaurium, II, 5.,3.

- chilensis, II, 5.52.

Erythriline, II, 63 .

Erythrina Corallodendron, III, 345-380.

Erythrine, II, 63.

Erythloléine, II, 64 .

Enythroxylées, III, 598.

Erythroxylum Coca, III, 602.

Escargot des forêts, IV, 360 .

- des haies, IV, 360 .

- des jardins, IV, 360 .

— des vignes, IV, 358 .

Escharde, IV, 174.

Ésérine, III, 382.

Esenbeckia febrifuga, III, 5',2.

Esor Lucius, IV, 176.

Espadon, IV, 175.

Esquine de Bourbon, II, 99.

Essence de bergamote, III, 6.32.

- de bigarade, III, 633.

- de cannelle, II, 410 .

- de citron, III, 630.

- de géranium, III, 299.

- de girofle, III, 272.

- de menthe, II, 466.

- de muscade, II, 421.

- de macis, II, 421.

- de néroli, III, 63't.

- d'Orient, IV, 17 s.

- de petit grain, III, 633 .

- de Portugal, III, 635.

- de rose, III, 297.

- de térébentline, II, 260.

- de winter-green, III, 4.

Essonite, I, 349.

Estragon, III, 38.

Esturgeon commun, IV, 190.

- (grand), IV, 120.

Ésule, II, 343.

- ronde, II, 342.

Étain (extraction et propriétés), I, 199. 
Étain de bois, I, 198.

— oxydé, I, 196.

- sulfuré, J, 195.

Etamine, II, 10.

États d'agrégation, I, 7 .

Ethal, IV, 117.

Éthiops végétal, II, 25.

Étoiles de mer, IV, 374 .

Étourneaux, IV, 130.

Eucalyptus dumosa, II, 595.

- Globulus, III, 278.

- mannifera, II, 585.

- resinifera, III, 4:32.

- robusla, III, 432.

Euchlore de la vigne, IV, ?II .

Euchroite, I, 228.

Euclase, I, 324.

Eudialite, I, 320.

Eupatoire d'Avicenne, III, 63.

- chanvrin, III, 63.:

- de Mésué, III, 51.

Eupatoriacées, III, 62.

Eupatorium Aya-pana, III, 6'́ .

- cannabinum, III, 63.

- Dalea, III, 64.

- triplinerve, III, 64.

Euphorbe (gomme-ré:ine), II, 340.

- auricılé, II, 342.

- des auciens, II, 338.

- des Canaries, II, 338.

- officinal, II, 339.

Euphorbia antiquorum, II, 338.

- canariensis, II, 338.

- Esula. II, 343.

- helioscopia, II, 343.

- Ipecacuanha, II, 342: III, 96.

- Lathyris, II, 342.

- officinarum, II, 339.

- Peplis, II, 342.

- Peplus, II, 342.

- resinifera, II, 339.

Euphorbiacées, II, 335.

Euphorbia Lilchi, III, 599.

Euphotide, I, 492.

Euphraise, II, 486.

Euphrasia officinalis, II, 486.

Eurite, I, 492.

Euryangium Sumbul, III, 210.

Euxénite, I, 316.

Evernia vul,ina, II, C0.

Evodia Ravensara, II, 402.

Exccecaria A gallocha, II, 345; III, 338.

Exocet volant, IV, 176.

Exocetus volitans, IV, $1 ; 6$.

Exogonium Purga, II, 525.

Exostemma currbeum, III, 187.

- floribundum, III, 186.
Faba sativa, III, 380.

Faces et facettes, I, 13.

Fagara heterophylla, III, 563.

- octandra, III, 529.

- piperita, III, 563.

Fagus sylvatica, II, 283.

Faham, II, 235.

Fahan ou fahun, II, 235.

Fahlerz, I, 223.

Faine, II, 283.

Faisans, IV, 132.

Falco Halicelius, IV, 137.

- ossifraga, IV, 137.

Familles natureltes botaniques, II, 21 .

- (classification des), II, 16.

Fanons de baleine, IV, 115.

Farine de blé, II, 118.

Faskook, III, 245.

Fascicularia ocularis, IV, 337.

Fasogh, III, 245.

Fau, II, 283.

Faucon, IV, 127.

Faujassite, I, 429 .

Fausse coloquinte, III, 262.

Fausse orange, III, 262.

- oronge, II, 41 .

Fausse poire, III, 262.

Fausses chenilles, IV, 222.

Faux bourdons, 1V, 226.

- colombo, II, 553.

- jalap, Il, 530.

- persil, III, 219.

- piment, II, 510.

- jlatane, III, 606.

- pucerons, IV, 243.

- scorpions, IV, 265.

Fayalite, I, 289.

Fayard, II, 283.

Fécule amylacée, II, 115.

- d'arracacha, III, 218.

- de tolomane, II, 229.

Federenz, I, 175-177.

Fedia grandiflora, III, 77 .

Feldspath apyre, I, 343.

- potassique, I, 473-479.

- sodique, I, 473-480.

Feldspatlıs, I, 473-479.

Fenouil, III, 226.

- âcre d'Italie, III, 229.

- amer de Nîmes, III, 230-232.

- doux majeur, III, 229-231.

- - mineur, III, 230-23I.

- sauvage, III, 226.

- tortu, III, 235.

- vulgaire d'Allemagne, III, 229-231.

Fenouillet, III, 230. 
Fenugrec, III, 379.

Fer (son extraction), I, 293.

- (ses propriélés), I, 295.

- arséniaté cubique, I, 281.

- - résinite, I, 281.

- - rhomboïdal, I, 282.

- arsenical axotome, I, 264.

- arséniuré, I, 264.

- calcaréo-siliceux, I, 292.

- carbonaté, I, 272.

- cliromé, I, 283.

- liydraté, I, 271.

- consrétionmé. I, 272.

- - géodique, I, 27?.

- - pisiforme, I, 272.

- - oolitique, I, $27 \%$.

- hydroxydé, 271.

- liydrosilicaté de Suderoë, I, 290.

- météorique, I, 257.

- micacé, I, 270.

- natif, I, 257.

- oligiste, I, 267.

- écailleux, I, z70.

- oxydé, I, 266.

- - concrétiomné, I, 270.

- - terreux, I, 270.

- oxydulé, I, 266.

- phosphaté, I, 278.

- - mangano-lithifère, I, 301.

- - résinite, I, 280.

- résinite, I, 277.

- silicaté, 1, 289.

- spathique, I, 272.

- spéculaire, I, 270.

- sulfaté, I, 274.

- néoplase, I, 276.

- sous-sulfaté telreux, I, $27 \%$.

- - alcalifère, I, 278.

- sulfo-arséniaté, I, 278.

- sulfo-arséniuré, I, 265.

— sulfuré blanc, I, 263.

- - intermédiaire, 1, 259.

- bisulfuré cubique, I, 260,

- prismatique, I, 263.

- protosulfuré, I, 258.

- titanaté, I, 284.

- - octaédrique, I, 286.

Fergusonite, I, 315.

Ferolia guianensis, III, 537.

Feronia elephantum, III, 445.

Ferraria purgans, II, $: 96$.

Ferret d'Espagne, I, 271.

Ferula Assa foetida, III, 239.

- erubescens, III, 247.

- gummosa, III, 247.

- rubricaulis, III, 247.

- teterrima, III, 240.

- tingitana, III, 245.
Feskouk, III, 243.

Festuca quadridentata, II, 94.

Festucaria lentis, IV, 339.

Feuille, II, 9.

Fève, III, 380 .

- du Bengale, III, 286.

- du Calabar, III, 381.

- d'Egypte, III, 731.

- de Saint-Ignace, JI, 560 ; III, 26 ?.

- tonka, III, 377 .

Fèves pichurim, II, 398.

— pichola, II, 398.

- pichonin, II, 398.

Févier à trois épines, III, 358.

Fevillea cordifolia, III, 263.

- hederacea, III, 264.

- Marcgravii, III, 264.

Fevillea trilobala, 26' .

Fiber, IV, 26,

Fibrolite, I, 341.

Ficaire, III, 705.

FicoïdéEs, III, 251.

Ficaria ranurculoides, III, 70.5.

Ficus bengalensis, II, 319 .

- Carica, II, 317.

- elastica, II, 319.

- indica, II, 319.

- religiosa, II, 319.

- Sycomorus, II, 318.

Fiel de bœuf, IV, 98 .

Figues blanches, It, 319.

- grasses, etc., II, 319.

Figuier, II, 317.

- d'Adam, II, 320.

- des Hottentots, II, 320.

- des Indes, II, 320.

- maudit, II, 320.

- sycomore, II, 318.

Filaires, IV, 33 i.

Filuria nedinensis, IV, 334.

- oculi, IV, 335.

Filet d'étamine, II, 10.

Filipendule, III, 306 .

Filoselle, IV, 240 .

Fimpi, III, 533.

Fine grey bark, III, 161 .

Fischtérite, I, 335.

Fissirostres, IV, 129.

Flamants, IV, 135.

Flamme, I, 58.

Flet, IV, 179.

Fleur, II, 10.

- de Turquie, II, 448.

Fleurs de cannellier, II, 408.

- de chardonnette, III, 20.

Flindersia amboinensis, III, 597.

Flores cassiae, II, 408.

Flos ferri, I, 416 . 
Fluate de chaux, I, 399.

Fluocérine, I, 311 .

Fluorine, I, 399 .

Flnorure alumino-sodique, I, 461.

- de calcium, I, 399.

Fœniculum dulce, III, 228.

- mediolanense, III, 227.

- officinale, III, 228.

- piperitum, III, 2:8.

- vulgare, III, 227.

Foliole, II, 10.

Follicule, II, 13.

Follicules d'Alep, III, 368.

- de Moka, III, 368.

- de la palte, III, 368.

- de séné, III. 368.

- de Syrie, III, 368.

- de Tripoli, III, 368.

Fonte, I, 295.

Formes cristallines, I, 13.

- de la molécule intégrante, I, 14.

- primitives, I, 14.

- secondaires, I, 14.

Formica rufu, IV, 225.

Fougère mâle, II, 68 .

Fovgères, $\mathrm{II}, 66$.

Foulques, IV, 135.

Fouraha, III, 621.

Fourmilier, IV, 40.

Fourmis, IV, 224.

- fauves, IV, 225.

- rouges, IV, 225.

Fous, IV, 136.

Fragaria vesca, III, 303.

Fragon épineux, II, 168.

Frai, IV, 170.

Fraisier commun, 111, 303.

- en arbre, III, 5 .

Framboisier, III, 302.

Franklinite, I, 368.

Frasera Walteri, 553.

Fraxinelle, III, 556.

Fraxinus chinensis, IV, 250 .

- excelsior, II, 582.

- Ornus, II, 583.

- rotundifolia, II, 583.

Frégates, IV, 136.

Frêne élevé, II, 582.

Friganes, IV, 221.

Fritillaire impériale, II, 153.

Froment, II.

Fruits, II, 11.

- agrégés, II, 13.

Frutex terrioilis, II, 460.

Fucus crispus, II, 32.

- serratus, II, 26.

- siliquosus, II, 26.

- vesiculosus, II, 24.
Fulgore, IV, 242.

Fumaria capreoluta, III, 702.

- media, III, 702.

- officinalis, III, 701.

- Vaillantii, III, 702.

Fumariacées, III, 700.

Fumeterre grimpante, III, 702.

- moyenne, III, 702.

- officinale, III, 701.

- de Vaillant, III, 702.

Funicule, II, 15.

Furcroya, II, 188.

Fuseaux, IV, 360 .

Fusogh, III, 245.

Fustet, III, 490 .

\section{G}

Gabbro de Corse, I, 492.

- de Gênes, I, 49:.

Gabronite, I, 471 .

Gadolinite, I, 316.

Gadus Aglefinus, IV, 181.

- Callarias, IV, 181.

- carbonarius, IV, 181.

- Lotta, IV, 181.

- Merlucius, IV, 181.

- Molus, IV, 181.

- Morrhua, IV, 180.

Gahnite, I, 386.

Gajacum arboreum, III, 553.

- officinale, III, 546.

- sanclum, III, 551.

Galactodendrum utile, II, 328 .

Galanga de la Chine, II, 200.

- grand, II, 201.

- de Java, II, 201.

- léger, II, 201.

- de l'Inde, II, 201.

- major, II, 201.

- minor, II, 200.

- officinal, II, 200.

- petit, II. 200.

Galba des Antilles, III, 618 .

Galbauum, III, 246.

- mou, III, 247.

- sec, III, 248.

- officinale, III, 248.

Galène, I, 173.

Galipea cusparia, III. 558.

- officinalis, III, 558.

Galipot, II, 262.

Galium Aparine, III, Si.

- luteum, III, 84.

- Mollugo, III, 84.

Galle blanche, II, 290.

- corniculée, II, 293. 
Galle couronnée d'Alep, II, 292.

- d'Alep, II, 290.

- de Bouklıara, III, 502.

- de Chine, III, 502.

- d'églantier, III, 295.

- de France, II, 295.

-.- de Hongrie, II, 293.

- d'Istrie, II, 293.

- du Levant, II, 287.

- de myrobalan, III, 286.

- du pétiole de chêne, II, 296.

- de pistachier, III, 502.

— de Smyrne, II, 290.

- de térébinthe, III, 499.

- en articliaut, 294.

- en cerise, II, 297.

- en groseilles, II, 297.

- marmorine, II, 293.

- noire, II, 290.

- ronde de chêne rouvre, II, 296.

— - de feuilles de chêne, II, 296.

— - de l'yeuse, II, 295.

- verte d'Alep, II, 290.

Galle-insectes, IV, 24 .

Gallinace, I, 492.

Gallinacés, IV, 131.

Gallizinite, I, 286.

Gallon de Hongrie, II, 293.

- de Piémont, II, 293.

Gallus bankiva, IV, 138.

Galuchat, IV, 197-200.

- faux, IV, 198.

Gambir, III, 406.

- aromatique, III, 424.

- brun celluleux, III, 422.

- hémisphérique, III, 422.

- circulaire estampé, III, 424.

- cubique, III, 419.

- amylacé, III, 423.

- en aiguilles, III, 422.

Garance, III, 81.

Garcinia cambugia, III, 611-616.

- cornea, III, 609.

- malabarica, III, 609.

- Mangostana, III, 609 .

- Morelli, III, 611-612.

Garipot, II, 262.

Garo, III, 338.

Garou, II, 387 .

Gastenonycètes, II, 38.

Gastéropodes, IV, 357 .

- cyclobranches, IV, 358.

- hétérobranches, IV, 358.

- inférobranches, IV, 358.

- nudibranches, IV, 358.

- pectinibranches, IV, 358 .

- pulmonés, IV, 358.

- scutibranches, IV, 358 .
Gasténopodes tectibranches, IV, 358.

- tubulibranches, IV, 358.

Gasterosteus, IV, 174.

- aculeatus, IV, 17 '.

Gateado, III, 539.

Gattilier, II, 482.

Gaude, III, 678.

Ganja, II, 33\%.

Gaultheria procunbers, III, 'f.

Gavials, IV, 148.

Gayac à couches irrégulières, III, 5is.

- à fruit tétragone, III, 551.

- à odeur de vanille, III, 518 .

- de Caracas, III, 553.

- du Chili, III, 553.

- officinal, III, 546.

- (écorce de), III, 548-552.

- (résine de), III, 549-552.

Gayacan, IlI, 553.

Gay-Lussite, I, 457 .

Gaz des marais, I, 111.

Gazelle commune, IV, is.

Geais, IV, 130.

Gedwar, II, 209.

Gehlénite, I, 427.

Gélatine animale, IV, 82.

Gelidium corneum, II, 34.

Gélose, II, 3't.

Gemmule, II, 15.

Génestrolle, III, 358.

Genette commune, IV, 21 .

Genêt à balais, III, 359 .

- commun, III, 359.

- d'Espagne, III, 359.

- herbacé, III, 359.

- purgatif, III, 359.

- des teinturier's, III, 358.

Genévrier comnun, II, ?:?!)

- des Bermudes, II, 242.

— de Virginie, II, 242.

- oxycèdre, II, 240.

Gengeli, II, $5 i 6$.

Genièvre (baie de), II, ?40

Génipi bâtarł, lII, 47 .

- blanc, IJI, 46.

- musqué, III, 4 ?.

- noil, III, 4(i.

- vrai, III, 45.

Génisse, IV, 82.

Genista juncel, III, 359.

- purgans, III, 359.

- sagittalis, III, 359.

- scoparia, III, 359.

- tinctoria, III, 358.

Gentiana Centaurium, II, $5.5 \%$.

- Chirayta, II, 555.

- lutea, II, 551.

- punctara, II, 5is?. 
Gentiana purpurea, II, 552 .

Gentianacées, II, 550 .

Gentiane jaune, II, 5.51 .

Géocorizes, IV, $\$ 41$.

Géocronite, I, $175-177$.

Geofrrées, III, 323.

Geoffrée de la Jamaïque. III, 332.

- de Surinam, III, 333.

Genffroya inermis, III, 332.

Géraniacées, III, 575.

Géranium des prés, III, 570 .

- sanguin, III, 576.

Geranium pratense, III, 576.

- maculatum, III, 577.

- robertianum, III, 576.

- sanguineum, III, 576.

Gerbilles, IV, 25.

Gerboises, JV, 25.

Gerboisiens, IV, 25.

Germons, IV, 175.

Germandrée d'eau, Il, 479.

- femelle, II, 478.

- maritime, 478.

- petit-chène, II, 478.

- sauvage, II, 479.

Geum urbanum, III, 305.

Ghandiroba, III, 263.

Ghitta Jemou, III, 610.

Ghorakn, III, 616.

Ghorka-pulli, III, 616.

Ghuilljir, III, 17.

Gibbar, IV, 118.

Gibbon, IV, 13.

Gibbsite, I, 332.

Gieseckite, I, 472.

Gigartina Helminthocorton, II, 30.

Gigeri, II, 546.

Gillenia trifoliata, III, 96.

Gingembre blanc, II, 20'.

- gris, II, 203.

- sauvage, II, 205.

Ginger.grass, II, 101.

Ginseng, III, 200 .

Giobertite, I, 380.

Girafe, IV, 74.

Girasol, I, 8\%.

Giraumon, III, 262.

Girofle des Moluques, III, "ĩ2.

- anglais, III, 272.

- de Bourbon, III, 272.

- de Cayenne, III, $27 \%$.

Giroflier, III, 271.

Gismondine, I, 428.

Gisement des minéraux, I, 60.

Glaciale, III, 252.

Glairine, I, 513-515.

Glans unguentaria, III, 386.

Gland de chêne, II, 286.
Glaubérite, I, 452.

Glaucier jaune, III, 705.

Glaucium flavum, III, 705.

- futvum, III, 706.

- corniculatum, III, 706.

Glauconie, I, 492.

Glankolite, I, 426.

Glayeul des marais, II, 192.

- puant, II, 192.

Glechoma hederacea, II, 475.

Glimmersehiefer, I, 493.

Globulaire turbith, II, 460 .

Globularia Alypum, II, 460.

Globulariées, II, 459.

Glossine morsitans, IV, 253.

Glossiphonies, IV, 297.

Gloutons, IV, 16.

Glucine, I, 320 .

- aluminatée, I, 322.

- silicatée, I, 323.

Gluten de froment, II, 110.

Glutine, II, 110.

Glycymhiza echinata, III, 327.

- glabra, III, 326.

Gnaphalium dioicum, III, 35.

Gneiss, I, 493.

Grou, IV, 76.

Gobe-mouches, IV, 129.

Goëlands, IV, 135 .

Gombo, III, 648.

Gommart, III, 525.

- balsamifère, III, 526.

Gomme d'acajou, III, 492.

- adragante, III, 446.

- ammoniaque, III, 243.

- - de Tanger, III, 245.

- arabique, III, 439.

- astringente de Butea, III, 428.

- - de Gambie, IJI, 408.

- d'Australie, III, 445.

- de Barbarie, III, 443.

- de Bassora, III, 450-453.

- du cap de Bonne-Espérance, III, 445.

- de cerisier, III, 318.

- élastique, II, 347.

- éléphantine, IIl, 444.

- de France, III, 413.

- Gonakée, III, 441.

- gutte, III, 610.

- - en bâtons, III, 614 .

- - en gâteaux, III, 615 .

- - dı cambogia, III, 616.

- de l'Inde, III, 444.

- - pelliculée, III, 444.

- kutera ou kutira, III, 453-635.

- lignirode, III, 443.

- look, III, 46\%.

- de Madagascar, III, 445. 
Gomme mamelonnée, III, 4t?.

- de nopal, III, 252-453.

- olampi, III, 46't.

- d'olivier, II, 593.

- pelliculée, III, 442.

- pseudo adragante, III, 4:0.

- Sadrabreida, III, 411.

- Salabreda, III, 441.

- sapote du Chili, III, 446.

- de Gassa, III, 450.

- du Sénégal, III, 441.

- séraplique, III, :42.

- de Sicile, III, 413.

- turcique, III, $\mathbf{1} 1$.

- verte, III, 412.

Gonmes-résines d'ombeclifìres, III, $23 \%$. Gommier blanc, III, 398.

- rouge, III, 390.

- - gonaké, III, 39'.

Gomplıolite, I, 493.

Gomphrena of ficinalis, III, 623 .

Goniomètre, I, 16.

Googol, gooyul, googula, III, 516-525.

Gorgone, IV, 380.

Gossypium arboreum, III, 650.

- herbaceum, III, 650.

- indicum, III, 650.

- racemosum, III, 650.

Goudron, II, 26't.

- de louille, II, 265.

Gouet, II, 86 .

Goujon, IV, 175.

Gourde en massue, III, 261.

- trompette, III, 261.

- des pèlerins, III, 261.

Gousse, II, 13.

Goyaves, III, 268.

Gettania, II, 599.

Gracilaria compressa, II, 36.

- lichenoicles, II, 3t.

Graine, II, 15.

- d'ambrette, III, 617.

- d'Andrinople, III, 542.

- d'Avignon, ill, 541.

- d'écarlate, IV, 249.

- des Moluques, II, 359.

- de Morée, III, 512.

- de paradis, II, 214.

- de Perse, III, 542.

Grains de Tilly, II, 359.

Graisse de porc, IV, 46.

Graminées, II, 93.

Grana actes, III, 194.

- zelim, III, 745.

Granatées, III, 279.

Grand-duc, IV, 137.

Grand paon de nuit, IV, 235.

Grand-soleil, III, 58.
Grand-yoiliers, IV, 135.

Granite, I, 493,

Granite stannifère, I, 49 is.

Granitelle, I, 494.

Glaphite, I, 89.

Grass oil of Namur, II, 98.

Grateron, III, 84.

Gratiole, II, 485.

Gratiola officinalis, II, 485.

Graugultigerz, I, 221.

Groustein, I, 494.

Grauwacke, I, 494.

- ì gros grains, I, 489 .

Green-leart, II, 399.

Greenovite, I, 424.

Greisen, I, 494-495.

Grémil, II, 519.

Grenade, III, 280.

Grenadier, III, 279.

Grenadille de Cuba, III, 35 4.

- jaune, III, 554.

- viaie, III, 553.

Grenat almandin, I, 347 .

- aplome, I, 350.

- calcaire, J, 319.

- cliromo-calcaire, I, 350.

- ferreux, I, 347.

- ferrico-calcaire, I, 350.

- grossulaire, I, 349.

- manganésien, I, 348 .

- - chromifère, I, 349.

- magnésien, I, 348 .

Grenats, I, 346.

Grenétine, IV, 91.

Grenouilles, IV, 16t.

- vertes, IV, 167.

Grès, I, 494.

- rudimentaire, I, 50t.

Griffe de girofle, III, 273.

Griffous, IV, 127.

Grimpereaux, IV, 130.

Grimpeurs, IV, 131.

Griottier, III, 316.

Grondin rouge, IV, 173.

Gros-becs, IV, 130.

Groseillier rouge, III, 250.

- noir, 251.

- à maquereau, III, 251.

Grosse rave, III, 6!) 3 .

Grossulaire, I, 3:49.

Grossulariéfs, III, 250.

Gruau d'avoine, II, 113.

Grues, IV, 134.

Grunstein, I, 495.

Guajacum officinale, III, 546.

- sanctum, JII, 5.51.

Guaco, III, 65.

Guanaco, IV, 57. 
Guano, I, 484 .

Guaranhern, II, 596.

Guarana, III, 600.

Guarea trichilioides, III, 593.

- purgans, III, 593.

Guarea cathartica, III, 59?.

Guazumu ulmifolia, II, 315.658.

Guède, III, 690.

Guenons, IV, 13.

Guépard, IV, 23.

Guêpiers, IV, 130.

Gui, III, 195.

Guibourtia copallifera, III, 465.

Guimauve officinale, III, 645.

Guilno, II, 96.

Guirapariba, II, 549.

Guizotia oleifera, III, 60.

Gum animi, III, 457 .

Gunjah, II, 332 .

Gurnard, IV, 173.

Gutta-gambra, III, 610.

Gutta percha, II, 599.

Guttce fera vera, III, 612.

Guttifieres, III, 608.

Gymnocladus triacanthos, III, 35.

Gymnote électrique, IV, 189.

Gynandropsis pentaphylla, III, 6.79.

- triphylla, III, 679 .

Gypse, I, 402.

Gypsophyllı paniculata, III, 663.

- Struthium, III, 663.

Gyrophora pustulata, II, 59.

\section{$\mathbf{H}$}

Haarkies, I, 244.

Habseli, III, 745.

Habzelia ethiopica, IJI, 744.

- aromatica, III, 745 .

Hacchich, III, 332.

Homanthus coccineus, II, 187.

- toxicaria, II, 187.

Homatoxylum campechianum, III, 34l.

Hæmopis clevaline, IV, 290.

Homopis nigra, IV, 28\%.

- sanguisorba, IV, 290.

- sanguisuga, IV, 290.

Hagenia abyssinica, III. 308 .

Haidingérite, I, 277, 422.

Haje, IV, 162.

Haléponges, IV, 383.

Halisponyin, IV, 383.

Halliroé à côtes, IV, 399.

Halloysite, I, $357,358$.

Halogetum tamariscifolium, II, 448.

Hamsters, IV, 25.

Hannebane, II, 500.
Hanneton, IV, 199.

Haplataris Costus, JII, 31 .

Hareng, IV, 178.

Haricot, III, 380 .

Harles, IV, 136.

Harmotome, I, 44.3.

Harpies, IV, 127.

Hashish, II, 322.

Hatchettine, I, 108.

Hausmanite, I, 299.

Haüyne, I, 476 .

Hebradendron cambogioidés, III, 612.

Heckiak, IV, 54 .

Hedenbergite, I, 429, 430.

Hedenbergite de 'Tunaberg, I, 289.

Hedera Helix, III, 197.

Hedwigia balsamifera, III, 528.

HÉDYSARÉES, III, 322.

Hélayiens, IV, 25.

Hélamys du Cap, IV, 25.

Helénine, III, 61.

Helianthus annuus, III, 57.

- tuberosus, III, 58.

Helichrysum argenteum, III, 36.

- orientale, III, 36.

- Stcochas, III, 36.

Helix aspera, IV, 360 .

- hortensis, IV, 360.

- naticoides, IV, 360 .

- nemoralis, IV, 360.

- pomatio, IV, 358.

HELLÉBORÉES, III, 752.

Helleborus fœtidus, III, 760.

- niger, III, 758.

- orientalis, III, 758.

- viridis, III, 760 .

Hellenia chinensis, II, 200.

Helminthocorton, II, 30.

Helonias officinalis, II, 150 .

Helxine, III, 26.

Hemidesmus indicus, II, 185.

Hémione, IV, 54 .

Hémiptères, IV, 240.

- hétéroptères, IV, 241.

- homoptères, IV, 241.

Hémitrène, I, 495.

Heracleum gummiferum, III, 24:.

Heracleum Panaces, III, 249.

IIerbe des Canaries, etc., II, 60.

- aux chantres, III, 688 .

-- aux charpentiers, III, 51.

- aux chats, II, 474, 478.

- à éternuer, III, 52.

- à l'esquinancie, III, 576.

- de la paralysie, II, 458.

- aux perles, II, 519.

- aux puces, II, 454 .

- à Robert, III, 576. 
IJerbe sacrée, II, 481.

- de Sainte-Barbe, III, 688.

- de Saint-Christophe, III, i6\%.

- aux tanneurs, III, 603.

- de la Triuite, HI, 673.

Hérissons, IV, 15.

Hermodacte, II, I 46 .

Héron, IV, 13'.

- aigrette, IV, 137.

Hérons, IV, 134.

Herschellite, I, 47\%.

Hétérodons, IV, 153.

Hétérosite, I, 30t.

Hêtre, II, 283.

Heuclelotia africana, 111, 515.

Heulandite, 1, 429.

Hibiscus Abelmoshus, III, 617.

- esculentus, III, 618.

- pheniceus, III, 649.

- Rosa-sinensis, III, 64\%.

- syriacus, III, 649.

Hibou, IV, $13 \%$.

Hiboux, IV, 128.

Hièble, III, 19' .

Hile, II, 15.

Hingisèh, Ill, 239.

Hippobdella sanguisuga, IV, 290.

Hippocastanées, III, 598.

Hippomane Mancenilla, II, 435.

Hippomarathrum, III, 226.

Hippopotame, IV, 45.

Hirondelle, IV, 370.

Hirondelles, IV, 130.

- de mor, IV, 135.

HIIUdiNÉS, IV, 281.

Hirudo chlorina, IV, 308.

- chlorogastra, IV, 308 .

- interrupta, IV, 308.

- medicinalis, IV, 291.

- flava, IV, 308.

- grisea, IV, 306.

- octoculata, IV, 28:3.

- nigrescens, IV, 306.

- tessellata, IV, 308.

- viridis, IV, 306.

- mysomelas, IV, 309.

- sanguisuga, IV, 287, 290 .

- sanguisorba, IV, 290.

- troctina, IV, 308.

- verbana, IV, 309.

- vorax, IV, 287.

- vulgaris, IV, 283.

Hisingérite, I, 291.

Hispanille, III, 537.

Hoa-tsiao, III, 563.

Hochequeues, IV, 129.

Hockiak, IV, 5 t.

II. O. Crown-bark, III, 1 ico.
Hlog-gum, HI, 489.

Hoitziloxitl, III. 473.

Holoturies, IV. 374.

Holoturia edulis, IV, 3i千.

- guamensis, IV, 374.

- tubulosa, IV, 37t.

Homard, IV, 276.

Homme, IV, 8 .

- race caucasique, IV, 11.

- éthiopique, JV, 11.

- mongolique, IV, 11.

- race nègre, IV, 11 .

Honigstein, I, 332.

Hordeum distichon, II, 111.

- hexastichon, II, 111.

- vulgare, II, 111.

Hornblende, I, 427, 434.

Hornblendeschiefer, I, 435.

Hornstein fusible, I, 483.

Hornstein infusible, I, 80.

Houblon, II, 333.

Houille, I, 94.

- compacte, I, 96.

- papyracée, I, 97, 106.

Houx apalachine, III, 54'.

- commun, III, 5i3.

Huile de baleine, IV, 116.

- de cachalot, IV, 117.

- de cade, II, 264.

- de cajeput, III, $27 \%$.

- de camplire, II, 418.

- de cétacés, IV, 116.

- de coco, II, 131.

- de croton, II, 360.

- de foie de morue, IV, 181.

- de raie, IV, 184 .

- d'Illipé, II, 597.

- de Liquidambar, II, 306.

- de Macassar, III, i43.

- de marmotte, III, $8,314$.

- de marsouin, IV, 116.

- d'œillette, III, 711.

- d'olive, II, 588.

- de palme, II, 132.

-- de poisson, IV, 181, 187 .

- de poix, II, 264.

- de ricin, II, 355.

Huître commune, IV, 36't.

- comestible, IV, 36t.

Huîtres, IV, 362.

Huîtriers, IV, 134.

Hurrias, IV, 153.

IIumboldtilite, I, 427.

Humulus Lupulus, II, 333.

Huppes, IV, 130.

Hura crepitanis, II, 436.

Hureaulite, I, 304.

Hutchinsia atro-rubescens, II, :2i. 
Hyacinthe de Ceylan, I, 319.

- de Compostelle, I, 78.

- (plante), III, 757.

Ilyacinthus orienialis, II, 153.

Hyalite, I, 82.

Hyalomicte, I, 495.

Hyalosidérite, I, 389.

Hydraires, IV, 375.

Hydrargilite, I, 332 .

Hyduaires, IV, 376.

Hydres, IV, 378.

Itydrobucholzite, I, 357 .

Hydrocorizes, IV, 241.

Hydrocotyle d'Asie, III, 215.

Hydrocotyle asiatica, III, 215.

Hydro!yte, I, 428.

Hydromys, IV, 25.

Hydrophane, I, 83.

Hydrophile, IV, 199.

Hydropliyte, de Taberg, I, 395.

Hyènes, IV, 22.

Hymencea Courbaril, III, 357, 457, 160.

- verrucosa, III, 457.

Hyménomycètes, $\mathbf{l l}, 39$.

Hyménoptères, IV, 222.

Hyménoptèles térébrants, IV, 2:3.

- porte-aiguillon, IV, 223.

Hyoscyamus albus, II, 500 .

- aureus, II, 500.

- niger, II, 498.

Hyperanthera Moringa, III, 387.

HYPÉriciNéES, III, 624.

Hypericum Androscemum, III, 624 .

- guianense, III, 624.

- perforatum, III, 625 .

Hypersthène, I, 389 .

HYPHOMY Ċ̇TES, Il, 37.

Hypociste, II, 81 .

Hypoglosse, II, 169.

Hypostilbite, I, 429.

Hylaceum, IV, 35.

Hyrax capensis, IV, 35 .

Hysope, II, 471.

IIyssopus officinalis, II, 471.

\section{I}

Ibirace, II, 596.

Ibirapilanga, III, 340 .

Ibis, IV, 134, 137.

Icica altissima, 402.

- Aracouchini, III, 534.

- Carana, III, 523.

- decandra, III, 531.

- guianensis, III, 531.

- heptaphylla, III, 532 .

Icicariba, III, 522.

- Tacamahaca, III, 529, 531. lcicariba, III, 522.

Icosaèdre, I, 25.

Ichthyocolle, IV, 191.

- fausse, IV, 192.

Ichu cascarilla, III, 142.

Idocrase, I, 4:7.

If, II, 237.

Ignames, II, 186.

Ignutia amara, 1I, 560 .

Iguana delicatissima, IV, 151.

Iguane, IV, 151 .

Iles de col'ail, IV, 376.

Ilex aquifoli.เm, III, 54:3.

- paraguariensis, III, 544.

- vomitoria, III, 544.

ILICINÉES, III, 542.

ILlictéEs, II, 747.

Illicium anisalum, III, 747.

- floridarum, elc., III, 717.

Ilménite, I, 284.

Ilvaïte, I, 292.

Imnortelle blanche, III, 36.

- jaune, III, 36.

Impatiens noli-tangere, III, 578.

Impératoire, III, 211.

Imperatoria Osíruthium, III, 211.

Indianite, I, 427.

Indicolite, I, 253.

Indigo, III, 481.

- blanc, III, 486 .

- Guatimala, III, 483.

Indigofera Anil, III, 481.

- argentea, III, 481.

- disperma, III, 481.

- tinctoria, III, 481 .

Indigotine, III, 486 .

INFUSOIRES HOMOGÈES, IV, 378.

Inga Avaremo-temo, III, 330.

- Barbatimão, III, 330.

- Marthce, III, 399.

- Sassa, III, 450.

Inquartation, I, 146.

INSECTES, IV, 201.

- sUCEURS, IV, 255.

- parasites, IV, 257.

Insectwores, IV, 15.

Inula Helenium, III, 60.

In uline, III, 61 .

Inzica, III, 330 .

Iolite, I, 395.

Ionidium brevicaule, III, 95.

- Ipecacuanhe, III, 9 í.

- Itouboa, III, 95.

- Marcutii, III, 95.

- parviflurum, III, 95.

Ipécacuanlıa amylacé, JII, $5 \%$.

- annelé gris rouge, III, 87. 
Ipecacuanha annelé mineur, III, 85.

- noirâtre, III, 86.

- de Carthagène, III, 89.

- blanc, III, 92.

- faux des Antilles, III, 96.

- - del'Amérique septentrionale,111,96.

- - de Bourbon, III, 96.

- - du Brésil, III, 94, 95.

- - dé Cayenne, III, 95.

- noir, III, 90.

- officinal, III, 85 .

- ondulé, III, 92 .

- strié, III, 90.

Ipomæea Jalapo, II, 5:24.

- macrorhiza, II, 521.

- operculata, II, 534 .

- orizabensis, II, 527.

- Purga, Hayne, II, 525.

- Quamoclit, II,

- simulans, II, 530 .

- Turpethum, II, 535.

In11ÉES, II, 190.

Iridium, I, 142.

Iris cominun, II, 190 .

- faux acore, II, 19?.

- fétide, II, 192.

- de Florence, II, 191.

- jaune, II, 192.

- des marais, II, 192.

Iris florentiva, II, 191.

- foctidissima, II, 192.

- germanica, II, 190.

- pallida, 1I, 192.

- pseudo-acorus, II, 192.

- tuberosa, II, 147.

lrvingia Barteri, III, 573.

Isutis tinctoria, III, 483-690.

Isérine, I, 286.

Isidium corallinum, II, (6:).

Isis nobilis, IV, 380.

Isonandra Gutta, II, 599.

Isopodes, 1V, 277.

Isopyre, I, 426.

Itacolumite, I, 496 .

Itinérite, I, 428, 471.

Iules, IV, 259.

Irette, II, 480 .

- musquée, II, 480.

Ivoile, IV, 43.

- végétal, II, 142.

Ivraie, II, 9 千.

Ixinè, III, 26.

Ixode, IV, 266.

Jabirus, IV, 134.

Jaborandi, III, 564 .
Jaca, II, 327,

Jacamars, IV, 1:31,

Jacanas, IV, 135.

Jacumas, IV, 137.

Jacaranda brasiliensis, II, 5ı .

- Cabiuna, III, 3i8.

- Caroba, III, 547.

- Copaia, II, 547.

- Tam, III, 348.

Jacée des prés, III, :2'.

Jacinthe, II, 153.

Jack-wasd, II, 3:7.

Jacquier, II, 327.

Jade ascien, I, 433.

- néphrétique, I, 43:3.

- oriental, I, 433.

- tenace de Saussure, 1, 13 í.

Jagual, IV, 23.

Jais, I, 99.

Jalap faux, II, 531.

Jalap digité, II, 5:9.

Jalap fusiforme, II, 5:2\%.

- à odeur de rose, II, 53̈l.

- officinal, II, 52:3.

- tuidéreux, II, 5:23.

Jambonneaux, IV, 370.

Jambose, III, 26 (i8.

Jamesonite, I, $175,178$.

Janipha Munihot, II, 319.

Japicanga, II, 182.

Jaquamarts, IV. 131.

Jargon de Ceylan, I, $31 \%$.

Jasmin d'Arabie, II, 581 .

- d'Espagne, II, 581.

- jonquille, II, 581 .

- officinal, II, 581 .

- de Virginie, I1, 550.

JASUINÉES, II, 580.

Jasminum grandiflorum, II, 581.

- odoratissimum, II, 581.

- officinale, II, 581 .

- Sambac, II, 581.

Jaspe, I, 80.

- schisteux, I, 501 .

Jatamansi, III, 78.

Jatropha Curcas, II, $35 \%$.

- gossypifolia, II, 356 .

- multifida, II, 358.

Jaune indien, IV, 99.

Jayet, I, 99.

Jeffersonia diphylla, III, 734.

Jérose hygronétrique, III, 687.

Jetaïba, III, 456.

Jonc aromatique, II, 97.

Josse, 1Il, 191.

Joubarbe des toits, III, 253.

- (petite), III, 254.

Joues cuirassées, IV, 173. 
Jubarte des Basques, IV, 115.

Jugeoline, II, 5 i6.

JugLANDÉES, II, 300.

Juglans cinerea, II, 30:.

- regia, II, 301.

Jujube, III, 539.

Juniperus bermudima, 11, 242.

- communis, II, 240.

- Lycia, III, 516.

- Oxicedrus, II, 240.

- Sabina, 11, 241.

- virginiana, II, 212.

Jurema, III, 330.

Jusquiame blanche, II, 500.

- dorée, II, 500.

- noire, II, 498.

Juvia, III, 269.

\section{li:}

Kadoukni, III, 286.

Kageneckia oblonga, 11I, 310.

Kamala, II, 369.

Kala-jira, III, 65-764.

Kati, II, 448.

Kaneelstein, I, 349.

Kanguroos, IV, 41.

Kaolin, I, 358, 480.

Karabé, I, 109.

Karsténite, I, 401.

Kaskti, III, 417.

Kassu, III, 40R, 413.

Katha-suffaid, III, 414.

Kato inschi Kua, II, 205.

Kawa, II, 276.

Katran rouge, II, 455 .

Kauri, II, 267.

Keil ou Khil, II, 220.

Kentrophyllum lanatum, III, 23.

Kérargyre, I, 160.

Kérasine, I, 189.

Kératite, $\mathbf{I}, 80$.

Ker'mès animal, IV, 249.

- natif, I, 132.

- végétal, II, 289).

Ketmie rouge, III, 619.

Whrath, III, 403.

Khadira, III, 403.

Khaya senegalensis, III, 595.

Kheir, III, 403.

Kieselschiefer, I, 496, 501.

Kilbrickénite, I, 175, 176.

Kikekunemalo, III, 46í.

Killinite, I, 473.

King-wood, III, 350.

Kinos, III, 408, 426.

- d'Amboine, III, 429 .
Kinos de Botany-Bay; III, 433.

-- du Brésil, III, 438.

- de la Colombie, III, 435.

- de l'Inde, III, 430.

- de la Jamaique, III, 434.

- de New-York, III, 4:8.

- de la Vera-Cruz, III, 439.

Kirschenwasser, III, $3\lfloor 5,582$

Kirwanite, I, 428.

Klaprothine, I, 337 .

Knautia arvensis, III, 67.

Kuébélite, I, 388, 359.

Kobellite, I, 193.

Koboldine, I, 251.

Korarima, II, 220.

Koss, IV, 191.

Koumiss, IV, 96.

Kouri-gum, Il, $26 \%$.

Krameria ixina, III, 669.

- lanceolata, III, 669.

- spartioïdes, III, 669 .

- tomentosa, III, 668.

- triandra, III, 666.

Krisuvigite, I, 237.

Kua, II, 210.

Kueni, III, 408.

Kumıs, IV, 96.

Kupfer-nickel, I, 242.

Kutira, III, 635.

$\mathbf{L}$

LABIÉES, II, 454, 460.

Labradorite, I, 426, 422, 481 .

Labrax Lupus, IV, 172.

Lac-dyc, II, 322.

Lac-laque, II, 322.

Lacerta agilis, IV, 151.

- Scincus, IV, 150.

LACERTIENS, IV, 148.

L acto-butyromètre, IV, 94 .

Lactoscope, IV, 93.

Lactuca capitata, III, 12.

- sativa, III, 16, 14.

- sylvestris, III, 14.

- virosa, III, 14.

Lactucarium, III, 13.

Ladanum de Crète, III, 671.

- d'Espagne, III, 674.

LEMODIPODES, IV, 273.

Laîche des sables, II, $9:$.

Lait, IV, 88.

— d'ânesse, IV, 91.

- de brebis, IV, 91.

- de chèvre, IV, 91.

- de fermine, IV, 91.

- de jument, IV, 91. 
Lait de vache, IV, 91.

Laitier, I, 294.

Laitue officinale, III, 12.

- romaine, III, 14 .

- sauvage, III, 14.

- vireuse, III, 1',

Lagenaria vulgaris, III, 26?.

Lagostomes, IV, 25.

Lagotis, IV, 25.

Lamas, IV, 57.

LAMELlirostres, IV, 136.

Laminaire saccliarine, II, 26.

Laminaria digitata, II, 27.

- saccharina, II, 26.

Lamium altum, II, 47\%.

Lamproie marine, IV, 201.

Lampyre, IV, 208.

Lampujum majus, II, 205.

Lanarkite, I, 188.

Langoustes, IV, 275.

- commune, IV, 275.

Languas chinensis, II, 200.

Lanhoa, III, 637.

Lanthane, I, 311.

Lapis lazuli, I, $4 \pi 4$.

Lappa major, etc., III, 18.

- minor, III, 19.

- tomentosa, III, 19.

Laque en bâtons, II, 321.

- en écailles, II, 321.

- en grains, II, 321.

- de Guatimala, II, 322.

Lard, IV, 46.

Larinus Cynara, etc., IV, 216.

- nidificans, IV, 216.

Larix Cedrus, II, 248.

- europcea, II, 248.

Larves, IV, 203.

Laserpitium Chironium, III, 250.

Lasionema rosea, III, 186.

Latrobite, I, 427.

Latrodectus Malmignathus, IV, 263.

Laumonite, I, 428.

Lauracées, II, 392.

Lauréole, II, 389.

Laurier alexandrin, II, 169.

- amande, III, 318.

- cerise, III, 318.

- commun, II, 393.

- rrose, II, 579.

- - des Alpes, III, 8.

LAURivéEs, II, 392.

Laurus Burmanni, II, 405.

- Camphora, II, 415.

- Cassia, II, 409.

- cinnamomum, 11, 404.

- Culilawan, II, 414. multiflora, II, 405.

Guibount, Drogues, 7e édit.
Laurus nobilis, II, 393.

- Sassafras, II, 393.

Lavande femelle, II, 462.

- mâle, II, 462 .

- officinale, II, 462 .

- Spic, II, 462.

Lavandula Spica, II, 462.

- Stcechas, II, 462.

- vera, II, 462.

Lave vitreuse du Cantal, I, 473.

Laves, I, 496.

Lazulite, I, 337, 474 .

Leadhillite, I, 188.

Lecanora affinis, II, 586.

- esculenta, II, 586.

- Parella, II, 61.

- tartarea, II, 61 .

Lecytindées, III, 268.

Lecythis grandiflora, III, 269.

- Ollaria, III, 269.

Ledum palustre, III, 8.

Légune, II, 13.

LÉgunineuses, III, 319.

Lemmings, IV, 25.

Lemon-grass, II, 99.

LÉMURIENS, IV, 13.

Lentille, III, 380 .

Lentisque, III, 497.

Lenzinite, I, 357.

Leontice Leontopetalum, III, 663.

Leontolon Taraxacum, III, 18.

Léopard, IV, 23.

Lepidium campestre, III, 659, 690 .

Lepidium sativum, III, 68́́.

Lépidomélane, I, 47I.

LÉpIDoptères, IV, 233.

- diurnes, IV, 234.

- crépusculaires, IV, 234.

- nocturnes, IV, 234.

Lepte rouget, IV, 266.

Leptospermées, III, 267.

Leptynite, I, 496.

I.eucite, I, 471.

Leucophane, I, 326 .

Leucostine, I, 496.

Levisticum officinale, III, 206.

Levyne, J, 428.

Lézard commun, IV, 151 .

Libellules, IV, 221.

Liber, II, 8.

Libéthénite, I, 231.

Libidibi, III, 398.

Lichen d'Islande, II, 55.

- des murailles, II, 58 .

- pixidé, II, 58.

- pulmonaire, II, 58.

- pustuleux, II, 59.

Lichen cocciferus, II, 58.

T. IV. -28 
Lichen esculen/us, II, 586.

- islandicus, II, 55.

- parellus, II, 61.

- parietinus, II, 59.

- pixidatus, II, 58.

- plicatus, II, 59.

- pulmorariue, II, 58.

- rangiferus, IV, 75 .

- suxatilis, II, 59 .

- vulpinus, II, 60.

LICHENS, II, 55.

Liéhens tinctoriaux, II, 60 .

Liebigite, I, 214.

Liége, II, 288.

Lielre commun, III, 197.

- terrestre, II, 475.

Lièvre, IV, 25.

Liévrite, I, 292.

Lignaloé, III, 538.

Lignite, I, 98.

- fibreux, I, 100.

- piciforme, I, 99.

- terrenx, I, 100.

Ligusticum Levisticum, III, 206.

Lilas, II, 574.

LiliacéEs, II, 152.

Lilium candidum, II, $15 i$.

Limaces, IV, 354.

Limaçon, iV, 358.

Limandelle, IV, 179.

Limandes, IV, 179.

Lime duuce, III, 631 .

Limettier, III, 631 .

- bergamotier, III, 632.

Limonier, III, 6?9.

Linaire, 1I, 490.

Linalué, IIl, 539.

Linaria vulgaris, II, 490.

Lin cultivé, III, 658.

- fossile, I, 432 .

LINÉES, III, 658.

Linguatules, IV, 279.

Lingue, IV, 181.

Linottes, IV, 130.

Linoufur, III, 729 .

Linum usinntissimum, III, 658 .

Lion, IV, 23.

Lippia citriodora, II, 482.

Liquidanbar blanc, II, 306 .

- liquide, II, 306.

- mou, II, 306.

Liquitambar Altingia, II, 311.

- orienlale, II, 309.

- styraciflua, II, 305.

Liriodendirine, III, 738.

Liriodendron tulipifera, III, 746.

Liroconite, I, 229.

I.is blanc, II. 154 .
Lis d'eau, III, 729.

- des étangs, III, 729.

- superbe, etc., II, 153.

Lit-cli, III, 599.

Lithine, II, 444.

Lithosperrnum officinale L., II, 519.

- tinclorium, II, 518.

Litscea zeylanica, II, 405.

Livèche, III, 206.

LoASÉES, III, 267.

Lobaria pulmonaria, II, 58.

Lobelia inflata, III, 10.

- laurentir, III, 10.

- syphititica, III, 10.

Lobéliacées, III, 9.

Lobélie cardinale, etc., III, 9.

- du Chili, III, 9,

- syphilitique, III, 10.

Loche d'étang, IV, 176.

- fianche, IV, 176.

Loddu putlay, II, 448.

LoganiacÉEs, II, 558 .

Loge, II, 13.

Loirs, IV, 25.

Loligo, IV,

Lolium ternulentum, II, 94.

Lombric, IV, 281.

LONGIPENNES, IV, 135.

Lovginosties, IV, 134.

Lonicera Caprifolium, III, 193

Lophobranches, IV, 171

Loranthacées, III, 19'.

Loriots, IV, 129.

LoTÉEs, III,

Lotos sacré, III, 731.

Lottes, IV, 179, 181.

Loup, IV, 18.

- doré, IV, 18.

- de mer, IV, 172.

Lucuma mammosum, II, 597.

Lumachelle, I, 411.

Lumbricus terrestris, IV, 281.

Lupin, III, 379.

Lupinus albus, III, 379.

Lupuline, II, 333.

Lychonis Githago, III, 764.

Lycium, III, 40 i.

Lycoperdon, II, 39 .

Lycopersicum esculentum, II, 503.

Lycopodiacées, II, 79.

Lycopode officinal, 79.

Lycopodium clavalum, II, 79.

Lycoses, IV, 262.

Lydienne, I, 497.

Lymnées, IV, 360.

Lynx, IV, 2.3.

Lyres, IV 129, 173. 
Lytta adspersu, IV, 218.

- vesicatoria, IV, 208.

\section{M}

Macaques, IV, 13.

Mâche, III, 76.

Machorium Allemani, $\$ 349$.

Machoiran, IV, 195.

Macis, II, 419.

Macigno, I, 497.

Macle, I, 343.

Maclura aurantiaca, II, 325.

- tinctoria, II, 315.

Macrodactyles, IV, 135.

Madi du Chili, III, 39.

Madia saliva, III, 59 .

Madiépores, IV, 376.

Magnésie, I, 376.

- boratée, I, 382.

- carbonatée anhydre, I, 380.

- - silicifère, I, 381 .

- - terreuse, I, 381.

- fluo-phosphatée, I, 387.

- fluo-silicatée, I, 387.

- hydratée, I, 379.

- liydrocrabonatée, I, 381.

- native, I, 379.

- silicatée, I, 387.

Magnésite, I, 393.

Magnésium, I, 376.

Magnétisme, I, 55 .

Magnoc, II, 350.

Magnolia glauca, III, 746.

- gracilis, III, 746.

- grandiflora, etc., III, 746.

Magnoliacées, III, 745 .

Magnoliées, III, 746.

Magots, IV, 13.

Maguey, II, 183.

Mahaleb, III, 316.

Mais, II, 114.

Makis, IV, 13.

Malabathrum, II, 411 .

Malachite, I, 235.

Malacolite, I, 429.

Malacon, I, 319.

Malacoprérygiens abdominaUx, IV, 175.

- APODEs, IV, 187.

- subrachiens, IV, 179.

Nalambo, II, 368.

Malanea racemosa, III, 189.

Malaptérure électrique, IV, 196.

Malherbe, II, 456.

Malicorium, III, 280.

Mallolus philippinensis, II, 369.

Malléabilité, I, 10.
Malmignatte, IV, 263.

Malpighiacées, III, 598.

Malt, III, 588.

Malthe, I, 103.

Malus acerbe, III, 290.

- sativa, III, 290.

Malva glabra, III. 647.

- rotundifolia, III, 617.

- sylvestris, III, 647.

Malvacées, III, 64 .

Mammea americana, III, 608.

Mammey d'Amérique, III, 608 .

Mamatéres, IV, 4.

- onguiculés, IV, 8.

- ongulés, IV, 8.

- à sabot, IV, 8.

Mammouth, IV, 43.

Mancenillier, II, 435 .

Manchots, IV, 135.

Mandelstein, I, 489.

Mandica, II.

Mandiibu, II

Mandragore, II, 501.

Mandragora officinalis, II, 5'll.

Mandrills, IV, 13.

Manganèse, I. 297.

- bi-oxydé, l, 301.

- alcalifère, I, 303.

- carbonaté, I, 308.

- et fer fluo-phosphatés, I, 305.

- hydiaté, I, 301.

- oxydé, I, 299.

- pliosphaté, I, 303.

- silicaté, I, 309.

- sulfuré, I, 298.

- tantalaté, I, 306.

- tungstaté, I, 305.

Mangifera domestica, III, 494.

- gabonensis, III, 573.

- indicn, III, 494.

Mango, III, 494.

Mangostann Cambogia, IlI, 611-616.

- Morella, III, 611-613.

Mangoustan cultivé, III, 609 .

- du Malabar, III, 609.

Mangouste (racine de), III, 765.

Mangoustes, IV, 22.

- de l'Inde, IV, 22.

- de Java, IV, 22.

Mani, III, 618 .

Maniguette, II, 224.

- (petite), II, 225.

- (grande) de Démérari, II, 225.

Manihot utilisvima, II, 350 .

Manioc ou manihot, II, 350.

Manne, II, 583.

- d'Alliagi, II, 585.

- de Briançon, I , 585. 
Manne d'Eucalyptus, II, 585.

- de Sinaĩ, II, 585.

- tombée du ciel, II, 585.

Mante religieuse, IV, 219.

Maquereaux, IV, 174.

Maranta arundinacea, II, 227.

- Galanga, III, 201.

- intica, II, 227.

Marantacées, II, 198.

Marathrum, III, 226.

Marbre, I, 410-497.

- de Bergame, I, 402.

- bleu de Wurtemberg, I, 402.

- bleu turquin, I, 410.

- brèche, I, 411.

- campan, I, 410 .

- de Carrare, I, 410.

- cipolin, I, 410-411.

- de Florence, I, 411.

- griotte, I, 410.

- jaune de Sienne, 410 .

- de Languedoc, I, 410.

- Iumachelle, I, 411.

- noir, I, 411.

- de Paros, I, 410.

-. portor, I, 410 .

- ruiniforme, I, 411.

- Sainte-Anne, I, 410.

- sarancolin, I, 410.

- vert antique, I, 400.

Marceline, I, 310.

Marékanite, 1, 497.

- opaque, I, 473.

Maringouins, IV, 252.

Marjolaine vivace, II, 467.

- vulgaire, II, 467.

Marmite de singe, III, 269.

Marmolite, I, 39't.

Marmottes, IV, 25.

Marne, I, 497.

- argileuse, I, 362.

Maroute, III, 54.

Marronnier d'Inde, III, 600.

Marrons cultivés, II.

Narrube blanc, II, 476.

- noir, II, 476.

Narrubium vulgare, II, 476 .

Marsupiaux, IV , 40.

Marsouins, IV, 112.

Marteau commun, IV, 370.

Martins, IV, 129.

Martins-pêcleurs, IV, 130.

Marum, II, 478.

Musang de vaca, IV, 99.

Massigno, I, 497.

Massoy de la Nouvelle-Guinée, II, 414.

Mastic, III, 497.

Mastodontes, IV, 43.
Maté, III, 544.

Matico, IV, $27 \%$.

Matricaire officinale, III, 49.

Matricaria Camomilla, III, 50.

- Parthenium, III, 49.

Maubèches, IV, 134.

Maurelle, II, 3 í.

Mauve en arbre, III, 619 .

- à feuilles rondes, III, 647 .

- sauvage, III, 847.

Méandlines, IV, 376.

Mechoacan, II, 532.

Meconium, III, 705 .

Médicinier, II, 357.

- d'Espagne, II, 358.

- multifide, II, 358.

- sauvage, II, 357 .

Mégathérium, IV, 40.

Méduses, IV, 374-376.

Méionite, I, 427-473.

Melaleuca minor, III, 277.

- Leucadendron, III, 277.

- viridiflora, III, 278.

Melampodium, III, 758.

Mélanite, I, 350.

Melanoxylum Brauna, II, 601 ; III, 33 .

MÉlanthacéEs, II, 143.

Melanthium, III, 763.

Mélaphyre, I, 497.

Mélas, IV, 23.

Neles Taxus, III, 17.

Meletla venenosa, IV, 179.

Mélette vénéneuse, IV, 179.

Mélèze d'Europe, II, 248.

Melia Azederach, III, 593.

MÉllacéEs, III, 593.

Mélilot des cliamps, III, 360.

- officinal, III, 359.

Melilotus arvensis, III, 360.

- officinalis, III, 359.

Mélique bleue, II, 96 .

Melissa Calamintha, II, 469.

- officinalis, II, 470.

Mélisse de Moldavie, II, 475.

- officinale, II, 470.

Mellite, I, 332.

Melocactus communis, III, 251 .

Mélochie, III, 641.

Méloé de mai, IV, 214.

- proscarabée. IV, 213.

Meloe vesicatorius, IV, 208.

Melon, III, 261.

- d'eall, III, 261.

Mélongène, II, 506 ,

Mélyre vert, IV, 211.

Ménakanite, I, 286.

Ményanthe, II, 557.

Menyanthes trifoliata, II, $55 \%$. 
Ménilite, I, 83.

MÉnispermacées, III, 73 i .

Menispermum Cocculus, III, 740.

- heteroclitum, III, 740.

Ménobranches, IV, 166.

Mentha uquatica. II, 46 .

- arvensis, II, 465 .

- crispa, 466.

- gentilis, Il, 465.

- hirsuta, II, 465.

- piperita, II, 464.

- Pulegium, II, 465.

- rotundifolia, II, 461.

- saliva, II, 465.

- sylvestris, II, 464 .

- viridis, II, 464.

Nentle aquatique, II, 46 i.

- baume, II, 465.

- des clianıs, II, 465.

- coq, III, 50.

- crépue, 1II, 465.

- cultivée, II, 465.

- poivrée, II, 464.

- pouliot, II, 465 .

- romaine, II, 46 t.

- ronde, II, 464.

- sauvage, II, 461 .

- velue, II, 465.

- verte, II, 464 .

Mercure, I, 165.

- (son extraction), J, 169.

- al'gental, I, 166.

- cliloruré, I, 168.

- sulfo-sélénié, I, 168.

- sulfuré, I, 167.

Mercuriale annuelle, II, 343.

- vivace, II, 3 it.

Mercurialis annua, II, 3 ł3.

- perennis, II, $3 \mathbf{4}$.

Mère de girofle, III, 273.

Mérinos d'Espagne, IV, 81 .

Mérions, IV, 25.

Merisier, III, 315.

- à grappes, III, 317.

- de Virginie, III, 317.

Merlan, IV, 181.

- noir, IV, 181.

Merles, IV, 129.

Merluche, IV, 179-181.

Mésanges, IV, 130.

Mesembryanthemum crislallinum, 252.

Mésocarpe, II, 11.

Mésole, I, 428.

Mésoline, I, 428.

Mésolite, I, 428.

Mésotype, I, 472.

Mespilodaphne pretiosı, II, 403.

Mespilus germanica, III, 293.
Messager's, IV, 127.

Météolites, I, 258.

Méthode de De Candolle, II, 17.

Méum, III, 212.

Meum athamanticum, HI, 212.

Mézéréon, II, 388.

Mialgyrite, I, 158.

Micas, I, 472-473-476.

Micaschiste, I, 498.

Michelia Champacca, III, 743-746.

- montana, III, 746.

- Tsjampacca, III, 746.

Miel, IV, 229.

Mikania Guaco, III, 65.

Milans, IV, 127.

Mil-homens, II, 379.

Mille-feuille, III, 51.

Mille-pertuis, III, 625.

Mille-pores, IV, 376.

Mimophyre, I, 498.

Mimosa arabica, III, 393.

- cochliocarpos, III, 330.

- farnesiana, III, 396.

- nilotica, III, 390.

- Senegal., III, 398.

Mimosées, 1II, 324.

Mimusops Balata, II, 600.

- dissecla, II, 595.

Mine d'acier, I, 272.

- d'étain blanche, I, 423.

- de fer blanche, I, 272.

- de plomb, I, 89.

Minéralogiquos (Classifications), 1, 62.

Mirabilis dichotoma, II, 451.

- Jalapa, II, 451.

- longiflora, II, 451.

Mispickel, I, 265.

Mite de la farine, IV, 267 .

- de la gale, IV, 269 .

- domestique, IV, 267.

- rhomboïdale, IV, 268.

Mites, IV, 265.

Mithridate mustard, III, 6;0.

Moelle, II, 9.

- de Cuba, II, 325.

Mohica, II, 596 .

Moineaux, IV, 130.

Molasse, I, 498.

Molène, II, 491.

Molinia carulea, II, 96.

Mollesse, I, 9.

Molluscoides, IV, 361.

Mollusques, IV, 3-348.

- acéphales, IV, 350-361.

- BRACHOPODES, IV, 350.

- céplialopodes, IV, 350-351.

- gastéropodes, IV, 350-356.

- ptéliorodes, IV, 35 J. 
Molybdène oxydé, I, 208.

- sulfuré, I, 208.

Mombin, III, 495.

Momordica Elaterium, III, 258.

Monazite, I, 312.

Monesia, II, 589.

Monimiacées, Il, 391.

Mongorium Sambac, III, 637.

Monotrèmes, IV, 41.

Monstera pertusa, II, 89.

Montain-tea, III, 4.

MonéEs, II, 315.

Morelle noire, II, 504 .

Morgeline, II, 452.

Morinda citrifolia, etc., III, 82 .

Moringa aptera, III, 388.

- pterygosperma, III, 353-387.

MoRingées, III, 324.

Moronobea coccinea, 1II, 618.

Morphil végétal, II, 142.

Morpion, IV, 258.

Morrhua vulgaris, IV, 181.

Morsès, IV, 24.

Morue, IV, 199.

- franche, IV, 180.

- longue, IV,-181.

Morus alba, II, 324.

- nigra, II, 323.

- papyrifera, II, 324.

- tinctoria, II, 325.

Morvénite, I, 413.

Moschus moschiferus, IV, 58.

Motelles, IV, 179.

Mouche domestique, 251.

Moucherolles, IV, 129.

Mouflon de Corse, IV, 81.

Moule commune, IV, 371.

- des peintres, IV, 370 .

Moules, IV, 370 .

Mouron bleu, II, 458.

- des oiseaux, II, 458.

Moussaclie, II, 351 .

- des Barbades, II, 227.

Mousse de Ceylan, II, 33.

- de Corse, II, 30.

- d'Islande, II, 32.

- perlée, II, 32.

- de Jafua, II; 33 .

Moustiques, IV, 252.

Mou-tan, III, 775.

Moût de raisin, III, 583.

Moutarde blanche, III, 696.

- noire, III, 69 í.

-. sauvage, III, 696 .

Moutons, IV, 80.

- domestiques, IV, 81 .

- (ægagrophile du), IV, 102.

Moutouchi, III, 346.
Moutouchi suberosus, III, 346.

Moxa, III, 48.

Mozambrum, II, 161.

Mucuna pruriens, III, 383.

- urens, III, 382.

Murlar, II, 574.

Mufle de veau, II, 490.

Muflier des jardins, II, 490.

Muguet, II, 167.

Mula cascarilla, III, 174.

Mulet, 1V, 53.

Mulette du Rhin, IV, 370 .

Mullérine, I, 150.

Mulle barbu, IV, 173.

Mulles, IV, 172.

Mullus barbatus, IV, 173.

- surmuletus, IV, 173.

Mundubi, Ill, 384.

Mungo, IV, 26.

Murènes, IV, 188.

Murex, IV, 360.

Muriate d'ammoniaque, I, 484.

Mûrier blanc, II, 324.

- noir, II, 323.

- à papier, II, 324 .

Musa paradisiaca, II, 197.

- sapientium, II, 197.

Musacées, II, 197.

Musaraigne, IV, 15.

Musc d'Assam, 1V, 63.

- du Bengale, IV, 63.

Musc de Chine, IV, 61.

- de Sibérie, IV, 65.

- falsifié, IV, 66.

- en poche, IV, 65.

- en vessie, IV, 65.

- Lor's vessie, IV, 65 .

- kabardin, IV, 65.

- tonquin, IV, 62.

Muscade de Cayenne, II, 421.

-- des Moluques, II, 419.

- Iongue, II, 421 .

- sauvage, II, 421.

Muscadier aromatique, II, 419.

Muséides, IV, 25.

Musimon, IV, 81 .

Musophages, IV, 131 .

Mussena, III, 334.

Mygale moscovita, IV, 89.

Mygale aviculaire, IV, 260.

Mylabre de la clicorée, IV, 212.

Myriapodes, IV, 259.

Myrica cerifera, II, 281.

- Gale, II, 280.

- pensylvanica, II, 281 .

Myricées, 11, 280.

Myricine, IV, 233.

Myristicées, Il, 419. 
Myristica aromatica, II, 419.

- dactyloides, II, 42.

- fatua, II, 421.

- moschata, II, 419.

- officinalis, II, 410.

- sebifera, II, 423.

- tomentosa, II, 421.

Myrmica, IV, 225.

Myrobalan belleric, III, 284.

- chébule, III, 284.

- citrin, III, 282.

- d'Amérique, III, 287.

- d'Égypte, III, 287.

- emblic, II, 364.

- indien, III, 284.

Myrobalans, III, 282.

Myrosine, III, 698 .

Myrospermum balsamiferum, III, 473.

- de Son Sonaté, II, 473.

- Pereiro, III, 473.

- peruiferum, III, 471.

- toluiferum, III, 474.

Myroxocarpine, III, 481.

Myroxylum peruiferum, III, 471 .

- toluiferum, III, 474.

Myrrha aminnea, III, 455.

Myrrhe, III, 511 .

- de l'Inde, III, 516.

Myrrhis odorceta, III, 215.

Myrtacées, III, 267.

Myrte bâtard, 280.

MYRTÉEs, III, 268.

Myrtus acris, III, 275.

- communis, III, 270.

- piment", III, 275.

- pimentoides, III, 276.

Mysorine, I, 234.

Mytilus edulis, IV, 370 .

\section{$\mathbf{N}$}

Narcissus Jonquilla, II, 188.

- odorus, II, 188.

- poeticus, II, 188.

- pseudo-narcissus, II, 188.

Nard celtique, III, 71.

- de Crète, lII, 7I.

- du Dauphiné, III, 78.

- du Gange, Ill, 75.

- foliacé de l'Inde, III, 77.

- indien, III, 73.

- jatamansi, III, 74.

- radicant, III, 75 .

- sauvage, II, 381.

Nardostachys Jatamansi, III, 74.

- grandiflora, III, 77.

Nartex Asa fotida, III, 239.

Narval, IV, 112.

Nasturtium officinale, III, 683.

- sylvestre, III, 684.

Natron, I, 454.

Natrospodumen, I, 481.

Nauclea Gambir, III, 407.

Nautile, JV, 353.

Nautilus pompilius, IV, 353.

Navet, III, 693.

Navette, III, 235, 694, 696 .

Naypaul Cupur, IV, 100.

Nebneb, III, 390.

Nectandra cymbarum, II, 399.

- pucluury mujor, II, 399.

- Rodei, II, 400.

Nèfles de Maurice, III, 268.

Néflier, III, 293.

Nélumbiacées, III, 730.

Nelumbium speciosum, III, $i 31$.

Nelumbo mucifera, III, 73I.

Némate, I, 499.

Nématoldes, IV, 328.

Némertes, IV, 340.

Nénuphar blanc, III, 728.

- jaune, III, 730 .

Néoctèse, I, 282.

Néoplase, I, 276.

Nèpe, IV, 241.

Nacascol, III, 398.

Nacre bâtarde, IV, 368.

- noire de Californie, IV, 369.

- de Nankin, IV, 368.

- de perle, IV, 366.

- vraie de Ceylan, IV, 367 .

Nacrite, I, 472, 473.

Nadelerz, I, 193, 176.

Nagelflue, I, 503.

Naìdes, IV, 281.

Najas, IV, 162.

- tripudians, IV, 162.

Napel, III, 772.

Naphte, I, 105.

Narcisse des prés, II, 188.

Nepeta Cataria, III, 474.

- Glechoma, II, 475.

Népléline, I, 47I.

Néphélis octoculée, IV, : 83.

- tessulata, IV, 283.

- vulgaris, IV, 283.

Néphrite, I, 433.

Nephrodium Filix-max, II, 68.

Nerium antidysertericum, II, 578.

- Oleander, II, 579.

- tinctorium, III, 482.

Nero!i, III, 633.

Nerprun, III, 540.

- des teinturier's, III, 541 . 
NÉvroptères, IV, 221.

Nhandirobe, III, 263.

Niauli, III, 278.

Nickel (son extraction), I, 248.

- antimonial, I, 243.

- arsenical, I, 242.

- arséniaté, I, 246.

- arsénité, I, 246.

- bi-arséniuré, I, 243.

- glanz, I, 244.

- gris, I, 244.

- liydro-silicaté, I, 247.

- natif, I, 244.

- sulfo-antimonié, I, 245.

- sulfo-arséniuré, I, 24 4.

- sulfuré, I, 244.

- vitriolé, I, 246.

Nickeline, I, 242.

Nicotiane, II, 493.

Nicotiana Tabacum, II, 493.

- rustica, II, 494.

Nicotine, II, 495.

Nids de salangane, II, 35 .

Nielle, III, 763.

- des blés, III, 764.

- fausse, III, 76f.

Nigella arvensis, III, 763 .

- damascena, IIl, 764 .

- sativa, III, 763.

Nigellast̂rum, III, 764 .

Nigelle cultivée, III, i63.

- des cliamps, III, 763.

- de Damas, III, 764.

- fausse, III, 764.

Nigelle romaine, III, $76 \%$.

Nigrine, I, 286.

Niloufar, III, 729.

Ninisin, III, 201.

Nitrate de magnésie, I, 377.

Nitre, I, 462.

- cubique, I, 453.

Noir animal, IV, 88.

- de fumée, II, 265.

- d'ivoire, IV, 43.

- d'os, IV, 88 .

Noisette purgative, II, 358.

Noisetier, Il, 283.

Noix d'acajou, III, 493.

- de Bancoul, II, 362.

- de cyprès, II, 239.

- de galle, II, 289.

- de girofles, II, 402.

- igasur, II, 560 .

- des Moluques, II, 362.

- pacanes, II, 301 .

- de palmier, II, 142.

- de lavendsara, II, 4ก2.

- de sassafras, II, 398.
Noix de serpent, III, 263.

Nombril de Vénus, III, 255.

Nontronite, I, 290.

Noona, III, 82.

NotorhizéEs, III, 681.

Noyel commun, II, 301.

- de la Guadeloupe, II, 326.

Nuculaine, II, 15.

Nummulites, IV, 356 .

Nunnari, II, 574.

Nunnari-vay r, II, 188.

Nuphar luteum, III, 730.

NyCtagynéEs, II, 450.

Nylgau, IV, 76 .

Nymphoea alba, III, 728.

- cœrula, III, 729.

- Lotus, III, 729.

- lutea, III, 730.

- Nelumbo, III, 731 .

Nymphe, IV, 203.

NYMPIÉACÉES, III, 727.

\section{O}

Obsidienne, I, 473, 495.

Ocelot, IV, 23.

Ochroma Lagopus, III, 650.

Ochrosia borbonica, II, 5 i8.

Ocimum basilicum, II, 461.

Ocotea cymbarum, II, 396, 399.

- Pichurim, II, 399.

Ocre, I, 499.

- jaune, I, 36t.

Octaèdı'e aigu, I, 21.

Octaèdre obtus, I, 21.

- régulier, I, 21.

Octopus moschatus, IV, 353.

- vulgaris, IV, 352.

Ocuje, III, 618.

Oculina virginea, IV, 382 .

Oculine, IV, 38:.

OEil de bourrique, III, 38?.

OEillet rouge, III, 660 .

OEnanthe crocata, III, $23 \dot{\text { i. }}$

- fistulosa, III, 233.

- pencedanifolia, III, 235.

- Phellandrium, III, 232.

- pimpinelloides, III, 235.

OEnanthe à feuilles de pimprenelle, III, 235.

- fistuleuse, III, 233.

- safranée, III, 234.

OEstre, IV, '253.

- du bœuf, IV, 254.

- du cheval, IV, 254.

- liémolrrlıoìdal, IV, 254. 
OEstre du mouton, IV, 255.

OEstrus, IV, 253.

OEufs de poule, IV, 138.

Oignon, II, 156.

Oisanite, I, 207.

Oiseaux, IV, 123.

- mouches, IV, 130.

- Paladis, IV, 130, 137.

- proie, IV, 126.

- - diurnes, IV, 126.

- nocturnes, IV, 127.

Olampi, III, 464.

Oldenlandia umbellala, III, 83.

Old Loxa bark, III, 145.

Olea europoea, II, 588.

- fragans, III, 63 .

Oléacées, II, 580 .

Oléo-résine de copalu, III, 467.

Oliban, III, 516.

Oligodons, IV, 153.

Oligoklasse, I, 473, 481 .

Olivenite, I, 227.

Olives et olivier, II, 588.

Olives, IV, 360.

Olivine, I, 38\%.

Ombellifìres, III, 202.

Ombilic, II, 15.

Ombre commune, IV, 178.

Omblettes, IV, 134.

Onagga, IV, 54 .

Ondatras, IV, 25-37.

Oniscus Armadillo, IV, 278.

- Asellus, IV, 27.

- murarius, IV, 277.

Ononis spinosa, III, 325 .

Onopordon acanthium, III, 20.

Onosma echioides, II, 518.

Onyx, I, 79.

Opale, I, 82.

Ophelia chirata, II, 555 .

Ophicalce, I, 499.

OpHidiens, IV, 151.

Ophiolite, I, 499.

Opliorhiza mungos, IV, 22-162.

Ophioxylum serpentinum, III, 76? ; IV, 2?.

Ophite, I, 499.

Ophris anthropophora, II, 236.

Opium, III, 713.

— de l'Algérie, III, 725.

- de Bénalès, III, 723.

- de Constantinople, III, 718-719.

- d'Égypte, III, 720.

- de l'Inde, I1I, 722.

- de Malwa, III, 722.

- de Patna, III, 723.

- de Per'se, III, 721.

- de Smyrne, III, 716.

- falsifié, III, 726 .
Opium indigène, III, 724.

Opobalsamum, III, 564 .

Opopanax, III, 249.

Opopanax Chironium, III, 243.

Opuntia cochinillifera, III, 251.

Or blanc, I, 122.

- de chat, I, 483.

- graplique, I, $122,149$.

- de Nagyag, I, 150.

- natif, I, 143.

- palladié, I, 148.

- problématique, I, 122.

- telluré, I, 149.

Orang-outang, IV, 13.

Orange amère, III, 631 .

Orange colored Cinchona bark, III, 153.

Orangettes, III, 633 .

Oranger (feuilles d'), III, 633.

- (fleurs d'), IHI, 632.

- vrai, III, 634.

Orcanette, II, 517.

Orcéine, ol'cine, II, 62.

Orchidées, II, 229.

Orchis fusca, II, 236.

- mascula, etc., II, 230.

Oreille d'homme, II, 381 .

- d'our's, II, 458.

Orelha de onça, III, 739.

Orfraies, IV, 137 .

Orge, II, 111.

- molldé, II, 111.

- perlé, II, 111.

Origan de Tournefort, II, $46 \mathrm{~s}$.

- vulgaire, II, 467.

Origanum Dictamnus, II, 468.

- Majorana, II, 467.

Origanum majoranoides, II, 467.

- Tournefortii, II, 468 .

- vulgare, II, 467.

Original Loxa bark, III, 145.

Oriza sativa, II, 113.

Or'me champêtre, II, 31 .

- fauve d'Anérique, Il, 315.

Ornithorhynques, IV, 41.

Oronge fausse, II, 41.

- vraie, II, 41.

Orpiment, I, 125.

- faux, I, 128.

Orpin, III, 253.

Orseille des Canaries, II, 60.

- de mer, II, 60.

- de terre, II, 60 .

Ortlite, I, 3 13.

Orthoplocées, III, 68I.

Orthoptères, IV, 219.

Orthose, I, 473, 479.

Ortie blanche, II, 477.

- brûlante, II, 329. 
Ortie dioique II, 329.

- grièche, II, 329.

Orvale, II, 473.

Orvets, IV, 151.

Oryctères, IV, 25.

Os marsupiaux, IV, 41 .

- de sèclie, IV, 354 .

Oseille, II, 425.

Osier blanc, Il, 312.

- jaune, II, 312.

- pourpre, II, 313 .

Osmium, I, 141.

Ostracés, IV, 361 .

Ostrapodes, IV, 273.

Ostrcea edulis, IV, 364.

- Malleus, IV, 370.

Osyris alba, II, 382.

Otours, III, 212 .

Ouattapana, III, 398.

Ou-pei-tse, III, 504.

Ou-poey-tse, III, 502.

Ouistitis, IV, 12.

Ours brun, IV, 16.

- blanc, IV, 16.

Oursins, IV, 374.

Outardes, IV, 134.

Outremer, I, 474, 471.

Ouwarovite, I, 350.

Ovaire, II, II.

Ovis Ammon, IV, 80.

- Aries, IV, 81.

- Musimon, IV, 81.

Oxalate de chaux (bézoard d'), IV, 109.

Oxalide crénelé, III, 574.

Oxalidées, III, 574.

Oxalis Acetosella, III, 574.

- crenata, III, 574.

Oxavérite, I, 428.

Oxicoccus palustris, III, 8.

Oxleya runthoxyli, III, 597.

Oxure mangano-manganique, I, 297.

- manganique, I, 298.

Oxyde d'antimoine sulfuré, I, 131.

- noir de manganèse, I, 301.

OAYURES, IV, 332.

Oxyuris vermicularis, IV, 332.

Ozokérite, I, 106.

\section{P}

Pachydermes, IV, 42.

- ordinaires, IV, 44.

- solipèdes, IV, 47.

Pacova, III, 745.

Paeonia corallina, III, 775.

- Moutan, III, 775.
Pceonia officinalis, III, 775.

- pajiaveracea, III, 775.

- peregrina, etc., III, 776.

PEONIÉES, III, 752.

Pagodite de Nagyag, I, 471 .

- de Chine, I, 471.

Paille-en-queue, IV, 136.

Pain de coucou, III, 574.

- de pourceau, II, 458.

Paku-kidang, II, 74,

Palissandre, III, 348.

Palladium, I, 142.

Palma Christi, II, 353.

Palma rosa, III, 299.

Palmiers, II, 126.

Palmier avoira, II, 132.

Palmipèdes, IV, 135.

Palo natras, II, 368.

Paludines, IV, 360 .

Panabase, I, 221.

Panaces Heracleum, III, 249.

Panacoco, III, 355.

Panais, III, 204.

Panax quinquefolium, III, 200.

Pangolins, IV , 40.

Pani, II, 570.

Panicaut, III, 213.

- de mer, III, 214.

Paricum Dactylon, II, 95.

Panna, II, 69.

Panthère, IV, 23.

Pao de aguila, III, 338.

- d'arco, II, 548.

- Pereira, II, 576.

- piquante, III, 750.

Paon de nuit (grand), IV, 235.

Paons, IV, 132.

Papaver album, III, 706.

- bracteatum, III, 713.

- nigr um, III, $\mathbf{i 1 0 .}$

- orientale, III, 712.

- Rhaes, III, 712.

- somrifer um, III, 706.

Papavéracées, III, 703.

Papayacées, III, 265.

Papayer commun, IlI, 266.

Papilio Podalyrius, IV, 235.

Papilionacées, III, 320.

Papillons, IV, 235.

Papyrus, II, 92.

Pâquerette, III, 62.

Paradisea apoda, IV, 137.

- magnifica, IV, 137.

- rubra, IV, 137.

Paraguatan, III, 182.

Parallélipipède, I, 18.

Paramécie du côlon, IV, 378.

Paramecium coli, IV, 378. 
Paranthine, I, 427.

Paratudo, II, 571.

- amer, II, 571.

- alomatiqus, III, 623.

Pardalianches, III, 3 . .

Pareira brava, III, 739.

Parelle, II, 61.

- d'Auvel'gne, II, 61.

Parenchyme, II, 2.

Paresseux, IV, 39.

Pariétaire, I, 329.

Parietaria, II, 329.

Parigline, II, 182.

Pari paroba, II, 277.

Parmacelles, IV, 358.

Parmelia esculenta, II, 586.

- parietina, II, 59.

- saxatilis, II, 59.

Partridge-berry, III, 4.

Partridge-wood, III, 356.

Pas-d'âne, III, 62.

Paspalum Dactylon, II, 95.

Passbreaux, IV, 128.

Passe-rose, III, 646.

Passiflorées, III, 265.

Pastel, III, 483-690.

- des teinturiers, IIl, 690.

Pastenagues, IV, 196.

Pastèque, III, 261.

Pastinaca Opopariax, III, 249.

-- sativa, III, 201.

- urens, III, 204.

Patisson, III, 262.

Pau de sangue, III, 408.

Paullinia Cururu, III, 600.

- pinnata, III, 600 .

- sorbilis, Iil, 600.

Patate purgative, II, 534.

Patchouli, II, 463.

Patience sauvage, II, 42 i.

Pavia rouge, III, 602.

Pavot blanc, III, 706.

- à graine noire, III, 726 .

- cornu, III, 705.

- d'Arménie, III, 709.

- déprimé, III, 708.

- d'Orient, III, 712.

- noir, III, 710 .

- pourpre, III, 726 .

- rouge, III, 712.

Peau d'aiguillat, IV, 199.

- de clien de mer, IV, 198.

- de leiclse, IV, 198.

- de requin, IV, 197.

- de roussette mouchetée, IV, 197.

- de sagre, IV, 199.

- de séplien, IV, 200.

Pechblende, I, 211.
Pêcher, III, 313.

Pechstein, I, j00, 505.

Péchurane, I, 211.

Péchurim, II, 397.

Pectolite, I, 471.

Pediculus, IV, 257.

Pédidalpes, IV, 263.

Péganite, I, 335 .

Pegmatite, I, 500.

Pe-la, IV, 250.

Pélagies, IV, 374.

Pelargonium capitatum, III, 577.

- fragrans, III, 577.

- odoratissimum, III, 577.

- roseum, III, 577.

- zonale, III, 577.

Pelias Berus, IV, 162.

Pélicans, IV, 136, 137.

Pelicanus Onocrotalus, IV, 137.

- Carbo, IV, 137.

Pelletiérite, I, 420.

Pélopium, I, 203.

Pelote de mer, IV, 105.

Peltogyne venosa, III, 349.

Pencea Sarcocolla, II, 594.

Pengawar Djambi, II, 74.

Pennine, I, 398.

Pensée cultivée, III, 673 .

- sauvage, III, 673.

Pépérine, I, 500.

Pepsine, IV, 97 .

Peramèles, IV, 41.

Perca fluviatilis, IV, 172.

Perclie, IV, 172.

Perches, IV, 172.

Perdlix, IV, 132.

Péricarpe, II, 11.

Périclase, I, 379.

Péricline, I, 473.

Péridot, I, 387.

- calcaire, I, 388.

- ferreux, I, 388.

- hydraté, I, 389.

- manganésien, 388 .

Periploca indica, II, 185.

- mauritiana, III, 96.

Périsperme, II, 15.

Perles, IV, 366, 369.

Perlite, I, 473, 500.

Perlon, IV, 173.

Perlstein, I, 500.

Perroquets, IV, 131.

Persea gratissima, II, 403.

Persica vulgaris, III, 313.

Persil cultivé, III, 220.

- de Macédoine, III, 236.

- des marais, III, 233.

Peruvian Calisaya bark, III, 159. 
Pervenche, II, 579.

Pesanteur spécifique, I, 43.

Pesse, II, 256.

Pétalite, I, 445.

Pétiole, II, 9.

Petite centaurée de l'Amérique, II. 555.

Petit chêne, II, 478.

Petit-grain, III, 633.

Petit houx, II, 168.

Petit-lait, IV, 89.

Petit pignon d'Inde, II, 359.

Petiveria alliacea, II, 452.

- tetrandra, II, 452.

Pétrelles, IV, 135.

Pétrole, I, 104.

Petromyzon marinus, IV, 201.

Petroselinum sativum, III, 220.

Pétrosilex, I, 47 3, 182.

Pétunzé, I, 480, 500.

Peucedanum Ostruthium, III, 211.

Peuplier blanc, II, 311 .

- d'Italie, etc., II, 314.

Phakolite, I, 428.

Phalangers, IV, 41.

Phalangites, IV, 265.

Phalène, IV, 235.

Pharbitis hispida, II, 521.

Pharmacolite, I, 421.

Pharmacosidérite, I, 281.

Phascolomes, IV, 41 .

Phaséolées, III, 322.

Phaseolus vulgaris, III, 380.

Phellandrie aquatique, III, 232.

Phellandrium aquaticum, III, 232.

Phénakite, I, 323.

Phillipsite, I, 219.

Pitecollobium avaremotemo, III, 330.

Phlorizine, III, 291.

Phœnix dactylifera, II, 128.

Pholérite, I, 357.

Phonolite, I, 501.

Phoques, IV, 23.

Phormium tenax, II, I5'.

Phosphate ammoniaco-magnésien, $I, 487$.

- calcaire (bézoard de), IV, 108.

Phosphore de Bologne, I, 442.

Phosphorite, I, 419.

Phrines, IV, 264.

Phtanite, I, 50 I.

Phthora, III, 760.

Phu, III, 71.

Phyllade, I, 501.

Phyllanthus Emblica, II, 364.

Phyllopodes, IV, 274.

Physalis Alkekengi, II, 509.

Physalles, IV, 374.

Physcia islundica, II, 55.

Physeter macrocephalus, IV,113, 117,119.
Physocalymna floribundum, III, 349.

Physsophores, IV, 374.

Physostigma venenosum, III, 380.

Physostigmine, III, 38\%.

Phytelephas macrocarpa, II, 14 .

Phytolacca decandra, II, 450.

Phytolaccacées, II, 450.

Picaud, IV, 179.

Picrcena excelsa, III, 569.

Picrolite de Taberg, I, 395.

Picropharmacolite, I, 422.

Pics, IV, 131.

Pictite, I, 424.

Pied-d'alouette, III, 768.

Pied-de-ch at, III, 35.

Pied-de-griffon, III, 760.

Pied-de-lion, III, 300.

Pied-de-veau, II, 86.

Pies, IV, 130.

Pies grièches, IV, 129.

Pielre à bâtir de Paris, I, 41

- à dresser, I, 50i.

- à faux, I, 50 千.

- à rasoir, I, 506.

- d'asperge, I, 419.

- de Bologne, I, 442.

- de bugie, IV, 103.

- de croix, I, 345.

- de Goa, IV, 103.

- de Labrador, 481.

- de lune, I, 500.

- de Malacca, IV, 105.

- de Marmarosch, 1, $4: 0$.

- de porc, IV, 105.

- de pol'c-épic, IV, 105.

- de serpent, IV, 103.

- de singe, IV, 103.

- de touche, I, 501.

- hématite, I, 270.

- lithographique, I, $\$ 11$.

- Iydienne, I, 501.

- meulière, I, 80.

- ollaire, I, 39', 499.

- pesante, I, 423.

- d'écrevisse, IV, 276.

Pigeons, IV, 133.

Pignon des Barbades, II, 357.

- d'Inde, II, 357.

Pilocarpus pinnatifolius, III, Pilori, IV, 38.

Pimélite, I, 247.

Piment de Cayenne, II, 510.

- couronné, III, 276.

- de l'île Maurice, II, 511.

- de la Jamaique, III, 2 i3.

- des jardins, II, 510 .

- royal, II, 280.

- Tabago, III, 275. 
Pimpinelia Anisum, III, 2:2.

- megna, III, 224.

- saxifraga, III, 224.

pimprenelle commune, III, 301.

- (petite), III, 301.

- d'Italie, III, 301.

- des montagnes, III, 301.

Pin austral, II, 245.

- Cembro, II, 245.

- de Corse, II, 243.

- Laricio, II, 243.

- maritime, Il, 243.

- à pignons, II, 243.

- sauvage, II, 243.

- de Weymouth, II, 245.

Pindaïba, Ill, 745.

Pingouins, IV, 135.

Pinguit de Wolkenstein, I, 290.

Pinite d'Auvergne, I, 471.

- de Saxe, I, 346.

Pinna nobilis, IV, 379.

Pinne noble, IV, 379.

Pinus Abies, II, 247.

- australis, II, 245.

- balsamea, II, 246.

- canadensis, II, 247.

- Cembro, 245.

- Laricio, II, 243.

- maritima, II, 243.

- Picea, II, 245.

- Pinaster, II, 243.

- Pinea, II, 243.

- rigida, Il, 245.

- Strobus, II, 245.

- sylvestris, II, 243.

Pinsons, IV, 130.

Pintades, IV, 132.

Pintadine, IV, 370.

Pintadina margaritifera, IV, 366.

Pipe-Camboge, III, 614.

Piper Afzelii, II, 275.

- Beíel, II, 277.

- Cubeba, II, 274.

- longum, II, 276.

- methysticum, II, 276.

- nigrum, II, 271.

- umbellatum, II, 277.

Pipérine, II, 273.

Pipéritées, II, 271.

Pipi (racine de), II, 452.

Piptostegia Pisonis, II, 534.

Pipula moola, II, 276.

Piqueria trinervia, lII, 64 .

Piratinera guianensis, II, 328 .

Piretro, II, 197.

Piscicole, IV, 297.

Pisseloeon, II, 264.

Pissenlit, III, 18.
Pistache de terre, III, 384.

Pistaches, pistachier, III, 495.

Pistacia atlantica, III, 498.

- Lentiscus, III, 497.

- Terebinthus, IIl, 498.

- vera, III, 495.

Pistil, II, 11.

Pisum sutivum, III, 380.

Pivoine, III, 774.

- en arbre, III, 775 .

- femelle, III, 775 .

- mâle, III, 775.

Pixide, II, 14.

Placentaire, II, 12.

Plagionite, I, 176, 178.

Planaires, IV, $3 \dot{1} 0$.

Plane, III, 606.

Planériens, IV, 282.

Planorbes, IV, 360.

Plantaginées, II, 453.

Plantago arenaria, II, 454 .

- lanceolata, JI, 453.

- major, II, 453.

- media, II, 453.

- Psyllium, II, 454.

Plantain, II, 453.

Plantigranes, IV, 16.

Platanées, II, 304.

Platesia Flesus, IV, 179.

- Limanda, IV, 179.

- Platessa, IV, 179.

- Pola, IV, 179.

Platine, I, 136.

Platinides, I, 135.

Plâtre, I, 403.

Plattérite, I, 181.

Ptatyceros, IV, 71 .

Plectognathes, IV, 171.

Pléonaste, I, 386.

Pleuronectes, IV, 179.

Pleurorhuzées, III, 681 .

Pleurotomes, IV, 361.

Plie franche, IV, 179.

Plocaria lihenoides, II, 33.

Plomb (son extraction), I, 175.

Plomb antimonité, I, 171.

- arséniatẻ, I, 184.

- carbonaté, I, 186.

- chloro-carbonaté, I, 189.

- chloro-arséniaté, I, 184.

- chloro-phosphaté, I, 184 .

- chloruré, I, 189.

- cliromaté, I, 182.

- chromé, I, 183.

- corné, I, 189.

- gomme, I, 190.

- hydro-aluminaté, I, 190.

- jaune de Carinthie, I, 181. 
Plomb molybdaté, I, 181.

- muriaté, I, 189.

- natif, I, 171.

- oxydé, I, 180.

- phosphaté, I, 184.

- rouge de Sibérie, I, 182.

- sélénié, I, 172.

- - cuprifère, I, 173.

- - hydrargyrifère, I, 172.

- sélénité, I, 172.

- sulfaté, I, 185.

- sulfo-arsénié, I, 175.

- sulfuré, I, 173.

- - antimonifère, I, 75 .

- - bismuthi-argentifère, I, 176.

- - bismuthi-cuprifère, 176.

- - stibio-argentifère, I, 176.

- - stibio-cuprifère, I, 176.

- telluré, I, 172.

- - aurifère, I, 150.

- tungstaté, I, 181.

- vanadaté, I, 181.

Plombagine, I, 89.

Plongeous, IV, 135.

Plongeurs, IV, $1: 55$

Plembaginées, II, 454.

Plumbago europaca, II, 454.

Plumule, II, 15.

Pluviers, IV, 134.

Pneumus Bolilus, II, 391.

Podophyllum pellatum, III, 734.

Podosperme II, 15.

Pogostemon Patchouli, II, 463.

Poireau, II, 156.

Poirée, II, 4 í.

Poirier's, III, 290.

Pois à gratter, III, 382.

- cultivé, JlI, 390.

- pouilleux, III, 382.

- - (petit), III, 383.

Poissoxs, IV, 169.

- cartilagineux, IV, 189.

- plats, IV, 179.

- suceurs, IV, 200.

- volivrs, IV, 173.

- à queue, II, 274.

- bétel, II, 277.

Poivre blanc, II, 273.

- cubèbe, II, 274.

- d'Éthiopie, III, 74'.

- de la Jamaílue, HI, 273.

- long, II, 276.

- de Thévet, III, 276.

- noir, 11, 271.

- de Guinée, II, 277.

Poix blanclie, II, 256.

- de Bourgogne, II, 256.

- de Lonille, II, 265.
Poix jaune, II, 256.

- minérale, I, 103.

- noire, II, 264.

- résine, II, 264.

- des Vosges, Il, 256.

Polamisia graveolens, IIl, 679.

Polatonche, IV, 25.

Pole, IV, 179.

Pollen, II, 11.

Polyarthes tuberosa, II, 154 .

Polybasite, I, 159.

Polycrase, I, 316.

Polygala amara, III, 666.

Polygala amer, III, 668.

- Senega, III, 6 li4.

- de Virginie, III, 664.

- vulgaire, III, 668.

Polygalées, III, 563.

Polygonatum vulgare, II, $1,7$.

Polygonées, II, 423.

Polygonum Bistorta, II, 424.

- tinctorium, III, 423.

Polyhalite, I, 453.

Polymignite, I, 316.

Polypes, IV, 375.

Polypes à bras, IV, 378 .

- d'eall douce, IV, $3: 8$.

Polypier, IV, 3i5.

Polypo-mévusaires, IV, 3 ió.

Polypode commun, II, 69.

- de chêne, II, 6\%.

Polyp'dium Baromez, II, if.

- Calaguala, II, 70.

- crossifolium, II, 70.

- Filix-mas, II, 68 .

- vulgare, II, 69.

Polypore, polyporus, IJ, 45.

Polypore amadouvier, Il, 45

- du mélèze, II, 44.

- ongulé, II, 45.

Polyporus fomentarius, II, fi.s.

- igniarius, II, 45.

- officinalis, II, 44.

Polyrrhiz's, II, 375.

Polysiphonin atro-rubescens, II, 27.

Polystomes, IV, 338.

Pomacérs, III, :98-289.

Pombilia Ipecacuanha, III, $9 \mathrm{i}$.

Pombdelles, IV, 297.

Pomme d'Adam, III, 625.

- d'acajou. III, 493.

- d'amour, II, 509.

- de chêne, Il, 298.

- de Pelse, III, 628.

- de Médie, III, 628 .

- de terre, II, 506.

- épinerse, II, 496.

pommier, III, 290 . 
Pommier à cidre, III, 290.

Pompoléon, III, 632.

Ponce, I, 473, 502.

Poncires, III, $6: 30$.

Populine, II, 314.

Populus alba, II, 314.

- balsamifera, III, 529.

- fastigiata, II. 314.

- nigra, etc., II, 314.

Porc, IV, 49.

Porc-épic, IV, 2;.

Porcelaines, IV, 360 .

Pores corticaux, II, 5.

Porliera hygrometrica, III, 553.

Porpliyre, I, 50 ?.

- noir, I, 497.

- orbiculaire de Corse, 1, 505.

- vert, I, 499.

Porte-musc, IV, 61.

Portulaca oleracea, III, 255.

Portulacées, III, 251.

Potasse litratée, I, 462.

- silicatée, I, 4i1.

- sulfatée, I, 465 .

Potassium chloruré, I, 462 .

Potentilla Anserina, III, 305.

- replans, III, 304.

- Tormentilla, III, 305.

Poterium Sanguisorba, III, 301.

Potiron, 1II, 261.

Potoroos, IV, 41.

Poudingues, I, 502.

- porphyroides, I, 498.

Pou de la tête, IV, 257.

- du corps liumain, IV, 257.

- du pubis, IV, 257.

Pouliot de montagne, II, 480.

Pouliot vulgaile, II, 465 .

Poulpe musqué, IV, 353.

Poulpes, IV, 352.

Pourpier cultivé, Ill, 255.

Pouzzolane, I, 503.

Poya do muto, III, 85.

Prase, I, 79.

Prelnnite, I, 428.

Prềle, II, 84.

Pressirostres, IV, 134.

Prickly-ash, III, 562.

Primevère, II, $45 \mathrm{~s}$.

Primuln veris, II, 458.

Primulacées, II, 457.

Prisme droit à base carrée, I, 19.

- - à base rectangle, I, 19.

- - rhomboïdal, I, 19.

- hexaèdire, J, 23.

- quadrangulaire oblique, I, 20.

Proboscidiens, IV, 42.

Dropolis, IV, 229.
Prosopis horrid', III, 399.

- slliquastrum, III, 399.

Protées, IV, 166.

Protogyne, I, 503.

Proustite, I, 156.

Plune d'Amérique, III, 287.

Pruncaux, III, 315.

Prunellier, III, 314.

Prunier cultivé, III, 315.

- d'Espagne, III, 495.

- épineux, III, 314.

- mombin, III, 495.

- sauvage, III, 31 f.

Prunus Armeniaca, III, 314.

- domestica, III, 315.

- insititia, III, 314 .

- Lauro-cerasus, III, 318.

- spinosa, III, 314.

Psammite, I, 50 i.

Psaturose, I, 156, 158.

Pséphite, I, 504.

Pseudo-albite, I, 471 .

Pseudo'sdella nigra, IV, $28 i$.

Psilomélane, I, 300.

Psycothria emetica, III, 91 .

Psylle, IV, 243.

Psyllium, II, 454.

Ptarmica Herba-rota, III, 48.

- moschata, III, 47.

- nann, III, 48.

Ptarmica vulgıris, III, 52.

Pterocarpus angolensis, III, 316.

- Draco, III, 346.

- erinaceus, III, 408-426.

- indciui, III, 34'1-346.

- marsupium, III, 431 .

- santalinus, III, 344-345.'

- suberosus, III, 346.

Pterygium costatum, II, 417.

Ptychotis Ajowan, III, 222.

- faniculifolıa, 1II, 221 .

- verticillata, III, 221 .

Puce commune, I V, 255.

Puces, IV, 255.

Puceron, IV, 243.

Pudingstone, I, 503 .

Pulassari, II, 578.

Pulex, IV, 2 55.

- penetrans, IV, 256.

Pulmonaire officinale, II, 514.

Pulmonaria officinalis, $\mathrm{II}_{3} 51 \%$.

Pulsatille, III, 756.

Pulu, II, 74 .

Pumite, I, 50う.

Punaise d'eau, IV, 241.

- des lits, IV, 241.

- de Miana, IV, 267.

Punica Granalum, III, 280. 
Purple-wood, III, 34\%.

Purree, IV, 100.

Purreon, IV, 101.

Pycnite, I, 339.

Pyrale de la vigne, IV, 235.

Pylèthre, III, 49.

Pyrethrum carneum, III, 50 .

- germanicum, III, 56.

- Darthenium, III, 49.

- roseum, III, 50.

- Tanacetum, III, 50.

Pyrite ar'senicale, I, 265.

- blanche, I, 263.

- capillaire, I, 244.

- commune, I, 260.

- cuivrense, I, 218.

- jaune, I, 260.

- magnétique, I, 258.

- martiale, I, 260.

Pyrola rotundifolia, III, 1.

- umbellata, III, 2.

Pyrolacées, III, 1.

Pyrole à feuilles rondes, III, I,

- ombellée, III, 2.

Pyrolusite, I, 301.

Pyroméride, I, 505.

Pyrophysalite, I, 339.

Pylorthite, I, 313.

Pyroxène, I, 426, 499.

Pyrus acerba, III, 290.

- Aria, III, 292.

- ancuparia, III, 292.

- Cydonia, III, "289.

- sorbus, III, 292.

Pythons, IV, 156.

\section{Q}

Quâ-leu, II, 218.

Quadrumanes, IV, 12.

Quadrupèdes vermiformes, IV, 17.

Qual, IV, 37I.

Quamoclit vulgaris, II, 520.

Quarat, III, 392.

Quartz, I, 75 .

- agate, I, 78.

- améthyste, I, 78.

- aventuriné, I, 78.

- blanc laiteux, I, 78.

- enfumé, I, 78.

- hématoïde, I, 78.

- liyalin, I, 75.

- liydraté, I, 82.

- jaspé, I, 80.

- jaune, I, 78.

- nectique, I, 82.

- résinite, I, 82.
Quartz rose, I, 78.

- silex, I, 80 .

- terreux, I, 81.

- thermogène, I, 82.

Quartzite, I, 505.

Quassia amer, III, 568.

- de la Jamaïque, IJI, 569.

- de Para, II, 553.

- de Tupurupo, II, 553.

- amara, III, 568.

- excelsa, III, 569.

- paraensis, III, 569.

- Simarutia, III, 570.

Quatelé de la Guyane, III, 269.

Quatre semences froides, III, 261.

Quepo Cascarilla, I, 159.

Quercitron, II, 288 .

Quercus Agylops, II, 286 .

- coccifera, II, 289 .

- infectoria, II, 289.

- pedunculata, II, 286.

- racemosa, II, 286.

- Robur, II, 285.

- sessiliflora, II, 285.

- Suber, II, 287.

- tinctoria, II, 288.

Quillai savonneux, III, 309.

Quillaja Molince, III, 310.

- saponaria, III, 310.

- smegmadermos, III, 309.

Quina amarilla, de Bogota, III, 1 i4.

- cena legitima, III, 160.

- carasquena, III, 148.

- do Campo, II, 5i0.

- naranjada, Ill, 152.

- negra, III, 178.

- primitiva, III, 152.

Quino bobo amarilla, III, 15 ?.

Quincyte, I, 393.

Quinoa, II, 446.

Quinquina Almaguer, III, 156.

- amygdalifolia, III, 159.

- à quinidine, III, 155.

- australis, III, 164.

- bicolore, III, 188.

- blanc de Loxa, III, 176.

- blanc de Mutis, III, 18\%.

- boliviana, 11I, 143.

- brun de Carthagène, III, 156.

- brun de Cuzco, III, 165.

- Calisaya, III, 140 .

- Josephiana, III, 142.

- morada, III, 143.

- Carabaya plat sans épiderme, III, 143.

- - roulé avec épiderme, III, 143.

- caraỉbe, III, 187.

- de Carthagène, III, 15'.

- - ligneux. III, 154. 
Quinquina de Carthagène rosé, III, 155.|Quinquina pareil au Calisaya, III, 156.

- Chahuarguera, III, 146.

- Colombia, III, 154.

- conglomerata, III, 173.

- cordifolia, III, 174.

- crispa, III, 148.

- d'Arica, III, 165.

- de Carthagène jaune pàle, III, $17 i$.

- - spongieux, III, 154 .

- decurrentifolia, III, 176.

- de Cuzco, III, 165.

- de Lima gris-brun, III, 163.

- - gris ligneux, III, 168.

- - très-rugueux imitant le Calisaya, III, 151.

- de Loxa biun compacte, III, 160.

- - cendıé, III, 148-175.

- - inférieur, III, 172.

- - jaune fibreux, III, I'6.

- - rouge fibreux du roi d'Espagne,145.

- - rouge-marron, III, 158.

- - gris compacte, III, 147.

- elliptica, III, 143.

- Havane, III, 167.

- hirsuta, III, 178.

- Huamalies blanc, III, 167.

- - ferrugineux, III, 167.

- - gris terne, III, 167.

- - mince et rougeàtre, III, $16 \%$.

- - rouge, III, 167.

- - rougeàtre, III, 167.

- Huanuco jaune pâle, III, 161-162.

- plat sans épiderme, III, 160.

- - roulé avec épiderme, III, 161.

- Jaën, III, 165.

- jaune de Cuzco, III, 166.

- jaune de Guayaquil, III, 150.

- - de La Condamine, III, 146.

- - de Mutis, III, 154.

- - du roi d'Espagne, III, 148.

- - orangé, III, 154-16'.

- - - de Mutis, III, 154.

- - - roulé, III, 154 .

- - royal, III, 140.

- lanceolata, III, 152.

- lancifolia, III, 152.

- lucumefolia, III, 151.

- macrocalyx, III, 148.

- maracaybo, III, 175.

- micrantha, III, 163.

- Mutisii, III, 177.

- nitida, III, 160 .

- nova, III, 180.

- officinalis, III, 145.

- obtusifolia, III, 144.

- orangé de Mutis, III, 154.

- ovata, III, 163.

- Palton, III, 14 S.

- payama de Loxa, III, 177.

- peruviana, III, 161 .

- pitaya, HI, 156.

- pitayensis, III, 150.

- pitayo, III, 156.

- Piton, III, 186.

- pubescens pelleteriana, MI, 165.

- jurpurea, III, 167.

- rouge de Carthagène, III, 156.

- - de Cuzco, III, 158.

- - de Ia Condamine, III, 14.7.

- - de Lima, III, 131.

- - de Loxa, III, 173.

- - de Mutis, III, 155-179.

- - pàle, III, 169.

- vif, III, 169.

- - non verruquenx, III, 169.

- - verruqueux, III, 169.

- scroticulata, III, 158.

- - genuina, III, 158.

- Delondriana, III, 159.

- subcordata, III, 175.

- suberosa, III, 179.

- succirubra, III, 169.

- ten foncé, III, 172.

- Urutusinga, III, 146.

Quinguinas, III, 10?.

- blancs, III, 115.

- faux, III, 179.

- gris, III, 114.

- jaunes, III, 11'.

- rouges, III, 114.

Quintefeuille, III, 30t.

\section{B.}

Raasch, IV, 196.

Rabioule, III, 693.

Racine, II, 5.

Racines annuelles, II, 5.

- bisannuelles, etc., II, 5.

Racine de Colombo, III, 735.

- d'alun, III, 577.

- de Drake, II, 317.

- de femme battue, II, 186.

- giroflée, III, 305.

- de Jean Lopez, III, 56 T.

- d'or, III, 765 .

- vierge, II, 186.

Rack, III, 589.

Radicule, II, 15.

Raie bouclée, IV, 196.

Raies, IV, 195.

Raifort sauvage, III, 685.

Rainettes, IV, 167.

Raisin aux Jubis, III, 582. 
Raisin au soleil, III, 58:.

- de caisse, III, 58\%.

- de Calabre, III, 581.

- de Corinthe, III, 583.

- de Damas, III, 581.

- de Malaga, III, 581.

- de Maroc, III, 583.

- de mer. IV, 354 .

- d'ours, III, 5.

— de Provence, III, 582.

- de Samos, III, 582.

- de Smyrne, III, 58?.

Raja clavata, IV, 196.

Râles, IV, 135.

Ramou, II, 570.

Ram-lill, III, 60.

Rana esculenta, IV, 167.

- Bufo, IV, 167.

Ranunculus acris, III, 757.

- asiaticus, JII, 757.

- bulbosus, III, 757.

- Ficuria, III, 705.

- Flammula, III, 757.

- Lingua, III, 757.

- scelerutus, IlI, 757.

- Thora, III, 772.

Rapaces, IV, 126.

Raphilite, I, 426.

Raquette, III, 254.

Rassa-mula, II, 311

Rutanhia, III, 666.

Ratanhia des Antilles, III, G68.

- de la Nouvelle-Grenade, III, 668.

- du Pérou, III, 666.

- de Savanille, III, 668.

- du Texas, III, 66!).

Ratels, IV, 16.

Rat musqué des Antilles, IV, 38.

- - du Canada, IV, 37.

- - de la Russie, IV, 39.

- de Pliaraon, IV, 22.

- taupe aveugle, IV, 25.

Rats, IV, 25.

Ratons, IV, 16.

Rave (gr'osse), III, 693.

Ravensara aromotica, II, 40 ?.

Ruyonnés, IV, 3-373.

Réalgar, I, 123.

- faux, I, 128.

Red Carabnya, III, 144.

- Cinchona, III, 169.

- wood, III, 597.

Redon, III, 603.

Redoul, 1II, 369-603.

Réfraction simple et double, I, 52.

Réglisse de Russie, III, 327.

- officinale, III, 326.

Règne inorganique, I, 2.
Règne olganique, I, 2.

Reine-des-prés, III, 307.

Renard, IV, 19.

Renne, IV, 70 .

Renongul acées, III, $75 \%$.

Renoucule âcre, III, 757 .

- bulbeuse, III, 757.

- flamme, III, 757.

- des jardins, III, 757.

- scélérate. III, 757.

Renonculées, III, 752.

Renoncules, III, 756.

Reprise, III, 253.

Reptiles, IV. 142.

Requin, IV, 195.

RésÉdACÉr:S, III, 6is.

Reseda huleola, III, 678.

- ordoratu, III, 678.

Résine alouchi, III, 533.

- animé, III, 455.

- cacicarita, III, 536.

- canarine, III, 523.

- cachibou, III, 525.

- clibou, III, 525.

- copal, III, 455.

- de Curucay, III, 536.

- I)ammara, II, 266.

- Etemi, III, 521 (voyez Élémij.

- à odeur d'élémi, IlI, 524.

- de Gommart, IlI, 525.

- - d'Afrique, III, 527.

- - balsamifère. III, 528.

- de Gommier, III, 527.

- de Highigate, I, 109.

- jaune commune, II, 263.

- kikekunemalo, III, 464.

- lactée, II, 269.

- laque, II, 321.

- de lierre, III, 198.

- de Madagascar, III, 527.

- de mani, III, (il8.

- mastic, III, 497.

- olampi, III, 464.

- sandaraque, II, 250.

Résines tacamaques ou tacamahaca, III, 529.

- de Nantherpliceu, II, 165.

Résinite, I, 8:, 505.

Rétinasplıalte, I, 108.

Rétinite, I, 108, 473, 505.

liéveille-matin, II, 343.

Rhaunées, III, 539.

Rhammes Aluternus, III, 512 .

- amygdnlimes, III, 54.2.

- catharticus, III, 5 i0.

- Frangula, III, 542.

- in/ertorius, III, 541.

- cleoides, III, 542. 
Rhamnus saxatilis, III, 542.

- Ziziphus, III, 539.

Rhapontic, II, 426.

- nostras, II, 427.

Rheum australe, II, 432.

- compactum, II, 428.

- officinale, II, 433.

- palmatum, II, 429.

- rhaponticum, II, 426.

Ribes, II, 429.

- tataricum, II, 499.

- undulatum, II, 423.

- webbianum, II, 410.

Rhinobate, IV, 195.

Rlinocéros, IV, 44.

- d'Afrique, IV, 4 4.

- de Java, IV, 44.

- de Sumatra, IV, 4 4.

- unicorne, IV, 44.

Rhipiptères, IV, 205.

Phizanthées, II, 84.

Rhizobolées, III, 593.

Rhizome, II, 7.

Rhizophora Mangle, III, $435-438$.

Rhizostomes, IV, 374.

Rhodium, I, 142.

Rhododendron, IlI, 8.

Rhododendron chrysantum, III, 8.

- ferrugine

Rhodonite, I, 309 .

Rhombu: barbatus, IV, 1 i9.

- muximus, IT, 179.

Rhubarbe, II, 4?7.

- d'Alexandrette, II, 438.

- anglaise, II, 441.

- de Chine, II, 437.

- de France, II, 441.

- de l'Himalaya, II, 439.

- des moines, II, 425.

- de Moscovie, II, 437.

- de Perse, II, 433.

- de Turquie, II, 438 .

Rhum, III, 589.

Rhus coppritinum, III, 489.523.

- Coriaria, III, 488.

- Cotinus, III, 490.

- glabra, III, 488.

- japonica, III, 505.

- metopium, III, 489.

- radicans, III, 489.

- semi-alntri, III, 505.

- succedureum, III, 491.

- toxicodendron, III, 489 .

- typhinum, III, 488 .

- vernix, III, 4 S8.

Ribes nigrum, III, 251.

- rubrum, III, 250.

- uva-crispa, III, 251.
Rirhardsonia brasiliensis, III, 92.

Ricin, IV, 258-266.

Ricins, II, 353.

Ricinus, IV, 35.3.

- communis, II, 353.

Rima, II, $3: 6$.

Ripidolite, I, 397.

Riz, II, 113.

Robinia panacoco, III, 354.

- pseudo-ncacia, III, 358.

Robin:er fanx-acacia, III, 3 s.

Rocambole, II, 156.

Riccella flaccidn, II, 60.

- fuciformis, II, 60.

- Montagni, II, 60.

- philcrpsis, II, 60.

- tinctoria, II, 60.

Rocceline, II, 63.

Roche de Topaze, I, 3:9.

Rochers, IV, 360 .

Rocou, III, 676.

Roitelets, IV, 129.

Rolliers, IV, 130.

Romarin, II, 474.

- sauvage, III, 8.

Roméine, I, 4:3.

Ronce lierbacèe, III, 303.

- odlorante, III, 302.

- sauvage, III, 302.

Rosgeurs, IV. 2f.

RoNGeurs a Clavicules impaligates, IV, 24.

- clavicilés, IV, $2 i$.

Roquet, IV, 15?.

Roquette cultivée, III, 691.

- sauvage, III, 69\%.

Porquals, IV, 115.

Rosa nlba, III, 297.

- comina, II, 29".

- centifolia, II, 296.

- damascena, III, 297.

- eglanterin, III, 29'.

- gallicu, III, 295.

- mallos, II, 311.

- moschita, III, 297.

- multiflira, III, 297.

- semperfloren:, III, 29\%.

- sulfurea. III, 297.

Rosacées, III, : 87.

Rosages, III, 8.

Rosaliba dı Brésil, III, 34 Ł.

Roseau commun, II, 96 .

Rose à cent feuilles, III, 296.

- de chien, III, 294.

- de Chine, III, 649.

- de Damas, III, 297.

- de Ilollande, III, 296.

- de Jéricho, III, 687. 
Rose de Milet, III, 295.

- mousseuse, III, 296.

- de Noël, III, 758.

- pâle, III, 297.

- des peintres, III, 296.

- de Provins, III, 295.

- des quatre-saisons, III, 297.

- rouge, III, 295.

- de tous les mois, III, 297.

- trémière, III, 646.

Rose-wood, III, 348.

Rosées, III, 288.

Rosier blanc, III, 297.

- du Bengale, III, 297.

- jaune, III, 297.

- multiflore, III, 297.

- musqué, III, 297.

- sauvage, III, 291.

- toujours fleuri, III, 297.

Rosmarinus officinalis, II, 474.

Rossignols, IV, 129.

Rothe China, III, 169.

Rottlera tinctoria, II, 369.

Rouge végétal, III, 22.

Rouget barbu, IV, 173.

Rouget camard, IV, 173.

- commun, IV, 173.

Rouhamon Curare, II, 570.

- guyanense, II, 570.

Rouleaux, IV, 153.

Roure des corroyeurs, II, 488.

Roussette (grande), IV, 194.

Roussettes, IV, 194.

Royal or guenuine yellow bark, III, 140. Rubellite, I, 353.

Rubia mungista, etc., III, 82.

- tinctorum, III, 81.

RubiacÉEs, III, 79.

Rubis de Bohême, I, 78.

- oriental, I, 330.

Rubus chamœmorus, III, 303.

-- fruticosus, III, 302.

- idaus, III, 301.

- odoratus, III, 302.

Rue des murailles, II, 77.

- officinale, III, 554.

Ruibarbo do Campo, II, 196.

Rumex Acetosa, II, 425.

- acutus, II, 425 .

- alpinus, II, $425-427$.

- obtusifolius L., II, 424.

- Patientia, II, 425.

- scutatus, II, 425 .

Ruminants, IV, 54.

Ruscus aculeatus, II, 168.

- hypoglossum, II, 169.

- hypophyllum, II, 169.

Rusty crown bark, III, 147.
Ruta graveolens, IlI, 554 .

Rutacées, III, 544 .

RutéES, III, 545.

Ruthénium, I, 143.

Rutile, I, 206.

- lamelliforme, I, 206.

Ryacolite, I, 473.

\section{S}

Sabatia angularis, II, 555.

Sabine, II, 241.

Sable vert du Pérou, I, 237.

Sablier élastique, II, 436.

Saccharum officinarum, II, 101.

Safran, II, 193.

- bâtard, II, 195.

- faux du Brésil, II, 196.

Safranum, II, 195; III, 21.

Safre, I, 248.

Sagapenum, III, 242.

Sagou, II, 138.

- tapioka, II, 141.

Sagouins, IV, 13.

Sagus genuina, II, 138.

- farinaria, II, 138.

- Rurnphii, II, 139.

Sahlite, I, 429.

Saïga, IV, 75.

Sain-bois, II, 387.

Saindoux, IV, 46.

Sakis, IV, 13.

Salangane, IV, 130.

Salep, II, 231.

Salicine, II, 312.

Salicinées, II, 311.

Salicor, II, 449.

Salix alba, II, 312.

- amygdalina, II, 312.

- babylonica, II, 313.

- caproea, II, 313.

- prcecox, II, 312.

- viminalis, II, 312.

- vitellina, II, 312.

Salmo Eperlarus, IV, 178.

- Fario, IV, 178.

- lemanus, IV, 177.

- Schiefermuleri, IV, 177.

- Solar, IV, 177.

- Trutta, IV, 178.

Salpêtre, I, 462.

Salsepareille, II, 173.

- aiguillonnée, II, 181.

- d'Allemagne, II, 184.

- du Brésil, II, 178.

- caraque, II, 178. 
Salsepareille des côtes, II, 178.

- fausse de Virginie, III, 200.

- grise d'Allemagne, II, 184.

- grise de Virginie, II, 184.

- de Guatemala, II, 180.

- de Honduras, II, 180.

- de l'Inde, II, 185.

- ligneuse, II, 181.

- de Lisbonne, II, 178.

- de Maracaïbo, II, 178.

- du Para, II, 178.

- du Pérou, II, 180.

- de Portugal, II, 178.

- rouge de la Jamaique, II, 177.

- de Ia Vera-Cruz, II, 176.

Salseparine, II, 182.

Salsifis blanc, III, 15 .

- noir d'Espagne, III, 14.

Salsola Soda, II, 448.

- Tragus, II, 449.

Saluth, IV, 177.

Salvia hispanica, II, 473.

- officinalis, II, 472.

- pratensis, II, 472.

- Sclarea, II, 473.

Samare, II, 14 .

Sambola, III, 210.

Sumbucus Ebulus, III, 194.

- nigra, III, 193.

Sambula, III, 210.

Sandaraque, II, 250.

- de Guatemala, III, 536.

Sang-dragon des Antilles, III, 346.

- du draccena Draco, II, 137.

Sang.dragon des Moluques, II, 135.

- du Pterocarpus Draco, II, 137; III, 346.

Sanglier, IV, 45.

Sangsue dragon, IV, 308.

- médicale, IV, 291.

- -.- blanchâtre, IV, 308.

- - fauve, IV, 308.

- - grise, IV, 306.

- - jame, IV, 308.

- marquetée, IV, 308.

- noire, IV, 306.

- obscure, IV, 308.

— - pâle, IV, 308.

- - truitée, IV, 308.

- - verte, IV, 306.

- du Sénégal, IV, 309.

- de Verbano, IV, 309.

- vulgaire, IV, 283.

Sanguenié, III, 41.

Sanguenita, 11I, 41 .

Sanguinaire du Canada, III, 703.

Sanguinaria canadensis, III, 703.

Sanguine, I, $270-363$.
Sanguisorba officinalis, III, 301.

SANGUISOREÉES, III, 288-300.

Sanicle, III, 215.

Sanicula europcea, III, 215.

Sant, III, 392.

Santalacées, II, 382.

Santal à odeur de musc, II, 386.

- - de rose, II, 386.

- citrin du Malabar, II, 38ł.

- - de Sandwich, II, 385.

- - de Timor, Il, 385.

- - faux, II, 387.

- - pâle, II, 385.

- rouge, III, 343.

- - d'Afrique, III, 345.

- - tendre, III, 346.

Santalum album, II, 383.

- freycinetianum, II, 383.

- myrtifolium, II, 383.

Santonine, III, 42.

Sanve, III, 696.

Sapajous, IV, 13.

Saphir blanc, I, 330 .

- d'eau, I, 130, 395.

- oriental, I, 330.

Saphirine, I, 79.

Sapin argenté, II, 245.

- du Canada, II, 247.

- élevé, II, 247.

- faux, II, 247.

- vrai, II, 245.

SAPINDACÉES, III, 598.

Sapindus arborescens, III, 599.

- divaricatus, etc., III, 599.

- frutescens, IIl, 599.

- saponaria, III, 598.

Saponaire d'Espagne, III, 662.

- d'Orient, III, 662.

- officinale, III, 661 .

Saponaria officinalis, III, 662.

Saponine, III, 662.

Saponite, I, 358.

SA PotéES, II, 595.

Sapotille, II, 597.

- mammée, II, 597.

Sarcocarpe, II, 11.

Sarcocolle, II, 594.

Sarcolite, I, $42 \%$.

Sarcopte de Galès, IV, 268.

Sardes, IV, 174.

Sardine, IV, 178.

Sardoine, I, 79.

Sariette, II, 469.

Sarigues, IV, 41.

Sarothamnus Scoparius, III, 359.

Sassafras de Guatemala, II, 397.

- de l'Orénoque, II, 396.

-- inodore, II, 306. 
Sassofras officinarum, II, 393.

Satin-wood, III, 537.

Satureia hortensis, II, 469.

Saturnia pavonina, IV, 235.

Sauge du port de la Paix, II, 364.

Sauge des prés, 4 i2.

- officinale, II, 472.

- sclarée, II, 473.

Saule blanc, II, 312.

- jaune, etc., II, 312.

Saumon, IV, 1 i\%.

Saunens, IV, 148.

Sauterelle, IV, 219.

Sauve-vie, II, 77.

Savacous, IV, 13 i.

Saveurs, I, 49.

Savomnier des Antilles, III, 598.

Saxifiage blanche, III, 223.

- (grande), III, 22'.

- (petite), III. 224.

Scabieuse des cliamps, III, (i⿱⺈.

- officinale, IlI, 67 .

Scabiosa arverisis, III, 67.

- succisa, III, 67.

Scalopes, IV, 15.

Scammonée, II, 537.

- d'Alep, II, 5 '0.

- d'Antioche, II, 5 \&1.

- de Montpellier, II, 512.

- de Smyrne, II, 5 ío.

- de Trébisonde, II, 510.

Scandix cerefolium, III, 215.

- Pecten, III, 216.

Scaphium scaphigerum, III, 653.

Scapolite, I, 427.

Sceau de Notre-Dame, II, 186.

Sceau de Salomon, II, 167.

Schéelin calcaire, I, 423.

Schéelite, I, 423.

Schéelitine, I, 181.

Scliéerérite, I, 107.

Schelot, I, 451, 452.

Schilfylaser: I, I; 16, 130 .

Scliiste, I, 505 .

Schorianthe des Indes, II, 98.

- officinal, II, 97.

Schanocaulon of ficinale, II, 150.

Schori bleu, I, 207, 341 .

- rouge, I, 206.

Schwartzguligerz, I, 224.

Scies, IV, 195.

Scilla maritima, II, 157.

Scille, II, 157.

Scincus officinalis, IV, 150 .

Scinque officinal, IV, 150.

Sciunievs, IV, 25.

SCLÉnONYCÈTES, II, 39.

Scolexérose, I, $4: 6$.
Scolézite, I, 429.

Scolite, IV, 208.

Scolopendre, II, 79.

Scolopendres, IV, 259.

Scolopentrium of ficinale, II, 79.

Scomber Scombrus, IV, 174.

- Thinnus, IV, 175.

Scombres, IV, 174.

Scops, IV, 128.

Scordium, II, 479 .

Scorodite, I, 282.

Scorodone, II, 479.

Scorodosma fatidum, III, 210.

Scorpio afer, IV, 26 .

- flivicaudus, IV, 265.

- occitanus, IV, 264.

Scorpion d'Afrique, IV, 234.

- d'Europe, IV, 265.

- roussâtre, IV, 26 '.

Scorzonera hispanica, III, 14.

Scorzonère d'Espagne, III, 14 .

Scrophulaire, II, 490.

Srophularia nodosa, II, 490.

Scrophulariacées, II, 483.

Scyllum Canicula, IV, 19'.

Scylalia chinensis, III, 599.

Sebastiano d'arruda, III, 349.

Sébeste, II, $51 \%$.

Setipira-guaç, III, 329.

Secale cereale, II, 110.

Sèches, IV, 35 4.

Secrétaire, IV, $12 \%$.

Sedum album, III, 254.

- acre, III, 254 .

- Telephum, III, 253.

Seigle, II, 110.

- ergoté, II, 46.

Sel ammoniac, I, 484.

- gemme, I, 446.

Sel marin, I, 446.

SélaCiens, IV, 194.

Sélagite, 1, 507.

Sélénite, I, 402.

Sélénium, I, 120.

Semecarpus Anacardium, III, 493.

Séméline, I, 42 t.

Semen-contra de Barbarie, III, 41.

- - du Levant, III, 39.

Semence de Ben, III, 3̈s6.

Semencine, III, 41 .

Sempervivum tectorum, Ill, 253.

Séné, III, 3360.

- d'Alep, III, 365.

- d'Amérique, III, 368.

- de l'Inde, III, 367.

- de Moka, III, 367.

- de la palte, III, 364 .

-- du Sénégal, III, 365. 
Séné de Syrie, III, 365.

- de Tripoli, III, 366.

SÉNÉCIONIDÉES, III, .

Sénégine, III, 6 $\$ 5$.

Sénevé, III, 694.

Sephen, IV, 197.

Sepia octopodia, IV, 35i.

- officinulis, IV, 354.

Serins, IV, 130.

Selpent d'Esculape, IV, 155.

- à lunettes, IV, 162 .

Serpents donble-marcheurs, IV, 152.

- non venimeux, IV, 153.

- venimeux, IV, 155.

- vrais, IV, 152.

Serpentaire commune, II, 87.

- de Virginie $1^{\text {re }}$, II, 375.

$-2^{\mathrm{e}}, \mathrm{II}, 377$.

- - à feuilles hastées, II, 377.

- - fausse, II, 378.

Serpentin, I, 497, 507 .

Serpentine, I, 39', 499.

Serpolet, II, 469.

Sertulaires, IV, 370 .

Sérum, IV, 90.

Serval, IV, 23.

Sésame, II, 546.

Sesamum orientale, II, $5: 6$.

Séseli de Marseille, III, 235.

Seseli tortuosum, III, 235.

Shorea robusta, III, 64t.

Siami, III, 403.

Sidérocriste, I. 507.

Sideroxylon inerme, II, 95.

Silene Ameria, III, 25.

- Behen, III, 25.

- inflata, III, 25.

SILÉNÉES, III, 660 .

Silex corné, I, 80.

- molaire, 1, 80 .

- pyromaque, I, 80.

Silice, I, 75 .

- hydratée terreuse, I, 83.

Silicule, II, 14 .

Siliqua dulcis, III, 370.

Silique, II, 14.

Sillimanite, I, 342.

Silphion, III, 238.

Silure électrique, IV, 196.

Silurus glanis, IV, 177.

Silybum mariann, III, 20.

Simaba Cedion, III, 5\%?.

Simaruba amara, III, 570.

- excelsa, III, 569.

- officinalis, III, 570 .

Simarubées, III, $5 i 6$.

Sinammine, IiI, 698 .

Sinapisine, III, 698.
Sinapis alba, III, 696.

Sinapis arvensis $1 \mathrm{II}, 690$.

- nigra, III, 694.

Singes, IV, 13.

Siphonia elastica, II, 317.

Siphonophores, IV, 376 .

Sirènes, IV, 163.

Sison Ammi, III, 22?.

- Amomum, III, 222.

Sisymbrium Nasturtium, III, 683.

- officinale, III, 688.

- tenuifolium, III, 694.

Sittelles, IV, 13!).

Sium Ninsi, III, 201-201.

- Sisarum, III, 201-204.

Smalt, I, 248.

Smaltine, I, 250.

Smaragdite, I, 390 .

Smaridié des moineaux, IV, 258.

Smegmadermos emarginatus, III, 309.

Smilacine, II, 182.

Smilax aspera, II, 174-184.

- China, II, 171.

- Japicanga, II, 182.

- laurifolia, II, 174.

- macrophylla, II, 174.

- medica, II, 173.

- olliquata, II, 181.

- officinalis, I1, 173.

- papyracea, II, 1:4-180.

- pseudoctima, II, 171.

- pseudo-syphilitica, II, 1i4.

- Sarsajarilln, II, 174.

- syphilitica, II, 174-179.

- sypingoides, II, 182.

- zeylanica, II, 185.

Smithsonite, I, 370.

Smyrna aminnea, III, 455.

Socchi, III, 182.

Sodalite, I, 471.

Sodium, I, 446.

- chloruré, I, 416.

SOLANACÉES, II, 492.

Solanun Dulcamara, II, 50 ј.

- Lyenpersicum, II, 509.

- Melongeni, II, 506.

- nigrum, II, 50 '.

- ovigerumi, II, 506.

- pseudo-capsicum, II, 5.5.

- pseulo-quina, II, 506.

- tuberosum, II, 5i)(i.

Sulea vulgaris, IV, 1 i9.

Soleil (grand), III, 57.

Solenostemma Arghel, III, 303.

Soles, IV, 1?9.

Solidago Virga aurea, III, 62.

Sopuloréŕs, III, 323.

Sorbier commun, IIf, 292. 
Sorbier des oiseaux, III, 292.

Sorbiel hybride, III, 292.

Sorbus aucuparia, III, 29:.

- domestica, III, 292.

Sorose, Il, 11.

Souche, II, 7 .

Souchet comestible, II, 9L.

- long, II, 91.

- à papier, II, 92.

- rond, II, 91.

- sultan, Il, 92.

Souci des champs, III, 33 .

- des jardins, III, 33 .

soude, II, 448.

- d'Alicante, II, 4 49.

- d'Aiguemortes, JI, 449

- artificielle, II, 449.

- épineuse, II, 449.

- boratée, I, 458.

- carbonatée, I, 454 .

- nitratée, I, 457.

- sulfạtée anhydre, I, 451.

- hydratée, I, 451.

Soufre, I, 113.

- végétal, II, 80.

Soymida febrifuga, III, 595-597.

Spargelstein, I, 419.

Spartium junceum, III, 359.

Spath brunissant, I, 413 .

- en tables, I, 425.

- fluor, I, 399.

- jaunissant, I, 413.

- perlé, I, 41'.

Spatule fétide, II, 192.

Spatules, IV, 134.

Speckstein, I', 391.

Speerkies, I, 263.

Spermaceli, IV, 113-11t.

Spermorlia, II, 49.

Spermoderme, II, 15.

Sperniole, IV, 165.

Spessartine, I, 348.

Sphacelia segetum, II, 50 .

Sphærostilbite, I, 429.

Sphène, I, 424.

Sphérolite, I, 473.

Splinx, IV, 2:35.

Spicanard, III, 73.

Spigelie antleelminthique, II, 559.

- de Maryland, II, 559.

Spilanthes oleracea, III, 56-(85.

Spillite, I, 489, 507.

Spina acacice, III, 393.

- agyptiaca, III, 393.

Spinacia oleracea, II, 436.

Spinax niger, IV, 199.

Spinellane, I, 4 i6.

Spinelle rouge, I, 385 .
Spinclle vert, I, 386.

Spinelle zincifère, I, 386 .

Spinelline, I, 4:4.

Spintlière, I, 424.

Spircea Filipendula, III, 306.

- trifoliata, III, 96.

- Ulmaria, III, 307.

SPIRAaCÉES, III, 288-306.

Spirolobées, III, 681.

Spiroptera hominis, IV, 33i.

Spode, IV, 43.

Spodumen à base de soude, I, 481 .

SPONDIACÉES, III, 487.

Spondias lutea, III, 287-495.

- purpurea, III, 495.

Spongiaires, IV, 379.

Spongodium Bursa, II, 36.

Squales, IV, 19i.

Squine, II, 171.

- fausse, II, 172.

- de Maracaïbo, etc., II, 171.

Stactè, II, 306.

Stæchas arabique, II, 462.

- citrin, III, 36.

Stalactites, I, 412.

Stalagmites, I, 413.

Stalagmitis cambogioides, III, 6I2.

Staphisaigre, III, 769.

Satice latifolia, II, 455.

- Limonium, II, 455.

Staulotide, I, 345.

Stéaschiste, I, 507.

Stéatite, I, 390.

Stellite, ，428.

Sterculia acuminata, Ill, 653.

- scaphigera, III, 653.

- tragocantha, III, 453.

Sterguliacées, III, 637.

Stercus diaboli, III, 242.

Stibine, I, 130.

Sticla pulmonaria, II, 58.

Stigmate, II, 11.

Stigmite, I, 505, 503.

Stilbite, I, 429.

Stillingia sebifera, II, 301.

Stipe, II, 7.

Stizolobium, III, $3 \$ 3$.

Stomapoles, IV, 273.

Stomates, II, 5 .

Storax, II, 603.

- amygdaloide, II, 605.

- blanc, II, 605.

- de Bogota, II, 606.

- en pains, Il, 311.

- en sarilles, II, 311.

- liquide, II, 309.

- noir, II, 311.

- rouge, II, 309. 
Stramen camelorum, II, 97.

Stramonium, II, 496.

Strelitzia regina, II, 197.

Strongle géant, IV, 330 .

Strongylus gigas, IV, 330.

- longevaginatus, IV, 330.

Strontiane carbonatée, I, $\mathbf{\text { i3s. }}$

- sulfatée, I, 439.

Structure des cristaux, I, 25.

- des minéraux, I, 43.

Struthio Camelus, IV, 133.

- Rhea, IV, 133.

Strychnos castelncea, II, 568.

- colubrina, II, 563.

- ligustrina, II, 563.

- Nux vomica, II, 562, III, 560.

- potatorum, II, 568 .

- pseudo-quina, II, 568.

- Tieute, II, 568.

- toxifera, II, 568.

Stryphnodendron Barbatimâ, III, 330.

Stryx Aluco, IV, 137.

- Bubo, IV, 137.

- Fammula, IV, 137.

- Otus, IV, 137.

Sturioniexs, IV, 189.

Style, II, 11.

Strracinées, II, 602 .

Styrax liquide, II, 306.

Styrax Benzoin, II, 602.

- officinale, II, 604.

Suc astringent du Pterocarpus erinaceus, III, 426.

- d'acacia d'Egypte, III, 400.

- d'hypociste, II, 85.

Succin, I, 109.

Succinite, I, 349.

Sucre, II, 103.

- de lait, IV, 90 .

Sucrier de montagne. III, 528.

Suif de montagne, 108.

Sulfate de magnésie, I, 377.

Sulfosinapisine, III, 698.

Sulfuraire, I. 515.

Sumac des corroyeurs, III, 488.

- glabre, IlI, 488.

- vénéneux, III, 489.

- vernis, III, 488.

- de Virginie, III, 483.

Sumbul, III, 210.

Sumbulus moschatus, III, 210.

Sureau, III, 195.

Surelle, III, 574.

Surmulet, IV, 173.

Swartzia tomentosa, III, 354.

Swartziées, III, 321 .

Swietenia Mahogoni, III, 56 .

Sycomore, III, 606.
Syénite, I, 508.

Sylvane, I, 149.

Sylvie, III, 756 .

Symphytum officinale, 1I, 508.

SYNANTHÉrÉES, III, 11.

Syndactyles, IV, 130 .

Scyphophorus cocciferus, II, 58.

- pixidatus, II, 58.

Syringa vulgaris, II, 581.

Système bino-singulaxe, I, 31 .

- cubique, J, 30. .

- hexagonal, I, 35.

- isoaxique, $\mathbf{I}, 30$.

- monoclinique, I, 40.

- octaédrique rectangulaire, I, 33.

- du prisme droit à base carrée, I, 31.

- - lectangulaire, I, 33.

- - rhomboìdal, I, 33.

- - oblique symétrique, I, 40.

- - non symétrique, I, 42.

- - rectangulaire oblique, I, 40.

- régulier, I, 30.

- rlombique, I, 33.

- rhomboctaèdre, 1, 33.

- singulaxe binaire, I, 33.

- terno-singulaxe, I, 35.

- tétragonal, I, 31.

- triclinique, I, 42.

- de Linné, II, 16.

Systèmes de cristallisation, I, 30 .

\section{T}

Tabac, III, 493.

Tabanus, IV, 253.

Tabasheer, tabaxir, II, 97.

Tableau des acides, I, 69.

- des bases, I, 68.

- des corps simples, I, 67.

- des lauracées, II, 394.

Tacamalıaca, III, 5?9.

Tacamaque angélique, III, 533, 621 .

- de Bourbon, III, 620.

- en coques, III, 533.

- huileuse incolore, III, 531.

- jaune huileuse, III, 530 .

-- jaune terne, III, 527. - terreuse, III, 532.

- ordinaire, III, 533.

- rougeâtre, III, 532 .

- sublime, III, 533.

Tacca pinnatifida, II, 186.

Tachi de la Guyane, II, 552.

Tachia guianensis, II, 552.

Tonia Conurus, IV, 345.

- flavopunctala, IV, 346. 
Tania elliptica, IV, 346.

- inerme, IV, 346.

- large, IV, 346.

Tania mediocanellata, IV, 3 ifi.

- Solium, IV, 341.

Taffia, III, 589.

Tagua, Il, 142.

Talc écailleux, I, 391.

- granulaire, I, 391.

- laminaire, I, 390.

- de Venise, I, 390.

Talschiste, I, 508 .

Tamarara, III, 721.

Tamaris, III, 374.

Tamarindus indica, III, 374.

Tamarix mannifera, II, 587.

Tamiel', taminiel', II, 186.

Tanus communis, II, 186.

Tanacetum Balsamita, III, 50.

Tanacetum vulgare, III, 36 .

Tanaisie vulgaire, III, 36.

Tanche vulgaire, IV, 175.

Tangaras, IV, 129.

Tanghinin venenifera, II, 575.

Tanguin, II, 575.

Tanikai, III, 286.

Tanroujou, III, $45 \%$.

Tanrouk-rouchi, III, 457.

Tantale, I, 202.

Tantales, IV, I34.

Tantalite de Bavière, I, 303.

- de Suède, I, $30 \%$.

Taons, IV, 253,

Taouia, III, 538 .

Tapioka, II, 351 .

Tapir, IV, 44 .

- d'Amérique, IV , 44.

- de l’Inde, IV, 44.

Taraxacum Dens leonis, III, 18.

T'arentule, IV, 262.

Tardigrades, IV, 39.

Tarte brut, III, 59?.

Tatai-ibu, II, 325 .

Tatous, IV, 40.

Taupes, IV, 15 .

Taureau, IV, 82.

Taurine, IV, 99.

Taxinées, II, 236.

Taxus huccata, II, $23 \%$.

Tchu, III, 635 .

Tclitugel-Sakcsey, III, $1 \%$.

Teagreen Carabaya quill's, III, 141 .

'Tecoma Leucoxylon, II, $\mathbf{3} 48$.

- radicans, II, 550 .

Tecomajaca de Guatimala, III, 527.

Tectona grandis, II, 482.

Tek, II, 48?.

Teka grandis, II, 482.
Tellure, I, 121.

Tellure graphique, I, 149.

Ténacité, I, 10.

Tendre à caillou, III, 324.

Tendreté des corps, I, 9.

T'ennantite, I, 223.

Tennecs, IV, 15.

Tenuirostres, IV, 130.

Téphrine, I, 508.

Terbium, I, 314.

Térébelles, IV, 280.

Térébintilacées, III, 486.

Térébinthe, III, 498 .

Térébenthine, II, 250.

- au citron, II, 253.

- au soleil, II, 253.

- d'Alsace, II, 253.

- de Bordeaux, II, 259.

- de Boston, II, 261.

- de Chio, III, 498.

- du mélèze. II, 251.

- du sapin, II, 253.

- de Strasbourg, II, 253.

- des Vosges, II, 25.

- Suisse, II, 253.

Téréniabin, II, 585.

Terminalia citıina, III, $2: 6$.

- Chebula, III, 286.

Termites, IV, 221.

Ternstroemlacées, III, 63 J.

Terra merita, II, 205.

Terrains diluviens, I, 62.

- de sédiment, I, 61 .

- de transition, I, 61.

- de transport, I, 6?.

- primitifs, I, 61.

- secondaires, I, 62.

- tertiaires, I, 62.

Terre à foulon, I, 36?.

Terre à porcelaine, I, 358 .

- de Chypre, I, $4 i 1$.

- de Cologne, I, 100.

- d'ombre, I, 364.

- de Sienne, I, 364.

- de Vérone, I, 471, 472.

- sigillée, I, 363.

- verte de la craie, I, 472.

- - d'Unghvar, I, 289.

Terre-noix, III, 224.

Terreau, I, 102.

Terres comestibles, I, 36 '.

Testacelles, IV, 358.

Testudo europern, IV, 145.

- graeca, IV, 144.

- imbricuta, IV, 147.

- lutaria, IV, 146.

- orbiculuris. IV, 145.

Têtard, IV, 165 . 
Tétraèdre, I, 18.

Tétraphylline, I, 305.

Tétras, IV, 132.

Teucrium aureum, II, 480.

- Botrys, II, $4: 8$.

- Chamadrys, II, 478.

- Chamcepitys, II, 480.

- flavescens, II, 480.

- Iva, II, 480.

- mairum, II, 478.

- montanum, II, 480.

- Polium, II, 480.

- Scordium, II, 4 i9.

- Scorodonir, II, 479.

Thalictrum sinense, III, 766.

Thallite, I, 427.

Thapsia, III, 214.

- garganica, III, 214.

- silphium, III, 238.

'Thé, III, 63ذ.

- bouy, III, 639.

- chulan, III, 637.

- des Apalachies, III, 544, 640.

- d'Europe, III, 640.

- du Labiador, III, 8.

- du Mexique, II, 4i6; III, 610.

- du Paraguay, III, 54́.

- hayswen, III, 637.

- noir, III, 6:8.

—-pekao, III, 639, 639.

- perlé, III, 63 .

- poudre à canon, III, 638.

- souchong, III, 638 .

Thea boliea, III, 636.

- clinensis, III, 636.

- viridis, III, 636.

Thecosoma hamatolobium, IV, '33'.

Téliphone, IV, :6\%.

Thénardite, 1, 451.

Theobroma bicolor, III, 656.

- Cacao, III, 655 .

- guianensis, III, 656.

- sijlvestris, III, 655.

- Guaruma, II, 315.

Théobromine, III, $65 \%$.

Thevetic Ahouai, II, 576.

- neriifoliu, II, 576.

Thiosinammine, III, (i93.

Thlaspi des champs, III, 690.

- officinal, 689 .

Thlaspi arverse, III, 690.

- campestre, III, 690.

- drabcefolio, III, 690.

- latifolium, III, 690.

- vulgare, III, ti90.

- vulgatiıs, III, 690.

Thomsonite, I, 428.

Thonporphyre, I, 508 .
Thons, JV, 175.

Thonschiefer, I, 50 s.

Thora, III, 772.

Thorium, I, 310.

Thraulite de Bodémaïs, I, 2:J0.

- de Riddarhytta, I, 290.

Thulite, I, 427.

Thuy articulata, II, 250.

Thym, II, 468.

Thymallus renifer, IV, 1 i8.

Thy MÉ LÉES, II, 388.

THYMéléACÉes, II, 38 \%.

Thymus Serpyllum, II, 469.

- vulgaris, II, 468.

Tilysanoures, IV, 208.

Ticorea febrifuga, III, 561.

Tige, II, 7.

Tigre, IV, 23.

Tilia europara, III, 6ł1.

- microphylla, III, Gil.

- platyphylln, III, $6 \dot{11 .}$

- rubra, III, 642 .

Tiliacérs, III, 610.

Tillandsia usneoiles, II, 190.

Tilleul argenté, III, 61:.

- d'Europe, III, 6'1.

- de Hollande, III, 6 ' 1 .

- rouge, III, 642.

- sauvage, III, Gíl.

Tilliot, II, (i41.

Tinckel, I, 458.

Tique des chiens, IV, 258, 266.

Tissu cellulaire, II, 2.

- fibreux, II, 2.

- utriculaire, II, 2.

Titan-cotte, II, 568 .

Titane anatase, I, 207.

- fluoruré ferrifère, I, 205.

- oxyde, I, 20 ;

- rutile, I, 206.

Titanides, I, 201.

Todiers, IV, 130.

Tocldalia aculeata, III, 565.

- paniculata, III, 568.

Tolomane, II,

Toluifer Balsamum, III, 474.

Tomate, II, 509.

Tommon, II, 212 .

- bezuar, II, 212.

- primum, II, 212.

Tonka, III, 377.

Tonnerre des Arabes, IV, 196.

Tooth-ache tree, III, 562.

Topasfels, I, 339.

Topaze, I, 337 .

- de Bohême, I, 78.

- du Brésil, I, 3Sı.

- d'Lnde, I, 78. 
Topaze orientale, I, 330.

Topazolite, I, 349.

Topinambour, III, 58.

Torcols, IV, 131.

Tormentilla erecla, III, 305 .

'Tormentille, III, 305.

Torpilles, IV, 195.

Toltelle, III, 689.

Tortue bourbeuse, IV, $14 \%$.

-- franche, IV, 147.

- géométrique, IV, 147.

- grecque, IV, 144.

- de l'Inde, IV, 145.

- ronde, IV, 145.

- verte, IV, 147.

'Tortues d'eau douce, IV, 145.

- de mer, IV, 146.

- de terre. IV, 144.

Totipalues, IV, 136.

Toucans, IV, 131.

Toucher, I, 50 .

Touloucouna, III, 594.

Toupies, IV, 360 .

Touraco, IV, 131.

Tourbe, I, 101.

Tourmaline, I, 351.

Tourne-pierres, IV, 131.

Tournesol en drapeaux, II, $3 i 5$.

- en pains, II, 64 .

Tourterelles, IV, 132.

Toute-bonne, II, 473.

Toute-épice, III, 273.

Toute-saine, III, 6?4.

Trachées, II, 8.

Trachyte, I, 508 .

Tragopogon porrifolius, III, 18.

- pratensis, III, 18.

Transparence. I, 52.

Trapézoèdre, I, 25.

Trapp, I, 489, 509.

Trappite, I, 509.

Trapporphyle, I, 497.

Trasi, JI, 92.

Travertin, I, 413.

Treacte mustard, III, 690 .

Trehala, IV, 214.

Trebel, III, 64.

Tiètle d'eau, II, 557 .

Trématodes, IV, 337.

Trémolite, I, 426, 431.

Trépangs, IV, 374.

Trichina spiralis, IV, 335.

Trichines, IV, 335.

Trichocéphales, IV, 332.

Tricocephalus dispar, IV, 333.

Trichomonades, IV, 379.

Trigla, IV, 173.

- Cucullus, IV, 173.
Trigla Guinardus, IV, 173.

- Hirundo, IV, 173.

- lineala, IV, 173.

- Lyra, IV, 173.

- pini, IV, 173.

Trigonella Fœnum graecum, III, 379.

Trigonocéphale jaune des Antilles, IV, 156.

Trigonocéphales, IV, 156.

Trikala, IV, 214.

Tringibin, II, 585.

Triphane, I, 445.

Triphylline, I, 304.

Triplite, I, 303.

Tripoli, I, 83.

Trique-madame, III, 25'.

Triticum cestivum, II, 108.

- hybernum, II, 108.

- repens, II, 108.

- sativum, II, 108.

- turgidum, II, 108.

Trocheta subviridis, IV, 286.

Trochète verdâtre, IV, 286.

Trochilus minimus, IV, 130.

Trochisques de Gambir, III, 424 .

Trochus, IV, 360 .

Trombidium autumnale, IV, 266.

Trombolite, I, 232.

Trona, I, 454.

Tronc, II, 7 .

TROPEOLÉES, III, 578.

Tropceolum majus, III, 578.

Trophosperme, II, 12.

Tropidonotus natrix, IV, 154.

- viperinus, IV, 154.

Truffe, II, 38.

Truie, IV, 46.

Truite commune, IV, 178.

- de mer, IV, 177.

- du Léman, IV, 177.

- saumonée, IV, 178.

Trygon Sepher, IV, 200.

Tsao-ksou, II, 215.

- -keu, II, 217.

- -quo, II, 218.

Tschewkinite, I, 313.

Tsetsé, IV, 253.

Tsjampacca, III, $7 \mathrm{i} 6$.

Tubéracées, II, 38.

Tubéreuse, II, 154 .

Tuf basaltique, I, 500 .

Tufaite, I, 500 .

TUlipacéES, II, 153.

Tulip-wood, III, 349.

Tulipier de Virginie, III, 746 .

Tungstein, I, 423.

Turban turc, III, 262.

Turbellariées, IV, 339. 
Turbith, II, 535 .

Turbot, IV, 179.

Turion, II, 9.

Turmeric, III, 205 ; III, 704.

Turneps, III, 693.

Turquoise, I, 336.

Turrilites, IV, 356 .

Turritelles, IV, 360 .

Tussilage, III, 62.

Tussilago Farfara, III, 62.

Tylophora asthmatica, III, 96.

Tyrans, IV, 129.

\section{$\mathbf{U}^{\circ}$}

Uerek, III, 398.

Ulmacées, II, 314.

Ulmaire, III, 306.

Ulmite, I, 100.

Ulmus campestris, II, 314 .

- fulva, II, 315.

Umbilicus pendulinus, III, 255.

Unau, IV, 39.

Uncaria gambir, III, 406-419.

Unio margaritifera, IV, 370.

Unicomocomo, II, 69.

Unona athiopica, III, 74t.

- aromatica, III, 745.

- musaria, III, 745.

Upas tieute, 11, 568.

Urane, I, 209.

- oxydulé, I, 211.

- hydroxydé, I, 212.

- phosphaté, I, 212.

Uranite, I, 213.

Urao, I, 454.

Urtica dioica, II, 329.

- urens, II, 329 ,

UnTICACÉES, II, 328.

Ursus arctos, III, 16.

- maritimus, III, 16.

Urupariba, II, 548.

Usnea plicata, II, 59.

Usnée du crâne humain, II, 59.

Utricule, II, 1.

Utricule (f'uit), II, 13.

Uva ursi, III, 5.

Uvaria odorata, III, 743.

\section{$\mathbf{V}$}

Vaccinium Myrtillus, III, 7.

- Oxicoccos, III, 8.

- Vitis idaa, III, 6.

Vache, IV, 82.
Vaginules, IV, 358.

Vaisseaux, II, 3.

- laticifères, II, 3.

- en spirale, II, 3.

Valeriana celtica, III, 71 .

- dioica, III, 69.

- Jatanansi, III, 73.

Valeriana officinalis, III, 68.

- Phu, III, 71.

Valériane celtique, III, 71.

Valériane grande, III, 71 .

- rouge, III, 79.

- sauvage, III, 68.

Valérianées, III, 67.

Valerianella olitoria, III, i9.

Vallesia, II, 570.

Valves, II, 12.

Vampire, IV, 15.

Vanilla planifolia, II, 233.

- Pompone, II, 234.

- sativa, II, 234.

Vanille, II, 233.

Vanillon, II, 234.

Vanneau, IV, 134.

Vare, 1I, 267.

Varec vésiculeux, II, 24.

Variolaria corallina, II, 61

- dealbata, II, 61.

- lactea, II, 61.

- orcina, II, 61.

Variolite, I, 495, 509.

- de la Durance, I, 509.

- du Drac, I, 509.

Vateria indica, III, 456.

Vautours, IV, 127.

Veau, IV, 82.

VÉGÉTAUX, I, 1 ; II, 1.

- (classification des), II, 16.

- endogènes, II, 8.

- exogènes, II, 8.

Vélar, III, 688.

Ver à soie, IV, 230.

- de Guinée, IV, 334.

- de terre, IV, 281.

- solitaire, IV, 341.

Vermiculaire brûlante, III, 254.

Vernicia muntana, II, 361.

Vérat, IV, 46.

Vératrées, II, 143.

Vératrine, II, 149.

Veratrum album, II, 148.

- nigrum, II, 150.

- officinale, II, 150.

- Sabadilla, II, 151.

- viride, II, 150.

Verbascum Thapsus, II, 491.

Verbena officinalis, II, 481 .

- triphylla, II, 482. 
Ver béNACÉES, II, $4 \delta 1$.

Verge d'or, III, 62.

Vernonia anthelminthica, III, 65.

Véron, IV, 176.

Veronica Beccrbunga, II, 484.

- officinalis, II, 484.

Véronique, II, 484 .

Verre d'antimoine, J, 13'.

Vert de Corse, I, 492,

- de montagne, I, :36.

Vert de vessie, III, 5 '1.

VERTÉbRÉS, IV, 3-í.

Verveine odorante, II, 48?.

- officinale, II, 481 .

Vesse de loup, II, 39.

Vésuvienne, I, 42 \%

Vétivier, II, 100.

Veuves, IV,130.

Vibrions, IV, 379.

Vicıées, III, 322.

Victoria regina, III, $7: 8$.

Victoriale, II, 156.

- longue, III, $\mathbf{i} 8$.

Vigne blanche, III, 257-753.

Vigne cultivée, III, 580.

Vigogne, IV, 57.

Vrolariées, III, 670.

Violette odolante, III, $6: 0$.

- tricolore, III, 673.

Viola ca!ceularia, III, 95.

- canina, III, 672.

- Ipecacuanha, III, 9i.

- Itouboa, III, 95.

- odorala, III, 670.

- parviftora, III, 95.

- tricolor, III, 673.

Vipera Aspis, IV, 156.

- Chersaca, IV, 161.

Vipère ammodyte, IV, 161.

- commune, IV, 156.

Vipères, IV, 156.

Vipérine commıne, II, 513.

- de Virginie, II, 375.

Villarsite, I, 389.

Vin, III, 583.

Vins (tableau des), III, 587.

Vinaigre, 1II, 590.

Vinca major, etc., II, 579.

Vincetoxicum officinale, II, 573.

Virgulines, IV, 379 .

Virola sebifera, II, 423.

Viscum album, III, 195.

Vitex Agnus castus, II, 482.

Vitis vinifera, III, 580 .

Vitriol bleu, I, 239.

Vittie-vayr, II, 100.

Viverra Civetta, IV, 19.

- Rasse, IV, 21.
Viverra Zibetha, IV, 19.

Vives, IV, 172.

Volutes, IV, 360.

Vouacapou, III, 356.

Vouacapoua americana, III, 337-356.

Vouapa bifolea, III, 462.

Voù̀de, III, 48:-690.

Vulvaire, II, 446.

\section{WV}

Wacke, I, 509.

Wackite, I, 509.

Wagnérite, I, 387.

Wavellite, I, 335 .

Webstérite, I, 33 '.

Weissgulligers, I, 159.

Wernérite, I, 42$\}.$

West coust Curthagena, III, 148.

Wild cabbage-tree, III, 332 .

Winter-green, III, 2.

Wintera aromatica, III, 748.

Winterana aromatica, III, 621-748.

Winteriana Cannel/a, III, 621.

Wiry Leru bark, III, 179.

Wismuth bleiers, I, 176.

Withe crown bark, III, 151.

Wolfram, I, 305.

Wollastonite, 1, 425-426.

Woo-pei-lsze, III, 504.

Wood-oil, III, 468-635.

Writhyia antidysenterica, II, 578.

- tinctoria, III, 483.

Wrightine, II, 578.

$\mathbf{x}$

Xanthochymus pictoriu;, III, 618.

Xanthorrhasa arborea, II, 166.

- hastilss, II, 166.

Xantite, $\mathrm{I}, 427$.

Xénolithe, I, 343.

Xiphin's Gladus, IV, 175.

Xylobalsamum, III, 510.

Xylopia fintescens, III, 745.

- grandiflora, III, i15.

- sericea, III, 745 .

\section{Y}

Yénite, I, 29?.

Yeux d'écrevisses, IV, 276.

Ypoléine, I, 232.

Yttro-cérite, I, 315. 
Yttro-cérite-lantalite, I, 315.

Yttrium, I, 314.

- et cérium fluorurés, I, 315.

- phosphaté, I, 317.

- silicaté, I, 316-217.

- tantalaté, I, 315.

- titano-tantalaté, I, 316.

- titanaté zirconifère, I, 316.

- tungsto-tantalaté, I, 315.

\section{Z}

Zanthopicrite, III, 562.

ZANTHOXYLÉES, III, 545.

Zanthoxylum alatum, III, 564 .

- carbaeum, III, 562.

- carolinianum, III, 563.

- clava-Herculis, III, 562.

- fraxineum, III, 562.

Zea.Mris, II, 114.

Zèbre, IV, 5 í.

Zebu, IV, 86.

Zédoaire jaune, II, 211.

- longue, II, 210.

- ronde, 210.

Zemrni, IV, 25.

Zéolite, I, 428-4:9.

Zérumbet, II, 205.

Zibeth, IV, 21.

Zinc (extraction), I, 373.

- arséniaté, I, 305.
Zinc carbonaté, I, 370.

- liydro-carbonaté, I, 370.

- hydro-silicaté, I, 37! .

- oxydé, I, 367.

- sélénié, I, 365.

- sulfaté, I, 369 .

- sulfuré, I, 365.

Zmgiber Cassumuniar, II, 205.

- latifolium, II, 205.

- Meleguettr, II, 219.

- nigrum, II, 214.

- officinale, II, 20?.

- sylvestre, II, 205.

- Zerumbet, II, 205.

ZiNGibéraCÉES, II, 198.

Zinkénite, I, 176-178.

Zircon, I, 318.

- hydraté, 1, 319.

Zircone hydro-silicatée, I, 319.

- alcaline, I, $31 \mathrm{~s}$.

- - silicatée, I, 320.

Ziziphus Lolos, III, 540.

- vulgaris, III, 539.

ZOANTIIAIRES, IV, 3 i 6.

Zoisite, I, 427.

Zoophthalmum, III, 382.

ZOOPHYTES, IV, 3-373.

- globuleux, IV, 373.

- radiaires, IV, 373.

Zocsporées, II, 2 '.

Zostera maritımı, IV, 102.

Zygorily LEes, IIl, 545.

FIN DE LA TABLE GÉNÉRALE. 


\section{ER R A T A}

Tome I, page 173, ligne 4, au lieu de sélénité, lisez: sélénié.

- I, - 412, - 28, au lieu de écrithes, lisez : cérithes.

- II, - 183, - 39, au lieu de magney, lisez: araguey.

- II, - 267, - 34, au lieu de Cowdce, lisez : Cowdee.

-- III, - 240, - 5, au lieu de Fela, lisez : Ferula.

- III, - 641, - dernière, au lieu de tillot, lisez: tilliot.

- III, - 684, - 37, au licu de officilanis, lisez : officinalis.

- III, - 750, - 1, au lieu de palo, lisez: pao. 





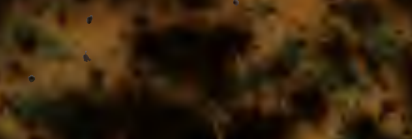

a

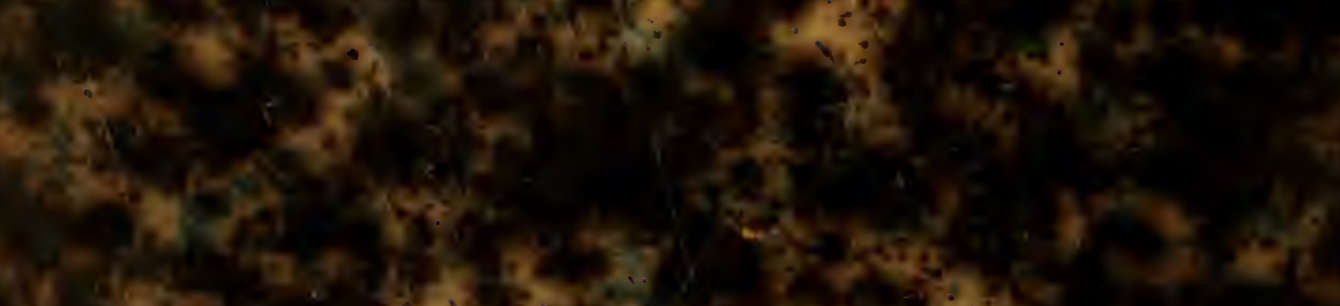

W. 5 .

0.5
0

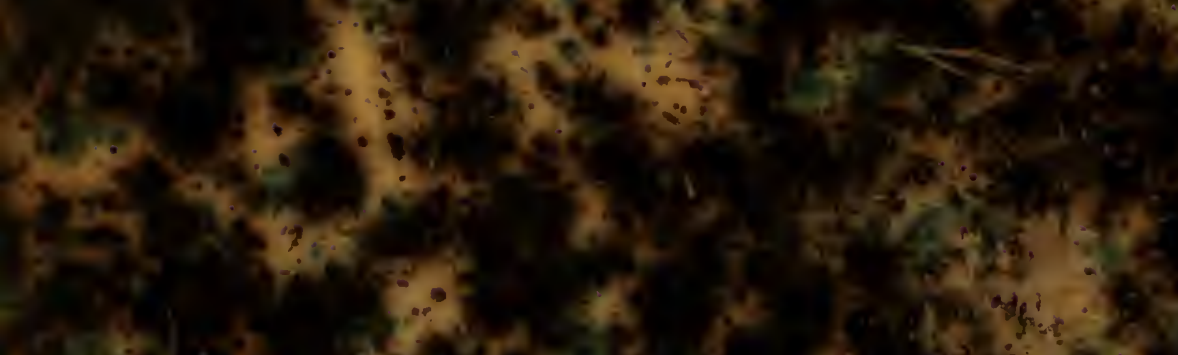

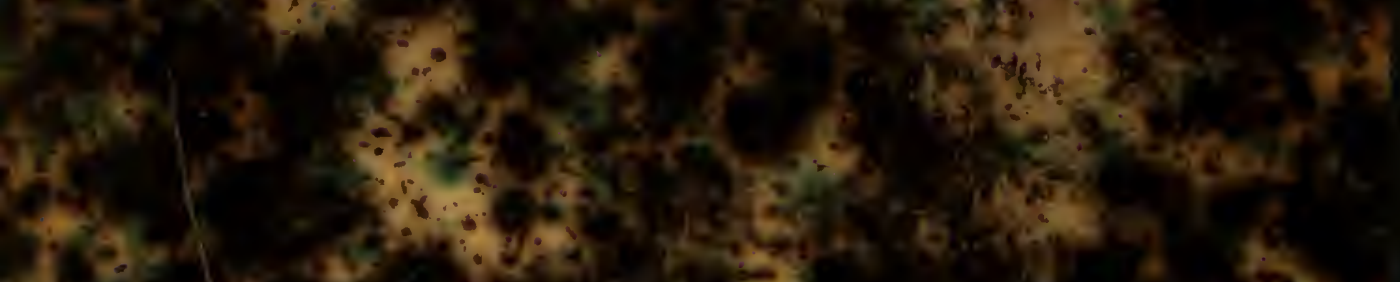

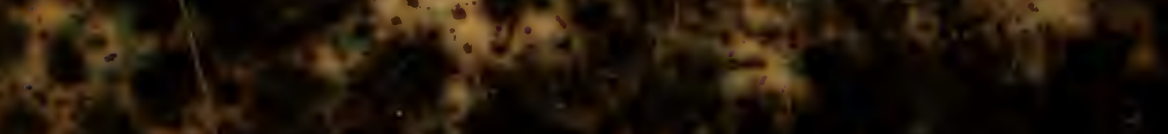

$\lim _{2} \rightarrow x^{2}$

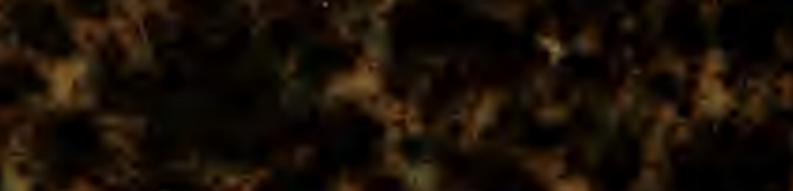

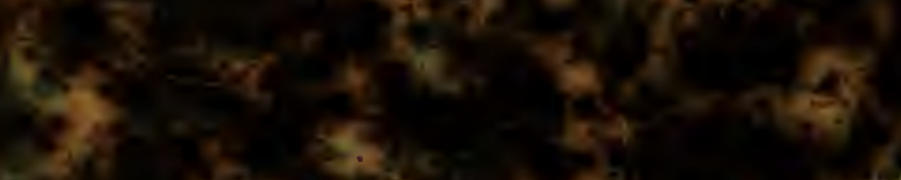

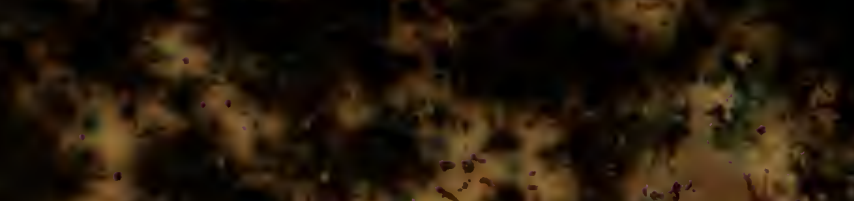

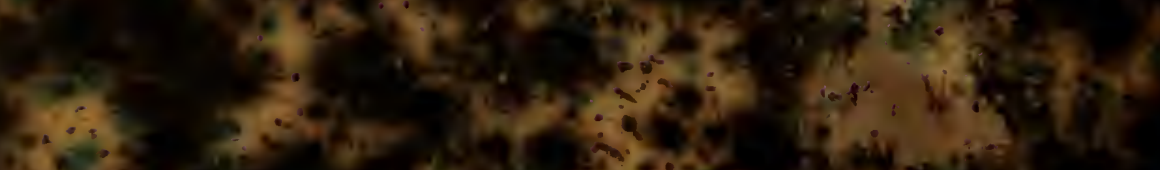

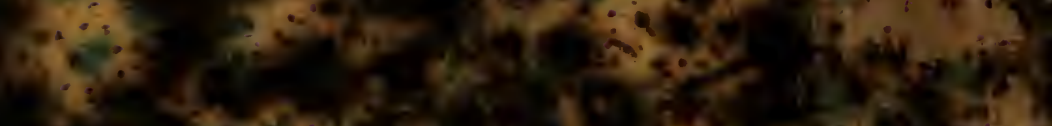

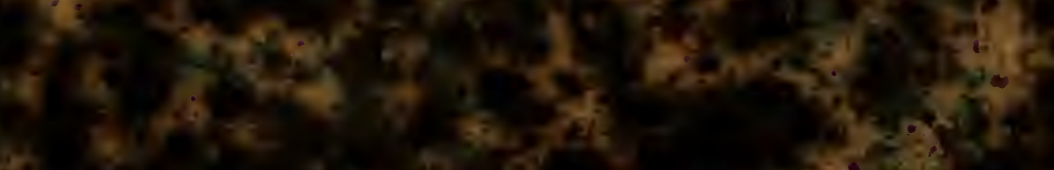
$\sin +10$
$8+20$

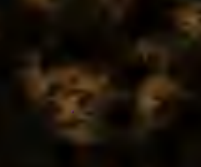

$x^{2}+2,2$

1. $x^{2}=$

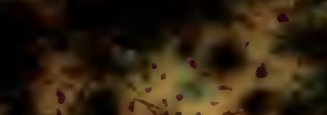

$x+2 x^{2}$

$\lim _{2}$

s.t.

4

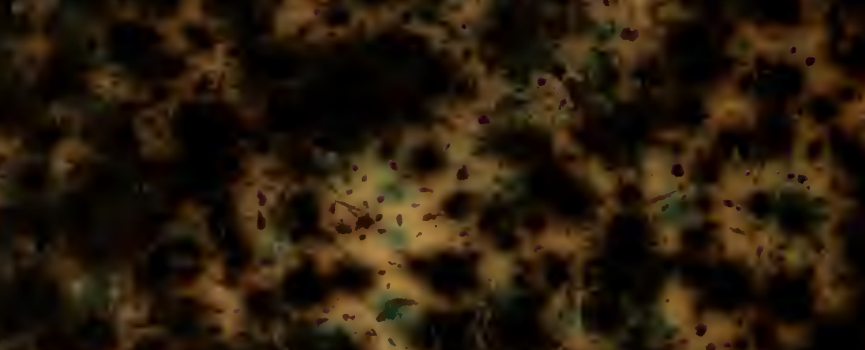

